\title{
Wege zum illuminierten Buch
}

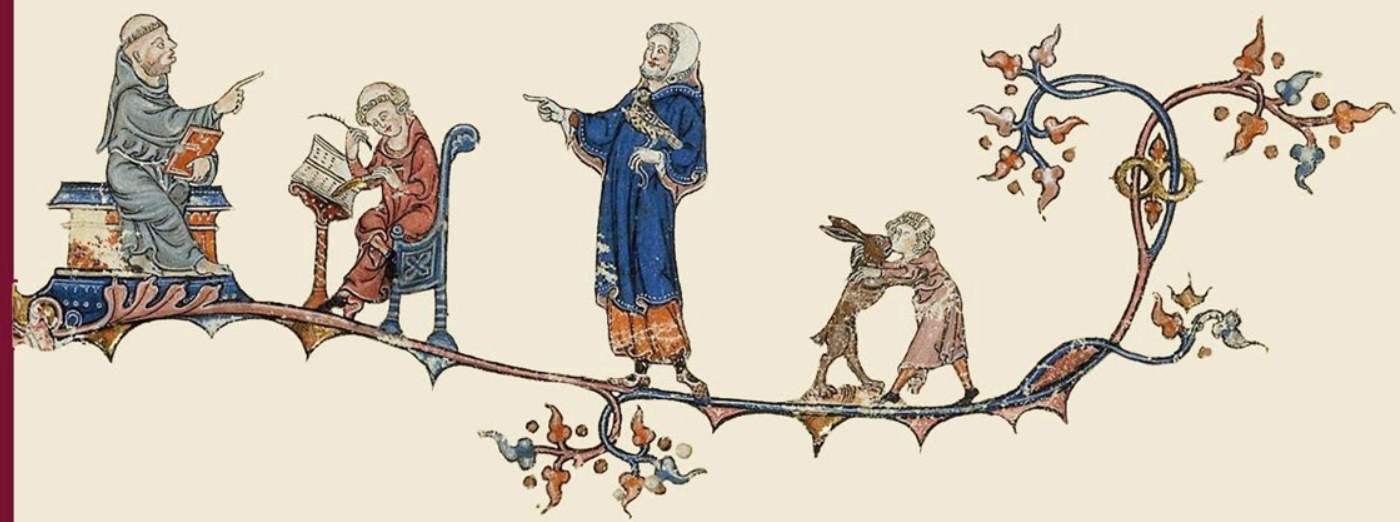

Herstellungsbedingungen für Buchmalerei in Mittelalter und früher Neuzeit 
böhlau 



\section{WEGE ZUM ILLUMINIERTEN BUCH}

HERSTELLUNGSBEDINGUNGEN

FÜR BUCHMALEREI IN MITTELALTER UND FRÜHER NEUZEIT

Herausgegeben von Christine Beier und Evelyn Theresia Kubina 


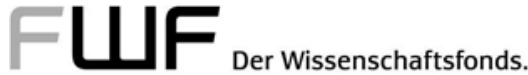

\section{Veröffentlicht mit Unterstützung des}

Austrian Science Fund (FWF): PUB 66-V21

Bibliografische Information der Deutschen Nationalbibliothek:

Die Deutsche Nationalbibliothek verzeichnet diese Publikation in der

Deutschen Nationalbibliografie; detaillierte bibliografische Daten sind im Internet über http://portal.dnb.de abrufbar.

Umschlagabbildung:

Detail aus Paris, Bibliothèque nationale, fr. 12400, fol. 1r

(C) 2014 by Böhlau Verlag GmbH \& Cie, Wien Köln Weimar

Wiesingerstraße 1, A-1010 Wien, www.boehlau-verlag.com

Alle Rechte vorbehalten. Dieses Werk ist urheberrechtlich geschützt.

Jede Verwertung außerhalb der engen Grenzen des Urheberrechtsgesetzes ist unzulässig.

Korrektorat: Magdalena Burghardt, Wien

Redaktion der englischen Texte: Tim Juckes, Wien

Einbandgestaltung: Michael Haderer, Wien

Reproduktionen: Pixelstorm, Wien

Druck und Bindung: Arrabona Print, Győr

Gedruckt auf chlor- und säurefreiem Papier

Printed in the EU

ISBN 978-3-205-79491-2 


\section{INHALTSVERZEICHNIS}

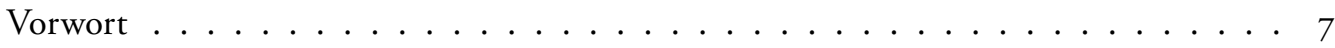

Johann Konrad Eberlein, Das Perikopenbuch Heinrichs II. (Clm 4452) ein Blick auf die Herstellungsweise der Miniaturen . . . . . . . . . . . . . . Io

Alison Stones, Manuscripts Illuminated in France I260-I320 and their Patrons . . . . . 26

Karl-Georg Pfändtner, Die Anziehungskraft der Universitäten.

Quellen zu Migrationsbewegungen von Schreibern und Buchmalern in der mittelalterlichen Boom-Region Bologna . . . . . . . . . . . . . . . 45

SusAnne Rischpler, Die Verhörprotokolle des Illuminators

Jehan Gillemer als Quelle für Kunsthistoriker . . . . . . . . . . . . . . . . . . 66

Armand Tif, Der Illuminator des Koloman-Antiphonars. Zur Frage der

Mobilität eines Buchausstatters im donauösterreichischen Raum um I480 . . . . . . . . 80

Michael Viktor Schwarz, Ubi pictor ibi Roma.

Local Colour and Modern Form in Stefaneschi's Codice di San Giorgio . . . . . . . . . I05

Carmen Rob-Santer, Die Trecento-Ausstattung des Visconti-Stundenbuches -

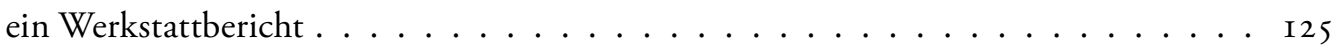

Katharina Hranitzky, Berthold Furtmeyr. Zuschreibungs- und Werkstattfragen . . . . I48

Lieselotte E. Saurma-Jeltsch, Der Einzelne im Verbund:

Kooperationsmodelle in der spätmittelalterlichen Buchherstellung . . . . . . . . . . I77

Christine Beier, Für Gottesdienst, Bibliothek und Verkauf Buchausstattung im Rooklooster bei Brüssel . . . . . . . . . . . . . . . . . 202

Lilian Armstrong, Benedetto Bordon and the Illumination of

Venetian Choirbooks around I 500: Patronage, Production, Competition . . . . . . . 22I 
Regina Cermann, „Astantes stolidos sic immutabo stultos“-

Von nachlässigen Schreibern und verständigen Buchmalern.

Zum Zusammenspiel von Text und Bild in Konrad Kyesers ,Bellifortis‘ . . . . . . . . . . 245

Christine SAuer, Die Handwerkerbilder in den Hausbüchern der

Nürnberger Zwölfbrüderstiftungen im künstlerischen Kontext ihrer

Entstehungszeit und im Spiegel der Jahresabrechnungen der Stiftungshäuser . . . . . . . 27 I

Verzeichnis der erwähnten Handschriften und frühen Drucke . . . . . . . . . . . . 289

Andere Werke . . . . . . . . . . . . . . . . . . . . . . . . 297

Verzeichnis der gekürzt zitierten Bibliotheken . . . . . . . . . . . . . . . 297 


\section{VORWORT}

Welche Voraussetzungen müssen gegeben sein, damit ein illuminiertes Buch hergestellt werden kann, und wie wirken sich die spezifischen Entstehungsumstände auf seine Gestalt aus? Die Bedingungen, unter denen Bücher im Mittelalter produziert wurden, gehören zu den zentralen Themen der Buchmalereiforschung. Dabei trifft sich das Forschungsinteresse von Kunsthistorikern mit dem von Wissenschaftlern anderer Fachdisziplinen, die Bücher als Zeugnisse mittelalterlicher Kultur untersuchen. Die ersten grundlegenden Abhandlungen mit umfangreichen, immer noch benutzten Quellensammlungen zum Thema stammen aus dem 19. Jahrhundert. Allen voran ist das I87I erschienene Werk zum Schriftwesen des Mittelalters von Wilhelm Wattenbach zu nennen, ${ }^{1}$ in dem mehrere der bis in die Gegenwart diskutierten Punkte angesprochen werden, von Schreibstoffen und -geräten über den Herstellungsprozess selbst und die daran Beteiligten bis hin zum Buchhandel und zu den Bibliotheken, in denen die Bücher schließlich zusammenfanden. Seither sind weitere Monographien, Sammelbände und Aufsätze erschienen, die unser Wissen über die mittelalterliche Buchherstellung erweitert haben, und auch in kunsthistorischen Untersuchungen sind die technischen, arbeitsorganisatorischen und soziologischen Bedingungen des Prozesses immer wieder berücksichtigt worden. ${ }^{2}$ Die umfassendste Publikation von Schrift- und Bildquellen zur Vorgehensweise der Illuminatoren bei der Ausstattung eines Buches hat Jonathan J. G. Alexander 1992 vorgelegt. ${ }^{3}$

In vorliegendem Band geht es nun darum, den kunsthistorischen Beitrag zum Thema aus fachinterner Sicht zu diskutieren, erprobte Methoden wie die auf stilistischer Analyse beruhende Händescheidung zu hinterfragen und anders ausgerichteten Forschungsansätzen gegenüberzustellen. Es werden Möglichkeiten für differenziertere Einschätzungen von Entstehungsort und -zeit eines Buches, für die Interpretationen figürlicher Darstellungen und für ein besseres Verständnis der Funktion des gesamten Buches geprüft, und gleichzeitig bieten kon-

I W. Wattenbach, Das Schriftwesen im Mittelalter, Leipzig I87i (4., erweiterte Auflage: Leipzig i896).

2 Es ist an dieser Stelle nicht möglich, eine vollständige Bibliographie zusammenzustellen, aber einige Aufsatzsammlungen und Monographien, die als Ausgangspunkt für weiterführende Studien und Literaturrecherchen dienen können, seien genannt: C. F. BüHLER, The Fifteenth-Century Book. The Scribes, the Printers, the Decorators, London 1960 - L.E. Sтамм, Die Rüdiger Schopf-Handschriften. Die Meister einer Freiburger Werkstatt des späten I4. Jahrhunderts und ihre Arbeitsweise. Aarau/Frankfurt a. Main/Salzburg I98I L. L. Brownrigg (Hrsg.), Medieval Book Production. Assessing the Evidence, Los Altos Hills I99o - E. ConDello (Hrsg.), Scribi e colofoni, Spoleto 1995 - R. H. Rouse/M. A. Rouse, Manuscripts and their Makers. Commercial Book Producers in Medieval Paris I200-I500. 2 Bde., London 2000 - R. Schlusemann (Hrsg.), Sources for the history of medieval books and libraries. Groningen 2000 - L. E. SAURma, Spätformen mittelalterlicher Buchherstellung. Bilderhandschriften aus der Werkstatt Diebold Laubers in Hagenau. 2 Bde., Wiesbaden 200I - J. L. Deuffic (Hrsg.), Du scriptorium à l'atelier: copistes et enlumineurs dans la conception du livre manuscrit au Moyen Âge. Turnhout 2OII - A. Gillespie (Hrsg.), The production of books in England. Cambridge 20II (Cambridge studies in palaeography and codicology I4).

3 J.J. G. Alexander, Medieval Illuminators and Their Methods of Work. New Haven/London 1992 
krete Beispiele Anhaltspunkte, wie der Erkenntnisgewinn für eine Beurteilung der künstlerischen Ausstattung nutzbar ist.

Den Anfang macht eine Studie zur Vorgehensweise von Buchmalern im Hochmittelalter bei der Konstruktion von Miniaturen (Johann Konrad Eberlein). Aus dieser Epoche gibt es kaum schriftliche Quellen zur Herstellung dekorierter Bücher, doch lassen sich in den Miniaturen selbst Phänomene ausmachen, die als Folgen des Entstehungsprozesses zu interpretieren sind und etwas über diesen verraten. Aus dem I3. bis I5. Jahrhundert blieb dagegen eine Fülle von Schriftgut erhalten, das ein differenziertes, lebendiges Bild von den sozialen Strukturen der Auftraggeberschaft und von den Arbeits- und Lebensbedingungen der Buchmaler zu entwerfen erlaubt und in drei Beiträgen vorgestellt und ausgewertet wird (Alison Stones, Karl-Georg Pfändtner, Susanne Rischpler). Eines der wichtigsten Phänomene, über das die Quellen Auskunft geben, sind die Ortswechsel mancher Buchmaler, die sich mitunter auch aus deren Werken rekonstruieren lassen (Armand Tif). Die häufig überregionale Ausrichtung von Buchherstellung und -rezeption, die an über Ländergrenzen hinweg agierende Auftraggeber geknüpft ist, zeigt, dass die Arbeiten der Künstler nicht in jedem Fall als Ausdruck örtlicher Gewohnheiten zu deuten sind (und dadurch nützliche Lokalisierungshilfen bieten), sondern auch bewusste Positionierungen sein können, die auf ein weitgespanntes Geflecht von Interessen und Ansprüchen reagieren (Michael Viktor Schwarz).

Die anschließenden Beiträge sind der arbeitstechnischen Organisation der Illuminatoren gewidmet. Da hierzu so gut wie keine schriftlichen Hinweise vorliegen, ist man auf formale Analysen angewiesen; dies führt häufig zu unterschiedlichen Interpretationen des Befundes, über die besonders dann, wenn es um Lokalisierungen geht, mitunter sehr emotional debattiert wird. Eine der Ursachen für Zuschreibungsprobleme dürfte, neben den Ortswechseln der Künstler, die Arbeitsteilung zwischen mehreren selbstständigen Malern oder zwischen Mitarbeitern eines Ateliers sein. Vor allem bei umfangreichen und anspruchsvollen Buchausstattungen oder bei höheren Stückzahlen sind, trotz grundsätzlicher Gemeinsamkeiten, immer wieder Schwankungen in der Ausführung zu erkennen, die sich am besten erklären lassen, wenn man von der Beteiligung verschiedener, möglicherweise unterschiedlich ausgebildeter Maler - zeitgleich oder zeitversetzt - ausgeht. Doch wie hat das funktioniert? Gab es Spezialisten für ornamentale und figürliche Malereien? Wie behandelten spätere Vollender einer Illuminierung die Werke ihrer Vorgänger, und kann man Nachahmungen/stilgerechte Ergänzungen von nur wenige Jahre zuvor entstandenen Malereien erkennen? Gab es bewusst eingesetzte Stillagen für unterschiedlich gut dotierte Aufträge? Wurden Handschriften und Drucke gleich behandelt? Dies sind nur einige der Fragen, zu deren Lösung methodisch verfeinerte, sämtliche Teile der Ausstattung berücksichtigende Stilanalysen beitragen können (Carmen Rob-Santer, Katharina Hranitzky). Ein entscheidender Faktor, der die Abgrenzung von Personalstilen grundsätzlich schwierig macht und sogar Versuche in dieser Richtung als fragwürdig erscheinen lässt, ist das Bemühen der Ateliers um ein einheitliches Erscheinungsbild ihrer Produkte. Diese Einsicht führt unter anderem zu Überlegungen, mit welchen Mitteln ein harmonisches Gesamtwerk erreicht wurde, was man überhaupt als einheitlich empfand und was die Unterordnung unter ein übergreifendes Ausstattungskonzept für die Ausdrucksmöglichkeiten eines Künstlers bedeutete (Lieselotte E. Saurma-Jeltsch). 
Anders als in den professionellen Ateliers, die vom Verkauf ihrer Werke lebten, ist die Buchausstattung in den spätmittelalterlichen Skriptorien der Klöster verlaufen: Unter den Bedingungen der Personalunion von Herstellern und Benutzern wurden eigene Regeln für die Handschriftenausstattung entwickelt (Christine Beier).

Ein wichtiger Punkt, der in allen Beiträgen zur Buchmalerei aus der zweiten Hälfte des I5. Jahrhunderts zumindest beiläufig angesprochen wird, ist der Buchdruck. Mit seiner Einführung hat eine schrittweise Veränderung der Situation eingesetzt, die man sich in der Rückschau leicht als Auseinandersetzung zwischen den Produzenten von gedruckten Büchern und denen von Handschriften vorstellt, bei der Letztere auf der Strecke blieben. Doch verliefen die Konkurrenzlinien durchaus anders, was bisher nur ansatzweise untersucht wurde. So lässt sich zum Beispiel gut nachweisen, dass an der Ausstattung von Drucken und Handschriften dieselben Personen beteiligt waren, und es sind nicht immer die Drucker gewesen, die den Ansprüchen der Auftraggeber am besten gerecht wurden (Lilian Armstrong).

Die Einführung des Buchdruckes hat nach dem in der Spätantike eingetretenen Wechsel von der Rolle zum gebundenen Buch zweifellos den grundlegendsten Wandel in der Buchherstellung mit sich gebracht, doch gab es auch in den Jahrhunderten dazwischen ständig Veränderungen, letztlich jedes Mal, wenn ein Text kopiert und ausgestattet wurde. Die Zeit und die damit verbundenen Interessensverschiebungen, Verständnisprobleme und Umdeutungen bestimmen maßgeblich das Aussehen, den Inhalt und das Zusammenspiel von Wort und Bild. Sie müssen bei Interpretationen berücksichtigt werden, denn sie machen aus den Kopien desselben Textes eigenständige, einzigartige Werke (Regina Cermann) und zeichnen sich auch in Büchern ab, an denen über Jahrzehnte, auf den ersten Blick nach einem einheitlichen Konzept und unter den gleichen Bedingungen, gearbeitet wurde (Christine Sauer).

Thema, Fragestellungen und ein Großteil der Beiträge des Bandes sind aus einem Kolloquium hervorgegangen, das unter dem Titel „Herstellungsbedingungen für Buchmalerei in Mittelalter und früher Neuzeit" vom 24. bis 26. Juni 201 I am Institut für Kunstgeschichte der Universität Wien (Pächt-Archiv/Forschungszentrum für Buchmalerei) stattfand. Für die finanzielle Unterstützung der Veranstaltung sind wir der Historisch-Kulturwissenschaftlichen Fakultät der Universität Wien, dem FWF (Fonds zur Förderung der wissenschaftlichen Forschung) und der Kunsthistorischen Gesellschaft Wien zu Dank verpflichtet. 


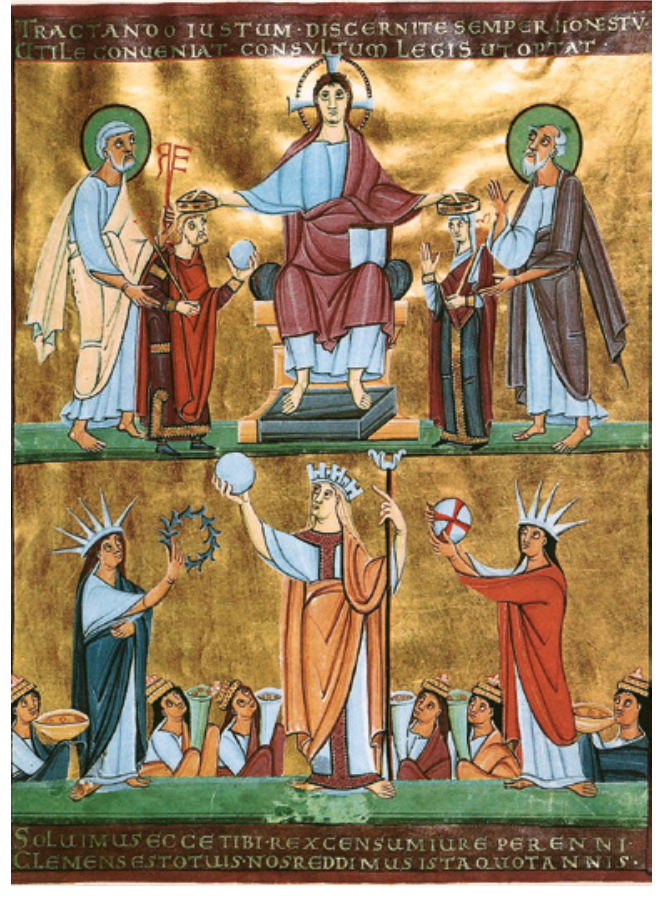

Abb. I: München, Bayerische Staatsbibliothek, Clm 4452, Perikopenbuch Heinrichs II., fol. 2r: Widmungsbild

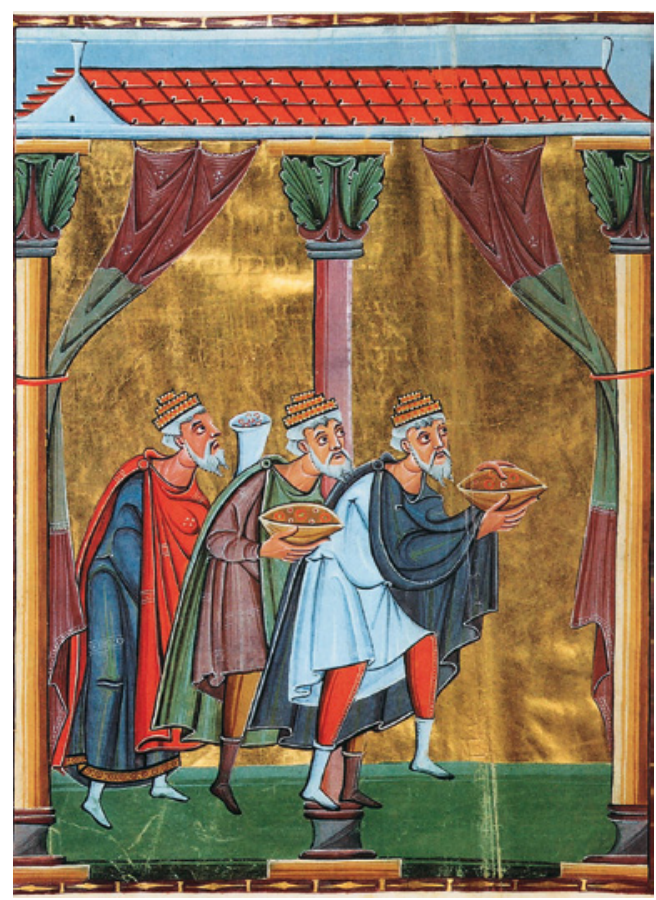

Abb. 3: wie Abb. I, fol. 17v: Heilige Drei Könige

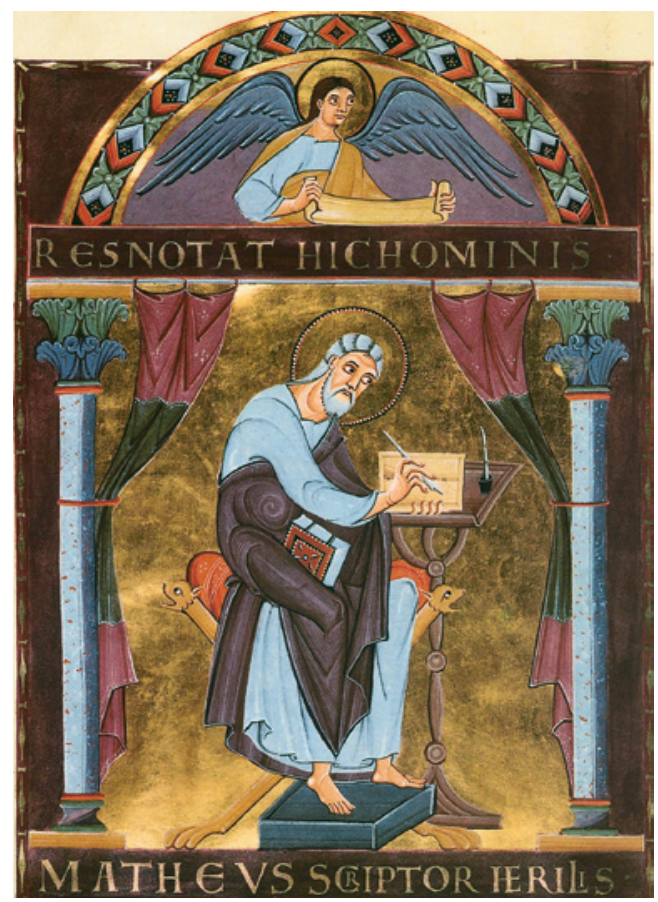

Abb. 2: wie Abb. I, fol. 3v: Matthäus

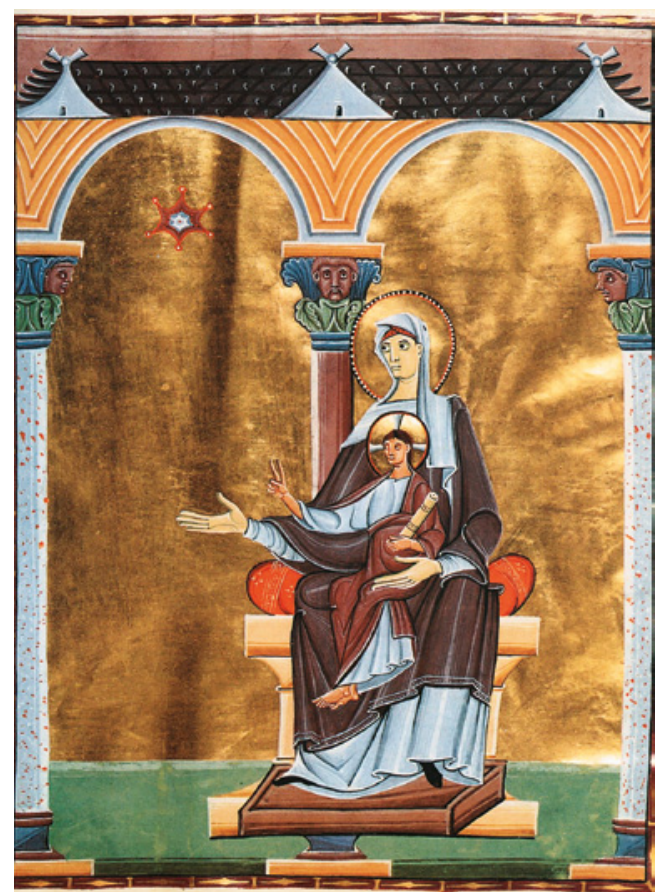

Abb. 4: wie Abb. I, fol. I8r: Maria mit Kind 


\title{
DAS PERIKOPENBUCH HEINRICHS II. (CLM 4452) - EIN BLICK AUF DIE HERSTELLUNGSWEISE DER MINIATUREN
}

\author{
Johann Konrad Eberlein
}

\section{VORWORT}

Der folgende Text listet - in der Hoffnung, einige Prolegomena zu einer Anleitung für die Untersuchung von hochmittelalterlichen Miniaturen überhaupt zu liefern - in abstrakter, systematisierender Form Aspekte der Bilder im Perikopenbuch Heinrichs II. auf. ${ }^{1}$ Auch wenn die Ergebnisse nur aus einer einzigen Handschrift stammen, können die dadurch legitimierten Fragen auch an andere gestellt werden. Ausgehend von der These, dass die mittelalterlichen Buchmaler generell nach Vorlagen arbeiteten, ${ }^{2}$ werden die Momente benannt, an denen diese Arbeitsweise zu Tage tritt. Infolge der Überlieferungslage, die uns nur in ganz seltenen Fällen unmittelbare Vorlagen erhalten hat, sind dies meist kritische Phänomene, also Brüche, Differenzen oder gar Fehler. Aber auch aus ihnen können Aussagen über die künstlerischen Konzepte und ihre Realisierungen gewonnen werden, deren Ergebnis die Bebilderung dieses Perikopenbuchs ist.

\section{DATIERUNG UND LOKALISIERUNG}

Die Gründe für die Datierung und Lokalisierung einer Handschrift liegen in der Regel außerhalb des Bereichs der Kunstgeschichte. Aus den Tatsachen, dass sich Heinricus, der Stifter des Codex, rex nennt, was Heinrich II. von I002-IOI4 war, dass das Bistum Bamberg IOO7 gegründet wurde und dass mit Petrus und Paulus die Heiligen des damaligen, IOI2 geweihten Domneubaus angerufen werden, kann man die geläufige Datierung zwischen 1007 und IOI2 und als Bestimmungsort Bamberg erschließen. Die Formulierung auf fol. Iv (Widmungsgedicht) ist indes sehr knapp und sachlich, ohne Nennung weiterer Personen: „Rex Heinricus ... obtulit hunc librum divina lege refertum ... in donaria templi“.

\section{TEXT}

Der Codex enthält 194 Perikopen von der Weihnachtsvigil bis zu den Adventssonntagen, dazu kommen die Gedächtnistage mehrerer Heiliger (commune sanctorum) sowie besondere Anlässe wie Kirchweihe oder Totenmesse (de diversis causis). Die Paläographen nehmen zwei Schreiber an. Insgesamt besteht der Codex aus 206 Pergamentblättern in 35 Lagen, die meist

I Da die Miniaturen leicht zugänglich sind (zum Beispiel in H. Filditz/R. KahsNitz/U. Kuder, Zierde für ewige Zeit. Das Perikopenbuch Heinrichs II., Frankfurt/Main 1994 (zugleich Ausst.-Kat. München 1994-95), dort auch alle Sachangaben), wurde hier auf eine vollständige Bebilderung verzichtet.

2 Grundlegend dazu J. K. EberLeIn, Miniatur und Arbeit. Das Medium Buchmalerei, Frankfurt/Main 1995. 
je vier Doppelblätter enthalten. Die Blattgröße ist $42,5 \times 32 \mathrm{~cm}$; die breiten Ränder der Seiten sind noch die ursprünglichen. ${ }^{3}$

\section{KUNSTHISTORISCHE EINORDNUNG}

Bei Prachtcodices diesen Ranges wird die kunsthistorische Einordnung in der Regel schon seit langem diskutiert. Das Perikopenbuch Heinrichs II. wird zur Reichenauer Schule gerechnet, innerhalb derer zur Liuthargruppe und wiederum innerhalb derer zu den vier großen illustrierten Codices, deren Abfolge so angenommen werden kann: Liuthar-Evangeliar, Evangeliar Ottos III., Bamberger Apokalypse und Perikopenbuch Heinrichs II. ${ }^{4}$ Die Eingliederung in das kunsthistorische Konstrukt „Reichenauer Schule“ kann hier nicht weiter diskutiert werden, ebensowenig, dass im Unterschied zum Bestimmungsort Bamberg der Herstellungsort der Handschrift offenbleiben muss.

\section{GLIEDERUNG DES SCHMUCKS}

Jede Perikope beginnt mit einer Initiale. Bei zehn Festen kommt dazu eine Zierseite mit Initiale und den ersten Worten des Textes auf Purpurgrund in einem farbigen Ornamentrahmen. Vor der Tagesmesse zum ersten Weihnachtstag kommt dazu eine zweite Zierseite mit dem Text: In die natalis Domini initium sancti evangelii.

Die Zierseiten verteilen sich auf folgende zehn Feste: Weihnachtsvigil (24. I2.): fol. 7r; dritte Messe zum ersten Weihnachtstag (25. I2.): fol. IIv-I2r; Epiphanias (6. I.): fol. I9r; Darbringung im Tempel (Mariae Lichtmess) (2. 2.): fol. 36r; Ostern: fol. II8r; Himmelfahrt: fol. I32r; Pfingsten: fol. I37r; Geburt Johannis des Täufers (24. 6.): fol. I5Ir; Petrus (und Paulus) (29.6.): fol. I53r und Mariae Himmelfahrt (15.8.): fol. I63r.

Die Verteilung der 28 Miniaturen ist folgende: fünf Miniaturen stehen am Beginn der Ausstattung: das Herrscherbild fol. 2r (nach dem Widmungsgedicht fol. Iv) und die vier Evangelisten Matthäus fol. 3v, Markus fol. 4r, Lukas fol. 5 v und Johannes fol. 6r. Die 23 Miniaturen vor den mit Zierseiten ausgestatteten Festtagsperikopen und ohne Zierseiten in der Karwoche und für Kirchweihe und Totenmesse verteilen sich wie folgt: Weihnachten fol. 8v-9r (zweiseitig, zwei Szenen); Epiphanias fol. I7v-18r (zweiseitig, eine Szene); Darbringung im Tempel (Mariae Lichtmess) fol. 35v (einseitig); Palmsonntag fol. 77v-78r (zweiseitig, zwei Szenen); Gründonnerstag fol. I05v (einseitig, zwei Szenen übereinander); Karfreitag fol. I07v-IO8r (zweiseitig, jeweils zwei Szenen übereinander); Ostern fol. II6v-II7r (zweiseitig, eine Szene); Himmelfahrt fol. I3Iv (einseitig); Pfingsten fol. 135v-136r (Ausgießung, lehrender Christus nach Jo I4, 23-3I) (zweiseitig, zwei Szenen); Geburt Johannis des

3 Die Angaben nach R. Kahsnitz, Inhalt und Aufbau der Handschrift, in: Fillitz/Kahsnitz/Kuder, Zierde für ewige Zeit (zit. Anm. I), S. 97-Ioo.

4 Aachen, Domschatz, Inv. Grimme Nr. 25; München, Bayerische Staatsbibliothek, Clm 4453; Bamberg, Staatsbibliothek, Ms. Bibl. I40; München, Bayerische Staatsbibliothek, Clm 4452: Diese Reihenfolge wird zum Beispiel in: G. Suckale-Redlefsen (Hrsg.), Das Buch mit 7 Siegeln. Die Bamberger Apokalypse, Ausst.-Kat. Bamberg 2000/200I (Luzern 2000) vertreten. 
Täufers fol. I49v-I5or (zweiseitig, jeweils zwei Szenen übereinander); Petrus (und Paulus) fol. I52V (Schlüsselübergabe) (einseitig); Mariae Himmelfahrt fol. I6Iv-I62r (Marientod, Jesus bei Maria und Martha nach Lu Io, 38-42) (zweiseitig, zwei Szenen); Kirchweihe fol. 2oor (Zachäus) (einseitig, zwei Szenen übereinander) und Totenmesse fol. 20Iv-202r (Jüngstes Gericht) (zweiseitig, zwei Szenen).

Die Illustration kann, was die von den Perikopen angesprochenen Themen betrifft, als sehr knapp charakterisiert werden. Dafür zeichnet sie eine einheitliche christologische Linie, zu der noch das Jüngste Gericht sowie Maria, Johannes und Petrus kommen. Vorangestellt sind den Perikopenminiaturen das Widmungsbild mit der Huldigung der Provinzen und anschließend ohne Unterbrechung die vier Evangelisten.

Eine oft konstatierte Besonderheit des Bildschmucks ist die häufige Verteilung der Miniaturen auf zwei gegenüberliegende Seiten. Im ganzen Codex gibt es nur fünf einseitige Miniaturen. Von den doppelseitigen zeigen sogar zwei (Epiphanias und Ostern) dasselbe Thema auf zwei Seiten verteilt. Die zweiseitigen Miniaturen sind oft auf eingebundene Doppelseiten gemalt. Es gibt acht solcher Doppelblätter, von denen sieben bemalt sind. Die Rückseiten dieser Doppelblätter sollten von Beginn an frei bleiben.

\section{FOLGEN DER BILDVERTEILUNG AUF ZWEI SEITEN}

Die Aufteilung von Bildthemen auf zwei gegenüberliegende Miniaturen hat Konsequenzen für ihre Gestaltung. Auf fol. 8v (Verkündigung an die Hirten) ist die Szene isoliert, die üblicherweise auf der Weihnachtsszene unterhalb der Krippe angeordnet ist (vgl. Bamberger Apokalypse fol. 63v). Der Zwang zur Raumfüllung erklärt die riesige Gestalt des Engels und seine Ausbreitung nach beiden Seiten, wobei die Faltenwürfe symbolisch seine göttliche Botschaft unterstreichen. Die Tendenz zur Symmetrie führte zum Verlust der üblichen turris gregis hinter dem Gebückten rechts. Die Schafe stehen sich symmetrisch gegenüber wie die zu einer Quelle oder einem Brunnen eilenden Tiere in symbolischen Darstellungen etwa auf Apsismosaiken. Auf fol. 9r (Geburt Christi) ist wegen des Fehlens der Hirten viel Fläche im unteren Drittel frei. Von den drei Verkündigungsengeln ist einer mit der Funktion einer atlantenartigen Tragefigur für die Geburtsstätte übriggeblieben, womit auch hier die zentralisierende, symmetrische Tendenz der Anordnung unterstrichen wird.

Auf fol. I7v (Anbetung der Weisen) kommt es infolge der Verteilung der sonst vereinten Darstellung (vgl. Evangeliar Ottos III. fol. 29r) auf zwei Miniaturen zur anaturalistischen Kollision der Füße mit der wieder zentralisierend um eine Mittelsäule erweiterten Ädikula, ebenso beim Thron der einsamen Marienfigur auf fol. I8r (Maria aus der Anbetung).

Auf fol. 77v (Die Jünger mit der Eselin und dem Füllen) führte das Verteilungsprinzip sogar zu einer Neuerfindung: Dem Einzug Christi in Jerusalem (fol. 78r) wurde die Darstellung der Jünger gegenübergestellt, die die Eselin für Christus abholen, ein Thema, das in der Reichenauer Buchmalerei einzigartig ist.

Auf fol. II6v (Drei Frauen am Grab) und fol. II7r (Der Engel am Grab) stehen die Figuren infolge der Verteilung des Themas auf zwei Seiten einsam vor dem Goldgrund. Zum Ausgleich wurde der Grabesengel so ausgedehnt, dass er möglichst viel von der Bildfläche ausfüllt. 
Er ragt mit allem, was an ihm beweglich ist, in den leeren Raum hinein und ist mit einer körperlichen Dimension ausgestattet, zu der der Kopf, der die Größe der sonstigen Figuren hat, nicht mehr passt. Trotz der Szenenverdoppelung ist die Ädikula auf beiden Seiten dieselbe, da es sich ja um dasselbe Grab handelt. Die Tendenz zur Füllung des leeren Raums findet sich auch auf Einzelszenen wie fol. 136r (Jesus spricht zu den Jüngern), wo Christus und in kleinerem Ausmaß Petrus in den Zwischenraum hineinragen. Infolge der Trennung der sonst verschmolzenen Szenen (vgl. Bamberger Apokalypse fol. 53r) Auferstehung der Toten (fol. 2orv) und Jüngstes Gericht (fol. 202r) ist erheblicher Platz für die Auferstehenden gewonnen, was sich auch in der großflächigen Gestaltung des Himmels niederschlägt.

\section{FIGURENADAPTIONEN}

Die Thronfiguren der Buchmalereien gehen auf wenige, aus der Antike stammende Grundtypen wie die frontale Herrscherfigur oder die nach rechts oder die nach links gewandte Schreiberfigur zurück. Trotz der langen Verwendungstradition kommt es auch nach Jahrhunderten noch zu Anpassungsschwierigkeiten. Die Evangelisten Matthäus (fol. 3v) und Johannes (fol. 6r) entstammen der Tradition der nach rechts gewandten Schreiberfigur, wie sie etwa die Petrusfigur in der Belauschungsszene des Papstes Gregor darstellt. ${ }^{5}$ Die neue Verbindung mit dem Faldistorium machte auf fol. $3 \mathrm{v}$ jedoch Schwierigkeit, so dass das linke Knie des Matthäus angehoben bzw. nach oben verlängert werden musste. Die Tradition der frontalen Thronfigur wurde auf fol. 4r (Markus) und fol. 5v (Lukas) benutzt, wobei der Kopf des Markus zwecks Blickverbindung mit dem Symbol neu nach oben gedreht wurde. Bei dem Lukas ist der Faltenstrahl nach links sicher nicht der Vorlagentradition zugehörig.

Die seltsame Bückhaltung der vorderen zwei Könige auf fol. I7v (Anbetung der Weisen) dürfte einer Vorlagentradition wie der des aufgerichteten Schreibers der genannten Gregorszene entstammen. Auf fol. I05v (Abendmahl - Fußwaschung) musste die Motivtradition der gebückten Figur bei dem Sandalenbinder wegen des Bildrandes zu einer kühnen Einwärtswendung des Fußes verändert werden. Der Tradition der nach links gewandten Schreiberfigur entstammt dagegen der Nikodemus auf fol. Io8r (Kreuzabnahme - Grablegung), der allerdings in solche Eile versetzt wurde, dass ihm gewissermaßen das rechte Knie vorausläuft.

Figurenadaptionen können auch das Alter oder das Geschlecht betreffen: Auf fol. I62r (Jesus bei Maria und Martha) ist Christus nicht wie sonst meist größenbetont und hat die helle Hautfarbe der beiden Frauen. Vielleicht ist seine Figur aus der Szene des zwölfährigen Jesus im Tempel entwickelt, wozu auch die Architektur mit dem Stadtbild passen würde. Die Verringerung der Schulterbreite und der kleine Kopf machen es wahrscheinlich, dass die Maria auf fol. I8r (Maria aus der Anbetung) aus der Tradition der männlichen Thronfigur entstand. Der Auferstehende links unten auf fol. 2oIv (Auferstehung der Toten) ist allerdings wohl keine Frau, da mit den Kugelformen auf den Schultern im Codex immer Gelenke bezeichnet werden, was bedeuten würde, dass in dieser Szene nur Männer auferstehen, es sei denn, man liest die Figuren als geschlechterübergreifende Formel für Tote.

5 Dazu J. K. Eberlein, Miniatur und Arbeit. Das Medium Buchmalerei, Frankfurt/Main i995. 
Auch bei Tieren konnten bei neuen Motivverbindungen Adaptionen notwendig werden. Damit der Löwe auf fol. 4r (Markus) das Buch halten kann, wurde eine Pfote stark nach oben verlegt, so dass sie aus der Schulter herauszukommen scheint.

\section{ADAPTIONEN VON ARCHITEKTURVORLAGEN}

Für die Rahmung von Miniaturen wird in der gesamten Buchmalerei häufig das Motiv der zweisäuligen Ädikula verwendet. Auf fol. I7v (Anbetung der Weisen) und auf fol. I8r (Maria aus der Anbetung) wurde es, wie schon gesagt, um eine Mittelsäule erweitert. Die zusätzlichen Dachformen entstammen der Formel: geöffnete Front mit seitlichen arkadengestützten Anbauten. Sie wird auf fol. 4r (Markus) und fol. 35v (Darbringung im Tempel) eingesetzt, wobei die Anbauten nach vorne, in die Bildebene gebogen sind. Bei den Adaptionen kann es zu Umdeutungen einzelner Elemente kommen. Auf fol. 4r (Markus) schmiegen sich die beiden äußeren Säulen des genannten Frontmotivs an die beiden großen roten Säulen der Bildädikula, als seien sie aus der vertikalen Farbteilung entstanden, mit der oft die Säulenrundung angedeutet wird. Schwer zu deuten sind die für die ganze Handschriftengruppe typischen bogenartigen bzw. einhüftigen Architekturabschlüsse nach unten wie bei der Darstellung Bethlehems auf fol. 9r (Geburt Christi). Vielleicht ist der Anschnitt als Reflex einer (fiktiven) terra undulata davor zu lesen.

\section{DER THRON MIT KISSEN UND SUPPEDANEUM}

In der karolingischen Kunst wird der aus der Antike übernommene Thron mit Kissen und Suppedaneum ausgestattet. Diese Hinzufügungen zur Motivtradition sind fast immer an der abweichenden Perspektive zu erkennen, die bemerkenswerterweise mit einer gewissen Bewusstheit vorgeführt wird. Diese gleichsam kanonische Ausstattung wird trotz der langen Tradition immer wieder neu im Bild hergestellt. Belege sind fol. 2r (Widmungsbild), fol. 3v (Matthäus), fol. 4r (Markus), fol. 5v (Lukas) und fol. 6r (Johannes). In derselben Weise wird auch der Thron des Kaiphas fol. I07v (Kreuzigung - Christus vor Kaiphas) ausgestattet. Interessant ist die Ausstattung auf fol. I05v (Abendmahl - Fußwaschung). Christus sitzt auf einem Kissen; sein Sitz hat einen prächtigen Behang, aber dem einfachen Sitz des Judas gegenüber wurde das Suppedaneum gegeben. Offenbar sollte bei Christus die traditionelle Throndarstellung, zu der auch noch die Schriftrolle in seiner Linken gehört, vermieden werden, indem sie um das Suppedaneum gekürzt wurde, was auch das stark einwärts gebogene linke Bein erklären würde, das nicht auf einen Fußschemel aufgestellt werden kann. Die Vorstellung eines Throns mit Suppedaneum bestimmt auch noch die Positionen von Sitz und Waschbecken bei dem Petrus in der Fußwaschung darunter.

Ansonsten kann der Thron den jeweiligen Erfordernissen angepasst werden. Auf fol. 6r (Johannes) hat er, entsprechend der Sitzrichtung des Evangelisten, nur links einen Abschluss. Auf fol. I6Iv (Marientod) wurde aus dem Sitzmöbel ein Bett, und auf fol. 2oor (Zachäus im Baum - Jesus bei Zachäus) wurde aus dem Thron Christi mit dem Kissen eine Bank, auf der alle sitzen. 


\section{EINFÜGUNGSPROBLEME BEI KLEINMOBILIAR}

Kissen und Suppedaneum gehören zum Thron Christi und der Evangelisten. Anders ist die Situation, wenn Kleinmobiliar, das zwar zu einem Thron gehört, aber nicht so eng mit ihm verbunden ist, eingefügt werden soll. Das betrifft vor allem die Pulte und Schreibständer der Evangelisten. Auf fol. 3v (Matthäus) ist das Pult offensichtlich aus einer anderen Vorlage appliziert. Dadurch kam eine zweite, kleinere, in einem Tintenfass steckende Feder überflüssigerweise zu den Gerätschaften dazu. Unten kollidiert das Pult unlogisch mit dem Suppedaneum und einem Löwenfuß. Auf fol. $4 \mathrm{r}$ (Markus) ist links ein Pult mit Tintenfass und Feder so eingefügt, dass letztere dem Evangelisten wie von selbst in die Hand kommt. Unten kollidiert wieder der Pultfuß mit den anderen Bildelementen. Auf fol. 5v (Lukas) steht das Pult vor dem Thron auf der unteren Schriftleiste. Auf fol. 6r (Johannes) steht rechts eine Säule mit einem leeren Tintenfass, dessen Feder offenbar wieder dem Goldgrund geopfert wurde.

\section{IO. DIE VERTEILUNG VON SCHREIBGER ÄTEN UND -GRUNDLAGEN}

Die Hersteller von Miniaturen standen immer wieder vor dem Problem der Verteilung von Codex und Buchrolle besonders zwischen den Evangelisten und ihren Symbolen. Im Perikopenbuch Heinrichs II. fiel die Entscheidung dahingehend aus, dass Symbol und Evangelist jeweils etwas anderes halten sollten, dass die Verteilung aber nicht durchgängig gleich sein müsse. Der Schreiber des Vorlagentypus auf fol. 3v (Matthäus) schrieb ursprünglich offenbar mit einem stilus in ein Diptychon. Weil der Engel eine Rolle erhielt, musste Matthäus ein Buch bekommen. Er hält zwar eine Feder in der Rechten, schreibt aber entsprechend der Vorlage weiter in ein Diptychon, das er von unten hält, daher erhielt er zusätzlich ein geschlossenes Buch, das in seinem Schoß liegt bzw. steht. Auf fol. 4r (Markus) erhielt der Evangelist eine Rolle, da das Symbol ein geschlossenes Buch hält. Auf fol. 5v (Lukas) wurde dem Evangelisten ein Schabmesser in die Linke gegeben, das nur für Pergament dienlich ist, nicht für die Buchrolle, die alternierend zum Buch des Symbols über dem Pult liegt. Der Feder in seiner Rechten fehlt ein Schreibobjekt. Die ursprünglich sicher in dem Tintenfass rechts steckende Feder wurde zugunsten des Goldgrundes aufgegeben. Auf fol. 6r (Johannes) hat der Evangelist kein Schreibgerät, da auch hier die im Tintenfass steckende Feder im Goldgrund aufging. Er hält in der Rechten einen geschlossenen Codex. Zu diesen Erscheinungen kann man fol. 2r (Widmungsbild) nehmen, wo Christus wegen des doppelten Krönungsaktes keine Hand frei hat, weswegen der aufgeschlagene Codex frei auf seinem linken Knie steht, sowie fol. Isor (Geburt Johannes des Täufers - Namensgebung), wo Zacharias wie Matthäus mit der Feder in ein Diptychon schreibt. Ein Reflex der Evangelienbücher ist wohl die Tatsache, dass auf fol. 202r (Jüngstes Gericht) außer Petrus und Paulus noch vier Apostel mit Büchern versehen wurden. 


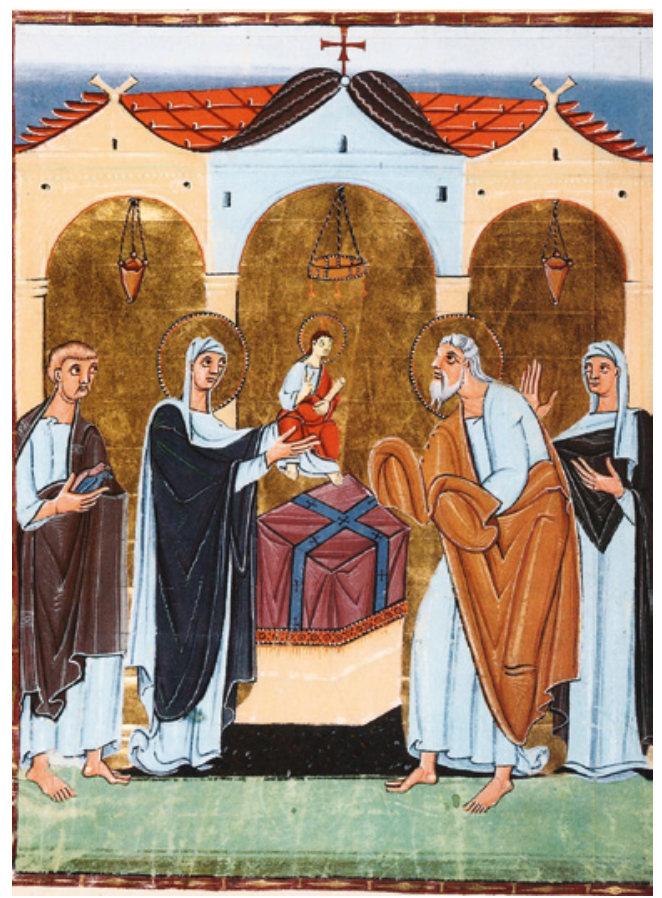

Abb. 5: wie Abb. I, fol. 35v: Darbringung im Tempel

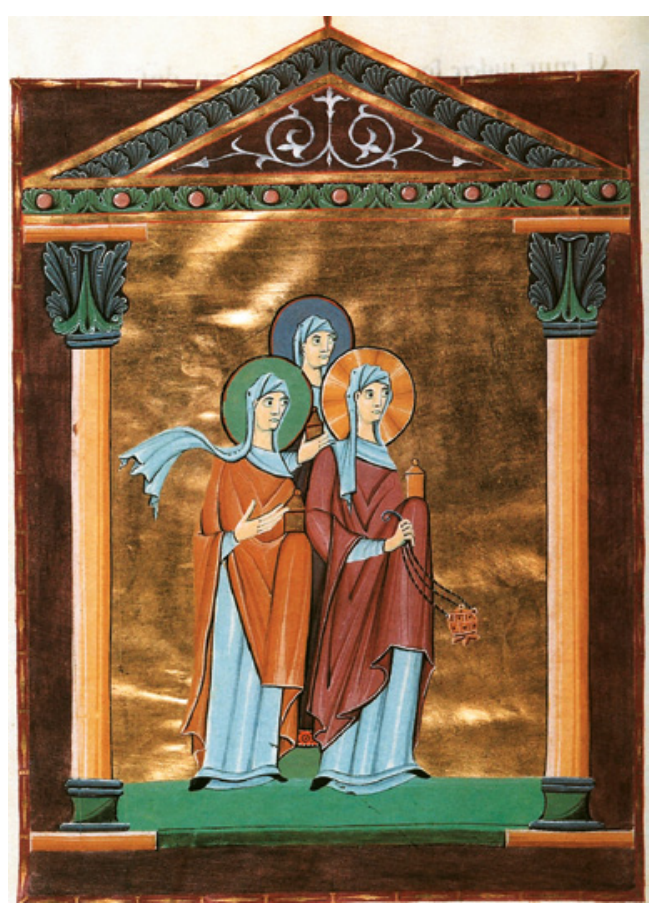

Abb. 7: wie Abb. I, fol. II6v: Die drei Frauen am Grab

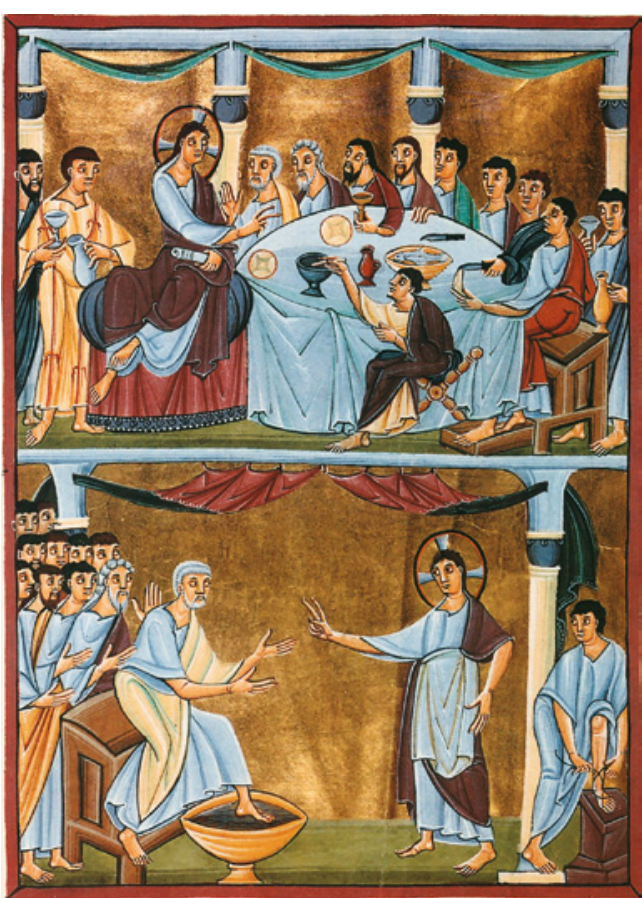

Abb. 6: wie Abb. I, fol. Iosv: Abendmahl Fußwaschung

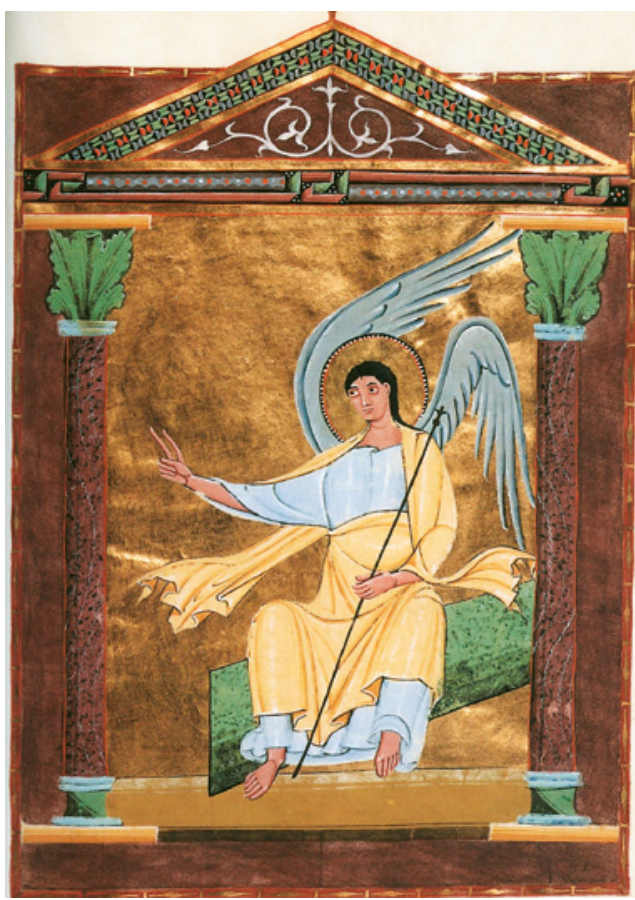

Abb. 8: wie Abb. I, fol. iı7r: Engel 


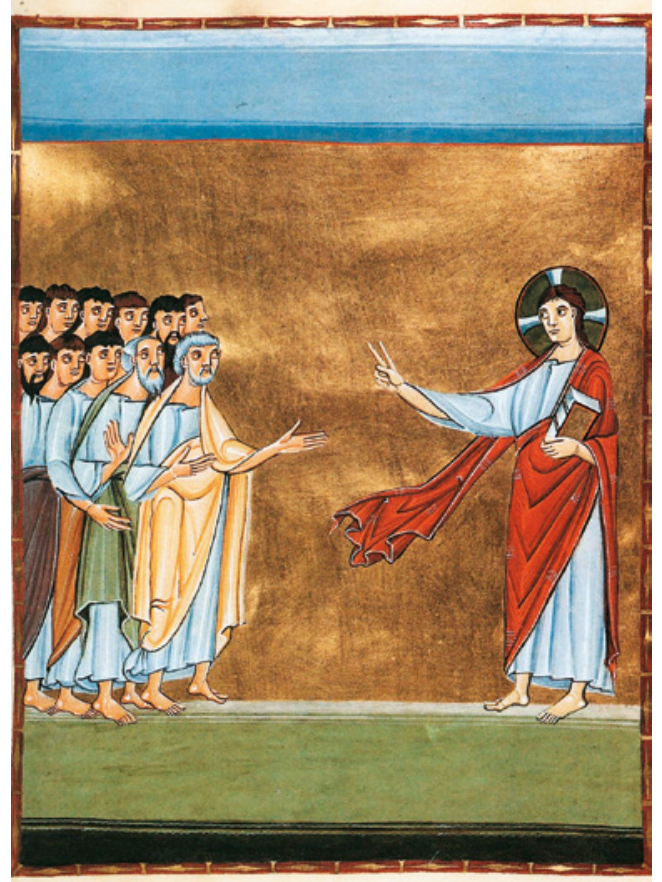

Abb. 9: wie Abb. I, fol. 136r: Jesus spricht zu den Jüngern

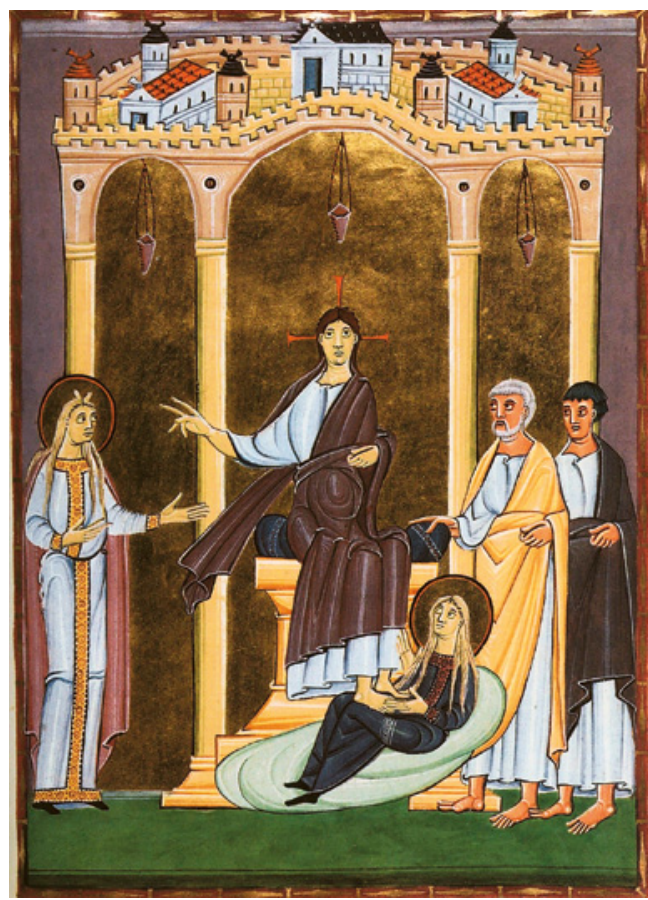

Abb. II: wie Abb. I, fol. I62r: Jesus bei Maria und Martha

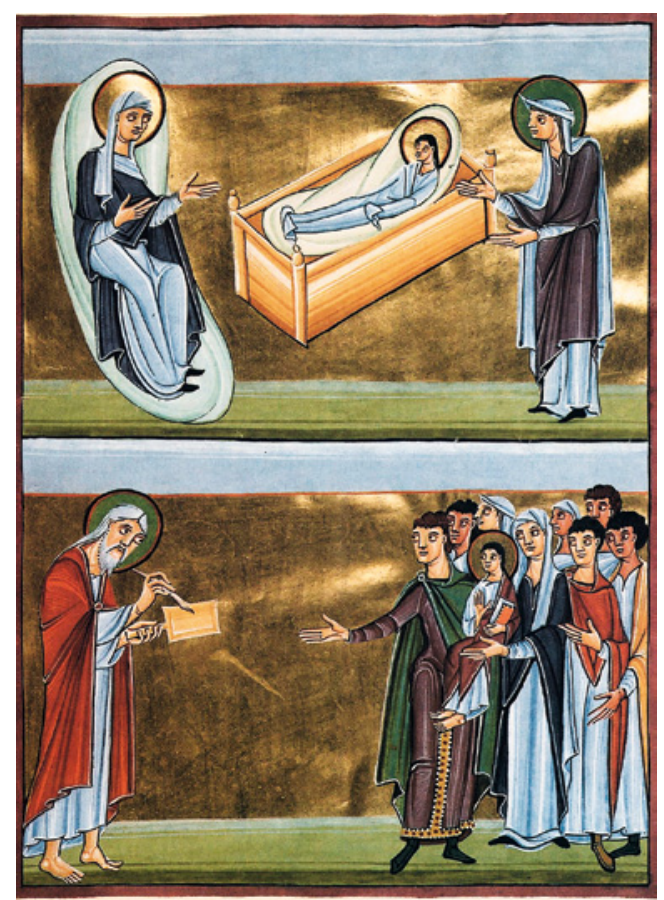

Abb. Io: wie Abb. I, fol. I5or: Geburt Johannes des Täufers - Namensgebung

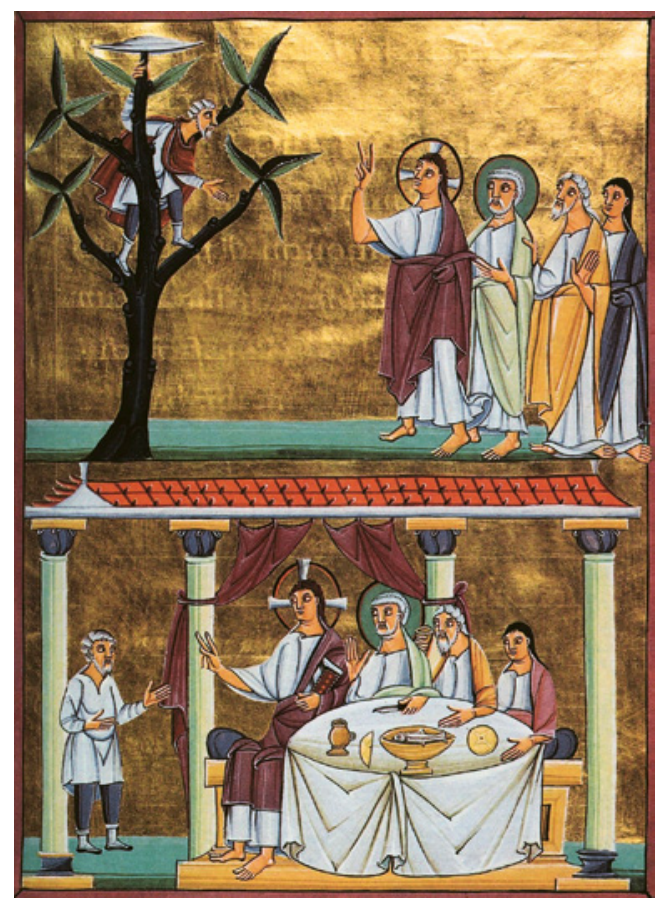

Abb. I2: wie Abb. I, fol. 2oor: Zachäus im Baum - Jesus bei Zachäus 


\section{ADAPTIONEN NICHT-ANTIKER MOTIVE}

Zwei Motive stellten eigene Adaptionsprobleme, was damit zusammenhängen dürfte, dass sie nicht der spätantiken Vorlagentradition entstammten: das byzantinische Tuchlager und die Krippe bzw. das Grab Christi.

Das Tuchlager wurde nicht als horizontale Liegefläche, sondern eher wie eine mandorlaartige Hinzufügung zur Figur aufgefasst, weswegen es auch vertikal aufgestellt werden kann. Auf fol. 9r (Geburt Christi) liegt Christus horizontal, Maria dagegen vertikal, ebenso Elisabeth auf fol. I5or (Geburt Johannes des Täufers - Namensgebung), eine Ausrichtung, die das Tuchlager zum Thron macht.

Da Christus auf fol. 9r (Geburt Christi) auf dem Tuchlager, also eigentlich auf dem Boden, liegt, entfällt die Krippe. Seine grüne Lagerstätte ist jedoch solide ummantelt, was wohl symbolisch auf das Grab vorausweist. Das der Grablegung dienende kistenartige Gebilde fol. Io8r (Kreuzabnahme - Grablegung) müsste in der Luft schweben, wenn der Fuß Josephs so unter ihm sichtbar wäre. Es hat keinen Deckel, während auf fol. Iı7r (der Engel am Grab) der Auferstehungsengel wohl auf dem verschobenen Sarkophagdeckel sitzt, der allein anzeigt, dass das Grab bereits leer ist. Auf fol. I5or (Geburt Johannes des Täufers - Namensgebung) liegt der neugeborene Johannes wie der Christus der Geburtsszene auf einem Tuchlager, weswegen sein Bett eher zur Kiste tendiert.

\section{I2. ÜBERSCHNEIDUNGEN}

Bei der Zusammenfügung der Vorlagen kommt es zu Überschneidungen bzw. Beschneidungen. Auf fol. 2r (Widmungsbild) ist der Nimbus Christi zu groß geraten und kollidiert mit dem Buchstaben $\mathrm{T}$ in der Überschrift, die offensichtlich vorher eingetragen wurde. Stark beschnitten, da offenbar die Möglichkeit zur Verkleinerung nicht bestand, sind die Symbole von Markus, Lukas und Johannes auf fol. 4r (Markus), fol. 5v (Lukas) und fol. 6r (Johannes).

\section{I3. ÜBERTREIBENDE WEITERENT WICKLUNG}

Eine seltsame Erscheinung ist die übertreibende Motivverwendung. Auf fol. 2r (Widmungsbild) sind die Strahlen der Kronen von Gallia und Germania von den vor allem auf Münzbildern überlieferten Kronen römischer Imperatoren abgeleitet, aber im Vergleich zu diesen übertrieben in die Länge gezogen. Ähnlich sind die Frisuren der Teufel auf fol. 202r (Jüngstes Gericht) geformt, die damit gleichfalls das von Münzen her bekannte Erscheinungsbild der heidnischen Kaiser reflektieren könnten. Aber diese Tendenz ergreift auch die Eselsohren auf fol. 9r (Geburt Christi), fol. 77v (Die Jünger mit der Eselin und dem Füllen) und fol. 78r (Einzug in Jerusalem). Sogar die Winde auf fol. 2oIv (Auferstehung der Toten) haben (wie in der Bamberger Apokalypse fol. I7v) zu den menschlichen Ohren zusätzliche lange Tierohren.

Einer vergleichbaren Übertreibung folgt die terra undulata auf fol. $77 \mathrm{v}$ (Die Jünger mit der Eselin und dem Füllen). 


\section{4. FIXIERUNGEN DURCH VORLAGEN}

Nach den Varianten der Adaptionsmöglichkeiten seien einige Beispiele genannt, auf denen Fixierungen durch Vorlagen auf Grund von Differenzen zu Lösungen festzustellen sind, die normaler bzw. einfacher gewesen wären. Auf fol. 35v (Darbringung im Tempel) hat das Kind keine natürliche Haltung, sondern die Thronhaltung, die es im Arm der Maria hat. Gewissermaßen überreicht Maria Simeon ein Stück Bild. Dasselbe geschieht auf fol. I5or (Geburt Johannes des Täufers - Namensgebung) bei Elisabeth und Johannes.

Die Anordnung der Apostel auf fol. I35v (Pfingsten) in einer Sechsergruppe folgt offenbar dem antiken Schema des Philosophen mit sechs Schülern, das in der Spätantike - etwa auf der sogenannten Lipsanothek von Brescia - von der christlichen Kunst übernommen wurde. Statt des lehrenden Christus erscheint hier das Buch, die fehlenden sechs Apostel mussten darüber ergänzt werden.

Auffallend ist ferner die Verteilung der Strahlen des Heiligen Geistes. Obwohl sie leicht in zwei symmetrische Sechsergruppen zu teilen gewesen wären, wurde ein Strahl zentral in der Mitte platziert, damit er vom Schnabel der Taube ausgehen kann (vgl. Bamberger Apokalypse fol. 73r).

Der Baum, auf den der Zöllner Zachäus kletterte, war nach Lukas ein Maulbeerbaum. Sorgfältig sind daher auf fol. 2oor (Zachäus im Baum - Jesus bei Zachäus) Maulbeerblätter an die Astenden des Baumes gemalt, der ansonsten dem Schema der aus der Pinie entwickelten spätantiken Formel für Baum folgt, die seit der Karolingerzeit als „Pilzbäume“ auftreten, weswegen auch hier der oberste Ast eine „Pilzkappe“ trägt, gewissermaßen als Bestätigung dafür, dass es sich um einen richtigen Baum handelt (Liutharevangeliar fol. I7ov).

\section{I5. AUSMALUNGSPROBLEME}

\section{a. Unklare Flächenbegrenzungen}

Auf fol. 2r (Widmungsbild) haben die Gewänder von Gallia und - in kleinerem Umfang - von Roma unten, zwischen den Füßen, eine unbegründete blaue Fortsetzung, die nicht konturiert ist. Bei allen Evangelistensymbolen (fol. 3v Matthäus; fol. 4r Markus; fol. 5v Lukas; fol. 6r Johannes) erscheint der geschichtete Himmel nicht, wie üblich, in waagerechter Trennung, sondern so, dass nur die Partie hinter dem Kopf und über den Flügeln eine andere Farbe hat. Das führt zu dem Problem, dass die Grenze rechts und links hinter den Flügeln nicht klar festgelegt ist. Auf fol. 78r (Einzug in Jerusalem) ist rechts unten das Blaugrau des Stadttors nur einseitig durchgezogen. Auf fol. IO5v (Abendmahl - Fußwaschung) ist bei Judas nicht zwischen Tischtuch und Gewand unterschieden. Keinen Sinn hat auf fol. I6Iv (Marientod) der blaue Streifen neben dem Clipeus, den die Engel halten.

\section{b. Berührungsprobleme}

Die gesamte mittelalterliche Kunst kennt das Problem der ungewollten Berührung von Flächen und Formen. So kommen sich auf fol. 2r (Widmungsbild) das Gewand der Halbfigur links unten und das der Gallia in Form und Farbe gefährlich nahe; eine Verschmelzung wur- 
de gerade noch vermieden. Eigentümlich ist auf fol. IO7v (Kreuzigung - Christus vor Kaiphas) der Abschluss des blauen Himmels unmittelbar am oberen Rand des Kreuzbalkens. Auf fol. 136r (Jesus spricht zu den Jüngern) balancieren Christus und die Apostelschar auf einem dünnen grauen Streifen, der das Grün nach oben abschließt und sonst nur als Begrenzung der Farbfläche dient, hier aber wie ein schmales Mäuerchen eingesetzt wird.

\section{c. Übermalte Hände}

Das Phänomen der Handübermalung, das besonders auftritt, wenn Haut- und Gewandfarbe sich ähneln, ist in der Liuthargruppe grundsätzlich nachzuweisen (vgl. Bamberger Apokalypse fol. I3v). Im Perikopenbuch Heinrichs II. kommt es immer wieder vor: beim Engel rechts oben auf fol. 9r (Geburt Christi), beim Anführer der Begrüßungsgruppe auf fol. 78r (Einzug in Jerusalem), bei den Engeln in der Mitte auf fol. I3Iv (Himmelfahrt Christi), auf fol. I49v (Verkündigung an Zacharias - Stummheit des Zacharias) bei der ersten Figur gegenüber dem stummen Zacharias, bei Christus selbst auf fol. I52v (Schlüsselübergabe an Petrus) und wieder bei Christus und dem hintersten Jünger auf fol. 2oor (Zachäus im Baum - Jesus bei Zachäus). Der Fehler kommt meist dadurch zustande, dass der Mantel der Figur über den Daumen gewickelt sein soll, um so gehalten zu werden, und dass der Ausmaler die ganze Hand dem Stoff zuordnet (vgl. Bamberger Apokalypse fol. 45r).

\section{I6. GRUPPENERG ̈̈NZUNGEN}

Bei Darstellungen von Figurengruppen trat häufig das Problem auf, dass die Vorlagen nicht die gewünschte Personenzahl aufwiesen und daher ergänzt werden mussten. So dürfte die linke Dreiergruppe auf fol. 78r (Einzug in Jerusalem) um die oberen Köpfe ergänzt worden sein. Zu der rechten Zweiergruppe dürften zwei Köpfe und ein Arm hinzugefügt worden sein. Unübersehbar ist der Vorgang auf fol. II6v (Drei Frauen am Grab), wo die ursprüngliche Zweiergruppe (vgl. Bamberger Tropar, Bamberg, Staatsbibl. Msc.Bibl.76, fol. 82r) mit dem Kopf dahinter auf die geforderte Dreizahl gebracht wurde. Dabei wurde unter ihren Füßen die grüne Standfläche ergänzt. Üblicherweise werden die Apostel von Petrus und Paulus angeführt. Letzterer wurde auf fol. I3Iv (Himmelfahrt Christi) situationsgemäß durch Maria ersetzt. Da hinter ihr sechs Apostel stehen, hinter Petrus gegenüber nur fünf, wurde der freie Platz durch eine gewaltige Verbreiterung seiner Figur gefüllt. Auf fol. I36r (Jesus spricht zu den Jüngern) ist die Szene bildlich als Dialog zwischen Christus und Petrus konzipiert. In dem verbliebenen Raum hinter diesem wurden zunächst neun Jünger untergebracht. Um auf die erforderliche Elfzahl zu kommen, wurde über Petrus noch ein Kopf eingefügt, wobei man die zu den anderen Gesichtern differierende Profilansicht in Kauf nahm, die in der mittelalterlichen Kunst grundsätzlich eine depravierende Bedeutung hat. Alle diese Vorgänge können in der Entwicklung der Konzeption aufgehoben gewesen sein, vielleicht mit Ausnahme von fol. II6v, wo die grünen und goldenen Grundlagen schon vorhanden gewesen sein dürften. 


\section{7. FUSS PROBLEME}

Der Umgang mit den Beinen bzw. Füßen ist eine Bestätigung der immer wieder auftretenden Problematik bei der Realisierung von Figurengruppen. Auf fol. I7v (Anbetung der Weisen) kollidieren die Beine der vorderen Könige unrealistisch mit der Mittelsäule. Fast könnten sie auch mit dem jeweils anderen Körper verbunden sein. Auf fol. 77v (Die Jünger mit der Eselin und dem Füllen) sollte eine Kollision mit den Eselsfüßen vermieden werden, weswegen der rechte Jünger einen merkwürdigen Ausfallschritt nach hinten macht. Auf der gegenüberliegenden Seite fol. 78r (Einzug in Jerusalem) haben zwar die Esel alle Füße, die Menschen der linken Sechsergruppe aber nur drei bloße und zwei beschuhte, die der Vierergruppe gegenüber zusammen lediglich drei Füße. Auf fol. I36r (Jesus spricht zu den Jüngern) stehen die elf Apostel auf sechs Füßen, auf fol. I5or (Geburt Johannes des Täufers - Namensgebung) die acht Personen auf sechs und die zwölf Apostel auf fol. I52v (Schlüsselübergabe an Petrus) auf sechs Füßen. Von den Sechsergruppen zuseiten des Kreuzes auf fol. 202r (Jüngstes Gericht) hat die linke neun, die rechte acht Füße. Die Zweiergruppe hinter Kaiphas auf fol. IO7v (Kreuzigung Christus vor Kaiphas) hat nicht nur zusammen zwei Füße, sondern einer der Löwenfüße des Faldistoriums von Kaiphas tritt auch noch auf den linken dieser beiden.

\section{8. INHALTLICHE AUFFÄLLIGKEITEN}

Da infolge der geschilderten Aufteilung mancher Themen auf zwei gegenüberliegende Seiten bis zu vier Szenen vorkommen können, stellte sich das Problem der Reihenfolge. In der zu erwartenden Abfolge von oben nach unten und insgesamt von links nach rechts ist zum Beispiel die Geschichte der Geburt Johannes des Täufers geschildert (fol. I49v: Verkündigung an Zacharias - Stummheit des Zacharias; fol. I5or: Geburt Johannes des Täufers - Namensgebung). Diese Reihenfolge ist jedoch bei so wichtigen Themen wie auf fol. I05v (Abendmahl - Fußwaschung) und fol. I07v (Kreuzigung - Christus vor Kaiphas) nicht eingehalten.

Wenn auf fol. 9r (Geburt Christi) mit dem Gebäude mit der goldenen Öffnung in der Stadtabbreviatur der Stall gemeint ist, dann käme er auf der Darstellung zweimal vor. Auf fol. I36r (Jesus spricht zu den Jüngern) erscheint hinter Petrus eine paulusähnliche Figur, was historisch nicht möglich wäre.

\section{I9. IDEOLOGISCHE SPUREN}

Es scheint sehr schwierig, in der durch Vorlagen genormten Welt der mittelalterlichen Buchmalerei nach Eingriffen zu suchen, die weltanschauliche, ideologische Meinungen preisgeben. Dennoch ist das möglich. Zum oben geschilderten Fußproblem gehört noch Folgendes. Auf fol. 2r (Widmungsbild) sind die nackten Füße der drei weiblichen Personifikationen sehr reduziert. Auf fol. gr (Geburt Christi) sind die Füße Mariens nicht zu sehen, die Josefs nackt und deutlich. Diese Differenz zieht sich durch das ganze Buch; immer sind die Frauenfüße beschuht und kaum zu sehen (fol. I8r; fol. 35r; fol. II6v; fol. I3Iv; fol. I5or; fol. I62r). 
Aufschlussreich ist die Darstellung auf fol. I62r (Jesus bei Maria und Martha). Martha, die Patronin der Hausfrauen, steht mit einer Frisur, die wohl die Geschlossenheit ihrer Haare andeuten soll, am Rand. Bei ihrer Hüfte ist die Rundung des Konturs vermieden, die Maria Magdalena hat. Sie liegt auf dem hier unmotivierten Tuchlager wie das sonstige Suppedaneum unter den Füßen Christi, der sie gewissermaßen mit Füßen tritt (Liutharevangeliar fol. I5Iv). In der Bamberger Apokalypse stehen die Tugenden genauso auf den dort nackten, weiblichen und langhaarigen Lastern (fol. 6or).

Dazu sei folgende Besonderheit genannt. Die Initialen des Codex sind nach Art der Reichenauer Schule mit spiraligen Pflanzenmotiven geschmückt. Eine Ausnahme ist die Initiale M auf fol. Iı8r, die für Maria Magdalena steht. Sie enthält zwei phantastische Palmetten, die sich mit rötlichen Rändern entfalten und von samenartigen Gebilden umschwirrt werden. Der Verweis auf sexuelle Symbolik ist unübersehbar.

$\mathrm{Zu}$ dieser Linie passt folgender Punkt: Auf fol. I05v (Abendmahl - Fußwaschung) scheint zunächst unklar, wer Judas ist. Nach dem Schema des Gleichnisses von der königlichen Hochzeit (vgl. Augsburg, Diözesanmuseum St. Afra, DMA Ioo3 [vormals Hs. I5a], fol. I22r oder München, Bayerische Staatsbibliothek, Clm 23338, fol. I54v) sitzt vor dem Tisch an der Stelle des unpassend Gekleideten, der dann hinausgeworfen wird, ein Apostel, der seine Hand mit Christus in den Kelch tauchen könnte. Judas ist aber der rechts außen, dessen Hinterteil als Hinweis auf das Laster der Sodomie obszön sichtbar ist. Er hält in der Linken den Bissen, den ihm Christus gereicht hat. Diese Deutung wird durch den größten Teufel auf fol. 202r (Jüngstes Gericht) bewiesen, der mit seiner obszönen Pose wieder sein Laster, die Sodomie, verrät, dessentwegen er auch in schwere Ketten gefesselt ist. Der entsprechende Teufel in der Bamberger Apokalypse (fol. 5Ir) weist dieses Laster nicht auf.

Wie genau die Figuren des Codex zu lesen sind, das zeigen auch die hässlich und unvornehm bewegten Kriegsknechte auf fol. I07v (Kreuzigung - Christus vor Kaiphas), mit denen so etwas wie eine soziale Spannung ins Bild kommt.

\section{RES ÜMEE}

Das Ergebnis der vorstehenden Auflistung muss insofern vorläufig genannt werden, als zum einen sicher nicht alle Diagnosemöglichkeiten ausgeschöpft wurden und zum anderen der Blickwinkel über die eine betrachtete Handschrift hinaus ausgeweitet werden müsste. Mit diesen Einschränkungen sei festgehalten, dass insgesamt nichts dafür spricht, dass es einen einzigen Meister gegeben hat, dessen Bemühungen die bildliche Ausstattung des Codex entstammt. Es fanden sich auch keine Hinweise auf eine örtliche Festlegung der Herstellung des Buches. Die Beobachtungen zeigen eher an, dass sich vier Handlungszentren unterscheiden lassen.

\section{Projektleitung/Organisation}

Es muss jemanden gegeben haben, der die Leitung des Projekts innehatte. Er sorgte für das überreiche Platzangebot, den breiten Rand, das Freilassen der Rückseiten, die Einbindung eigener Doppelblätter für die Miniaturen mit der Absicht ihrer Aufteilung auf zwei Seiten bzw. die zweimalige Spaltung eines Themas in zwei ganzseitige Miniaturen. Es mussten offenbar 
keine Einschränkungen aus ökonomischer Sicht getroffen werden. Der Platz wurde als ranggebender Luxus eingesetzt, hinter dem man den höchsten Anspruch vermuten kann, einen herrscherlich-repräsentativen Ausstattungs-Willen, der sich der Ausdehnung in die Fläche, also eines gewissermaßen territorialen Prinzips, bediente.

\section{Bildkonzeption}

Es muss jemanden gegeben haben, der diese Tendenz in der Bebilderung umsetzte. Hier kann man an die von Beat Brenk postulierte Position des Concepteurs denken. ${ }^{6}$ Jemand musste die Bilder entwerfen, die nach der Platzausweitung und Zerschlagung der Vorlagen zu schaffen waren, und der entsprechend die Szenen neu konzipierte oder die Figuren an- und abschwellen ließ. Er folgte den Herstellungspraktiken der damaligen Miniaturmaler, die Figuren als nach Vorlagen durchgepauste, flache Gebilde auffassten, die übereinandergelegt werden konnten, so dass man Gruppen bis zur gewünschten Personenzahl mit Köpfen ergänzen und Füße anfügen konnte, die der korrekten Zahl nicht folgen mussten. Am wichtigsten war für diese Arbeitsweise die Verfügungsmacht über die Figurenmotive mit den antiken Gewändern. Der Gewandkörper wurde als Einheit behandelt, als Makroelement, an den die Mikromelemente Köpfe und Füße nach Notwendigkeit hinzugefügt wurden. Hier liegt der Beginn der künstlerischen Faltenpsychologie, die bis zum Schnitzaltar und Dürer reicht.

\section{Ausmalung}

Eine dritte Position nahmen in diesem Gefüge die Ausmaler der konzipierten Miniaturen ein. Ihre abschließende Farbgebung erzeugte eine Bildansicht, die nicht wie in der Kunst der Neuzeit eine Fläche ist, in der alles vorher Gedachte und Verarbeitete aufgehoben ist, sondern in der diese Elemente auch nebeneinander stehen können. Die kritischen Phänomene, in denen wir manchmal Fehler sehen, sind mit ihrer Entstehungsgeschichte identisch. Sie haben verschiedene historische Tiefen. Die Problematik der Vereinigung von antikem Thron und den herrscherlichen Zutaten Kissen und Suppedaneum entstammt der Karolingerzeit. Die Vorlagen, die den traditionellen „Pilzbaum“ mit dem geforderten Maulbeerbaum in der Zachäusszene verschmolzen oder Christus seine Füße auf den Leib Maria Magdalenas wie auf ein überwundenes Laster stellen lassen, entstammen bereits der sogenannten Reichenauer Schule. Fehler wie die Übermalungen der Hände geschahen in der Gegenwart. Die Bilder verschweigen ihre historischen Entstehungsbedingungen nicht.

\section{Ideologische Vorgabe}

Es muss jemanden gegeben haben, der seine Ansichten über bestimmte Dinge in die Bilder einfließen lassen konnte. Es gibt eine deutlich erkennbare moralische Linie, die in der zweimaligen Verdammung der Sodomie, in der Gestaltung der Maria-Martha-Szene, dem Verbergen

6 B. Brenk, Le texte et l'image dans la „Vie des Saints" au Moyen Age: Rôle du Concepteur et rôle du peintre, in: Texte et image, Paris 1984, S. 3I-39. Es gibt noch die Begriffe „Instruktor, Produktions-Redaktor, Gesamtredaktion, Präzeptor": B. R. TAMmEN, Engelsmusik in der Buchmalerei des I4. und I5. Jahrhunderts. Erscheinungsweisen und Funktionen eines allzu vertrauten Bildmotivs, in: Das Mittelalter II, 2006, Heft I, S. 49-85, 53 Anm. 30. 
der Frauenfüße und vielleicht noch in der Maria-Magdalena-Initiale zum Vorschein kommt. Möglicherweise darf man auch die Vermeidung der Zierseiten in der Karwoche hier anführen. Wenn man dem Bild folgt, das sich die Nachwelt von ihm gemacht hat, dann könnte man hier an Heinrich II. selbst denken bzw. an jemanden, der seine Gedankenwelt vertrat. ${ }^{7}$

Die vorgeschlagene Betrachtungsweise ist mutatis mutandis auf alle mittelalterlichen Miniaturen anzuwenden. Sie folgt ihrer Herstellungsweise aus verschiedenen Vorlagen und berücksichtigt die Probleme der Beschaffung und Herkunft der einzelnen Vorlagen und ihrer Neu-Zusammenstellung. Nur so kann etwas von der Spannung und den diversen Kräften nachvollzogen werden, die in diesen Bildern stecken.

Abbildungsnachweis: Abb. I-I2: nach H. Fillitz/R. Kahsnitz/U. Kuder (zit. Anm. I).

7 Abt Gerhard von Seeon nannte Heinrich II. bereits zu Lebzeiten „pius“ (MGH Poetae latini 5, 397). Zur Frömmigkeit Heinrichs II. zuletzt O. KraffT, Papsturkunde und Heiligsprechung, Köln-Weimar 2005, S. 90-97. 


\section{MANUSCRIPTS ILLUMINATED IN FRANCE 1260-1320 AND THEIR PATRONS}

\section{Alison Stones}

This paper outlines the rationale for a book on illuminated manuscripts of the High Gothic period made in France, and summarizes some of its findings. ${ }^{1}$ Conceived as a contribution to a series aimed at presenting a French equivalent to the Survey of Manuscripts Illuminated in the British Isles edited by J. J.G. Alexander and published by Harvey Miller, the French series was launched more than a decade ago by Walter Cahn's contribution on Romanesque manuscripts. ${ }^{2}$ Gothic illuminated books were not entirely terra incognita. Already in 1907 Georg GrafVitzthum published his remarkable study of Paris and northern French manuscripts in the time of St Louis, still an indispensable research tool. ${ }^{3}$ Exhibition catalogues presented highlights, from the Burlington Fine Arts exhibition of 1908 to the Rois maudits exhibition of I998, with Jean Porcher's 1955 exhibition of manuscripts from the XIII-XVth centuries between the two. ${ }^{4}$ Manuscripts around 1400 were the focus of Millard Meiss' monumental series of 5 volumes, ${ }^{5}$ and figured in the Paris: 1400 exhibition in 2004, while Robert Branner's book on Paris manuscripts during the reign of St Louis and John Lowden's study of the Moralized Bibles meant that substantial aspects of book illumination in the period from c. I200-1500 were well known. ${ }^{6}$ Other scholars were to devote separate studies to the era inaugurated by Jean Pucelle and later, and to the centuries preceding the Romanesque.

The limits of my contribution are first and foremost stylistically defined. The last third of the i3th century marks the entrenchment of what has come to be called the 'courtly style' in French painting, distinct from the Muldenfaltenstil of the first half of the century; and by the I320s Jean Pucelle and his associates in Paris were beginning to launch a new phase in French painting, and had assimilated approaches to architectural and landscape aspects of space and to three-dimensional modelling of figures pioneered in Italy in the work of Duccio and Giotto. The dates of the reigns of Louis IX and his son, grandson and great-grandsons, it seemed to me, were merely one dimension in a complex web of social, intellectual and cultural determinants: the growth of the universities and their faculties of law, medicine and theology, the re-introduction

I Manuscripts Illuminated in France: Gothic Manuscripts I260-1320, London/Turnhout 2012.

2 W. CaHn, Manuscripts Illuminated in France: Romanesque Manuscripts, London 1998.

3 G. Graf Vitzthum, Die Pariser Miniaturmalerei zur Zeit des heiligen Ludwigs bis zu Philipp von Valois und ihr Verhältnis zur Malerei in Nordwesteuropa, Leipzig 1907.

4 Burlington Fine Arts, Exhibition of Illuminated Manuscripts, London 1908; F. AvrIL, Manuscrits, in: L'art au temps des rois maudits, Philippe le Bel et ses fils, Paris I998, pp. 256-334; J. Porcher, Manuscrits à peintures du XIII au XVe siècle, Paris 1955 .

5 M. MeIss, French Painting in the Time of Jean de Berry, 5 vols., London 1967-1974; Paris I400: les arts sous Charles VI, Paris 2004.

6 R. Branner, Manuscript Painting in Paris during the Reign of St Louis, Berkeley/Los Angeles 1977; J. LowDEN, The Making of the Bibles moralisées, University Park, PA 2000. 
of Aristotelian texts and their commentaries, renewed efforts to understand the structure of the brain and the loci and functions of the senses and the soul; studies of natural phenomena - the movements of the heavens, birds, animals, the human body; the growth of urban societies and of civic consciousness, their expanding networks of commerce and trade abroad and their changing living spaces and shifting patterns of work and leisure at home; the church and its institutions and their multiple manifestations of liturgical, meditational, visionary and auditory material given particular emphasis through the requirement of annual communion at the Fourth Lateran Council in I2I4, resulting in a need for devotional books - and the emergence of the mendicant orders; the creation of vernacular literary texts in verse and prose, often with musical as well as artistic accompaniment. The illuminated books of the period c. 1260-1320 bear witness to a shift from a culture of polarities, from a Latin religious and exegetical culture on the one hand and a vernacular oral and aural culture on the other, to a culture of variety and visual plurality in which factors of geography and agency played a critical part. Political boundaries - royal domain, ducal and comital territorial limits formed one set of structures and hierarchies which intersected and overlapped with linguistic and ecclesiastical boundaries. The Province of Reims included the diocese of Cambrai in Hainaut, a fief of the Empire, while Flanders, part Flemishspeaking, was in this period a fief of France; Verdun and Metz were suffragans of the Province of Trier, but French-speaking, while the Province of Narbonne extended well into the kingdom of Aragón and in the Provinces of Rouen, Tours, and Bourges, the corresponding duchies and counties were in English hands for much of the period. In Avignon the papacy under Clement $\mathrm{V}$ and John XXII drew Italians, attracted also to the medical school of Montpellier and the law school at Toulouse and to Avignon itself, all vibrant centres for the production of illustrated books, while the emergence of illustrated customaries and cartularies attest to the growth of civic consciousness, especially in the south, in the years leading up to the Hundred Years War.

While religious books belonged to long traditions of illustration, many texts in Latin and the vernacular were newly composed or were illustrated for the first time in this period; for many of these new texts, illustrations were envisaged from the start and are referred to explicitly, often with comments as to what their purpose was. ${ }^{7}$ I adopt a two-part approach in which stylistic criteria determine the regional and chronological anchors of manuscript clusters, as best they can be reconstructed - and many attributions remain arbitrary at best - while comparative tabulation allows the iconographical variants within a textual tradition to emerge. The tables are structured so as to group stylistic cognates together within an iconographical framework and comprise a varied selection: Bibles, Gospel Books, Psalters, Books of Hours, Apocalypses, Roman d'Alexandre, Roman de la Rose, Gratian's Decretum, Roman de Sidrach, the Vie de saint Denis, the Speculum historiale of Vincent de Beauvais. Several copies of the Lancelot-Grail romance are included in the Catalogue and comparisons may be found on my web site. ${ }^{8}$ Inevitably a selection had to be made, on varying criteria - artistic quality, evidence

7 A. Stones, Why Images? A note on some explanations in French manuscripts ca. 1300, in: Quand la peinture était dans les livres: mélanges en l'honneur de François Avril, ed. M. Hofmann and C. ZöHL, Turnhout 2007, pp. 312-329.

8 http://www.lancelot-project.pitt.edu/lancelot-project.html 
of heavy use, popularity, rarity, or circumstances of production. Lists summarize the stylistic and geographical clusters of manuscripts, as many as possible, and of those which are dated and datable, or whose artist, scribe, or patron is known.

Changes in the patterns of patronage in this period are particularly striking, and in what follows I examine some of the trends in more detail. Members of the clergy and of the royal and princely courts now took their places alongside lesser nobles and members of the bourgeoisie, a social class now wealthy enough to afford the cost of expensive books embellished with pictures and gold, educated enough to be able to read their text, particularly texts in French, and sufficiently concerned about their ownership to record it in portraits, names, or documents. Lay women came to constitute a significant class of owners, particularly of small devotional books whose contents included components written in the vernacular. Civic documents and charters, particularly in the South, were embellished with illustrations. Inventories, wills, and payment records supplement the information contained in the manuscripts themselves to offer a wide-ranging if still partial picture of who owned books in this period, and what those books were. ${ }^{9}$

What survives must represent only a fraction of the number of books made. Records are patchy, they tend not to mention illustration, and only rarely do they correspond to the books that actually survive. However, we are well informed about book production in Artois, Flanders and Hainaut thanks to the work of de la Grange, ${ }^{10}$ Dehaisnes, ${ }^{11}$ Vanwijnsberghe, ${ }^{12}$ and Derolez; ${ }^{13}$ in Burgundy of Bautier and Sornay; ${ }^{14}$ in Paris, of Rouse and Rouse; ${ }^{15}$ in the south of Jullien de Pommerol and Monfrin. ${ }^{16}$ Exceptional records survive for Rodez, ${ }^{17}$

9 See also A. Stones, Some Portraits of Women in their Books, Late I3th-Early I4th c., in: Livres et lectures de femmes en Europe entre Moyen Age et Renaissance, ed. A.-M. Legare, Turnhout 2007, pp. 3-27, and for civic documents, Le Sacré et le Profane dans quelques manuscrits français du XIIIe et début XIVe siècles, in: Thèmes religieux et thèmes profanes dans l'image médiévale: transferts, emprunts, oppositions (Actes du Colloque du RILMA, Institut Universitaire de France, Paris, INHA, mai 20II) (Répertoire iconographique de la littérature du moyen âge, Les Études du RILMA I), ed. C. Heck, Turnhout (forthcoming).

Io A. De la Grange, Choix de testaments de Tournai antérieurs au XVIe siècle, Tournai I897.

i C. Dehaisnes, Documents et extraits divers concernant l'histoire de l'art dans la Flandre, l'Artois et le Hainaut avant le XVe siècle, 3 vols., Lille i886, vol. I.

i2 D. Vanwijnsberghe, "De fin or et d'azur": Les commanditaires de livres et le métier de l'enlumineur à Tournai à la fin du Moyen Age (XIVe-XVe siècles) (Corpus of Illuminated Manuscripts io, ed. B. CARdon), Leuven 200I.

I3 Corpus Catalgorum Belgii. The Medieval Booklists of the Southern Low Countries, ed. A. Derolez et al., 7 vols., Brussels I999-20I0.

I4 R. H. Bautier and J. Sornay, Les Sources de l'histoire économique et sociale du moyen âge, Les États de la maison de Bourgogne, I, Archives des principautés territoriales, 2, Les principautés du Nord, Paris 1984.

I5 R. H. and M.A. Rouse, Manuscripts and their Makers in Medieval Paris, I200-I500: Illuminati et uxorati, 2 vols., Turnhout 2000.

i6 M.-H. Jullien de Pommerol, Les livres dans les dépouilles des prélats méridionaux, in Livres et bibliothèques, XIII-XIVe siècle (Cahiers de Fanjeaux 3I), I996, pp. 285-3I4; ead. / J. Monfrin, Bibliothèques ecclésiastiques au temps de la papauté d'Avignon II, Inventaires de prélats et de clercs français, Paris $200 I$.

I7 Fasti Ecclesiae Gallicanae, Répertoire prosopographique des évêques, dignitaires et chanoines de France de I200 à I500, VI: Diocèse de Rodez, ed. M. Desachy, Turnhout 2002. 
while the informative articles by Garand, Hasenohr and Stirnemann in the Histoire des bibliothèques françaises series, ${ }^{18}$ and Busby's study of manuscripts in French verse, ${ }^{19}$ have drawn together much valuable material.

Royal collections are represented both in written sources and in the manuscripts themselves, although the royal library of Charles $\mathrm{V}$ was yet to come into being and ambiguity surrounds many of the surviving books. The names of kings and queens are scarce: they are not recorded in the books they most likely owned, such as the Psalter traditionally thought to have been made

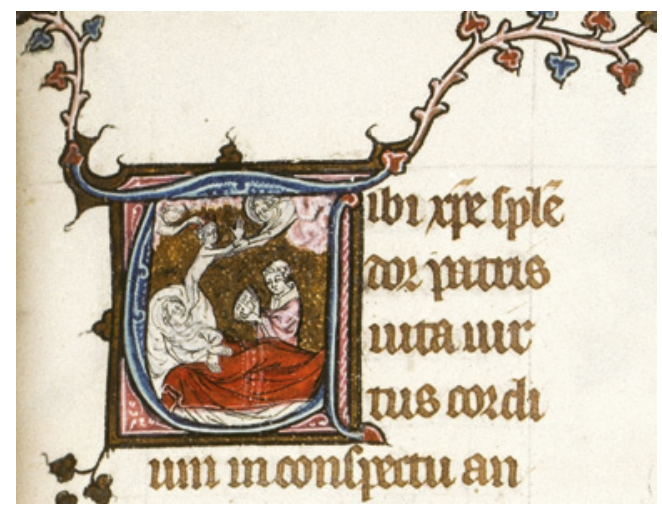

Fig. I: New York, New York Public Library, Spencer Ms. 56, fol. 380, Psalter-Hours: Blanche on her deathbed, her soul crowned by an angel (Paris, c. 1320?) for Louis IX (Paris, BNF lat. I0525), or the Breviary of Philippe le Bel (Paris, BNF lat. I023), the latter convincingly identified with payment records for the making of a breviary for the king at vast expense. The Psalter-Hours in Cambridge (Fitzwilliam Museum 300), made for someone named Isabelle, leaves open the question as to which Isabelle is meant: the daughter of Louis IX or his sister, or another royal Isabelle? Heraldic line-endings with the arms of France, Navarre, and Champagne only hint at ownership, while the obit of Robert of Artois, brother of Louis IX, in the calendar would be appropriate in a book made for his sister, but confirmation is lacking. Similarly the royal Blanche for whom prayers are addressed in the psalter-hours in New York Public Library (Spencer 56) may have been made for one of several royal ladies named Blanche. Royal portraits are surprisingly few - those of Blanche in the hours part of Spencer 56 are exceptional, and show her wearing a wimple and veil in Io tiny portraits, but only in one of them does a crown appear - placed on the head of her soul as Blanche lies on her deathbed (Fig. I). Otherwise royal portraits mostly occur in presentation copies where the dedicatee was the recipient but may not have played an active rôle in the commission, as in the following examples: the Grandes chroniques de France, a project initiated by Louis IX († I270) but completed only in I274 and presented to Philippe le Hardi sometime thereafter, with a dedication miniature (Paris, Bibliothèque Sainte-Geneviève 782); the Liber natalis pueri parvuli Christi Jhesu offered by Ramon Llull to Philippe le Bel (Paris, BNF lat. 3323), the gift recorded pictorially; the Breviculum of Thomas le Myésier offered in text and painted page to Queen Jeanne de Bourgogne-Artois, wife of Philippe V (Karlsruhe, Badische Landesbibliothek St Peter perg. 92); the queen (Jeanne de Navarre, wife of Philippe IV le Bel?) kneeling before the Virgin and

I8 Histoire des bibliothèques françaises, I, Les Bibliothèque médiévales du VIe siècle à I530, ed. A. VERnET, Paris I989, particularly M.-C. GARAND, Les anciennes bibliothèques du XIIIe au XVe siècle, pp. 44-63; P. STIRNEMANn, Les bibliothèques princières et privées aux XIIe et XIIIe siècles, pp. I72-9I; G. Hasenohr, L'essor des bibliothèques privées aux XIVe et XVe siècles, pp. 213-63.

I9 K. Busby, Codex and Context: Reading Old French Verse Narrative in: Manuscript (Faux titre: études de langue et littérature française publiées, 22I), Amsterdam/New York 2002. 


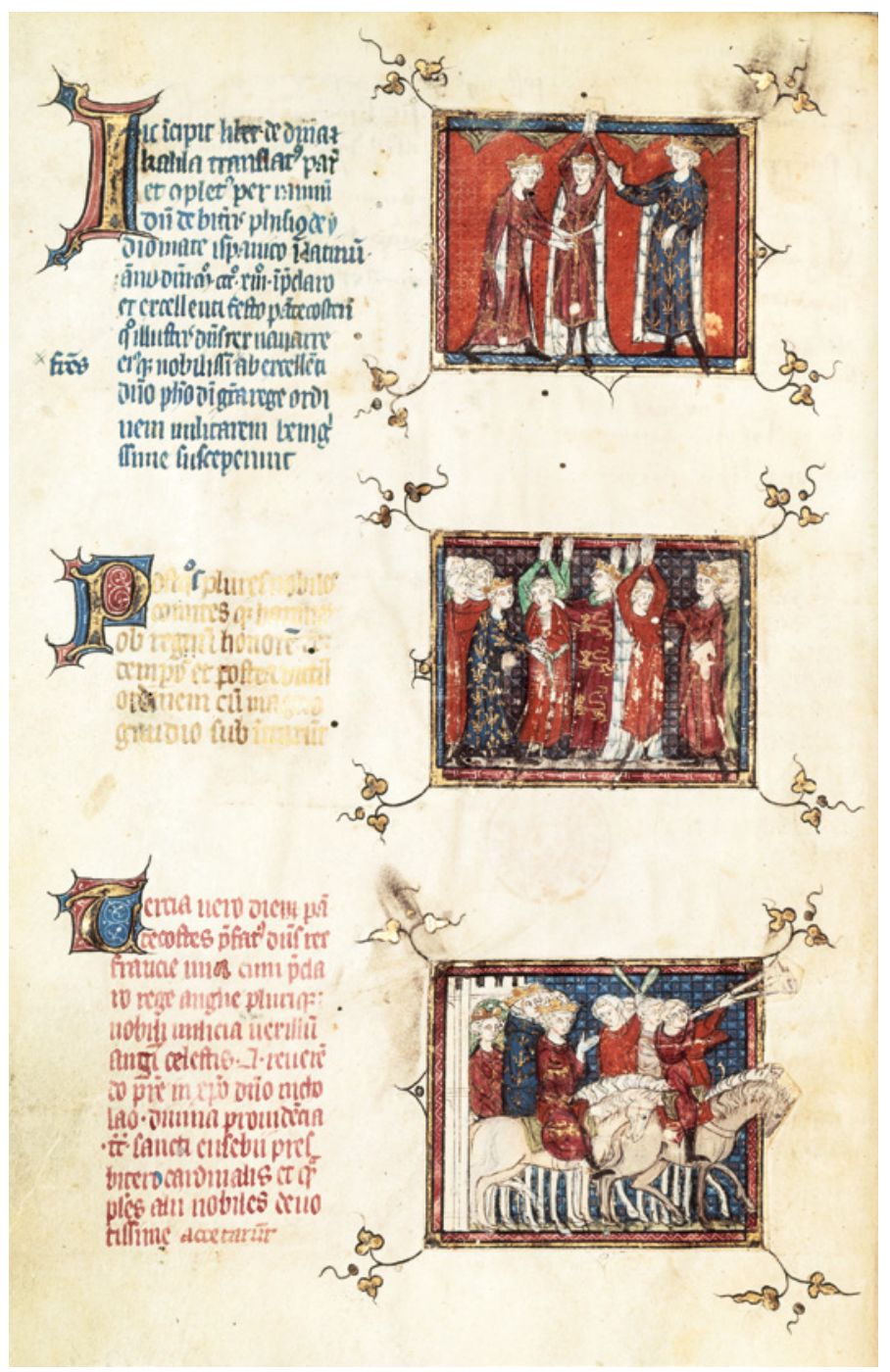

Fig. 2: Paris, Bibliothèque nationale de France, lat. 8504, fol. Bv: Knighting ceremonies in Paris, I3I3

Child in the fragmentary Breviary in The Pierpont Morgan Library (M. IO42), a counterpart to the Breviary of Philippe le Bel in which images of Philippe as King David are no doubt deliberately ambiguous; the Liber de Kalila et Dimna, its text translated from the Spanish into Latin for Jeanne de Navarre (Paris, BNF lat. 8504), which includes not only a heraldic group portrait facing the text opening but a series of small miniatures, pasted in and identified by inscriptions, of the events of Pentecost 1313, when the son of Philippe IV and Jeanne de Navarre, the future Louis X, was knighted along with other young men of the court (Fig. 2). Representations of patrons or owners in French texts are overall less common and of uncertain significance, such as the royal ladies clustered around Marie de Brabant and her young nephew in the compendium of the works of Adenet le Roi (Paris, Bibliothèque de l'Arsenal 3I42), the royal ladies and the young Philippe le Bel with courtiers in Girart d'Amiens' Roman de Méliacin (Paris, BNF fr. 1633, Fig. 3) and its later copy (BNF fr. 1589), in both of which Raoul de Nesle 


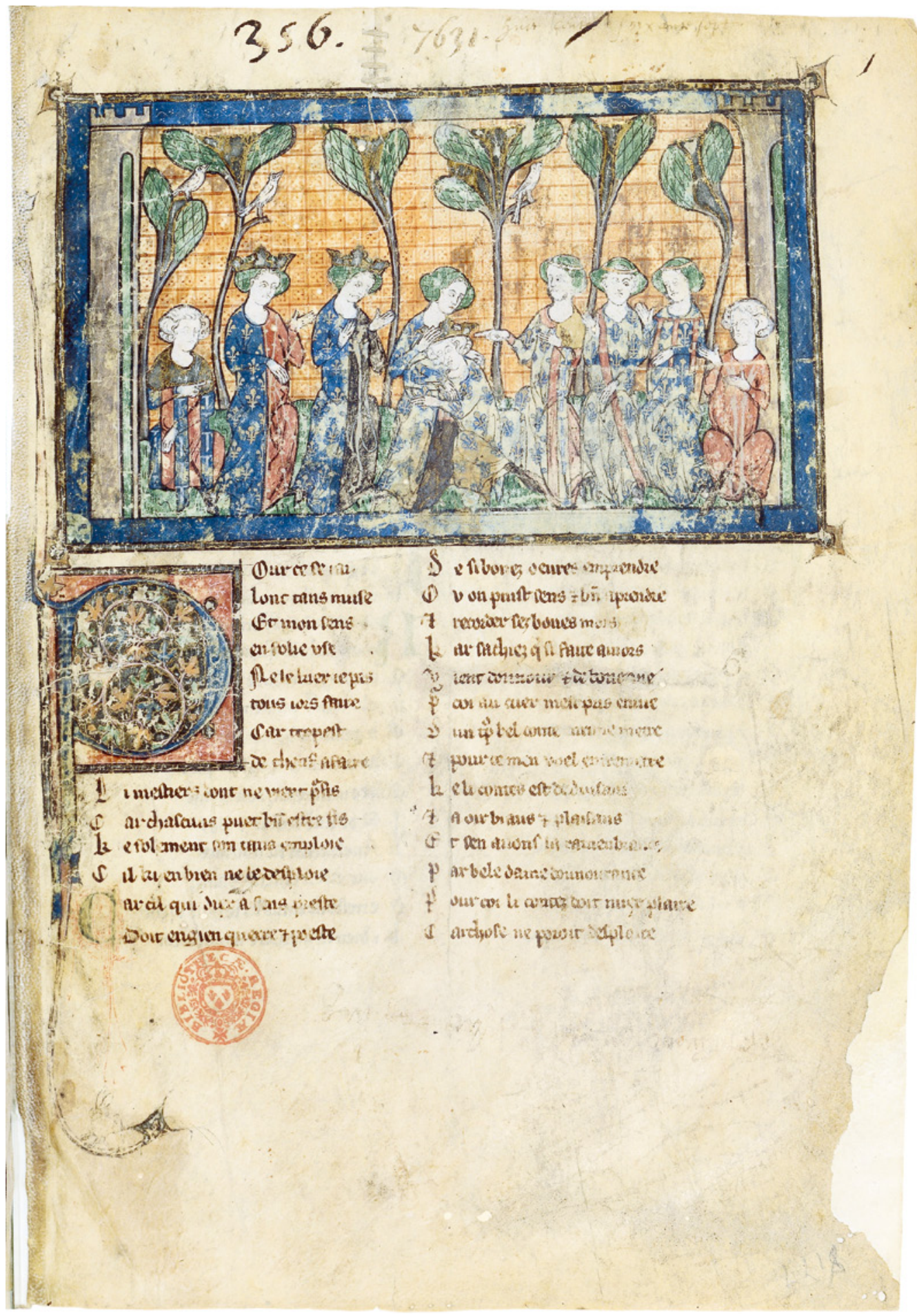

Fig. 3: Paris, Bibliothèque nationale de France, fr. 1633, Girart d'Amiens, Roman de Méliacin: dedication page (Paris, c. I285-I29I) 


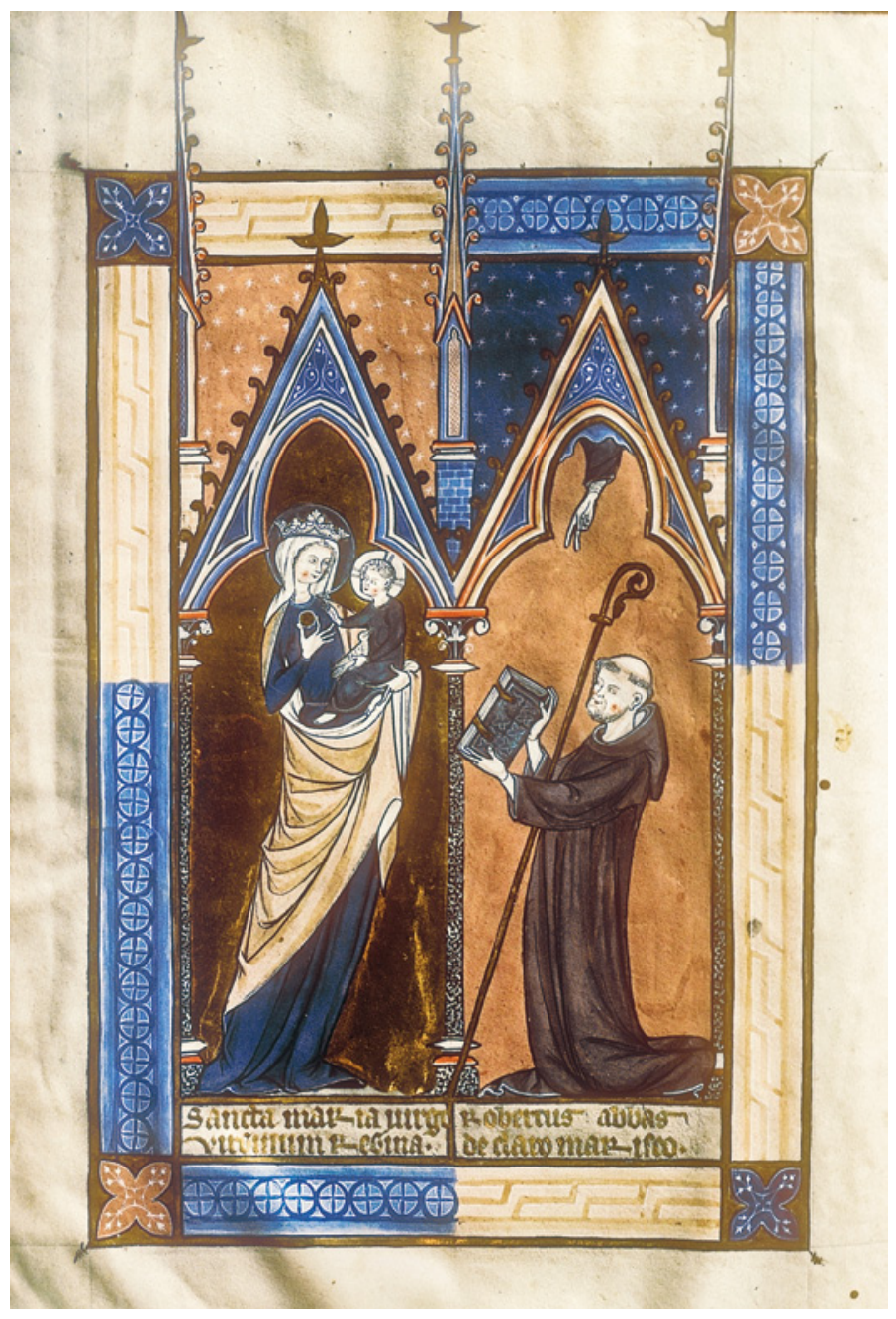

Fig. 4: Saint-Omer, Bibliothèque d'agglomération, Ms. I74, fol. 2v: Robert de Béthune, Abbot of Clairmarais, before the Virgin and Child (Saint-Omer, Tournai, or Cambrai, c. I257-I266)

connétable de France († at Courtrai in 1302) and Gaucher de Châtillon, comte de Porcéan, Constable of Champagne from I284, who succeeded Raoul de Nesle as Constable of France, are included on the right and left of the royal group, recognizable by their heraldic robes - but it is by no means clear which of the people depicted owned these copies.

Clerical donors or patrons are more often depicted than kings or queens in this period. Did that reflect a desire on the part of the clergy to assert their spiritual authority vis à vis the kings in a period when conflict with the papacy culminated in the aggression of Philippe le Bel against Boniface VIII ( $†$ 1303), the capture of the papacy and the elimination of the Templars (1307-1312)? Several ecclesiastical patrons are shown in full-page or half-page pictures, from the I26os onwards: Robert de Béthune before the Virgin and Child (Saint-Omer, Bibliothèque d'agglomération, Ms. 174, f. 2v, Fig. 4), the Hospitaller kneeling before St John the Baptist in the Burdett Psalter-Hours (Private Collection, Fig. 5), Dominique Grima offering his commentary on Genesis and Exodus to Pope John XXII (Paris, BNF lat. 375, f. I), or the 

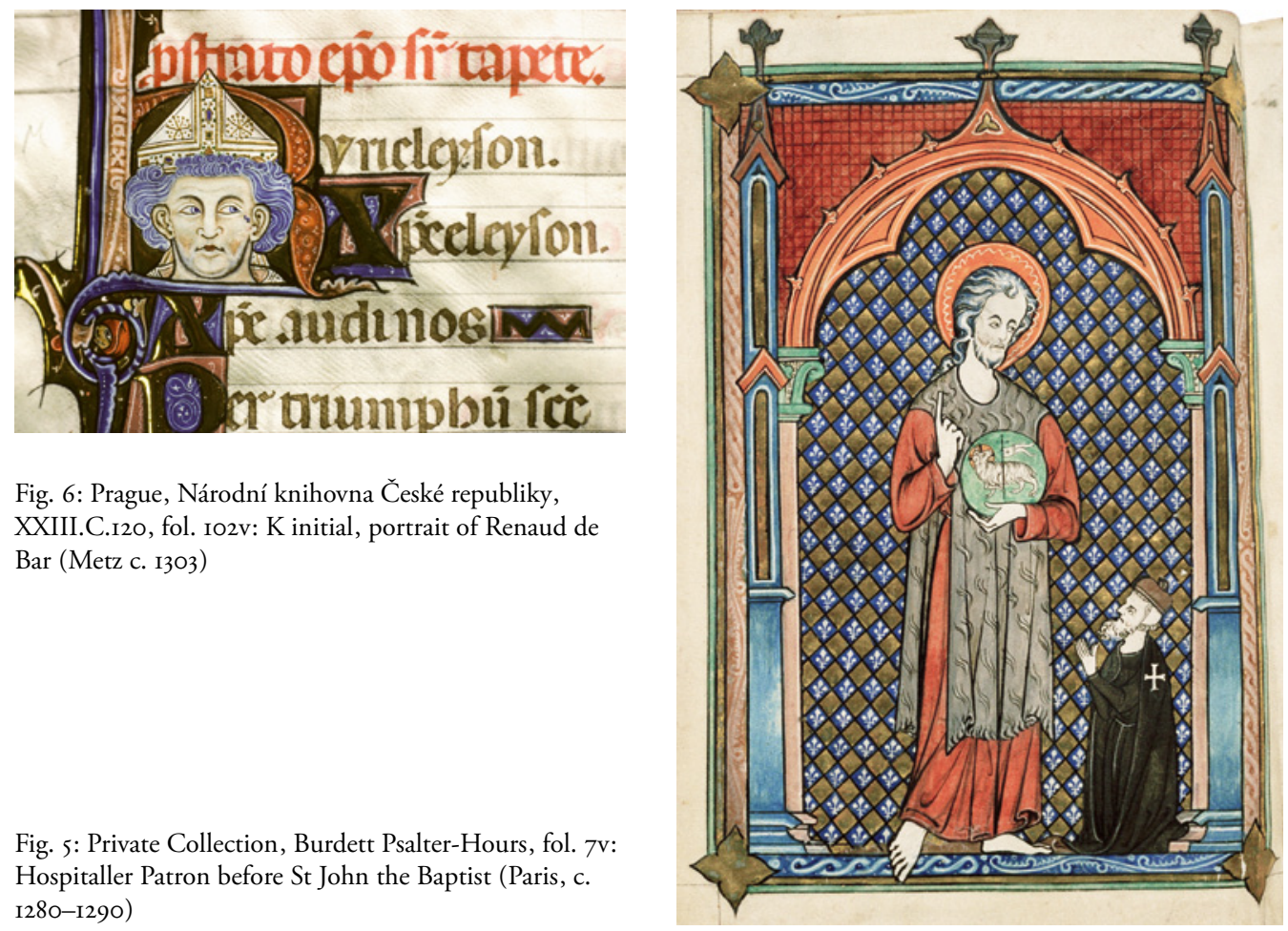

Fig. 6: Prague, Národní knihovna České republiky, XXIII.C.I2O, fol. IO2v: K initial, portrait of Renaud de Bar (Metz c. 1303)

Fig. 5: Private Collection, Burdett Psalter-Hours, fol. 7v: Hospitaller Patron before St John the Baptist (Paris, c. I280-I290)

episcopal portrait heads in the Prague section of Renaud de Bar’s Pontifical (Prague, Národní knihovna České republiky, XXIII. C.I2O, ff. IO2v, II8v, Fig. 6), while bishops and abbots would have seen themselves performing the actions depicted in their liturgical books, like Enguerrand de Créquy performing the consecration of a church (Toledo, Archivo Catedral 56. 19, f. Ioov, Fig. 7). The pictorial record of the episcopacy of Bishop Guillaume le Maire of Angers in his Journal (Angers, AD Maine et Loire $\mathrm{G}_{7}$ ) is unique in the period - he is shown at his own consecration as bishop, and himself leading the procession to Saint-Aubin on the Sunday after Ascension Day; also exceptional is Étienne de Mornay, Abbot of Saint-Martin, Tours, translating the head of St Martin to a new head-reliquary, with Philippe V and his wife and daughter at prayer at an altar below - an image that combines two separate events into a single commemoration (Tours, BM IO23, f. IOI, Fig. 8). The Missal of Jean de Marchel, Abbot of Saint-Jean, Amiens, concludes with inscriptions and portraits of Jean, both alone and receiving the book from one of his craftsmen (The Hague, KB 78 D 40, f. I77, Fig. 9). Here the name of the artist, Petrus de Raimbaucourt, is written in gold, privileging him and his craft above that of the scribe Garneri de Morolio, written in the black ink of the text. Did Petrus add his own name in gold? And is it he who hands the book to the abbot in the accompanying miniature? The figure is certainly a lay craftsman since he is not tonsured - and could represent either the scribe or the miniaturist. Other prelates were depicted in more modest images - small marginal figures, like the abbot of Ter Duinen (O. Cist, Diocese of Thérouanne), either Willelmus II de Hulst (1305-I318), or Lambertus II Uppenbroeck (1318-1354) (Bruges, GS 77/98, f. 50, Fig. IO). Both were responsible for substantial building works at the abbey, Willelmus on the cloister 


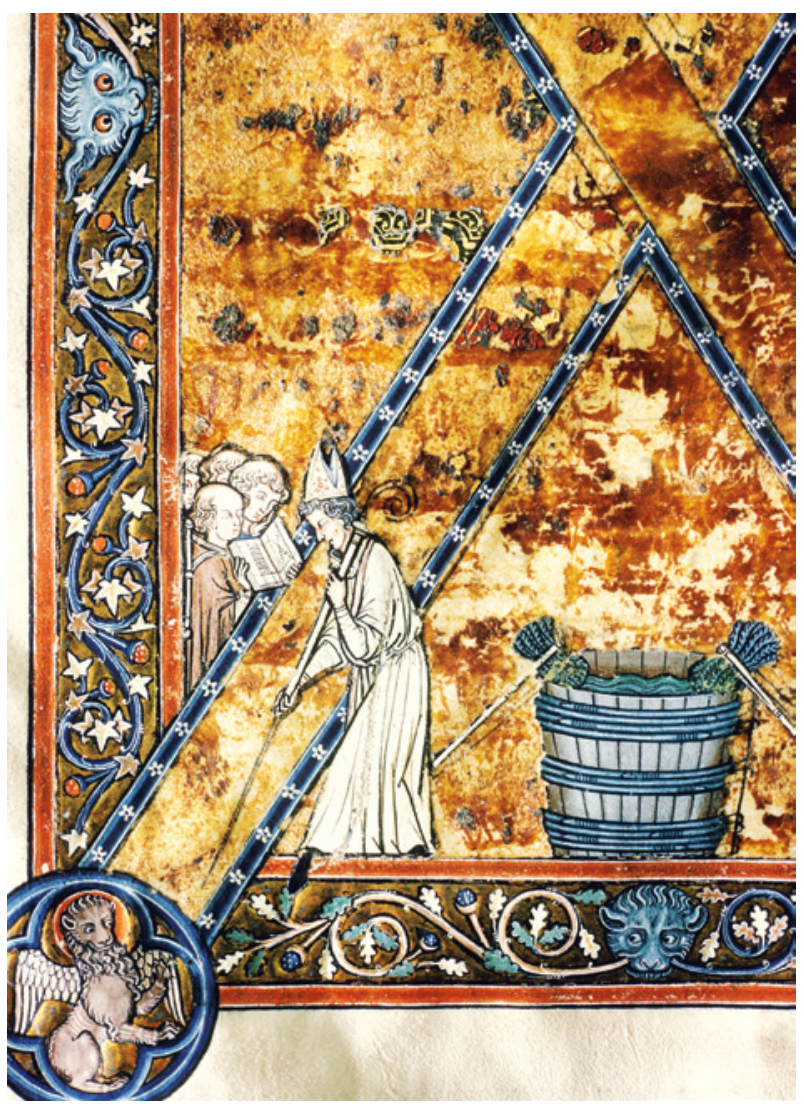

Fig. 7: Toledo, Archivo de la Catedral, Ms. 56. 19, fol. Ioov: Enguerrand de Créqui consecrating a church (Cambrai, c. I275)

and lavatory, and Lambertus on the church portal, chapels, and towers to the dormitories; he also instituted a daily ration of wine for the monks, the quantity of which was doubled by his successor in office (GCV, 283-95). Augier de Cogeux (Gogenx), Abbot of La Grasse, was also known for extensive building work at his abbey - to the point that he was dismissed as abbot by the bishop of Carcassonne, accused of over-spending, in I308. The Missal made for use in his private chapel, dedicated to St Bartholomew, shows a tiny portrait of him with his shield, the latter depicted no fewer than 40 times (London, BL Add. 17006, f. I3, Fig. II). Augier's shield may also be detected in a copy of Uguccio's Summa super Decretum Gratiani (Verona, Bibl. Capitolare, CXCIV), written by Johannes de Limoges in I3I7 - suggesting that his patronage did not cease with his deposition as abbot - and his artist may be detected at work on a Bible (perhaps also originally containing Augier's shield), a Gratian, two Justinians, two copies of the Clementinae, and a copy of Matfre Ermengau's Breviari d'amor. By contrast, 17 books owned by Bernard de Castanet, Bishop of Albi (1276-1308), then of Le Puy (1308-1316), Cardinal of Porto $(\mathrm{I} 3 \mathrm{I} 6, \dagger \mathrm{I} 3 \mathrm{I} 7)$ survive, and several record his commission. Their decoration however is limited to pen-flourishing or foliate initials.

Other clerical libraries were considerably more extensive, although the books are not extant, and it is unclear how many were illustrated: Armanieu d'Armagnac, Archbishop of Auch (el. c. I262-I3I8), had IO7 items on his library list: liturgical books, biblical commentaries, five Gospel 
books, five Epistle books, five glossed Gospels of St Matthew, six Psalters, twelve Sermon collections, three copies of De oculo by Pierre de Limoges; a Régime des princes, probably the one by Gilles de Rome, a Panthéon of Godefroy of Viterbo, a commentary of Bede on the canonical Epistles, Isidore of Seville's Sententiae, Martin of Oppava's Chronicle, two copies of Caesar's Chronicles, and a cartapellus of Ovid. ${ }^{20}$ A collection like this was not unusual, for the 1317 inventory of Hugues Géraud, Bishop of Cahors (I312-1316) lists one hundred books, ${ }^{21}$ while Pierre de Plane Cassanhe, Bishop of Rodez (Prov. Bourges) (1302-I3I9 n. s.) held the biggest collection, with 152 items on his library list. ${ }^{22}$ More routine collections numbering between 25 and 50 items were owned by Cardinal Michel du Bec $\left(\dagger\right.$ I3I8), ${ }^{23}$ Pierre de Ferrières, Archbishop of Arles (1303-1307) and Chancellor of Sicily, whose holdings included books by five of his contemporaries, ${ }^{24}$ Pierre Rodiez, Bishop of Carcassonne (1324-I330 n. s.), ${ }^{25}$ Raymond

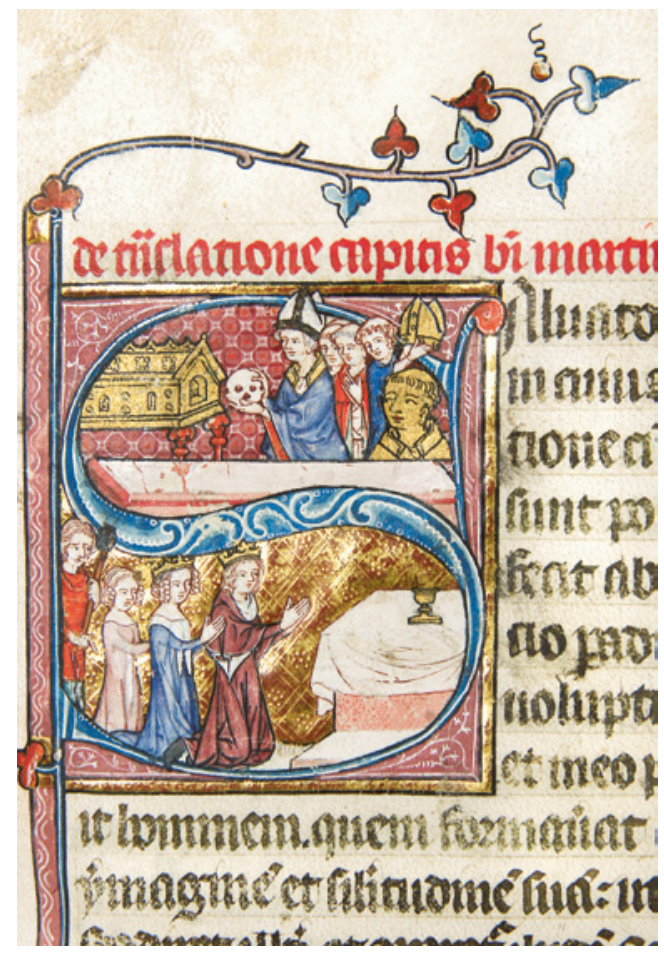

Fig. 8: Tours, Bibliothèque municipale, Ms. IO23, fol. IOI: Translation of St Martin's skull (Tours I323-I329)

20 Hasenohr, L'essor (cit. n. i8), 237; Jullien de Pommerol, Les livres (cit. n. I6), p. 299; three inventories transcribed by Jullien de Pommerol/Monfrin, Bibiothèques ecclésiastiques (cit. n. i6), no. 318.7.

2I Hasenohr, L'essor (cit. n. I8), p. 237; 4 inventories transcribed by Jullien de Pommerol/Monfrin Bibliothèques ecclésiastiques (cit. n. I6), no. 317.5.

22 Hasenohr, L'essor (cit. n. i8), 237; Jullien de Pommerol, Livres (cit. n. i6), p. 298, citing P. Calmet, Pierre de Pleine Chassagne: son testament, inventaire de ses meubles, Annales de Saint-Louis des Français, I, i896, pp. 487-529; 4 inventories transcribed by Jullien de Pommerol and Monfrin, Bibliothèques ecclésiastiques (cit. n. I6), no. 319.I; Fasti Ecclesiae Gallicanae, Diocèse de Rodez, ed. M. Desachy (cit. n. I7), pp. 80-83, no. 395.

23 Bequeathed 25 volumes to the Carmelites of the Place Maubert (A. FrankLIN, Les anciennes bibliothèques de Paris: églises, monastères, collèges, séminaires, institutions, fondations, hôpitaux des origines au moyen âge jusqu'au XIXe siècle, 3 vols., Paris 1867-73, repr. Amsterdam I968, II, p. 2; Hasenohr, Lessor (cit. n. I8), p. 230. For the commemorative miniature of him at his funeral in the Martyrology-Obituary of Notre-Dame, Paris (Paris, BNF lat. 5185 CC), see Rois maudits (cit. n. 4), p. 287, no. I82, and C. A. STANFord, The Body at the Funeral: Imagery and Commemoration at Notre-Dame, Paris, about 1304-18, in: Art Bulletin, 89, 2007, pp. 657-73 at pp. 659-63 and Fig. 2 (f. 265); his statue at the entrance to the chapel he founded at Notre-Dame, known from Gaignieres, is Stanford Fig. Io.

24 Jacques de Revigny ( $†$ I296), Guy de Baysio ( $†$ I313), Jean le Moine ( $†$ I313), Guillaume de Mandagout ( $†$ I32I) and Jean d'André († 1348) (Hasenohr, L'essor (cit. n. I8), p. 238; 47 books listed in Jullien de PommeROL/MONFrin, Bibliothèques ecclésiastiques (cit. n. I6), no. 307.8.

25 The inventory at death lists 30 books (HASENOHR, L'essor (cit. n. I8), p. 237); 27 books listed by JULLIEN DE Pommerol/Monfrin, Bibliothèques ecclésiastiques (cit. n.I6), no. 329.9. 


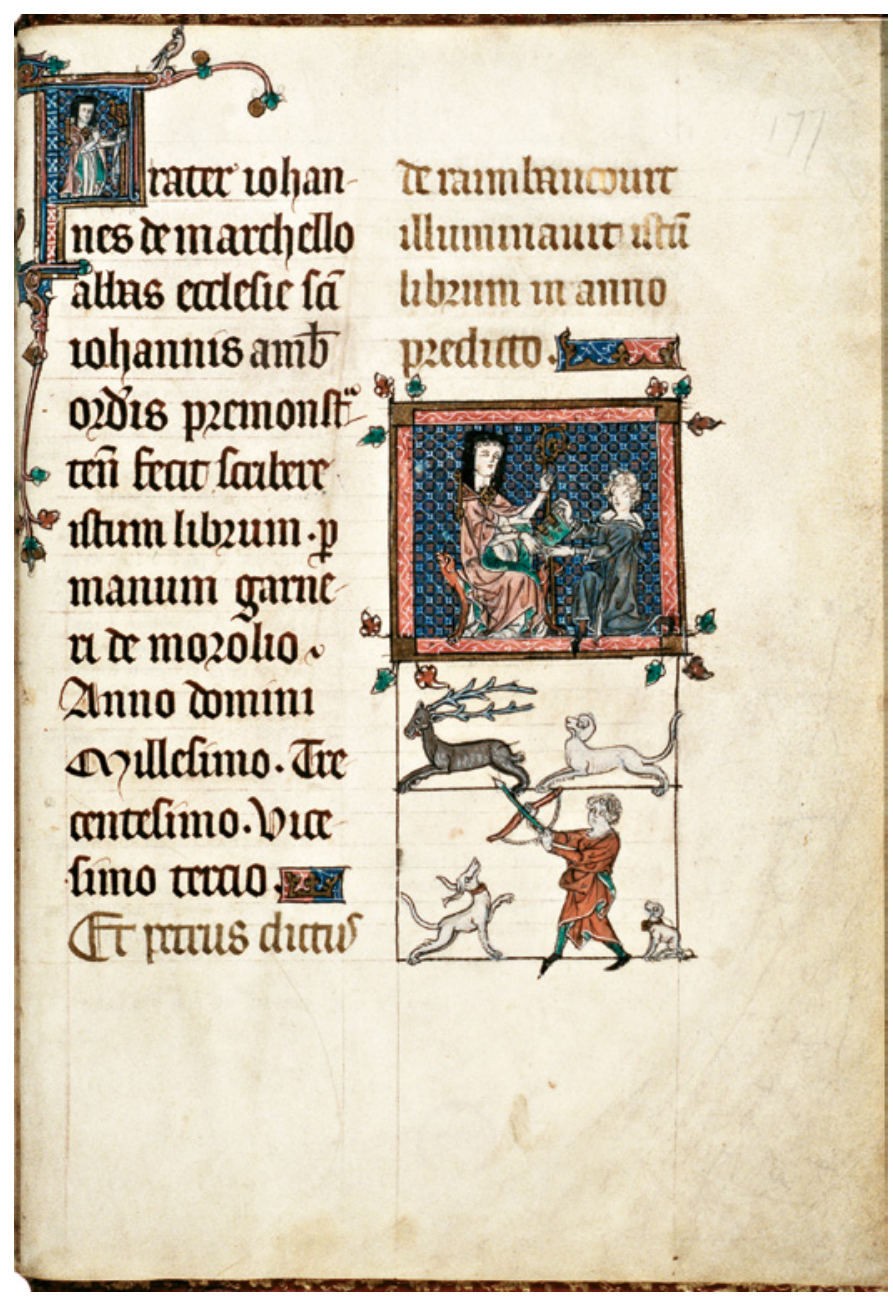

Fig. 9: The Hague, Koninklijke Bibliotheek, 78 D 40, fol. I77: Jean de Marcheuil, Abboot of Saint-Jean, Amiens, receiving the book written by Garneri de Morolio, illustrated by Pierre de Raimbaucourt (Amiens, 1323)

Athon, Bishop of Mirepoix (I318-1326) (Prov. Toulouse), ${ }^{26}$ while Raymond [de Benquerio] (†c. 1327), rector of the church of Augerac (Dioc. Dax, Prov. Auch), had only six books. ${ }^{27}$ The holdings of Raymond de Durfort, Bishop of Périgueux (Prov. Bordeaux) (I3I4-I34I) included a Livre de Sidrach, a Lancelot du Lac and a romancium by Matfre Ermengau among his 68 books. ${ }^{28}$ Bernardus de Mayrinhaco, Canon of Rodez Cathedral (Prov. Bourges) and Rector of Carcenac (I285-I324) bequeathed five books to the church of Carcenac: a Missal, a Breviary, a Psalter, and two Bibles; ${ }^{29}$ and Bernardus de Vayraco, Canon of Rodez, in 1300 bequeathed seven liturgical books to various people and churches: his vicar Guilhem Folcam, his nephew Bernard Jean, rector of Pinet, and the churches of Saint-Pierre de Mondalasac and Saint-Étienne de Vayrac. ${ }^{30}$

26 4I books listed by Jullien de Pommerol/Monfrin, Bibliothèques ecclésiastiques (cit. n. i6), no. 326. 2.

27 ibid., no. 326.6 .

28 ibid., no. 34r. 2.

29 Fasti Ecclesiae Gallicanae, Diocèse de Rodez, ed. M. Desachy, (cit. n. I7), p. I7 (3 G 402, AA, will of I324). 30 ibid., 17,3 G 334, M, will of 1300 . 
In the north, the sale of the civil and canon law books owned by Cardinal Jean

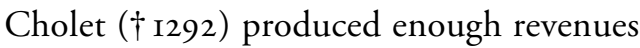
to found the Collège des Cholets in Paris for poor students of theology, while his theological books were bequeathed to the abbey of Saint-Lucien de Beauvais, where his brother was abbot and where his tomb was located; other books went to the Franciscans of Paris and several to individuals, while his Missal and Epistolary, of Parisian manufacture, survive in Padua (Biblioteca Capitolare D 34 and C 47). ${ }^{31}$ Bernard de Fargues, Archbishop of Rouen (I306-I3II) then of Narbonne (I3II-I34I) owned twentyfive books, ${ }^{32}$ of which an unillustrated Ordo of the early fourteenth century, inscribed on f. I in a modern hand, Hic liber est domini Bernardi de Fargis archiepiscopi Narbone, survives at Narbonne. ${ }^{33}$ Prelates in general were concerned to bequeath books to their home institutions, whether to the library or altar or for their own commemoration.

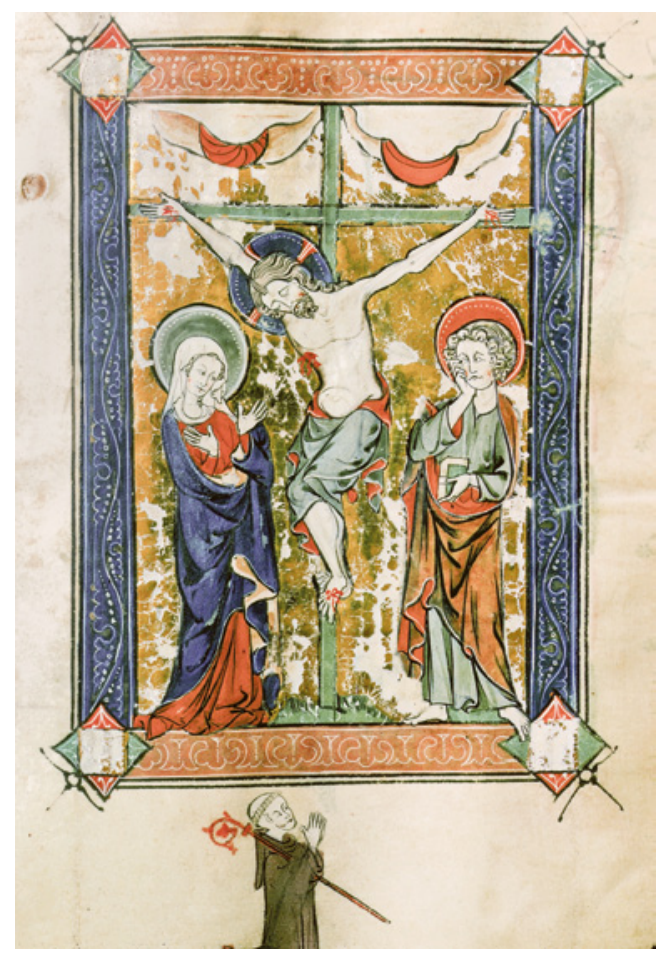

Fig. Io: Bruges, Grootseminarie, Hs. 77/98, fol. 49: Ritual for the Abbot of Ter Duinen, Abbot before the Crucifixion (Bruges or Ghent, c. 1315-1330) Among the more colourful is Guilhem Mercadier, Prior of Arcanhac (Dioc. Rodez), who in 1302 bequeathed to the anniversaries of Rodez Cathedral his brown donkey and his Breviary for the foundation of his obit. ${ }^{34}$

How did the female religious compare with their male counterparts? There are far fewer indications of female ownership than of male. Inventories are lacking, so the evidence is in the books themselves. The Cistercians are surprisingly well represented in portraits, despite St Bernard's notable aversion to decoration of any kind: Abbess Beatrice de Grammont of Beaupré and her Prioress (name unknown) are depicted in their Antiphoner, written in 1289 and 1290 (Baltimore, Walters Art Museum W. 759-762, 915, and other fragments); the Abbess of Notre-Dame-des-Prés, Douai, appears in the abbey's Martyrology (Valenciennes, BM 838);

3i A. Paravicini Bagliani, I Testamenti dei cardinali del Duecento (Miscellanea della Società romana di storia patria XXV), Rome i980, pp. 5I-54, 250-67; E. Chatelain, 'Note sur les manuscrits du Collège des Cholets, Paris i889; A. Stones, 'Les manuscrits du cardinal Jean Cholet et l'enluminure beauvaisienne vers la fin du XIIIe siècle', dans: L'art gothique dans l'Oise et ses environs, ed. P. Bonnet-Laborderie, Beauvais, GEMOB 200I, pp. 239-68. Listed by Jullien de Pommerol/Monfrin, Bibliothèques ecclésiastiques (cit. n. I6), no. 34I. 3. D. De Courcelles, 'La Bibliothèque du chapitre de la cathédrale Saint-Just de Narbonne' (Livres et bibliothèques XIII-XVe siècles), Cahiers de Fanjeaux, 3I, 1996, pp. I85-207, at pp. 193-96). 


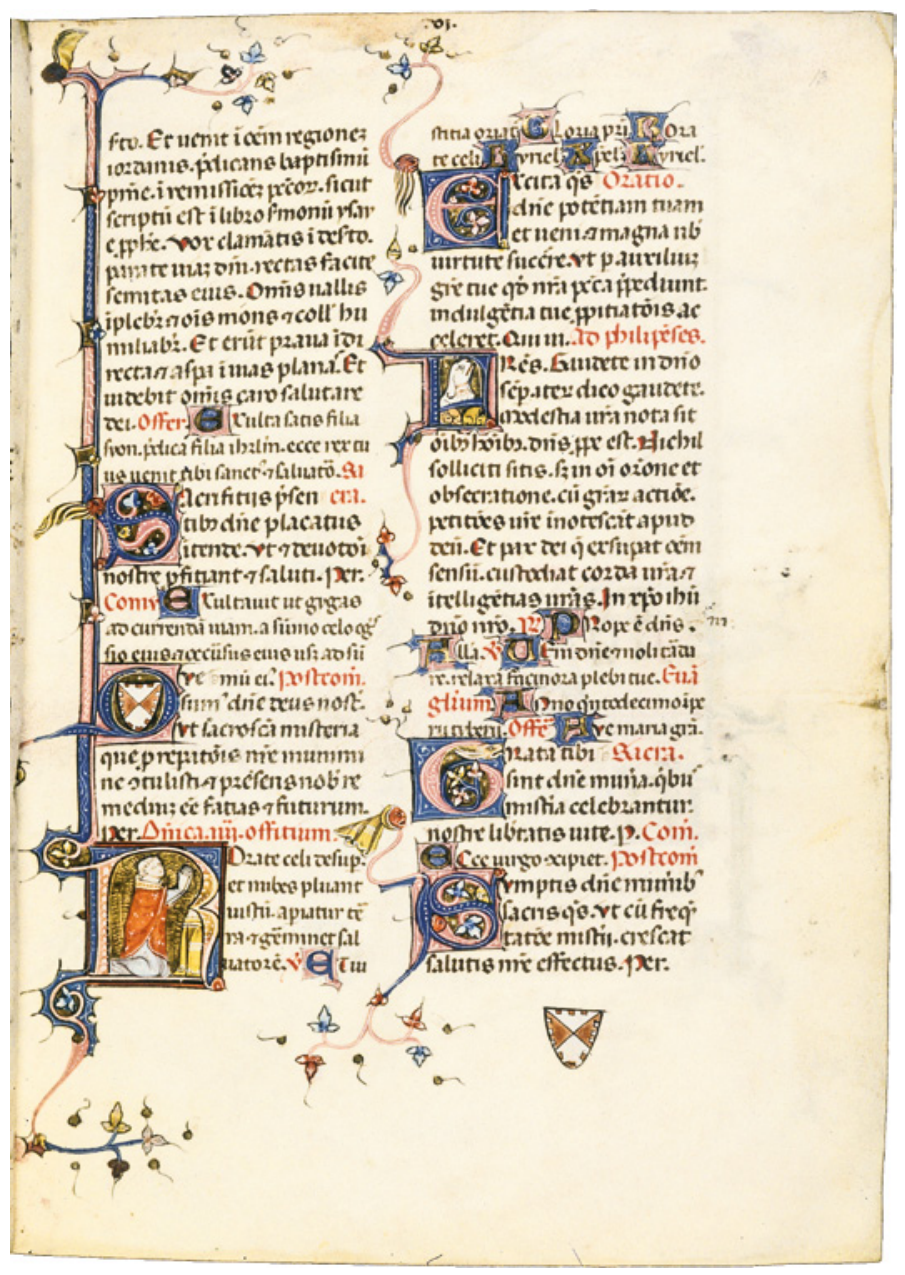

Fig. II: London, British Library, Add. 17006, fol. I3, Missal of Augier de Cogeux: Abbot of La Grasse (Toulouse, Carcassonne, or Narbonne, before I308)

Cistercian nuns are depicted in the wonderful frontispiece of the Lille Passionary (BM 607), made for an unknown abbey (Fig. I2), and in the margins of the Breviary for the nuns of Spermalie (Bruges, GS 54/IO0); an unknown nun kneels before Crucifixion in the Breviary of Marquette (Cambrai MM 99 (IOO), f. 5v); an unknown abbess is before the Virgin and Child in the Cistercian Diurnal (The Hague, KB 74 G 3I, f. I7v), and nuns before St Bernard are included in a series of related books (Brussels, BR 2512, I787; Vienna, ÖNB s. n. I277I). Nuns of other orders seem less frequently represented in their books: Abbess Aelis de Condé in the Charter of Sainte-Glossinde (OSB), Metz (Metz, AD de la Moselle, H 4085-5), attendant upon the abbey's patron St Glossinde on the first recto of the Charter, or Hélouis d'Escoufflans, nun of Origny Sainte-Benoite (OSB), no doubt the nun depicted at the end of the extensively illustrated Vie de sainte Benoite which she commissioned (Berlin, SMPK Kupferstichkabinett 78 B I6, f. 56, Fig. I3), are rare examples.

Among the records are mentions of the borrowing of books: Walterus de Sancto Amando (Saint-Amand), Canon of Saint-Germain, Mons, residing in Paris, had a loan of books for 
Fig. I2: Lille, Bibliothèque municipale, Ms. $607(92)$, fol. Av, Passionary: Crucifixion with Cistercian nuns (Arras, c. 1275-80)

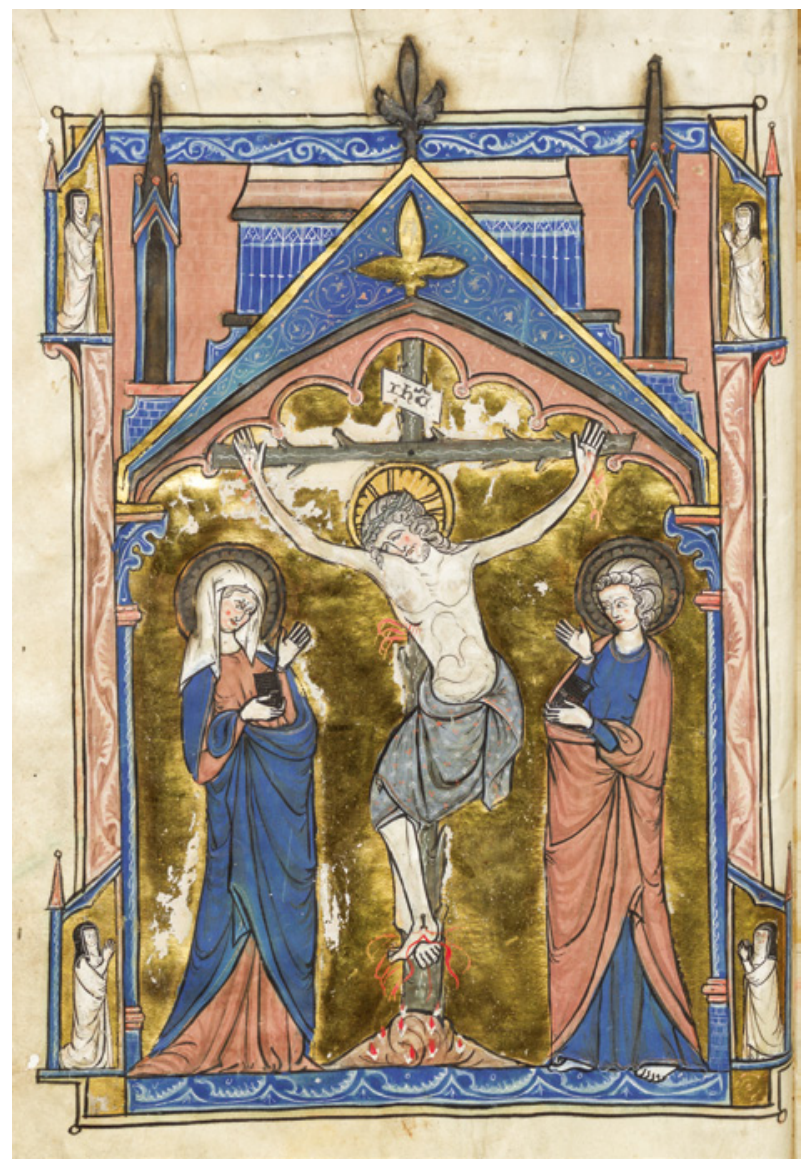

his lifetime from the Chapter Library of Tournai Cathedral. A document drawn up in Paris on 13 November 1308 lists the books and their values: Librum de anima cum quibusdam aliis libris, precii XLVs. Par.; Librum de celo et mundo, precii L.s. Par., commentatos ab Averroys; Librum de animalibus, precii XXs. Par.; Librum moralium Aristotelis cum quibusdam aliis libris, precii triginta quinque s. Par.; Librum politicorum, etichorum et rethorice, precii XLs. Par.; Epistolas Petri Blesentis, precii XIIs. Par.; Librum phisicorum Aristotelis, continemtem plures alios libros, precii Xs. Par.; Librum continentem rimatha magistri Petri de Castellione, Ovidium Nasonem et librum de membrorum officiis, precii VIIIs. Par.; Et librum Aristotelis de motibus, continentem librum de progressu animalium et quosdam alios libros, precio XVs. Par. He promised they would be returned at his death. ${ }^{35}$ Aldebertus de Petraforti, ouvrier, in 1319 acknowledged the loan from the goods of Bishop Pierre de Plane Cassanhe, whose formidable collection was mentioned above: he borrowed a commentary of St Augustine on John’s Gospel. ${ }^{36}$ Marguerite de Constantinople, Countess of Flanders († I280), borrowed a

35 Tournai, AC Cartulaire D, fol. 25orb; Derolez (cit. n. I3), IV, p. 309, no. 123.

36 Fasti Ecclesiae Gallicanae, Diocèse de Rodez, ed. M. Desachy (cit. n. I7), p. I8 (Città del Vaticano, BAV Arch. Sgr. Vat., coll. 2IO, f. 5I, inventory after death of Pierre de Plane Cassanhe, I February I319). 


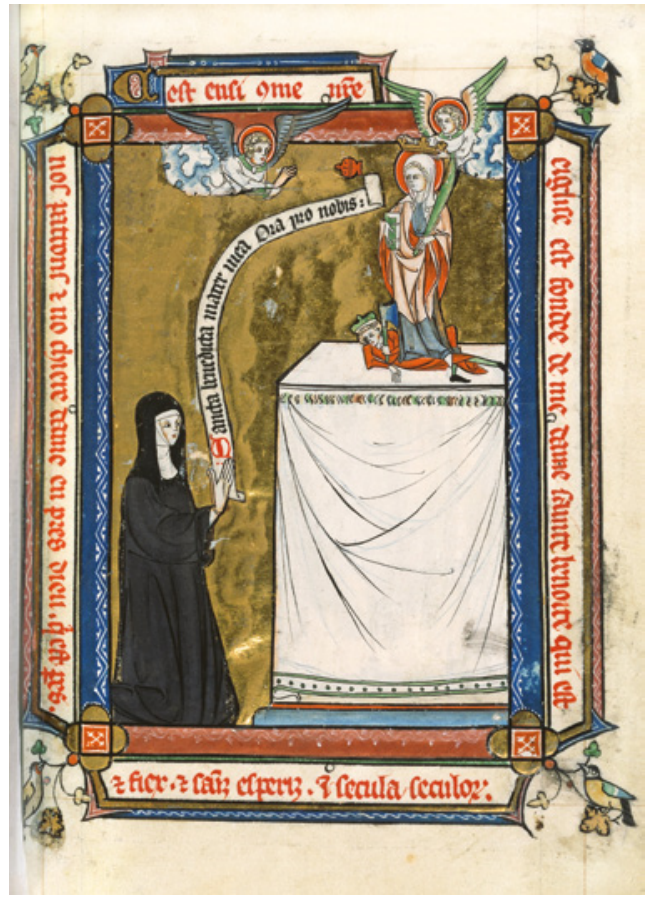

Fig. I3: Berlin, Staatliche Museen zu Berlin Preußischer Kulturbesitz, Kupferstichkabinett, Ms. 78 B I6, fol. 56 : Héluis d'Escoufflans before a statue of St Benoite (Laon or Saint-Quentin, I312) book (unspecified) from Dame Cole (Christian name unknown) in 1279 and paid her Io s. for it, Adont a Dame Cole sour son livre preste $X s .{ }^{37}$

Dame Cole would appear to be a bourgeoise, in the absence of further qualifications. Was she related to Jean Cole, bourgeois of Tournai, who bequeathed a Merlin to his son Jean in I305? Jean also owned Geste des Lorrains, Garin de Monglane, Roland, Berthe aux grands pieds, a Mappemonde and Le senefiance des Macabés. ${ }^{38}$ Further tournaisian bourgeois book owners were women: Katerine de le Fontaine, wife of Gossuin dou Maresse, of Tournai, who, in her will of August 1324, bequeathed to Katherine, daughter of Bauduin de le Fontainne, mes eures et II fuellais ki sont en II pieches; ${ }^{39}$ Ysabius Meurande, wife of Andrieu Trikart, of Tournai, bequeathed on 9 December I3II to Annecon, daughter of Andrieu Trikart, an Hours and a Psalter; ${ }^{40}$ Ysabiaus Warisons, of Tournai, bequeathed in March 1303 (I304 n.s.) Io s. and her Hours

to Katerine, daughter of Jehan de Ronc; ${ }^{41}$ and Maroie, dit Malebranke, in her will of 1324 , gave her Psalter to the Bons Enfants. ${ }^{42}$ In another northern town not far from Tournai, the Mulet family owned and transmitted books: Gerard Mulet, bourgeois of Douai, left books to his brother in his will of October 1272: A maistre Jakemon Mulet, men frere, tous mes livres, c'est assavoir un code, une Esforcade, une digeste viele, une digeste nueve, et un petit volume; ${ }^{43}$ Marguerite Baudaine, bourgeoise of Douai, wife of Gilles Mulet, in her will of April I274 bequeathed to... Gressent, me fille, I dyamant, XII coussins de plus, et men grant sautier et

37 Ghent, Rijksarchief, inv. Gaillard 29, listed in Bautier and Sornay, Sources (cit. n. I4), p. 62.

38 De la Grange (cit. n. IO), no. 39; Vanwijnsberghe (cit. n. I2), p. I63, no. i; Derolez (cit. n. I3), IV p. 329, no. 137 (adds the Mapemonde and Senefiance des Macabés to the list given in DE LA Grange and VanwiJnsBERGHE).

39 Dehaisnes, Documents et extraits (cit. n. II), p. 257; VAnwijnsberghe (cit. n. I2), no. 8.

40 de la Grange (cit no. io), no. 46; Vanwijnsberghe, (cit. n. i2), no. 3.

4I De la Grange (cit. no. io), no. 4I; Vanwijnsberghe, (cit. n. i2), no. 2.

42 Dehaisnes, Documents et extraits (cit. n. II), I, p. 257; Archives de Tournai, Actes passés devant échevins, I324; de la Grange (cit. n. IO), no. 72; Vanwijnsberghe, (cit. n. I2), no. 9: Je lais mon sautier as Bons Enfans.

43 Dehaisnes, Documents et extraits (cit. n. II), p. 65, from Douai, Bibliothèque de la Ville, Fonds de la maison des Huit-Prêtres. 
mes roumans... Marguerite herself was bequeathed bona mobilia, jocalia et libros by her brother-in-law, Jacques Mulet, provost of Saint-Barthélemy de Béthune, Canon of SaintPierre and Saint-Amé, Douai, on 20 April $1309 ;{ }^{44}$ her second will of August 1320 included bequests to ... Angnies de Placi, me nieche ... le sautier qui fut le mere de ledicte Angnies, et mes milleurs eures..., which were to be given at Agnes's death to her descendents. And Jean de Houdaing paid 24 lb.p for unes grandes Decretales and 30 lb.p. for other books sold to him by Marguerite's executors. ${ }^{45}$

Could these people read their books, did they merely look at the pictures, or were the books simply valuable objects? A hint may be found in the will of 8 May 1305, revised in August I308, of Marguerite de Tonnerre (I248-I308), daughter of Eudes, duc de Bourgogne, who in I268 became the second wife of Charles I d'Anjou, King of Naples, Sicily and Jerusalem. ${ }^{46}$ Following a list of jewels, devotional books are mentioned ... a Mahaut, ma niece, mes bacins d'argent dorés à laver les mains et mon sautier qui fut madame ma mere (Mahaut II, daughter of the Duke of Bourbon); ${ }^{47}$... a la princesse d'Antioche (Marguerite de Beaumont, daughter of Louis de Brienne, widow of Bohemond VII, prince of Antioch) qui demeure avec moi mes eures d'argent, mon livre blanc; a monseigneur Robiert de Luzarches mon breviaire, en quoy je lis qui est en deuz parties; a Gillete, niece dudit monsseigneur Robiert, mon autre breviaire, en quoy elle maide a dire mes heures... ${ }^{48}$ These latter references suggest on the one hand that Marguerite could and did read, but that saying the hours was something that required the participation of another person - not Robert himself (perhaps her confessor ?) but another woman. Perhaps Gilette as the niece of a cleric, if that is what Robert was, had greater fluency in deciphering the complex text of a Breviary. It is interesting too that Marguerite used a Breviary, the preferred devotional book of royalty (cf. the queen in the partial Breviary of the Sainte-Chapelle at The Pierpont Morgan Library, M.IO42 mentioned above; many royal commissions made by ladies in the early fourteenth century were also breviaries rather than books of hours).

Portraits of lay people, particularly women, are far more common than kings, queens, and clerics. Most are small, portrayed in historiated initials or in margins, and they are predominantly found in pocket-size devotional prayer books, suggesting that women were the primary recipients and users of these types of book; the majority of them are anonymous. Especially notable, if atypical, examples are the Psalter in Padua (Biblioteca del Seminario

44 ibid., p. 187.

45 ibid., p. 67, from Douai, Bibliothèque de la Ville, Fonds des Huit-Prêtres, nos. 2, 24, 25.

46 Europäische Stammtafeln: Stammtafeln zur Geschichte der europäischen Staaten, neue Folge, ed. D. ScHweNNICKE, 2I vols., Marburg 1978 ff., II, Taf. 2I.

47 The inherited Psalter bequeathed to Mahaut is Paris, Bibliothèque Sainte-Geneviève I273, mid-I3th century, of Saint-Bertin Use, but illuminated by an English artist, and it contains additions concerning the pious death of Pierre d'Alençon (C. GuggenbüHL, Recherches sur la composition et la structure du ms. Arsenal 35I6, Basel/Tübingen I998, p. 232, citing V. Leroquais, Les Psautiers manuscrits latins des bibliothèques publiques de France, 2 vols., Mâcon 1940-4I, II, pp. I52-54, no. 359; see also X. HÉLARY, La mort de Pierre, comte d'Alencon (I283), fils de saint Louis, dans la mémoire capetienne, in: Revue d'histoire de l'eglise de France, 94, 2008, pp. 5-22 at I2-I4.

48 Dehaisnes, Documents et extraits (cit. n. II), p. I66; AD Nord, Fonds de la Chambre des Comptes de Lille, B. 486 , no. 4621 . 


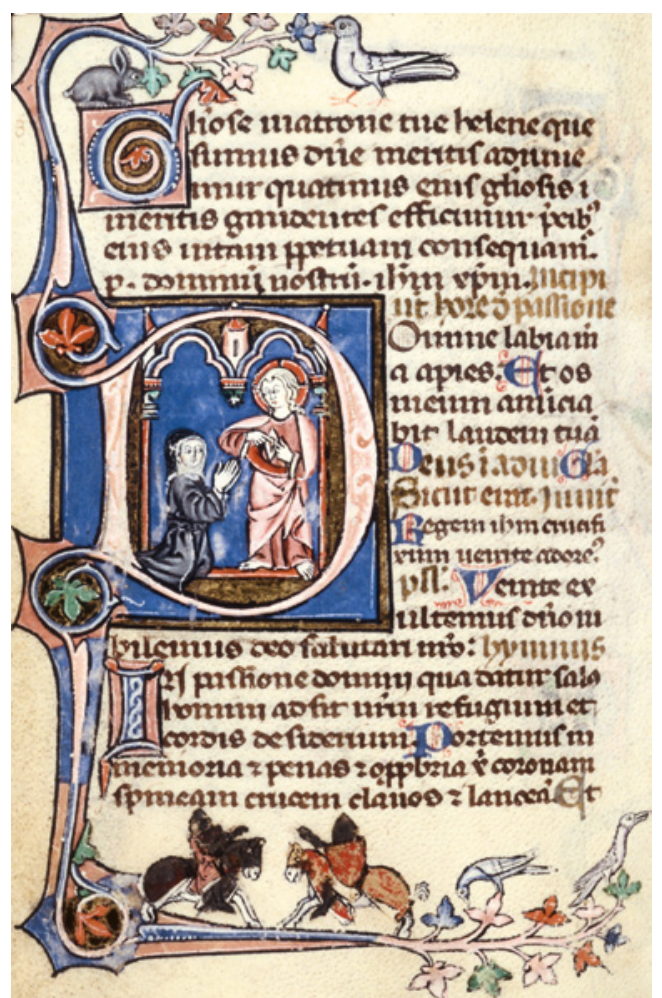

Fig. I4: London, British Library, Egerton 945, fol. 237v, Devotional Miscellany: Hours of the Passion, Franciscan nun before Christ revealing the Wounds; jousting knights (Périgueux? c. 1319)
353), whose female patron, of uncertain identity, kneels in a full-page miniature before the Virgin and Child, or Madame Marie's picture-book, in which Marie was depicted before her to favourite saints (Paris, BNF n. a. fr. I625I). The full-page portrait of Comtesse de la Table in her Psalter-Hours is without parallel in scale and in its use of heraldry, showing the recipient in a full-page miniature wearing a robe decorated with the arms of Coeuvres, her book adapted for her step-daughter Yolande de Soissons, who did not have her own portrait added, only her husband's family shield placed in the borders (New York, The Pierpont Morgan Library M. 729); in the Somme le roi of Jeanne d'Eu et de Guines (Paris, Bibliothèque de l'Arsenal 6329), Jeanne, plainly robed, is shown before the Virgin and Child with her shields discretely placed on the corners of the frame. The Psalter of the Clary and Mailly families (Paris, BNF lat. I0435) and of the Aspremont-Kievraing families - perhaps not Jofffroi and Isabelle but their son Gobert or daughter Marie (Oxford, Bodleian Library, Douce II / Melbourne, National Gallery of Victoria, Felton 1254/3), the Missal leaf now in Antwerp with the shield of the Munchensy family (Antwerp, Museum Mayer van den Bergh, MS Inv. 607, Cat. I 298), the Hours of Gautier de Châtillon d'Autresche and his (otherwise undocumented) wife (Cambrai, MM 87 ) are all distinguished by their heraldry, and most of these people are depicted in person as well. A hint of patronage is offered in the Franciscan devotional miscellany from Périgueux (London, BL Egerton 945, f. 273v) by the presence of jousting knights holding damaged shields that suggest the arms of the Talleyrand-Périgord family, members of which were nuns and abbesses of the Périgueux Franciscan house (Fig. I4). Yet many other books include heraldry that has so far defied identification as parallels and sources are lacking - or where the presence of shields has encouraged premature conclusions about ownership, as with the Psalter 'of' Gui de Dampierre, where the shields have been heavily overpainted (Brussels, BR I0607), or those in the Psalter 'of' Louis le Hutin (Tournai Cathedral BCT A I7), where they have been added and largely misinterpreted.

Original inscriptions of ownership are comparatively rare. Among the most striking is the mention of the patrons of the French translation of Frederick II's Falcon book, made, as the preface says (f. Iv) for Jean de Dampierre et de Saint-Dizier and his wife Dame Ysabel 


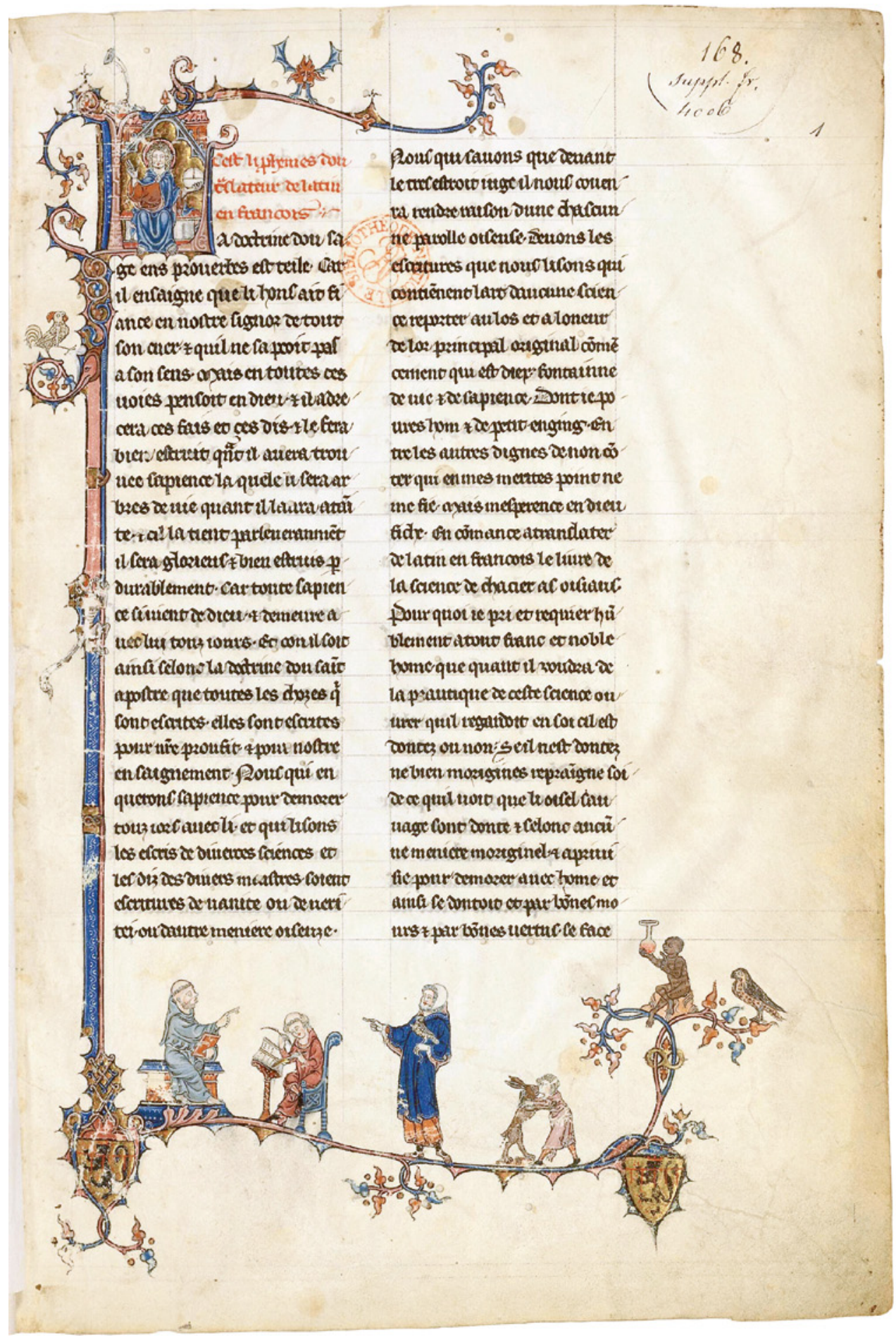

Fig. I5: Paris, Bibliothèque nationale de France, fr. I2400, fol. I Frederick II's Falconbook in French: Jean de Dampierre et de Saint-Dizier commissioning the translation, illuminated by Simon d'Orléans (Reims? c. 1305-1310) 
(Isabelle de Brienne, daughter of Jean d'Eu and Béatrix de Châtillon-de Saint-Pol), ${ }^{49}$ and their son Guillaume and his wife Iehanne de woingnonri ma dame ione (named as Jeanne de Vignori, more usually known as Jeanne de Chalon, daughter of Étienne, seigneur de Rouvres et de Montenot, second son of Jean, comte de Chalon-sur-Saône, and Jeanne de Vignory). ${ }^{50}$ Also of note is the name of the illuminator, Simon d'Orléans, given in the colophon the end of the volume. But in his border illustration on f. I (Paris, BNF fr. I2400, Fig. I5), Simon painted family shields and a single male patron, falcon on wrist, debating with a tonsured cleric (the name of the translator is unknown), with another tonsured cleric seated between them, writing, despite the credit given to both wives in the dedicatory text. Guillaume's sister Marguerite, married in I30s to Gaucher de Châtillon, comte de Porcéan (†1325, son of Gaucher de Châtillon, comte de Porcéan, connétable de France, † 1329) adopted a different strategy: she was the likely owner of Stockholm, KB Vu I6, Athis et Prophilias, written in 1299 by Jehan Clart, living at Fontenoy; on f. 245 she is named in a decorated box in the margin as Marguerite de Dompaire. ${ }^{51}$ Was it she herself who added her name?

These few people and their collections must also stand for the hundreds of others, some depicted without a name in their books, others not identified or known at all, who also valued illuminated manuscripts and set the stage for the great collectors and lesser figures of the fourteenth and fifteenth centuries.

University of Pittsburgh

Illustration credits: Fig. I: James H. Marrow. - figs. 2, 3, 15: Paris, Bibliothèque nationale de France. - figs. 4, 6, 7, Io: author. - Fig. 5: London, Courtauld Institute of Art. - Fig. 8: Tours, Bibliothèque municipale. - Fig. 9: Den Haag, Koninklijke Bibliotheek. - figs. II, I4: London, The British Library Board. - Fig. I2: Lille, Bibliothèque municipale. - Fig. I3: Berlin, Staatliche Museen zu Berlin - Preußischer Kulturbesitz, Kupferstichkabinett.

49 Schwennicke, Europäische Stammtafeln (cit. n. 46), III, Taf 5I, IIII / 4-Taf. 683.

50 ibid., II-Taf. 60, III-Taf. 5I, XV-Taf. 197.

5I She was the sister-in-law of Marie de Châtillon (ES III-Taf. 5I), whose name is also found in a decorated panel in a later copy of Athis et Prophilias, London, BL Add. I644I, written in I330 (Busby, Codex and Context (cit. n. 19), p. 704). 


\section{DIE ANZIEHUNGSKRAFT DER UNIVERSITÄTEN \\ QUELLEN ZU MIGRATIONSBEWEGUNGEN VON SCHREIBERN \\ UND BUCHMALERN IN DER MITTELALTERLICHEN BOOM-REGION \\ BOLOGNA}

Karl-Georg Pfändtner

Mit der Blüte der Universitäten im ausgehenden I2. und beginnenden I3. Jahrhundert setzten vor allem in Paris und Bologna Migrationsbewegungen von Studenten aus allen Ländern Europas ein, die aufgrund der erhaltenen und schon im 19. und frühen 20. Jahrhundert veröffentlichten Matrikeln als bestens erforscht gelten können. ${ }^{1}$ Der neue Wissenschaftsbetrieb führte an den Universitäten mit ihren gut gefüllten, mitunter wohl auch schon überfüllten „Hörsälen“ zu einem noch nie dagewesenen Bedarf an wissenschaftlichen, von der Universität kontrollierten Textabschriften. Um diesen Bedarf zu decken, wurde eine neue, ökonomisch innovative Art der Buchherstellung und des Buchhandels entwickelt. Es entstand ein blühender Markt für Bücher, der Schreibern, Buchmalern und Händlern Beschäftigung und Einnahmequellen bot. Dieser Buchmarkt ist vor allem für die Universitätsstadt Paris aufgearbeitet, ${ }^{2}$ doch auch in Bologna, der für das Rechtsstudium bekannten Universität in der Emilia, existiert eine Fülle von Quellen zur Buchproduktion, Qualitäts- und Preiskontrolle. Bemerkenswert ist, dass eine relativ große Zahl dieser Quellen auf eine internationale Ausrichtung von Buchproduktion und -markt deutet, was der wichtigsten Käuferschicht, die sich aus Studenten aus ganz Europa zusammensetzte, entsprach:

Dixit pater filio (...) vade Parisios vel Bononiam et mittam tibi annuatim centum libras. Iste quid fecit: ivit Parisios et fecit libros suos babuinare de litteris aureis3

(Es sprach der Vater zum Sohn (...) gehe nach Paris oder Bologna und ich werde dir jährlich hundert Pfund schicken. Was aber machte dieser: Er ging nach Paris und ließ seine Bücher mit Drôlerien und goldenen Buchstaben ausstatten).4

I Für Bologna wichtig ist vor allem: G. C. KNOD, Deutsche Studenten in Bologna (I289-I562). Biographischer Index zu den Acta nationis Germanicae Universitatis Bononiensis, Berlin I899.

2 R. Branner, Manuscript Painting in Paris during the Reign of Saint Louis IX. (I226-I270). A Study of Stiles. R. Hausherr, Rezension zu Branner in: Kunstchronik, I980, S. I65-I73. - Chr. De Hamel, The Book. The History of the Bible, London 200I, insbes. S. II4-I39. - R. H. Rouse/M. A. Rouse, Illiterati et uxorati. Manuscripts and Their Makers. Commercial Book Producers in Medieval Paris I200-1500, Turnhout 2000.

3 Odofredus da Bononia, Lectura super Codice (Nachdruck Forni Bologna, 1968, Bd. I, 226 ad C.4. 2. 8.5). Siehe hierzu auch N. Tamassia, Odofredo, Forni i98i, S. I80f.

4 Siehe zur Diskussion der Bedeutung von babuinare H. Rouse/M.A. Rouse, The Commercial Production of Manuscript Books in Late-Thirteenth-Century and Early-Fourteenth Century Paris, in: L. BrownRIGG (Hrsg.), Medieval Book Production. Assessing the Evidence. Proceedings of the 2nd Conference of the Seminar in the History of the Book to I500, Oxford, July 1988, Los Altos Hills 1990, S. I03 mit Anm. 2. 


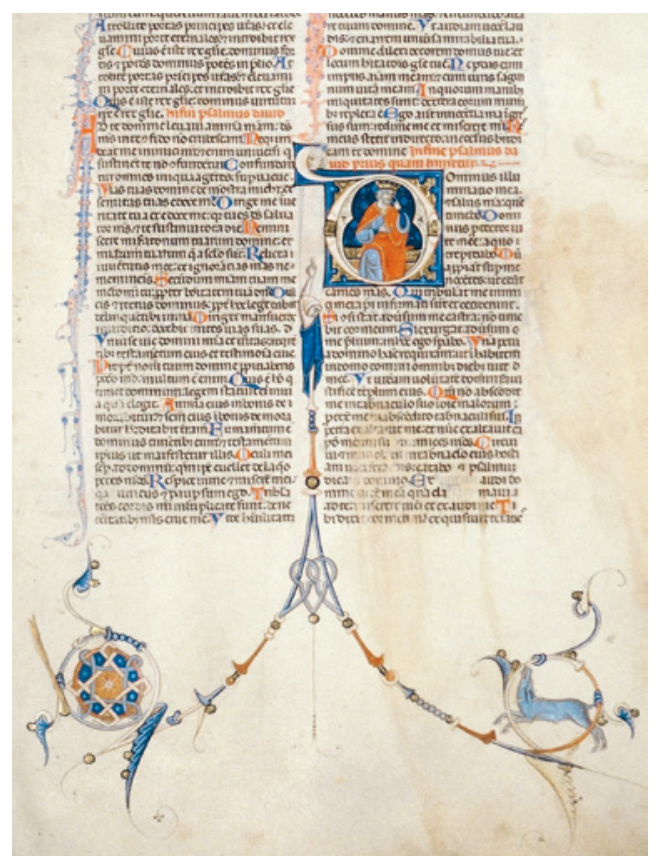

Abb. I: Paris, Bibliothèque nationale de France, lat. 22, Bibel, fol. 95r: König David zu Psalm 26 (Detail); Bologna, um I267
Dieses berühmte Zitat des Odofredus von Bologna (gest. 1265) belegt die Situation beispielhaft und ist ein Zeugnis für die Internationalität des Studiums und die bevorzugten Universitätsstädte, nämlich Paris und Bologna. Und es gab nicht wenige, denen aufgrund von früh erworbenen Pfründen bereits während des Studiums viel Geld zur Verfügung stand, das sie auch für Bücher ausgaben. Fredol de Saint Bonnet, Eigentümer einer Bibel, die heute in der Bibliothèque nationale in Paris als lat. 22 (Abb. I) aufbewahrt wird, besaß, wie wir aus anderen Quellen wissen, unter anderem zwei Dekretalenhandschriften und war zur Zeit seines Studiums in Bologna bereits Kanoniker. Später wurde er Bischof von Le Puy-en-Velay (von I284-I289). Ein weiteres Beispiel ist Guilelmus de Mandagotus, berühmter Autor kanonistischer Standardwerke und als Student bereits Kanoniker in Nîmes. ${ }^{5}$

\section{DIE HERKUNFT DER SCHREIBER}

Die wichtigste Quelle für die Herkunft der Schreiber sind die Kolophone, die unterschiedlich ergiebig in ihrem Informationsgehalt sein können. Wenig überraschend ist es, dass die Schreiber häufig angeben, sich in Bologna aufzuhalten oder dort sogar geboren zu sein. So berichtet der sich namentlich nicht nennende Schreiber, der die um I300/ı3IO ausgestattete Bibel Ms. II77 der Bibliothèque Sainte-Geneviève in Paris geschrieben hat, dass er in Bologna geboren ist: Nomen meum non pono quia me laudare non volo, bononie natus dominus semper sit glorificatus. Amen. ${ }^{6}$ Die Bibel Ms. a. I. 5 der Königlichen Bibliothek im Escorial, um 1290 entstanden und reich mit Miniaturen ausgestattet, wurde nach Auskunft ihres Kolophons auf fol. 474v von Ugolinus bononius geschrieben, ${ }^{7}$ und auch Codex 96 der Universitätsbibliothek Erfurt enthält einen Vermerk, der sie als I30I in Bologna geschrieben ausweist. ${ }^{8}$

In einer 1272 datierten Bibel der Biblioteca Nacional in Madrid (Ms. Vitr. 2I-4), nennt der Schreiber zwar nicht den Ort, an dem er sich befindet, doch nennt er seinen Namen und sei-

5 J.F. v. Schulte, Die Geschichte der Quellen und Literatur des canonischen Rechts von Gratian bis auf die Gegenwart, Bd. II, Stuttgart I875, S. I85 f. und K.-G. Pfändtner, Die Psalterillustration des i3. und beginnenden I4. Jahrhunderts in Bologna. Herkunft - Entwicklung - Auswirkung, München-Neuried I996, S. LXVII. 
nen Status: Johannes filius Jacobini notarius. Aufgrund dieser Angaben konnte er in den Bologneser Akten als in dieser Stadt ansässig identifiziert werden. ${ }^{9}$

Häufig lässt sich der Herkunftsort der Schreiber aus ihrem Namen ermitteln, wie zum Beispiel in der Dekretalenhandschrift Ms. 5I der Biblioteca Antoniana in Padua: Sie wurde, worauf im Kolophon auf fol. 259v ausdrücklich Wert gelegt wird, in Bologna von einem Bonaventura aus Verona geschrieben: Anno domini MCCLXXXXIIi bonaventura veronensis scriptor Die iovis VI. excut. iunio in civitate bononie hoc opus consumavit. Deo gratias. ${ }^{10}$ Vom selben Schreiber stammt vielleicht auch Msc.Bibl.s der Staatsbibliothek Bamberg, eine Vulgata in gotischer Buchschrift. Im Kolophon nennt sich ebenfalls ein Bonaventura veronensis, der das Buch allerdings in Faenza kopierte - favencie comorans -, und zwar für Frater Mattheo de Bononia (Abb. 2). ${ }^{11}$ Das heißt, diese in Bologna reich mit Miniaturen ausgestattete Handschrift wurde für einen wohl in Bologna sesshaften oder aus Bologna stammenden Frater von einem Franziskaner in Faenza, $56 \mathrm{~km}$ von Bologna entfernt, geschrieben. Die Nennung und Hervorhebung des favenciae comorans deutet wohl darauf hin, dass sich der Schreiber nur zeitweise dort aufhielt.

Auch ein Jacopino da Reggio taucht des Öfteren in Bologneser Akten auf. Er nennt sich im Decretum Gratiani Cod. Vat. lat. 1375 der Biblioteca Apostolica Vaticana in Rom als Schreiber und wird gemeinhin mit dem Buchmaler dieser Handschrift und weiterer Codices gleichgesetzt. ${ }^{12}$

Ausdrücklich als zugereist bezeichnen sich die Schreiber der Bibel Ms. Conv. Soppr. 582 der Biblioteca Medicea Laurenziana in Florenz, die um 1260/70 von einem Johannes vocatus de Monte Sancto geschrieben wurde, ${ }^{13}$ und der Schreiber einer relativ frühen, prächtig in Bologna ausgestatteten Bibel, Ms. Canon. Bibl. lat. 56 in der Bodleian Library Oxford. Letztere wurde von Lanfrancus de Pancis aus Cremona im Jahre 1265 geschrieben. ${ }^{14}$ Wohl derselbe Schreiber nennt sich auf fol. 315v in der bereits I258 datierten Dekretalenhandschrift Ms. Plut. V sin. 2 der Biblioteca Medicea Laurenziana in Florenz, die allerdings von einem anderen Buchmaler ausgestattet wurde. ${ }^{15}$

Nur ca. $50 \mathrm{~km}$ von Bologna entfernt, also im direkten Einzugsgebiet der bedeutenden Universitätsstadt, liegt Modena, eine Stadt, aus der gleich mehrere Schreiber nachweisbar sind. So ist eine frühe illuminierte Dekretalenhandschrift in der Bodleian Library in Oxford

9 Siehe zur Bibel Pë̈ndTner, Psalterillustration (zit. Anm. 5), S. I7 und XXXIX.

Io PFändtner, Psalterillustration (zit. Anm. 5), S.V.

II Millesimo CCLXIII indictione VI. die iovis XV novembris bonaventura veronensis scriptor favencie comorans scripsit hanc bibliam fratri Matheo de Bononia.

I2 Siehe zu Jacopino da Reggio: M. Medica, Jacopino da Reggio (Maestro della Bibbia Lat. I8), in: M. Bollaті/M. Bosкоviтs (Hrsg.), Dizionario Biografico dei Miniatori italiani, Mailand 2004, S. 344-346.

I3 Der Schreiber lässt sich sonst nicht nachweisen. Siehe zur Handschrift Pfändtner, Psalterillustration (zit. Anm. 5), S. XXV.

I4 Das Kolophon befindet sich auf fol. 469v und lautet: Finitio libro referamus gracias xpisto MCCLXV I indict. VIIi. Ego lanfrancus d'pancis d'cremona scriptor scripsi.

Is Finitio libro referamus gracias xpisto qui scripsit scribat semper cum domino vivat vivat in celis lanfrancus de panics de Cremona in nomine felix. Actus est anno domini MCCLVIII indictionis prima die mercurii XVI intrant Januar. Siehe zu dieser Handschrift PFäNDTNer, Psalterillustration (zit. Anm. 5), S. I mit weiterführender Literatur. 


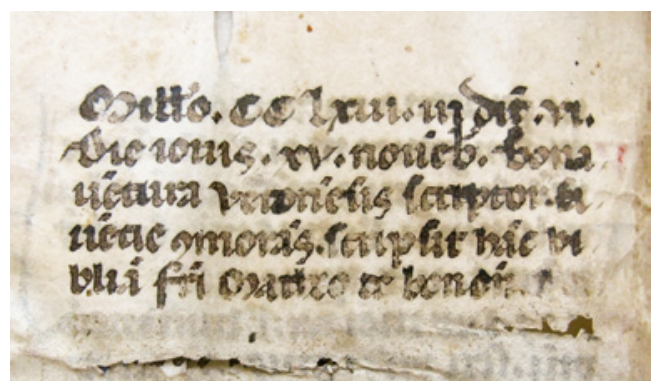

Abb. 2: Bamberg, Staatsbibliothek, Msc.Bibl.5, Bibel, fol. 524v: Kolophon des Bonaventura veronensis; Bologna/ Faenza, I263
(Ms. Lat. Th. b. 4) im Jahre I24I laut Kolophon von Leonardo Groppi da Modena geschrieben. Sinibaldus de Mutina schrieb I29I den in Bologna ausgestatteten Codex Ms. I336 der Biblioteca Oliveriana in Pesaro. ${ }^{16}$ Zwei der am prächtigsten im byzantinischen Stil ausgestatteten Bologneser Bibeln können ebenfalls einem Modenesen zugewiesen werden. In der um I270/1300 entstandenen Bibel C. 52 des Kathedralarchivs Gerona in Katalanien nennt sich ein Magister Bernardinus aus Modena auf fol. 493v: Explicit biblia. magister Bernardinus Mutina fecit, laus tibi sit xpiste quoniam liber explicit iste. In Ms. Res. 25 der Domkapitelsbibliothek Toledo hat Albertinus de Mutina auf fol. 217r am Ende des Psalters seinen Namen eingetragen: explicit psalterium albertini de mutina. ${ }^{17}$

Eine respektable Anzahl von Schreibern ist aber auch aus verschiedenen europäischen Ländern eingewandert. Frank Soetermeer beobachtete in den Bologneser Archiven einen relativ hohen Anteil von Briten im Bologneser Buchhandel. ${ }^{18}$ Sehr aufschlussreich in vielerlei Hinsicht ist das Kolophon, das Raulinus de Fremington aus Devon in England in die um I270 in Bologna kopierte und hier ausgestattete Bibel Ms. nouv. acq. lat. 3189 der Bibliothèque nationale in Paris eingetragen hat. ${ }^{19}$ Er berichtet über sein bisheriges, sehr bewegtes Leben: Aus Devon stammend, studierte er nach dem Tode seines Vaters, wohl mit dem Geld aus der Erbschaft, in Paris die artes und verschwendete hier das Geld mit „Frauen“, bis nichts mehr übrig war. Erst dann zieht er nach Bologna, empfiehlt sich reuig der Gottesmutter Maria und schreibt ihr zum Lobe die Bibel, in welcher sich das Kolophon auf Blatt $422 \mathrm{r}$ befindet:

Raulinus Devoniensis Almarici filius oriundus fremitone pauper pauperibus post parentis sui mortem veniens Parisius. Ibidem per biennium studit in artibus. Qui nefandis mulierum se miscens amplexibus. Earumque nexu pravo consumatis omnibus. Est tandem Bononie peccatis exigentibus. In honorem Sancte Genitricis Marie. Que tocius pietatis fons et vena venie. Per peccata depravatis spes est indulgentie. Scripsit istam laude dignam bibliam lentie. Cuius infallibili penes Domini peccamine. A perplexo vitiorum solutus ligamine. Per condignos ante mortem fructus penitentie.

I6 Pfändtner, Psalterillustration (zit. Anm. 5), S. V, Taf. I6 mit weiterführender Literatur.

I7 Siehe zu diesen beiden Bibeln Pfändtner, Psalterillustration (zit. Anm. 5), S. XXVII und XCVI. Zur Bibel in Gerona jüngst: Annette Hoffmann, Die Bibel von Gerona und ihr Meister. Berlin/München 20I3.

i8 F. P. W. Soetermeer, "Á propos d'une famille de copistes: quelques remarques sur la librarie à Bologne aus XIIIe e XIVe siècles. Studi medievale ser 3, 30 (1989), S. 425-478, hier S. 430. Siehe zu dieser Bibel Pfändtner, Psalterillustration (zit. Anm. 5), S. LXXI mit weiterführender Literatur und R. H. Rouse/M.A. Rouse, Wandering scribes and travelling artists: Raulinus of Fremington and his Bolognese Bible, in: A Distinct Voice: Medieval Studies in Honor of Leonard E. Boyle, O. P. ed. J. Brown and W. P. Stonemann, University of Notre Dame Press 1997, S. 32-67. 
Ad superne Syon arcem mereatur scandere. Quod praestare supplicanti digneris piissime. Qui subire mortem crucis venisti pro homine. Jhesu pie Jhesu bone Jehsu dator venie. Qui cum padre regnas et cum sancto flamine.

\section{Paris - Bologna: Konkurrenz und Austausch}

Während die aus den genannten Regionen nach Bologna eingewanderten Schreiber und Buchmaler sich in der Regel auf den Bologneser Stil (sowohl in Schrift als auch in der Malerei) einstellten, hatte der Austausch mit Paris, der anderen großen Metropole der Buchherstellung, Folgen für die Konzeption der in Bologna hergestellten Bücher.

Rouse und Rouse haben den Anteil auswärtiger Künstler in Paris und Bologna herausgearbeitet und vermuten auch die Tätigkeit Pariser Schreiber in Bologna, die dort beste Arbeitsbedingungen vorfanden. ${ }^{20}$ In der Bibel des Raulinus arbeiten zwei Bologneser Buchmaler, aber auch, hierauf verwies erstmals Avril, zwei französische Buchmaler, der Corpus-Meister und der Johannes-Grusch-Meister, der in Paris in den I240er- und I25oer-Jahren tätig ist. ${ }^{21}$

Gerade für die Bibeln, die in Bologna neben Rechtshandschriften entstehen, lassen sich französische Vorlagen nachweisen, sowohl was den Text der korrigierten Pariser Universitäts-Vulgata betrifft als auch den Buchschmuck mit gliedernden Initialen, von denen stilisierte Akanthusblattranken ausgehen. Aber auch die Pariser Ikonographie und die konsequente Achtteilung des Psalters in der Bibel wurde für die meisten Illustrationen der Bologneser Bibeln vorbildlich. ${ }^{22}$

Wie die Vermittlung dieser Vorlagen funktionierte, darüber wissen wir so gut wie nichts. Vielleicht geschah dies durch die Schreiber oder die nachweislich auch in Italien wirkenden französischen Buchmaler, vielleicht auch durch die häufig in Paris ebenso wie in Bologna studierenden Auftraggeber. Nicht auszuschließen ist auch ein seitens der Universität und der Stationarii erwarteter Standard. Eine wichtige Rolle könnten die Stiftungen von glossierten Studienausgaben an die Bettelordenskonvente gespielt haben. So erhielten vor allem die jungen Bettelordenskonvente neue Pariser Handschriften. Dem Konvent von San Antonio in Padua stiftet um 1240 ein in Paris ausgebildeter Kanoniker eine 25-bändige(!) glossierte Pariser Bibel. ${ }^{23}$ Der Franziskanerkonvent Assisi erhielt, wohl auf Veranlassung König Ludwigs IX. von Frankreich, eine um I255/56 entstandene mehrbändige illustrierte Pariser Vulgata, die sich heute unter der Signatur Ms. I-I5 in der Biblioteca Communale in Assisi befindet. ${ }^{24}$ Dem Franziskanerkonvent von Santa Croce in Florenz stiftete im Jahre 1285 Fra Enrico dei Cerchi eine I7-bändige, mit Glossen des Petrus Lombardus versehene Bibel, von der aber nur zwei Bände in Frankreich ausgestattet wurden (darunter der Psalter), die anderen wurden von Bologneser

20 R. H. Rouse/M. A. Rouse, Wandering Scribes (zit. Anm. 19), S. 32-67.

2I Siehe zu dieser Fragestellung S. L'Engle, Production and Purchase: Scribes, Illuminators and Customers, in:

R. Gibbs/S. L'Engle, Illuminating the Law. Legal Manuscripts in Cambridge Collections. Ausstellungskatalog Cambridge, Fitzwilliam Museum 3 November - I6 December 2991, London 2001, S. 39-53, hier S. 45.

22 Pfändtner, Psalterillustration (zit. Anm. 5), S. 60, 65.

23 Pfändtner, Psalterillustration (zit. Anm. 5), S. 24.

24 Branner, Manuscript Painting in Paris (zit. Anm. 2), S. 80. 
Künstlern illuminiert. ${ }^{25}$ Hier konnten die Bologneser Buchmaler direkt im bereits in Frankreich fertiggestellten Teil französische Buchmalerei kennenlernen. Für den Bologneser Dominikaner- oder Franziskanerkonvent ist leider bis heute noch keine solche französische Bibel nachgewiesen, ${ }^{26}$ doch wird man vom Besitz solcher Vorlagen auszugehen haben.

\section{DIE ENTWICKLUNG DER BUCHMALEREI IN BOLOGNA UND DIE HERKUNFT DER BUCHMALER}

Schon Dante nennt in seiner göttlichen Kommödie, Vers. 79-84 des II. Gesangs zwei Bologneser Buchmaler. Eigentlich will er mit der Nennung auf die Vergänglichkeit des Ruhms hinweisen: Oderisi da Gubbios Ruhm (Stern), einst Stolz seiner Heimatstadt und Buchmaler in Bologna, verblasse vor der Kunst des Franco Bolognese. Er gibt hiermit aber auch Herkunftsbezeichnungen zweier wichtiger Bologneser Miniaturisten, deren Oeuvre trotz des bekannten Namens im Bestand Bologneser Handschriften bisher noch nicht identifiziert werden konnte. Oderisi kam offenbar aus Gubbio. Ob sich Franco nur in Bologna aufhielt oder bereits der Generation der in Bologna aufgewachsenen Buchmaler angehörte, lässt sich nicht mit Sicherheit sagen, Letzeres ist aber anzunehmen. Während Dvorák, der im Jahre 1900 als erster Stil und Ausstattung Bologneser Handschriften der zweiten Hälfte des I3. und des I4. Jahrhunderts beschrieb, meinte, Oderisi da Gubbio und Franco Bolognese hätten nicht anders gemalt als die sonstigen Bologneser Buchmaler, ${ }^{27}$ beansprucht Venturi 1904 die einfacheren Handschriften des I. Bologneser Stils für Oderisi da Gubbio, die prächtigeren des byzantinisierenden 2. Stils für Franco Bolognese. ${ }^{28}$ Mit dem heutigen Wissenstand ist diese Fährte nicht seriös weiter zu verfolgen, da die wenigen Informationen über diese Maler, von denen nur Oderisi in zwei Bologneser Dokumenten genannt ist, für eine Zuschreibung von bestimmen Handschriften nur Spekulationen zulassen, sofern nicht weitere, näher spezifizierende Quellen oder Handschriften mit Signaturen der Buchmaler aufgefunden werden.

Die frühesten nach Bologna gegebenen Handschriften mit Deckfarbenminiaturen finden sich in einer Dekretalenhandschrift in der Biblioteca Medicea Laurenziana in Florenz aus dem Jahre I239 (Ms. Plut. III sin. 9, fol. ir) und in der oben genannten Oxforder Dekretalenhandschrift aus dem Jahre I24I. Aus dem Jahre I258 stammt die Ausstattung der Dekretalenhandschrift Ms. Plut. V sin. 2 der BML Florenz (Gregor IX. decretales), aus dem Jahre 1265 eine Bibel in Oxford (Ms. Canon. Bibl. lat. 56). Der Stil dieser zeitlich nahe entstandenen Handschriften ist nicht sehr einheitlich und zeugt von der unterschiedlichen Schulung dieser Buchmaler, ein

25 Die Bibel hat heute die Signatur Plut. I dex. I-I7. Siehe hierzu Pfändtner, Psalterillustration (zit. Anm. 5), S. 65, mit Anm. 331. Zum Stil der Handschriften A. Contr, La miniatura Bolognese. Scuole e botteghe I270I340, Bologna i98I, S. 3I ff.

26 Pfändtner, Psalterillustration (zit. Anm. 5), S. 57 f., Anm. 277.

27 M. Dvorák, Byzantinischer Einfluss auf die italienische Miniaturmalerei des Trecento, in: Mitteilungen des Instituts für österreichische Geschichtsforschung, 6, Ergänzungsband, Innsbruck 1900, S. 792-820 (Wiederabdruck in: M. Dvorák, Gesammelte Aufsätze zur Kunstgeschichte, München 1929, S. 45-73, hier S. 65).

28 A. Venturi, Storia dell arte italiana, Mailand 1904, S. 453, 373. 
Phänomen, das für Bologna insbesondere in der Zeit bis ca. I260 typisch bleibt, auch wenn sich der Stil bald in zwei Richtungen kanalisiert. Gemeinsam ist allen Bologneser Erzeugnissen das Layout, der Schmuckapparat und die Ornamentik, die sich letztlich an französischen Vorbildern orientieren. Erst mit dem sogenannten „Ersten Stil“, von Robert Gibbs ,accademic manner" genannt, entwickelt sich in Bologna ab ca. I260 ein einheitlicheres Erscheinungsbild. Dieser erste Stil ist wohl der autochtone, in Bologna an der Universität ausgebildete Stil, in dem auch die Masse der Bologneser Buchproduktion ausgestattet wurde. Wenig später treten die ersten Erzeugnisse des stark byzantinisierenden zweiten Stils auf.

Ein dritter Stil verarbeitet die Fresken der Arenakapelle in Padua. Hauptwerk sind die um I306 entstandenen Choralhandschriften der Biblioteca Capitolare der Kathedrale von Padua (Ms. A I4-I6 und B. I4-16). Ein schönes Beispiel für diesen Stil ist auch die Ausstattung des Troiaromans Cod. 257I der Österreichischen Nationalbibliothek Wien. ${ }^{29}$ Der Paduaner Einfluss kann, muss aber nicht durch die steten Studentenbewegungen von Bologna nach Padua und vice versa veranlasst worden sein, von denen uns die Quellen bereits im I3. Jahrhundert berichten. Mehrfach zogen Studenten und Professoren von Bologna nach Padua und umgekehrt, wenn bessere Bezahlung und Studienbedingungen zu erwarten waren. ${ }^{30}$ Schreiber und Buchmaler folgten den Auftraggebern und brachten so einerseits vielleicht Bologneser Stilismen nach Padua, andererseits Paduaner Modelle nach Bologna zurück.

Woher die nicht aus Padua und Oberitalien stammenden Künstler sonst noch kamen, lässt sich nicht im Einzelnen nachweisen, denn ihnen standen bis auf wenige Ausnahmen keine Kolophone zur Verfügung, in denen sie entsprechende Angaben machen konnten, doch vermutlich war das Spektrum ebenso weit gestreut wie bei den Schreibern.

Wie vor allem Morelli anhand von Quellen zu Buchherstellung und -vertrieb in Bologna verdeutlicht hat, existierte hier ein florierendes Handwerk mit Arbeitsteilung. ${ }^{31}$ Ab I259 regeln Stadtgesetze die Anfertigung und das Kopieren von Büchern ebenso wie den Buchhandel innerhalb der Stadtgrenzen. Die Schreiber und auch die Miniatoren waren frei und gehörten einzelnen Werkstätten an. Arbeitsteilung war dort vor allem aufgrund der Langwierigkeit des Schreibvorgangs auch bei wenig voluminösen Büchern gang und gäbe. Vor allem beim Durchblättern von Rechtshandschriften wird dies auch für den Bilderschmuck offensichtlich. So sind zum Beispiel an der Ausführung der sieben Bilder der um 1270 entstandenen Dekretalenhandschrift Ms. Plut. I sin. Io der Biblioteca Medicea Laurenziana Florenz vier verschiedene Buchmaler tätig. Daneben gab es aber auch Handschriften, die nur von einem Meister ausgemalt sind.

Die gut erhaltenen städtischen Bologneser Akten bieten eine Fülle weiterer Informationen über Buchmaler, die sich leider nur selten mit Malereien in erhaltenen Handschriften in Zusammenhang bringen lassen. Laut den archivalischen Quellen sind es häufig Notare, die, in kleineren Familienbetrieben zusammengeschlossen, nicht nur das Schreiben sondern auch

29 Conti, La miniatura Bolognese (zit. Anm. 25), S. 67 ff., 72.

30 Siehe hierzu demnächst: R. Gibbs, K.-G. Pfändtner, Byzantine Beauty and Bolognese Beasts, Bolognese Illumination before 1259 and the evolution of the accademic style (in Druckvorbereitung), S. 26.

$3 \mathrm{I}$ G. Morelli, Das mittelalterliche Buchwesen in Bologna, in: Alma Mater Librorum. Nove secoli di editoria bolognese per l'università, Ausstellungskatalog Bologna und Frankfurt 1988, S. 56-59. 


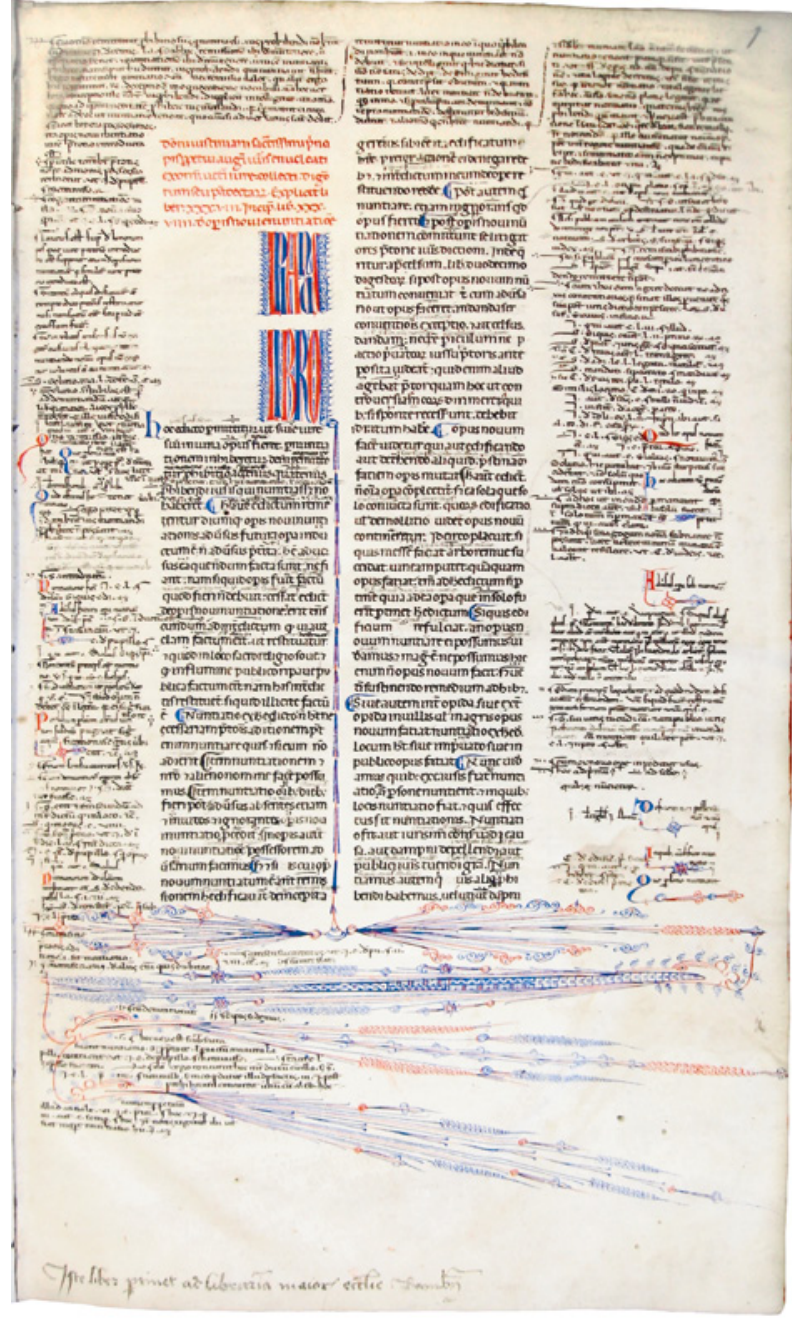

Abb. 3: Bamberg, Staatsbibliothek, Msc. Jur.I9, Compilationes I-IV Decretalium mit Glossen, fol. Ir: Federzeichnungsschmuck zu Beginn der Handschrift; Bologna oder Padua, Ende I2. Jahrhundert

das Illuminieren übernahmen. In diesen Familienbetrieben arbeiteten auch Frauen als Schreiberinnen und Malerinnen mit. Genannt werden zum Beispiel in den Stadtarchivalien in Bologna zwischen I268-I279 die Schreiberinnen Flandina, Montanaria, und Donella, Witwe des Guilelmo miniatore. Letztere hat als Ehefrau eines Miniaturmalers Handschriften geschrieben und ausgemalt und diese Beschäftigung auch nach dem Tod ihres Mannes weiter ausgeübt. ${ }^{32}$ Eine weitere Quelle berichtet von Rodolfo di Gandolfo, der für die Qualität der von seiner Tochter Antonia ausgeführten Miniaturen bürgt. ${ }^{33}$

Wie die Miniaturen der malenden Notare ausgesehen haben könnten, von welchen die Quellen seit Beginn des Duecento berichten, wissen wir nicht. Allerdings konnte in der monumentalen Ausstellung Duecento, forme e colori zum Milleniumswechsel im Jah-

32 Contı, La miniatura Bolognese (zit. Anm. 25), S. I3 mit Anm. i9.

33 Contr, La miniatura Bolognese (zit. Anm. 25), S. I3. 
re 2000 in Bologna eine größere Anzahl von wenig professionellen Zeichnungen in Büchern und Dokumenten einzelnen Notaren zugeschrieben werden. ${ }^{34}$ Doch scheint der Buchschmuck dieser frühen, von Advokaten und Notaren ausgestatteten Handschriften insgesamt recht einfach gewesen zu sein. Typisch für die Bologneser Produktion des ausgehenden I2. und beginnenden I3. Jahrhunderts sind einfaches Fleuronnée und Federzeichnungen, wie sie sich etwa in Msc. Jur.I9 der Staatsbibliothek Bamberg ${ }^{35}$ oder Msc.Can.I9 derselben Bibliothek ${ }^{36}$ erhalten haben, die kurz vor bzw. kurz nach 1200 zu datieren sind (Abb. 3). Bis auf Ausnahmen fehlt die wohl in Deckfarbenmalerei geplante Ausstattung mit Miniaturen oder Initialen zum Textbeginn. Jüngst wurde im Paduaner Ausstellungskatalog „Splendore nella Regola" ein sehr frühes Digestum vetus für Bologna in Anspruch genommen, ${ }^{37}$ allerdings auch mit relativ bescheidenem Schmuck.

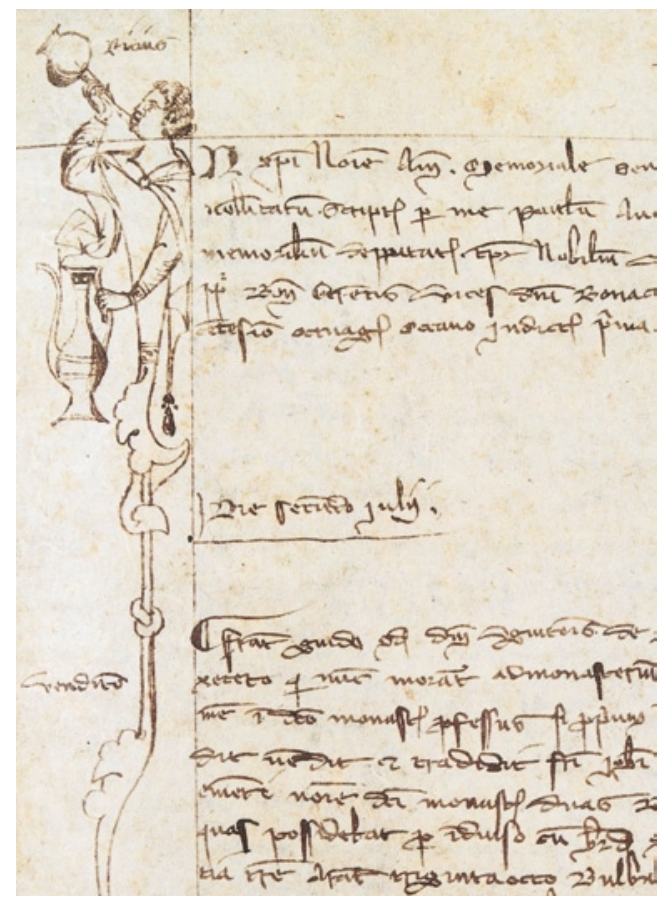

Abb. 4: Bologna, Archivio di Stato, Registro memoriale, Ufficio dei memoriali 73, fol. 2r: Zeichnung von Paulus avoccati notarius(?); Bologna, I288 Gemeinhin sieht man auch die frühen Federzeichnungen von Arbores, den Verwandtschaftsgraden aus dem Ende des I2. Jahrhundert, als Bolognesisch an, hauptsächlich aufgrund des Textes in dem sie sich befinden, nämlich des Decretum Gratiani, das vor allem in Bologna studiert und kopiert wurde. ${ }^{38}$ Fest nach Bologna lassen sie sich bisher allerdings nicht lokalisieren. Mit Ms. Ior des Sidney Sussex College in Cambridge finden sich in einem solchen Codex auch frühe textillustrierende Randzeichnungen. ${ }^{39}$

Doch waren diese Randillustrationen durchaus auch qualitätvoller, wie eine schöne Zeichnung zeigt, die wahrscheinlich von einem Notar stammt. Sie befindet sich im Registro memoriale, Officio dei memoriali 73, einem Stadtregister des Jahres $1288 \mathrm{im}$ Archivio di Stato in Bologna (Abb. 4). Der Schreiber dieses Registers, Paulus avvocati notarius, könnte auch der

34 Siehe hierzu: M. Vallerani, I disegni dei notai, in: M. Medica, S. Tumidei (Hrsg.), Ausstellungskatalog Duecento. Forme e colori del Medioevo a Bologna, Bologna 2000, S. 75-83.

35 Die Handschrift ist Ende des I2. Jahrhunderts entstanden.

36 I. Viertel I3. Jahrhundert.

37 F. Toniolo/ P. Gnan (Hrsg.), Splendore nella Regola. Codici miniati da monasteri e conventi nella Biblioteca Universitaria di Padova, Ausstellungskatalog Padua 20II, Kat. Nr. I (L. Granata).

38 S. L'Engle/R. Gibbs, Illuminating the Law (zit. Anm. 2I), Kat. Nr. 5.

39 L'Engle/Gibbs, Illuminating the Law (zit. Anm. 2I), Kat. Nr. 5. 


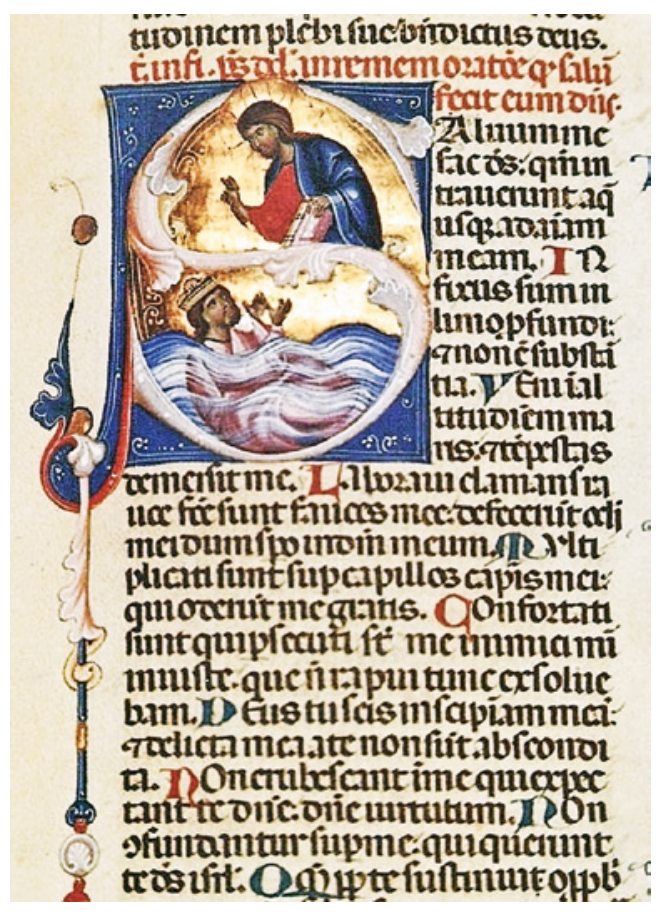

Abb. 5: Toledo, Archivo de la Catedral, Ms. Res. 25, Bibel, fol. 205r: König David in den Fluten, von Christus gerettet. Illustration zu Psalm 68; Bologna, um I260?
Maler gewesen sein, wie jüngst Massimo Medica überzeugend dargelegt hat. ${ }^{40}$

Für die Frage, ob Schreiber und Maler im Bologna des I3. Jahrhunderts dieselben Personen waren, könnte die Tatsache wichtig sein, dass viele der am reichsten im byzantinischen Stil ausgestatteten Handschriften im Kolophon angeben, dass der Schreiber, der Buchmaler oder der Besitzer aus Modena stammt. Ausgehend von dem in den Bologneser Quellen genannten Paolo di Jacopino Avvocato, dessen Tätigkeit als Notar, Miniator und Wandmaler archivalisch belegt ist ${ }^{41}$ - er malte unter anderem auch im Jahre 1287 Bilder im Palazzo Comunale in Bologna - wurden in der Forschung zur Bologneser Buchmalerei die sich in den Kolophonen nicht expressis verbis als Schreiber nennenden Personen oft als Buchmaler angesehen. Unterstützt wurden solche $\mathrm{Zu}$ schreibungen auch durch Formulierungen in Kolophonen wie das feci et scripsi etwa in

der um I295/1300 in Padua von Grasulpho da Mutina für Nicolo de Montenaro, Kanoniker in Padua (I295 erwähnt), geschriebenen Bibel der Pierpont Morgan Library in New York, M. 436, das schwierig zu deuten ist. Scripsi bezieht sich eindeutig auf die Schreibtätigkeit, doch das feci? ${ }^{42}$ Der Schreiber und eventuelle Buchmaler ist mehrfach in den Quellen zwischen I286 und 1324 genannt, jeweils ohne eindeutige Bezeichnung der Tätigkeit. ${ }^{43}$

Letztlich erscheint es mehr als fraglich, dass sich ein professioneller Buchmaler auch die Schreibarbeit einer 500 Blatt starken Bibel auferlegt hat, insbesondere, wenn der Buchmaler prächtige, sich an der zeitgleichen byzantinischen Hofkunst orientierende und daraus nährende Miniaturen geschaffen hat wie in den Bibeln in Toledo (Abb. 5), im Escorial oder in Gerona. Die hohe Qualität und der enge Bezug zur byzantinischen Kunst mit vielen griechischen Einträgen könnte vielleicht gar auf Miniaturmaler verweisen, die zur Zeit der lateinischen Besetzung des byzantinischen Reiches (I204-I26I) auf der Suche nach finanziell potenten Auftraggebern in den Westen gelangt sein könnten. Dies würde das Schreiben

40 Siehe zu diesem jüngst: M. Medica/S. Tumidei, Duecento (zit. Anm. 34), Kat. ios (M. Medica).

4i M. Medica/S. Tumidei, Duecento (zit. Anm. 34), Kat. ios (M. Medica) mit Verweis auf Referenzliteratur.

42 Das Kolophon lautet im ganzen: explicit biblia domini nichole de montenaro dei gratia cum omnibus sanctis: ego magister mutinensis de grasulpho qui fui de mutina feci et scripsi in padua. Siehe zur Bibel PFäNdTnER, Psalterillustration (zit. Anm. 5), S. LII mit weiterführender Literatur. 


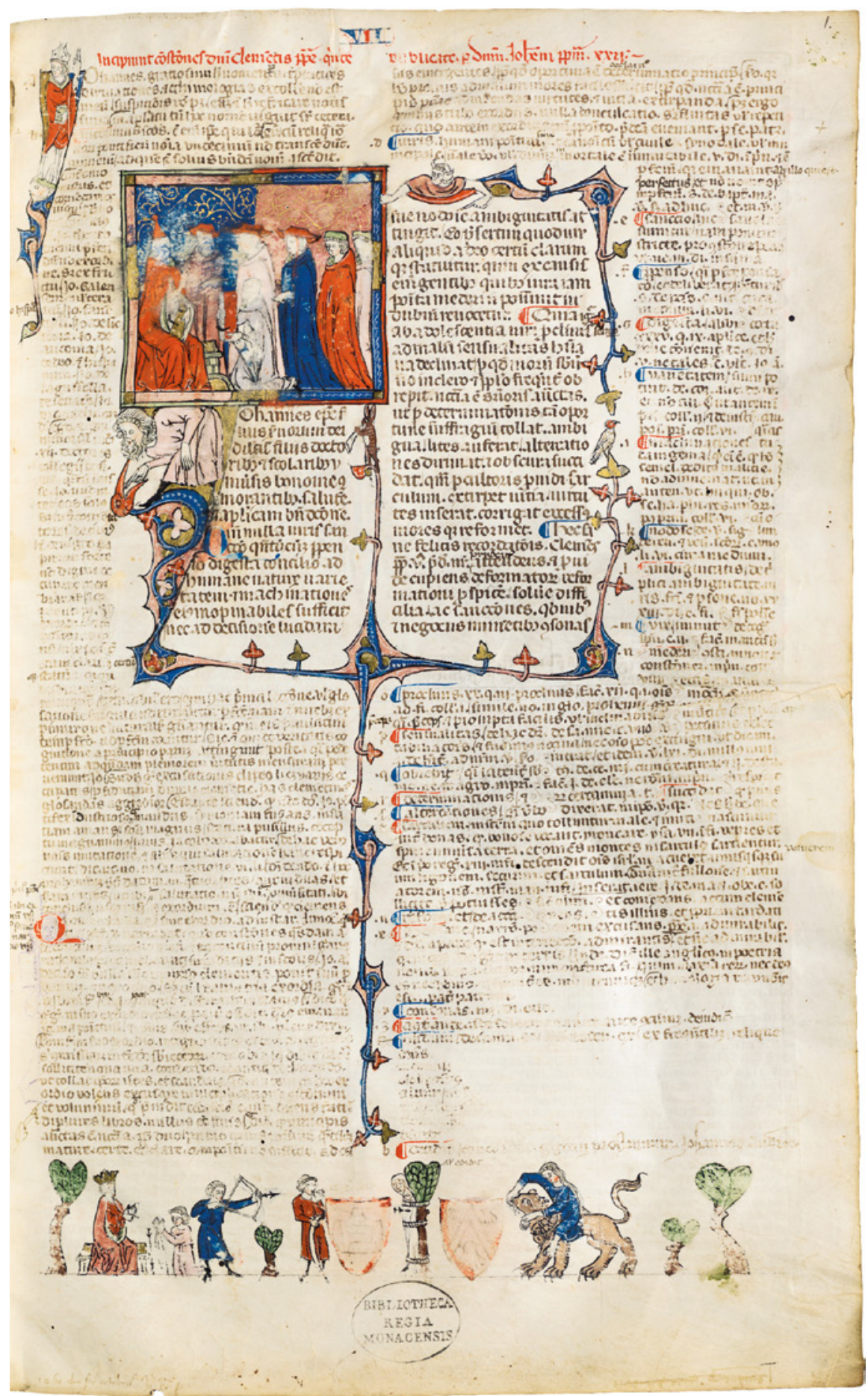

Abb. 6: München, Bayerische Staatsbibliothek, Clm 6347, Juristische Sammelhandschrift, fol. Ir: Papst Clemens V. übereicht sein Buch einer Versammlung von Kardinälen und kirchlichen Würdenträgern; Bologna (unter französischer Mitwirkung), 1326 


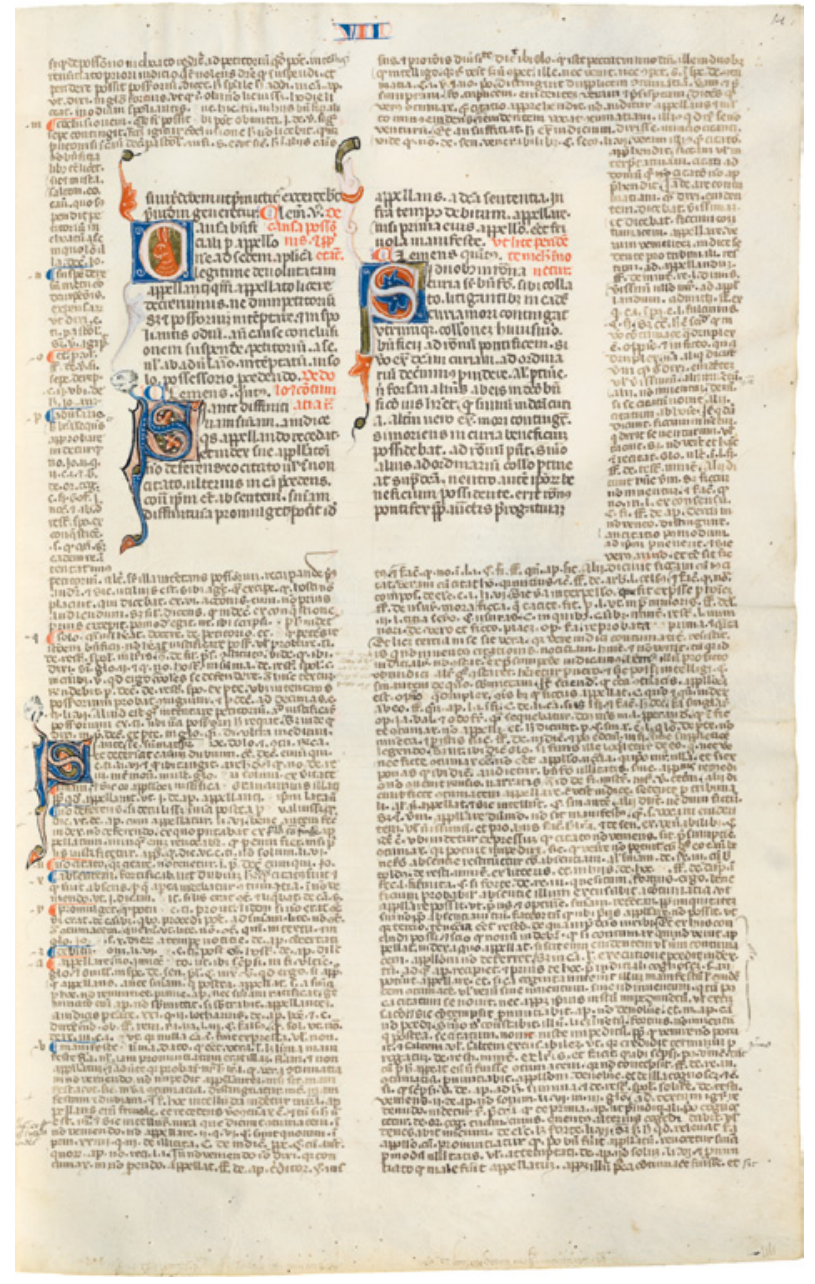

Abb. 7: München, Bayerische Staatsbibliothek, Clm 6347, Juristische Sammelhandschrift, fol. I4r: bolognesische und französische Initialen; Bologna (unter französischer Mitwirkung), 1326

eines lateinischen Textes durch den Miniator noch unwahrscheinlicher machen. Eher wird es zutreffen, dass sich bestimmte, in unserem Fall aus Modena stammende Schreiber in einer wie auch immer zusammengesetzten Symbiose mit den Buchmalern dieses Stils verbunden haben. Die Anlage der Handschriften, das Seitenlayout, die Ornamentik und die Anlage der Initialen orientiert sich hingegen, wie auch sonst in Bologna, an französischen, wohl direkt Pariser Erzeugnissen.

\section{Bologneser Handschriften mit Buchschmuck aus Frankreich und England}

In einigen Handschriften, die in Bologna hergestellt worden sind, lassen sich sowohl in Bologna als auch in Frankreich geschulte Buchmaler nebeneinander tätig nachweisen. ${ }^{44}$ Eine

44 Eine erste Zusammenstellung von Handschriften, in welchen französische und Bologneser Miniatoren gleichzeitig arbeiteten, findet sich bei PfäNdTner, Psalterillustration (zit. Anm. 5), S. 67. Genannt sind hier drei Bibelhandschriften: Ms. Z 4 (= I538-I539) der Biblioteca Marciana in Venedig, Ms. 2 des Balliol College in 


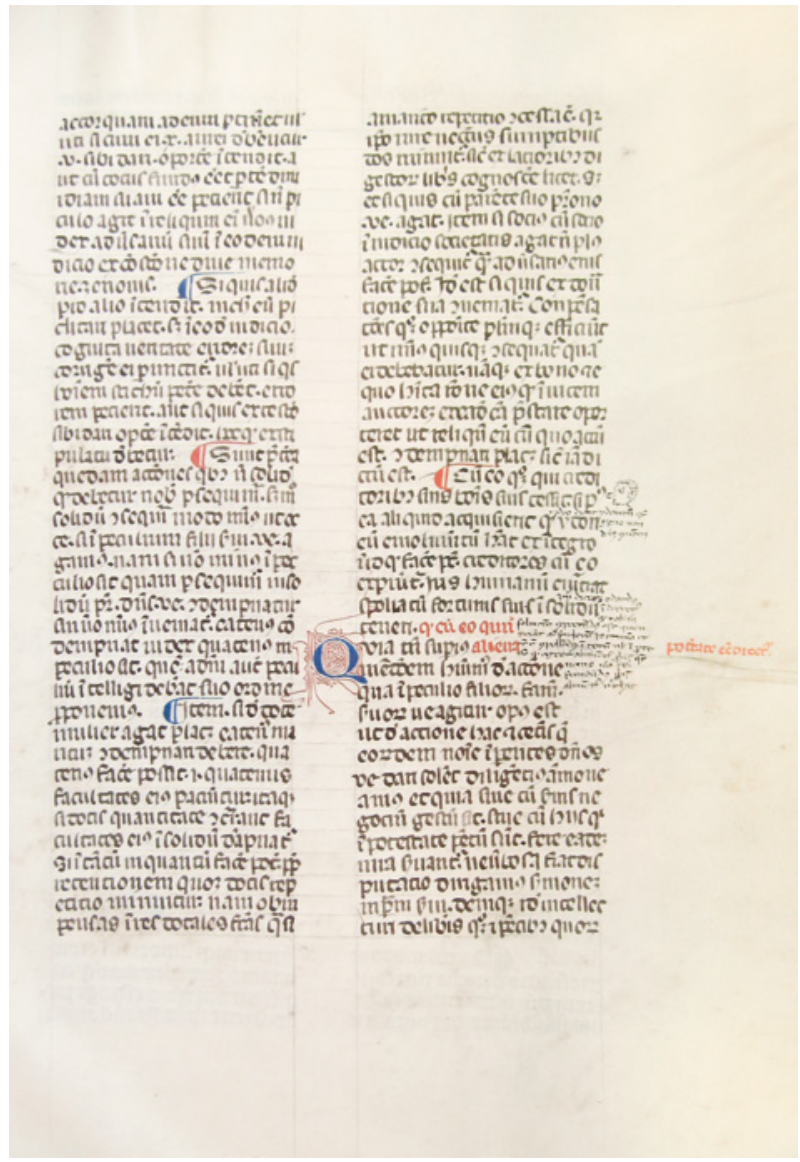

Abb. 8: Bamberg, Staatsbibliothek, Msc. Jur.Io, Iustinianus, Institutiones mit glossa ordinaria, fol. 53r: Bologneser Schrift und südfranzösisches Fleuronnée; Südfrankreich (Toulouse oder Avignon?), kurz nach 1300

Münchner Sammelbandhandschrift, Clm 6347 (Abb. 6-7), die jüngst Ulrike Bauer-Eberhardt vorgestellt hat, ist ein schönes Beispiel für die Mitwirkung eines französischen Künstlers in einer Bologneser Handschrift. Hier zeigt sich exemplarisch, wie die Zusammenarbeit ausgesehen haben kann: Der Text wurde im Jahre 1326 von Guilelmus de Marchia, ${ }^{45}$ also von einem Schreiber, der nicht aus Bologna, sondern wohl aus den Marken stammte, in Bologneser Schrift gefertigt, zudem im Bologneser Peciensystem. Es handelt sich also um ein Buch, das im direkten Umkreis und unter Kontrolle der Bologneser Universität gefertigt wurde. Ausgestattet ist es mit Fleuronnée, ornamentalen und historisierten Initialen

Oxford (die Handschrift ist bis fol. I23v von Bologneser Künstlern des zweiten Stils ausgestattet, ab dort von französisch geschulten) und Ms. Vat. Lat. I7 der Biblioteca Apostolica Vaticana (Bologneser Ranken auf fol. 296v, 297r, 297v. etc). Siehe zu dieser Thematik auch G. Scнмidt, Beobachtungen betreffend die Mobilität von Buchmalern im I4. Jahrhundert, in: G. Sснміdт, Malerei der Gotik. Fixpunkte und Ausblicke, (Hrsg. M. Roland), Bd. 2, Graz 2005, S. 64-87.

Die Signatur befindet sich auf 72v. Siehe zu der Handschrift U. Bauer-Eberhardt, Die illuminierten Handschriften italienischer Herkunft in der Bayerischen Staatsbibliothek Teil I. Vom Io. bis zur Mitte des I4. Jahrhunderts (Katalog der illuminierten Handschriften der Bayerischen Staatsbibliothek in München 6), Wiesbaden 2011 , Kat. Nr. 209. 


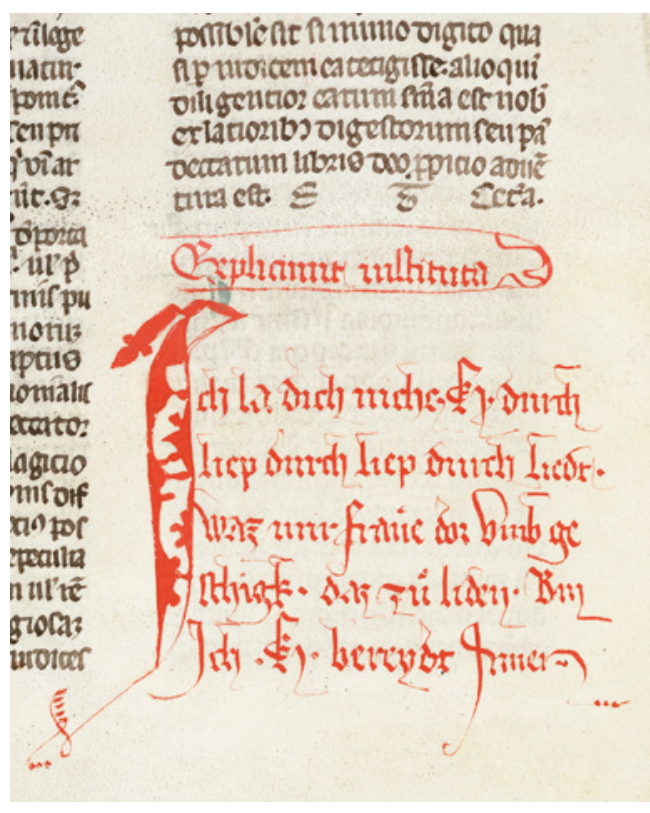

Abb. 9: Bamberg, Staatsbibliothek, Msc.Jur.Io, Iustinianus, Institutiones mit glossa ordinaria, fol. 59v: Schreibervermerk; Südfrankreich (Toulouse oder Avignon?), kurz nach I300 von einem Bologneser Künstler. Später hat dann ein französischer Buchmaler Miniaturen eingefügt, die zum Teil von den Bologneser Glossen überschrieben sind - ein Beweis, dass er in Bologna tätig war. ${ }^{46}$ Auffällig ist, dass der französische Buchmaler die Bologneser Initialen bisweilen in seinem französischen Stil nachahmt.

Ausstattung dreierlei Stils enthält Ms. C. I. 6 der Chapter Library in Durham, eine Justinian-Codex-Handschrift, die um I280/90 in Bologna geschrieben und von einem in Bologna ausgebildeten Buchmaler, aber auch von einem französischen Buchmaler und einem englischen ausgemalt wurde. ${ }^{47}$ Wo diese Ergänzungen geschehen sind, in Bologna, in Südfrankreich oder gar in England, wohin diese Handschrift früh gelangte, ist bis heute noch nicht ausreichend geklärt. Jedenfalls enthalten weitere in Durham aufbewahrte Handschriften eine ähnlich vielfältige Ausstattung: Ms. C. I. 3. und

Ms. C.I. 9, die zusammen mit C.I. 6 ein Set der wichtigsten Rechtstexte ausmachen und wohl für denselben Auftraggeber geschaffen worden sind. ${ }^{48}$

Auch die von Raulinus de Fremington geschriebene oben genannte Bibel enthält neben Bologneser Buchschmuck Miniaturen zweier Pariser Buchmaler. Weitere Beispiele der Tätigkeit englischer und französischer Buchmaler in Bologneser Handschriften sind etwa Ms. Edili. 86 der Biblioteca Medicea Laurenziana in Florenz, geschrieben in Bologna um I290/1300, ${ }^{49}$ und Ms. 766 der Bibliothèque Mazarine in Paris. An der Ausstattung letzterer war der Meister der Bibel Ms. lat. I8 der Bibliothèque nationale in Paris („Jacopino da Reggio“) neben einem weiteren Bologneser Buchmaler und einem französischen Buchmaler beteiligt. ${ }^{50}$

46 Von der ersten Bologneser Hand stammen ornamentale Initialen mit Hunden auf fol. I5v, 30v, 42v, mit Vögeln auf fol. 8r, I6r, 3Iv, mit Hasen auf fol. I3v, mit ganzleibigen Fischen auf fol. 22v, 23r, 36v, mit Mischwesen auf fol. Ior, 35v, mit menschlichen Büsten auf fol. I8r, 33r, mit Mönchen auf fol. $3 \mathrm{r}$ und mit einem Priester auf fol. I3v. Von der zweiten Hand stammen Ornament-, Drôlerie- und Figureninitialen, die häufig Bologneser Vorbilder derselben Handschrift kopieren: zum Beispiel fol. 4r (Hundekopf), 8r (Vögel). Die Titelminiatur: Papst Clemens V. überreicht sein Buch einer Versammlung von Kardinälen und kirchlichen Würdenträgern, ist französisch und zeigt Randranken mit Dornblättern.

47 L'Engle/Gibbs, Illuminating the Law (zit. Anm. 2I), Kat. Nr. I2 mit Abbildungen.

48 L'Engle/Gibbs, Illuminating the Law (zit. Anm. 2I), S. I6I-I63 (R. GibBs) mit zugehörigen Katalognummern.

49 M. Medica/S. Tumidei, Duecento (zit. Anm. 34), Kat. Nr. 93 (S. Nicolini).

50 M. Medica, S. Tumidei, Duecento (zit. Anm. 34), Kat. Nr. ir6 (M.-Th. Gousset). 


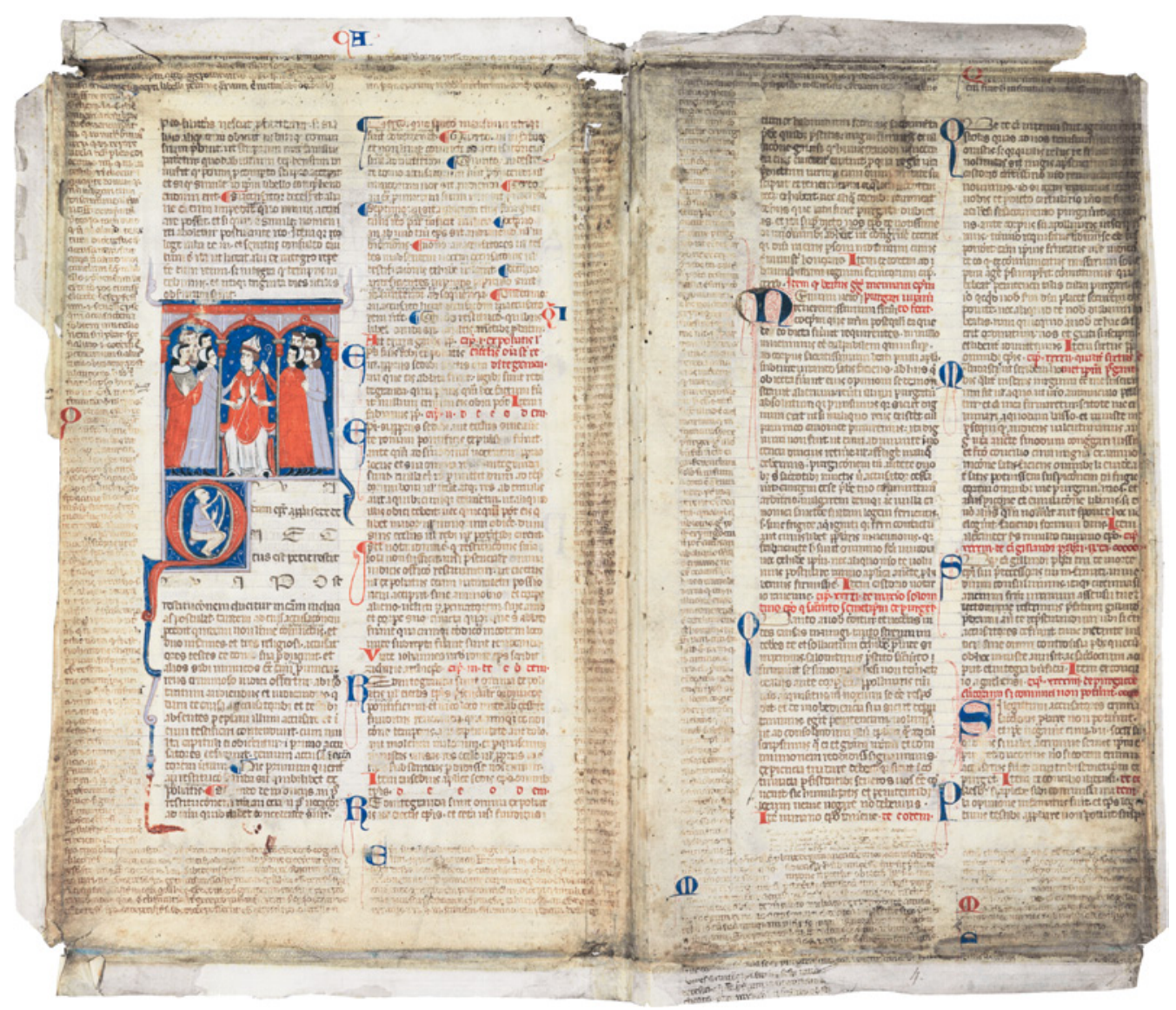

Abb. I0: Bamberg, Staatsbibliohek, IX. A. 28, Fragment eines Decretum Gratiani: Die Entfernung des angeklagten Bischofs vom Thron. Illustration zur Causa III.; Toulouse(?), um I290/1300

\section{Die Ausbreitung des Bologneser Stils durch wandernde Buchmaler}

Häufig fanden Buchmaler ihren Weg in andere wichtige europäische Zentren. Mit der Verlegung des päpstlichen Hofes nach Avignon wanderten noch vor der Mitte des I4. Jahrhunderts verstärkt Bologneser Kräfte nach Südfrankreich, entweder an den päpstlichen Hof selbst, oder in die nahen Universitätsstädte. Zwar dominierten in Avignon zu Beginn des päpstlichen Aufenthaltes französische Illuminatoren, doch noch vor der Mitte des Trecento finden wir dort auch Bologneser Buchmaler. Ein schönes Beispiel hierfür ist Ms. lat. 947 der Bibliothèque nationale in Paris, das Pontifikale des Guillaume d'Aigrefeuille, das von einem französischen Schreiber geschrieben, mit dem Wappen und Besitzeintrag des Cardinals versehen und von einem Bologneser Maler im Umkreis des Meisters von 1346 illuminiert wurde. ${ }^{51}$ Dieser war, zusammen mit anderen, auch im Missale des Bertrand de Deux tätig.

5I Siehe zu diesem und der Situation der Buchmalerei in Avignon zu dieser Zeit: F. MANZARI, La miniature ad Avignone al tempo dei papi (I3IO-I4IO), Prefazione di F. Avril, Modena 2006, S. I37f. mit Abb. 64. 


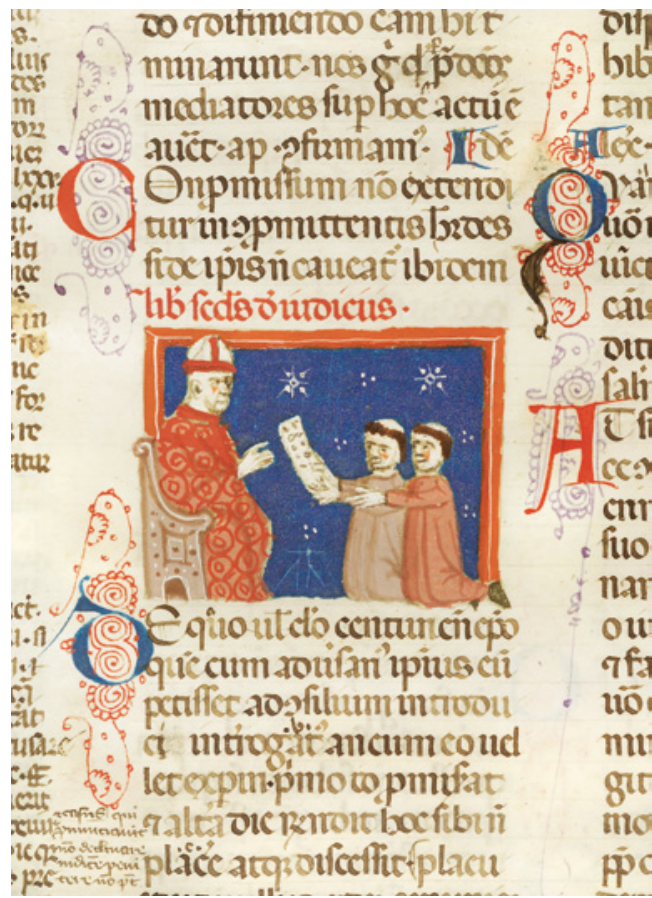

Abb. II: Bamberg, Staatsbibliothek, Msc.Can.25, Decretalen Gregors IX., fol. 92v: Zwei kniende Mönche übergeben dem thronenden Papst eine Klageschrift; Bologna, um $\mathrm{I} 3 \mathrm{IO} / 2 \mathrm{O}$
Aufschlussreiche Beispiele wandernder Künstler sind die in St. Florian wirkenden Bologneser Buchmaler, auf die Gerhard Schmidt aufmerksam gemacht hat. ${ }^{52}$ Sie veränderten dort offensichtlich ihren Stil so weitgehend, dass ihre Werke mit möglicherweise zuvor in Italien geschaffenen Arbeiten nicht mehr vergleichbar sind, weshalb man sie in italienischen Handschriften bisher nicht nachweisen kann. Gleiches trifft für die bekannte, aus Padua stammende Malerschule des Giovanni da Gaibana zu, die in Österreich sowohl Handschriften als auch Wandmalereien ausgeführt hat und bis nach Schlesien gelangte, um dort, ebenfalls unter leichter Anpassung an den dort üblichen Stil, Aufträge auszuführen..$^{53}$

Ein Beispiel für die Ausbreitung des Bologneser Stils nach Frankreich ist Msc.Jur.Io der Staatsbibliothek Bamberg. Das Buch wird von französischen Fleuronnée-Initialen gegliedert, doch das Kopieren des Textes haben deutlich ein französischer und ein in Bologna geschulter Schreiber übernommen. Ersterer stammte vielleicht, darauf könnte das deutsche Schlusswort hinweisen, gar aus dem deutschsprachigen Raum (Abb. 8-9). Ein Beispiel einer im Bologneser Stil gehaltenen Miniatur, die sehr wahrscheinlich von einem in Bologna ausgebildeten und in Toulouse wirkenden oder aber von einem nur Bologneser Miniaturen nachahmenden Südfranzosen gefertigt worden ist, haben wir mit dem um I290/I300 entstandenen Fragment IX. A. 28 der Staatsbibliothek Bamberg (Abb. Io) vorliegen. Sehr ähnlich sind auch Teile des wohl ebenfalls in Toulouse illuminierten Ms. McClean 136 des Fitzwilliam-Museums in Cambridge. ${ }^{54}$

Die in der Staatsbibliothek Bamberg aufbewahrten Dekretalen Gregors IX. mit einer Glosse des Bernhard von Parma (Msc.Can.25) wurden in Bologna geschrieben und erhielten die figürliche Ausstattung von einem sich an Bologneser Formen orientierenden, wohl aber nicht in Bologna geschulten, vielleicht nicht einmal in Bologna wirkenden Buchma-

52 G. Schmidt, Die Malerschule von St. Florian. Beiträge zur süddeutschen Malerei zu Ende des I3. und im I4. Jahrhundert, Köln/Graz 1962, S. 135-I43.

53 Siehe zu dieser Gruppe jüngst N. Morgan/S. Panayotova, Illuminated Manuscripts in Cambridge I/r. The Frankish Kingdoms, Northern Netherlands, Germany, Bohemia, Hungary, Austria (A Catalogue of Western Book Illumination in the Fitzwilliam Museum and the Cambridge Colleges), London-Turnhout 2009, S. I49-157, Kat. 75 mit Verweis auf die ältere Literatur.

54 L'Engle/GibBs, Illuminating the Law (zit. Anm. 2I), Kat. Nr. I4. 
ler. ${ }^{55}$ (Abb. II). Wir stehen auch hier vor der Frage, ob der Buchschmuck in der Universitätsstadt Bologna von auswärtigen Kräften oder nach dem Export der Handschrift in auswärtigen Gegenden geschaffen wurde. Das erhaltene Material belegt eine Vielfalt von Möglichkeiten, Regelmäßigkeiten lassen sich kaum erkennen, weshalb der Frage nach der Entstehungssituation dieser internationalen Gemeinschaftswerke für jedes Stück neu nachgegangen werden muss.

\section{EXPORTSCHLAGER BUCH : DIE INTERNATIONALE DIMENSION DES BOLOGNESER BUCHHANDELS}

Der Weg der Bologneser Handschriften führte, dies zeigt jede Sammlung mit größeren mittelalterlichen Handschriftenbeständen, bald nach ganz Europa. Eine der Quellen, die den in Dantes Göttlicher Komödie genannten Odierisi da Gubbio betrifft, weist darauf hin, dass bereits zur Zeit der Entstehung der Handschriften auch von Buchmalern selbst sogar große Mengen von Büchern international vertrieben wurden. Oderisi wohnt im Jahre 1269 einem Tauschakt bei, der sich auf den Transport einer großen Menge von Büchern nach Paris bezieht. ${ }^{56}$

Aber auch die Studenten selbst sorgten für die Verbreitung der Bologneser Produktion, indem sie am Studienort Bücher bezogen und diese sowohl beim Wechsel der Universität als auch an ihren späteren Wirkungsort mitnahmen, zumal die in Arbeitsteilung und in Konkurrenz geschaffenen, nach städtisch kontrollierten Preisen hergestellten Handschriften wohl nicht nur schöner, in der Textedition korrigiert und von der Universität autorisiert, sondern auch günstiger zu erhalten waren als in der Heimat der Studierenden. ${ }^{57}$

Manche der in Bologna geschriebenen und ausgestatteten Handschriften wurden offensichtlich direkt für den Heimatort der in Bologna lebenden Studenten angelegt. So weist der Kalender des Psalters Ms. Smith-Lesouëf 2I der Bibliothèque nationale in Paris auf einen Bestimmungsort in der Diözese Tournai. ${ }^{58}$ Codex 346 der Universitätsbibliothek Bologna, ebenfalls ein in Bologna überreich ausgestatteter Psalter, weist im Kalender auf das reiche Benediktinerkloster Santa Giustina in Padua. Auffallenderweise orientiert sich gerade die Ausstattung des Psalters in Paris mehr an französischen Gewohnheiten (Abb. I2-I3). Der übliche polierte Goldgrund, wie er etwa im Psalter für S. Giustina in Padua angewandt wird, wird durch einen französisierenden Rautengrund ersetzt. Dasselbe Phänomen finden wir auch in der Bibel Ms. lat. I8 der Bibliothèque nationale in Paris, die vom selben Buchmaler wie die Handschrift Smith-Lesouëf ausgestattet worden ist, der meist mit Jacopino da Reggio identifiziert wird.59

55 K.-G. Pfändtner, Illuminierte Bologneser Handschriften der Staatsbibliothek Bamberg. I260-I340, Ausstellungskatalog Staatsbibliothek Bamberg 1996, Kat. Nr. 9.

56 E. Aeschlimann / P. D’Ancona, Dictionnaire des Miniaturistes du Moyen Âge et de la Renaissance dans les différentes contrées de l'Europe, Mailand 21949, S. I6I und Pfändtner (zit. Anm. 5), S. 5. Siehe R.H. Rouse/M.A. Rouse (zit. Anm. 2), S. IIo.

58 Pfändtner, Psalterillustration (zit. Anm. 5), S. LXXIII mit Verweis auf die grundlegende weitere Literatur.

59 Siehe zu dieser Handschrift insbesondere M. Medica/S. TumideI, Duecento (zit. Anm. 34), Kat. II3 mit weiterführender Literatur. 


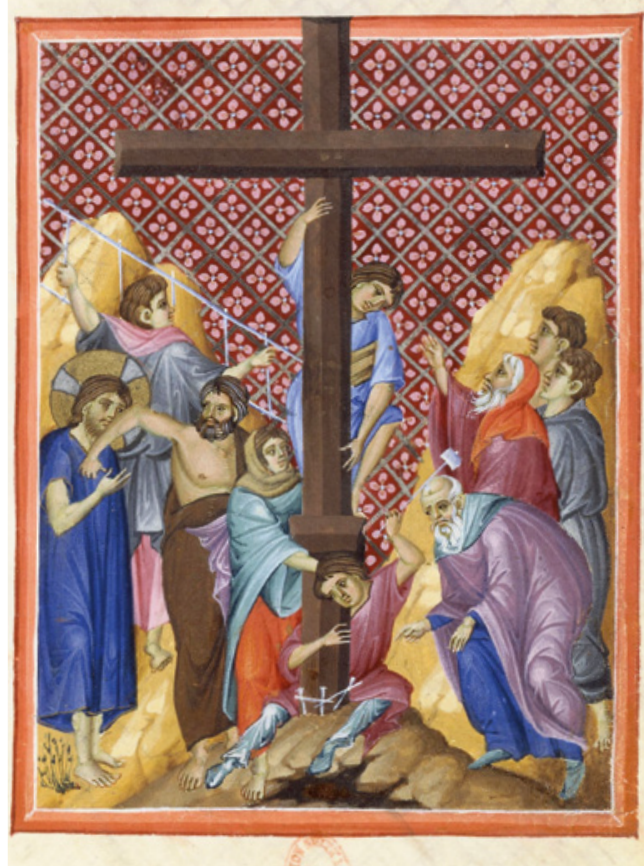

Abb. I2: Paris, Bibliothèque nationale de France, SmithLesouëf 2I, Psalter, fol. 2or: Kreuzigung Christi; Bologna, um 1280

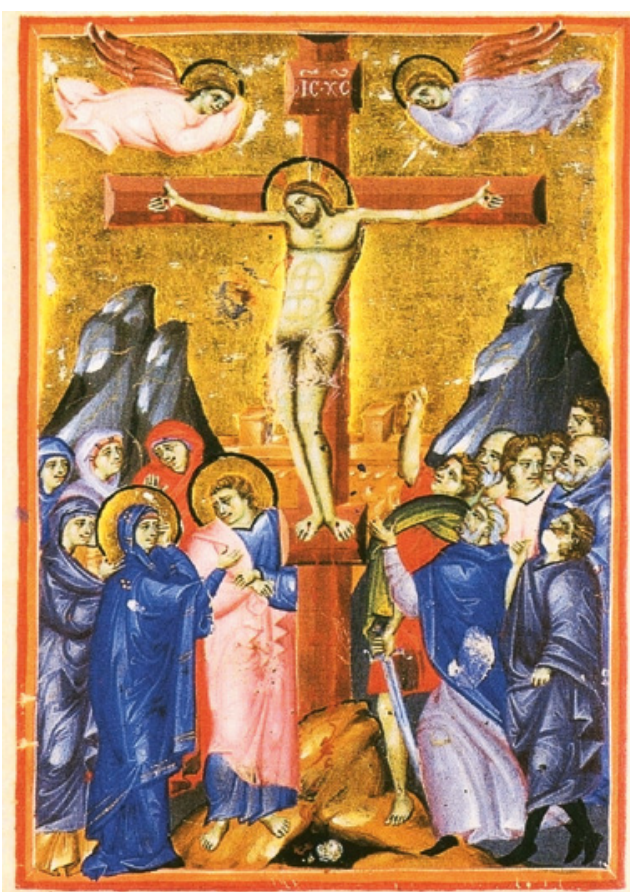

Abb. 13: Bologna, Universitätsbibliothek, Cod. 346, Psalter, fol. I3v: Kreuzigung Christi; Bologna, um 1270

Ms. lat. 22 der Bibliothèque nationale Paris hingegen wurde um 1267 von den Brüdern Cardinalis und Rugerinus aus Forlì expressis verbis in Bologna für Frédol von Saint-Bonnet (I284I289 Bischof von Le Puy-en-Velay/Auvergne) geschrieben, der schon zu Zeiten seines Studiums mehrere Kanonikerpfründen innehatte. Das Kolophon auf fol. 432v lautet: Nos Cardinalis et Rugerinus fratres de Forlivio et nunc Bononie moramur presentem bibliam scripsimus de invicem domino Fredolo de Sancto Bonetto canonico Magalonensi in civitate Bononie. Die Handschrift zeigt, obwohl für einen französischen Studenten gefertigt, keinerlei französisierenden Elemente. Vielleicht waren diese vor allem in Paris erwünscht oder Frédeol gefiel einfach der südliche Stil besser. ${ }^{60}$

Ähnlich scheint es Ernst von Pardubitz, dem späteren ersten Erzbischof von Prag und engen Vertrauten Kaiser Karls IV., gegangen zu sein. Er hatte lange in Italien gelebt und im Bologneser Stil reich ausgestattete Handschriften erworben, wie etwa das um I320/30 illuminierten Mariale Cod. 1389 der Österreichischen Nationalbibliothek Wien, das sein Wappen, das des Reiches und des Erzbistums Prag (nach 1343) enthält. Darüber hinaus ließ Pardu-

6o Von den beiden Schreibern Cardinalis und Rugerinus ist in Bologneser Dokumenten des Weiteren bezeugt, dass sie für denselben Frédol, der zu diesem Zeitpunkt in Bologna studierte, im Jahre I267 zwei Dekretalencodices geschrieben haben. Siehe hierzu: F. Filippini / G. Zucchini, Miniatori e pittori a Bologna. Documenti dei secoli XIII e XIV, Florenz I947, S. 44-45. 
bitz auch in Prag Handschriften nach italienischem Vorbild anlegen. ${ }^{61}$

Die von den Studenten in Bologna oder Padua erworbenen Handschriften gelangten häufig nach deren Ableben in Kloster- und Kapitelsbibliotheken. Nicht selten aber endeten sie erst nach mehrfachem Besitzerwechsel dort, wie etwa Msc.Can.5I der Staatsbibliothek Bamberg (Abb. I4), eine Handschrift mit dem Apparatus in quinque libros Decretalium Papst Innocenz IV. Der um I330 entstandene Codex kam über Heinrich von Heydeck (I335 in Bologna immatrikuliert) in den Besitz des Abts von Neuweiler, Lampert von Brun (um I320/30-I399), der ab I374 dann wiederum Bischof von Bamberg wurde. ${ }^{62}$ Ein Eintrag am Ende des Codex verweist auf diese Besitzgeschichte: Iste liber Innocentii est domini Lamperti camerarii monasterii Novillarensis [Neuweiler]. et concessus est Magistro Henrico de Heyde (...). Die Dombibliothek Bamberg, deren Bestände säkularisationsbedingt in Besitz der heutigen Staatsbibliothek Bamberg gelangten, kann ca. I5 reich illuminierte Bologneser Handschriften des I3. und I4. Jahrhunderts ihr Eigen nennen, die Zahl der ohne oder nur mit geringem Buchschmuck versehenen ist bis heute nicht ermittelt.

Auch der weitere Weg der oben genannten 1326 geschriebenen Münchner Handschrift Clm 6347 mit dem Bologneser und französischen Schmuck ist bezeichnend für die Mobilität der Handschriften. Im Jahre I4II kaufte sie Georg von Parsberg/Bayern in Bologna. Auf fol. 72v befindet sich der Kaufvermerk: anno I4II ego Georgius Parsberg scolans Bononiensis comparavi librum hunc pro octo florenis cum medio Bononiense, d. h., auch noch im I5. Jahrhundert bestand Interesse am Erwerb von fast hundert Jahre alten Handschriften; vermutlich so lange, bis gedruckte Ausgaben vorlagen. ${ }^{63}$ Mit Georg von Parsberg gelangt die Handschrift nach Freising, als er dort Domherr wurde. Ein weiterer Eintrag nennt als späteren Besitzer Johann IV. Tulbeck (I453-I473 Bischof von Freising) und die Jahreszahl I460.

6I Siehe zu dieser Handschrift: H. J. Hermann, Die italienischen Handschriften des Dugento und Trecento. 2. Oberitalienische Handschriften der zweiten Hälfte des XIV. Jahrhunderts (Beschreibendes Verzeichnis der illuminierten Handschriften in Österreich NF Bd. V, Teil V), Nr. 85 mit Taf. LXII.

62 Siehe zu dieser Handschrift demnächst: Katalog der illuminierten Handschriften der Staatsbibliothek Bamberg (in Druckvorbereitung). Siehe zu Heydeck G. C. Knod, Deutsche Studenten in Bologna (zit. Anm. I), S. 190, Nr. 1367 .

63 Ein schönes Beispiel für die späte Verwendung einer eine Bologneser Handschrift ist Clm 5 der Bayerischen Staatsbibliothek, die I304 datiert ist und verschiedene Texte von Galen enthält. Diese Handschrift befand sich im 15. Jahrhundert im Augustinerkloster Nürnberg. Im Jahre I503 kaufte Hartmann Schedel die Handschrift für 8 Gulden und ließ von Elsner eine Engelsfigur mit seinem Wappen hineinmalen. Siehe zu der Handschrift U. Bauer-Eberhardt, Handschriften italienischer Herkunft (zit. Anm. 45), Kat. 193. 


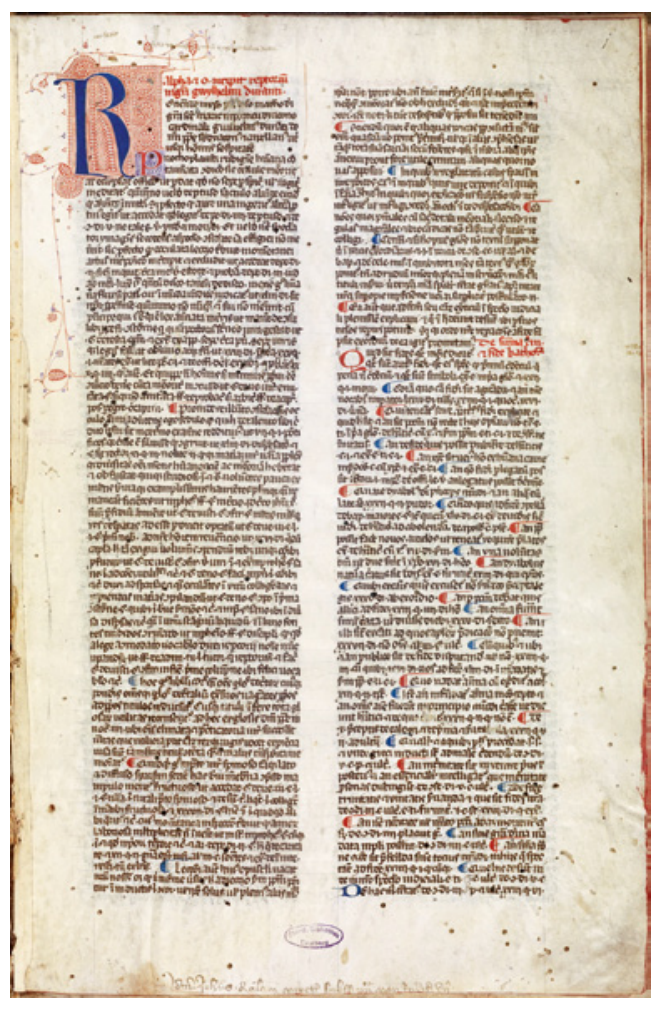

Abb. I5: Bamberg, Staatsbibliothek, Msc.Can.6o, Juristische Sammelhandschrift, fol. ir: Textbeginn; Bologna oder Padua 2. Drittel I4. Jh.

\section{Steuerbefreiung für Bücherimporte}

Der Transport von Handschriften scheint zumindest für den persönlichen Gebrauch kaum Hindernisse gekannt zu haben. Offensichtlich konnte man sie zumindest im I4. Jahrhundert einfach „im Handgepäck“ mit nach Hause nehmen. Hierauf deuten selten erkannte, aber wohl häufiger vorkommende Zollvermerke in den Handschriften selbst. Im Bestand der Staatsbibliothek Bamberg haben sich in vier Handschriften solche kaum lesbaren Zollvermerke erhalten. ${ }^{64}$ Nur eine Handschrift unter diesen enthält Buchschmuck, Bologneser Fleuronnée erster Qualität: Codex Msc.Can.6o (Abb. I5-16), eine juristische Sammelhandschrift, die in Bologna oder Padua im zweiten Drittel des I4. Jahrhunderts entstanden ist. Auf fol. $\mathrm{I}^{\mathrm{r}}$ unten steht der Paduaner Zollvermerk des späten I4. Jahrhunderts: domini Johannis de Allamannia miretus (?) subscripsi iiii ${ }^{\text {or }}$ maij indictione vii ${ }^{\text {a }}{ }^{65}$ Auch in einer ganzen Reihe von Handschriften der Dombibliothek Freising, heute in der Bayerischen Staatsbibliothek München, finden sich solche Zollvermerke, wie etwa in der ohne Buchschmuck verbliebenen Bologneser Handschrift der ersten Hälfte des I4. Jahrhundert, die heute als Clm 6346 in der Bayerischen Staatsbibliothek

64 Msc.Can.I6, Msc.Can.26, Msc.Can.46 und Msc.Can.6o. Ich danke für den Hinweis Günter Glauche von der Bayerischen Staatsbibliothek München.

65 Siehe zu den „Conduxit“-Vermerken G. Glauche, Katalog der lateinischen Handschriften der Bayerischen Staatsbibliothek München. Die Pergamenthandschriften aus dem Domkapitel Freising, Bd. 2, Wiesbaden 20II, S. XIII. 
aufbewahrt wird. ${ }^{66}$ Auch hier handelt es sich um einen Zollvermerk aus Padua: D. Rabani de Alemannia. Benevenutus subscripsi iiii ${ }^{\text {a }}$ octobris Xiiii a indictione (1376). Beide Personen lassen sich laut Glauche in Paduaner Akten als Zöllner nachweisen. ${ }^{67}$

\section{ZUSAMMEN FASSUNG}

Nicht nur Studenten, auch Schreiber und Buchmaler kamen aus den verschiedenen Ländern Europas nach Bologna, vor allem in

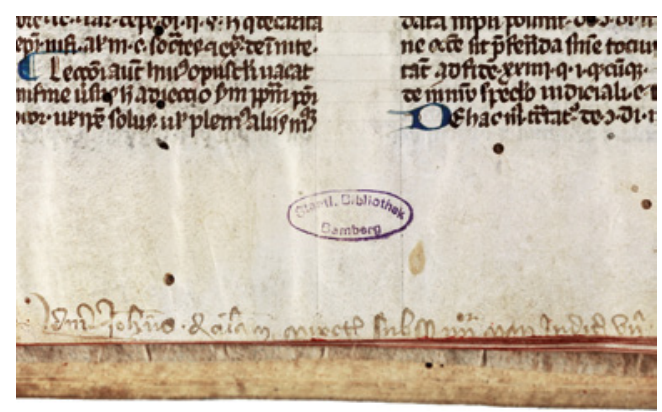

Abb. I6: Bamberg, Staatsbibliothek, Msc.Can.6o, Juristische Sammelhandschrift, fol. Ir: Detail: Zollvermerk; Bologna oder Padua 2. Drittel I4. Jh. den Boomjahren der Universität im I3. und I4. Jahrhundert, und hatten Anteil sowohl an der Produktion der Bücher als auch an ihrer Verbreitung. Da die Lehrer an der Universität und die Studentenschaft zwischen den großen Universitäten wechselten, mussten auch die nötigen Bücher so angelegt sein, dass sie hier wie dort benutzt werden konnten. Zudem garantierte ein gut durchorganisierter und von der Universität kontrollierter Büchermarkt mit korrigierten Texten, die somit Abschriften aus etwa deutschen Buchmalereizentren in der Authentizität konkurrenzlos überlegen waren, auch erschwingliche Preise. Vor allem das in Bologna so wichtige, international anerkannte und rege besuchte Rechtsstudium trug zur Verbreitung Bologneser Rechtshandschriften bei, die sich heute in fast allen größeren Bibliotheken Europas finden. Unter den Buchmalern lassen sich ebenso auswärtige Kräfte aus Frankreich und England, sehr wahrscheinlich auch aus Byzanz nachweisen und zeigen ein günstiges Klima für frühe Massenproduktion sowohl preiswerter Studienausgaben als auch exklusiv ausgestatteter Prachtbände für den gehobenen Bedarf. Der internationale Bildungsmarkt brachte europaweite Migrationsbewegungen von Studenten, Schreibern und Buchmalern und nicht zuletzt der Bücher selbst in Gang.

Bayerische Staatsbibliothek München, Abteilung für Handschriften und Alte Drucke, Handschriftenerschließungszentrum

Abbildungsnachweis: Abb. I, I2: Paris, Bibliothèque nationale de France. - Abb. 2, 3, 8-II, I4-I6: Bamberg, Staatsbibliothek. - Abb. 4, I3: nach M. Medica/S. Tumidei, Duecento (zit. Anm. 34), 331, 321. - Abb. 5: Karl-Georg Pfändtner. - Abb. 6, 7: München, Bayerische Staatsbibliothek.

66 Johannes Andreae, Quaestiones super.... Regulis iuris.

67 Glauche, Katalog der lateinischen Handschriften (zit. Anm. 65). 


\title{
DIE VERHÖRPROTOKOLLE DES ILLUMINATORS JEHAN GILLEMER ALS QUELLE FÜR KUNSTHISTORIKER
}

\author{
Susanne Rischpler
}

Der französische Illuminator Jehan Gillemer, der in den Verdacht geraten war, ein politischer Spion bzw. Verräter zu sein, wurde zu Beginn des Jahres I472 in Tours verhört. Die dabei angefertigten Protokolle stellen für die spätmittelalterliche Buchmalerei eine Quelle von außerordentlichem Wert dar, da sie eine Fülle von Informationen über das Leben eines wandernden französischen Buchmalers in der zweiten Hälfte des I5. Jahrhunderts bieten.

Die insgesamt 13 Seiten umfassenden Protokolle, deren Originale im Pariser Centre historique des Archives nationales unter der Signatur "J 950, ${ }^{\text {os }}$ I3, I4 “ aufbewahrt werden, sind gut erschlossen. Ende des 19. Jahrhunderts wurden sie von Albert Lecoy de La Marche ediert und mit ausführlichen Erläuterungen versehen. ${ }^{1}$ Véronique P. Day verfasste 2002 einen detaillierten Kommentar sowie eine englische Übersetzung von etwa zwei Dritteln des Protokolltextes. ${ }^{2}$

\section{GESCHICHTLICHER HINTERGRUND}

Gillemers Ergreifung und Befragung fällt in die Zeit der Konflikte und Nachwirkungen der Ligue du Bien Public. I465 hatte sich der Adel gegen den seit I46I regierenden König Louis XI. (I423-I483) zu einem kriegerischen Bündnis zusammengeschlossen, da die Vasallen durch ihn eine Schmälerung ihrer Macht befürchteten. ${ }^{3}$ Die nachfolgenden Ausführungen nehmen speziell Bezug auf drei historische Persönlichkeiten, die bei dieser Adelsrevolte eine mehr oder weniger gewichtige Rolle gespielt haben, hier aber von besonderem Interesse sind, da sie in den Verhörprotokollen Erwähnung finden: Charles d'Anjou (I4I4-I472), ab I434 als Charles IV. Comte de Maine: ein Onkel des Königs; Charles de France (I446-I472): der jüngste Bruder des Königs; Madeleine de France (I443-I495), Princesse de Viane durch ihre Vermählung (I46I) mit Gaston de Foix († I470): eine Schwester von Louis XI. und Charles de France.

I A. Lecoy de La Marche, Interrogatoire d'un enlumineur par Tristan l'Ermite, in: Revue de l'art chrétien, ser. 5/III, I892, S. 396-408, Kommentar: S. 396-405, Edition: S. 406-408; diese Edition wurde 2009 von J.L. Deuffic in seinem Blog Pecia online zur Verfügung gestellt (I8. II. 2009, URL: http://blog.pecia.fr/?q=Gillemer; Stand: 27. OI. 20I4) - - 2OIo habe ich die Protokolle auf der Basis der Edition von Lecoy De La Marche ins Deutsche übersetzt (URL: http://www.ksbm.oeaw.ac.at/kat_illumHss_gillemer.html; Stand: 27. OI. 20I4).

2 V.P. DAy, Portrait of a Provincial Artist: Jehan Gillemer, Poitevin Illuminator, in: Gesta 4I/I, 2002, S. 39-49, Kommentar: S. 39-44, Übersetzung: S. 44-49. Die Wichtigkeit der Protokolle als (kunst)historische Quelle umreißt sie wie folgt (S. 39): „No other extant document provides so intimate and candid a description of the professional routine of a provincial artist of the late Middle Ages. (...) Although the document was published over a century ago, its value as a source of information about the professional and social world of the late medieval illuminator has yet to be realized." stadt 2009, S. 36I-387, insbes. S. 363-366 und 370, sowie J. FAvIER, Geschichte Frankreichs, 6 Bde., Stuttgart 1989-1995, hier Bd. 2 (Stuttgart 1989), S. 433-449, insbes. S. 434-439 und 443. 
Nomineller Führer der Revolte war Charles de France, der jedoch als schwache Persönlichkeit charakterisiert wird. ${ }^{4}$ Weitaus gefährlicher war für Ludwig XI. die Feindschaft Karls des Kühnen, Comte de Charolais (I433-I477), der im April I465 von seinem Vater, Philipp dem Guten von Burgund, die Regierungsgeschäfte übertragen bekommen hatte, nachdem er nach einem Zerwürfnis 1457 von diesem stets von der Regierung ferngehalten worden war und Philipps ausgleichende Politik gegenüber Frankreich als zu nachgiebig eingestuft hatte. Im Juli I465 war es zur offenen Feldschlacht bei Montlhéry (Île-de-France) gekommen, bei der Karl der Kühne den militärischen, Ludwig XI. jedoch den politischen Sieg davongetragen hatte und in Paris eingezogen war. Zu den vielen Zugeständnissen, mit denen sich der König in der Folge Loyalität sicherte, gehörte auch, dass er Charles de France die Normandie als Apanage zuerkannte. Später musste Charles unter anderem auf diesen Besitzanspruch verzichten und erhielt I469 das Herzogtum Guyenne im südwestlichen Frankreich, ${ }^{5}$ wo er keine unmittelbare Gefahr mehr für den König darstellte.

Auch gegenüber seinem Onkel Charles d'Anjou dürfte Louis XI. Argwohn gehegt haben. Denn dieser hatte in der Schlacht von Montlhéry mit der Nachhut die Flucht ergriffen und sich in der Folge bereit erklärt, der Ligue du Bien Public beizutreten. ${ }^{6}$

I47I/72 schmiedete Charles de France ehrgeizige Heiratspläne: Er wollte Maria von Burgund (I457-I482), damals die reichste Erbin in Europa, ehelichen - was sein königlicher Bruder allerdings mit Hilfe des Papstes zu vereiteln wusste. Zu dieser Zeit hielt sich auch seine Schwester Madeleine de France gemeinsam mit ihrem Mann Gaston de Foix, der ebenfalls ein Gegner des Königs war, bei Charles in Saint-Sever auf [5]. ${ }^{7}$

Hochzeitspläne und militärische Planungen machten Besprechungen notwendig, in deren Verlauf Boten auch zwischen den Provinzen Guyenne und Maine hin- und hergeschickt wurden. Ebendort war der in Le Mans geborene und zeitweise in Poitiers [insbes. I und 28] ansässige Illuminator Jehan Gillemer unterwegs (Abb. I) und führte noch dazu eine beträchtliche Menge kleiner Schriftstücke, sogenannte brevets, ${ }^{8}$ mit sich, die leicht für vertrauliche Nachrich-

\section{Abb. I.}

7

Vgl. G. TrefFer, Geschichte Frankreichs, Regensburg 1998, S. 99.

Siehe Karte „Frankreich zur Zeit Ludwigs XI.“, Favier, Geschichte Frankreichs (zit. Anm. 3), S. 488 sowie Lecoy de La Marche, Interrogatoire d'un enlumineur (zit. Anm. I), S. 399.

Vgl. Lecoy de La Marche, Interrogatoire d'un enlumineur (zit. Anm. I), S. 400. - Die Ziffern in eckigen Klammern beziehen sich auf die Abschnittsnummerierung der Texte unter der URL: http://www.ksbm.oeaw. ac.at/kat_illumHss_gillemer.html (Stand: 27.0I. 20I4).

8 Von lat. „brevia“ im Sinne von „Amulett“ (vgl. CH. DU CANGE, Glossarium ad scriptores mediae et infimae latinitatis, 3 Bde., Paris 1678; Ausgabe Niort I883-1887, hier Bd. I, Sp. 745a: „Characteres magici in Brevibus descripti, quos secum deferre solent, qui iis utuntur.“ - Seit karolingischer Zeit wurde der Begriff „breve, brevis“, im Sinne von „Brief“, für Zauberformel(n) auf Pergament benutzt und fand dann Verbreitung in den Vulgärsprachen, zum Beispiel „brieve“ im Italienischen und „brev, brevet“ im Französischen; vgl. J.-P. BouDET, Les brevets et manuscrits suspects d'un enlumineur poitevin, Jehan Gillemer, in: J. Claustre/N. Offenstadt / O. Mattéoni (Hrsgg.), Un Moyen Âge pour aujourd'hui, Paris 2oro, S. 72-79, hier S. 72. - Eine gute Vorstellung vom Aussehen spätmittelalterlicher brevets dürfte das bei E. BоzоKY, Les moyens de la protection privée, in: Cahiers de recherches médiévales et humanistes, 8, 200I, S. 175-192 (auch unter der URL: http://crm.revues.org//index397.html; Stand: 27. OI. 20I4), ill. 2 abgebildete (mit $59 \times 56 \mathrm{~cm}$ zugegebenerma- 


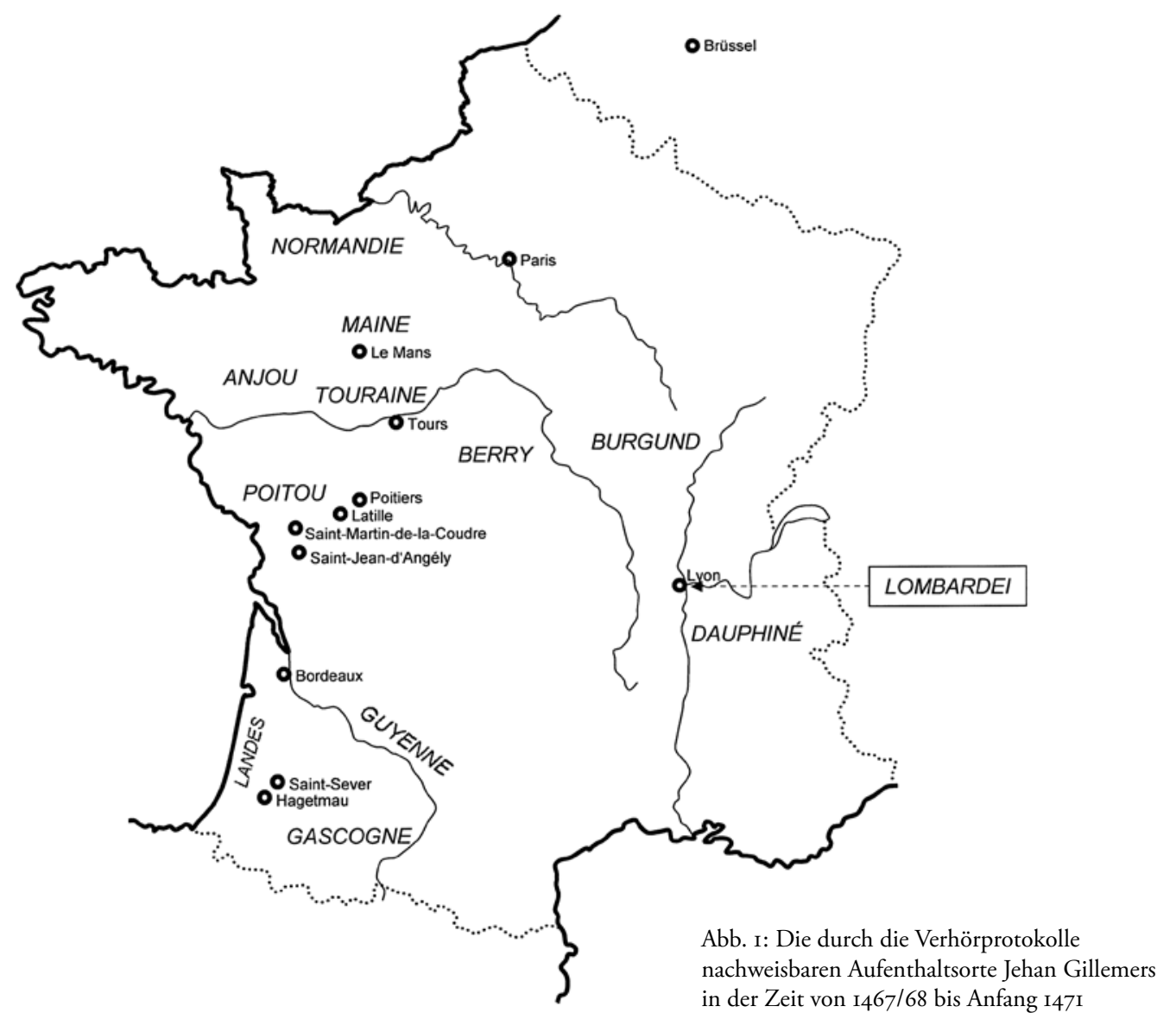

ten oder Geheimbotschaften gehalten werden konnten: Zettelchen, Streifen, Rollen aus Pergament und Papier mit Notizfunktion bzw. Talisman- und Zauberformelcharakter, die man eng am Körper trug oder sich um den Hals hängte. Gillemers brevets, die er (für wenig Geld) gekauft, selbst abgeschrieben oder geschenkt bekommen hatte, waren lateinisch oder in der Volkssprache beschriftet und enthielten zuweilen ,unverständliche“ Zaubersprüche oder auch Zeichen und bildliche Darstellungen. Insgesamt dürfte es sich um is bis 20 Stücke gehandelt haben. So ist es nicht verwunderlich, dass Gillemer unter Verdacht und in die Fänge der Justiz geriet.

Nachdem Gillemer in Le Mans aufgegriffen und dort einem ersten Verhör unterzogen worden war, wird einer der Hauptberater und -vertrauten des Königs, der Prévôt des maréchaux

ßen relativ große) Schriftamulett liefern, das unter anderem Auszüge aus der „Vie de sainte Marguerite“ beinhaltet (Mitte I5. Jh., Paris, Musée des Arts et Traditions, ico. 77. 2. I); zu diesem Schriftamulett auch: L. CAROLUS-BARRÉ, Un nouveau parchemin amulette et la légende de Sainte Marguerite, patronne des femmes en couches, in: Comptes rendus des séances de l'Académie des Inscriptions et Belles-Lettres, 1979, S. 256-275 mit Abb. - Für „(Schrift-)Amulett“ wird zuweilen auch der Terminus „Phylakterium“ (griech. Phylakterion: Amulett, Verwahrort, von $\phi \cup \lambda \dot{\alpha} \tau \tau \omega$, ich beschütze, bewache) verwendet, der speziell einen am Körper getragenen Behälter für magische Schutzmittel bezeichnet. - Grundlegend zu Schriftamuletten im Mittelalter siehe DoN C. Skemer, Binding words. Textual Amulets in the Middle Ages, University Park (PA) 2006. 
Tristan l'Ermite, auf ihn aufmerksam und lässt ihn nach Tours bringen, wo er eingekerkert und am 23. Januar sowie I. Februar I472 zu weiteren Befragungen vorgeführt wird. ${ }^{9}$ Am Morgen des 24. Januar unterzieht man Gillemer sogar einer question extraordinaire: il a esté geheyné, lié et estandu [9]. Aber auch die Folter bewegt ihn keineswegs dazu, seine Angaben zu ändern oder gar Geständnisse abzulegen. Vielmehr dürfte Gillemer aus Mangel an Beweisen - mehr oder weniger - heil davongekommen sein; es hat sich zumindest kein einschlägiger Urteilsspruch Tristans erhalten. ${ }^{10}$ Zudem stirbt Charles de France im Mai I472, und in der zweiten Hälfte des Jahres I472 scheint es keine Verfolgungen seiner Anhänger mehr gegeben zu haben (siehe Anm. 9). Es ist also anzunehmen, dass Jehan Gillemer auch noch nach dieser Konfrontation mit der königlichen Justiz als Illuminator tätig gewesen ist.

\section{ILLUMINATORENTÄTIGKEIT UND LEBENSUMSTÄNDE JEHAN GILLEMERS IM SPIEGEL DER PROTOKOLLE UND brevets}

In ihrer primären Eigenschaft als Justizprotokolle belegen die darin festgehaltenen Aussagen Gillemers, dass der Illuminator - aus gutem Grund - versuchte, den Verdacht der königsfeindlichen Spionage und der Zauberei von sich abzuwenden.

Es gelingt Gillemer darzulegen, dass die mitgeführten Schriftstücke keine Geheimbotschaften im Kontext der Ligue beinhalten. Für seine Unschuld spricht dabei, dass er außer über seine Verbindungen mit dem Comte de Maine und dem Duc de Guyenne auch freimütig über seine Kontakte zu einigen Personen aus dem Umkreis des Herzogs berichtet, was ihm durchaus hätte gefährlich werden können. ${ }^{11}$ Dabei handelt es sich jedoch zumeist um Verhandlungen, die Stundenbücher betreffen. Gillemer nennt die Gemahlin des Loys Baudet (bzw. Loys d'Aubeterre), eines Maître d'hôtel von Charles de France [2, 9, 23], zudem den Kammerdiener

9 Das Protokoll vom 23. Januar trägt die eigenhändige Unterschrift des Illuminators: JGillemer (mit kalligraphischer Paraphe), siehe Abbildung dieser Protokollseite bei DAY, Portrait (zit. Anm. 2), S. 40. - Zu Tristan l'Ermite (l'Hermite): Lecoy de La Marche, Interrogatoire d'un enlumineur (zit. Anm. I), S. 396-399 sowie jüngst Boudet, Les brevets (zit. Anm. 8), S. 74 mit Anm. I (mit weiterer Literatur). Das Amt des Prévôt des maréchaux (Oberster Feldrichter) bekleidete Tristan von 1467 bis 1477; 1470/7I war er zugleich Prévôt de l'hotel royal. - Weitere im Centre historique des Archives nationales aufbewahrte Protokolle dokumentieren, dass sich Tristan Ende I47I bzw. Anfang I472 verstärkt auf der Jagd nach suspekten Anhängern des Duc de Guyenne befand: Am 20. Dezember I47I befragte er den im Hennegau geborenen Ernoulet Honbruteq, der in den Diensten des Herzogs stand und verdächtige Reden geführt hatte (J 950, no I2), und am 25. Februar I472 wurde ihm Nicole de La Croix vorgeführt, ein aus Neuville-en-Caux in der Normandie stammender Priester, der wie Gillemer von Guyenne gekommen war (J 950, no I5); siehe hierzu: H. DE Curzon, Série J, Trésor des Chartes, Supplément: Inventaire J 946 à J 950, dactylographié par A. Ganeval, vérifié par B. Galland et O. Poncet, Centre historique des Archives nationales, Paris 2002-2003, unter der URL: http://www.archivesnationales.culture.gouv.fr/chan/chan/fonds/EGF/SA/InvSAPDF/SA_index_J/J_suppl_pdf/Jo946_0950. pdf (Stand: 27. OI. 20I4). - Zu diesen Befragungen siehe auch Lecoy de La Marche (zit. Anm. I), S. $398 \mathrm{f}$. DAY, Portrait (zit. Anm. 2), S. 48, Anm. 3. - Dabei galt Tristan l'Ermite als hart durchgreifender königlicher Beamter, der auch bei der Verhängung von Todesurteilen keineswegs zögerlich war, siehe BoudET, Les brevets (zit. Anm. 8), S. 77 f. mit Anm. 3. 
des Herzogs, le petit Anthoine [5], ${ }^{12}$ des Weiteren den herzoglichen Schreiber Johannes Demeré $[2,3,4,24]$ und nicht zuletzt Madeleine de France [2, 9].

Um gegen den Verdacht der Zauberei anzugehen, gibt Gillemer stets an, dass er keine brevets weitergegeben bzw. verkauft hat, womit er unterstreichen will, dass er niemanden zu magischen Praktiken angestiftet hat. Überdies beteuert er hartnäckig, dass er sich der eigentlichen Bedeutung so mancher brevets gar nicht bewusst gewesen sei $[8, \mathrm{I} 4, \mathrm{I} 7, \mathrm{I} 8,2 \mathrm{O}-23,25$, insbes. 33], und schwört dabei wiederholt bei seiner Seele [zum Beispiel 19]. Als er abschließend [33] explizit befragt wird, ob er irgendwelche schlechten Familiengeister (gehabt) habe und ob er Teufelsanrufungen durchgeführt habe, die ihn befähigt hätten, magische Ziffern und Buchstaben anzufertigen, streitet er selbstverständlich alles ab. ${ }^{13}$ Führt man sich vor Augen, dass seit den sechziger Jahren des I3. Jahrhunderts der Gebrauch von Schriftamuletten inquisitorisch verfolgt wurde, ${ }^{14}$ dann wird deutlich, auf welch bedrohliches Terrain Gillemer hier geraten war. ${ }^{15}$ Zwar hatte man sich Mitte des 15 . Jahrhunderts in Paris zu einer toleranteren Handhabung dieses weitverbreiteten Usus entschieden, doch Tristan l'Ermite scheint kein Vertreter dieser Strömung gewesen zu sein - konsequent und immer wieder nachhakend befragt er Gillemer zu jedem der mitgeführten brevets.

Des Weiteren liefern die umfangreichen Protokolle vielfältige Informationen zur Illuminatorentätigkeit Jehan Gillemers sowie zu einzelnen Facetten seines Alltagslebens. Das Salz in der Suppe sind dabei die brevets, über deren Inhalte, Funktionen und Verbreitungswege man durch die Niederschriften erfreulich viel erfährt.

Aus den Protokollen lässt sich - schenkt man allen Zeit- und Ortsangaben Gillemers Glauben - sein Itinerar der fünf Jahre vor der Gefangennahme ablesen, das nicht nur von der Vielzahl der „geschäftlichen“ und „privaten“ Kontakte des Illuminators, zu denen Höflinge, Kleriker, Händler, Soldaten, eventuell Pilger sowie andere Illuminatoren und andere in die Handschriftenherstellung involvierte Personen zu zählen sind, sondern vor allem von seiner enormen Mobilität Zeugnis ablegt (Abb. I): ${ }^{16}$ I467/68 war er in Brüssel [I7], I468/69 hielt er sich sowohl in Paris [I4] als auch in Lyon [25] auf, wohin er aus der Lombardei kommend zurückkehrte. Ob er von Brüssel aus in die Lombardei wanderte oder erst nach Paris ging und danach die Alpen überquerte, ist unklar. Von Lyon aus wendete er sich jedenfalls nach Poitiers

I2 In den Rechnungsbüchern des Duc de Guyenne erscheint im Januar I472 unter den Kammerdienern ein $A n$ thoine de Termes, der für das Quartal 45 Pfund erhält; siehe Boudet, Les brevets (zit. Anm. 8), S. 77, Anm. 5.

I3 Generell zum Anklagepunkt „Familiengeister und individuelle Dämonen“ siehe J.-P. BoudET, Entre Science et Nigromance. Astrologie, divination et magie dans l'Occident médiéval (XIIe-Xe siècle), Paris 2006, S. 468475, der Fall Gillemers erwähnt auf S. 473.

I4 Thomas von Aquin beschäftigt sich in der Summa theologica (IIa IIae, q. 96, art. 4) mit der Frage, ob es erlaubt sei, sich göttliche Worte um den Hals zu hängen: Wenn man dies tut, dann muss man darauf achten, dass die göttlichen Worte nicht von irgendetwas Unnützem bzw. Eitlem (aliqua vana) begleitet werden, wie zum Beispiel von Formeln bzw. Zeichen (puta aliqui characteres inscripti). Erlaubt ist nur das Zeichen des Kreuzes.

I5 Zum Umgang der Justiz mit Schriftamuletten siehe Boudet, Les brevets (zit. Anm. 8), S. 72-76.

I6 Siehe hierzu auch die Landkarte bei DAy, Portrait (zit. Anm. 2), S. 43, sowie die Karte „Frankreich zur Zeit Ludwigs XI.“ (siehe Anm. 5). 
[25], wo er für längere Zeit (ca. I468-I47I) blieb [vgl. I, 2, I5, 20, 22, 26]; in dieser Zeit hatte er auch eine Werkstattleitung (hierzu siehe S. 75 f.) inne [28]. Ferner verbrachte er im ausgehenden Jahr I47I gut vier Monate in dem nahe bei Poitiers gelegenen Ort Latille [2, 23]. Von dort aus begab er sich - wohl über Saint-Jean-d'Angély [3, 4] - nach Bordeaux und Saint-Sever, dem damaligen Aufenthaltsort des Duc de Guyenne (ca. $150 \mathrm{~km}$ südlich von Bordeaux, in den Landes), um dann wahrscheinlich denselben Weg zurück in den Norden bis nach Le Mans (Maine) zu nehmen, wo er letztendlich aufgegriffen wurde. ${ }^{17}$ Maximal hat er im angegebenen Zeitraum $3.500 \mathrm{~km}$ zurückgelegt. Wenn man davon ausgeht, dass er auch vor 1467/68 und vermutlich auch noch nach seiner Freilassung - ähnlich mobil gewesen ist, dann dürften sich seine Reisen im Laufe seines Buchmalerlebens zu einer beeindruckenden Wegstrecke von mehreren tausend Kilometern summiert haben.

Als Gillemer I47I nach der sesshaften Phase in Poitiers Richtung Bordeaux weiterzieht, trifft er in Latille, wo er sich in einem Gasthaus bei François Lévesque aufhält [2], den herzoglichen Schreiber Johannes Demeré, den Madeleine de France als Boten zu ihm geschickt hat. Johannes selbst logiert bei einem gewissen Simon Luillier in dem ca. Ioo km südlich von Latille gelegenen Ort Saint-Jean d'Angély [3], wo ihn Gillemer bei der Arbeit gesehen hat - eventuell an dem Brevier, das Demeré für den Herzog en lettre rommaine geschrieben hat [4]. Ob Gillemer dieses illuminieren soll, ist unklar. Explizit angesprochen wird dagegen ein möglicher Auftrag für die Ausmalung eines kleinen Psalters, den Demeré ebenfalls für den Duc de Guyenne angefertigt hat [3]. Im weiteren Verlauf des Protokolls ist auch noch von Stundenbüchern aus der Produktion des herzoglichen Schreibers die Rede, die Gillemer ausstatten solle [24: certaines heures]. Darüber hinaus verweist Demeré auf einen weiteren Schreiber, Jehan Breton, der für Gillemer Arbeit haben bzw. ihm weitere Kontakte vermitteln könne [2, insbes. 3]. Ein nicht geringer Anteil der Aufträge Gillemers kam also mit Hilfe von weltlichen Schreibern zustande.

Im Gasthaus in Latille trifft Gillemer auch den Diener der Ehefrau des Hofmeisters Loys Baudet, Meister Phillebert, der ihm rät, zu seiner Herrin nach Saint-Martin-de-la-Coudre (knapp $20 \mathrm{~km}$ von Saint-Jean-d'Angély entfernt) zu gehen, die ein Stundenbuch haben wolle [2]. Falls Gillemer schöne Stundenbücher auf Vorrat hätte, solle er sie Madame Baudet bringen [23]. Wenn nicht, dann würde sie sich gerne ein Stundenbuch anfertigen lassen. Phillebert nennt auch den Preis, den die Dame für ein Stundenbuch zu zahlen bereit ist: 25 Écus. Es könnte also sein, dass Gillemer mit einem gewissen Bestand an Stundenbüchern, eventuell auch an Psaltern und Brevieren, unterwegs war, die er potentiellen Kunden anbieten konnte. Vornehmlich scheint er aber auf Bestellung gearbeitet zu haben. Den Abstecher nach SaintMartin-de-la-Coudre, der sich für ihn durchaus hätte rentieren können, hat der Illuminator allerdings nicht unternommen; vielmehr zog er es vor, sich nach Bordeaux bzw. Saint-Sever zu begeben, um Madeleine de France aufzusuchen, die wegen Stundenbüchern et autres cho-

I7 Die Strecke von Poitiers über Saint-Jean-d'Angély und Bordeaux in die Landes ist Teil der Via Turonensis, des nördlichsten der vier französischen Jakobswege, der von Paris aus nach Santiago de Compostela führt (vgl. DAy, Portrait, zit. Anm. 2, S. 43). Daher die Annahme, dass auch Pilger zu den Kunden des Jehan Gillemer gezählt haben könnten. 
ses de son mestier d'enlumineur [2] nach ihm geschickt hatte. Sicherlich erhoffte er sich von ihr lukrativere Aufträge als von der Gemahlin des Maître d'hôtel.

Ende I47I bzw. Anfang 1472 ist Jehan Gillemer auch deshalb verstärkt unterwegs, weil die politische Lage prekärer und die Gesundheit des Duc de Guyenne fragiler wurde, so dass sich der Illuminator gezwungen sieht, nach anderen hochrangigen Auftraggebern zu suchen. ${ }^{18}$ Von Guyenne begibt er sich nach Le Mans, um dort den Hof des Comte de Maine aufzusuchen, da er sich von Charles d'Anjou die Bezahlung von Schulden für bereits ausgeführte Handschriftenilluminationen sowie die Aufnahme in dessen Haushalt und damit eine dauerhafte Versorgung erhofft $[6,9]$ - ein Ansinnen, das sich nicht erfüllt hat. Weiterhin erwartet er sich vom Comte de Maine Fürsprache bei einem Auftrag für ein Brevier nach römischem Gebrauch für dessen Neffen, den Duc de Guyenne, den Gillemer kurz zuvor in Saint-Sever gesehen hatte, als dieser von Fieber heimgesucht sein Pferd bestieg, um nach Hagetmau zu reiten [5, insbes. 9]. Es ist anzunehmen, dass der Illuminator in dieser Aufbruchssituation nicht das rechte Gehör des Herzogs gefunden hatte, dessen Fieber bereits ein Anzeichen seines nahen Todes im Mai gewesen sein könnte. Obwohl Gillemer bei Charles d'Anjou in die Waagschale wirft, dass er bereits mit seiner Nichte Madeleine de France über einen Auftrag für ein Stundenbuch verhandelt habe [9], zeitigen seine Anstrengungen in Sachen Brevier-Auftrag für Charles de France offenbar nicht den erwünschten Erfolg. Der einzige weitere Auftrag am Hofe von Guyenne scheint das Stundenbuch für Antoine, den Kammerdiener des Herzogs, gewesen zu sein [5]. Gillemer versuchte demnach, sich möglichst finanzkräftige und einflussreiche Kundschaft zu sichern, am besten die Barone selbst, aber auch Personen aus der Adelsentourage. Zudem wird deutlich, dass für ihn Gunstzuweisungen und Schutz durch potente Auftraggeber lebensnotwendig waren.

Ein ansehnlicher Teil von Gillemers Schriftamuletten veranschaulicht, wie sich der Illuminator auf seine Reisen vorbereitet bzw. gegen die Gefahren, denen Reisende ausgesetzt sind, gewappnet haben könnte. So besitzt er sowohl eine Planetenliste zur Beurteilung des Abreisetages und des Reiseverlaufs [29] ${ }^{19}$ als auch eine Papierrolle mit Namen bzw. Buchstaben, die es ihm ermöglichen, den Verlauf einer Reise mit Hilfe von Namenmantik vorherzusagen: Der Name der ersten Person, die ihm bei der Abreise am Stadttor begegnet, gibt Auskunft darüber, ob sich die Reise positiv oder negativ gestalten wird [22]. ${ }^{20}$ In diesen Zusammenhang gehört auch eine Liste mit sogenannten jours desvoyez [15, 27]. Zwar gibt Gillemer nicht explizit an, dass es sich bei diesen Unglückstagen (auch: dies nefasti bzw. egyptiaci) um Tage handelt, an denen man nicht auf Wanderschaft gehen soll, doch lässt sich dies aus anderen Kontexten erschließen. So findet sich in dem Abschnitt, den Hans Vintler in seinen Pluemen der tugent (I4II) dem Aberglauben und der Zauberei widmet, ein Hinweis auf Personen, die an solchen Tagen nicht wandern wollen. ${ }^{21}$ Die jours desvoyez sind darüber hinaus ein schönes Beispiel für

I8 Vgl. Boudet, Les brevets (zit. Anm. 8), S. 77.

I9 Incipit: Les bons voyages que je doiz faire au signe de virgo, en aoust ou en septembre.

20 Zur Namenmantik (Ono[mato]mantie): Сн. Tuczay, Magie und Magier im Mittelalter, München 2003, S. 187.

2I Edition I. von Zingerle (Hrsg.), Die pluemen der tugent des Hans Vintler, Innsbruck I874, Vv. 7694-7995, hier insbes. Vv. $7767 \mathrm{f}$ : „... und vil die wellent nicht wandern/An den verworfnen Tagen“. - In dem illuminierten Vintler-Codex Wien, ÖNB, Cod. Ser. nov. I2819 (Tirol?, um I450/55) werden diese Verse auf dem lin- 
Gillemers Taktik, sich unwissend zu stellen: Er behauptet, dass er nicht ablesen könne, wie viele Unglückstage es genau in jedem Monat gibt, im Januar könnten es zwei sein [27]. ${ }^{22}$ An besagtem brevet ist außerdem interessant, dass Gillemer die jours desvoyez in Poitiers in der Bibliothek der Kirche Saint Hilaire (Saint-Hilaire-le-Grand) selbst aus einem lateinischen Buch herausgeschrieben hat. Ein Franzose namens Jehan Adveu, der mittlerweile verstorben sei, habe ihm die Worte ins Französische übersetzt [15]. Daraus lässt sich nicht nur ersehen, dass Gillemer die lateinische Sprache nicht ausreichend beherrschte, sondern auch, dass es in dieser Kirchenbibliothek gewissen Personengruppen, zu denen der Buchmaler gehörte, gestattet war, aus den Büchern zu kopieren. ${ }^{23}$

Für einen Reisenden kann es lebensrettend sein, nicht in bedrohliche Streitigkeiten zu geraten und bei eventuellen Krankheitsfällen Abhilfe zu wissen. Hierfür hat Gillemer Schriftamulette zur Hand, die sehr wohl Zauberworte bzw. -sprüche beinhalten.

Sozusagen vorbeugend gegen Hader und Zank besitzt er ein unter anderem mit Versen (rondeaulx) beschriftetes brevet, das er Ende I47I in Bordeaux von einem Mann aus Navarra erhalten hat $[8, \mathrm{I} 8]$. Ihm zufolge erfreut man sich, wenn man die Worte auf Jungfernpergament, einen kostbaren und damit besonders wirkungsvollen Beschreibstoff, kopiert, ${ }^{24}$ überall und bei jedem großer Beliebtheit. Für den Ernstfall ist Gillemer mit folgendem brevet gerüstet, das ihm Anfang I47I (oder schon früher) in Poitiers ein Kleriker namens Guillaume gegeben hat: ein mittlerweile entzweigerissenes Pergamentstück, auf dem unter anderem (?) das Wort Hadan steht [20]. Gerät man in eine Schlägerei, dann soll man dieses Wort auf einen Apfel schreiben und ihn zwischen die Kontrahenten auf den Boden werfen. Dadurch würde der Streit geschlichtet. Auch hier schwört der Illuminator bei seiner Seele, dass er diesen Zauber niemals ausprobiert und an niemanden weitergegeben habe.

Fieber [7, I2, 2I] und vor allem Zahnschmerzen [7, I2, I3, 26, 30, 3I], von denen Gillemer besonders geplagt gewesen zu sein scheint, sind die gesundheitlichen Beschwerden, die er mit-

ken Seitenrand von fol. I48v mit einem Jüngling, der mit verschränkten Armen verdrossen in die Ferne blickt, bebildert; siehe das über den HANNA-Katalog der ÖNB (URL: http://aleph.onb.ac.at/F?func=file\&file_ name=login\&local_base=ONBo6, Eingabe: „Vintler“) zugängliche Digitalisat dieser Handschrift (Scan 312), Stand: 27. OI. 20I4; zu Cod. Ser. n. I2. 819 siehe Katalog der deutschsprachigen illustrierten Handschriften des Mittelalters, Bd. 2, München 1996, S. 343-345 (Kat.-Nr. I8. I. 5, U. Bodemann).

22 Zu den Unglückstagen: R. Steele, Dies Aegyptiaci, in: Proceedings of the Royal Society of Medicine, I2, I9I9, Section of the History of Medicine, Supplement, S. IO8-I2I. - H. Grotefend, Zeitrechnung des Deutschen Mittelalters und der Neuzeit, in der HTML-Version von H. RutH (URL: http://www.manuscripta-mediaevalia.de/gaeste/grotefend/grotefend.htm; Stand: 27. OI. 20I4) im Glossar zu dies egyptiaci mit Beispielen für Merkverse, in denen ebenfalls zwei Tage pro Monat, also insgesamt 24 pro Jahr, als Unglückstage angegeben werden. - Siehe auch Boudet, Les brevets (zit. Anm. 8), S. 75, Anm. 2. - Die Beobachtung der dies nefasti wird auch bei Thomas von Aquin angesprochen (IIa IIae, q. 96, art. 3, hier: dies infausti). Seiner Ansicht nach sind es die Folgen der Götzenanbetung, die die Menschen Vorzeichen, glückliche und unglückliche Tage beobachten lassen, was wiederum eng mit der Sterndeuterei zusammenhängt; es handelt sich um unlogische und grobe Beobachtungen, die abergläubisch und unnütz sind.

23 Lecoy de La Marche, Interrogatoire d'un enlumineur (zit. Anm. I), S. 402.

24 Vgl. hierzu ebenfalls Hans Vintler in den Pluemen der tugent: ,... maniger auch characteres macht/Auf pirmet virgineum" (Zingerle, Die pluemen der tugent, zit. Anm. 2I, Vv. 78ז3 f.). 
tels Schriftamuletten abzuwehren bzw. zu kurieren versucht. Ein Beispiel hierfür ist die Formel Lyessetel dominum Sudaly Crucis Crucis Gelyn Agantabell Oyel, welche, von Kreuzen durchsetzt, auf einem von fünf Pergamentstreifen steht, die an eine lange Papierrolle mit Gebeten angeheftet sind [26]. ${ }^{25}$ Dieses brevet hatte sich der Illuminator bei seinem längeren Aufenthalt in Poitiers aus einem Buch herausgeschrieben, das dem Franziskanerpater Jean Boussin gehörte, von welchem er auch die Rolle mit den Namen und Buchstaben für die Vorhersage des Reiseverlaufs erhalten hatte [22]. Gegen sein Zahnleiden hat Gillemer zudem ein Gebet an Apollonia, die dafür zuständige Schutzheilige, parat. Etwa Anfang I469, als er akut an Zahnweh litt, kaufte er auf der Durchreise in dem nahe Poitiers gelegenen Ort Croutelle in einem Gasthaus von einem Unbekannten für 2 Sous und 6 Deniers tournois ein Pergamentstück mit der besagten Anrufung [12, 31]. Der Mann hatte ihm das brevet an einer Schnur um den Hals gehängt, was nach den Aussagen Gillemers sofort heilende Wirkung zeitigte. Als er später erneut von Zahnweh gepeinigt wurde, habe das Schriftamulett jedoch versagt. Der Buchmaler gibt zu Protokoll, dass er seither niemals mehr versucht habe, sich selbst zu helfen, da er erkannt hatte, dass es ihm nichts brachte [13].

Auch gegen den plötzlichen Tod hat sich Gillemer mit einem brevet gerüstet [25]. Diese lange Papierrolle mit Gebeten und Kreuzen hatte der Illuminator 1468/69 bei seinem Aufenthalt in Lyon von einem gewissen Jehan Potier bekommen, der ihm folgende Informationen über dieses „multifunktionale“ Schriftamulett mit auf den Weg gab: Wenn man die darauf stehenden Gebete täglich spricht, weiß man den eigenen Sterbetag drei Tage im Voraus. Darüber hinaus hat man damit ein Hilfsmittel für Geburtshilfe und Exorzismus zur Hand. Wirft man die Rolle auf eine leidende Gebärende, so wird der Geburtsverlauf erleichtert; wirft man sie auf eine besessene Person, dann wird der Teufel aus dieser ausgetrieben. Außerdem soll man die Rolle bei sich tragen, wenn man Angst vor Feuer, Wasser et autres malles adventures hat. Es ist müßig hinzuzufügen, dass Gillemer auch bei diesem brevet schwört, dass er es selbst nie ausprobiert habe und es auch niemand anderen habe ausprobieren lassen.

Von ganz speziellem Wert, da von besonders apotropäischer und heilender Kraft, war für Gillemer sicherlich eine sogenannte „Länge Christi“ $[17],{ }^{26}$ die er I467/68 in Brüssel von einem Soldaten, einem poursuivant (Unterherold) aus dem Gefolge Kaiser Friedrichs III., bekommen hatte. Hierbei handelte es sich um eine auf ein Stück Papier aufgezeichnete und von mehreren Kreuzen sowie lateinischen und französischen Beischriften begleitete Maßeinheit, die man mal sechzehn nehmen musste, um die wahre Größe Jesu Christi zu erhalten. Der Soldat wiederum hatte die Länge Christi aus einem Franziskanerkloster in Jerusalem mitgebracht.

25 Bei diesen Worten handelt es sich laut Boudet, Les brevets (zit. Anm. 8, S. 74, Anm. 3) um göttliche oder pseudogöttliche Engelsnamen; Lyessetel und Oyel könnten Deformationen hebräischer Engelsnamen sein; Sudaly kommt von „Saday“ (hebr. „Shadday“: Gott der Wüste); Gelyn und Agantabell sind Hapaxlegomena; zu Crucis, dem Zeichen des Kreuzes, vgl. Anm. I4: Laut Thomas von Aquin ist das Kreuz Christi das einzige Zeichen, das auf Schriftamuletten mit göttlichen Worten erlaubt ist. Auch auf etlichen weiteren brevets von Gillemer findet sich das Kreuzzeichen [14, I7, I8, 21, 25].

26 Zur „Länge Christi“ siehe Bozoky, Les moyen (zit. Anm. 8), Absatz 3I der Online-Version, sowie Skemer, Binding words (zit. Anm. 8), S. I42f., I5I f., I7I (Anm. I), 262, 264 mit Abb. I2; zu gedruckten Exemplaren: S. 223 f. und 228-230 mit Abb. 9. 
Heilige Maße bzw. Längen, wie beispielsweise auch das Maß der Seitenwunde Christi oder der Fuß bzw. Gürtel Mariens, waren im Volksglauben sehr verbreitet. Mit ihnen verbindet sich die Vorstellung, dass eine Heilsperson oder ein verehrter Gegenstand durch deren genaue Größenangabe vertreten werden kann. Besitzt man einen Papier- oder Stoffstreifen von der Größe (oder einem Teil der Größe) einer bestimmten Person oder eines Objekts, so kommt man in den Genuss von deren Heilskraft.

Überdies geben die Protokolle und brevets Auskunft über Gillemers Angebotspalette. Die voranstehenden Ausführungen machten bereits deutlich, dass vorrangig Stundenbücher [2, 9, 23, 24] sowie Breviere [4, 9] und Psalterien [3] für adlige Kunden wie den Duc de Guyenne [3, 4, 9] und seine Schwester [9] sowie für Angehörige des herzoglichen Hofes [2, 5, 23] die am häufigsten von Gillemer ausgestatteten Handschriftentypen waren. Außerdem hatte er Anfang I470 ein kleines Missale an den Priester Girault Cressonnier verkauft. Hierzu notierte der Illuminator auf einem Merkzettel [32], den er zusammen mit anderen Schriftstücken [26-3I] an eine Papierrolle mit Gebeten angeheftet hatte: Messire Girault Cressonnier, de Saint-Andrieu, demourant à l'oustau de mons ${ }^{\mathrm{r}}$ de Saint James. Resta prosa Prope est claritudinis, que est quarta dominica Adventus. Dieser Vermerk sollte ihn daran erinnern, so erklärt er Tristan l'Ermite, dass er in das Missale, das er dem aus Saint Andrieu stammenden und zurzeit in Bordeaux im Hause von Monseigneur de Saint James wohnenden Priester verkauft hatte, noch das bewusste lateinische Textstück einfügen musste. Gillemer betätigte sich also - obschon in geringem Umfang - auch als Schreiber. Ferner ließ er für seine Kunden auch Handschriften binden. So sagt er aus, dass er das Stundenbuch für den herzoglichen Kammerherrn Antoine von Saint-Sever nach Bordeaux zum Binden gebracht habe [5]. ${ }^{27}$ Für diese Dienstleistung nimmt er eine beträchtliche Wegstrecke in Kauf, da die einfache Entfernung von Saint-Sever nach Bordeaux ca. $150 \mathrm{~km}$ beträgt.

Der interessanteste Aspekt, den die Protokolle in Bezug auf die Arbeitspraxis eines Illuminators liefern, sind Gillemers Äußerungen über „seine“ Werkstatt ${ }^{28}$ - insbesondere, da sie einen Blick hinter die Kulissen eines Buchmalerateliers gewähren. Während seines längeren Aufenthaltes in Poitiers muss er - wohl im Jahr I469 - für einige Zeit eine größere Werkstatt geleitet haben [28]. Allein sieben Gehilfen werden im Protokoll mit ihren Vornamen genannt: Charles, Simon, André, Pierre, Guillaume, Jehan und Etienne, die allesamt recht widerspenstig gewesen zu sein scheinen. Denn Gillemer klagt, dass er mehrere erwachsene Hilfskräfte hatte, von denen er sich keine Unterstützung erwarten konnte und die ihm, schlimmer noch, Schaden hätten zufügen wollen, wenn er ihnen Anweisungen gab: plusieurs grans serviteurs dont il ne se pouvoit aidier... et avoit doubte qu'ilz le voulsissent maller s'ilz lui disoient aucune chose. ${ }^{29}$ Auch in dieser Angelegenheit hat sich der Illuminator an den Franziskaner Jean Boussin gewandt, der für ihn mithin eine Art Vertrauter gewesen zu sein scheint. Bei diesem Führungsproblem konsultiert der Pater ein astrologisches Werk und stellt für den Buchmaler eine

27 Der Protokolltext ist hier widersprüchlich. Doch ist es wahrscheinlicher, dass Gillemer das Buch von SaintSever, dem Aufenthaltsort des Herzogs und eben auch von dessen Kammerdiener, nach Bordeaux, der wichtigsten Stadt des französischen Südwestens, zum Buchbinder gebracht hat und nicht umgekehrt.

28 Vgl. R. Watson, Illuminated Manuscripts and their Makers, London 2003, S. II.

29 Lecoy de La Marche, Interrogatoire d'un enlumineur (zit. Anm. I, S. 403) ist der Ansicht, dass es sich bei den serviteurs eventuell um Schüler handelte. 
Auflistung zusammen, aus der ersichtlich ist, an welchen Tagen Gillemer mit welchem Werkstattmitglied, bezogen auf dessen Temperament, am besten zurechtkommen kann. ${ }^{30}$ Das ergibt etwas enigmatische Anweisungen wie Guillaume, au mercredi; et, se le dit Guillaume vous assault, si vous deffendez; Etienne, au jeudi ou au lundi, et vous accordez. ${ }^{31}$

Die Ansicht Boudets, dass Jehan Gillemer aufgrund der starken Nachfrage der Adelsgesellschaft nach Codices einen recht hohen Lebensstandard gehabt haben dürfte, ${ }^{32}$ ist zu bezweifeln. Vielmehr wird er durch die Verhörprotokolle und seine brevets als einfacher Buchmaler-Handwerker widergespiegelt, der ein eher beschwerliches Leben führte. ${ }^{33}$ Er musste außerordentlich mobil sein, um genügend Aufträge zu requirieren, wobei er - zumindest in dem Zeitraum, der durch die Protokolle beleuchtet wird - wohl nur mäßig erfolgreich war. Von seinem Selbstverständnis her ist er eher Geschäftsmann als Künstler; denn als er zu dem Schriftamulett mit der Planetenliste zur Beurteilung des Reiseverlaufs [29, siehe S. 72 mit Anm. 19] befragt wird, äußert er, dass ihm dieses Kenntnis verleihe über:... les bons voyages qu'il devoit faire, tant en marchandise que autrement, en quelconque lieu qu'il deust aller. ${ }^{34}$

Gillemers Itinerar veranschaulicht, dass nicht nur Hofkünstler wie Jean Fouquet, die ihre adligen Auftraggeber auf deren diplomatischen Missionen sowie Reisen zu den jahreszeitlich wechselnden Residenzen begleiteten, ${ }^{35}$ häufig unterwegs waren, sondern auch unabhängige Buchmaler aus den Provinzen. Auch sie hatten - zumindest theoretisch - die Möglichkeit, künstlerische Einflüsse direkt in kulturellen Zentren der Zeit aufzunehmen, wie dies Gillemers Aufenthalte in Paris, Lyon, Brüssel und in der Lombardei belegen. ${ }^{36}$

Die brevets legen zum einen beredtes Zeugnis ab von Gillemers Aberglauben und darüber hinaus vom Volksglauben der Zeit, zum anderen zeigen sie, wie Schriftamulette aus geographisch weit auseinanderliegenden Regionen von Klerikern und Laien kostenlos oder für wenig Geld zusammengetragen wurden. ${ }^{37}$ Die Verteilung lief über Kaufleute, Soldaten ${ }^{38}$ [ 17 , siehe S. 74] und - obwohl der Gebrauch von Schriftamuletten durch die Kirche offiziell mehr

30 Dienstag und Samstag, die beiden unheilvollen, von Mars und Saturn beherrschten Tage, und Sonntag, der Tag des Herrn, tauchen in dieser Auflistung selbstverständlich nicht auf (Boudet, Les brevets, zit. Anm. 8, S. 75). Das ist in etwa folgendermaßen zu verstehen (zur besseren Verständlichkeit in der Du-Form paraphrasiert): Mit Guillaume kommst du am Mittwoch am besten zurecht; wenn er dich angreift, dann verteidige dich. Mit Etienne arbeitest du am besten am Donnerstag und Montag zusammen; an diesen Tagen kannst du dich mit ihm einigen. Boudet, Les brevets (zit. Anm. 8), S. 77: „Il semble néanmoins avoir un assez haut niveau de vie, en bénéficiant de la forte demande de la société de cour en matière de livres liturgiques." Vgl. DaY, Portrait (zit. Anm. 2), S. 42, 44.

34 „... die guten Reisen, die er zu machen habe, ob nun in Handelsangelegenheiten oder anderen, wo auch immer er hingehen müsse."

35 Day, Portrait (zit. Anm. 2), S. 42.

36 Vgl. Day, Portrait (zit. Anm. 2), S. 44 und Lecoy de La Marche, Interrogatoire d'un enlumineur (zit. Anm. I), S. 404 .

37 Skemer, Binding words (zit. Anm. 8), S. I64.

38 So werden im „Hexenhammer“ (I486) neben Kaufleuten speziell Soldaten als Träger und Distributoren von Amuletten erwähnt bzw. angeprangert, siehe Bozoky, Les moyens (zit. Anm. 8), Absatz I3 der Online-Version mit Anm. isf. 
als kritisch gesehen wurde - über Geistliche. So erhält Gillemer in Poitiers das streitschlichtende brevet [20, siehe S. 73] von dem Kleriker Guillaume und diverse weitere Schriftamulette von dem Franziskaner Jean Boussin [22, 26 und 28; siehe S. 74 f.]. Ebenfalls von Franziskanern hatte der Soldat die Länge Christi [I7] erhalten, der sie in Brüssel an Gillemer weitergab. Wie die Menschen im Spätmittelalter, eingeschlossen Jehan Gillemer, über diese klerikale Vermittlerrolle dachten, lässt sich hervorragend an folgenden Versen aus Vintlers Pluemen der tugent ablesen: „... und wissent doch wol da pei/das zauberei got ist unwert/Auch sprechent si: „mich hatz gelert/Ain pfaff, wie möcht es pös gesein?“39 Dass von Seiten gelehrter Theologen nicht nur der Aberglaube der einfachen Leute moniert, sondern die fatale Rolle von Klerikern wie Jean Boussin klar erkannt wurde, zeigen Schriften wie De potestate daemonum des Kartäusers Jacobus de Paradiso (I38I-I465). ${ }^{40}$ Neben Ars notoria, Wahrsagen und Losen kritisiert er explizit Schriftamulette und Zaubersprüche, insbesondere die Praktik, Anhänger mit beschriebenen Zetteln um den Hals zu tragen, wobei er missbilligt, dass zur Wirkungsverstärkung heilige Wörter hinzugefügt werden. Für Jacobus ist Unwissenheit - sowohl der Gläubigen als auch des Klerus - der Quell allen Übels, da sie den besten Nährboden für Dämonen biete. Noch schlimmer als die Unwissenheit der Laien sei es, wenn die Ignoranz der Gläubigen von den Klerikern nicht aufgeklärt werde. Aufgrund ihres deplorablen Bildungsniveaus seien die Geistlichen, speziell aus dem niederen Klerus, oft nicht fähig, die Fehler zu erkennen, verfielen selbst den suspekten Praktiken und verbreiteten sie weiter. In Anlehnung an Richard Kieckhefer bezeichnet Boudet dieses Phänomen als ,inframonde clérical“, wobei er verdeutlicht, dass die von der „klerikalen Unterwelt“ vermittelten magischen, insbesondere nekromantischen Schriften und Rituale nicht nur von „einfachen“ Gläubigen rezipiert wurden, sondern - neben den Klerikern selbst - auch von Adligen. ${ }^{41}$

\section{KUNSTHISTORISCHE EINORDNUNG JEHAN GILLEMERS}

Das Bild Jehan Gillemers, das sich durch die Verhörprotokolle und brevets abgezeichnet hat, wäre unvollständig ohne einige Bemerkungen zu seiner Identifikation als Buchmaler.

Der Illuminator Gillemer ist der Forschung seit längerem bekannt - so bezog ihn bereits Paul Viollet in seine Betrachtungen über Fouquet und dessen Zeitgenossen ein. ${ }^{42}$ Immer wie-

39 Zingerle, Die pluemen der tugent (zit. Anm. 2I), Vv. 7699-7702. - Im Vintler-Codex Wien, ÖNB, Cod. Ser. nov. I28I9 (siehe Anm. 2I) werden diese Verse auf dem Bas-de-page von fol. I47r durch einen Kräuter verteilenden Geistlichen illustriert, den ein Mann mit einer Keule verprügeln will; siehe das über den HANNAKatalog der ÖNB (URL: http://aleph.onb.ac.at / F?func=file $\&$ file_name=login \& local_base=ONBo6, Eingabe: „Vintler“) zugängliche Digitalisat dieser Handschrift (Scan 309), Stand: 27. OI. 2014.

40 K. Bracha, Die Kritik des Aberglaubens der Irrtümer und Missbräuche im Kult bei Jacobus Cartusiensis, in: S. Lorenz (Hrsg.), Bücher, Bibliotheken und Schriftkultur der Kartäuser (Contubernium 59), Stuttgart 2002, S. $15 \mathrm{I}-163$, insbes. S. $156 \mathrm{f}$. und 162.

4I Boudet, Les brevets (zit. Anm. 8), S. 79 mit Anm. I. - R. Kieckhefer, Magic in the Middle Ages, Cambridge I989, S. I5I-I75.

42 P. Viollet, Jehan Fouquet et quelques-uns de ses contemporains, in: Gazette des Beaux-Arts, 23, I867, S. 97II3, hier: S. I06-IIO. 


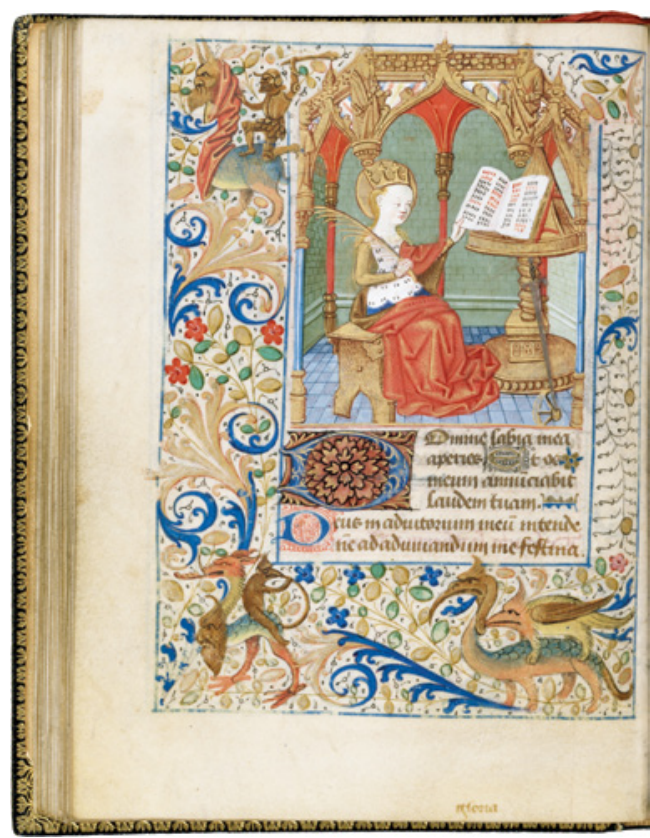

Abb. 2: „Master of Walters 222“ (Jehan Gillemer?), hl. Katharina. Stundenbuch für den Gebrauch von Poitiers, 3. Viertel I5. Jahrhundert. Baltimore, Walters Art Museum, MS W. 222, fol. 3ov.

der hat man versucht, Gillemer mit einem der nur unter einem Notnamen bekannten französischen Buchmaler des I5. Jahrhunderts in Übereinstimmung zu bringen. François Avril schlug vor, Gillemer mit dem „Maître de Charles de France" zu identifizieren, da die aufwendige und fein ziselierte Baldachinarchitektur in einer Verkündigungsminiatur aus einem Stundenbuch, das dieser Meister für Charles de France gefertigt hat, formale Parallelen zum Mailänder Dom habe, den der Illuminator mit eigenen Augen gesehen haben musste. ${ }^{43}$ Gillemer war nachgewiesenermaßen in der Lombardei [25] und könnte dabei durchaus die Hauptstadt Mailand aufgesucht haben. Gegen ihn als Illuminator dieses (vor) 1465 entstandenen Stundenbuchs spricht jedoch, dass er kein Hofkünstler von Rang gewesen ist und sich wohl nie die Gunst von Charles de France hatte sichern können. Das ist einer der Gründe, warum Véronique Day für eine Identifizierung Gillemers mit dem „Master of Walters 222“ plädierte, der nach dem im Walters Art Museum in Baltimore aufbewahrten Stundenbuch MS W. 222 benannt worden ist (Abb. 2). ${ }^{44}$ Dieser war ein gelegentlicher Mitarbeiter des „Meisters der Ade-

43 F. Avril / N. Reynaud, Les manuscrits à peinture en France, I440-1520. Katalog zur Ausstellung „Quand la peinture était dans les livres: Les manuscrits enluminés en France, I440-1520 “ in der Bibliothèque nationale de France (16. Okt. 1993-16. Jan. 1994), Paris 1993, S. 157-163, hier S. 158; vgl. DAY, Portrait (zit. Anm. 2), S. 39, Anm. 9. - „Les Heures de Charles de France“: Paris, Bibliothèque Mazarine, ms. 473, (vor) I465, unvollendet und verstümmelt, 2I8 Bll., I8I × I32 mm, I8 Miniaturen (siehe auch unter der URL: http://liberfloridus.cines. $\mathrm{fr} /$, hier unter „Les bibliothèques et leurs manuscrits“: „Bibliothèque Mazarine/Accès aux manuscrits et aux images“, Handschrift unter „ms. 0473“ zugänglich; Stand: 27. OI. 20I4); zwei Einzelblätter (I7I × I24 mm) aus diesem Stundenbuch befinden sich in New York, The Cloisters Collection (I958), 58.7I a,b. - Zuvor hatte man den „Maître de Charles de France“ mit Jean de Laval in Verbindung gebracht, siehe M. B. Freeman, The Annunciation from a Book of Hours for Charles of France, in: The Metropolitan Museum of Art Bulletin, New ser. I9/4, I960/6I, S. I05-II8, insbes. S. II7 (hier auch Gillemer erwähnt), Fig. 8: Abb. der erwähnten Verkündigung; der Artikel auch unter der URL: http://www.metmuseum.org/pubs/bulletins/I/pdf/3257865.pdf.bannered.pdf (Stand: 27. OI. 20I4).

44 Day, Portrait (zit. Anm. 2), S. 4of. mit einer Werkliste und der Ankündigung einer ausführlichen Studie in Anm. I3; siehe zudem die unveröffentlichte Dissertation von V. P. DAY, Manuscript Production in FifteenthCentury Poitiers. Northwestern University 1993, insbes. S. II6-I30; zum „Master of Walters 222“ siehe auch ein ihm (bzw. „Gillemer?“) jüngst zugeschriebenes Stundenbuch (um I480) unter der URL: http://www. medievalbooksofhours.com/search.php („Reference Number“: 65; Stand: 27. OI. 20I4), freundlicher Hinweis 
laide von Savoyen“45 und arbeitete zuweilen für denselben Auftraggeber wie der „Meister des Yvon du Fou“. Die Codices, die dem „Master of Walters 222“ zugeschrieben werden, zeichnen laut Day eine eher bescheidene Karriere nach, die in der Mitte der I48oer-Jahre endete. Die Auftraggeber der Handschriften waren lokale Kleriker und gelegentlich wichtigere Kunden aus der Region. Die Werke wurden in Zusammenarbeit mit Gehilfen und regionalen Meistern ausgeführt und lassen an die Karriere eines wandernden Buchmalers auf der Suche nach Aufträgen denken: ein Szenario, das sehr gut zu dem Illuminator passt, den man mittels der vorgestellten Verhörprotokolle und der darin examinierten brevets kennenlernt.

Würzburg

Abbildungsnachweis: Abb. I: A. Gimpl und Verfasserin. - Abb. 2: nach Randall (zit. Anm. 44), Bd. 2/2, pl. XVIa (S. 572).

Dr. R. Cermann, Universität Wien, der ich auch für das Korrekturlesen des Artikels zu danken habe. - Zum namensgebenden Stundenbuch: L. M. C. Randall (Hrsg.), Medieval and Renaissance Manuscripts in the Walters Art Gallery, Bd. 2 (France, I420-I540), Baltimore/London I992, S. 207-2I2, Kat.-Nr. I42: Stundenbuch für den Gebrauch von Poitiers, 3. Viertel I5. Jh., mit Wappen der späteren Besitzerfamilie Tourotte; drei beteiligte Hände, von der Haupthand: ff. I5r (Verkündigung, Abb. bei DAy, Fig. 2), 3ov und sir.

45 Dieser Buchmaler wurde von E. König, basierend auf dem für einen Kanoniker aus Poitiers geschaffenen Missale, heute Poitiers, Bibliothèque municipale, MS 30, „Meister aus Poitiers 30“ genannt; E. KöNIG, Französische Buchmalerei um I450. Der Jouvenelmaler, der Maler des Genfer Boccaccio und die Anfänge Jean Fouquets, Berlin 1982, siehe auch Ders., Der Meister von Poitiers 30. Ein unbekanntes Gegenstück zum Stundenbuch der Adelaide von Savoyen (Illuminationen. Studien und Monographien, XII; zugleich Katalog Nr. 57 des Antiquariats Tenschert, vormals Rotthalmünster, seit 2009 Ramsen, CH). Rotthalmünster 2006. 


\title{
DER ILLUMINATOR DES KOLOMAN-ANTIPHONARS
}

\author{
ZUR FRAGE DER MOBILITÄT EINES BUCHAUSSTATTERS IM \\ DONAUÖSTERREICHISCHEN RAUM UM 1480
}

Armand Tif

Die Mobilität mittelalterlicher Kunstschaffender gehört mit Sicherheit zu den interessantesten und schwierigsten Themen der kunsthistorischen Forschung. Zu selten sind Beispiele vom künstlerischen Werk mit dazugehörigen schriftlichen Nachrichten so gut überliefert, dass daraus gesicherte Daten zu den geographischen Bewegungen einer Künstlerpersönlichkeit eindeutig gewonnen werden können. ${ }^{1}$ Vor allem bei einer Gattung wie der Buchmalerei, deren Träger - der Codex - im höchsten Maß mobil ist, wird die Lokalisierung der künstlerischen Ausführung zu einer zusätzlichen Variablen in der wissenschaftlichen Gleichung. Hier stellt sich die berechtigte Frage, ob für die Ausstattung der Buchmaler zum Codex oder der Codex zum Buchmaler geführt wurde. Beides ist denkbar und beides kam vor. Wie soll aber im Einzelfall festgestellt werden, ob und welches Gebiet ein Buchausstatter bereiste? Schließlich ist dies nicht nur eine Frage der Lokalisierung künstlerischer Tätigkeit, sondern auch eine Frage territorialer Mobilität im Rahmen von regionalen oder überregionalen Kulturnetzwerken im Mittelalter.

Dass Buchmaler für Aufträge oft lange Strecken zurücklegten, ist in manchen Fällen durch schriftliche Quellen belegt, ohne dass ein bestimmtes Euvre damit in Verbindung gebracht werden könnte. ${ }^{2}$ In anderen Fällen ist wiederum das Euvre eines Buchmalers bekannt und die Frage nach dem Ausstattungsort klärungsbedürftig. ${ }^{3}$ Vor allem in der zweiten Hälfte des I5. Jahrhunderts wurden mehrfach Ortswechsel von Buchmalern im mitteleuropäischen Raum festgestellt, wenn die Tätigkeiten für bestimmte, gut lokalisierbare Auftraggeber langjährige Aufenthalte in unterschiedlichen Regionen glaubhaft machten. ${ }^{4}$ Ungleich problematischer

I Eine Ausnahme bilden dabei wenige italienische Künstler, die vor allem in Florenz, Siena und Rom ab dem I3. Jahrhundert im Kulturbewusstsein ihrer Zeitgenossen bereits ein hohes Ansehen erlangt hatten, welches die historische Überlieferung ihrer Lebensdaten einigermaßen sicherte. Zu denken ist in diesem Zusammenhang etwa an Giotto, dessen Lebenswege aufgrund der Quellenlage vergleichsweise gut nachvollzogen werden können. Dazu M. V. Schwarz, Giottus Pictor I. Giottos Leben. Mit einer Sammlung der Urkunden und Texte bis Vasari (zusammen mit Pia Theis), Wien 2004 und ders., Giottus Pictor II. Giottos Werke (Mitarbeiterin Michaela Zöschg), Wien 2008.

2 Siehe zum Beispiel den Beitrag von Susanne Rischpler über das Verhör des Buchmalers Jehan Guillemer im vorliegenden Band.

3 Ein prominentes Beispiel, der sogenannte Georgscodex für Kardinal Stefaneschi, wird im Beitrag von Michael Viktor Schwarz im vorliegenden Band besprochen.

$4 \mathrm{Zu}$ den drei Schaffensperioden des sogenannten Meisters des Friedrichbreviers, Olmütz (vor ca. I477), Wien (ca. I477 - ca. I48I) und Brünn (nach ca. I48I), siehe G. Schмidt, Die Buchmalerei, in: Die Gotik in Österreich, Ausstellungskatalog, Krems-Stein, Minoritenkirche, 19.05. 1967-I5. 10. 1967, Krems an der Donau 1967, S. 173; ders., Die zwei Stile des „Meisters des Friedrichsbreviers“. Ein spätgotischer Buchmaler kopiert Stiche des Meisters E. S., in: J. F. Hamburger/A.S. Korteweg (Hrsg.), Tributes in Honor of James 
stellt sich die regionale Verankerung sogenannter Wandermaler dar, deren Wirken von weitaus größerer bzw. dynamischerer Mobilität geprägt war, da sie für Aufträge offensichtlich regelmäßig reisten. ${ }^{5}$

Im Laufe meiner Forschungen zur Rekonstruktion der im Zuge der josephinischen Klosteraufhebungen aufgelösten mittelalterlichen Bibliothek des ehemaligen Augustiner-Chorherrenstiftes Dürnstein wurde ich auf einen Buchausstatter, den sogenannten Illuminator des Koloman-Antiphonars ${ }^{6}$, aufmerksam, welcher um I480 mehrfach für die Augustiner-Chorherrenstifte entlang der Donau zwischen Klosterneuburg und Passau tätig war und diese vermutlich auftragsbedingt bereiste. ${ }^{7}$ Er ist als Buchmaler und Buchbinder für verschiedene Klöster und Privatpersonen im donauösterreichischen Raum fassbar. Da er einen großen Teil seiner Werke zwischen 1478 und I482 datierte, erlaubt die Werküberlieferung eine vergleichsweise genaue chronologische Rekonstruktion seines Wirkens.

H. Marrow. Studies in Painting and Manuscript Illumination of the Late Middle Ages and Northern Renaissance, London/Turnhout 2006, S. 44I-452; ders., Der Meister des Friedrichsbreviers als Inkunabel-Illuminator. Ein Gruss aus dem Otto-Pächt-Archiv, in: K. Benešovská/J. Chlíbec (Hrsg.), V zajetí středověkého obrazu. Kniha studií 2I autorů tvoří poměrně kompaktní celek-většina textů je totiž věnována knižní malbě (nebo dílům, jež s ní nějakým způsobem souvisí) hlavnímu ohnisku zájmu Karla Stejskala, Prag 20I2, S. I92202. Vgl. auch die Tätigkeit Ulrich Schreiers in Salzburg, Wien und Bratislava in M. Schuller-Juckes, Ulrich Schreier und seine Werkstatt. Buchmalerei und Einbandkunst in Salzburg, Wien und Bratislava im späten Mittelalter, phil. Diss., Wien 2009, hier S. Is ff. In diesen Fallbeispielen basieren die Argumentationen hauptsächlich auf statistischen Auswertungen der Anzahl und Datierung illuminierter Codices für ermittelbare Auftraggeber bzw. Erstbesitzer aus einem geographischen Gebiet.

5 Ein Beispiel hierfür bietet der Diskurs um den sogenannten Illuminator der Münchener Gutenbergbibel, dem um die Mitte des I5. Jahrhunderts vereinzelte Aufträge von Südtirol über Süddeutschland und aus dem heutigen österreichischen Raum bis nach Ungarn nachgewiesen werden konnten, weshalb er gelegentlich als Wandermaler bezeichnet wird. J. H. Marrow, Missal, in: J. G. Alexander/L. Freeman-Sandler/J. H. Marrow (Hrsg.), The Splendor of the Word. Medieval and Renaissance Illuminated Manuscripts at the New York Public Library, Ausstellungskatalog, New York, Public Library, 2I. I0. 2005-I2. 02. 2006, New York 2005, S. I77I8I, hier S. I8I, Anm. 6, Kat. 36. Zur Benennung als Südtiroler Wandermaler: M. Roland, Die Buchmalerei der Gotik, in: Kunst in Tirol I. Von den Anfängen bis zur Renaissance, Innsbruck 2007, S. 267-294, hier S. 274 f. Näheres zur Münchner Gutenbergbibel als Referenzwerk: B. WAgner/K.-G. Pfändtner, Kat. Nr. I4, in: B. WAGNER (Hrsg.), Als die Lettern laufen lernten. Medienwandel im I5. Jahrhundert. Inkunabeln aus der Bayerischen Staatsbibliothek München, München, Bayrische Staatsbibliothek, I8. 08. 2009-3I. 10. 2009, München 2009, S. 52-55; C. BEIER, Die illuminierten Handschriften und Inkunabeln der Universitätsbibliothek Graz. Die illuminierten Handschriften I400 bis I550. 2 Bde., (Österreichische Akademie der Wissenschaften, Philosophisch-historische Klasse, Denkschriften 390 = Veröffentlichungen der Kommission für Schrift- und Buchwesen des Mittelalters, Reihe V: Die illuminierten Handschriften und Inkunabeln in Österreich außerhalb der Österreichischen Nationalbibliothek I), Wien 20I0, I, S. I4 ff., Kat. 6.

6 Die Benennung nach dem Referenzwerk in St. Pölten, Diözesanbibliothek, Cod. I wurde von Haidinger vorgenommen und hat sich seitdem nicht verändert. A. Haidinger, Verborgene Schönheit. Die Buchkunst im Stift Klosterneuburg, Katalog zur Sonderausstellung 1998 des Stiftsmuseums Klosterneuburg 1998, Klosterneuburg/Wien 1998, S. 60.

7 Zur Rekonstruktion der mittelalterlichen Bibliothek des Augustiner-Chorherrenstiftes Dürnstein: A. TrF, Buchkunst in der mittelalterlichen Bibliothek des Stiftes Dürnstein, in: H. Penz/A. Zajic (Hrsg.), Stift Dürnstein. 600 Jahre Kloster und Kultur in der Wachau, Horn 2010, S. 64-73, hier S. 65 ff. 


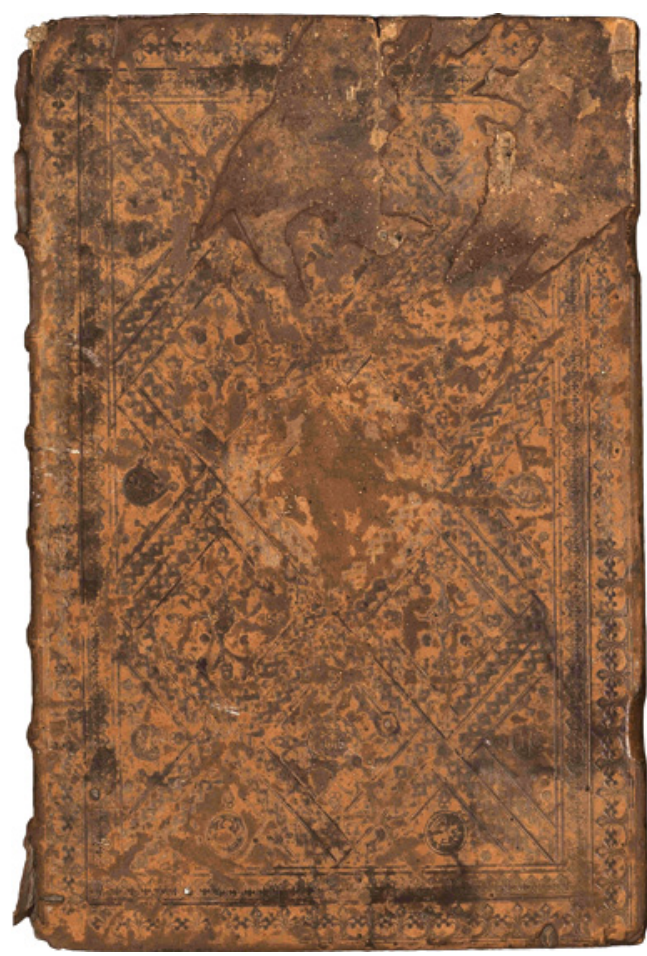

Abb. I: St. Pölten, Diözesanbibliothek, Cod. I (Koloman-Antiphonar), Einband, Vorderdeckel
Bei der Vorstellung seines Euvres bietet es sich an, zunächst die geographische $\mathrm{Zu}$ ordnung der Auftraggeber für die Illuminierung von Handschriften und Inkunabeln zu besprechen. In weiterer Folge soll auf seine Einbandkunst näher eingegangen werden, da die Buchbindung aufgrund der technisch notwendigen Vorrichtungen stärker ortsgebunden als die malerische Ausstattung von Codices war, weshalb sich daraus besser gesicherte Daten zur jeweiligen Lokalisierung der Tätigkeiten ableiten lassen. ${ }^{8}$ Das Zusammenspiel zwischen Buchmalerei, Auftraggeber bzw. Provenienz und buchbinderischem Werk ergibt schließlich die Route seiner auftragsbedingten Arbeitsreisen zwischen 1478 und I488. Ein kurzer Ausblick auf die Nachfolge, welche sich im geographisch breit gestreuten Umfeld des Buchausstatters herausbildete, liefert abschließend einen letzten Hinweis auf die hohe Mobilität des Buchmalers und Einbandkünstlers.

\section{BUCHMALEREI UND AUFTRAGGEBER}

Der Notname des Illuminators des Koloman-Antiphonars leitet sich von einer Choralhandschrift (Abb. I-4) für Propst Koloman (I486-I488) des Augustiner-Chorherrenstiftes St. Pölten ab. ${ }^{9}$ Die früheste buchmalerische Ausstattung des Antiphonars wurde aufgrund formaler Kriterien zunächst der Werkstatt des Salzburger Buchausstatters Ulrich Schreier oder einer niederösterreichischen Nachfolge-Werkstatt zugeschrieben. ${ }^{10}$ Derselben Hand wies

8 Eine Ausnahme bilden dabei die sogenannten Buchführereinbände, welche von mittelalterlichen Buchhändlern mit demselben Stempelmaterial an unterschiedlichen Orten hergestellt werden konnten. Als Beispiel sei der Leipziger Buchführer Johannes Schmidhofer genannt. G. LoH, Die Leipziger Buchbinder im I5. Jahrhundert, phil. Diss. (masch.), Humboldt-Universität, Berlin I990, S. $88 \mathrm{ff}$.

Die Handschrift ist in mindestens zwei zeitlich unterschiedlichen Phasen dekoriert worden. Frühe Ausstattungsphase: Zum Beispiel Prunkseiten fol. Iv, 38v, 70v, II2r, II5r, I66r, I86r, 207r, 218v, 285v, 334r, 335r, 39Iv, 402v, wobei auf fol. Iv in den Randleisten die Konventsmitglieder des Augustiner-Chorherrenstiftes St. Pölten zwischen I463 und I488 und in der Hauptinitiale die Pröpste dieser Periode, Georg, Johannes, Thomas und Koloman, abgebildet sind. Spätere Ausstattungsphase: Zum Beispiel auf fol. 2r werden die Konventsmitglieder bis zum Chorherrn Michael Stubenfol († I52I) von einer anderen Hand ergänzt. Als Illuminator des Koloman-Antiphonars wird der Buchmaler der Erstausstattung bezeichnet. Schmidt schrieb die ältere Ausstattung zuerst einem niederösterreichischen Nachfolge-Atelier, der sogenannten Schreier-Werk- 
Gerhard Schmidt die Buchmalerei im sogenannten Morandus-Offizium ${ }^{11}$ von 1482 und in zwei Bänden einer I48I datierten Inkunabel aus Dürnsteiner Provenienz ${ }^{12}$ in der ÖNB in Wien sowie in einem 4479 vollendeten Missale des Schreibers Hieronymus Sitznberger $^{13}$ in der Bibliothek des Augustiner-Chorherrenstiftes Klosterneuburg zu. ${ }^{14}$ Kurt Holter erweiterte die Werkgruppe des Illuminators durch Zuschreibungen von drei Inkunabeln in der Bibliothek des Augustiner-Chorherrenstiftes St. Florian. ${ }^{15}$ Aufgrund des gemalten

statt, zu und datierte die Buchmalerei in die Zeit I480/88. G. Schмidt, Die Buchmalerei, in: Die Gotik in Niederösterreich. Katalog der ausgestellten Handschriften, Ausstellungskatalog, Krems-Stein, Minoritenkirche, 21.05. 1959-18. 10. 1959, Wien 1959, S. 36-54, hier S. 52 f. und Kat. Nr. I30 mit Abb. eines Details von fol. Iv. Wenige Jahre später revidierte der Autor seine Meinung und betrachtete das Antiphonar als Werk der Schreier-Werkstatt nach I480. G. Sснміdт, Die Buchmalerei, in: Die Gotik in Niederösterreich. Kunst und Kultur einer Landschaft im Spätmittelalter, bearbeitet von F. DwOrschaK/H. KüHNEL, Wien 1963 , S. I08, Nr. II7.

II Wien, Österreichische Nationalbibliothek (ÖNB), Cod. 1946 (sogenanntes Morandus-Offizium Kaiser Friedrichs III.). Die I482 datierte Handschrift wurde in weiterer Folge aus der Werkgruppe um das Koloman-Antiphonar ausgegliedert und als Referenzhandschrift eines mutmaßlich Wiener Buchmalers mit dem Notnamen Morandus-Meister betrachtet. Zur Trennung der Werkgruppen und Benennung des MorandusMeisters, dem Holter neben dem Morandus-Offizium die Ausstattung der Inkunabel Wien, ÖNB, Ink. 25.D.5 zuwies: K. Holter, Zwei spätgotische Dominikaner-Gradualien in Wien. Ein Beitrag zur Nachwirkung des Salzburger Miniators Ulrich Schreier, in: Von österreichischer Kunst. Franz Fuhrmann gewidmet, Klagenfurt 198I, S. 43-54, hier S. 49 ff. und Abb. 6-7. Haidinger bekräftigte die Händescheidung zwischen dem Illuminator des Koloman-Antiphonars und dem Morandus-Meister und wies die Beteiligung des Letzteren zusätzlich an der Ausstattung der Handschriften CCl I028, CCl II93 und CCl II95 in der Stiftsbibliothek Klosterneuburg nach. Haidinger, Klosterneuburg (zit. Anm. 6), S. 67. Demselben Buchmaler konnte Beier auch die Buchmalerei in Graz, Universitätsbibliothek (UB), Cod. 459 zuweisen und Wien als wahrscheinlichen Wirkungsort postulieren. BeIER, Universitätsbibliothek Graz (zit. Anm. 5), S. 6I Kat. I6. Zum Stifter bzw. Auftraggeber des Morandus-Offiziums: K.-G. Pfändtner, Die Handschriften des Lehrbüchermeisters, in: Codices Manuscripti Supplementum 4, Purkersdorf 20II, hier S. 36, Anm. 217 sowie ders. /A. Haidinger, Ain pergamene geschribne tafel die anfaht mit dem a.b.c. etc. und pater noster in rot gepunden mit pucklen von praiten donat plettern. Das ABC-Lehrbuch für Kaiser Maximilian I. (Faksimile-Ausgabe Codex 2368 der Österreichischen Nationalbibliothek Wien), Graz 2004, S. 53, Anm. 273. Des Weiteren können die Inkunabeln Ink. 4.G.7 (mit Besitzwappen von Wiguleus Fröschl von Marzoll, der in den I48oer-Jahren in Wien residierte), Ink. 2.E.4 und Ink. 25.C.23 in der ÖNB in Wien sowie ein Handschriftenfragment in Zweitverwendung als Einband in Kremsmünster, Stiftsbibliothek, $2^{\circ} \mathrm{Kb}$ 49, dem Werk des Morandus-Meisters zugeordnet werden.

I2 Wien, ÖNB, Ink. I8.A.I3, Bd. 2 und 3, Ausstattung 148I datiert, Druck: GW 2186, Antoninus Florentinus, Summa theologica. Nürnberg, Anton Koberger, I977-I479; Gesamtkatalog der Wiegendrucke (GW), hrsg. von der Kommission für den Gesamtkatalog der Wiegendrucke, Bd. I-II, Leipzig 1925-I940 und Stuttgart/ New York 1968-2003 (2. Aufl., durchgesehener Neudr. der I. Aufl. von Bd. I-7 und Bd. 8-II). URL: http:// www.gesamtkatalogderwiegendrucke.de [II. 02.20I4].

I3 Klosterneuburg, Stiftsbibliothek, CCl 612 mit I479 datiertem Kolophon des Schreibers, Chorherr Hieronymus Sitznberger im Augustiner-Chorherrenstift Klosterneuburg.

I4 Schмidt, Buchmalerei Niederösterreich (zit. Anm. Io), Kat. Nr. I30.

I5 Es handelt sich um St. Florian, Stiftsbibliothek, Ink. X/IO7 (GW 2186: Antoninus Florentinus, Summa theologica. Nürnberg, Anton Koberger, I977-I479); Ink. X/282 (GW II459: Gregor IX., Decretales. Venedig, Nicolas Jenson, 8. V. I479) und Ink. X/289 (GW 7108: Clemens V., Constitutiones. Venedig, 


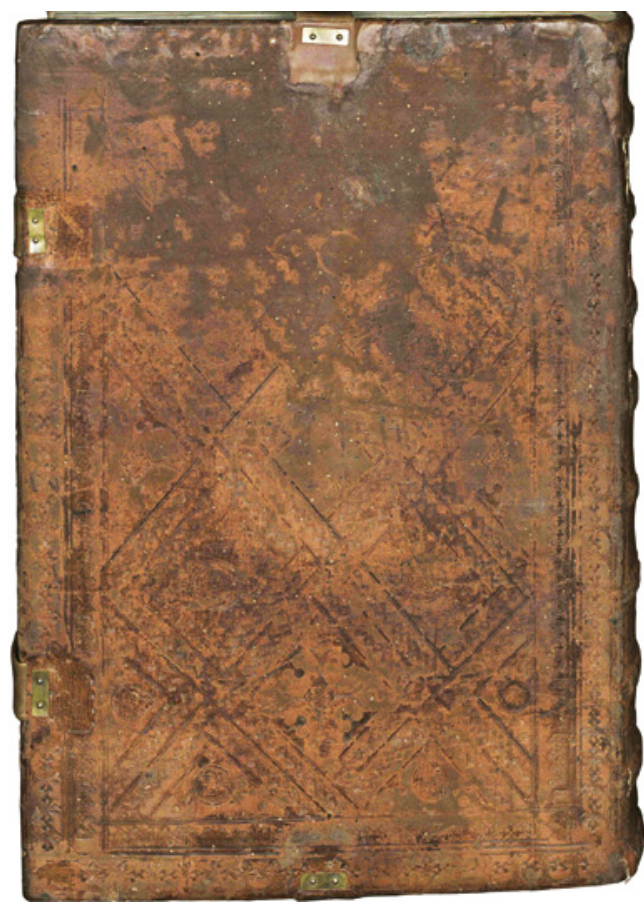

Abb. 2: St. Pölten, Diözesanbibliothek, Cod. I (Koloman-Antiphonar), Einband, Hinterdeckel
Wappens des Stiftes und des Datums I48I in zwei dieser Codices ${ }^{16}$ sind sowohl Auftraggeber als auch Entstehungsdatum gesichert überliefert, jedoch äußerte der Autor die Vermutung, dass es sich um einen Wandermaler handeln könnte, da das Werk nicht aus der lokalen Kunsttradition des Stiftes zu erklären sei. Die Verbindung der St. Florianer Inkunabeln zum St. Pöltener Antiphonar, dem Klosterneuburger Missale und den Dürnsteiner Inkunabelbänden leitete er aus der gemeinsamen Ordenszugehörigkeit der Augustiner-Chorherrenstifte ab, die um I480 offenkundig als Auftraggeber des Buchkünstlers fungierten.

Die zahlreichsten überlieferten Buchausstattungen führte der Buchkünstler zwischen I478 und I482 für das Augustiner-Chorherrenstift Dürnstein aus. Neben den zwei von Schmidt zugeschriebenen Bänden der Österreichischen Nationalbibliothek in Wien wurde er mit der Hauptdekoration von weiteren sechs Inkunabelbänden beauftragt, wel-

che Besitzvermerke der Dürnsteiner Stiftsbibliothek aus dem I5. Jahrhundert aufweisen und vom Illuminator selbst datiert wurden (Abb. 7-IO und I6). ${ }^{17}$ Nach Passau verweisen wiederum zwei Inkunabeln aus den Beständen der dortigen Staatlichen Bibliothek, wobei der Illumina-

Johann von Köln und Johann Manthen, 7. VI. I479). - K. Holter, Die spätmittelalterliche Buchmalerei im Augustiner-Chorherrenstift St. Florian, in: Oberösterreichische Heimatblätter 40, I986, S. 30I-324, hier S. 315 f. und Abb. 38-40.

I6 Dies sind St. Florian, Stiftsbibliothek, Ink. X/282 und Ink. X/289. Holter, Buchmalerei St. Florian (zit. Anm. I5).

I7 Wien, ÖNB, Ink. 2.C.2 Bd. I (GW M36924: Rainerius de Pisis, Pantheologia. Mit Praefatio von Jacobus Florentinus. [Basel: Berthold Ruppel, I477/79]) datiert I478; Wien, ÖNB, Ink. I6.A.23 (GW 2751: Astesanus, Summa de casibus conscientiae. [Straßburg: Johann Mentelin, nicht nach I473]) datiert I479; Wien, ÖNB, Ink. 6.A.I4 (GW 2885: Aurelius Augustinus, De civitate dei. Mit Komm. von Thomas Waleys und Nicolaus Trivet. Basel, Michael Wenssler [und Bernhard Richel], 25. III. I479.) datiert I48I; Wien, ÖNB, Ink. Io.A.20 (GW M36940: Rainerius de Pisis, Pantheologia. Mit Praefatio von Jacobus Florentinus. [Nürnberg], Anton Koberger, I2. II. I477) datiert I482; Wien, ÖNB, Ink. I7.D.I5 (GW II946: Guillermus, Postilla super epistolas et evangelia. Nürnberg, Anton Koberger, I48I); Budapest, Szécsényi Nationalbibliothek, Ink. IOo (GW M50560: Vincentius Bellovacensis, Speculum doctrinale. [Straßburg: Adolf Rusch, um I478]) datiert I48I. Zur Provenienz: Tıғ, Buchkunst Dürnstein (zit. Anm. 7), S. 65 ff. mit Abb. 49-56 zu den Dürnsteiner Bänden des Illuminators des Koloman-Antiphonars. 
tor die eine für ein Mitglied der Familie Überacker ${ }^{18}$ (Abb. I3) und die andere für das Augustiner-Chorherrenstift St. Nikola ${ }^{19}$ (Abb. I4-I5) dekorierte. ${ }^{20}$

Neben Klosterneuburg, St. Pölten, Dürnstein und St. Florian ist St. Nikola das fünfte Augustiner-Chorherrenstift, welches Aufträge zur Buchausstattung an diesen Buchkünstler vergab. Dass seine Tätigkeit nicht ausschließlich auf den Orden beschränkt war, belegen einige wenige überlieferte Codices mit anderen Besitzmerkmalen, wie etwa das Wappen der vorhin erwähnten Überacker, sowie eine Inkunabel in der Göttweiger Stiftsbibliothek, welche das Familienwappen der Kuenringer im Deckfarbenschmuck aufweist (Abb. 6). ${ }^{21}$ Der kaiserliche Sekretär und Pfarrer in Unternalb bei Retz, Thomas Nieschensteiner, ist wiederum als Erstbesitzer einer 1482 vom Illuminator des Koloman-Antiphonars illuminierten Inkunabel (Abb. I6) eingetragen, welche noch im I5. Jahrhundert in die Dürnsteiner Stiftsbibliothek überführt wurde. ${ }^{22}$ Einzelpersonen gehörten demnach durchaus zum Kundenkreis des Illu-

I8 Passau, Staatliche Bibliothek, Ink. 28 (GW II459: Gregor IX., Decretales. Venedig, Nicolas Jenson, 8. V. I479). Das Wappen in der rechten Randleiste auf Bl. aza ist das Familienwappen der Überacker in Passau. Vgl. Siebmacher Wappenbuch 1605, Bayrische 94/3. Möglicherweise handelt es sich dabei um den Dekan des Passauer Bistums, Petrus Überacker, welcher 1478 die ebenfalls vom Illuminator des Koloman-Antiphonars ausgestattete Ink. 2.C.2, Bd. I der Wiener ÖNB dem Dürnsteiner Augustiner-Chorherrenstift schenkte. Näheres zum Donationsvermerk bei Tif, Buchkunst Dürnstein (zit. Anm. 7), S. 64, Abb. 50 und $68 \mathrm{ff}$.

I9 Passau, Staatliche Bibliothek, Ink. 26 (GW Mig2Is Ludolphus de Saxonia, Vita Christi. Nürnberg: Anton Koberger, 20. XII. 1478). Der überlieferte Einband weist folgende Stempel des Augustiner-Chorherrenstifts Passau auf: EBDB woo23OI (so29589, s029588, s029592, s029604, s029590, s029595, s029593, s02959I, soI8332, s029603, s029594). Einbanddatenbank gefördert durch die Deutsche Forschungsgemeinschaft (EBDB), URL: http://www.hist-einband.de [II. 02. 20I4].

20 Die Erstzuschreibung des Buchschmucks in den Passauer Inkunabeln an den Illuminator des Koloman-Antiphonars: Schuller-Juckes, Ulrich Schreier (zit. Anm. 4), Anm. 364.

2I Göttweig, Stiftsbibliothek, Ink. I47 (GW M20099: Junianus Maius, Liber de priscorum proprietate verborum. Treviso, Bernhard von Köln, I477). Für den freundlichen Hinweis zur Bestimmung des Wappens auf Bl. aza und zur Deutung des Kuenringer Buchbesitzes danke ich Andreas Zajic. Zu den Kuenringer-Wappen siehe K. Brunner, Die Kuenringer. Das Werden des Landes Niederösterreich, Ausstellungskatalog, Zwettl, Stift Zwettl (Niederösterreichische Landesausstellung), I6. 05. 198I-26. I0. 198I, Wien 198I, S. 43 ff. Da es sich um ein Grammatikbuch handelt, liegt die Vermutung nahe, dass es ursprünglich als Lehrbuch zur Ausbildung eines Kuenringer Familienmitglieds gedient hatte. Über dem Kolophon befindet sich ein Kaufvermerk des Johannes Schütz und seiner Frau Barbara, Tochter des Wiener Bürgers Thomas Durchzieher, die als Zweitbesitzer zu verstehen sind.

22 Ob die Deckfarbenmalerei auf fol. 33r und 34r im Auftrag Nieschensteiners oder der Dürnsteiner Chorherren ausgeführt wurde, kann nicht mit Sicherheit festgestellt werden. Wien, ÖNB, Ink. Io.A.2o Bd. I (GW M36940: Rainerius de Pisis: Pantheologia. Mit Praefatio von Jacobus Florentinus. [Nürnberg], Anton Koberger, I2. II. I477); vgl. auch Anm. 17. Aus dem Besitz Thomas Nieschensteiners wurden im I5. Jahrhundert zwei mehrbändige Druckwerke von der Stiftsbibliothek in Dürnstein übernommen. Hierbei sind die Besitzvermerke des Erstbesitzers getilgt und durch Besitzeinträge des Stifts ersetzt worden. Zwei Inkunabelexemplare belegen diesen Vorgang: Wien, ÖNB, Ink. Io.A.20, Bd. I. Sie weist einen mittelalterlichen Blindstempeleinband mit dem Wappenstempel des Benediktinerklosters Melk, einen schriftlichen Besitzeintrag von Thomas Nieschensteiner und dessen Wappenbild in Deckfarben und Gold auf, allerdings von einer anderen Hand ausgeführt als die I482 datierte Dekoration des Illuminators des Koloman-Antiphonars. Sowohl aufgrund der kurzen Zeitspanne zwischen dem Druckjahr I477 und dem Jahr I482 für die Buchmale- 


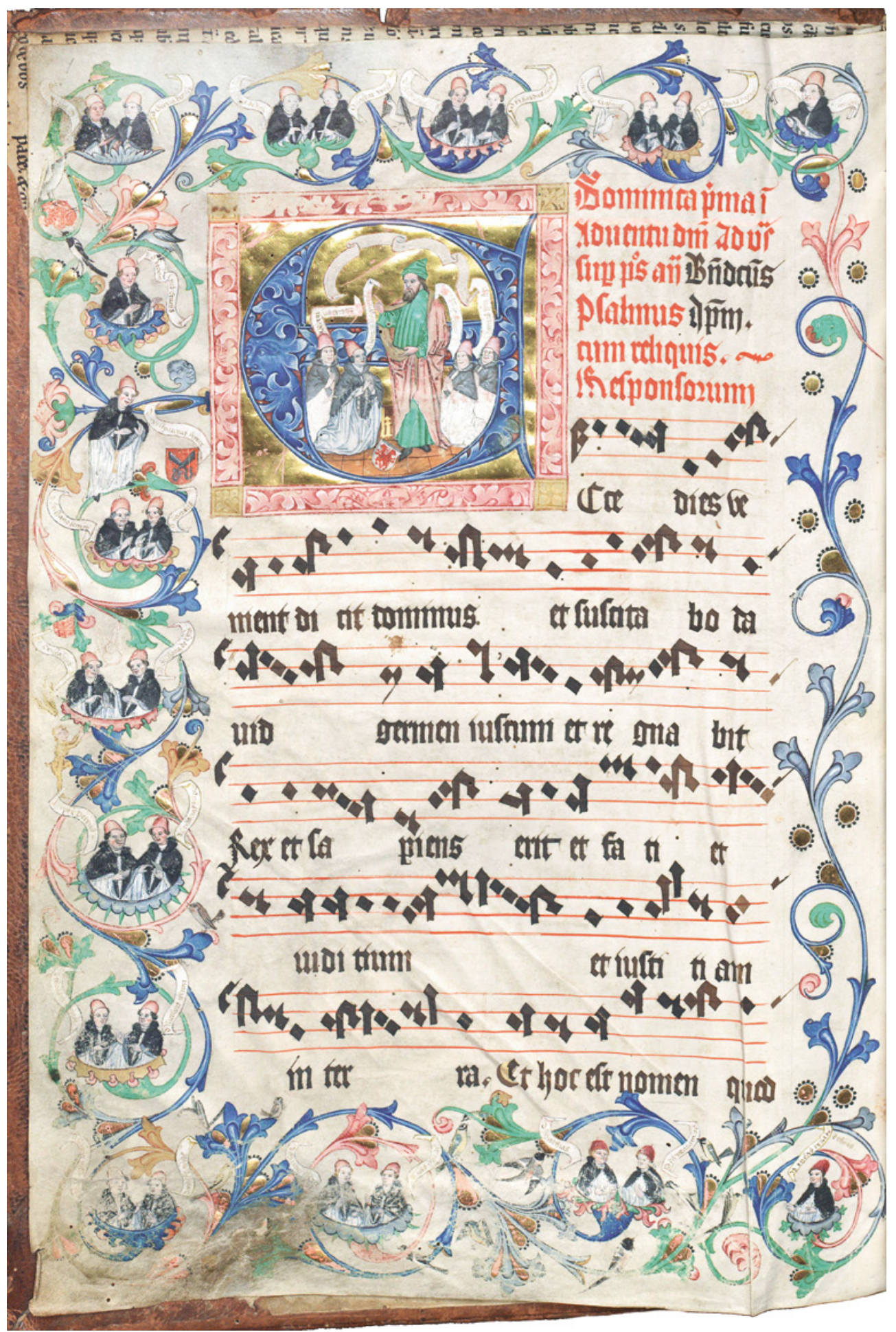

Abb. 3: St. Pölten, Diözesanbibliothek, Cod. I (Koloman-Antiphonar), fol. Iv 
Abb. 4: St. Pölten,

Diözesanbibliothek, Cod. I

(Koloman-Antiphonar), fol. 39rv

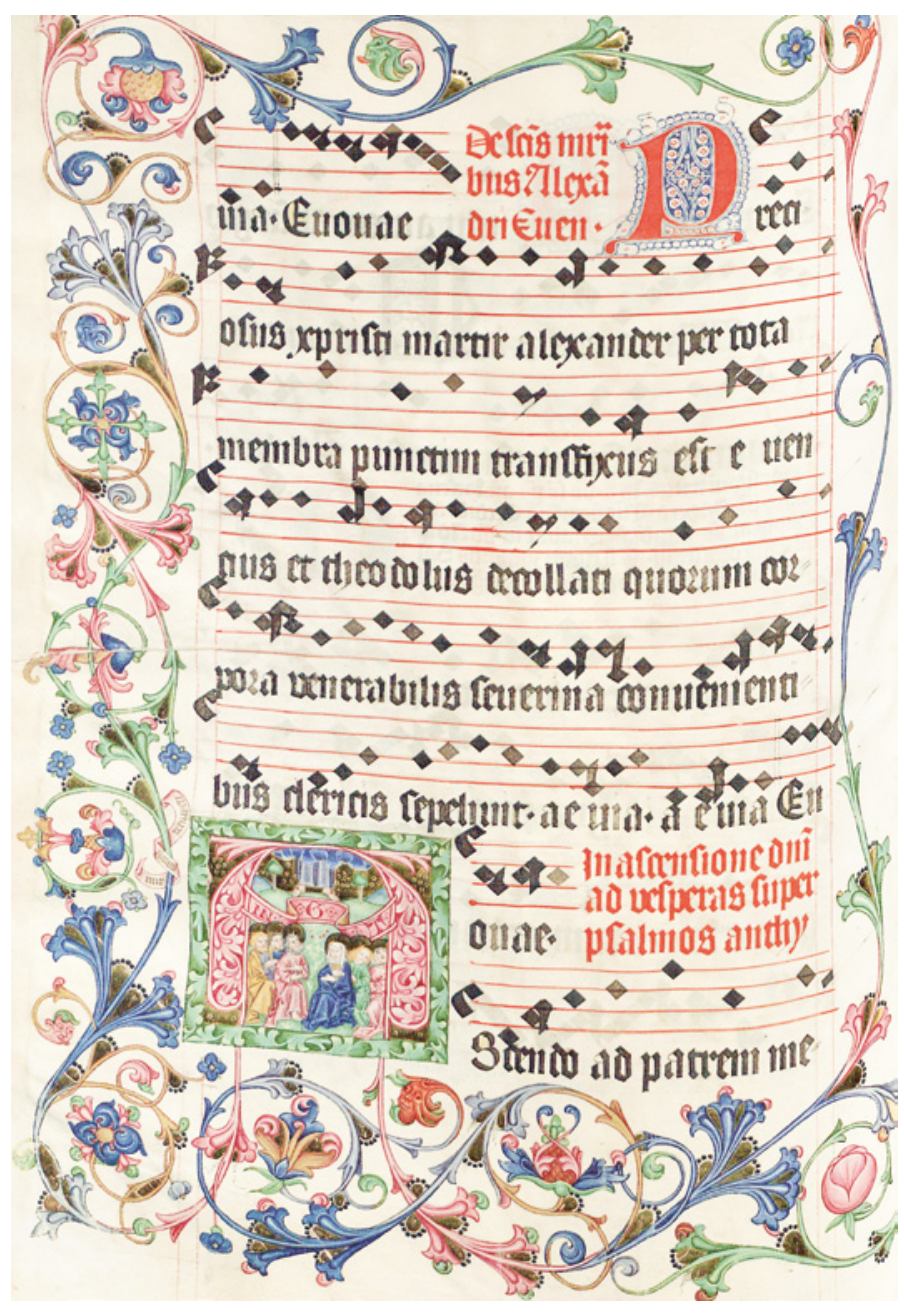

minators, auch wenn dessen künstlerische Tätigkeit hauptsächlich von den Augustiner-Chorherren gefördert wurde.

Bei einigen Werken konnte die Frage nach der mittelalterlichen Provenienz bislang nicht geklärt werden. Die Zuschreibung erfolgte in diesen Fällen nach stilistischen Kriterien. Einige Anhaltspunkte geben jedoch zusätzlich Sicherheit bei der Werkzuweisung. Hierzu gehört un-

rei als auch in Anbetracht des Melker Einbandes ist es wahrscheinlicher, dass Nieschensteiner Auftraggeber für die Ausstattung war. Die zweite Inkunabel: Nürnberg, Stadtbibliothek, Inc. 505.2 $2^{\circ}$ war ursprünglich der erste Band von Wien, ÖNB, Ink. I8.A.I3, bevor er in der Wiener Hofbibliothek wohl im I9. Jahrhundert durch den derzeitigen Band ausgetauscht wurde, um offenkundig mittels einer Auktion in die Inkunabelsammlung des Nürnberger Fabrikanten Carl Kempe zu gelangen, woher der Codex 1940 in die Nürnberger Stadtbibliothek kam. Der genaue Zeitpunkt der Überführung dieser Codices in die Dürnsteiner Bibliothek ist nicht bekannt. Sie wurden jedoch noch im I5. Jahrhundert mit Besitzvermerken des Stiftes gekennzeichnet. Vgl. die Provenienzangaben für die Nürnberger Stadtbibliothek in INKA 27000I5I. Eberhard Karls Universität Tübingen, Inkunabelkatalog (INKA), URL: http://www.inka.uni-tuebingen.de [II. 02. 20I4]. 


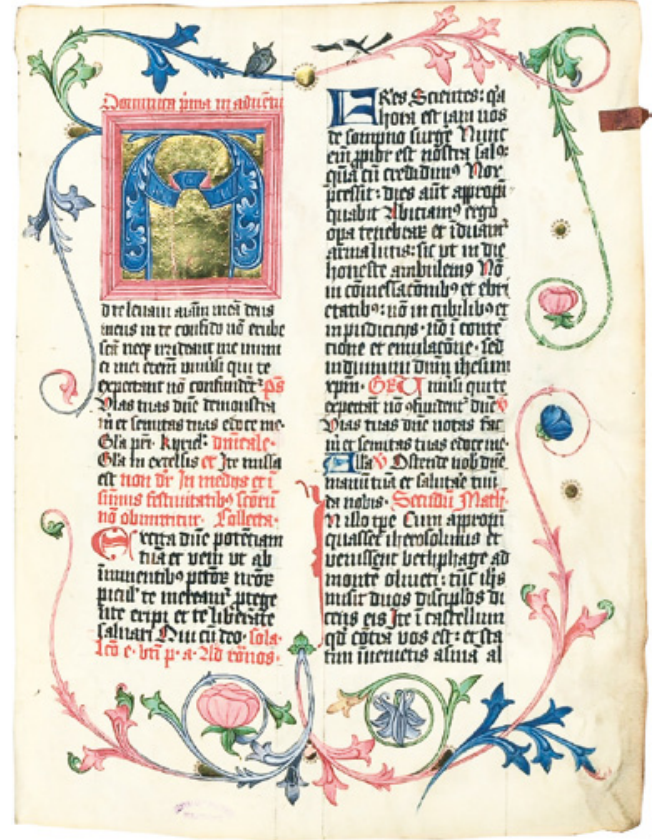

Abb. 5: Alba Iulia, Biblioteca Națională a României, Filiala Batthyaneum, Ms. II-3, fol. 7r ter anderem das gelegentliche Vorkommen der Buchstabenkombination „MGT“, welche sich als Abkürzung des Spruches „Mit ganzer Treue“ auflösen lässt. ${ }^{23}$ Dieses Motto findet sich zunächst in den historisierten Initialen des Koloman-Antiphonars auf fol. Iv (Abb. 3), fol. 2I8v und 39Iv (Abb. 4), wobei es in einem Schriftband unmittelbar neben der zuletzt erwähnten Initiale einmal vollständig ausgeschrieben wurde. Die gekürzte Form verwendete der Illuminator ein weiteres Mal in der A(d te levavi)-Initiale eines Passauer Missales (Abb. 5) in der Batthyaneum-Bibliothek, das als ein Hauptwerk des Buchmalers zu betrachten ist, nicht zuletzt aufgrund des Kanonblattes, welches die einzige überlieferte großformatige Miniatur des Künstlers zeigt. ${ }^{24}$ Nach stilistischen Kriterien schrieb Alois Haidinger ein weiteres Missale in der Stiftsbibliothek Heiligenkreuz dem Illuminator des Koloman-Antiphonars zu, dessen frühe Provenienz unklar ist. ${ }^{25}$ Auch in dieser Handschrift ist die abgekürzte Devise „MGT“ in einem Spruchband auf fol. Io6r zu finden. Der Heiligenkreuzer Codex darf mit seinen zahlreichen historisierten Initialen als figurenreichste und deshalb auch prunkvollste bekannte Arbeit des Künstlers gelten. Schließlich wurden drei Stellen auf dem Querbalken der Deckfarbeninitiale in der bereits erwähnten Kuenringer Inkunabel (Abb. 6) zu einem unbestimmbaren Zeitpunkt ausgekratzt, wobei ein Vergleich mit der Initiale im Batthyaneum-Missale (Abb. 5) nahelegt, dass es sich sehr wahrscheinlich um die „MGT“-Schriftzeichen handelte.

23 TIF, Buchkunst Dürnstein (zit. Anm. 7), S. 7ıf.

24 Alba Iulia, Batthyaneum, Ms. II-3. Für den Hinweis auf den Codex gilt mein Dank Regina Cermann. Der Kalender weist Festtage (zum Beispiel die in August in Rot eingetragenen Inventio S. Steffani/Translatio S. Valentini ep. / Dedicatio ecclesiae Pataviensis) auf, welche eindeutig den Gebrauch in der Passauer Diözese belegen. Der mittelalterliche Blindstempeleinband weist Passauer Stempelmaterial auf: EBDB (zit. Anm. I9): woo2404 (sol6372), woo3153 (so25449, s03165I), woo2402 (sor6208, sol570I). Da die Stempel EBDB so25449 und s03165I dem Passauer Nikolauskloster zugeordnet werden, vermute ich das Augustiner-Chorherrenstift als Auftraggeber.

25 Heiligenkreuz, Stiftsbibliothek, Cod. Neukloster A 4. Der Codex gehörte ursprünglich nicht zum Heiligenkreuzer Buchbestand, sondern wurde im Zuge der Aufhebung des Zisterzienserklosters Neukloster in Wiener Neustadt erst im 20. Jahrhundert dorthin überführt. Der Besitzvermerk „Ex bibliotheca Gwisiana“ auf dem Spiegel des Einbandvorderdeckels konnte noch nicht geklärt werden. Ein Eintrag des 17. Jahrhunderts auf dem Spiegel des Einbandhinterdeckels deklariert die Handschrift als Konstanzer Missale, allerdings scheint diese Zuweisung problematisch. Haidinger, Klosterneuburg (zit. Anm. 6), S. 60 und Fig. 33. 
Überliefert sind auch nicht fertiggestellte Werke des Illuminators, deren mittelalterliche Besteller ebenfalls unbekannt bleiben. Dazu gehört zunächst eine Inkunabel, die als Adligat verschiedener 1482 in Nürnberg gedruckter juristischer Texte in der Sammlung des Zisterzienserstifts Zwettl zu finden ist (Abb. 17). ${ }^{26}$ Aus welchen Gründen die für die buchmalerische Ausschmückung leer gelassenen Felder auf fol. Ir und II5r (Abb. I7) vom Illuminator nicht vollständig ausgemalt wurden und lediglich auf Initialen und Ranken auf dem Bas-de-page beschränkter Buchschmuck vorliegt, lässt sich nicht ausmachen. Sehr wahrscheinlich war eine mit den juristischen Inkunabeln in St. Forian vergleichbare Ausstattung vorgesehen, jedoch nicht fertiggestellt worden. ${ }^{27}$

Des Weiteren sind einige Handschriftenfragmente von Chorbüchern mit Malerei des Illuminators des Koloman-Antiphonars in Sammlungen in Moskau, Santa Barbara (Kalifornien), New York, London und München erhalten. Zunächst wies Ekaterina Zolotova auf die Verwendung druckgrafischer Vorlagen von Israhel von Meckenem und Meister E. S. in mehreren Fragmenten eines Graduales hin, die in den Sammlungen der Staatsbibliothek in Moskau und in der Mark Lansburgh Collection in Santa Barbara (Kalifornien) aufbewahrt werden. ${ }^{28}$ Die bei Zolotova abgebildeten Werke waren schließlich dem donauösterreichischen Künstler zuzuweisen. ${ }^{29}$ Bedauerlicherweise sind die Wappenfelder auf der Incipit-Seite des Graduales leer geblieben, wodurch der Adressat der Handschrift nicht überliefert ist. Da es sich aber um ein Chorbuch handelte, darf dieser mit Sicherheit im kirchlichen Bereich angenommen werden. Weitere Fragmente eines Antiphonars mit Buchschmuck des Buchmalers haben sich in München, London und New York erhalten. ${ }^{30}$

26 Zwettl, Stiftsbibliothek, Cod. typ. I/II (Pars I GW 04868: Bonifaz VIII., Liber sextus Decretalium. Mit der Glosse des Johannes Andreae. Nürnberg, Anton Koberger, I2. III. I482; Pars II GW 07095: Clemens V., Constitutiones. Nürnberg: Anton Koberger, I5. I. I482; Pars III GW 9815: Johannes Petrus de Ferrariis, Practica nova judicialis. Nürnberg, Anton Koberger, 28. II. I482).

27 St. Florian, Stiftsbibliothek, Ink. X/282 und X/289. Vgl. Anm. I5.

$28 \mathrm{Zu}$ den Fragmenten in Moskau, Staatsbibliothek, F 205, fol. I, I2 und I3 sowie zu den entsprechenden Fragmenten in der Mark Lansburgh Collection mit Abbildungen von Details der Buchmalerei: Е. Ю. ЗолотовА [E. J. Zolotova], Книжная миниатюра XV века и гравюра: новые материалы к теме. [Buchminiatur des 15. Jahrhunderts und Kupferstich. Neue Materialien zum Thema], in: Аазаревские чтения. Искусство Византии, Аревней Руси, Западной Европы. Материалы научной конференции 20о8. М. МГУ им. М. В. Һомоносова [Lazarev-Vorlesungen: Byzantinische, altrussische und westeuropäische Kunst. Materialien der wissenschaftlichen Konferenz 2008 der Moskauer Universität Im. M. W. Lomonossow], hrsg. von B. A. ААщина, Е. А. Ефимова [W. D. Dažina/E. A. Efimova], Moskau 2008, S. 25I-265.

29 Tif, Buchkunst Dürnstein (zit. Anm. 7), S. 7I.

30 Die Zusammengehörigkeit der Antiphonarfragmente in London, Victoria \& Albert Museum, Museum No. 276.4-276.17 und in München, Staatliche grafische Sammlung, Inv. Nr. 18847 Z wurde von Pfändtner erkannt, der Buchschmuck zunächst nach Mainz lokalisiert und um I490 datiert. K.-G. Pfändtner, Das große Puzzle„cuttings“ und illuminierte Handschriften-Fragmente, in: K. G. Beuckers/C. Jobst/S. Westphal (Hrsg.), Buchschätze des Mittelalters. Forschungsrückblicke - Forschungsperspektiven [Beiträge zum Kolloquium des Kunsthistorischen Instituts der Christian-Albrechts-Universität zu Kiel vom 24. bis zum 26. April 2009], Kiel 2009, S. 28I-292, hier S. 287 und Abb. 6-7. Es handelt sich allerdings um ein Werk des Illuminators des Koloman-Antiphonars um I480, wobei nicht nur die Deckfarbenausstattung, sondern auch das Fleuronnée von derselben Hand ausgeführt wurde, wie zum Beispiel jenes im Missale in Heiligenkreuz, Stiftsbibliothek, Cod. 


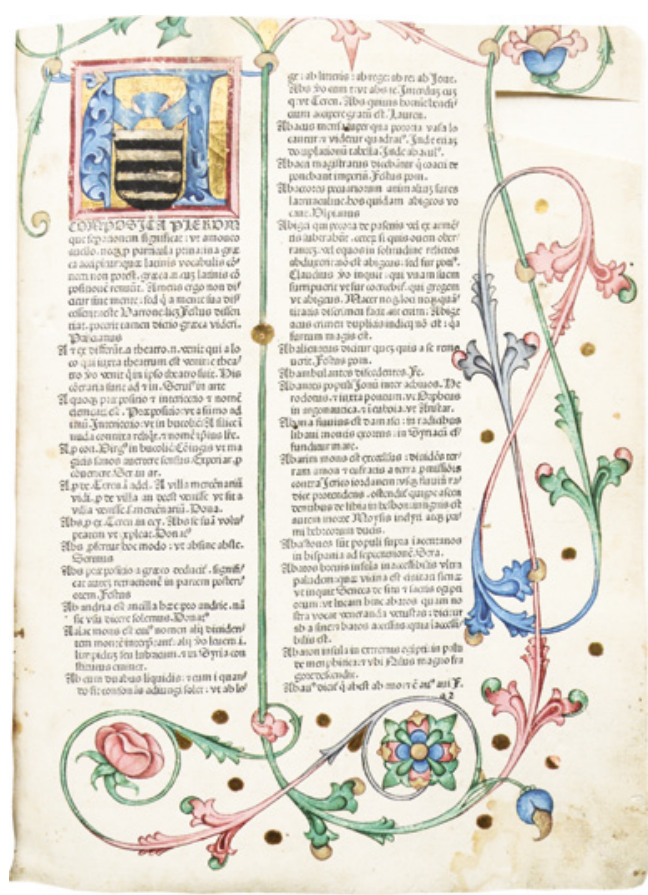

Abb. 6: Göttweig, Stiftsbibliothek, Ink. I47, Bl. a2a

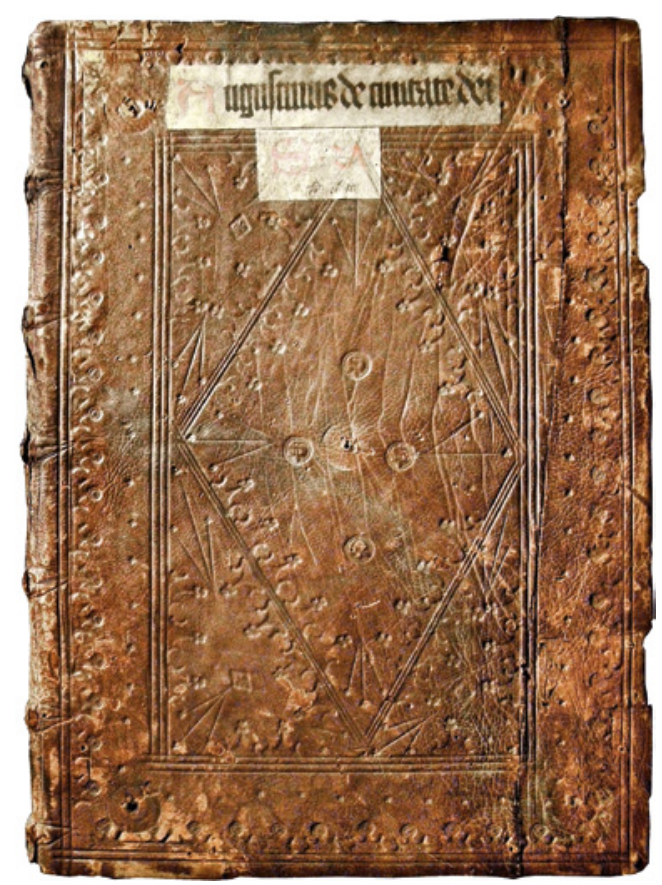

Abb. 7: Wien, Österreichische Nationalbibliothek, Ink. 6.A.I4, Einband, Vorderdeckel

Es kann festgehalten werden, dass in erster Linie die Augustiner-Chorherren in Klosterneuburg, St. Pölten, Dürnstein, St. Florian und Passau die Klientel dieses Buchausstatters bildeten. Die illuminierten Codices waren entweder für den Chorgebrauch bestimmt, oder sie enthielten durchweg theologische und juristische Texte, die im monastischen Bereich benutzt wurden. Der Passauer Dekan Petrus Überacker ließ I480 seinen „Vita Christi“-Druck offensichtlich für den Eigengebrauch illuminieren, allerdings war er zwei Jahre davor der großzügige Schenker einer prunkvoll ausgemalten „Pantheologia“-Ausgabe an das Dürnsteiner Stift. Der kaiserliche Sekretär Thomas Nieschensteiner konnte wiederum als Erstbesitzer zweier Inkunabeldrucke identifiziert werden, die aber noch im 15. Jahrhundert in Dürnsteiner Besitz überwechselten. Auch wenn die Auftraggeber der nur fragmentarisch überlieferten Chorbücher (Antiphonar und Graduale) und der zwei Missalien in Heiligenkreuz und Alba Iulia nicht bekannt sind, so handelt es sich doch eindeutig um Handschriften, die ohne Zweifel für den

Neukloster A 4. Die Initiale mit Profilmasken von London, Victoria \&Albert Museum, Museum No. 276.9 weist nicht nur dieselben kalligraphischen Fleuronnée-Elemente des Florators in der Heiligenkreuzer Handschrift auf, sondern sie zeigt auch eine charakteristische Konzeption von karikaturhaften, mit Hut bedeckten Köpfen und überzeichneten hochstehenden Nasen, welche nur aus der Tradition der Schreier-Werkstatt erklärt werden kann. Zum Fleuronnée der Schreier-Werkstatt: Schuller-Juckes, Ulrich Schreier (zit. Anm. 4), S. 9r ff. Ein weiteres Antiphonarfragment vom Illuminator des Koloman-Antiphonars befindet sich in Zweitverwendung als Einband eines Codex in New York, Public Library, MA I3. Die Kenntnis dieses Fragments verdanke ich dem freundlichen Hinweis von Regina Cermann. 
Abb. 8: Wien, Österreichische Nationalbibliothek, Ink. 6.A.I4, fol. 2 r

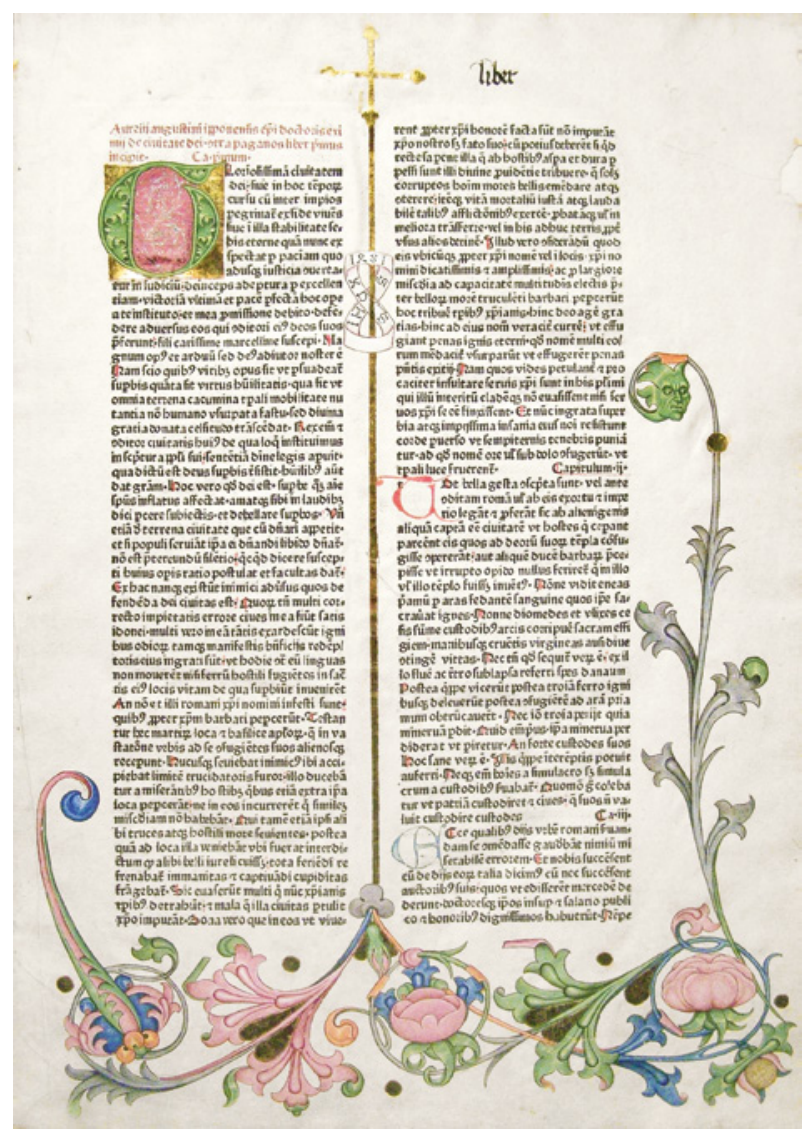

kirchlichen Gebrauch bestimmt waren. In mancherlei Hinsicht stellt das Grammatikbuch im Kuenringerbesitz eine Ausnahme dar, jedoch war Elisabeth von Kuenring eine der zentralen Stifterfiguren von Dürnstein, wodurch unmittelbare Beziehungen zwischen dem Stift und den Kuenringern existierten. ${ }^{31}$ Zusammenfassend darf daher festgehalten werden, dass der gesamte Kundenkreis des Illuminators des Koloman-Antiphonars zwischen I478 und I488 im Umfeld der Augustiner-Chorherrenstifte entlang der Donau verankert werden kann.

Dass der Buchmaler bei der Erstellung seiner Werke gerne auf Kupferstichmotive zurückgriff, bezeugt zum Beispiel die Darstellung des Heiligen Andreas im Binnenfeld der Initiale auf Bl. aza der Überacker-Inkunabel von I480 in Passau (Abb. I3), die nach einem Stich des Meisters E.S. (L 94) ausgeführt wurde. ${ }^{32}$ Nicht nur figurale, sondern auch Blumen- und Tiermotive für die Rankenornamente des Illuminators können auf druckgrafische Vorlagen

3I Siehe Anm. 2I und A. ZajIC/M. Roland, Eine spätmittelalterliche Urkundenfälschung aus dem AugustinerChorherrenstift Dürnstein in Niederösterreich. Zugleich ein Beitrag zu illuminierten Urkunden des Mittelalters, in: Archiv für Diplomatik 5I, 2005, S. 33I-432, hier S. 338.

32 Zur Kupferstichvorlage des Meisters E.S. siehe die Darstellung des Heiligen Andreas bei Lehrs 94 (St. Petrus und St. Andreas) mit Abbildung bei H. Appunn, Meister E. S. Alle 320 Kupferstiche, Dortmund I989, Abb. 126. 


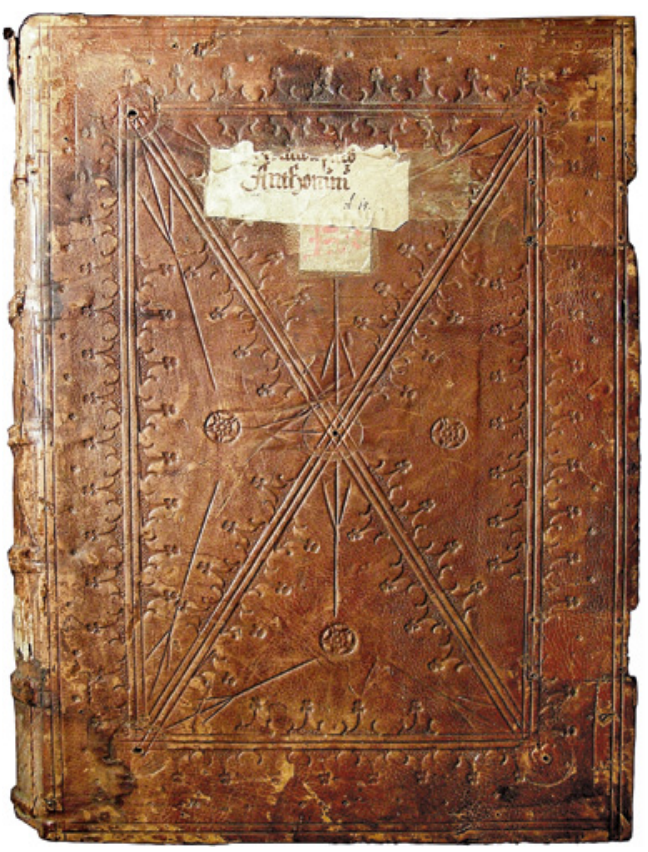

Abb. 9: Wien, Österreichische Nationalbibliothek, Ink. I8.A.13 Bd. 2, Einband, Vorderdeckel zurückgeführt werden. Sehr beliebt waren offenkundig die unterschiedlichen Rosenvarianten aus Kupferstichen des Meisters der Spielkarten (G 34 und G 35), die vielfach in das buchmalerische Werk des Buchausstatters übernommen wurden. ${ }^{33}$ Diese technische Usance führte schließlich zu einem Stilpluralismus, welcher vor allem in der zweiten Hälfte des I5. Jahrhunderts in der Buchmalerei im deutschsprachigen Kulturraum auf ähnliche Weise bei unterschiedlichen Künstlern relativ häufig zu beobachten ist. Im unmittelbaren Umfeld des Illuminators konnte dieses Phänomen unter anderem beim sogenannten Meister des Friedrichbreviers und bei Ulrich Schreier festgestellt werden. ${ }^{34}$

In der Tradition des Salzburger Buchkünstlers Ulrich Schreier stehen zudem die sowohl im Rankenwerk (Abb. 3, 4, 8, Io und I6) als auch gelegentlich in Blattfüllungen der Buchstabenkörper der Initialen (Abb. 3) vor-

kommenden Blattmasken, welche karikaturhaft individualisierte Gesichtszüge aufweisen. ${ }^{35}$ Diese Charakterköpfe, welche aus den vegetabilen Ornamenten entwickelt werden, sind wie ein Markenzeichen des Buchmalers und erleichtern die Identifizierung seiner künstlerischen Tätigkeit. Auf Schreier zurückzuführen ist außerdem die häufige Anbringung von Schriftbändern und die bei mittelalterlichen Buchmalern verhältnismäßig selten anzutreffende Angewohnheit, ihr Werk mit einer gewissen Konsequenz eigenhändig zu datieren. Im Gegensatz zum Salzburger Künstler, der eine sehr weiche Modellierung der vegetabilen Dekoration und ein pastellfarbenes Kolorit verwendet, wirken die durchaus plastischen Formen des Illuminators des Koloman-Antiphonars metallisch, hart geschnitten und stark stilisiert, wobei er kräftige, leuchtende

33 Unter den unzähligen Beispielen an Übernahmen von Varianten der Rosenmotive aus Kupferstichen des Meisters der Spielkarten (Geisberg 34 und 35) im Werk des Illuminators des Koloman-Antiphonars seien hier folgende genannt: Wien, ÖNB, Ink. 2.C.2, Bd. I, fol. 33r; Wien, ÖNB, Ink. 6.A.I4, fol. 2r; Wien, ÖNB, Ink. I6.A.23, fol. Ir; Wien, ÖNB, Ink. I8.A.ı3, Bd. 2, fol. 2r; Wien, ÖNB, Ink. I8.A.ı3, Bd. 3, Tit. I Cap. I; Wien, ÖNB, Ink. Io.A.2o, Bd. I, fol. 34r; St. Florian, Ink. X/289, Bl. aza; Passau, SB, Ink. 26, Bl. aza; St. Pölten, Diözesanbibliothek, Cod. I, fol. 39Iv; Klosterneuburg, Stiftsbibliothek, CCl 6I2, fol. IIr und I48r; sowie Göttweig, Stiftsbibliothek, Ink. I47, Bl. a2a.

34 Schmidt, Stile (zit. Anm. 4). Zur Verwendung druckgrafischer Vorlagen bei Ulrich Schreier: SchullerJuckes, Ulrich Schreier (zit. Anm. 4), S. iss ff.

35 Für Vergleiche aus dem Werk Ulrich Schreiers sei zum Beispiel auf Salzburg, UB, W III 36, Bl. aza und W III 38, datiert 1477 verwiesen. Abbildungen von beiden Codices finden sich im Webauftritt der UB Salzburg, URL: http://www.ubs.sbg.ac.at/sosa/webseite/schreier.htm [II. 02. 20I4]. 
Farben und starke Kontraste bevorzugt. Sein gesamtes künstlerisches Repertoire ist jedoch eindeutig von Schreier entlehnt, dessen Einbandkunst er mit seinem Werk ebenfalls fortsetzt.

\section{E I N B A N D K U NST}

Die Methodik der Einbandkunde ist zum überwiegenden Teil darauf ausgerichtet, Abreibungen von Einzelstempeln statistisch auszuwerten und Stempeltabellen von Buchbinderwerkstätten zu erstellen, um diese anhand überlieferter Provenienzdaten zu lokalisieren. Seltener sind Untersuchungen zu spezifischen Layouts mittelalterlicher Blindstempeleinbände. ${ }^{36}$ Solche Analysen werden hauptsächlich an Lederschnitteinbänden durchgeführt, da diese näher am Bild und seinen Gestaltungsprinzipien und daher für die Bildwissenschaften interessanter sind. Das ästhetische Gestaltungskonzept eines Buchbinders kann allerdings auch bei Blindstempeleinbänden aufschlussreich sein. Denn auch wenn ein bestimmtes Werkzeug eine Werkstatt nicht verlässt, so kann es dort doch von unterschiedlichen Personen verwendet werden. Bei einem Buchbinder, der ein bestimmtes Gebiet auftragsbedingt bereist, wäre es daher denkbar, dass er seine eigenen Gestaltungsprinzipien des Layouts mit unterschiedlich lokalisierbaren Stempelwerkzeugen umsetzte. Dies scheint meines Erachtens der Fall beim Illuminator des Koloman-Antiphonars zu sein, der offensichtlich auch als Buchbinder tätig war. Durch die Lokalisierung des Stempelmaterials in einer ortsgebundenen Buchbinderwerkstatt und die Zuschreibung der Einbandlayouts an diesen Buchausstatter sollen Ortswechsel aufgezeigt werden, die seine Mobilität nachweisen können.

Als Besonderheit der Dürnsteiner Werkgruppe des Illuminators des Koloman-Antiphonars hat Otto Mazal erkannt, dass die Stiftseinbände derselben Periode datierte Kopfstempel mit den Jahreszahlen I479, I480 und I48I aufweisen. ${ }^{37}$ Aufgrund der Übereinstimmung von

36 Vgl. etwa G. Laurin, Zur Einbandkunst des Salzburger Illuminators Ulrich Schreier, in: Gutenberg-Jahrbuch 34, 1959, S. 299-309. - G. Laurin, Der Salzburger Einbandstil Ulrich Schreiers, in: Gutenberg-Jahrbuch 35, I960, S. 37I-379. - K. Holter, Die mittelalterliche Buchkunst der Chorherrenstifte am Inn, in: 900 Jahre Stift Reichersberg, Augustiner Chorherren zwischen Passau und Salzburg, Ausstellungskatalog, Stift Reichersberg am Inn, 26.04. 1984-28. I0. 1984, Linz 1984, S. 205-231. - O. MAZAL, Datierte gotische Einbände aus dem Augustiner Chorherrenstift Dürnstein an der Donau, in: Gutenberg-Jahrbuch 36, I96I, S. 286-29I. - O. MazAL, Gotische Einbände mit Kopfstempeldekoration aus der Inkunabelsammlung der Österreichischen Nationalbibliothek, in: Gutenberg-Jahrbuch i962, S. 473-481.

Mazal, Datierte Einbände (zit. Anm. 36). Die Einbandstempel der ersten Dürnsteiner Binderwerkstatt oder sogenannten Hauptwerkstatt finden sich erfasst unter EBDB (zit. Anm. 19): woo2542. Die Lokalisierung des Stempelmaterials nach Dürnstein ist gesichert, da die verwendeten datierten Kopfstempel ausschließlich auf Codices mit Dürnsteiner Besitzeinträgen aus dem 15. Jahrhundert vorkommen, wobei zur Bindung von Wien, ÖNB, Ink. I8.A.13, Bd. 2 (mit Kopfstempel von I48I) Dürnsteiner Urkunden und Briefe aus der Zeit vor I469 als Makulatur verwendet wurden. Mazal, Datierte Einbände (zit. Anm. 36), S. 290. Die von Mazal postulierte Anschaffung des Stempelmaterials aus Krems ist nach neuesten Beobachtungen nicht haltbar, weil Friedrich Simader den sogenannten „Fabelwesen“-Stempel EBDB (zit. Anm. I9): soI7825 auf den Einbänden von zwei Wiener Handschriften (Wien, ÖNB, Cod. 4575 und Cod. 4632) um I450 nachweisen konnte. Für den wertvollen Hinweis und die Überlassung der entsprechenden Stempelabreibungen danke ich Friedrich Simader an dieser Stelle. Auch wenn einzelne Stempel offenbar aus Wien nach Dürnstein gebracht wurden, ist die Stempelkombination mit den datierten Kopfstempeln der Dürnsteiner Werkstatt einmalig und darf zur Lokalisierung 
Einbänden und buchmalerischer Ausstattung hinsichtlich Datierung und formaler Herleitung der Gestaltungsformen aus der Werkstatt Ulrich Schreiers äußerte er die These, dass Bindung und Buchmalerei von demselben Buchausstatter ausgeführt sein könnten. ${ }^{38}$ Zwei später entdeckte Dürnsteiner Inkunabeln stimmen mit diesen Beobachtungen ebenfalls überein und untermauern die Vermutungen Mazals. ${ }^{39}$

Insgesamt handelt es sich um sechs Dürnsteiner Inkunabelbände, welche zwischen I 478 und I48I diese Gleichzeitigkeit aufweisen und sowohl in buchmalerischer als auch in buchbinderischer Hinsicht homogene Gruppen bilden, bei welchen die formalen Charakteristika auf denselben gemeinsamen Nenner der Gestaltungsmodi der Werkstätten von Ulrich Schreier zurückzuführen sind. Kennzeichnend für die Blindstempeleinbände der Schreier-Werkstatt (Abb. II) ist vordergründig die Verwendung von Kopfstempeln zur Herausarbeitung von Blattformreliefs, welche durch die zusätzliche Einprägung gebogener oder gerader Streicheisenlinien ein vegetabil geädertes Erscheinungsbild erhalten. Dasselbe Konzept, durch wenige Mittel eine reizvolle Wirkung zu erzielen, lässt sich auch an den datierten Dürnsteiner Einbänden beobachten. ${ }^{40}$ Dass in Dürnstein in derselben Werkstatt und zur selben Zeit auch andere Personen Codices gebunden haben, bezeugt zum Beispiel eine in Herzogenburg aufbewahrte Handschrift mit Kopfstempeleinband von I480 (Abb. I2) und Dürnsteiner Besitz-

herangezogen werden. Auflistung aller überlieferten mittelalterlichen Dürnsteiner Kopfstempeleinbände: TIF, Buchkunst Dürnstein (zit. Anm. 7), S. 66 f. Eine zweite Dürnsteiner Binderwerkstatt war später im I5. Jahrhundert tätig und unterscheidet sich wesentlich von der ersten, nicht nur weil auf die datierten Kopfstempel verzichtet, sondern auch weil das übrige Stempelmaterial ausgetauscht wurde. Ilse Schunke spricht deshalb vorsichtig von einer „Dürnstein nahverwandten Werkstatt“. Siehe dazu Schwenke/Schunke II, 69; sowie EBDB (zit. Anm. 19): wo0278I. Die Werkgruppe der späteren Dürnsteiner Buchbinderwerkstatt kann hier um folgende Einbände erweitert werden: Wien, ÖNB, Ink. Io.G.22, Ink. II.H.24, Ink. I7.D.I5.; Herzogenburg, Stiftsbibliothek, Cod. I2, Cod. 329, Ink. I09. Siehe zu den letztgenannten Codices: A. Tif / M. Roland im Fond Augustiner-Chorherrenstift Herzogenburg in den online verfügbaren Bilddatenbanken des Forschungszentrums Buchmalerei / Pächt-Archiv des Instituts für Kunstgeschichte der Universität Wien, URL: http:// kunstgeschichte.univie.ac.at/forschung/buchmalerei/bilddatenbanken/ [II. 02. 20I4].

38 Diese Übereinstimmungen beobachtete Mazal an den Ink. I6.A.23 (I479), Ink. 6.A.I4. (I48I) und Ink. I8.A.I3, Bd. 2 und 3 (I48I) der ÖNB. Zur Herleitung des Stils der Einbände und der Buchmalerei aus der Tradition Ulrich Schreiers: MaZAL, Datierte Einbände (zit. Anm. 36), S. 290. Zu Ulrich Schreier als Buchbinder: LAURIN 1964.3, Sp. 1502. Zur Verwendung von Kopfstempeln und gebogenen Streicheisenlinien für die Bildung von vegetabilen Blattornamenten auf Einbänden der Werkstatt Ulrich Schreiers: Schuller-Juckes, Ulrich Schreier (zit. Anm. 4), S. I39f.

39 Näheres zu den Inkunabeln Ink. IOo in Budapest mit I48I datiertem Kopfstempeleinband und buchmalerischer Ausstattung und 2.C.2, Bd. I der ÖNB mit Einband und Buchmalerei von 1478 findet sich in Anm. I7.

40 Mazal betonte dabei, dass diese besondere Art der Gestaltung in der Einbandkunst des donauösterreichischen Raums so selten ist, dass eine Verbindung zwischen dem Buchbinder in Dürnstein und der Schreier-Werkstatt nicht geleugnet werden kann. Mazal, Datierte Einbände (zit. Anm. 36), S. 286 und 290. Im Rahmen einer späteren Untersuchung stellte Mazal fest, dass unter ca. 22.80o von Ernst Kyriss ausgewerteten Blindstempeleinbänden des deutschsprachigen Kulturraums nur I94 dem Typus der Kopfstempeleinbände zugeordnet werden konnten. Neben den Salzburger (vor allem Schreier) und Dürnsteiner Einbänden stellte der Autor in den Beständen der ÖNB nur noch einige Wiener Einbände fest, die im österreichischen Gebiet diese Art der Blindstempeldekoration aufwiesen. Mazal, Gotische Einbände (zit. Anm. 36), bes. S. 473 u. Anm. I. 
Abb. Io: Wien, Österreichische Nationalbibliothek, Ink. 18.A.13 Bd. 2, fol. 2 r

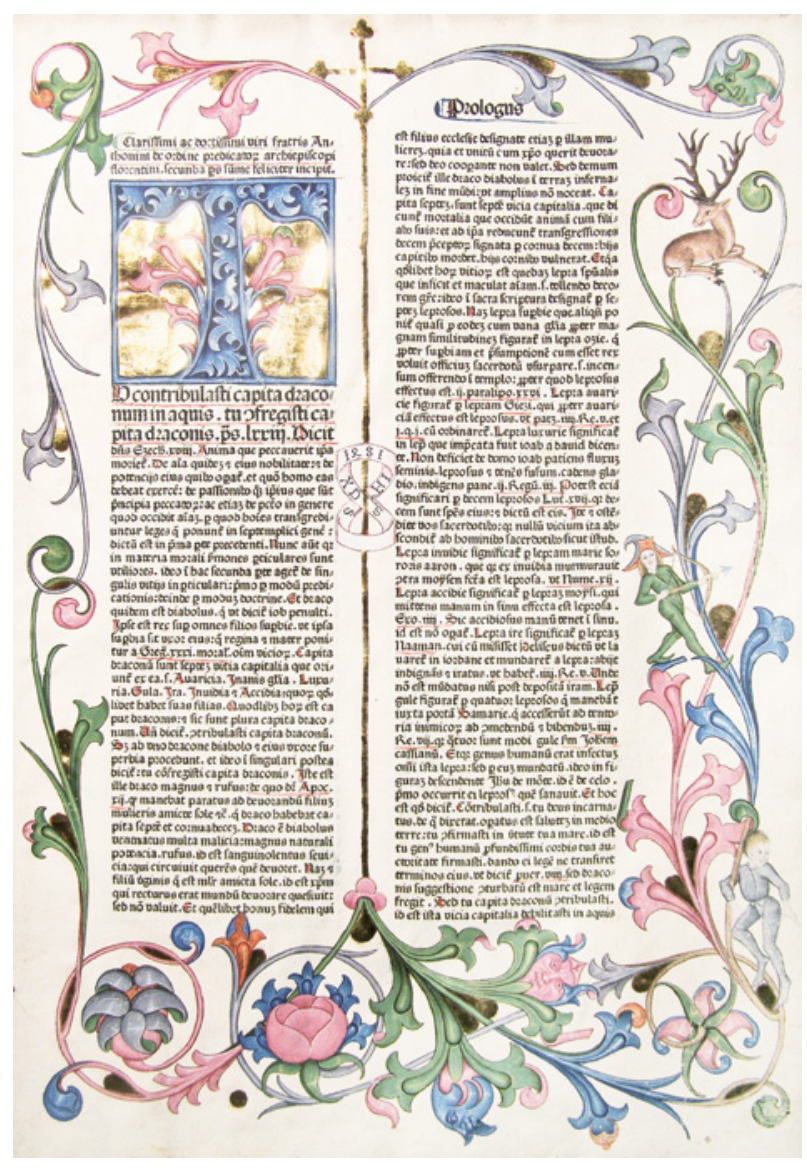

vermerken. ${ }^{41}$ Während die Einbände der vom Illuminator des Koloman-Antiphonars ausgestatteten Codices einen gestalterisch kreativen Einsatz des Stempelmaterials bezeugen, ist der dilettantisch hergestellte Einband in Herzogenburg lediglich durch den Versuch einer symmetrischen Anordnung einzelner Stempel gekennzeichnet, jedoch ohne dem Anspruch eines höheren ästhetischen Gestaltungskonzepts gerecht zu werden. Hinzu kommt die Tatsache, dass kein einziger Dürnsteiner Codex mit Buchmalerei des Illuminators des Koloman-Antiphonars aus dem Jahr I480 überliefert ist. Wahrscheinlich war er zum Zeitpunkt der Bindung der in Herzogenburg aufbewahrten Handschrift andernorts beschäftigt, da dieses Datum in der Passauer Überacker-Inkunabel (Abb. 13) eingetragen ist. Bedauerlicherweise ist bei diesem Exemplar der Originaleinband nicht erhalten.

Die von Mazal festgestellte formale Parallelität zwischen Buchmalerei und Einband als Rezeption von Gestaltungsprinzipien Ulrich Schreiers lässt sich wiederum auch am Referenzwerk des Buchkünstlers, am Koloman-Antiphonar in St. Pölten, feststellen. Der Einband (Abb. I-2) weist eine rautenförmige Feldeinteilung auf, welche mit vegetabilen Blattformreliefs durch Verwendung von Kopfstempeln und Streicheisenlinien dekoriert ist. Dieselbe Dekorations-

4I Herzogenburg, Stiftsbibliothek, Cod. 75. Tif / Roland, Bilddatenbank Herzogenburg (zit. Anm. 37). 
struktur finden wir auf dem Einband der Schreier-Werkstatt (Abb. II). Die Blindstempel auf dem Einband des Koloman-Antiphonars sind mit den Werkzeugen der Buchbinderwerkstatt des Augustiner-Chorherrenstiftes St. Pölten erstellt worden, wobei die übrigen mir bekannten St. Pöltener Stiftseinbände keine Gestaltung mit Blattformreliefs zeigen. ${ }^{42}$ Analog zur Dürnsteiner Werkgruppe möchte ich daher vorschlagen, auch hier Buchmaler und Buchbinder als eine Person zu betrachten, welche in den formalen Konzeptionen der Schreier-Werkstatt geschult war und diese als eigenständiger Buchausstatter fortsetzte, wobei er für die Bindung das Stempelmaterial benutzte, welches ihm jeweils vor Ort zur Verfügung stand. Demnach lässt sich für den Illuminator des Koloman-Antiphonars in den I48oer-Jahren zunächst eine auftragsbedingte Arbeitsreise zwischen Dürnstein und St. Pölten nachzeichnen.

Unter den mittelalterlichen Blindstempeleinbänden der Codices mit Buchmalerei des Illuminators des Koloman-Antiphonars folgen somit die Dürnsteiner und der St. Pöltener dem seltenen Gestaltungsprinzip zur Ausformung geäderter Blätter als Hauptdekoration in der oben beschriebenen Ausprägung. Die mittelalterlichen Einbände der St. Florianer Inkunabeln sind bedauerlicherweise in Verlust geraten. ${ }^{43}$ Zwei weitere Originaleinbände sind jedoch bei Werken des Buchmalers für die Augustiner-Chorherren in Klosterneuburg ${ }^{44}$ und in Passau $^{45}$ (Abb. I4-15) erhalten. In beiden Fällen handelt es sich wieder um sogenannte Kopfstempeleinbände, die sich im Layoutkonzept und durch den spezifischen Einsatz der Kopfstempel zur Dreieckblattbildung von den lokalen Traditionen der Buchbinderwerkstätten des jeweils lokalisierten Stempelmaterials unterscheiden. Zudem kann festgestellt werden, dass der Klosterneuburger und der Passauer Einband im Grunde dieselbe Feldeinteilung aufweisen, die etwa beim Dürnsteiner Einband von Ink. I8.A.I3, Bd. 2 der Österreichischen Nationalbibliothek (Abb. 9) zu beobachten ist, nämlich ein diagonal unterteiltes, zentrales Rechteck, wobei die daraus resultierenden Dreiecke durch Einprägung von Kopfstempeln zu Blattreliefs geformt werden. Damit könnten auch diese Einbände vom Illuminator

42 Dasselbe Stempelmaterial findet sich auf einer Reihe von mittelalterlichen St. Pöltener Einbänden, zum Beispiel St. Pölten, Diözesanarchiv, Ink. II2 und Ink. 305.

Es soll an dieser Stelle darauf hingewiesen werden, dass Holter in seiner Untersuchung zu den Bucheinbänden des Stiftes St. Florian das Werk eines Buchbinders definieren konnte, den der Autor entweder als Wanderbuchbinder oder als in Enns ansässigen - jedenfalls nicht zum Stift gehörig - versteht. K. HoLter, Verzierte mittelalterliche Bucheinbände des Stiftes St. Florian, in: Mitteilungen des Oberösterreichischen Landesarchivs IO, I97I, S. I83-209, hier S. I9I und Abb. 6. Das dort gezeigte Beispiel weist eine seltene Feldeinteilung eines mit zwei Diagonalen unterteilten Rechtecks mit eingeschriebener Raute auf, die auch am Dürnsteiner Einband von Wien, ÖNB, 2.C.2, Bd. I beobachtet werden kann. Das zur Verfügung stehende Material ist allerdings zu gering, um entscheiden zu können, ob hier derselbe Buchbinder anzunehmen ist.

44 Klosterneuburg, Stiftsbibliothek, CCl 6r2. Siehe dazu Anm. 13. Die Stempel auf dem Einband sind in unterschiedlichen Kombinationen beispielsweise auf den Einbänden folgender Klosterneuburger Codices zu finden: $\mathrm{CCl}_{239}, \mathrm{CCl}_{325}$ (datiert I476), $\mathrm{CCl} 958$, Cod. typ. 29 und Cod. typ. 30, wobei die Einbände von $\mathrm{CCl}_{958}$, Cod. typ. 29 und Cod. typ. 30 Stempel mit dem Stiftswappen von Klosterneuburg aufweisen, wodurch die Lokalisierung des übrigen Stempelmaterials eindeutig geklärt ist.

45 Passau, Staatliche Bibliothek, Ink. 28. Die Zuschreibung des Einbands an die Werkstatt von St. Nikola, EBDB (zit. Anm. 19): woozzor in Anm. I8. Zur Passauer Buchbinderwerkstatt von St. Nikola auch Holter, Chorherrenstifte (zit. Anm. 36), S. 226. 
des Koloman-Antiphonars angefertigt worden sein, obwohl sie weniger spezifisch sind als jene in Dürnstein und St. Pölten.

\section{CHRONOLOGIE DER}

ARBEITSAUFENTHALTE

Einige Indizien, die sich aus den Verbindungen zwischen Buchschmuck und Einbandkunst ergeben, untermauern die bisherigen Beobachtungen. Die von Petrus Überacker I478 vorgenommene Schenkung der Ink. 2.C.2, Bd. I der Österreichischen Nationalbibliothek an Dürnstein trägt den entsprechenden Donationsvermerk in Goldschrift auf dem Spiegel des Einbandvorderdeckels. Da der Illuminator des Koloman-Antiphonars der einzige für Dürnstein nachweisbare Buchausstatter war, bei dem Vergoldungen als Teil der Buchmalerei zu sehen sind, steht es außer Frage, dass nur er für die Ausführung des Schenkungsvermerks verantwortlich gemacht

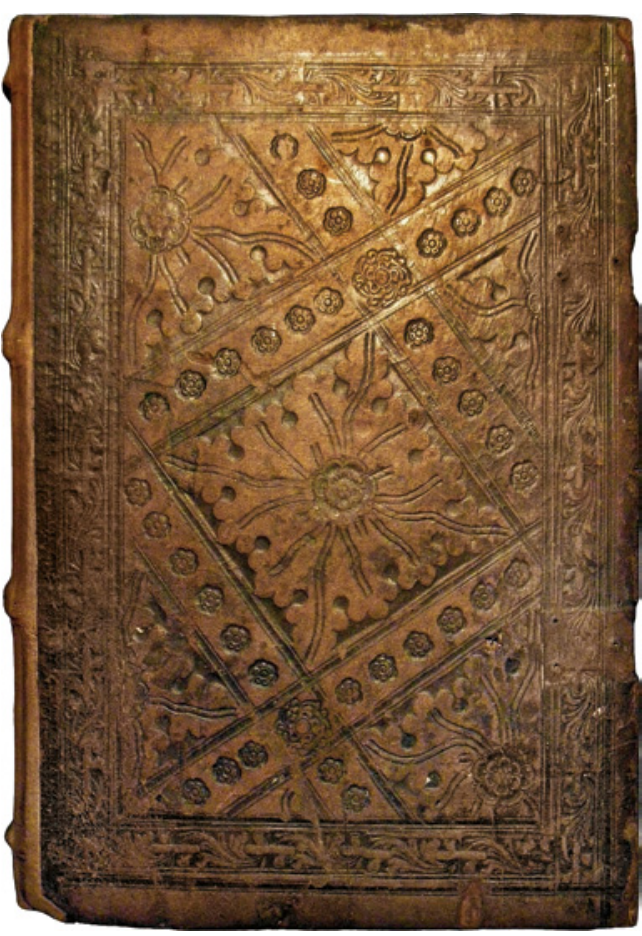

Abb. II: Wien, Österreichische Nationalbibliothek, Ink. 2.E.4, Einband, Vorderdeckel werden kann. Seine ebenfalls I478 eigenhändig datierte Buchmalerei ist eingebunden, sodass sie vor der Anfertigung des Einbands fertiggestellt worden sein muss. Somit ist es nur denkbar, dass die Reihenfolge der Arbeitsschritte zur buchmalerischen Ausstattung, gefolgt von der Einbindung und anschließender Anbringung des Donationsvermerks in Blattgold, in einem Arbeitsgang erfolgte. Dies kann nur vor Ort in Dürnstein geschehen sein, weil der Einband die dorthin lokalisierten Stempel aufweist.

Die Dürnsteiner Inkunabel mit 1479 datiertem Einband enthält ihrerseits lediglich eine nicht fertiggestellte Vorzeichnung des Illuminators. Es ist kaum denkbar, dass ein auswärtiger Auftrag in diesem unfertigen Zustand ausgeliefert wurde. Die Vorzeichnung kann daher nur vor Ort angefertigt worden sein. Vermutlich mit dem Vorsatz zur späteren Fertigstellung der Buchmalerei wurde der Codex ebendort gebunden. Dies darf wieder als Beleg dafür verstanden werden, dass der Buchkünstler 1479 in Dürnstein arbeitete. Dass er allerdings nicht als ein dem Dürnsteiner Stift angehöriger Buchmaler betrachtet werden darf, möchte ich aus der Tatsache ableiten, dass keine seiner prunkvoll ausgestatteten Handschriften für dieses ausgeführt wurde.

Eine dieser Handschriften ist das Sitznberger-Missale in Klosterneuburg. Im Kolophon nannte der Chorherr Hieronymus Sitznberger das Datum 5. Juni 1479 als Vollendung seiner Schreibleistung. ${ }^{46}$ Wie aus der eingetragenen Jahreszahl im Querbalken der Initiale auf

46 Zum sogenannten Sitznberger-Missale Haidinger, Klosterneuburg (zit. Anm. 6), S. 6o ff. und Kat. 79 mit Abb. 8I und Fig. 32-37. 


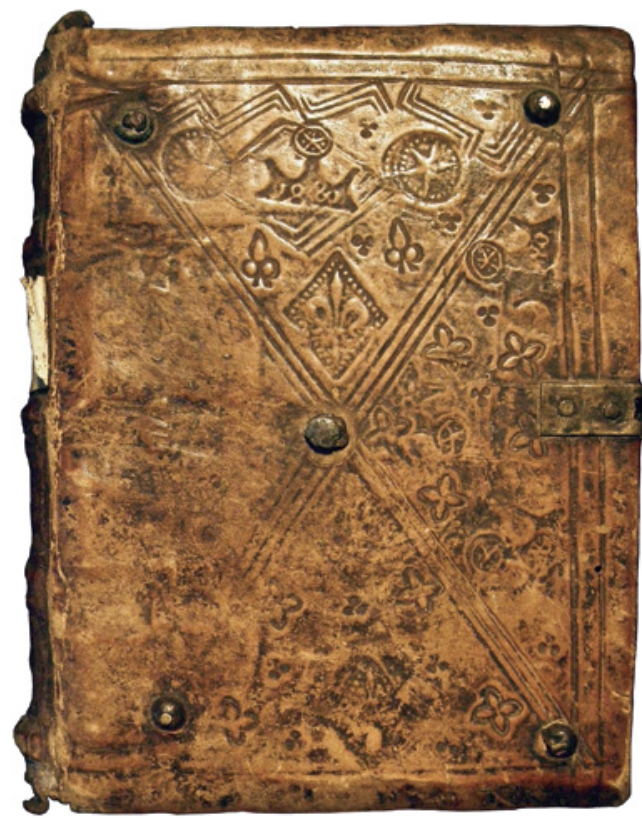

Abb. I2: Herzogenburg, Stiftsbibliothek, Cod. 75, Einband, Vorderdeckel fol. IIr zu schließen ist, wurde im selben Jahr der Auftrag zur Hauptausstattung mit Buchmalerei vom Illuminator des Koloman-Antiphonars ausgeführt. Der Buchschmuck weist drei Künstlerhände auf, wobei der hier besprochene Buchmaler für fol. IIr (Adventsonntag), I48r (Te igitur), I52V (Schmerzensmann) und 2IIv (Fest des Hl. Hieronymus, Namenspatron des Schreibers) verantwortlich war. Die übrigen illuminierten Seiten sind von zwei Wiener Künstlern, dem Illuminator des Engelbrecht-Graduales ${ }^{47}$ und einem weiteren anonymen Buchmaler ${ }^{48}$, ausgeführt worden. Das Stempelmaterial auf dem Originaleinband ist ohne Zweifel der Klosterneuburger Buchbinderwerkstatt zuzuweisen. ${ }^{49}$ Es ist wohl kaum vorstellbar, dass das vollendete Prestigewerk des Schreibers im Jahr 1479 in einzelnen Lagen zum Teil nach

47 Haidinger schrieb folgende Codices dem Illuminator des Engelbrecht-Graduales zu: Klosterneuburg, Stiftsbibliothek, CCl 6I2 (fol. I9r, 23r, 24r, 7Ir, 84v, 96r, 97v, I03r, I04v, I06v, I28r, I30r, I57r, I66r, I85r, I98v, 200v, 20Ir, 203r, 208v, 2IOr, 217r und 222r), CCl II92, CCl 604, CCl 75; Wien, Dominikanerbibliothek, Cod. 415/212, Cod. 416/213, Cod. 122/89, Cod. I48/118, Cod. 33/33, Inc. W 55, Inc. W I29, Inc. W I94 und die namensgebende Handschrift Heiligenkreuz, Cod. Neukloster A 13, (olim Wr. Neustadt, Neukloster, Cod. D 3 bzw. XII. A.I3). Haidinger, Klosterneuburg (zit. Anm. 6), S. 6o. Die Codices Graz, UB, Ink. III 9704, Bd. I und 2, sowie Budapest, Szécsényi Nationalbibliothek, Cod. lat. 222 wurden von Beier derselben Hand zugeschrieben. BeIER, Universitätsbibliothek Graz (zit. Anm. 5), S. 85. Die Werkgruppe darf an dieser Stelle um die Codices Wien, ÖNB, Ink. 2.A.2 Bd. I und 2, Ink. 5.B.8, Ink. 6.D.7, Ink. 6.G.8, Ink. II.A.24, Ink. I5.A.9, Ink. I5.A.ıo; St. Pölten, Diözesanbibliothek, Cod. I05; sowie Melk, Stiftsbibliothek, P 129 und P 586 erweitert werden. Aufgrund der Provenienzen und der zum Teil überlieferten mittelalterlichen Einbände ist die Tätigkeit des Buchmalers in den I47oer- und I48oer-Jahren in Wien als sehr wahrscheinlich anzusehen. F. UNTERKIRCHER, Inventar der illuminierten Handschriften, Inkunabeln und Frühdrucke der Österreichischen Nationalbibliothek. Teil 2: Die griechischen, slawischen, hebräischen und orientalischen Handschriften, kleinere Handschriftengruppen; Inkunabeln, Frühdrucke und spätere illuminierte Drucke, Wien I959, S. I49.

48 Dem Buchmaler in Klosterneuburg, Stiftsbibliothek, CCl 6I2 (fol. 24Iv und 245r) schrieb Haidinger den Buchschmuck in $\mathrm{CCl}_{30}$ s derselben Bibliothekssammlung zu. HaIdinger, Klosterneuburg (zit. Anm. 6), S. 6I. Demselben Illuminator ist die Ausstattung von Graz, UB, Ink. II 9780 zuzuweisen. Näheres zur Grazer Inkunabel: BeIER, Universitätsbibliothek Graz (zit. Anm. 5), S. 84, 86f. und III, sowie Abb. I3I. Des Weiteren ist sein Werk meines Erachtens in Wien, ÖNB, Ink. 4.B.I3, Ink. 5.F.4, Ink. 5.F.34, Ink. 6.F.24, Ink. 26.B.I, Ink. 26.C.6; Linz, Oberösterreichisches Landesmuseum, Inv. Nr. I89-I906 Ms. I (zum Beispiel fol. I8Iv, I87v, I88r, I98r, 202r, 203r, 204v, 209r und andere) überliefert. Einbände und Provenienzdaten lassen auch hier mehrheitlich auf eine Tätigkeit des Buchmalers im letzten Viertel des I5. Jahrhunderts in Wien schließen. 
Abb. I3: Passau, Staatliche Bibliothek, Ink. 26, Bl. a4a

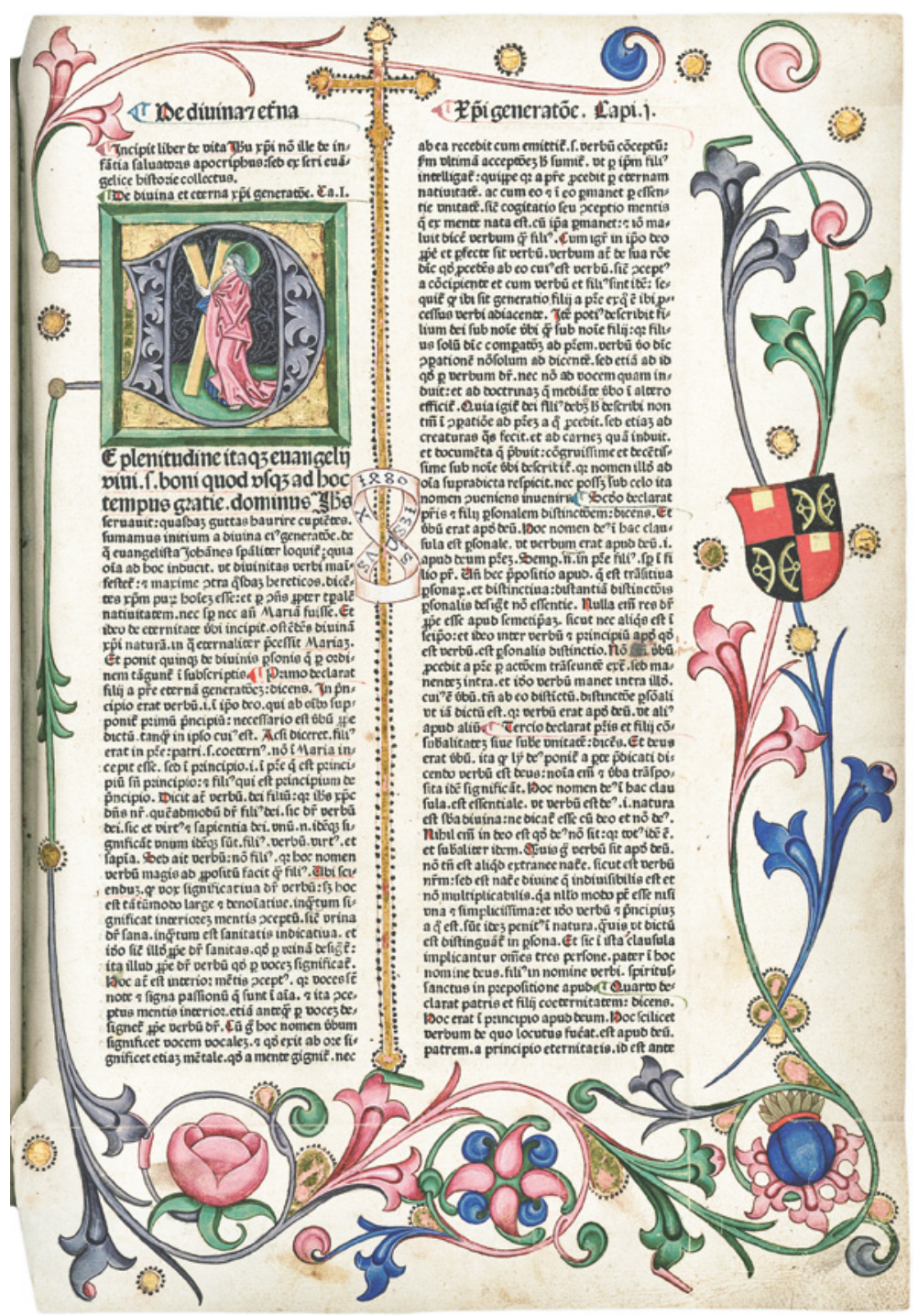

Dürnstein (Incipit, Canon und Fest des Namensheiligen des Schreibers) und zum Teil nach Wien (alle restlichen Lagen) geschickt wurde, um nach der Fertigstellung der Buchmalerei im selben Jahr zurück nach Klosterneuburg geholt und dort gebunden zu werden. Das Einbandlayout ist, wie bereits erwähnt, durch den Einsatz von Kopfstempeln zur Bildung von Blattformreliefs im mittleren Rechteck der Deckel charakterisiert, wodurch es sich von dem anderer Klosterneuburger Blindstempeleinbände unterscheidet. ${ }^{50}$ Es erscheint mir auch in diesem Fall

so Eine Ausnahme bildet der Einband von Klosterneuburg, Stiftsbibliothek, $\mathrm{CCl}$ 239, der meines Erachtens vom selben Buchbinder wie das Sitznberger-Missale CCl 612 angefertigt wurde. Es handelt sich dabei um die in der zweiten Hälfte des I5. Jahrhunderts vorgenommene Neubindung einer Klosterneuburger Handschrift des I3. Jahrhunderts. Für den Hinweis auf den Einband, die Überlassung von Arbeitsmaterialien und weitere Informationen zum $\mathrm{CCl} 239$ gebührt Franz Lackner der größte Dank. 


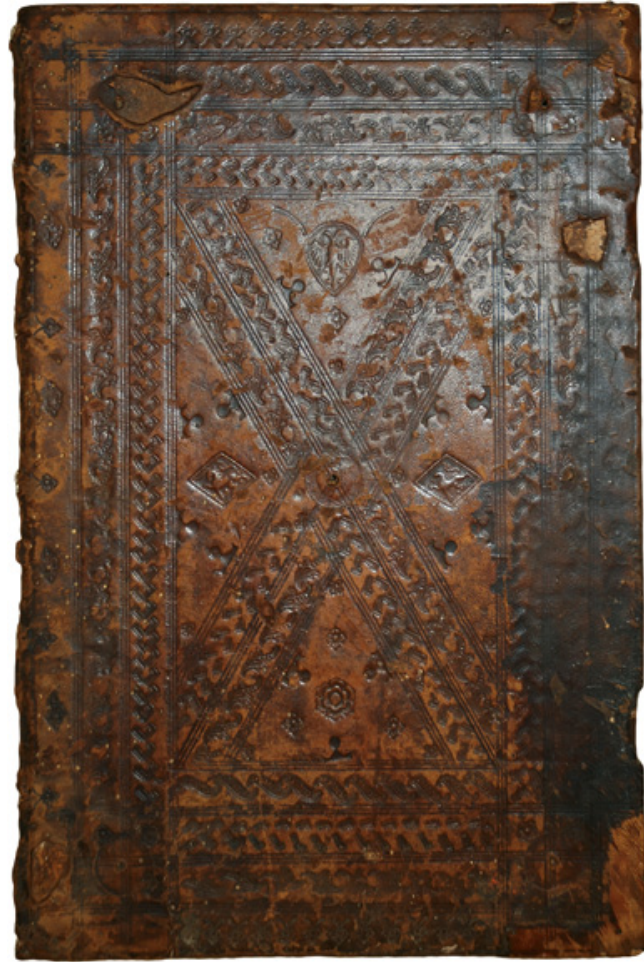

Abb. I4: Passau, Staatliche Bibliothek, Ink. 28, Einband, Vorderdeckel

plausibler, dass alle Arbeitsschritte zur Ausstattung der Handschrift vor Ort in Klosterneuburg ausgeführt wurden, wobei meines Erachtens unser Illuminator ebendort für die Illuminierung der Hauptseiten und vermutlich für die abschließende Bindung verantwortlich war. In Anbetracht seines zuvor besprochenen Aufenthaltes in Dürnstein kann auch hier eine Reise entlang der Donau zwischen Dürnstein und Klosterneuburg nachgezeichnet werden.

Ob die Passauer Überacker-Inkunabel von I480 in Passau oder andernorts illuminiert wurde, lässt sich nicht mit Sicherheit feststellen. Aufgrund des oben besprochenen Einbandes der St.-Nikola-Inkunabel ist aber ein Aufenthalt des Buchausstatters in der süddeutschen Donaustadt glaubhaft. Eine neuerliche Anwesenheit in Dürnstein im Jahr I48I darf wiederum durch die vier entsprechenden Inkunabelbände mit erhaltenen datierten Einbänden und gleichzeitig datierten Buchmalereiausstattungen als gesichert betrachtet werden. ${ }^{51}$ Abschließend möchte ich noch an den aufgrund des Einbandes und des Auftraggebers bzw. Adressaten des Koloman-Antiphonars im Zeitraum I 486 bis I 488 postulierten Arbeitsaufenthalt des Illuminators in St. Pölten erinnern.

\section{NACHFOLGE}

Die von Ulrich Schreier neu bzw. weiterentwickelten Dekorationsformen wurden in den letzten Jahrzehnten des I5. Jahrhunderts von einer noch nicht einschätzbaren Anzahl an Buchmalern im ostösterreichischen und süddeutschen Raum beinahe unverändert übernommen und weiterhin verwendet. ${ }^{52}$ Bei der Erstellung des Euvres des Illuminators des Koloman-Antiphonars versuch-

5I Wien, ÖNB, Ink. 6.A.I4; Ink. I8.A.ı3, Bd. 2 und 3; sowie Budapest, Szécsényi Nationalbibliothek, Ink. Ioo.

52 Einige der Codices, die im donauösterreichischen Raum im letzten Viertel des I5. Jahrhunderts entstanden bzw. illuminiert wurden, sind bislang zu einer inhomogenen Werkgruppe unter der Bezeichnung SchreierNachfolge gerechnet worden, da dort eine dem CEuvre des Salzburger Buchmalers sehr ähnliche stilistische Formensprache, jedoch in unterschiedlicher Ausprägung, anzutreffen ist. Vor allem Holter hat hierzu grundlegende Untersuchungen vorgelegt: Holter, Dominikaner-Gradualien (zit. Anm. II); sowie ders., Buchmalerei St. Florian, (zit. Anm. I5). Zuletzt hat Schuller-Juckes weitere Differenzierungen zwischen dem jeweiligen Umfeld des Morandus-Meisters und des Illuminators des Koloman-Antiphonars vorgenommen: SchullERJuckes, Ulrich Schreier (zit. Anm. 4), S. I49 f. Anm. 363 und 364. Aus heutiger Sicht waren diese zwei Buch- 
te ich eine Kerngruppe herauszuarbeiten, indem ich nicht nur rein stilistische Kriterien, sondern auch in seinem Werk häufig vorkommende Spruchbänder, Masken und die Verwendung druckgrafischer Vorlagen vom Meister der Spielkarten und Meister E.S. berücksichtigte. Wenn diese Eigenheiten im Rankendekor eines Codex aus der donauösterreichischen Schreier-Nachfolge fehlen, ist es oft nicht leicht, eine eindeutige Zuweisung an diesen Buchkünstler vorzunehmen.

Dem Illuminator des Koloman-Antiphonars kommt meines Erachtens eine besondere Rolle als Multiplikator zu. Es lassen sich nämlich mehrere homogene Werkgruppen einzelnen Buchmalern im Donauraum zuweisen, welche in seinem unmittelbaren Umfeld geschult worden sein müssen. Dazu gehören zum Beispiel zwei Buchmaler in Niederösterreich, von denen einer mit großer Wahrscheinlichkeit hauptsächlich in St. Pölten ${ }^{53}$ und ein zweiter in Dürnstein $^{54}$ tätig war. Aufgrund der hohen Qualität in der Ausführung bedeutender ist aber ein Buchmaler im oberösterreichisch-süddeutschen Gebiet, der dem Illuminator des KolomanAntiphonars auch stilistisch am nächsten steht. Sein Euvre ist noch weitgehend unbekannt, jedoch lassen sich Buchmalereiausstattungen in drei Codices bereits zu einer kleinen Werkgruppe zusammentragen: das Canonblatt eines Missales in St. Florian, ein Missale für das Benediktinerkloster Vornbach und eine prachtvoll illuminierte hebräische Passah-Haggada in München. ${ }^{55}$ Die Rankenbildung dieses Buchkünstlers ist vor allem den vegetabilen Deko-

maler ohne Zweifel die wichtigsten und vor allem produktivsten Vertreter der Künstlergruppe in der SchreierNachfolge in Wien und Niederösterreich.

53 Zur Werkgruppe des Buchmalers zähle ich die Codices St. Pölten, Diözesanbibliothek, Ink. II2, Ink. 274, Ink. 293, Ink. 295, Ink. 296 und Ink. 305; sowie Herzogenburg, Stiftsbibliothek, Ink. 123 Bd. 2. Abb. vom letzteren Beispiel: Tif / Roland, Bilddatenbank Herzogenburg (zit. Anm. 37). Die Datierung der von ihm illuminierten Drucke weist auf eine Wirkungszeit in den I480er-Jahren. Das Rankenwerk und die vegetabilen Blütenmotive des Buchmalers entsprechen in formaler Hinsicht dem Werk des Illuminators des Koloman-Antiphonars, sind jedoch qualitativ deutlich schwächer, flach wirkend und matter im Farbauftrag. Für ihn charakteristisch ist die Verwendung von Dekorationselementen aus dem Formenvokabular von Fleuronnée-Zeichnern, die von ihm in Deckfarbenmalerei übertragen werden. Vermutlich war er zu Beginn seiner Tätigkeit hauptsächlich als Florator beschäftigt, woraus sich seine Vorliebe für entsprechende dekorative Muster erklären könnte. Des Weiteren zeichnet ihn aus, dass er etwa süddeutsche (vor allem Augsburg und Nürnberg) Gestaltungsformen, die er vermutlich aus in seiner Umgebung importierten Codices mit Buchmalerei kannte, rezipiert (vgl. dazu zum Beispiel St. Pölten, Diözesanbibliothek, Ink. 295). Die Lokalisierung des Buchmalers ergibt sich aus dem mir derzeit bekannten Werk mit mehrheitlichen St. Pöltener und Herzogenburger Provenienzen und zwei Blindstempeleinbänden des Augustiner-Chorherrenstifts St. Pölten (Ink. II2 und Ink. 309 in der ebendortigen Diözesanbibliothek). Die Kenntnis der St. Pöltener Inkunabeln verdanke ich Katharina Hranitzky, wofür ich mich herzlich bedanken möchte.

Die Hand eines nicht besonders qualitätvoll arbeitenden Buchmalers mit sehr lavierendem Farbauftrag zeigt sich in den Dürnsteiner Codices in Wien, ÖNB, Ink. II.E.I2 und Ink. II.H.24; sowie in Herzogenburg, Stiftsbibliothek, Cod. I2, fol. 84r. Tif / Roland, Bilddatenbank Herzogenburg (zit. Anm. 37). Die Tätigkeit dieses Buchmalers ist ab den späten I480er-Jahren bis ins frühe I6. Jahrhundert zu datieren.

55 Das zur Debatte stehende Canonblatt ist offensichtlich eine spätere Ergänzung des Missales St. Florian, Stiftsbibliothek, Cod. XI/385. Das Werk wurde mehrfach von Holter in Verbindung mit dem Morandus-Meister und dem Illuminator des Koloman-Antiphonars diskutiert und zur selben Werkgruppe in der Schreier-Nachfolge gezählt. Siehe dazu Holter, Verzierte Bucheinbände St. Florian (zit. Anm. 43), hier S. 325; ders., Dominikaner-Gradualien (zit. Anm. II), S. 52; sowie ders., Buchmalerei St. Florian (zit. Anm. 15), S. 316. Die hebräische Handschrift befindet sich in München, Bayerische Staatsbibliothek, Cod. hebr. 200 und ist nicht nur die figurenreichste und prunkvollste Arbeit des Illuminators, sondern aufgrund des hebräischen Passah-Haggada- 


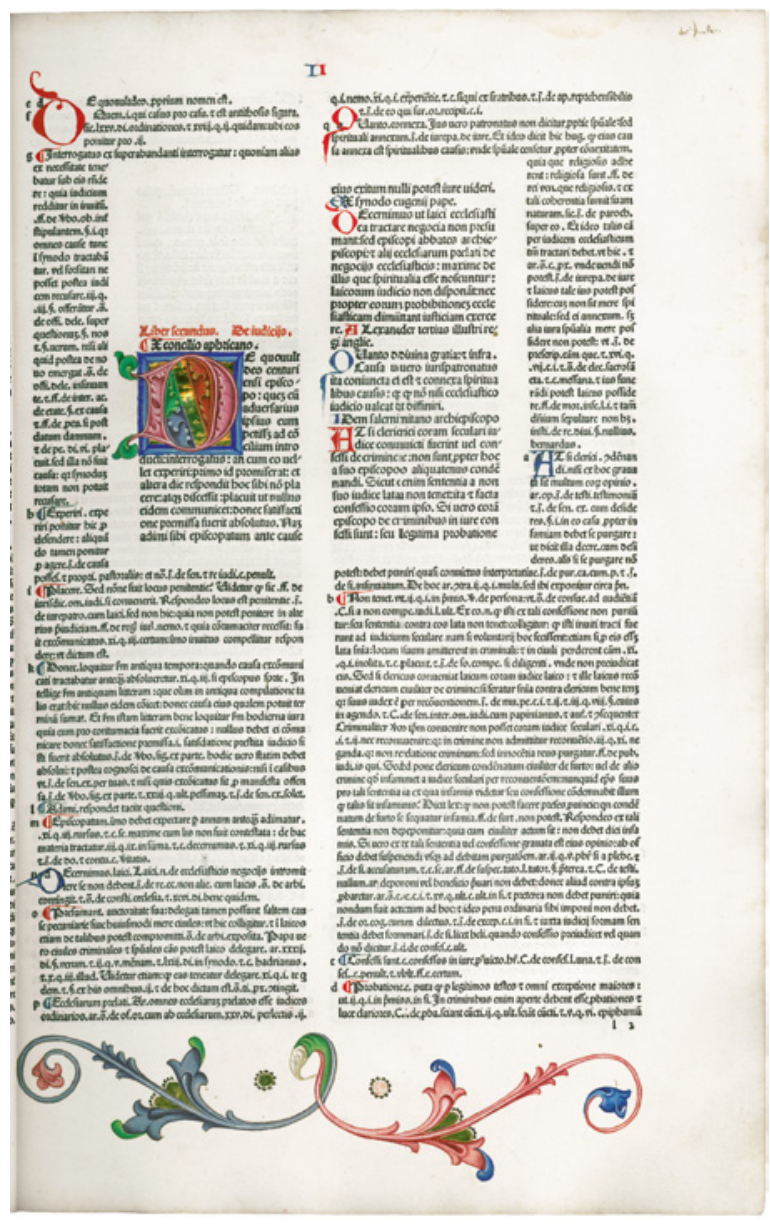

Abb. I5: Passau, Staatliche Bibliothek, Ink. 28, Bl. l2a

rationsteilen im Heiligenkreuzer Missale des Illuminators des Koloman-Antiphonars so ähnlich, dass bis auf geringfügige Details fast eine Identität der ausführenden Hand vermutet werden könnte. Der große Unterschied besteht allerdings im Figurenstil, der unmöglich demselben Buchmaler zugeschrieben werden kann. Sowohl die gegenwärtigen Aufbewahrungsorte

Textes auch das interessanteste Beispiel. Eine mitgebundene Lage mit lateinischem Text trägt das Datum I493 und wird mit einer Handschrift des Klosters Tegernsee in Verbindung gebracht. Eine Lokalisierung des Buchmalers nach Tegernsee lässt sich damit meines Erachtens nicht nachweisen. Pfändtner schreibt die Buchmalerei dem Umfeld des Morandus-Meisters zu. Pfändtner, Lehrbüchermeister (zit. Anm. II), S. 36. Volldigitalisat der Handschrift: URL: http://daten.digitale-sammlungen.de/ -db/ooor/bsbooor4964/images/index. html [II. 02. 20I4]. Weitere Ergebnisse zur Handschrift lassen die derzeit laufenden Untersuchungen von Aliza Cohen-Mushlin (The Hebrew University of Jerusalem), die diesbezüglich im Austausch mit mir steht, erwarten. Für die vielen Fachgespräche, die schließlich zu der von mir angegebenen Gruppenbildung führten, möchte ich mich an dieser Stelle bei Regina Cermann bedanken, die mich während meiner Recherchen zum Illuminator des Koloman-Antiphonars unter anderem auf das Vornbacher Missale in Passau, Staatliche Bibliothek, Mst. 2 hinwies und mir ihre geschätzte Meinung und Kritik niemals vorenthielt. 
Abb. I6: Wien, Österreichische Nationalbibliothek, Ink. Io.A.20 Bd. I, fol. $34 \mathrm{r}$

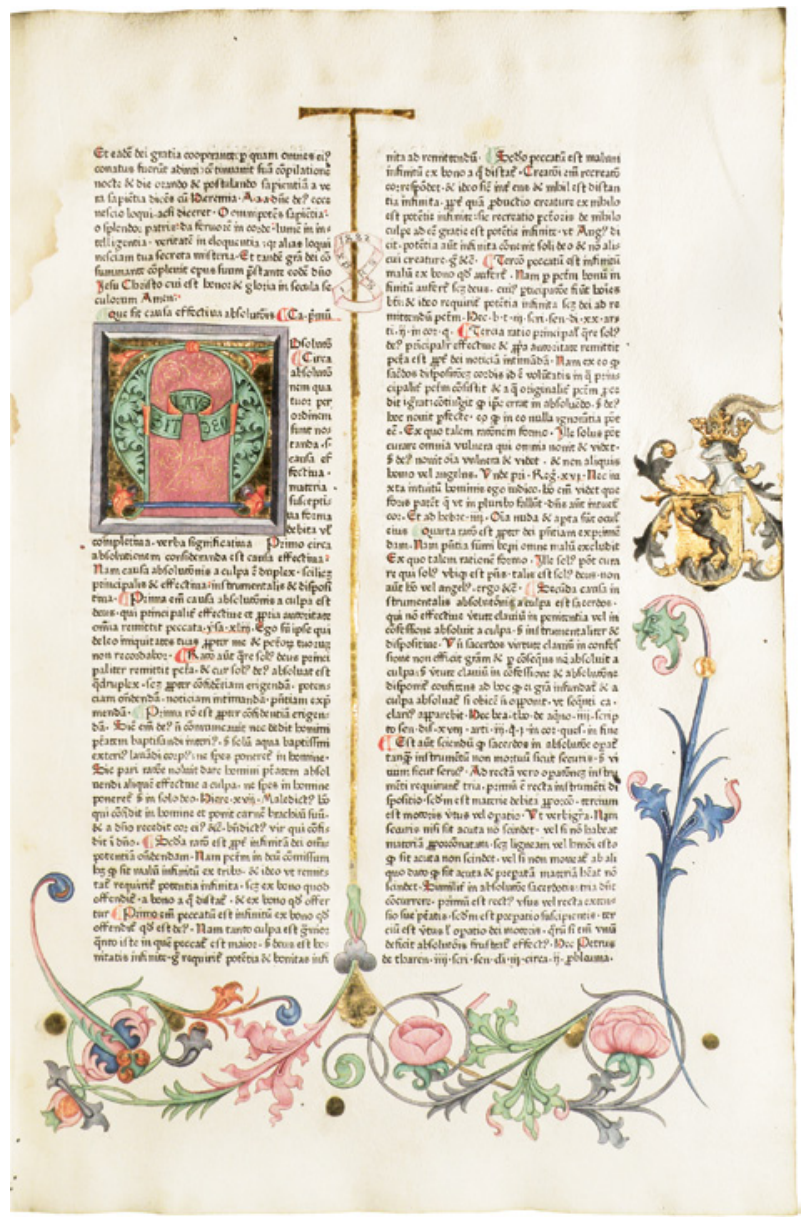

und Provenienzen der drei ihm zuzuordnenden Handschriften als auch die Tatsache, dass kein Werk in Wiener oder niederösterreichischen Beständen nachgewiesen werden kann, verweisen auf eine Tätigkeit des Künstlers, für den sich nach seinem Hauptwerk in der hebräischen Handschrift in München der Notname Illuminator der Münchner Passah-Haggada anbietet, im oberösterreichisch-süddeutschen Gebiet im letzten Viertel des I5. Jahrhunderts. Die überregionale Verbreitung der dekorativen Formensprache durch unmittelbare Schulung oder Rezeption in seiner Nachfolge darf zusätzlich als Indiz für die postulierte Mobilität des Illuminators des Koloman-Antiphonars entlang der Donau zwischen Klosterneuburg und Passau gedeutet werden. Da bislang kein Codex aus seinem CEuvre auf Wiener Auftraggeber oder Erstbesitzer zurückgeführt werden kann, ist eine Tätigkeit in Wien mit hoher Sicherheit auszuschließen.

\section{FA Z I T}

Durch die Lokalisierung der Einbandherstellung mit Hilfe der Arbeitsutensilien, die am Ort ihrer Verwendung aufbewahrt werden - wie dies beim Stempelwerkzeug mittelalterlicher Buch- 


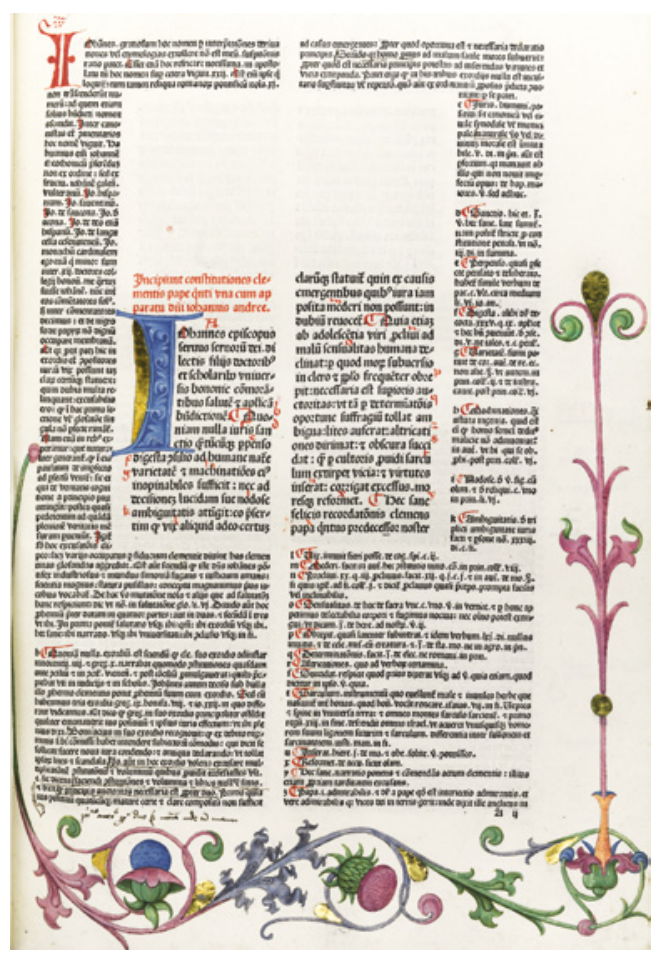

Abb. I7: Zwettl, Stiftsbibliothek, Cod. typ. I/II, fol. II5r binderateliers in der Regel der Fall ist -, war es bei gleichzeitiger Zuweisung charakteristischer Layouts an den Illuminator des Koloman-Antiphonars möglich, Anhaltspunkte für sein Itinerar als reisender Buchausstatter zu gewinnen. Er war, wie der Buchkünstler Ulrich Schreier, sowohl als Buchmaler als auch als Buchbinder tätig und tradierte dessen Gestaltungsprinzipien im donauösterreichischen Raum um I480. Sein überliefertes CEuvre besteht aus etwa sieben Handschriften und is Inkunabelbänden, wobei die prunkvolleren figuralen Ausstattungen in den Handschriften und die einfacheren, überwiegend ornamentalen in den Drucken zu beobachten sind. Es zeigt sich dabei, dass der Buchdruck in den I470erund I48oer-Jahren zu einer neuen Auftragslage für Buchausstatter geführt hat. Durch den erschwinglicheren Kaufpreis kam es häufiger zu Bücheranschaffungen für die Bibliotheken der Klöster oder von Privatpersonen. Die Codices mussten rubriziert, gebunden und gegebenenfalls etwas aufwendiger dekoriert werden.

Die hohe Mobilität entlang der Donau ermöglichte dem Illuminator des Koloman-Antiphonars offenkundig mehr Flexibilität in der Annahme rasch aufeinander folgender Auftragsanfragen aus den zwischen Klosterneuburg und Passau angesiedelten Augustiner-Chorherrenstiften. Dadurch konnte er einen verhältnismäßig großen Kundenkreis in einem Zeitraum von etwa zehn Jahren bedienen und seine Existenz als Buchausstatter sichern. Dass seine Arbeit hoch geschätzt wurde, zeigt die Tatsache, dass er stets für die Hauptausstattung der Codices herangezogen wurde, auch wenn mehrere Buchmaler an der Dekoration beteiligt waren. Diesen Erfolg hatte er meines Erachtens nicht zuletzt seiner Bereitschaft zu verdanken, zu seinen Auftraggebern zu reisen, um dort ihre Codices - je nach Bedarf mit Buchmalerei und/oder Einbänden - vor Ort auszustatten.

Universität Wien

Abbildungsnachweis: Abb. I-4: St. Pölten, Diözesanbibliothek (Digitalisat: URL: http://www.manuscriptorium. com [II. 02. 20I4]). - Abb. 5: Alba Iulia, Biblioteca Națională a României, Filiala Batthyaneum. - Abb. 6: Göttweig, Stiftsbibliothek (Foto: R. Cermann/K. Hranitzky/A. Tif). - Abb. 7-II und I6: Wien, Österreichische Nationalbibliothek (Foto: A. Tif). - Abb. I2: Herzogenburg, Stiftsbibliothek (Foto: M. Roland/A. Tif). - Abb. I3-15: Passau, Staatliche Bibliothek. - Abb. I7: Zwettl, Stiftsbibliothek (Foto: M. Haltrich). 


\title{
UBI PICTOR IBI ROMA
}

\author{
LOCAL COLOUR AND MODERN FORM IN \\ STEFANESCHI'S CODICE DI SAN GIORGIO
}

\author{
Michael Viktor Schwarz
}

The manuscript under consideration (or, more correctly, the workshop in which it was illuminated) has been variously localized in Rome, Florence, and Avignon. ${ }^{1}$ Against this background, an investigation of its production conditions should seek either to establish where the desk really stood, or to read the question as follows: how is it possible that the decoration of a manuscript combined the characteristics of such different regions, and so deceived two of three critics? What does that tell us about the intentions, horizons, and working methods of an illuminator? And what is to be made of the interests and methodology of the critics? Does their focus lie on the individual manuscript or on the (assumed) achievements of a local school or forgotten master, deserving of a place in Vasari's Vite?

\section{A MISSAL FOR ST PETER'S}

The codex in the Bibliotheca Apostolica Vaticana (BAV, Archivio di San Pietro, C. I29) is normally regarded as one volume of an unusually extensive missal: it contains the Proprium de Sanctis from 25 March to 7 June, with the mass on St George's day (23 April) preceded by the text of a legend of the saint. But the book has also been seen as a sort of compilation manuscript, with parts of a missal bound in before and after a legend of St George. ${ }^{2}$ While both readings are possible codicologically speaking, the first seems more plausible in terms of palaeography, content, and decoration. What is clear is that the conception and production of the codex were no routine matters, and involved joining together independently written units. Another part of the same work may be in New York (Pierpont Morgan Library, M. 713): according to the colophon, this represents the seventh volume of a missal; it contains the Ordo Missae and votive masses. ${ }^{3}$ The patron, at least of the Vatican codex, was Jacopo

Material for this article was kindly provided by the Bibliotheca Apostolica Vaticana, the Pierpont Morgan Library in New York, and the Bibliothèque Nationale in Paris. For specific suggestions, I would like to thank Costanza Cipollaro, Karl-Georg Pfändtner, and Tim Juckes, who also translated the text into English.

I Rome: M. G. Ciardi Duprè Dal Poggetto, Il maestro del codice di San Giorgio e il cardinale Jacopo Stefaneschi, Florence 198I, among others. Florence: M. Bosкovits, The Painters of the Miniaturist Tendency (A Critical and Historical Corpus of Florentine Painting 9), Florence 1984, among others. Avignon: F. ManZARI, La miniatura ad Avignone al tempo dei papi, Modena 2006, among others.

2 M. Dykmans, Le Cérémonial Papal de la fin du Moyen Âge à la Renaissance II: De Rome en Avignon ou le Cérémonial de Jacques Stefaneschi, Brussels and Rome I98I, p. 98-I00. Detailed descriptions of the manuscript can be found in: Ciardi Duprè Dal Poggetto, Il maestro (see n. i), p. 25I-257, and L. B. Kanter et al., Painting and Illumination in Early Renaissance Florence I300-I450 (Exh. Cat. New York), New York 1994, p. 89-95 (B. Drake Boehm).

3 Kanter et al., Painting and Illumination (see n. 2), p. 96-ioo (B. Drake Boehm). 
$\therefore$

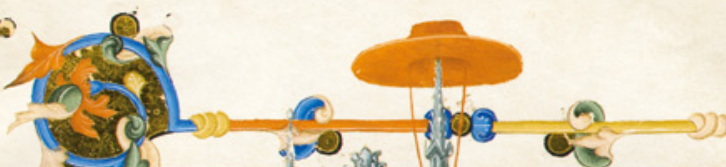

32

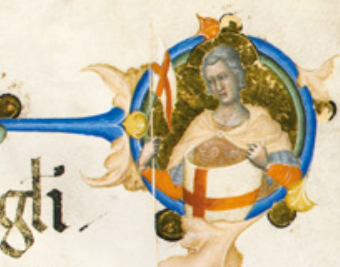
$\int i \operatorname{lig}$

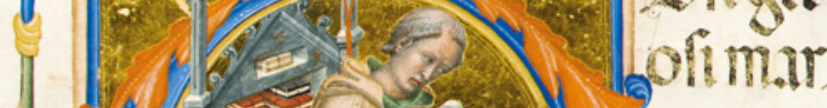

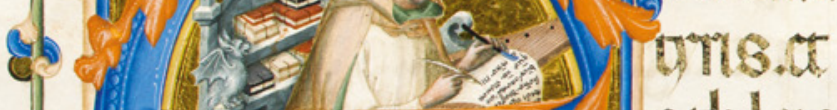

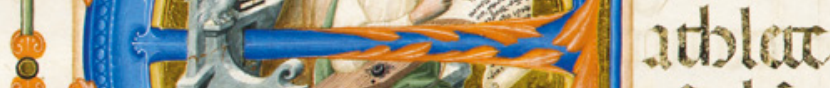

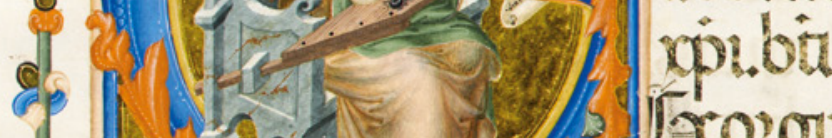

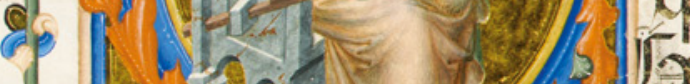

2018.

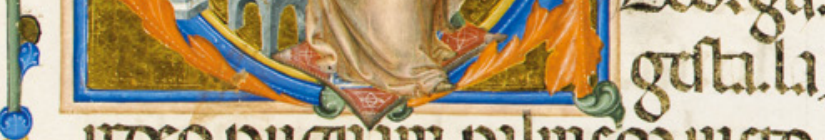

uacs.pugmin?.pluncq 11100

(4) 11.111. m.11024m1110b fatptat

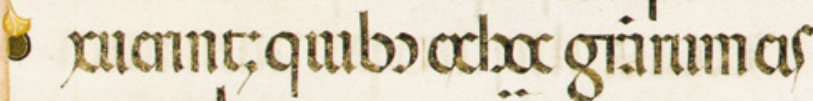

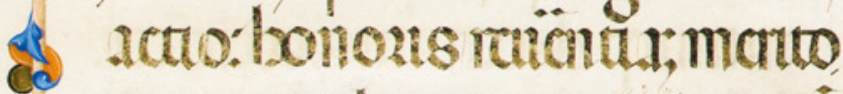
MmM cum?

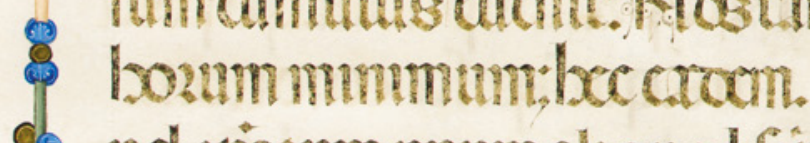

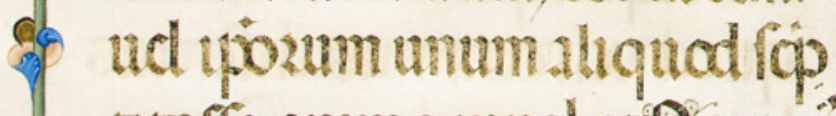
ntaric anmo mumbrthuarti.
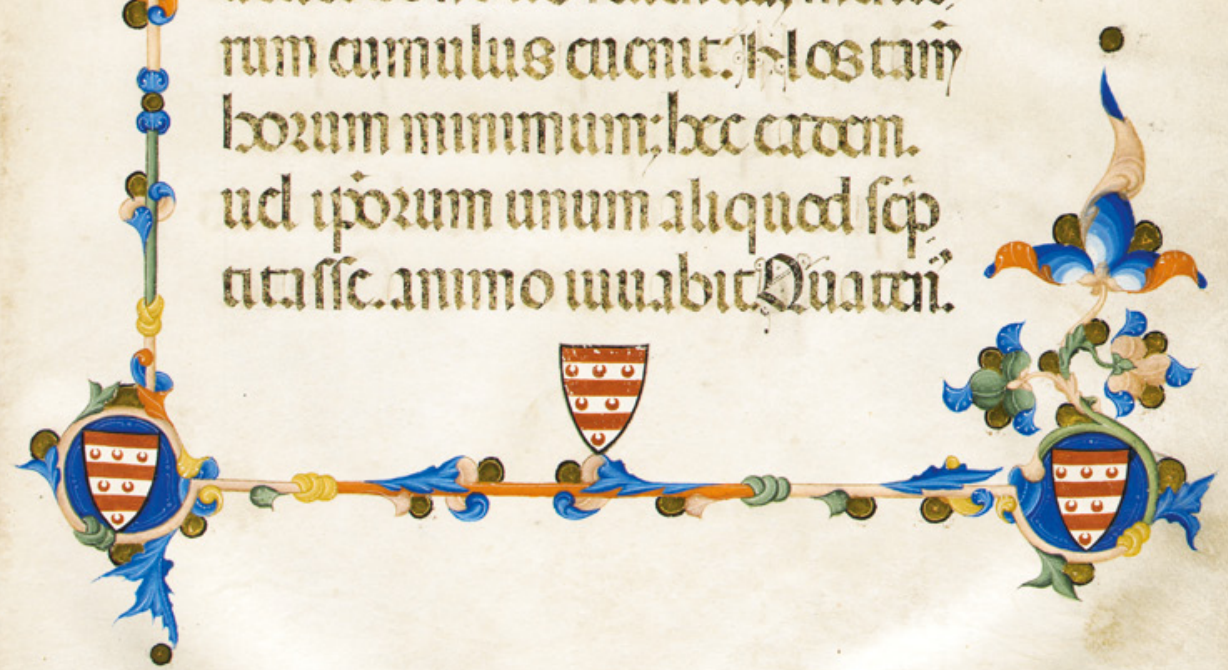

Fig. I: Missal, Vatican City, Biblioteca Apostolica Vaticana, Archivio di San Pietro, C. 129, fol. 17r 
Stefaneschi during his long cardinalate, as is attested by the Stefaneschi arms and the galero (cardinal's hat) presented signally on fol. I7r (Fig. I).

This also provides a framework for the dating: the Roman from Trastevere became cardinal in 1296; he died in Avignon in I343. ${ }^{4}$ The missal is an old possession of the chapter of St Peter's, which fits well with Stefaneschi's patronage: he was a canon of St Peter's from 1294, and appeared regularly as a benefactor of the Vatican basilica - neither his cardinal's purple nor the transferral of the curia to Avignon in 1309 changed that. Giotto received a series of splendid pictorial commissions revealing Stefaneschi as an important and assured patron of art: this began in I 298 with the monumental Navicella mosaic - which laid the groundstone for Giotto's career - and continued in the fourteenth century. ${ }^{5}$ Particularly significant with regard to the manuscript is the so-called Stefaneschi altarpiece, a bilateral polyptych in the Vatican Pinacoteca. ${ }^{6}$

Our missal is connected in several ways with this altarpiece, and especially with the central image on its reverse side. Alongside Stefaneschi, both works feature St George and St Celestine: on the altarpiece, George

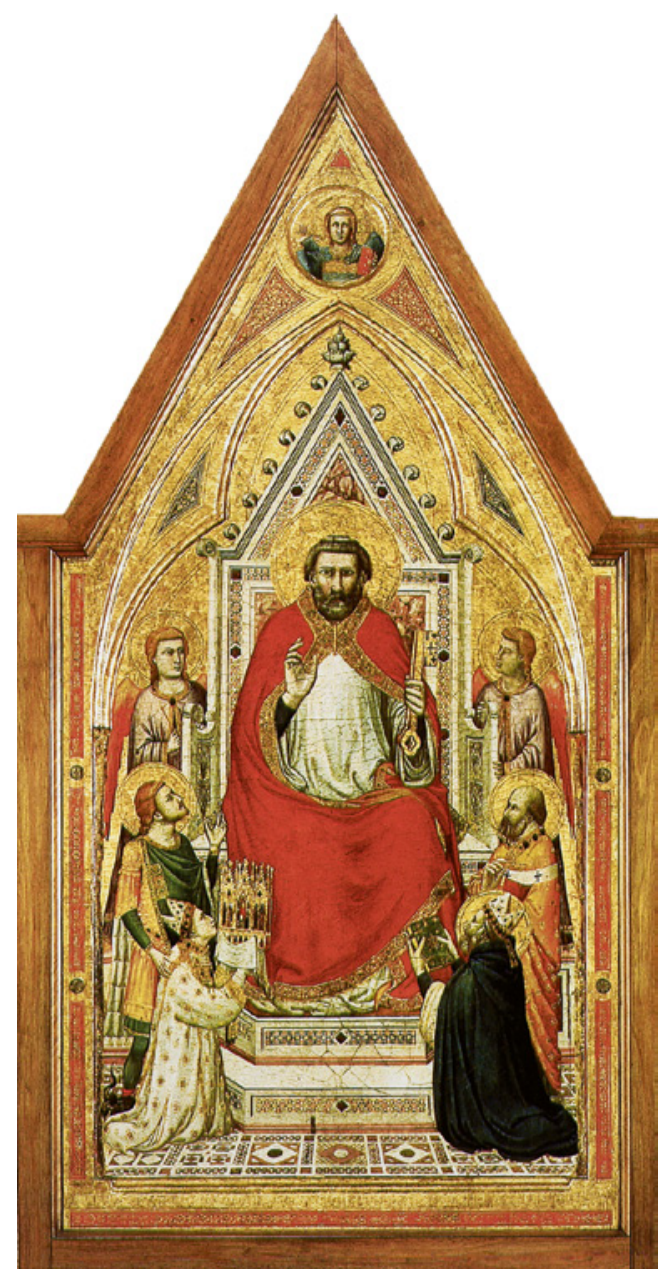

Fig. 2: Giotto, Stefaneschi altar, reverse side of the central panel, Vatican City, Pinacoteca Vaticana accompanies the kneeling cardinal and donor, while opposite him Celestine kneels in a black habit (Fig. 2); in the manuscript, the liturgy for George is highlighted by the legend and hymns adjoined, which are complemented by the pictorial decoration; and the only initial for a saint's day to rival the initials of the George passages is that opening the mass on the feast of St Celestine (Fig. 3). On the panel, Celestine presents the apostle Peter with a book, which probably refers to the Celestine legend that has always been regarded as an autobiography. ${ }^{7}$ In the missal, an initial shows Stefaneschi,

4 Biography: I. Höss, Kardinal Jacobus Gaietani Stefaneschi, Ein Beitrag zur Literatur- und Kirchengeschichte des beginnenden vierzehnten Jahrhunderts, Berlin 1908, as well as Dyкмans, Le Cérémonial Papal (see n. 2). For the documents see: M. V. Schwarz/P. Theis, Giottos Leben (Giottus Pictor I), Vienna 2004, I d 5, e I; II a $4,6, \mathrm{~b} 5$.

6 M. V. Schwarz, Giottos Werke (Giottus Pictor 2), Vienna 2008, p. 50I-524.

7 T. Head, Medieval Hagiography: An Anthology, New York and London 2000, p. 729-743. 


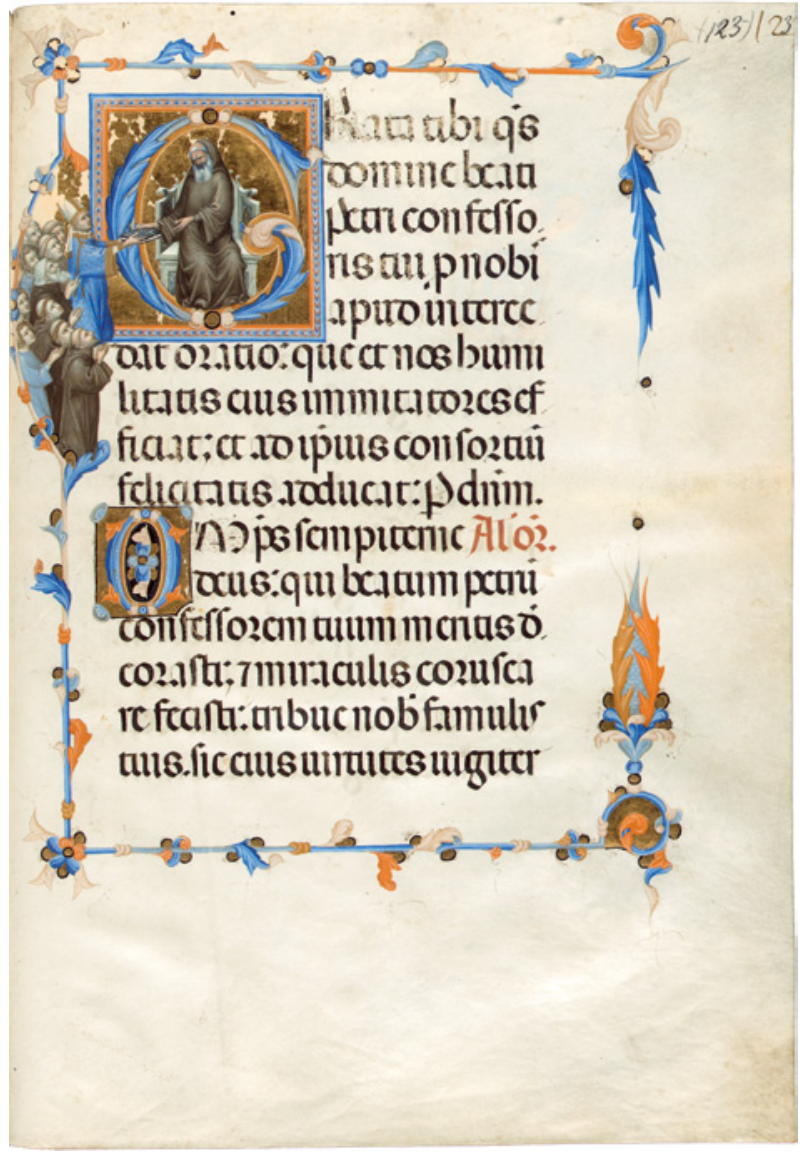

Fig. 3: Missal, Vatican City, Biblioteca Apostolica Vaticana, Archivio di San Pietro, C. 129 , fol. $123 \mathrm{r}$

accompanied by monks and lay people, as he gives a book to Celestine. This almost certainly refers to Stefaneschi's Opus Metricum, a work of history that contained a life of the saint-pope. ${ }^{8}$

Both missal and polyptych are personalized in a similar way for the patron: as a pious cardinal of S. Giorgio in Velabro, he stood under the protection of the knight-saint George; and it was part of his identity to have witnessed the charisma of Celestine V, a.k.a. Peter of Morrone, whose holiness and failure contributed decisively to the church's exile in Avignon. Celestine's appearances also help with the dating of the altar and missal: the canonization took place in 1313 - the terminus post quem for the altar; the parts of the Opus Metricum relating to Celestine had been finished by I3I9 - the terminus post quem for the missal. ${ }^{9}$

Earlier research regarded the Stefaneschi retable as the former pictorial decoration of the high and papal altar of Old St Peter's. It has since become clear that it was made for the altar in the choir of the chapter, the chapel of S. Maria in Cancellis, an enclosed area in the north-west

8 F.X. Seppelt, Monumenta Coelestiniana: Quellen zur Geschichte des Papstes Coelestin V., Paderborn I92I, p. I-I46.

9 Ibid., p. XXXVII; R. Morghen, Il cardinale Iacopo Gaetano Stefaeschi e l'edizione del suo Opus Metricum, Bullettino dell'Istituto Storico Italiano e Archivio Muratoriano, 46, I93I, p. I-39. 
part of the basilica's central aisle, where the canons' stalls were situated. The Marian altar there was effectively the second high altar of the church; in the pope's absence or incapacity, it was used for the celebration of high mass. So instead of decorating the liturgy of the pope (when he was in Rome), the polyptych provided a splendid backdrop for that of the canons. ${ }^{10}$ The missal was probably for use at the same altar. ${ }^{11}$ This would also correspond with the Marian accent in the painted decoration: there are no less than three figural initials in the texts for the feast of the Annunciation, the first of which shows the Virgin as a refuge for believers and suggests a context with a Marian shrine (fol. Ir). If this is right, then the polyptych and missal are parts of the same programme: from his new base in Avignon, the cardinal showed the Virgin, St Peter, and his brother canons that he continued to take seriously his duties at St Peter's. Through his portraits and spiritual preferences, he also brought himself into the liturgy of a church that remained the most important pilgrimage destination in Christendom. In fact, the tomb of St Peter had become more attractive than ever following the holy year of 1300 , which had been heavily promoted - among others, by Stefaneschi. ${ }^{12}$ The strategy of magnificence, finally, also joins the two works: if the cardinal commissioned one of the first large polyptychs for the altar (the second according to current knowledge, after the Maestà of Siena Cathedral), and, in Giotto, chose the most renowned mural and panel painter of the time, then for the no-less ambitious missal he engaged an illuminator unrivalled in the first half of the Trecento.

\section{THE ARTIST AND HIS MODELS}

An impression of his brilliance can be gained from the initial " $E$ " at the beginning of the George legend composed by Stefaneschi himself, which shows a highly sophisticated variation on the theme of Auctor in littera (fol. I7r, Fig. I). The body of the initial appears to be not so much painted with, as cast in, ultramarine. Around it lies lambent foliage work in iron-oxide red. Its stylization is Gothic, although such thistle forms are unknown in the core lands of the Gothic. The chair is of marble - the sharp edges leave no room for doubt - but should we imagine that it is placed on the lower curve, or hung into the

io B. Kempers/S. de Blaauw, Jacopo Stefaneschi, Patron and Liturgist: A new hypothesis regarding the date, iconography, authorship and function of his altarpiece for Old Saint Peter's, Mededeelingen van het Nederlands Instituut te Rome, 47, N. S. I2, 1987, p. 83-II3; S. DE BlaAuw, Cultus et Decor: Liturgia et Architettura nella Roma Tardoantica e Medievale, 2 vols, Vatican City I994, vol. 2, p. 66I-668, 700-707.

iI Kempers/de BlaAuw, Jacopo Stefaneschi (see n. Io), p. IO2. Three further suggestions have been made so far: that it was for Stefaneschi's private use; that it served the George altar founded by Stefaneschi in St Peter's at the tomb of his mother; and that it was for Stefaneschi's titular church, S. Giorgio in Velabro (B. Drake Boenm in Kanter et al., Painting and Illumination, see n. 2, p. Ioo). The first theory can be rejected because Stefaneschi was never ordained as a priest, and so never read a mass himself (HösL, Kardinal Jacobus Gaietani Stefaneschi, see n. 4, p. I7-18). Regarding the second theory, it is certainly possible that the missal was used at both of these altars in St Peter's - the Marian altar of the chapter and that of St George. The third theory has to deal with the questions of not only how, but also why the book was removed from the church of S. Giorgio in Velabro and came into the possession of the chapter of St Peter's.

I2 G. Ragionieri, Jacopo Stefaneschi e il De Centesimo: un cardinale testimone del primo giubileo, in: La storia dei Giubilei I: 1333-I423, Rome I997, p. 216-223. 
letter? Closer examination shows that the transom of the "E" penetrates an opening in the back of the chair - an arresting motif which inhibits a stringent representation of space and simultaneously enhances the impression of tangibility. The paradoxical effect strengthens the semantic reading of the seat: it is throne, bookshelf, and galero-stand in one - and, furthermore, equipped with a wooden writing surface, the simplicity of which contrasts with the marble work. The manifold character of the chair clearly refers to the multiple roles of its occupant: author, prince of the church, donor.

He sits attentively between pretentious marble and raw wood. The throne almost seems too small for him and to slide away backwards, while Stefaneschi's figure pushes into the foreground, even though the writing surface and transom of the letter cut across his figure. This impression partly derives from his prominently lit knee and the cushion for his feet, which seems to slip through the picture plane - although the viewer might doubt that the painter had any concept of a picture plane. Primarily through Giotto's work, this concept (Leon Battista Alberti's "velum"), which was destined to enable a consistent pictorial space, was gaining ground among painters in the first quarter of the Trecento, but was by no means common currency; ${ }^{13}$ (it was also more difficult to apply to figural initials and illumination in general than to panel and mural painting). As a whole, the initial presents an elaborate construction, but without being in any sense rushed or deficient. While offering an easily accessible meaning, it problematizes and intensifies perception.

This continues in the narrative: on the right-hand side, St George appears in a medallion. Only upon closer inspection is one struck by his open mouth and the two index fingers with which he points towards himself. The addressee can hardly be Stefaneschi, who writes listening to an inner voice, but rather the marble dragon on the throne whose alert, bat-like face is the most lively moment of the image: the punctum, one might say. Apparently unbeknown to Stefaneschi, the story of George and the dragon is re-enacted in the drollery mode. This involves the saint being pushed to the edge of the page, and the figure that actually belongs there, namely the dragon, being turned to stone in the initial.

The last motifs mentioned provide insight into the illuminator's stock of models: in terms of facial features and manner of representation, right down to hair-styling and modelling, the head of St George is based on a model of Simone Martini or his circle, such as the angels' heads in the Maestà of the Palazzo Pubblico in Siena (around I315; Fig. 4). ${ }^{14}$ The dragon, by contrast, is taken directly or indirectly from a French model and from the field of marginal decoration: a similarly alert creature can be found in a south French manuscript from shortly before 1300 in Graz (Universitätsbibliothek, Cod. 32, fol. 3r; Fig. 5) ${ }^{15}$ Finally, the plastic leaf that effectively completes the half-figure of George also has definite origins. This is undulatory foliage (or Buckellaubwerk in German), a form of Gothic architectural ornament that was developed in Western Europe in the late thirteenth century, spread slowly in the fourteenth century and

I3 M. V. Schwarz, Giotto, Munich 2009, p. I24.

I4 A. Martindale, Simone Martini: Complete Edition, Oxford 1988, p. 16-17, 204-209. The fresco cannot be dated precisely: it was begun after I3II, influential by 1316-17, reworked in I32I.

is E. Kubina/M. Schuller-Juckes, Die Illuminierten Handschriften I200 bis I300 (Die Illuminierten Handschriften der Universitätsbibliothek Graz) (in preparation). 
reached other media, before becoming the dominant Gothic ornamental form in the fifteenth century. ${ }^{16}$ Its appearances in book illumination of the first half of the fourteenth century were rare. The only other example I could find is in the book of hours of Jeanne d'Evreux from 1325-28 (New York, The Cloisters), where - as in the Stefaneschi missal - the form is only applied once (fol. 35r). ${ }^{17}$ Yet the lack of similarities beyond this foliage type implies that these are independent examples of the reception of architectural ornament. It is, however, less surprising to find Jean Pucelle attempting to integrate modern Gothic ornament in a commission for the French crown than to observe the same phenomenon in the patronage of a cardinal from a Roman family. Here the extent of our painter's interest in exquisite and modern motifs becomes particularly manifest.

Exquisiteness and modernity are also apparent on fol. 85r, the best known (and most worn) page of the manuscript, where the mass in honour of $\mathrm{St}$ George begins (Fig. 6). The lake motif is particularly attractive. Only at first glance, however, does this appear to be a study of nature (of the sort that could anticipate the experience of coming generations $)^{18}$. A second look reveals a simple schema: the water surface consists of undulating parallel lines, through which fish, as though drawn, are visible. This is derived from classical representations of the sea, and Giotto depicted the Sea of Galilee in this manner in his
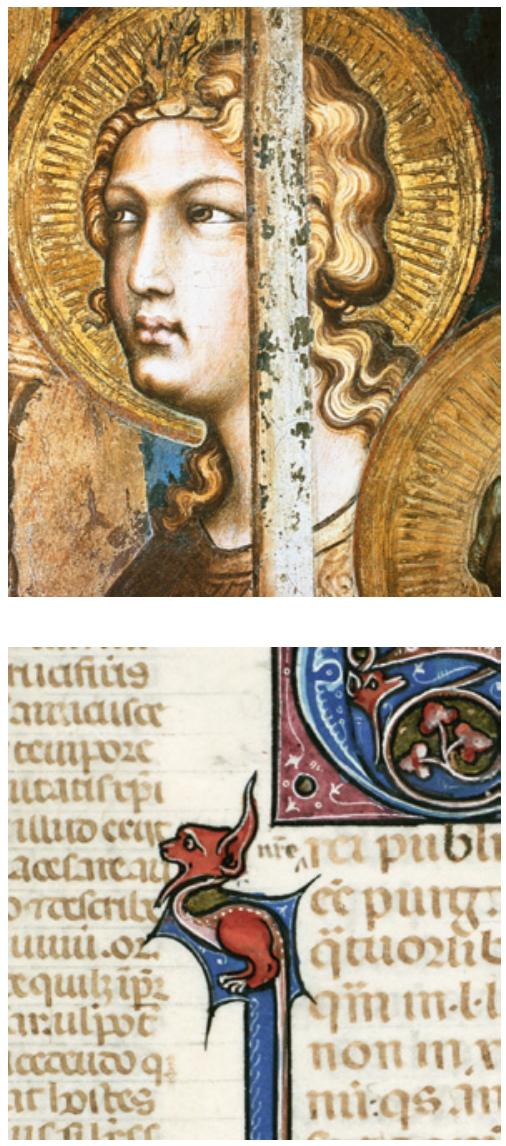

Fig. 4: Simone Martini, Maestà (detail), Siena, Palazzo Pubblico

Fig. 5: Digestum vetus, Graz,

Universitätsbibliothek, Cod. 32, fol. $3 \mathrm{r}$ Navicella. ${ }^{19}$ Unfortunately, the mosaic, which was also commissioned by Stefaneschi, is not preserved in the original, and the comparison therefore relies on reconstructions of Giotto's picture. Nonetheless, the method was applied by Giotto in his Jonas medallion in the Arena Chapel, and the result is close to the missal not only in terms of the pattern but also of the water's visual effect. What the illuminator adds, thus heightening the impression of nature, are the reeds and the larger animals.

I6 F. Bond, Gothic Architecture in England, London 1905, p. 436-438. H. WeIgerT, Das Kapitell in der deutschen Baukunst des Mittelalters, Zeitschrift für Kunstgeschichte 5, I936, p. 7-47, IO3-I24, esp. II3-II5.

I7 M. Krieger, Grisaille als Metapher: Zum Entstehen der Peinture en Cameau im frühen I4. Jahrhundert, Vienna 1995, p. I7-36. - F. Avril, Buchmalerei am Hofe Frankreichs. 1310-I380. München 1978, Farbtafel 4.

I8 K. Stierle, Francesco Petrarca: Ein Intellektueller im Europa des I4. Jahrhunderts, Munich and Vienna 2003, p. 57.

I9 W. PAESELER, Giottos Navicella und ihr spätantikes Vorbild, Römisches Jahrbuch für Kunstgeschichte, 5, I94I, p. $49-162$. 


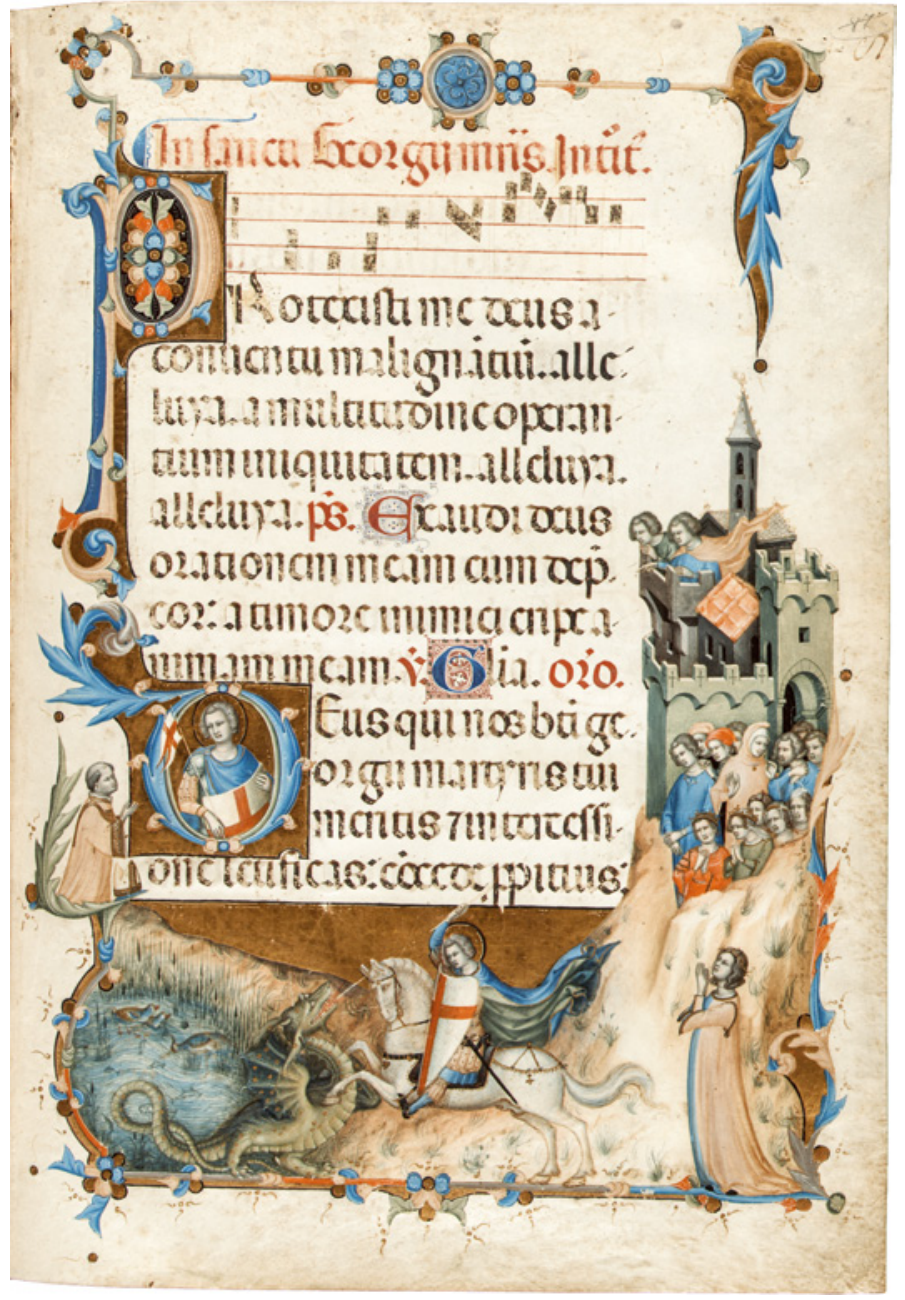

Fig. 6: Missal, Vatican City, Biblioteca Apostolica Vaticana, Archivio di San Pietro C. I29, fol. $85 \mathrm{r}$

It is also possible to identify which models he had in mind when designing the righthand margin of the leaf. Here it is necessary to refer to two panels by Duccio for the back of the Maestà of Siena Cathedral (I308-II). In his picture of Christ's Entry (Fig. 7), the Jerusalemites recall the group of inhabitants assembling before the town gate in the missal. ${ }^{20}$ The vague and yet efficient linkage with the gateway is similar in both works, as is the rhythm of the variously inclined heads. But whereas Duccio strived to suggest chance, the figuration in the missal appears elegant and conscious of form - that is, more artificial. This impression is strengthened by comparison with Simone Martini's reworking of Duccio's solution for the so-called Antwerp polyptych, which was created for a member of the Orsini family and thus for a relative of Stefaneschi: the small panel with the Road to Calvary in the Louvre shows, pushing out of the town gate, a crowd in which no one head or body moves in the same

20 J. White, Duccio: Tuscan Art and the Medieval Workshop, London 1979, p. II4-II6. 
way as another. ${ }^{21}$ Either our illuminator was unaware of these developments, or they did not fit into his scheme.

The form of the town itself also goes back to Duccio. Particular mention should be made of the towns in the panel with the Temptation of Christ from the predella of the Maestà (New York, Frick Collection; Fig. 8): ${ }^{22}$ the similarities are apparent right down to the distinctions in colour between the walls and the buildings they harbour, or the tactile and enlarged portrayal of roof tiles (the red of which has faded in the codex). In both cases perspectival effects generate stereometric bodies, and in both cases the methods - at least by our standards - are applied inconsequently: the painters were not really certain whether their vanishing lines should converge or diverge (in the sense of socalled reverse perspective, which is with some justification regarded as typical of Byzantine art). Ultimately the representations are perhaps more similar in terms of projection than was advisable in the context of the manuscript. While the view from above and the toy effect in the panel were motivated by the narrative

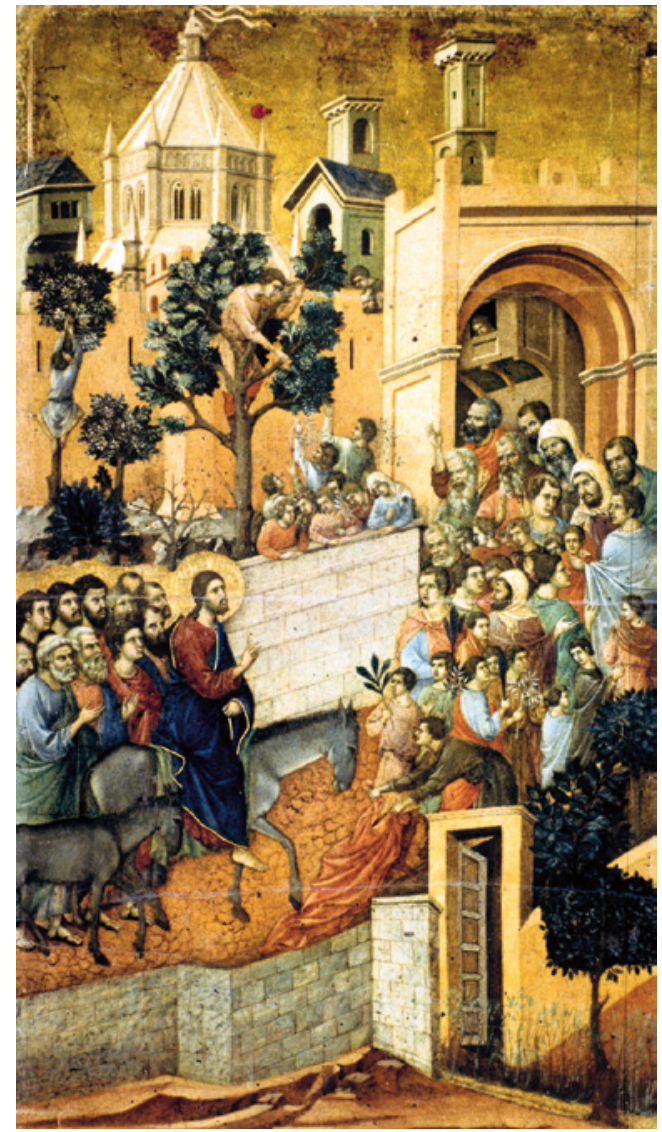

Fig. 7: Duccio, Christ's Entry into Jerusalem, Siena, Museo dell'Opera del Duomo (Christ and Satan stand on the mountain and look across the country), the customary manner of presentation would have been more appropriate for the town in the codex, and that can only mean projection from a lower standpoint. That this requirement is not ahistorical is shown by other examples, including once again Duccio's Entry into Jerusalem from the Maestà and the Orsini Way to Calvary by Simone, but also a miniature in a Jean Pucelle manuscript - the edition of the Miracles de Notre-Dame of Gautier de Coincy, which was written around 1330-35 (Paris, BN, Ms. nouv. acq. fr. 2454I, fol. 70v; Fig. 9). As Stefaneschi's illuminator had done, Pucelle resorted to a Sienese city view (this time even with traits of the real Siena), and again the perspective is contradictory in detail. But the architectural complex as a whole appears to the viewer as seen from below, so that the towering forms are both impressive and realistic. ${ }^{23}$ The contrast with

2I Martindale, Simone Martini (see n. I4), p. 52, I7I-I73.

22 White, Duccio (see n. 20), Fig. I9.

23 H. Focillon, Le peintre des Miracles Notre-Dame, Paris I950. Cf. Giotto e il Trecento: "Il piu sovrano Maestro stato in dipintura" (Exh. Cat. Rome), ed. A. TomeI, Milan 2009, Le opere, no. I24 (M. Besseyre). 


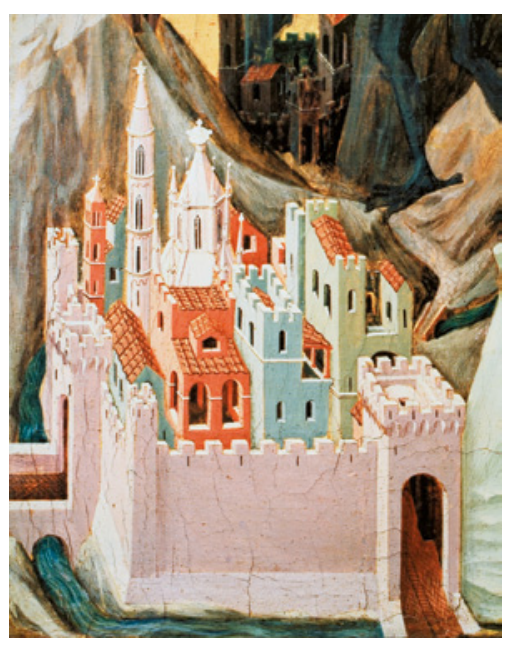

Fig. 8: Duccio, Temptation of Christ (detail), New York, Frick Collection the missal makes clear the unreal and almost belittling effect of the bird's-eye view chosen there.

There are also Florentine characteristics. The connections to Giotto's Navicella, which drew on Roman traditions, do not really belong to this category. More relevant are certain traits of the initial " $\mathrm{D}$ " marking the beginning of a prayer during the mass for the Annunciation (fol. Iv; Fig. Io). Elements of the art of the (post-) Paduan Giotto appear here like citations and almost in deliberate contrast with the other paintings of the codex: clear positioning, simple outlines, the draperies plainly composed and accentuated by straightforward lighting. The likely source was the Stefaneschi altar, particularly the middle panel of the front side where Christ sits enthroned in full corporeality (Fig. II), a figure with which Giotto connected to the Ognissanti Madonna. The unusual kneeling motif of the angel on the Stefaneschi altar is also striking: the leg closer to the viewer is raised, the foot further away is turned towards us; if it were not covered by cloth, the sole of the foot would be visible. This dancerishly elegant posture is known in French Gothic sculpture; in Italian painting it appears rarely, if at all, before the Stefaneschi altar and missal. Such a kneeling position has a dynamism still more appropriate for a freshly landed angel annunciate than for the worshipping angel on the panel. In the missal, the effect is underlined by the angel's wing equipment and the protuberant foliage work on the ascender of the letter.

The connection with the Stefaneschi altar is strengthened by a further motif in the second representation of Stefaneschi as the author of the George legend (fol. 4Ir), which in many respects follows the initial "E". Instead of the Gothic throne (that reflected the latest developments in High Gothic microarchitecture, as too did the lost frame of the altar, which can be seen in the donor's portrait in the central panel of the front side) ${ }^{24}$, the illuminator chose here a half-round marble chair with vase-like finials, a variant of the classicizing throne of the Madonna on the predella of the altar. Incidentally, before it left Giotto's atelier for Rome, Stefaneschi's polyptych had already attracted the attention of Florentine artists. Among those who profited was the painter and illuminator, Pacino di Bonaguida, whose biography and style are well documented. ${ }^{25}$ In cases where there are stylistic or motific indications of a relationship between the missal and Florentine works, it must therefore be asked whether these were not indirect - the consequences of the model function of the Stefaneschi altar, firstly on the Arno and then on the Tiber. It is correspondingly difficult to prove the aforementioned theory that the codex was made in Florence or by an illuminator who was Florentine, an idea that has been

24 Schwarz, Giottos Werke (see n. 6), p. 496-50I.

25 Ibid., p. 592. For a reaction to the Stefaneschi altar in a miniature executed by Pacino, see Cambridge, Fitzwilliam Museum, Marley Cutting It. 83 (Kanter et al., Painting and Illumination, see n. 2, no. 4j). 
Fig. 9: Miracles de Notre-Dame, Paris, Bibliothèque nationale de France, nouv. acq. fr. 2454I, fol. $70 \mathrm{v}$

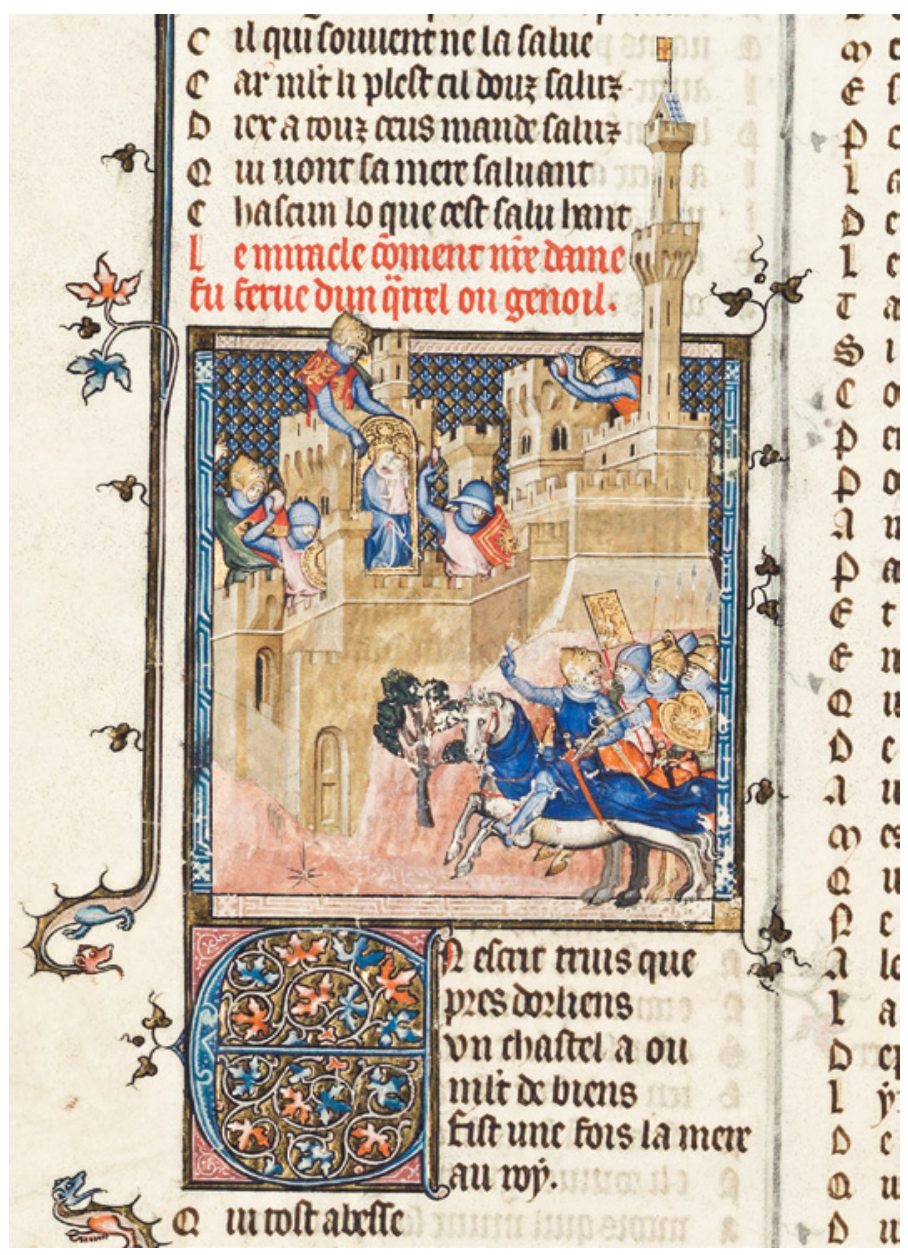

based exclusively on visual evidence and yet has proved virulent. ${ }^{26}$ What remains plausible is that he had studied the Stefaneschi altar and incorporated parts of it within his repertoire.

By way of preliminary conclusion: Stefaneschi's illuminator was at once a creative and an eclectic artist, who was able to combine material from different sources. There is Giotto with the Navicella and Stefaneschi altar - Roman works from distinctly different periods. There is much Sienese from the second decade of the Trecento. And there are also patterns from Gothic decorative art, which, however, only appear in a marginal and alienated manner. These elements were brought together by the painter in a way that definitely did not correspond to the general trend of the first decade of the Trecento. This would have meant using them for mutual authentication and for the creation of appearances analogous to reality. Where he refused to be dominated by the Stefaneschi altar, our illuminator created artificial effects that questioned the reality of what was being represented, emphasizing delicacy and elegance. Alongside the

26 Cf. F. Manzari, La miniatura nel secolo do Giotto, in: Giotto e il Trecento (see n. 23), I saggi, p. 27I-289, esp. 279. 


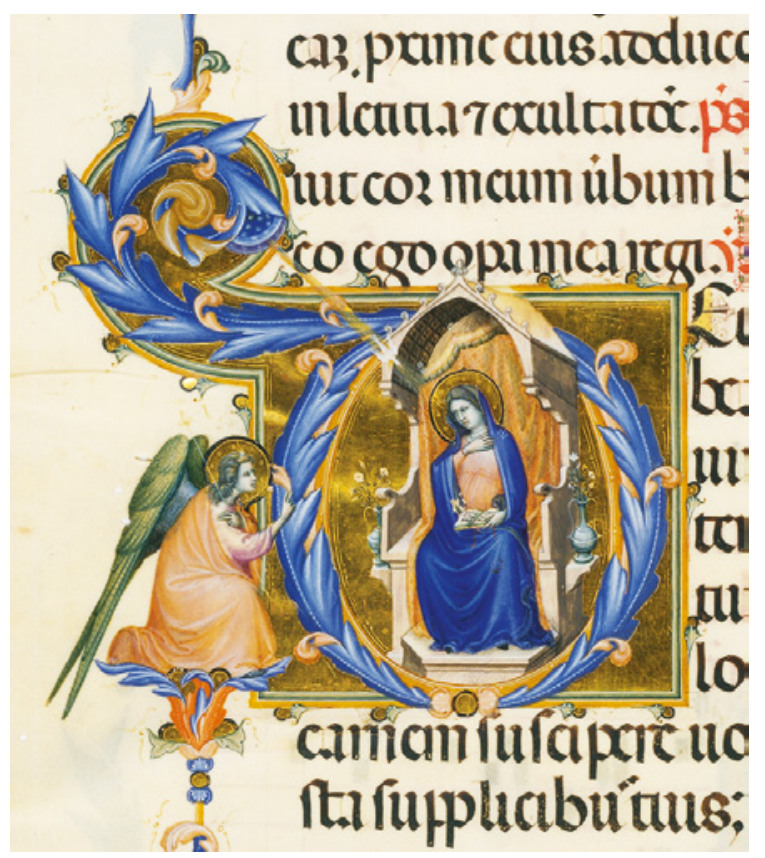

Fig. Io: Missal, Vatican City, Biblioteca Apostolica Vaticana, Archivio di San Pietro, C. I29, fol. Iv

writing author on fol. $\mathrm{I} 7 \mathrm{r}$, another paradigmatic invention is the equestrian saint on the lower border of fol. 85r: the boyish knight, the overtly late classical or Byzantine horse, the flapping cloth completing the composition of the picture. Dragon, horse, and rider find themselves turned into a vignette. In order to make further progress here, it must be asked whether the deviations from the Trecento mainstream are simply idiosyncratic, or whether the art of the painter has an unidentified component that prompted such an interpretation of his sources.

Emphasis should also be placed on the virtuosity with which the artist plays with the medium of book illumination: how he distributes pictorial elements between the initial and the margin at the beginning of the George legend, and employs the comic mode in doing so; how he accommodates the Annunciation partly inside, partly outside the letter; how he organizes the page with the dragon battle so that the viewers in the town look through or beyond the text-field. If the decorative and elegant are among the core elements of his art, then so is the familiarity with the medial potential of the parchment sheet as unifier of text and painting.

\section{LOCAL COLOUR}

There has so far been little mention of non-figural illumination, neither in this article nor in the existing literature on the manuscript. The dominant motif is the thin and material bars, which are composed of stems varying between blue, pink, and iron-oxide red with buds opened to different degrees, as well as small knots and pearls. These frame the text of certain pages at the upper, lower, and either the inner or outer border, while the remaining border is decorated by dynamically fluttering offshoots that emanate from above and below. In terms of form and colour, very similar bars can be found in the book production of Bologna - albeit without such 
exclusive application for three-sided marginal decoration, and not in works of the early to midfourteenth century, but rather of the late thirteenth century (i. e. the so-called second style). Here they occur in richly decorated bibles that, at least in part, were produced for members of the curia. ${ }^{27}$ What emerged from Bologna in the time of the Stefaneschi missal - this means works of the so-called third style, which was no longer elitist but rather mass-produced - shows the bars in aesthetic decline: the colours heavy and dark, the motifs swollen and disassociated. ${ }^{28}$ It would be tempting to attribute to our painter or his patron retrospective interest in Bolognese bibles of the late Dugento - if it were not for a series of Roman manuscripts made largely for the curia or its orbit around $1300 .{ }^{29}$ The marginal decoration of these works appears to be an intermediate stage between the older Bolognese manuscripts and the missal - corresponding to the Bolognese bars in form, but to the missal in the mise en page. This partly involved codices connected with the young Stefaneschi - i. e. with the canon and cardinal, who was still based in Rome - although they were not necessarily from the same workshop or painter as the missal. ${ }^{30}$ In other cases, there is no apparent link to Stefaneschi: this applies to the Hebrew manuscripts showing near identical marginal decoration, ${ }^{31}$ and to the two most magnificent and high-quality codices of the group - a collection of texts on the history of Rome made for Landolfo Colonna (Paris, BN, Ms. lat. 5690) ${ }^{32}$ and the Exultet of St Peter's (BAV, Archivio di San Pietro, B. 78; Fig. I2 $)^{33}$.

Moreover, it would be better to speak less of retrospective intentions than of a striving for continuity, since the painter clearly and subtly modernized the marginal motifs for application in the Stefaneschi missal: the Gothic thistle leaves, which in fact replaced palm leaves, have already been mentioned, as has the exquisite undulatory foliage. The desire to update motifs is most clear, however, in the painter's remodelling of the typical flabella - with their golden backing and black outline - into blazing and vegetable objects, which surpass

27 A. Contr, La miniatura Bolognese: Scuole e botteghe I270-I340, Bologna I98I, p. 37-54.

28 It is precisely these characteristics that show similarities with marginal decoration in Florentine and other Tuscan manuscripts from the first decades of the Trecento. The frames in the missal are thus not directly related to either contemporary Bolognese or Florentine production. For a contrasting view, see: Giotto e il Trecento (see n. 23), p. 288 (F. MANZARI).

29 Roman illumination of the late thirteenth century has attracted little attention. Important works are: V. PACE, Per la storia della miniatura Duecentesca a Roma, in: Id., Arte a Roma nel Medioevo: Commitenza, ideologia e cultura figurativa in monumenti e libri, Naples 2000, p. 20I-2I7 (updated version of an older text); Id., Codici miniati a Roma al tempo del primo Giubileo, in: Roma I300-1875: La città degli anni santi, ed. M. FIGiolo and M. L. Madonna, Milan 1985, p. 319-332; S. Maddalo, Da Magister Nicolaus al Maestro del Codice di San Giorgio: Linee di sviluppo del libro miniato a Roma nella seconda metà del Duecento, in: Bonifacio VIII e il suo tempo (Exh. Cat. Rome), ed. M. Righetti Tosti-Croce, Naples 2000, p. 99-io2.

30 For counter-arguments from a palaeographical perspective: Emma Condello, I codici Stefaneschi: uno scriptorium cardinalizio del Trecento tra Roma e Avignone?, Archivio della Società Romana di Storia Patria IIo, I987, p. 2I-6I.

3I For example, Cambridge, Emmanuel College Ms. I. I. 6. G.Z. Zanichelli, Manoscritti Ebraici Romani, in: Bonifacio VIII e il suo tempo (see n. 29), p. III-II6, esp. Fig. 5.

32 F. Avril and M.-T. Gousset, Manuscrits enluminés d’origine Italienne: XIIIe siècle, Paris I984, no. I66. Bonifacio VIII e il suo tempo (see n. 29), no. I76 (M.-T. Gousset).

Bonifacio VIII e il suo tempo (see n. 29), no. 133 (E. Condello). 


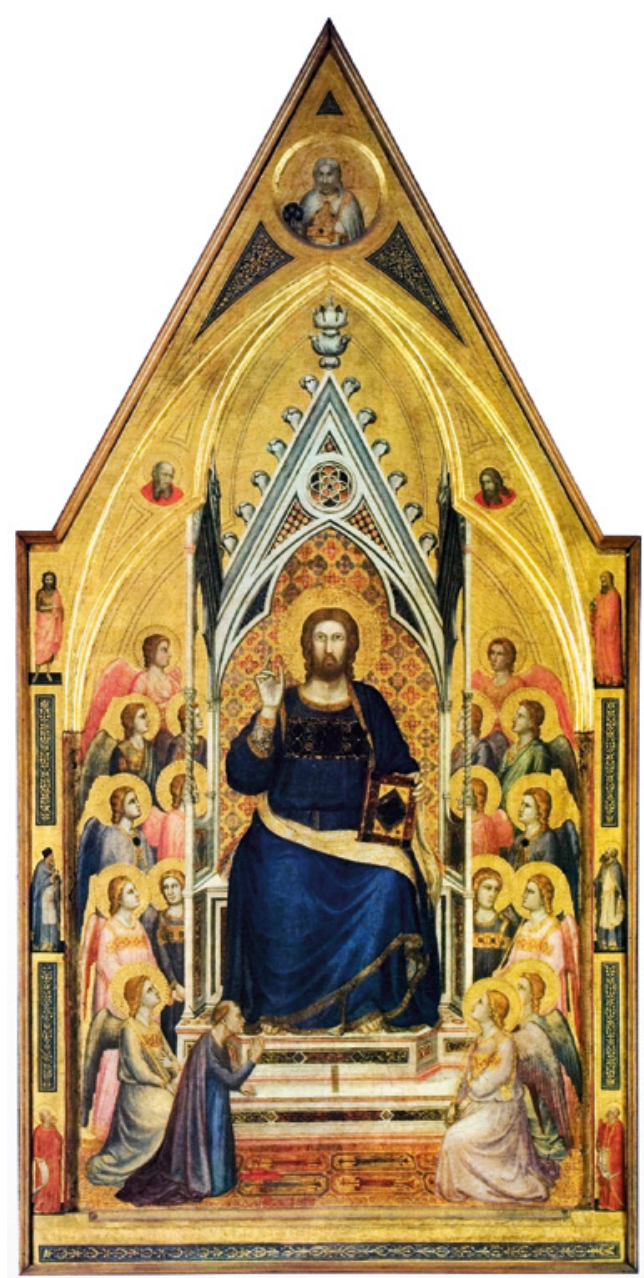

Fig. II: Giotto, Stefaneschi altar, front side of the central panel, Vatican City, Pinacoteca Vaticana much of the figural detailing in expressive power. Thus, as far as marginal decoration is concerned, Stefaneschi's missal represents an inspiringly modernized continuation of Roman traditions, which themselves were interwoven with Bolognese traditions. The continuity-forming element in the overall structure appears as strong as the striving for modernity in detail.

Examination of examples of Roman production around I300, such as the Exultet of St Peter's, is also worthwhile for the figural elements (Fig. I2). In the figural initial "E" on fol. $3 \mathrm{r}$, the tangibility of the ambo and the very presence of the architectural forms catch the eye. Just as the perspective is uncertain and, to our eyes, partly contradictory, so the individual stone parts seem real. It is not least of all because the painter projected each block and slab independently that they demand to be touched and examined in terms of their stability. This effect is reminiscent of the initial on fol. $17 \mathrm{r}$ of the missal, where the pinnacle on the left is set slightly askew to the throne, and so seems haptically real and unstable.

In the scene on the lower border of fol. $3 \mathrm{r}$ of the Exultet, it is striking that the form and decoration of the sarcophagi show the application of classical elements - a thought that fits well into the artistic culture of Rome

around 1300 . Similarly fitting is that the protagonists are conceived as combinations of classical and late Byzantine figures. The parallel for this in monumental art is found in the figures of Pietro Cavallini - in their corporeality, roundly modelled by means of light and shadow, in their perfection and elegant vagueness. And, little different from the actors of the narrative at the bas de page, the celebrants appear in the liturgical scene of the initial in convincing plasticity and with youthful beauty, encased in richly detailed drapery - antecedents of the figurines in the Stefaneschi missal, but also of the less harmoniously conceived figures of Giotto, whose artistic path, as can be shown, began in late Dugento Rome. ${ }^{34}$

34 Schwarz, Giottos Werke, (see n. 6), p. 219-25. Before assuming that the figures in the missal's miniatures were directly connected to Giotto, it is thus important to consider the common prehistory in Roman painting and 


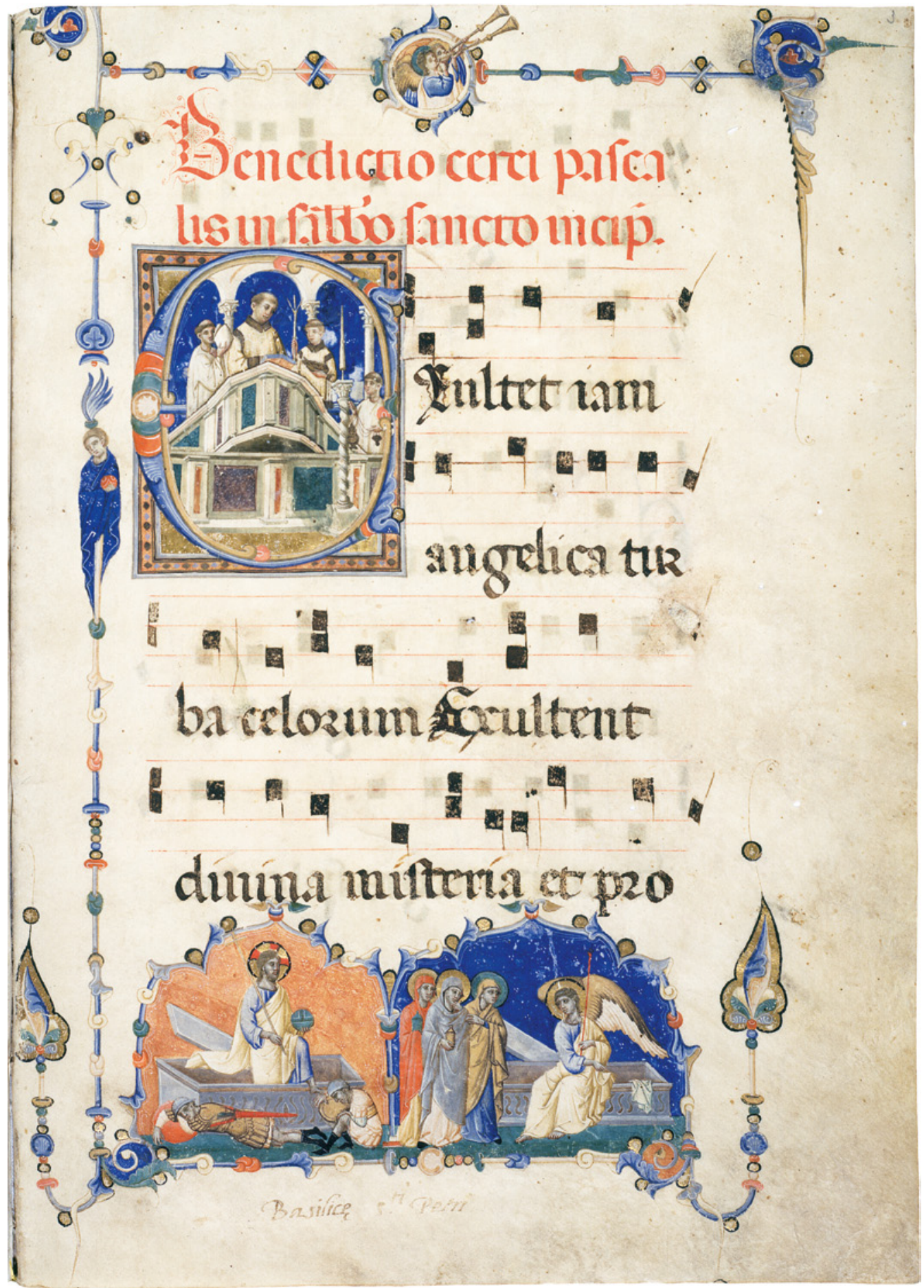

Fig. I2: Exultet, Vatican City, Biblioteca Apostolica Vaticana, Archivio di San Pietro, B. 78, fol. 3 r 


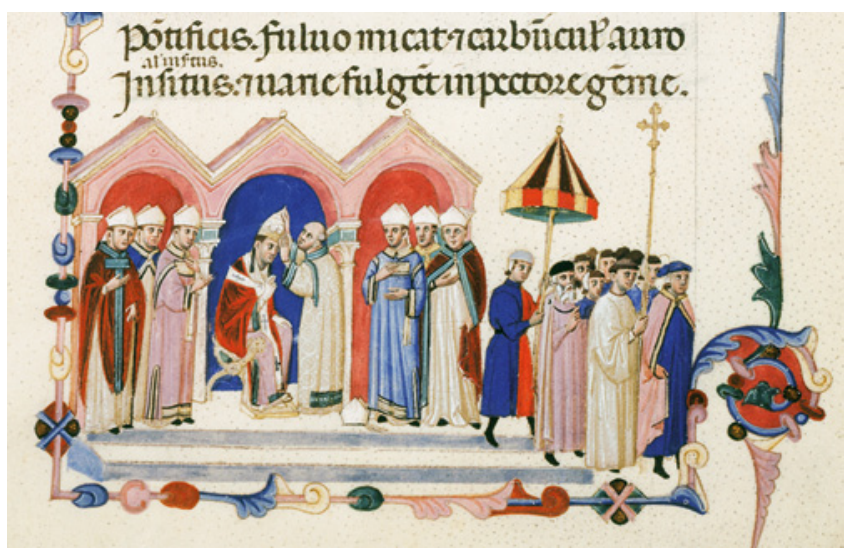

Fig. 13: De Coronatione, Vatican City, Biblioteca Apostolica Vaticana, Vat. Lat. 4933 , fol. $7 \mathrm{v}$

In Roman manuscripts around 1300 , the described characteristics sometimes approach the delicate. A copy of Stefaneschi's work De Coronatione (BAV, Ms. Vat. Lat. 4933) 35 $^{35}$ which was made between I298 and I3OI probably for Pope Boniface VIII, contains marginal decoration close to the Exultet - clearly a product of the same artistic culture, but certainly not of the same painter or atelier: the motif of the bars shows a handling too sub-divided, additive, and stiff. The key scene is on the lower border of fol. $7 \mathrm{v}$ with the crowning of Boniface VIII (Fig. 13). The frequency with which the image has been used as an illustration by historians contrasts with its general absence from art historical studies, even though it is not easy to attribute to the scene any source value for the pontificate of the Gaetani pope, which was anything but idyllic. The act of coronation itself is represented unspecifically. The cardinal who put the tiara on Boniface's head was Stefaneschi's uncle and patron, Matteo Rosso Orsini, but the painter made little of this: just an old man in pontificalia. The motifs that lend the scene credibility are the soliculum (the papal parasol), which is very concrete and depicted swaying, and the lovingly detailed folds of the cross-bearer's clothing. The figures appear real, but also like dressed-up children who are acting the event. Certain miniatures in the Parisian manuscript made for Landolfo Colonna can be described in similar terms: in the picture of a cavalry battle illustrating a passage from Titus Livius (fol. 2IIv), for instance, the painting convinces not through drama, but rather confuses with its harmony of composition and the beautiful ponderation of the protagonists, who once again seem childlike. If Stefaneschi's illuminator thus steered against the current of the early Trecento, it can probably be explained as a reference to this visual culture. Unlike most of his central and north Italian contemporaries, our painter preferred artificiality to naturality, delicacy to

illumination. Gosebruch, for example, wanted to attribute the Exultet as well as the Stefaneschi missal (and further related manuscripts; see below) to Giotto or his collaborators: M. Gosebruch, Giotto und die Buchmalerei der Dantezeit, in: Scritti di Storia dell'arte in onore di Roberto Salvini, Bologna 1984, p. I83-I89. This adventurous construct reflects the fact that a considerable part of Giotto's repertoire came from Rome in the time around 1300 (represented by the Exultet), as a consequence of which he and the painter of the missal had a degree of shared artistic experience.

Bonifazio VIII e il suo tempo (see n. 29), no. 75 (E. Condello). 
monumentality, tangibility to pictoriality: he thus continued that - one might say - rococo tendency of curial art under Boniface VIII, which according to Julian Gardner was ended by exile in Avignon. ${ }^{36}$

\section{“PATTERNS OF INTENTION”}

I would like to summarize and contextualize my observations by addressing, firstly, the question of localization. It should have become clear that there is little evidence favouring the Florentine option. The two alternatives to discuss are therefore Rome or Avignon. As I have shown, the base layer of the forms applied in the codex is Roman, and that was probably intended to be visible. In any case, the artist not only adapted motifs: he also sought to retain or create a degree of general similarity with, for instance, the Exultet of St Peter's - a codex of comparable pretensions, together with which our missal spent centuries in the liturgical use of the clergy of the Vatican basilica. That the modernizing elements come primarily from central Italian sources also implies the volume's production on the banks of the Tiber.

The case for Avignon, of course, is strengthened by the patron's presence there. But it is also supported by art historical evidence. Here it should be mentioned that there has been much stylistic research on the missal in the tradition of a history of artists. If in the present study the illuminator assumes an abstract form derived from an investigation of his work (a "model author" without biography and destiny, but capable of anticipating his audience's expectations), ${ }^{37}$ then the other body of research focuses on his empirical figure. Thus he is given not only a name (Il Maestro del Codice di San Giorgio), but also an oeuvre compiled on the premise that his painting had almost biometric characteristics - or more precisely: that a painting's formal features are inevitably biometric instead of social, cultural, functional, etc. ${ }^{38}$ From this group of works (alongside the aforementioned New York volume), the pontifical in the Bibliothèque Municipale of Boulogne-sur-Mer (Ms. 86) and the pontifical of the Parisian Bibliothèque Nationale (Ms. lat. I5619) deserve to be taken seriously as possible products if not of the same painter, then at least emerging from the same situation and atelier. ${ }^{39}$ The figural motifs in the two codices, however, hardly rival those in the missal. Along with the script (an

36 J. Gardner, Opus Anglicanum, Goldsmithswork, Manuscript Illumination and Ivories in the Rome of Bonifacio VIII, in: Le culture di Bonifacio VIII (Atti del convegno ... Bologna 2004), ed. M. Andaloro, Rome 2006, p. 163-179.

37 I refer here to discourses of literary theory as developed in the following work: U. Eco, Six Walks in the Fictional Woods, Cambridge (Mass.) / London 1994.

38 A. Venturi, Storia dell'arte Italiana 5: La pittura del Trecento, Milan 1907, p. 631, IO22-IO30; Z. Ameisenowa, Opere inedite del Maestro del Codice di San Giorgio, Rivista d'arte, 2I, 1939, p. 97-I25; CIARDi Duprè DAL Poggetto, Il maestro (see n. I). Boskovits, The painters (n. I). For a modern concept of style with more solid theoretical foundations: M. BAXANDALL, Painting and Experience in Fifteenth Century Italy, Oxford 1972. Cf. also: M. V. Schwarz, What Is Style For?, Ars, 39, 2006, p. 2I-32.

With regard to the panel paintings attributed to him in Florence, Cracow, and New York, as well as the Graduale Sanctorum in the library of S. Croce in Gerusalemme in Rome (Cor. D), the stylistic counter-arguments are concisely and convincingly presented by Gosebruch (see n. 34). Non-stylistic evidence for the attributions has not been presented. 
Italian rotunda), it is the marginal decoration that constitutes the group - the multi-coloured stems, the thistle leaves, the flaming flabella. Anyone assuming that these forms were distinctly Roman - in line with the arguments presented here - is thus confronted by a group of artists specialized in the production of elitist liturgica with a Roman touch. With regard to the Parisian pontifical, however, it seems that its documented use in Rome during the coronation of Emperor Charles IV was only possible after a long journey: the codex probably arrived in the city with the luggage of the cardinal in charge of the coronation, Pierre du Colombier, who had travelled from Avignon. ${ }^{40}$

There is also a non-liturgical work - a copy of the Liber Visionis Ezechielis of Henricus de Carreto (Paris, BN, Ms. lat. 503, fol. Ir) - with two high-quality figural initials that are stylistically close to the missal, even if their execution is less refined. The cursive text of this codex was almost certainly written in Avignon between 1320 and 1323 by a hand trained in Italy, while the series of full-page miniatures was added by southern French illuminators. ${ }^{41}$ Furthermore, according to François Avril, a southern French draughtsman may well have contributed the series of pen-flourished initials (see fol. $2 \mathrm{r}$ and I4Iv for especially elaborate examples - one with palmettes, one with Gothic leaves), and the same hand seems to have decorated the corresponding initials in the Vatican missal, the volume in New York, and the pontifical in Paris. ${ }^{42}$ This makes it tempting to refer back to the dragon and undulatory foliage on fol. $\mathrm{I} 7 \mathrm{r}$ in the missal, even if Gothic dragons in initials and margins were already acclimatized in Rome ${ }^{43}$, and the use of undulatory foliage in book illumination is too eccentric to have a clear regional affinity. Reference should also be made to Karl-Georg Pfändtner's contribution to the present volume, with its evidence for the presence of French scribes and illuminators in Trecento Italy. ${ }^{44}$ Nevertheless, if one sees the codex as one of a group of manuscripts, then alongside Rome - Avignon represents a plausible place of production.

Is it possible to reach a decision? And, if not, is this due to material or methodological problems? In this context, it is important to bear in mind that the choice "Rome or Avignon" involves places that have been subjected to very different conceptualizations. The empirical city of Rome is a reality that quickly disappears behind Rome as an idea. ${ }^{45}$ Avignon, in contrast, was an administrative centre entirely without aura - where "Rome" was simulated, true to the principle formulated as early as the thirteenth century, "ubi est papa ibi est

40 M. Andrieu, Le pontifical romain au moyen-âge 2: Le pontifical de la curie romaine au XIIIe siècle, Vatican City 1940, p. 9I-98.

4I Dykmans, Le Cérémonial Papal (see n. 2); Il Gotico a Siena: Miniature pitture oreficerie ogetti d'arte (Exh. Cat. Siena), Florence 1982, p. 174-I75 (F. Avril); MAnZARI, La miniatura ad Avignone (see n. I), p. 53-57, 76.

42 Il Gotico a Siena (see n. 4I), p. 172. Avril gives no comparative examples. Nor have I found anything comparable in the published material apparently pertaining to Avignon in the early fourteenth century. Cf. Manzari, La miniatura ad Avignone (see n. I), p. 2I-72.

43 Cf. e.g. Bonifazio VIII e il suo tempo (see n. 29), no. I3I (Ms. Vat. Lat. II55, M. TorQuati) and no. I62 (Ms. Vat. Lat. 7793, F. MANZARI).

44 K.-G. Pfändtner, Die Anziehungskraft der Universitäten: Quellen zu Migrationbewegungen von Schreibern und Buchmalern in der mittelalterlichen Boom-Region Bologna.

45 F. SChneIder, Rom und Romgedanke im Mittelalter. München 1926. 
Roma”. ${ }^{46}$ This raises the question of whether the manuscripts' stylistic apparatus is a symptom of their production in Rome, or rather a signal of the ideal Rome and its traditions; whether the manuscripts' Gothic features were side-effects of the local artistic culture of Avignon, or rather served to convey the vitality and magnificence of the ideal Rome with prestigious modern forms. What one scholar declares to be Avignonese production in order to localize further high-level codices in southern France and establish Avignon as a centre of book illumination ${ }^{47}$, while another scholar perceives a Roman product in order to posit a Stefaneschi-maintained Roman school of Trecento painting, ${ }^{48}$ was more probably the visual medium of a conception of Rome that would have become concrete in the liturgy, whether inside or outside the urbs. This medium's characteristics include an independence not only of its place of use, but also of its place of physical creation. Wherever the painter's desk actually stood as he painted, whether in Rome or Avignon, he was a Roman in terms of culture, and worked in an ideal Rome.

When seen in this light, the application of models from Rome and the Stefaneschi circle requires no further explanation; nor does the resort to Gothic forms. This conclusion is important when it comes to relating the results of the present study to the intentions, horizons, and working methods of the artist. Thus far the missal appears typical of a highly ambitious work: the expectations of the patron and the repertoire of the artist converge to form something coherent and meaningful for the patron. What still requires explanation is the high volume of Sienese forms. These have no obvious meaning, and yet their trace is so evident that the illuminator was previously regarded as a pupil of Simone Martini - and, in fact, this was the original argument for production in Avignon, where the Sienese was active from the middle of the i330s. At that time he painted for Petrarch the famous miniature with Virgil (Milan, Bibliotheca Ambrosiana, Ms. A 79 inf., Iv), and, under the patronage of Cardinal Annibaldo di Ceccano, Stefaneschi's nephew, executed a fresco of St George for the church of Notre-Dame des Doms; ${ }^{49}$ he was probably also commissioned by a member of the Orsini

46 G. Kerscher, Architektur als Repräsentation: Spätmittelalterliche Palastbaukunst zwischen Pracht und zeremoniellen Voraussetzungen. Avignon - Mallaroca - Kirchenstaat, Tübingen and Berlin 2000, p. I8I and passim; M. Maccarrone, Ubi est papa ibi est Roma, in: Aus Kirche und Reich: Studien zu Theologie, Politik und Recht im Mittelalter. Festschrift für F. Keмpғ zu seinem 75. Geburtstag und fünfzigjährigen Doktorjubiläum, ed. H. MordeK, Sigmaringen I983, p. 37I-382.

47 Cf. Manzari, La miniatura ad Avignone (see n. I), p. 83 and I4I ff. The author regards the painter of the Stefaneschi missal as something like the teacher of the painter who played a leading role in the decoration of the Liber Regulae of S. Spirito in Sassia in Rome (Rome, Archivio di Stato, Reg. 3193). In my view - apart from the evidence suggesting that the painter of the Stefaneschi missal worked in Avignon - everything points towards this manuscript's origins in Rome.

48 Ciardi Duprè Dal Poggetto, Il maestro (see n. i). This includes a late dating of the Navicella.

49 E. Müntz, Les peintures de Simone Martini à Avignon,, Paris I885, p. 22 (Offprint from: Mémoires de la Société des Antiquaires de France 45); G. De Nicola, L'affresco di Simone Martini ad Avignone, L’arte, 9, 1906, p. 336-344; Id., Opere del Miniatore del Codice di San Giorgio, L'arte, II, I908, p. 385-386; L. Bellosi, in contrast, regarded the references of our painter to Sienese art as being more of a general nature: Il Gotico a Siena (see n. 38), p. I66. The significance of the Sienese forms has recently been restated: V. Kubík, Na okraj k výzdobě Kodexu sv. Jiři, in: Regnum Bohemiae et Sacrum Romanum Imperium (Festschrift J. KuTHAN), Prague 2005, p. 337-354. 
family to make the aforementioned Antwerp polyptych. ${ }^{50}$ Indeed, the possible authorship or collaboration of Simone would still have to be considered if our painter had not so clearly been such an accomplished book painter (in contrast to the impression made by Simone on parchment in his picture for Petrarch), and if he had not made such an idiosyncratic use of the Sienese motifs. When Sienese illuminators engaged with the large-format inventions of their compatriots during the first decades of the Trecento, the results were quite different: they took on details, but did not confront the challenge posed by the complex visual and narrative structures of a Duccio or Simone. And when they did take up the challenge towards the middle of the century, the results never reached the level of the Stefaneschi missal. ${ }^{51}$ This further implies that our illuminator really must have had works by Duccio and Simone in mind, and did not get his ideas indirectly from other book painters.

Sienese forms enjoyed interregional success from the second decade of the Trecento, and were widely adopted in combination with local forms, particularly in panel painting - even in Florence. ${ }^{52}$ At the same time, they show similarities to Roman forms - as is revealed, for instance, by comparing the figures in Duccio's pictorial narratives with those from the scenes at the bas de page of fol. Ir of the Exultet of St Peter's (Fig. I2): similar proportions, similar modelling, a liveliness that draws on late Byzantine innovations. Sienese art of the Trecento is attributed a tendency towards the lyrical and decorative, something involving characteristics that can also be connected to Roman book illumination under Boniface VIII. In retrospect, the art of Duccio and his successors can be seen as a possible future for Roman illumination of the time around 1300. And it was precisely this role that Sienese painting assumed in the Stefaneschi missal, subtly expanding and modernizing the Roman repertoire. Nonetheless, it remains astonishing that our illuminator turned to Sienese mural and panel painting for material, thus looking well beyond the boundaries of the visual and book culture relevant for his commission. The conditions of the missal's production therefore include, on the one hand, a clear consciousness of tradition, but, on the other, an artist with broad horizons and a surprising openness to workable alternatives.

Universität Wien

Illustration credits: Figs. I, 3, 6, IO, I2, I3: Bibliotheca Apostolica Vaticana. - Fig. 5: Universitätsbibliothek Graz. - Fig. 9: Paris, Bibliothèque nationale de France. - All other illustrations are visual citations from the literature discussed.

50 D. Vingtain, Le séjour avignonnaise de Simone Martini, in: A. M. Guiducci / D. Vingtain, L'héritage artistique de Simone Martini (Exh. Cat. Avignon), Avignon 2009, p. 8-IO.

5 I A. Labriola/Chr. De Benedictis/G. Freuler, La miniature senese i270-I420, Milan 2002. The only exception I have found is the miniature in the life of St Romuald (BAV, Lat. 13674, fol. 2r, attributed to Lippo Vanni), which, however, is far removed from the Stefaneschi missal (Tav. LXXXVII).

52 R. van Marle, The Development of the Italian Schools of Painting Vol. III, The Hague 1924, p. 348-453. 


\title{
DIE TRECENTO-AUSSTATTUNG DES VISCONTI- STUNDENBUCHES - EIN WERKSTATTBERICHT
}

\author{
Carmen Rob-Santer
}

Das Visconti-Stundenbuch stellt ein Schlüsselwerk lombardischer Buchmalerei und eines der prunkvollsten italienischen Stundenbücher überhaupt dar. Was landläufig als das ViscontiStundenbuch tituliert wird, sind heute zwei getrennte Volumina, ein Psalter (BR 397) und ein - an merkwürdiger Stelle davon abgetrenntes - Stundenbuch (LF 22), die heute beide in der Biblioteca Nazionale Centrale di Firenze liegen. ${ }^{1}$ Man muss wohl davon ausgehen, dass die Aufteilung in zwei Bände sich aus dem Wunsch ergab, einen ersten bereits fertiggestellten Teil zu benutzen. ${ }^{2}$ Bis 1969 bzw. 1945 befanden sich die häufig nach ihren Letztbesitzern benannten Codices Visconti di Modrone und Landau-Finaly, die in der Forschung allgemein als Einheit gesehen werden, in Privatbesitz und rückten wohl deshalb - gemessen an ihrem Stellenwert innerhalb der italienischen Buchmalerei - erst relativ spät in den Fokus einer breiteren wissenschaftlichen Betrachtung.

I Die letzten drei Texte im Anhang an den Psalter, Pater noster, Credo in Deum und Quicumque vult, sind zwischen den zwei Teilen des Visconti-Stundenbuches aufgeteilt (die ersten zwei befinden sich am Schluss von BR 397, der dritte zu Beginn von LF 22), obwohl sie eng miteinander verbunden sind. Es folgen die sieben Bußpsalmen in gekürzter Form sowie über die Grenze der ersten Lage (fol. I-8) hinweg die Heiligenlitanei (fol. 4 r-IOv), an die sich innerhalb der zweiten Lage auf fol. IIr das Incipit des Marienoffiziums, der eigentliche Beginn des Stundenbuches, anschließt, sodass nicht auf einen ursprünglichen Plan geschlossen werden kann, die Handschrift in diesem Bereich zu teilen. Allerdings bleibt zu bemerken, dass vor fol. II, dem Beginn des Marienoffiziums, das Gegenblatt zu fol. I3 fehlt; E. Kırsch, Five Illuminated Manuscripts of Giangaleazzo Visconti, University Park und London 1991 (Monographs on the fine arts, 46), S. 89, geht davon aus, dass dieses Gegenblatt wohl nie bestanden hat. Auffällig ist das völlige Fehlen eines Kalendars, entweder vor dem Psalter oder vor dem Marienoffizium. Eine ähnliche Zweiteilung findet sich bei den zeitnahen Très Belles Heures von Giangaleazzos bibliophilem Schwager, dem Duc de Berry, durch Robinet d`Estampes um I4I3, also noch zu Lebzeiten des Herzogs, in den eigentlichen Stundenbuchteil (heute Paris, BNF, Ms. nouv. acq. lat. 3093) sowie ein Gebetbuch und ein Missale, die erst im frühen 18. Jahrhundert in das 1904 verbrannte Turiner Gebetbuch (Turin, Biblioteca Nazionale, K. IV. 29) sowie das vormals Mailänder Missale (heute Turin, Museo Civico d'Arte Antica, Ms. 47) aufgespalten wurden. Einen Forschungsüberblick zu den Très Belles heures liefert E. KöNIG, Die Très Belles Heures von Jean de France Duc de Berry. Ein Meisterwerk an der Schwelle zur Neuzeit, München 1998, S. 239-267. Mit den Handschriften des Duc de Berry kann sich das Visconti-Stundenbuch mit insgesamt 128 Miniaturen auch im Hinblick auf die reiche Ausstattung vergleichen: Die Petites Heures (Paris, BNF, Ms. lat. I8oI4) umfassen II9, die Belles Heures (New York, The Cloisters, Acc. No. 54. I. I) I72 Miniaturen.

2 Dass die beiden Bände wohl nie zusammengebunden waren, hat eine Untersuchung der Heftlöcher von I97I ergeben, als das Visconti-Stundenbuch für fotografische Aufnahmen ausgebunden war. Vgl. M. MeIss / E. KIrsch, The Visconti Hours. Biblioteca Nazionale, Florenz/London 1972, S. 259, Anm. 7. Da sich BR 397 in der Restaurierwerkstätte der BNCF befand, konnte ich keinen direkten Vergleich hinsichtlich der Heftlöcher anstellen. Während für BR 397 im Zuge der aktuellen Restaurierung ein Schema der Heftung angefertigt wurde, ließen sich keine Aufzeichnungen über eine dementsprechende Untersuchung von LF 22 finden. 
Mit Ausnahme der Arbeiten von Millard Meiss und Edith W. Kirsch befindet sich die Forschung zum Visconti-Stundenbuch fest in italienischer Hand. In einer ersten Bearbeitungsphase haben Pietro Toescas Studien ab 1905 bis hin zu dessen Schwarz-Weiß-Faksimile von I95I das „Ufiziolo Visconteo Landau-Finaly“ einer wissenschaftlichen Öffentlichkeit bekannt gemacht und gleichzeitig mit dem Codex Visconti di Modrone in engste Verbindung gebracht. ${ }^{3}$ Im Zentrum standen dabei Fragen des Stils und der ausführenden Künstler bzw. Werkstätten, die Toesca als Giovannino de Grassi und Belbello da Pavia identifizierte.

Zwölf Farbtafeln von LF 22 publizierte Umberto Baldini 1963, wobei es sich jedoch um Details handelte; in den Zuschreibungen folgte Baldini weitestgehend Toesca. ${ }^{4}$ Edoardo Arslan setzte sich zur selben Zeit vor allem mit Datierung (zwischen 1370 und 1390$)^{5}$ und Stil des Visconti-di-Modrone-Codex auseinander und fand darin weniger lombardische und italienische, denn französische, nordische und böhmische Einflüsse. Er setzte den Codex in engste Beziehung zu einem Pariser Stundenbuch (BNF, Ms. lat. 757, um I380) und dem Liber Viaticus des Johannes von Neumarkt aus der Prager Bibliothek des Nationalmuseums (Ms. XIII A I2). ${ }^{6}$

In den I970ern datierte Luisa Cogliati Arano das Stundenbuch in das Jahr 1370. ${ }^{7}$ Millard Meiss und Edith W. Kirsch legten schließlich 1972 eine Faksimilierung der 37 hauptsächlich ganzseitigen Miniaturen und historisierten Initialen von BR 397 sowie der 9I von LF 22 samt Kommentar vor und stellten die Forschung zum Visconti-Stundenbuch somit auf eine neue Basis. ${ }^{8}$ In der Vertiefung mancher Thesen trat Kirsch 1991 für eine Datierung des Arbeitsbeginns am Visconti-Stundenbuch in Zusammenhang mit der Geburt von Giangaleazzos Sohn Filippo Maria I388 ein; eine These, der sich die Forschung seitdem weitgehend angeschlossen hat. ${ }^{9}$

Ebenfalls ab den I970ern hat Antonio Cadei in seinen Untersuchungen zum Visconti-Stundenbuch vorrangig nach den beteiligten Künstlerpersönlichkeiten gefragt und dabei versucht, weitere Künstler zu identifizieren, die Filippo Maria nach dem Tod seines Vaters Giangaleazzo († I402) zur Fortführung der Arbeiten an LF 22 - noch vor der Weiterführung durch Belbel-

3 P. Toesca, Michelino da Besozzo e Giovannino de Grassi, in: Larte, 8, 1905, S. 32I-339; Ders., A proposito di Giovannino de Grassi, in: L’arte, 9, I906, S. 56 f.; Ders., Di alcuni miniatori lombardi della fine del Trecento, in: L'arte, I0, 1907, S. 184-196; Ders., La pittura e la miniatura in Lombardia. Dai più antichi monumenti alla metà del'400, Mailand ı9ı2, ND Mailand 1966 (Biblioteca di storia dell'arte, 6); Ders., Il Trecento, Turin I95I; Ders., L’Ufiziolo Visconteo Landau-Finaly, Florenz I95I. U. BAldini, Uffiziolo Visconteo, Mailand 1963 (Pittura Universale).

5 E. ArSLAN, Riflessioni sulla pittura gotica ,internazionale “ in Lombardia nel tardo Trecento, in: Arte Lombarda, 8.2, 1963, S. 25-66, S. 60. Die Datierung des Arbeitsbeginns am Visconti-Stundenbuch in das Jahr 1370 resultiert aus einer irrigen Lesart der Jahreszahl in der Miniatur mit der Vertreibung Joachims aus dem Tempel (BR 397, fol. 2r). Vielmehr ist auf dem Parapet des Tempels 1320 zu lesen. Кirsch, Manuscripts (zit. Anm. I), S. 6o, hat vorgeschlagen, dieses Datum auf die versuchte Vertreibung von Giangaleazzos Urgroßvater, Matteo I., aus Mailand zu beziehen.

6 Arslan, Riflessioni (zit. Anm. 5), S. 6o-62.

7 L. Cogliati Arano, Miniature lombarde. Codici miniati dal VIII al XIV secolo, Mailand i970, S. 405; Dies. (Hrsg.), Tacuinum Sanitatis. Das Buch der Gesundheit. Einf. v. Heinrich Schipperges u. Wolfram Schmitt, München 1976 , S. 25.

8 Meiss/Kirsch, Hours (zit. Anm. 2).

9 M. Rossi, Giovannino de Grassi. La corte e la cattedrale, Mailand I995, S. 63, 8I, Anm. 9. 


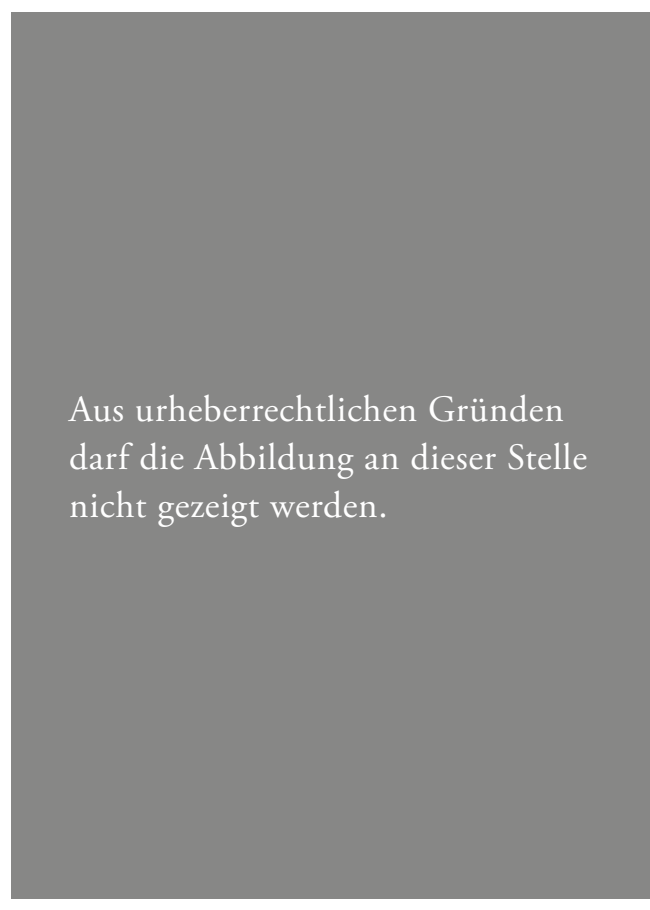

Abb. I: Florenz, Biblioteca Nazionale Centrale, BR 397, fol. 6Ir: S(alvum me fac)-Initiale: David ruft Gott aus dem Wasser an; mit Visconti-Wappen und Gott innerhalb der Visconti-Sonne.

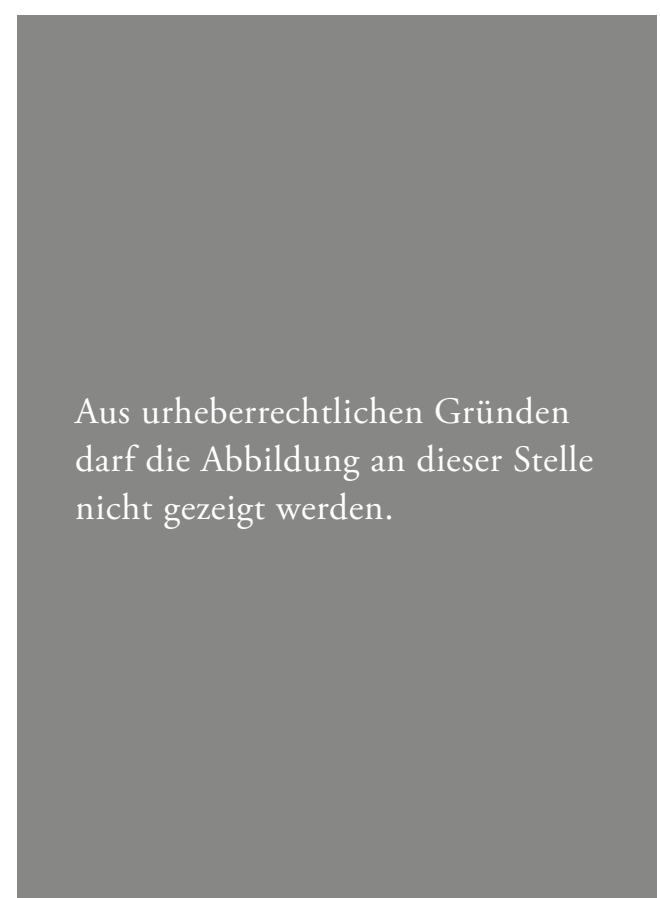

Abb. 2: Florenz, Biblioteca Nazionale Centrale, BR 397, fol. 76v: E(xultate deo)-Initiale: David und die Musiker; Wahlspruch a buon droyt im Initialkörper, als Rahmen sowie als Körper einer Sonne in der Bordüre.

lo - herangezogen hat. ${ }^{10}$ Die zeitnah entstandenen komplexen historisch-politischen Interpretationen von Mirella Levi D’Ancona lassen den ikonographischen Bezug zum Text weitestgehend außer Acht und kehren die Chronologie um, liefern im Detail aber neue Ansätze zur Interpretation. ${ }^{11}$

Demgegenüber weiß sich das Großprojekt einer vollständigen Faksimilierung der beiden Codices begleitet von zwei Kommentarbänden unter der Herausgabe von Milvia Bollati und Adriana Di Domenico aus den Jahren 2002/3 der ,inscindibile unità di parola e immagine, di testo scritto e testo figurativo" verpflichtet ${ }^{12}$ und betrachtet nicht nur die großformatigen

io A. Cadei, Belbello. Miniatore Lombardo. Artisti del libro alla corte dei Visconti, Rom i976 (Studi di Storia dell'Arte, 6); Ders., Studi di Miniatura Lombarda: Giovannino de Grassi, Belbello da Pavia, Rom 1984 (Studi di arte medievale, I).

i M. Levi D’Ancona, La Vergine Maria nell'Offiziolo Visconteo I: Il Ms. BR 397 della Biblioteca Nazionale di Firenze, in: Bibliofilia, 92/2, I990, S. I09-I43; Dies., La Vergine Maria nell'Offiziolo Visconteo II: Il Ms. LF 22 della Biblioteca Nazionale di Firenze, in: Bibliofilia, 92/3, 1990, S. 237-268; Dies., The Rabbit Hutch and Political Allusions in the Visconti Hours, in: Arte Lombarda, N. S., 50, 1978, S. 7-19.

I2 A. Di Domenico, Premessa, in: Dies. (Hrsg.), Il Libro d'Ore Visconti. Schede Descrittive, Modena 2002, S. 9-17, S. Io; Il Libro d'Ore Visconti: Firenze, Biblioteca Nazionale Centrale: Mss. BR 397 e LF 22. Ed. in facsimile, Modena 2003. 


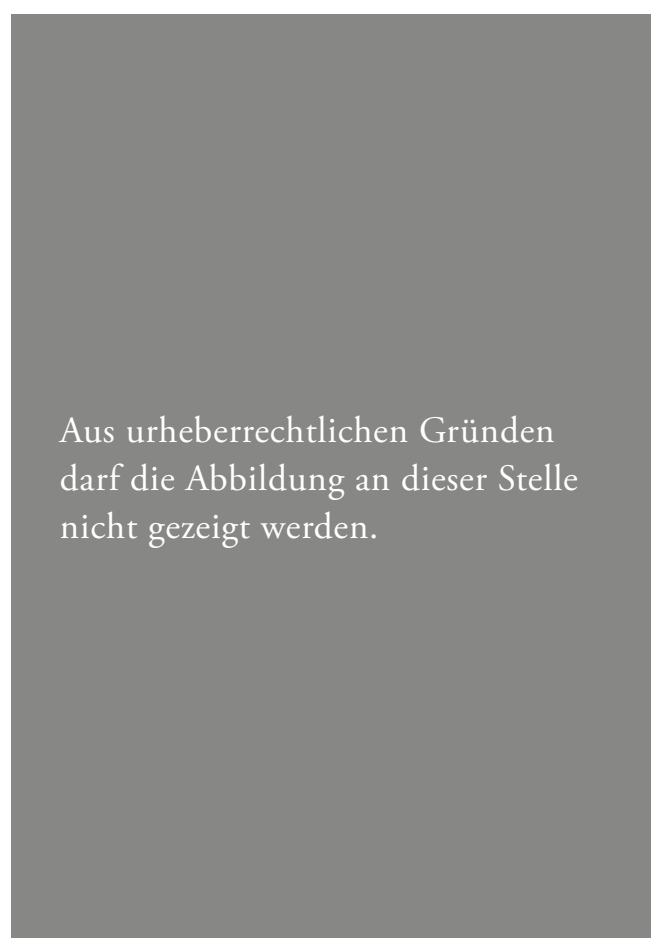

Abb. 3: Florenz, Biblioteca Nazionale Centrale, BR 397, fol. Io5r: D(ixit)-Initiale: Trinität; bas-de-page: Porträt von Giangaleazzo Visconti.
Miniaturen und historisierten Initialen, sondern in reduzierter Weise auch den geringeren Buchschmuck mit Rücksicht auf den Textbezug. Der ansonsten sehr detaillierte Kommentarband von Adriana Di Domenico enthält sich dabei jeglicher Zuschreibung an ausführende Künstler oder Werkstätten; ${ }^{13}$ unter anderem damit setzt sich Milvia Bollati in ihrem Band auseinander, der sich vor allem dem Entstehungskontext des Stundenbuches widmet. $^{14}$

Gemein ist den Studien zum ViscontiStundenbuch, dass sie die große Eigenständigkeit der Ausstattung innerhalb der lombardischen Kunst des ausgehenden Trecento betonen. Dabei liegt das Herausfordernde am Visconti-Stundenbuch nicht nur ,nella sua singolare bellezza, ma anche nella complessità dell' intreccio di differenti committenti, artisti e contesti artistici." 15

Neben der unsicheren Datierung ist es gerade dieses Geflecht aus unterschiedlichen Auftraggebern und vor allem Künstlern, das trotz einer inzwischen nicht unbeträchtlichen

Anzahl von Studien zum Visconti-Stundenbuch immer noch nicht hinreichend geklärt ist. Dazu gehört auch, dass die Seiten mit dem geringeren Buchschmuck - trotz der Bemühungen im Zuge der jüngsten Faksimilierung - bislang erst ansatzweise untersucht wurden.

Relativ fester Boden lässt sich beim ursprünglichen Auftraggeber des Stundenbuches und beim Schreiber gewinnen: Neben einer überreichen Verwendung des Visconti-Wappens (Abb. I, 5), von Visconti-Symbolen (Abb. I, 5), des Mottos A (bon) droyt (Abb. 2) sowie drei Porträtdarstellungen (BR 397, fol. I05r, II5r, I28r, Abb. 3-5) im Bas-de-page wird Giangaleazzo Visconti (I35I-I4O2) zweimal innerhalb des Textes genannt, davon einmal namentlich: famulo tuo [...] nostro domino Galeaz Comiti Virtutum (LF 22, fol. 9v, Abb. 6) ${ }^{16}$. Die Anrede

I3 Di Domenico (Hrsg.), Libro (zit. Anm. I2).

I4 M. Bollati (Hrsg.), Il Libro d’Ore Visconti. Commentario al codice, Modena 2003.

is E. Welch, Nel segno della vipera. Il contesto culturale e politico del Libro d'ore Visconti, in: Bollati (Hrsg.), Libro (zit. Anm. I4), S. I4.

I6 Eigenartig mutet sowohl das vom Standardtext der Heiligenlitanei abweichende $i$ mit Kürzungsstrich am Zeilenende als auch der freie Platz $(2 \mathrm{~cm})$ mitten in der Zeile zwischen Omnipotens sempiterne deus $i[\mathrm{~m}] /$ miserere famulo und nostro/domino Galeaz Comiti uirtutum/et dirige eum secundum tuam clementiam/in uiam salutis eterne an. S. Anm. I7. 


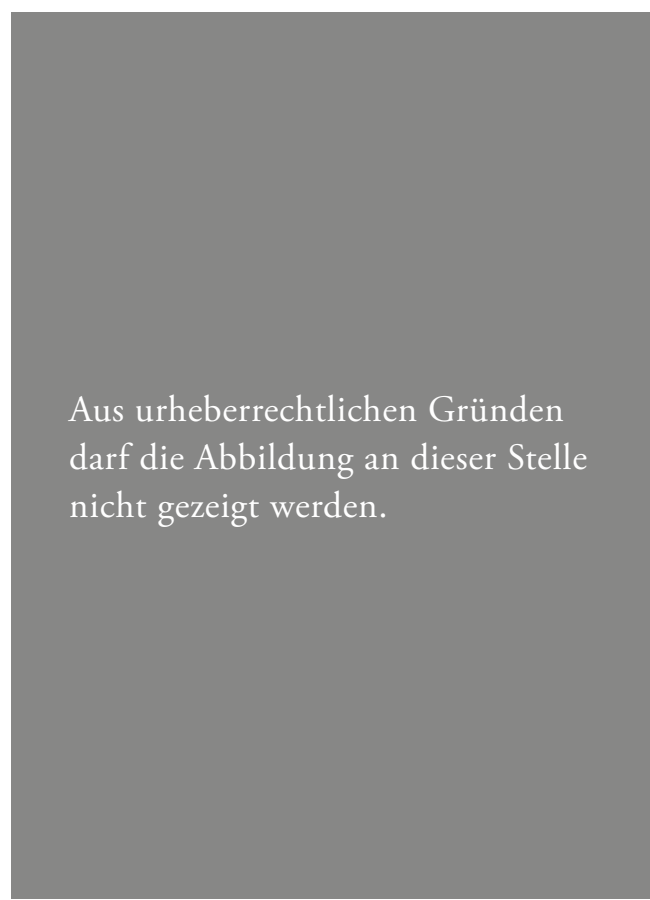

Abb. 4: Florenz, Biblioteca Nazionale Centrale, BR 397, fol. IIsr: D(efecit)-Initiale: König David; bas-de-page: Porträt von Giangaleazzo Visconti.

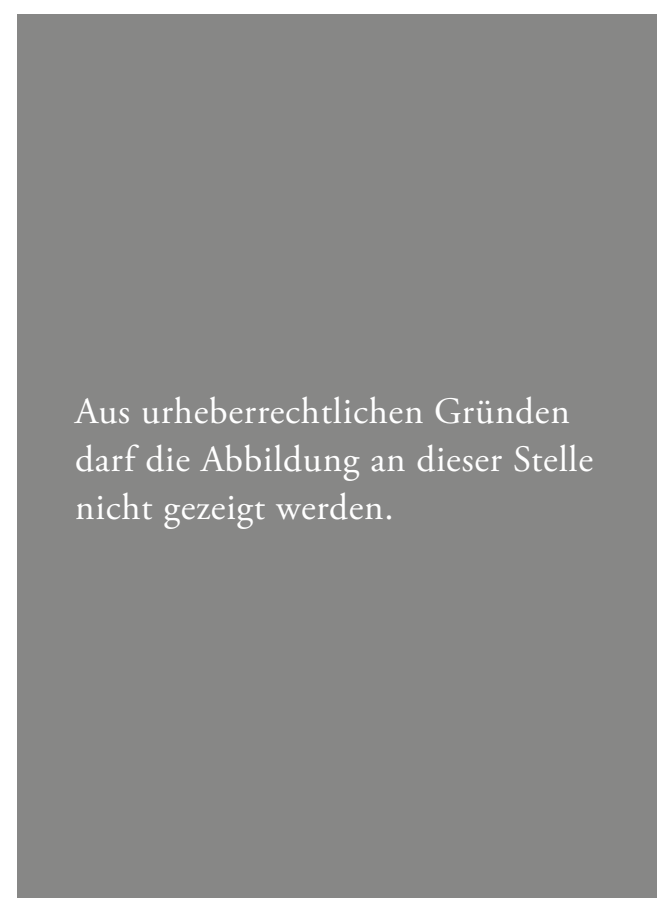

Abb. 5: Florenz, Biblioteca Nazionale Centrale, BR 397, fol. I28r: C(onfitebor)-Initiale: David und der Herr; basde-page, Detail: Porträt von Giangaleazzo Visconti.

Giangaleazzos als Graf von Vertus ${ }^{17}$ hilft dabei, den Text der Codices zwischen I365, dem Jahr der Verleihung der Grafschaft, und 1395, als Giangaleazzo die Herzogswürde verliehen wurde, einzugrenzen. Der Schreiber beider Teile, Frater Amadeus, hat auf LF 22, fol. Io9r ebenso seine Signatur hinterlassen wie in einer eleganten, von Gregorio da Genova im Jahre 1385 illuminierten Boethius-Handschrift der Universität von Glasgow (Ms. Hunter 374).

An der Ausstattung des Visconti-Stundenbuches waren mindestens ${ }^{18}$ zwei Werkstätten unter der Leitung von Giovannino de Grassi und später dessen Sohn Salomone sowie unter Belbello da Pavia beteiligt. Die Zuschreibung der Ausstattung von BR 397 und einem Teil von LF 22 an Giovannino de Grassi (und seine Werkstatt) beruht auf der Gleichsetzung mit dem Zeichner von Blättern des Musterbuches aus Bergamo (Biblioteca Civica Angelo Mai, Cassaf. I.2I), ${ }^{19}$

I7 S. auch LF 22, fol. I22r: ut dominum nostrum Comitem sanitatem et pacem eum regere digneris. Erstaunlich ist in beiden Textpassagen, dass nicht Giangaleazzo als Sprecher auftritt. Für diesen Hinweis danke ich Regina Cermann.

I8 Welch, Segno (zit. Anm. I5), S. I4.

I9 In die Nähe Giovanninos wurde besonders der Beroldo der Biblioteca Trivulziana in Mailand (Cod. 2262) gerückt, so zum Beispiel CADEI, Studi (zit. Anm. IO), S. I5, der inzwischen jedoch (neben einem an Giovannino orientierten Hauptmaler) dokumentarisch mit Giovanninos Sohn Salomone de Grassi zu verbinden ist: Auch wenn die Auftragserteilung des 1396 kopierten Codex an Giovannino ergangen sein muss, wurde Salomone bereits 1397 als deputatus ad miniandum librum qui apelatur Beroldus genannt und erhielt 1398 auch die Abschluss- 


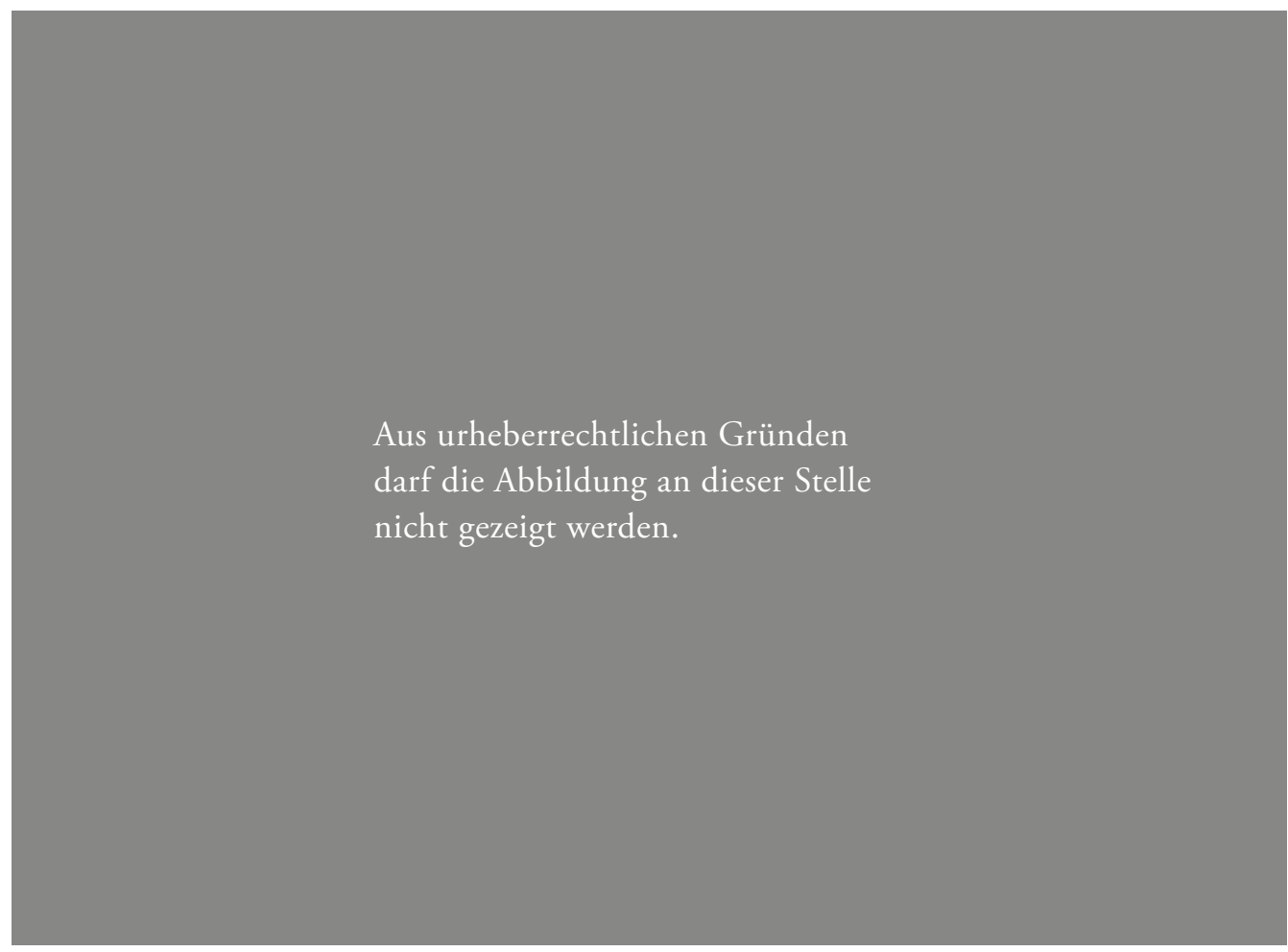

Abb. 6: Florenz, Biblioteca Nazionale Centrale, LF 22, fol. 9v/ıor: geringerer Buchschmuck; namentliche Erwähnung von Giangaleazzo Visconti.

das auf fol. 4v signiert ist: Iohininus de grassis designavit; die Identifikation geht auf Pietro Toesca zurück. ${ }^{20}$ Die Forschung hat diese Zuschreibung allgemein akzeptiert.

zahlung für die Handschrift. S. Rossı, Giovannino (zit. Anm. 9), S. I29-139, Dok. Nr. ı82, I94f., S. I68 f.; M. Bollati, Il Libro d'ore di Gian Galeazzo Visconti: Giovannino, Salomone de Grassi e il Maestro del libro d'ore di Modena, in: Dies. (Hrsg.), Libro (zit. Anm. I4), S. 259-346, S. 314-319. Auch die Historia Plantarum der Biblioteca Casanatense in Rom (Ms. 459), ein überaus reich ausgestatteter Codex Giangaleazzos für Wenzel IV., wird inzwischen (überwiegend) als Arbeit Salomone de Grassis und der de-Grassi-Werkstatt beurteilt. J. Treuherz, The border decoration of milanese manuscripts 1350-I420, in: Arte Lombarda, 36, 1972, S. 7I-82; Abb. S. 50-55, S. 74; Bollati, Libro d'ore (zit. Anm. I9), S. 312; V. Segre Rutz, Historia plantarum, in: Dies. (Hrsg.), Historia Plantarum. Volume di commento. Erbe, oro e medicina nei codici medievali, Modena 2002, S. 69-I22, bes. S. III, hat im Begleitband zur Faksimile-Edition wieder zehn Illustrationen der Historia plantarum der Hand Giovanninos zugeschrieben. Somit bleibt Giovanninos buchmalerisches Schaffen nach heutigem Kenntnisstand weitgehend auf einzelne Blätter im Musterbuch von Bergamo sowie auf das Visconti-Stundenbuch beschränkt, eventuell zu ergänzen um einige Interventionen im Beroldo und der Historia Plantarum.

20 L. Stefani, Per una Storia della Miniatura Lombarda da Giovannino de' Grassi alla scuola Cremonese della II metà del Quattrocento: appunti bibliografici, in: E. Sesti (Hrsg.), La Miniatura Italiana tra Gotico e Rinascimento II. Atti del II Congresso di Storia della Miniatura Italiana. Cortona 24-26 settembre i982, Florenz I985, S. 82I-88I, S. 823. Das Tacuinum wurde von Toesca, Michelino (zit. Anm. 3), S. 332-336, i905 ursprünglich gänzlich Giovannino de Grassi zugeschrieben, später revidierte er diese Ansicht und beschränk- 
Die Quellen zu Giovannino de Grassi aus den Annalen des Mailänder Domes beziehen sich auf seine Tätigkeit als Maler und Ingenieur der Fabbrica in seinem letzten Lebensjahrzehnt (1389-98), geben jedoch weder Aufschluss über seine Ausbildung noch über seine Tätigkeit als Buchmaler. Sie stellen Giovannino aber in einen engen Konnex zum ViscontiHof, da schon der erste urkundlich belegte Auftrag als Maler, ein Banner mit dem Bild des Hl. Gallus, für Giangaleazzo und dessen Gattin Caterina erfolgte. ${ }^{21}$ Die Ausführung herzoglicher Aufträge bleibt auch im Weiteren bestimmend: ${ }^{22}$ Giovannino war maßgeblich an den Großprojekten Giangaleazzos, den Arbeiten am Mailänder Dom sowie am Castello Visconteo und der Certosa di Pavia, beteiligt. ${ }^{23}$ Aus diesen Arbeitsumfeldern werden unterschiedliche Einflüsse angenommen: aus dem Dombau architektonische Details, ${ }^{24}$ ein neuer Sinn für Raum und Komposition sowie der häufig erwähnte Kontakt zu französischen Künstlern ${ }^{25}$; disegno, Giovanninos besondere Stärke, ${ }^{26}$ und Farbe über Vermittlung der im Castello Visconteo tätigen Maler. ${ }^{27}$

Stilistisch wird Giovanninos Arbeit am Visconti-Stundenbuch in engem Zusammenhang mit der französisch geprägten Werkstätte des lombardischen Stundenbuches Paris, BNF, Ms. lat. 757 gesehen $^{28}$ und dadurch eine Nahebeziehung zu Giovanni di Benedetto da Como, Anovelo da Imbonate, dem Lancelot-Meister, Tomasino da Vimercate sowie dem Meister von

te die Zuschreibung auf wenige Blätter. Vgl. dazu die Zusammenfassung in Stefani, Storia (zit. Anm. 20), S. 824 , Anm. 6.

2I Rossi, Giovannino (zit. Anm. 9), S. 2I. Eine Darstellung der biographischen Quellen zu Giovannino findet sich ebd., S. 2I-32; im dokumentarischen Anhang, ebd., S. I49-170, wurden 202 Dokumente zu Giovannino de Grassi, vor allem aus dem Archivio della Fabbrica del Duomo di Milano, vollständig transkribiert.

22 Ebd., S. 26. Für M. Bollati, Libri per i Visconti: commitenza a corte tra Galeazzo II e Filippo Maria Visconti, in: Lombardia gotica e tardogotica: Arte e architettura, Mailand 2005, S. 188-203, S. 196, ist Giovannino derjenige Künstler, „il cui nome forse più di ogni altro è legato alla corte viscontea e a Milano.“

23 Vgl. Treuherz, Border (zit. Anm. 19), S. 79; Rossi, Giovannino (zit. Anm. 9), S. 2I-33; Bollati, Libro d'ore (zit. Anm. 19), S. 265-267.

24 Vgl. M. Rossi, Fantasie architettoniche di Giovannino de Grassi, in: Arte Lombarda, N. S., I46-8, 2006, S. $45-54$.

25 Unter anderem Treuherz, Border (zit. Anm. 19), S. 78.

26 Bollati, Libro d'ore (zit. Anm. 19), S. 297.

27 Rossi, Giovannino (zit. Anm. 9), S. 78. Ebenso pinctor, inzignerius und wohl auch Buchmaler in Personalunion war der aus Brügge stammende und in Paris tätige Jacques Coene, 1399 als inzignerius beim Mailänder Dombau ein direkter Nachfolger Giovanninos, der sich zwar dokumentarisch, nicht jedoch über seine Werke sicher fassen lässt. Hinweis von Regina Cermann. Grundlegend und die Dokumente wiedergebend: M. MeIss, French Painting in the Time of Jean de Berry: The Boucicaut Master, London 1968, S. 60-62, I4I; aus jüngerer Zeit: U. Heinritz, Eine Überlegung zu Jacques Coene, in: Zeitschrift für Kunstgeschichte, 56, I993, S. II3-II5; F. Avril, Das Buch der Wunder, Hs. fr. 281o der BNF, in: M.-H. Tesnière/F. Avril/M.-Th. Gousset (Hrsg.), Marco Polo. Le Livre des Merveilles. Kommentar zum Faksimile, Luzern 1996, S. 19-54, bes. S. 49 f.; G. Bartz, Der Boucicaut-Meister. Ein unbekanntes Stundenbuch (Kataloge, 42), Rotthalmünster 1999, S. 47-49.

28 Zuletzt wieder Rossi, Giovannino (zit. Anm. 9), S. I2. 
Smith Lesouëf 22 hergestellt. ${ }^{29}$ Bezüglich der weichen Schattierungen wurde auf einen Einfluss durch den böhmischen Weichen Stil hingewiesen, vertreten beispielsweise durch den Liber Viaticus von 1366, heute in der Bibliothek des Prager Nationalmuseums (Ms. XIII A I2) eine Einschätzung, die in der jüngeren Zeit an Bedeutung verloren hat. ${ }^{30} \mathrm{Oft}$ erwähnt sind die Einflüsse der französischen (Buch-)Malerei im Bereich der architektonischen Rahmung, der naturalistischen Tendenzen sowie Figureninitialen, wobei zuletzt besonders die Nähe zur Werkstätte des Guiron le Courtois ${ }^{31}$ betont wurde. ${ }^{32}$ Mit Michelino da Besozzo verbindet Giovannino der naturalistische Stil, der sich bei Letzterem vor allem in der Darstellung von Tieren zeigt. ${ }^{33}$ Die Architekturelemente werden auch mit der Parler-Architektur in Beziehung gesetzt. ${ }^{34}$ Dass eine Einschreibung Giovanninos in die Stiltendenzen seiner Zeit jedoch nur bedingt möglich ist, liegt an der Eigenständigkeit seiner Darstellungsweise: „[...] lo stile di Giovannino de Grassi è alla radice autonomo, non si inserisce senza riserve nel decorso verso lo ,stile dolce ' [...], ma sviluppa una peculiare variante ,spinosa' del tardogotico pittorico. [...] Giovannino rinnova soprattutto la metodologia di decorazione della pagina miniata, con preferenze specifiche per quel tipo di pagina che accompagna la decorazione alla scrittura; in essa sviluppa gli ornati marginali in scene o figurazioni, assume la drôlerie e l'inserto araldico a mo-

29 Toesca, Pittura (zit. Anm. 3), S. I47; Rossı, Giovannino (zit. Anm. 9), S. 40. Da jedoch die künstlerische Herkunft der beiden Schwesterhandschriften BNF, Ms. lat. 757 sowie deren kleinerer Version Smith-Lesouëf 22 erst ansatzweise geklärt, der Auftraggeber unsicher (Bertrando de' Rossi?) und das Entstehungsdatum (zwischen 1380 und der zweiten Hälfte der I380er, eventuell auch erst aus der ersten Hälfte der I39oer) umstritten ist, führt der Vergleich mit den beiden Handschriften für eine Bestimmung des Visconti-Stundenbuches kaum über den Nachweis eines Kontakts Giovanninos mit französischer bzw. französisch geprägter Kunst hinaus. Vgl. Arslan, Riflessioni (zit. Anm. 5), S. 3I-34; Ders., Aspetti della pittura lombarda nella seconda metà del Trecento, in: Critica d’Arte, 9, 1964, S. 33-45, S. 32 f.; Cogliati Arano, Due libri d'ore lombardi eseguiti verso il 1380, in: Arte Lombarda, I5.I, I970, S. 37-44, S. 40; Dies., Miniature (zit. Am. 7), S. 4IO4I2; K. Sutton, The original patron of the Lombard Manuscript Latin 757 in the Bibliothèque Nationale, Paris, in: The Burlington Magazine, I24, I982, S. 88-94, 264; Dies., A Lombard manuscript, Paris B. N. latin 757, associated manuscripts and the context of their illumination, Univ.-Diss., Warwick 1984; F. AvrIL, Dix siècles d'enluminure italienne (VIe-XVI e siècles), Ausst.kat., Paris i984, S. 96-99; A. Zaccaria/K. Sutton, The Original Patron of MS Latin 757 in the Bibliothèque Nationale, Paris, in: The Burlington Magazine, I25, I985, S. I60 f.; Kirsch, Manuscripts (zit. Anm. I); B. S. Tosatti, Rapporti tra immagini e testi nella miniatura lombarda. La bottega delle Ore latin 757, in: M. Ceccanti / M. C. Castelli (Hrsg.), Il codice miniato. Rapporti tra codice, testo e figurazione. Atti del III Congresso di Storia della Miniatura. Cortona 20-23 settembre 1988, Florenz 1992, S. 195-227; F. ManZARI, Tipologie di strumenti devozionali nella Lombardia del Trecento, in: Bollati (Hrsg.), Libro (zit. Anm. I4), S. 64-217, bes. S. 83-103.

30 Die böhmische Komponente wurde seit Arslan, Riflessioni (zit. Anm. 5), S. 33, wenig ins Kalkül gezogen; findet sich bei S. TASSETto, La miniatura tardogotica lombarda e i suoi rapporti con l'Europa. Il Messale-Libro d'Ore Lat. 757, Arte Lombarda, N. S. 126.2 (1999), S. 29-60, S. 32 f., aber wiederbelebt. S. auch SEgRE Rutz, Historia (zit. Anm. 19), S. 54.

3I Paris, BNF, Nouv. Acq. Fr., 5243. Der Auftrag für den Guiron wird Bernabò Visconti zugeschrieben. Bollatı, Libri (zit. Anm. 22), S. 190.

32 Vgl. Rossi, Giovannino (zit. Anm. 9), S. I2, 33.

33 M. Boskovits, Arte in Lombardia tra Gotico e Rinascimento, Mailand I988, S. Io; Welch, Segno (zit. Anm. I5), S. 40.

34 Rossi, Giovannino (zit. Anm. 9), S. 9. 
tivo per annotazioni di un naturalismo che fa scuola in Europa [...]. “35 Meiss / Kirsch bezeichneten Giovannino als „erste[n] italienische[n] Künstler des I4. Jahrhunderts, der einen ganz eigenen Stil der Buchmalerei schuf.“36

Am 5. Juli 1398 stirbt Giovannino; am 7. bezahlt die Fabbrica des Domes sein Begräbnis. Für ein Drittel von Giovanninos Gehalt übernimmt sein Sohn Salomone dessen Aufgaben als pittore und disegnatore in der Fabbrica und wird für jeweils eine Woche im Monat für Arbeiten für den Herzog freigestellt; wie vermutet wird, für die Ausstattung des ViscontiStundenbuches und anderer Codices. ${ }^{37}$

Schon Toesca hat einige Miniaturen Giovanninos Sohn Salomone zugeschrieben, während in der Folge im Wesentlichen eine Zuschreibung an Giovannino und seine Werkstatt vertreten wurde. Erst Antonio Cadei hat sich wieder der Händescheidung im Visconti-Stundenbuch gewidmet. Cadei bringt Salomone besonders mit den architektonischen Elementen in dekorativer Funktion für Initialen und Bordüren in Zusammenhang und verweist auf deren wesentlich häufigeres Vorkommen in den ersten sieben Lagen von LF 22 gegenüber BR $397 ;^{38}$ er geht sogar so weit, Giovannino gänzlich von der Arbeit an LF 22 auszuschließen, ${ }^{39}$ eine Ausstattungspause zwischen den zwei Volumina des Visconti-Stundenbuches zu postulieren, in die er die Entstehung des Beroldo (Mailand, Biblioteca Trivulziana, Cod. 2262) legt, ${ }^{40}$ und die ersten sieben Lagen von LF 22 ausschließlich Salomone und Belbello da Pavia zuzuschreiben. ${ }^{41}$ Nach Cadei sind die Spuren Salomones aber auch schon am Ende von BR 397 zu identifizieren, wo ein Eindringen „di un modo più greve, di colori più densi e scuri, di un pennellare più rapido, sfatto e compendiario, di un meno avvertito controllo delle proporzioni“ zu bemerken sei, so zum Beispiel an der Szene mit David und Goliath (BR 397, fol. 132r, Abb. 7). ${ }^{42}$

In Folge hat sich besonders Milvia Bollati mit der Unterscheidung von Vater und Sohn auseinandergesetzt und grenzt von den „calibrate creazioni“ Giovanninos Salomones ,apparente disordine compositivo, $[\ldots]$ molteplicità e diversità dei motivi decorativi“ sowie dessen

BR 397 I370-89, den Beroldo I396-98 sowie LF 22 ab I399 (bei „I389“, ebd., S. 76, handelt es sich um einen Schreibfehler) ansetzt. Ebd., S. 76. Diese Chronologie lässt sich schon vom Ausstattungsbeginn von BR 397 im Jahre I370, der wesentlich aus der seit Arslan, Riflessioni (zit. Anm. 5), S. 59-62, falsch tradierten Lesart der Jahreszahl auf der Vertreibung Joachims aus dem Tempel (BR 397, fol. 2r, ) resultiert, nicht aufrechterhalten. Vgl. hier Anm. 5. Gegen diese Chronologie der Werke: Kırsch, Manuscripts (zit. Anm. I), S. 66.

$4 \mathrm{I}$

42 Ebd., S. 6o. 


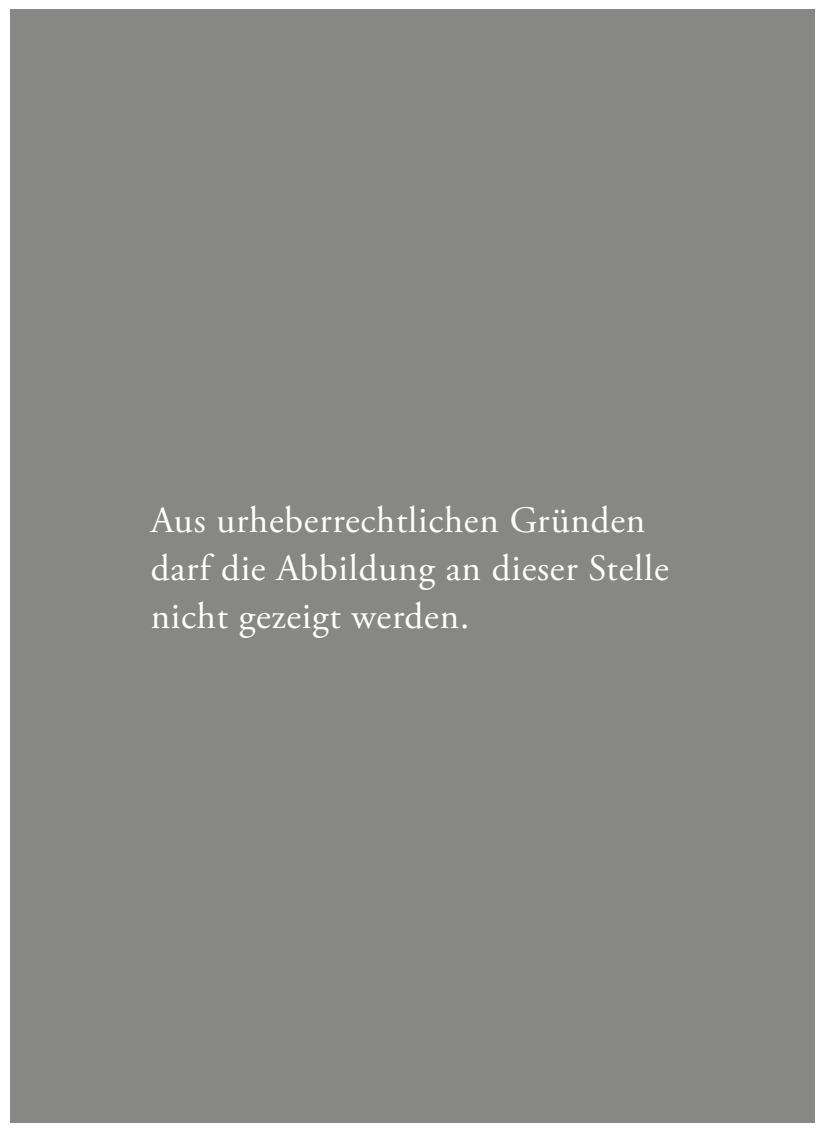

Abb. 7: Florenz, Biblioteca Nazionale Centrale, BR 397, fol. I32r: B(enedictus)Initiale: David und Goliath.

„sovraporre ed accostare, quasi casulamente, [dei] motivi diversi“ $a b,{ }^{43}$ so in der Trennung von Land und Wasser (LF 22, fol. 3or, Abb. 8). ${ }^{44}$ Dagegen zeige sich in Salomones feinen und schlanken Figuren stark die Herkunft aus Giovanninos Werkstatt, sodass die Figuren leicht zu verwechseln seien. Dennoch scheint Bollati auch hier eine Händescheidung möglich, wie sie im Vergleich der beiden Porträts Giangaleazzos auf BR 397, fol. IO5r und fol. II5r (Abb. 3, 4) von Giovannino mit den Köpfen der Könige und Kaiser im Rahmen der Erbsünde (LF 22, fol. 5Ir, Abb. 9) von Salomone exemplifiziert: „Giovannino lavora quasi in punta di pennello con tratti leggeri e finissimi, la materia pittorica è talmente sottile da lasciar trasparire quasi il disegno. Salomone invece modella con decisione le sue figure attraverso il chiaroscuro e pennellate più larghe di colore, evocando la morbidezza delle carni e la leggerezza delle capigliature. “45 Doch gerade in BR 397, fol. IO5r (Abb. 3), Bollatis Bezugspunkt für die Arbeit Giovanninos, sah Kirsch Salomones Präsenz im ersten Teil des Stundenbu-

43 Bollati, Giovannino (zit. Anm. 37), S. 215.

44 Die Trennung von Himmel und Erde (LF 22, fol. 19r) schreibt Bollatı, Libro (zit. Anm. 19), S. 304, nach Sichtung des Originals nun nicht mehr Salomone, sondern Giovannino zu.

45 Bollati, Giovannino (zit. Anm. 37), S. 215. 
Abb. 8: Florenz, Biblioteca Nazionale Centrale, LF 22, fol. 3or: $\mathrm{D}$ (eus in adiutorium)-Initiale: Trennung von Land und Wasser.

\section{Aus urheberrechtlichen Gründen darf die Abbildung an dieser Stelle nicht gezeigt werden.}

ches; ${ }^{46}$ Levi D’Ancona fand dagegen gerade im Porträt auf fol. Iı5r (Abb. 4) keine stilistischen Bezüge zu den anderen Figurendarstellungen Giovanninos in BR $397 .{ }^{47}$

Jüngst hat Milvia Bollati Giovannino die Gesamtverantwortung für die Dekoration des ersten Teiles mit einer wahrscheinlichen Ausnahme von fol. Io8v, I28r (Abb. 5) und I32r zugesprochen. ${ }^{48}$ Neben Interventionen Salomones ${ }^{49}$ sei nicht auszuschließen, dass weitere Künstler mit Farbe vollendet hätten, was Giovannino vorgezeichnet habe, wie zum Beispiel auf fol. 6Ir (Abb. I) und II2v. Bereits zuvor hat Kirsch neben Salomone, den sie vor allem gegen Ende von BR 397 vorfand, ${ }^{50}$ mindestens einen weiteren Mitarbeiter innerhalb

46 Kirsch, Manuscripts (zit. Anm. I), S. 67. Darüber hinaus weist Kirsch Salomone BR 397, fol. I04v, I28r und I46v sowie eine Beteiligung an LF 22, fol. 26r und 40v ergänzt um die Rahmendekorationen von BR 397, fol. I28r, I32r, I36r, I46v, I47v und I48v sowie LF 22, fol. Ir, IOv, I7r, I8r, 25v, 26r, 29v und 40v zu. Ebd.

47 Levi D’Ancona, Vergine I, S. 138, Anm. 21. Demgegenüber sieht Cadei, Studi (zit. Anm. io), S. 63, die Seite als „capolavoro miniatorio“ Giovanninos.

48 Bollati, Libro d'ore (zit. Anm. I9), S. 302

49 So die Figur Gottvaters auf fol. II7v, die von derselben Hand herrühre wie die beiden Heiligen Ambrosius und Augustinus in LF 22, fol. 47r. Ebd., S. 302, 310-318.

50 Kirsch, Manuscripts (zit. Anm. I), S. 64 f. 


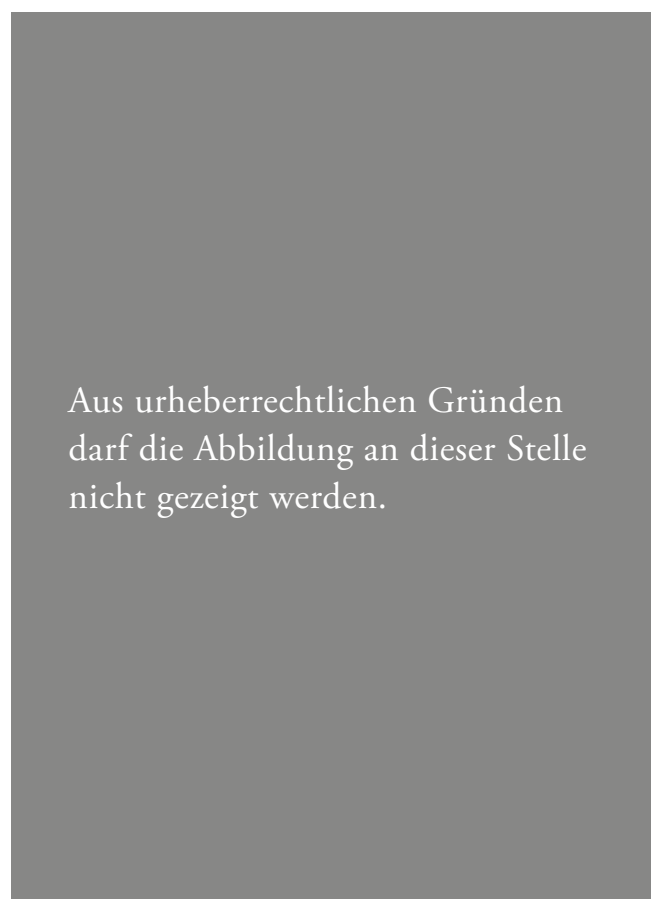

Abb. 9: Florenz, Biblioteca Nazionale Centrale, LF 22, fol. 5Ir: E(ructavit cor)-Initiale: Sündenfall. der Miniaturen des ersten Stundenbuchteils vorgeschlagen. ${ }^{51}$

Darüber hinaus tritt bei der Ausführung der Seiten mit geringerem Buchschmuck als weitere Hand ein Bordürenmaler zutage, welcher die Rahmen von BR 397 sowie der ersten Lage von LF 22 mit dreiseitigen Leisten in geringer Varianz gestaltet hat, die in ihrer Schlichtheit wohl kaum Giovannino zugeschrieben werden können (Abb. Io). Diese Seiten besitzen einzeilige goldene Initialen auf alternierend rotem oder blauem Grund (meist in Verbindung mit ornamentalem, vegetabilem oder heraldischem Schmuck) für die einzelnen Versanfänge innerhalb der Psalmen sowie aufwendigere mit gegenständlichem Schmuck versehene dreizeilige Initialen auf Goldgrund für die Psalmanfänge. Jede Seite mit dreizeiliger Initiale besitzt zudem eine dreiseitige Rahmenleiste in alternierend Blau bzw. Rosa und Gold (mit gezackten Ausläufern), die jeweils nach rechts hin geöffnet ist. Die Rahmenleiste umwinden bzw. aus ihr erwachsen Triebe mit vierblättrigen Rosetten in Grün, Blau, Rosa und Rotorange, Palmetten, Eicheln und Blättern sowie teilweise Goldtropfen (mit und ohne Strahlenkranz). Dazu kommen über den Rand verteilt vierblättrige goldene Rosetten und/oder in Fortführung der Rahmenleiste an der rechten Seite drei farbige Rosetten zwischen vier Goldtropfen. Während die Gestaltung des Randschmucks sehr einheitlich anmutet, weisen die dreizeiligen Initialen einen weitaus größeren Formenreichtum auf und verbinden sich durch ihre Ausläufer teilweise mit der Bordüre.

Im Gegensatz zum einheitlichen Eindruck, den der erste Teil des Visconti-Stundenbuches vermittelt, herrscht im zweiten Teil ein relativ buntes Stilneben- und -ineinander. Dies betrifft sowohl die ganzseitigen Miniaturen und großen Initialseiten als auch den geringeren Buchschmuck. Der Anteil Giovanninos an der Ausstattung von LF 22 scheint gegenüber dem Salomones deutlich zurückzutreten. Milvia Bollati hat Giovannino zuletzt in LF 22 nur noch die fol. Ir (Abb. II), 4v, IOv, 25v und 3or sowie die Initiale von fol. I9r zugeschrieben; Cadei, wie erwähnt, dessen Beteiligung an LF 22 sogar gänzlich abgelehnt. ${ }^{52}$ Jedenfalls lässt sich die Arbeit der de Grassi allein innerhalb der ersten sieben Lagen von LF 22 beobachten, während

5I KIrsch, ebd., S. 67, hielt die Himmelfahrt Mariens auf BR 397, fol. 76r, weder für ein Werk Giovanninos noch Salomones, sondern hat sie in die Nähe des Modena-Meisters gerückt; ebd., S. 64, Anm. 82.

52 CadeI, Studi (zit. Anm. Io), S. 63. 
Abb. Io: Florenz, Biblioteca Nazionale Centrale, LF 22, fol. 3v: geringerer Buchschmuck.

Aus urheberrechtlichen Gründen

darf die Abbildung an dieser Stelle nicht gezeigt werden.

ab der achten Lage nur mehr die Quattrocento-Ausstattung entgegentritt. Diese folgt allerdings nicht in hartem Bruch auf den de-Grassi-Teil, sondern durchzieht auch schon die ersten sieben Lagen von LF 22. Giovanninos Aufgaben in der Fabbrica des Mailänder Domes legen nahe, dass er seit Beginn der I390er-Jahre zunehmend weniger Zeit für die Ausstattung des Visconti-Stundenbuches übrig hatte und seinem Sohn im Gegenzug mehr Verantwortung und Autonomie bei der Arbeit am Stundenbuch übertrug. ${ }^{53}$

Bleibt man bei der Betrachtung nicht, wie die überwiegende Zahl der Studien, bei den illuminierten Prunkseiten stehen, sondern bezieht auch die Seiten mit dem geringeren Buchschmuck ein, ${ }^{54}$ so zeigt sich gerade in dem Übergangsbereich zwischen Tre- und Quattrocento-Ausstattung, also in den ersten sieben Faszikeln, ein eindeutiger stilistischer Wandel bereits nach der ersten Lage: Folgt die Gestaltung der Seiten mit dem geringeren Buchschmuck in

53 Welch, Segno (zit. Anm. I5), S. 4o f.

54 Dies dürfte einem Gutteil der Forscher durch das Fehlen von Abbildungen zum geringeren Buchschmuck bis zum Erscheinen der jüngsten Faksimile-Ausgabe 2002/03, die aber ihrerseits nur schwer greifbar ist, auch nur eingeschränkt möglich gewesen sein. So vermerkt beispielsweise Bollatı, Libro d’ore (zit. Anm. I9), S. 300, dass sie erst im Zuge der Faksimilierung die beiden Codices im Original betrachten habe können und deshalb einige ihrer früheren Schlussfolgerungen revidieren müsse. 


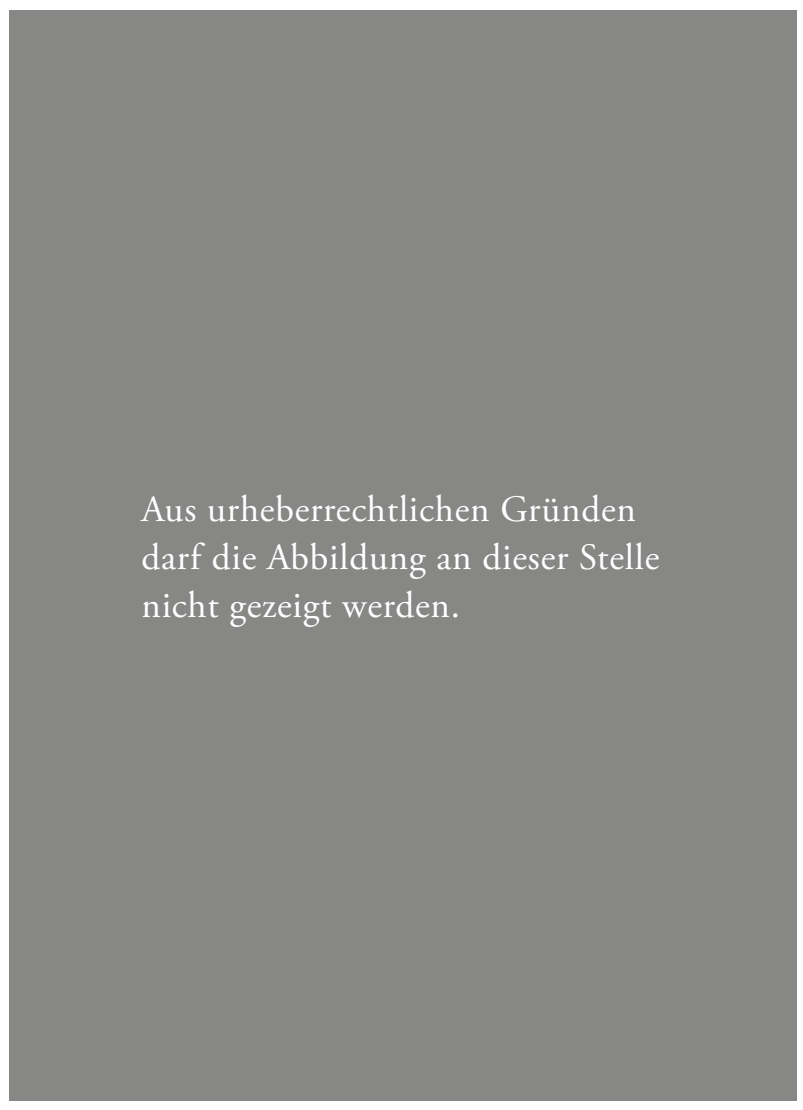

Abb. II: Florenz, Biblioteca Nazionale Centrale, LF 22, fol. Ir: Q(uicunque vult)-Initiale: Der Bischof spricht zu seiner Gemeinde; Detail: punzierter und musierter Goldgrund mit Feldungen.

der ersten Lage noch dem Schema von BR 397, ändert sie sich ab fol. 9r in Formensprache und Varianz radikal.

$\mathrm{Ab}$ fol. $9 \mathrm{r}$ setzt ein großer qualitativer, aber auch - textlich zu begründender - quantitativer Sprung bei der Gestaltung der dreizeiligen Initialen im Text ein; so findet sich ab fol. 9v (Abb. 6) sehr oft figürlicher Schmuck in den Initialen, häufig die Darstellung eines Kopfes oder einer Brustfigur wie auf fol. Ior (Abb. 6) ${ }^{55}$. Diese Art von dreizeiligen Initialen herrscht bis zum Ende von LF 22 vor und tritt über weite Strecken sogar auf jeder Seite auf, wobei hier eindeutig mehrere Hände am Werk sind.

Auch wenn die dreizeiligen Initialen der ersten Lage der Formensprache von beispielsweise fol. 9r (Abb. I2) teilweise nahekommen, unterscheiden sie sich doch gravierend in ihrer Plastizität. Während die mit Blattmotiven gestalteten Initialkörper (so die $D$-Initialen von fol. $3 \mathrm{v}$, Abb. Io, wie auch das $P$ auf fol. $6 \mathrm{v}$ ) durch die markanten weißen Linien graphisch flach bleiben, erreicht die in derselben Motivik gestaltete $E$-Initiale von fol. $9 \mathrm{r}$ (Abb. I2) durch die zahlreichen Farbverläufe zwischen dem Blau als Grundfarbe und dem Deckweiß wesentlich mehr an Volumen bzw. Dreidimensionalität. Besonders deutlich wird der neue Formenreichtum ab fol. 9v (Abb. 6): Auf fol. I2v findet sich selbst in einer einzei-

55 Die vier blauen Blumen auf fol. Ior im Bas-de-page sind wohl eine Zutat der Quattrocento-Ausstattung. 
Abb. I2: Florenz, Biblioteca Nazionale Centrale, LF 22, fol. 9r: geringerer Buchschmuck.

Aus urheberrechtlichen Gründen

darf die Abbildung an dieser Stelle nicht gezeigt werden.

ligen Q-Initiale ein Gesicht (Abb. 13); wenngleich in ähnlicher Größe und auf demselben roten Grund gemalt wie das Gesicht der Sonne in BR 397, fol. 8Ir (Abb. I4), ist das von LF 22 doch wesentlich feiner ausgearbeitet, zu erkennen an der klareren Herausarbeitung von Nasenrücken, Wangen, Kinn- und Mundpartie, die in BR 397 wesentlich schematischer aufgefasst sind. Ansonsten weisen die einzeiligen Initialen von fol. $9 \mathrm{r}$ bis f. $55 \mathrm{v}$ Blumen- und Blattmotive auf, aber keine Wappen bzw. Visconti-Symbole. ${ }^{56}$

Besonders markant ändern sich innerhalb der zweiten bis zur siebten Lage die Bordüren (Abb. 6, I2). Während die dreiseitige Rahmung als Grundschema beibehalten wurde, löst sich die bislang weitgehend lineare Rahmenleiste vegetabil auf, verzweigt und verästelt sich mannigfach, teilweise um andere Formen zu umschließen, und endet in unterschiedlichsten Blattund Doldenformen, Rosetten, Goldtropfen etc., welche jeder Seite einen gänzlich eigenen Aspekt verleihen. Die Bordüren sind nun stets mit den Initialkörpern der dreizeiligen Initialen verbunden, teilweise entwickeln sie sich sogar gänzlich daraus. Wesentlich deutlicher als bei den innerhalb der bislang meist in Augenschein genommenen und bei Meiss / Kirsch re-

56 Diese kommen erst ab der achten Lage (fol. 56 ), in dem Belbello zugeschriebenen Teil, vor, zum Beispiel der biscione auf LF 22, fol. 6ov. 


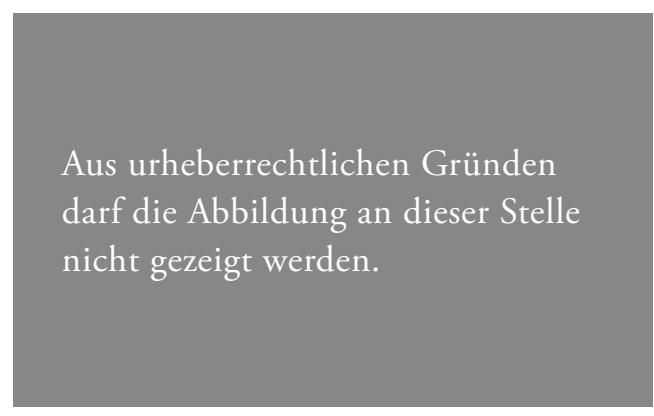

Abb. 13: Florenz, Biblioteca Nazionale Centrale, LF 22, fol. I2v, Detail: einzeilige Q-Initiale mit Gesicht.

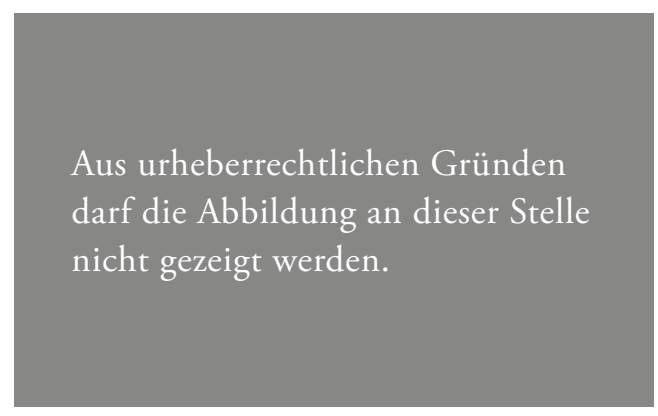

Abb. I4: Florenz, Biblioteca Nazionale Centrale, BR 397, fol. 8Ir, Detail: dreizeilige D-Initiale mit Sonnengesicht.

produzierten Seiten zeigt sich innerhalb des geringeren Buchschmuckes eine zweite Ausstattungskampagne, die mit fol. $9 \mathrm{r}$ beginnt, deren Tendenzen in qualitativ äußerst unterschiedlicher Ausführung bis in die siebte Lage hinein bestimmend bleiben und - besonders in der Verbindung von Initiale und Rahmenleiste - auch die alleinige Quattrocento-Ausstattung ab der achten Lage beeinflussen.

Somit kann innerhalb des geringeren Buchschmuckes mit fol. 9r-55v von LF 22 (zweite bis siebte Lage) eine weitere Ausstattungsphase abgegrenzt werden, die weder Giovannino de Grassi noch - bis auf Ausnahmen - Belbello zugerechnet werden kann und die bereits Meiss / Kirsch als „Phase II des de Grassi-Stils“ bezeichnet haben. ${ }^{57}$ Auch Milvia Bollati verweist auf das neue Dekorationssystem ab der zweiten Lage: „I fregi si differenziano a ogni foglio con una varietà sorprendente di motivi e con una ricchezza nell'uso della folglia d'oro che non ha confronti nel precedente volume dell'Offiziolo." ${ }^{58}$ Den Wandel im dekorativen Programm ab der zweiten Lage von LF 22 sieht Bollati am ehesten mit der wachsenden Rolle Salomones zu vereinbaren, die jedoch nicht notwendigerweise erst nach dem Tod des Vaters anzusetzen sei. Salomone müssten dementsprechend alle geringeren Initialen sowie die Rahmendekoration anvertraut gewesen sein, Giovannino hingegen die ganzseitigen Miniaturen, die jedoch großteils nur bis in das Stadium der Vorzeichnung gediehen seien. ${ }^{59}$ Die unterschiedliche Qualität der Bordüren, aber auch der Initialen legt die Vermutung nahe, dass hier mehrere Buchmaler am Werk waren, wobei eine zeitliche Einordnung kaum möglich erscheint. ${ }^{60}$ In Verbindung

57 Meiss / Kirsch, Stundenbuch (zit. Anm. 8), S. II. Charakterisiert sehen die beiden Autoren die zweite Phase des de-Grassi-Stils durch das Vorherrschen von goldenen Weinranken und -blättern sowie Pastellfarben, vor allem Blassrosa und -blau, wobei die Ränder häufig große durchgebildete Formen, mächtige Ranken, ein paar Bäume oder häufiger noch Türme enthielten.

58 Bollati, Libro d'ore (zit. Anm. I9), S. 303.

59 Nach der ersten Lage von LF 22 seien Giovannino nur mehr die Ausführung der Initiale von fol. 19r, nicht jedoch der Rahmen, sowie fol. 25v mit der Flucht nach Ägypten und, nun ändern sich Bollatis Festschreibungen binnen weniger Seiten, fol. 29r, 29v, 3or bzw. fol. 34r mit der Erschaffung der Pflanzen zuzuschreiben. Bollati, Libro d'ore (zit. Anm. i9), S. 304 f., 3 Iо.

6o Manche der Bordüren folgen dabei zwar dem freien Schema Salomones, wirken in ihrer Ausgestaltung aber dennoch wesentlich schwerfälliger und lassen sich kaum auf eine Stufe mit den luftigen Kompositionen Salo- 
Abb. I5: Florenz, Biblioteca Nazionale Centrale, LF 22, fol. IIr: Geburt Christi.

Aus urheberrechtlichen Gründen

darf die Abbildung an dieser Stelle nicht gezeigt werden.

mit der Arbeit von Giovannino und Salomone de Grassi taucht Porrino de Grassi, der Bruder Giovanninos, auf, der zwar für Arbeiten in der Fabbrica belegt ist, ${ }^{61}$ aufgrund fehlender sicher zuschreibbarer Werke im Moment aber nur schwer zu fassen ist. ${ }^{62}$ Konkreter greifbar wurde zuletzt die Mitwirkung des Meisters des Modena-Stundenbuches (namengebend das Stundenbuch aus der Biblioteca Estense, Ms. 842), dessen Mitarbeit am Visconti-Stundenbuch bereits Edith Kirsch vorgeschlagen hat, ${ }^{63}$ und dem Bollati die Miniaturen bzw. Initialen auf LF 22, fol. IIr (Abb. I5), 22r, 24v, 3Irv sowie 35r-36v zuschreibt. ${ }^{64}$

Eine Sonderstellung innerhalb der ersten Lagen von LF 22 nimmt das Einzelblatt fol. 13 ein, das in den Hauptfarben Belbellos (intensivem Purpur, Smaragdgrün und Blau) ausgestat-

mones ab fol. 9r stellen, so zum Beispiel die Bordüre auf fol. I2v. S. auch Bollatı, ebd., S. 303: „Si ha proprio l'impressione che questo cambiamento di regia sia dovuto all'intervento di più miniatori che con grande libertà reinterpretano il progetto decorativo. Risulta difficile ipotizzare i motivi e soprattutto i tempi di questa seconda fase di decorazione del Libro d'ore."

6I Kirsch, Manuscripts (zit. Anm. I), S. 64, Anm. 82.

62 Bollati, Libro d'ore (zit. Anm. I9), S. $320 \mathrm{f}$.

$63 \mathrm{KIRSCH}$, Manuscripts, S. 64 (zit. Anm. I), Anm. 82, hat dem Modena-Meister die Himmelfahrt Mariens in BR 397 , fol. 76 r, zugeschrieben.

64 Bollati, Libro d'ore (zit. Anm. 19), S. 307-310; Dies., Libri (zit. Anm. 22), S. 200. 


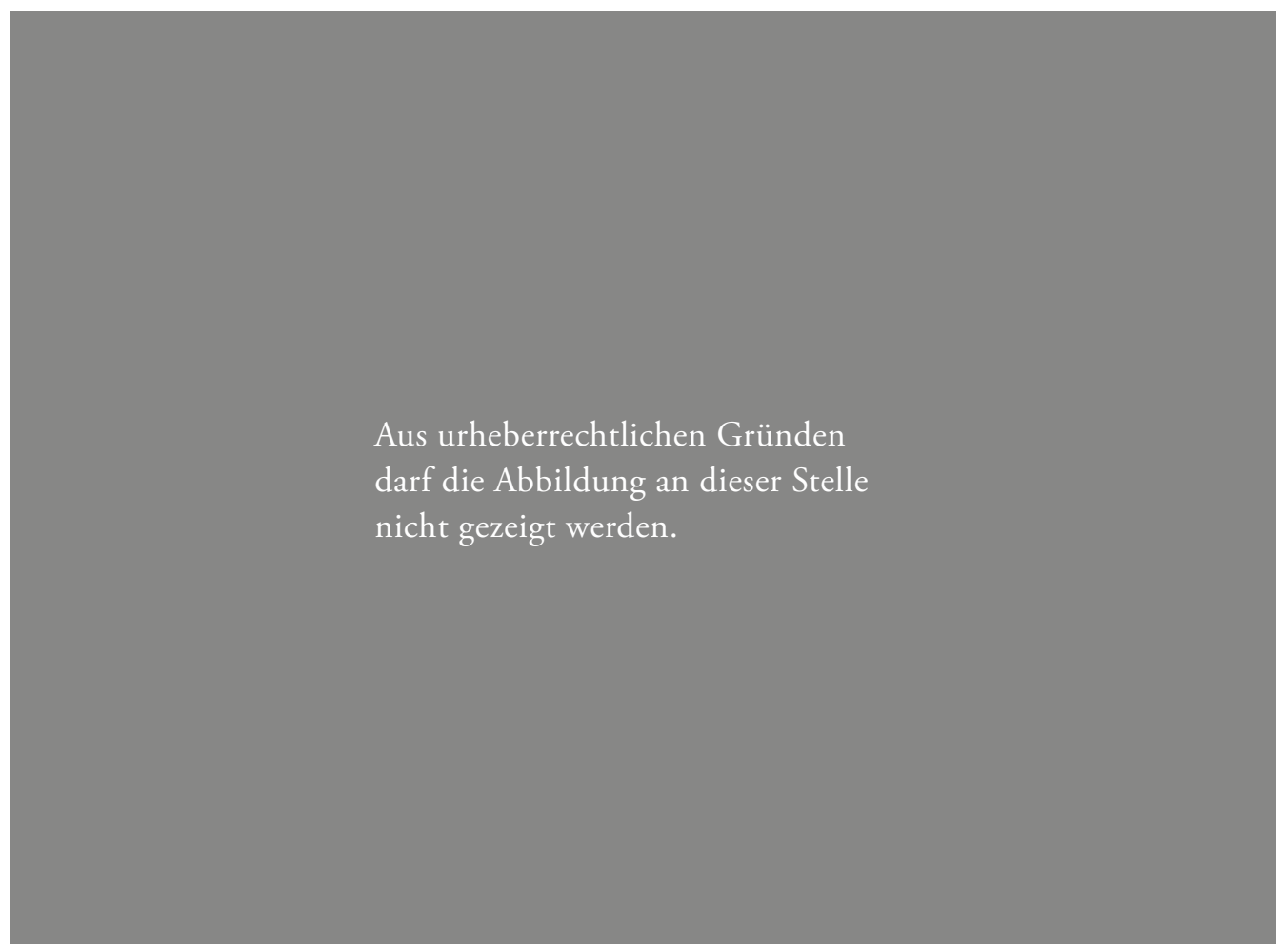

Abb. I6: Florenz, Biblioteca Nazionale Centrale, LF 22, fol. 38v/39r: geringerer Buchschmuck.

tet ist, die sonst erst später in LF 22 (fol. 33r, ${ }^{65} 37 \mathrm{r}$, 38rv, Abb. 16, einheitlich ab fol. 56r, also dem Beginn der achten Lage) auftauchen. Neu gegenüber dem ersten Teil des Stundenbuches erweist sich auf fol. I3r auch die Grundierung der einzeiligen Initialen, die jeden neuen Satz beginnen: nun nicht mehr nur einheitlich abwechselnd in Blau oder Rot, sondern als Kombination von Blau, Purpur und Grün bei einer Initiale oder als Kombination von Blau und Purpur (fol. I3v). Die Rahmen wirken deutlich schwerer als die der Kampagne ab LF 22, fol. 9r, wohl der Salomones, und basieren auf dem Grundschema von BR 397; die dreizeiligen Initialen verbinden sich bei Belbello nur teilweise mit dem Rahmen und das weit weniger raffiniert als bei Salomone (Abb. I6).

Fragt man nach dem Zustand von LF 22, in dem Belbello mit einigem zeitlichen Abstand den zweiten Teil des Visconti-Stundenbuches erhalten haben dürfte, so scheint er innerhalb der ersten sieben Lagen neben vollständig ausgeführten Seiten teils nur skizzierte oder partiell ausgemalte Seiten vorgefunden zu haben, während die restlichen Lagen noch jeglichen Buchschmuckes entbehrten. Aufgrund solcher bestehenden Vorarbeiten scheint Belbello beispielsweise die Geburt Christi (LF 22, fol. IIr, Abb. I5) die Erschaffung der Pflanzen (LF 22, fol. 34r), die Erschaffung von Sonne, Mond und Sternen (LF 22, fol. 37v) sowie Tod (LF 22, fol. 37r) und

65 Auf der Rückseite, fol. 33v, kann Belbello mit der Ankündigung des Todes Mariens wohl die erste vollständige Ausgestaltung einer Miniatur samt Rahmen zugeschrieben werden. Ebd., S. 307. 
Krönung der Jungfrau Maria (LF 22, fol. 50v, Abb. 17) entgegen früheren Meinungen nur fertiggestellt, nicht aber selbst entworfen $\mathrm{zu}$ haben. ${ }^{66}$

In dem Bereich, wo sowohl die de-GrassiWerkstatt als auch Belbello bzw. nachfolgende Künstler tätig waren, wird häufig die Konzeption noch den de Grassi zugerechnet; Rahmen oder ein Teil davon werden wiederum oft Belbello zugeschrieben, aber auch die de-Grassi-Werkstatt erscheint als Urheberin von Details. Weshalb es innerhalb der ersten sieben Lagen zu diesen unterschiedlichen Fertigstellungsstadien kam, wurde bisher kaum gefragt; auch nicht, ob diese zumindest teilweise auf technischen Aspekten (Gold- und Farbauftrag etc.) gründen. ${ }^{67}$ Eine ähnliche Situation findet man im Turin-Mailänder Stundenbuch, eigentlich Teil der Très Belles Heures des Duc de Berry, vor:

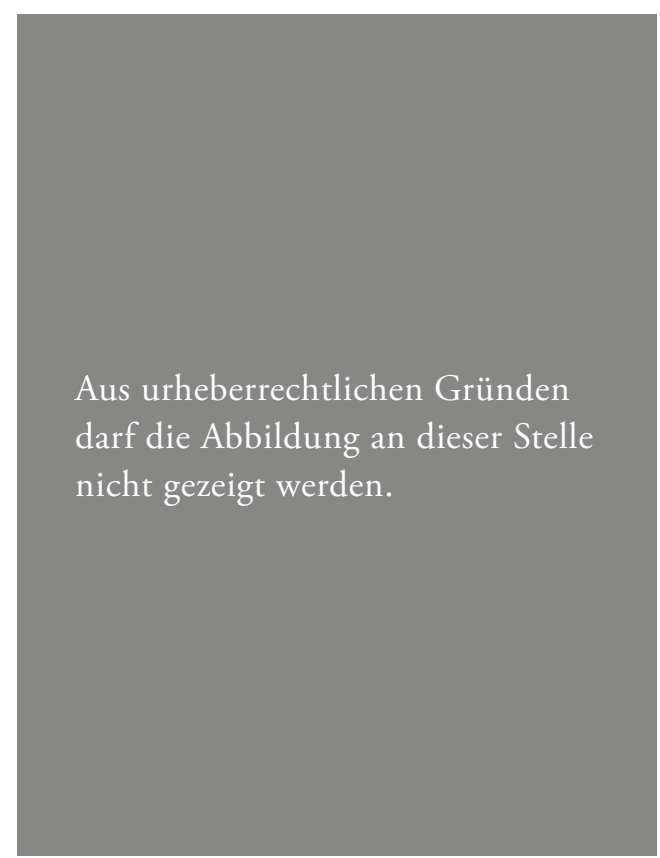

Abb. 17: Florenz, Biblioteca Nazionale Centrale, LF 22, fol. 5ov: Krönung der Jungfrau Maria. „Berrys Buchmaler hatten [...] die ungewöhnlichen Gebetsfolgen und die Messen, also immerhin zwei Drittel des vorbereiteten Textes, nur recht unsystematisch bearbeitet; hier und da waren zwar einzelne Seiten ganz zu Ende gebracht, andere blieben dagegen halbfertig, wieder andere nur mit Vorzeichnungen versehen und eine ganze Reihe noch völlig leer. Spätestens in den I430er Jahren gelangten die unvollendeten Blätter in die Hände niederländischer Buchmaler, die das Fertige weitgehend respektierten, einige alte Miniaturen aber übermalten, um sie zu vollenden, oder tilgten, um dort oder auf noch ganz leer gebliebenen Bildfeldern eine völlig neue Kunst zu schaffen. "68

Im Gegensatz zu den deutlicheren Eingriffen der Niederländer in den bestehenden Buchschmuck des Turin-Mailänder Stundenbuches steht die Arbeit Belbellos in den ersten sieben Lagen von LF 22 deutlich in der Tradition Giovanninos: „delle parti più antiche Belbello dà un'interpretazione che ne rimodella alla radice la sostanza figurativa e che con esse non

66 Bollati, Giovannino (zit. Anm. 37), S. 216.

67 Vgl. J. Alexander, Medieval Illuminators and Their Methods of Work, New Haven/London I992, S. 35-5I. Dass gerade die Polimentvergoldung in LF 22 nicht die erste Ausstattungsstufe einer Seite repräsentiert, mag nach den üblichen Arbeitsschritten erstaunen (siehe unten). Auch in einem weiteren Codex aus dem Umfeld von Giangaleazzo Visconti, dem schon erwähnten Missale-Stundenbuch Paris, BNF, Smith Lesouëf 22 hat Belbello, wohl jedoch erst um die Mitte des I5. Jahrhunderts, interveniert und zumindest eine Miniatur gefertigt (Anbetung der Heiligen Drei Könige, fol. 44v). Avril, Dix siècles (zit. Anm. 29), S. 98 f.; Manzari, Tipologie (zit. Anm. 29), S. Ior.

68 Paris, BNF, Ms. nouv. acq. lat. 3093; Turin, Museo Civico d'Arte Antica, Ms. 47; Turin, Biblioteca Nazionale, K.IV. 29 (verbrannt). Vgl. Anm. I. KöNIG, Très Belles Heures (zit. Anm. I), S. 240. 


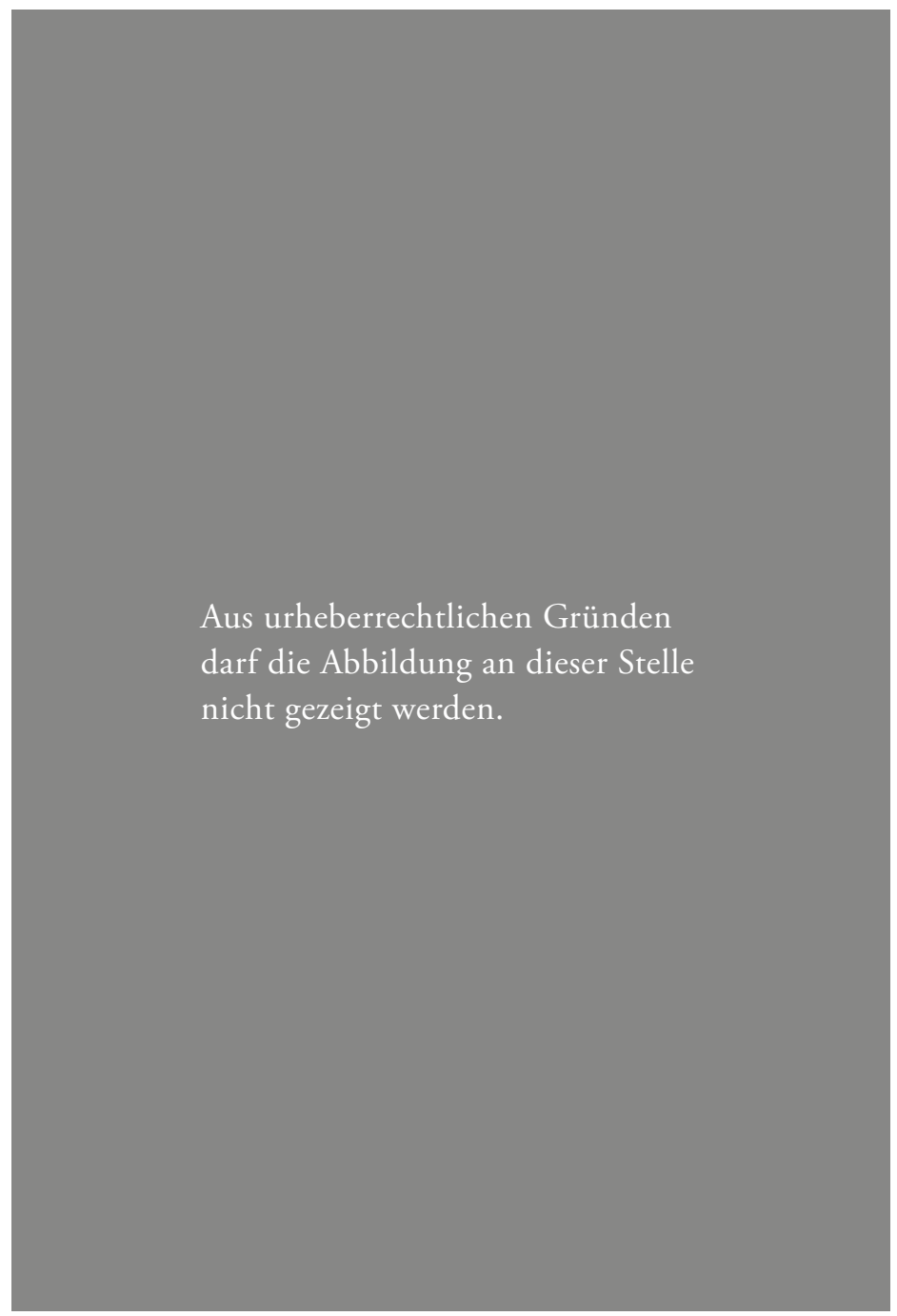

Abb. 18: Florenz, Biblioteca Nazionale Centrale, BR 397, fol. I5Ir: C(redo in Deum)Initiale: Apostel.

si pone in linea di continuità diretta, ma determina piuttosto una sorta di curioso revival giovanniniano [...]." ${ }^{\text {"69 }}$ Man muss wohl davon ausgehen, dass innerhalb der ersten sieben Lagen weitgehend die Vorzeichnungen der de Grassi vorhanden waren, die Belbello auch großteils respektierte. Diese Nähe zur Ausstattung der de Grassi bewirkt wohl auch, was niemand klar formulieren will, aus den nicht wenigen unterschiedlichen Zuschreibungen jedoch geschlossen werden darf: dass die Scheidung der beiden Künstler bzw. Werkstätten bei weitem nicht immer eindeutig ist. Selbst die gegenüberliegenden Seiten LF 22, fol. 5ov (Abb. I7) und fol. 5Ir (Abb. 9), die im Original besonders augenfällig auf ihr unterschiedliches Herkommen verweisen, sind bei näherer Betrachtung nicht zweifelsfrei durch die vorherrschenden Charakteristika des kräftig-bunten Kolorits in intensiven Blau-, Grün- und

69 Cadei, Studi (zit. Anm. Io), S. I8. 
Purpurtönen sowie der derberen Figurendarstellung Belbello sowie der zurückhaltenderen Farbigkeit und des besonders bei den Figuren eleganten disegno Giovannino de Grassi zuschreibbar. Auf fol. 5ov (Abb. 17) wird durchaus auch ein Anteil Giovanninos gesehen, ${ }^{70}$ während die Kaiserköpfe der „typischen“ Giovannino-Seite fol. 5Ir (Abb. 9) auch gänzlich Salomone zuerkannt wurden. ${ }^{71}$

Ein Distinktionsmerkmal zwischen der Trecento- und der Quattrocento-Ausstattung, das vor den Originalen deutlich wird, ${ }^{72}$ scheint bisher kaum beachtet worden zu sein: die Bearbeitung des Goldgrundes. ${ }^{73}$ Während auf die Polimentvergoldung innerhalb der ersten Ausstattungsphase nur andere Farben, Deckweiß, Goldemulsion oder auch roter Lack, was zu besonders spektakulären Effekten führt (vgl. BR 397, fol. I5Ir, Abb. I8), ${ }^{74}$ aufgetragen wurden, wird der Goldgrund in der Quattrocento-Ausstattung mit Vorliebe durch Feldungen gegliedert, mit Lochmustern punziert oder musiert. ${ }^{75}$ Dies zeigt sich schon am Goldgrund auf der ersten Seite von LF 22 (fol. Ir, Abb. II), die meist Giovannino de Grassi zugeschrieben wurde, dessen Ausgestaltung sich aber ausschließlich mit Beispielen aus der zweiten Ausstattungsphase deckt (vgl. LF 22, fol. 90v, 99r, IO2r). Dementsprechend muss auch die Ausgestaltung des Goldgrundes von LF 22, fol. I2r, 33v, 37v, 4Ir und 46v zweifel-

70 Kirsch, Manuscripts (zit. Anm. I), S. 90.

7I Bollati, Giovannino (zit. Anm. 37), S. 215.

72 Das Faksimile von MeIss/Kirsch, Hours (zit. Anm. 2) lässt hinsichtlich einer Bearbeitung des Goldgrundes kaum valide Schlüsse zu. Vor allem die Lochmuster sind gar nicht zu erkennen, aber auch andere Bearbeitungsformen sind kaum nachvollziehbar.

73 Meiss / Kirsch, ebd., LF I, bemerken lediglich zu LF 22, fol. Ir: „Novel, however, is the punched and squared gold-leaf behind the initial on LF I. In each compartment, a four-petaled-flower is painted in gold-emulsion against a burnished ground. This is a favorite design of Belbello da Pavia [...]. It recurs frequently in his part of the manuscript [...]“ sowie zu LF 22, fol. I2r: „Like Giovannino, he [= Belbello] enjoys gold. He applies it to heavier designs, however, and in association with denser colors. "Zum Umgang mit Gold in der Buchmalerei vgl. K. Whitley, The Gilded Page: The History and Technique of Manuscript Gilding, New Castle 200o, bes. S. 71, 80, I63-I77; R. Straub, Tafel- und Tüchleinmalerei, in: H. KüHN u. a., Reclams Handbuch der künstlerischen Techniken, I: Farbmittel, Buchmalerei, Tafel- und Leinwandmalerei, Stuttgart ${ }^{2}$ I988, S. I25259, I80-198; K. Nicolaus, DuMont's Handbuch der Gemäldekunde. Material, Technik, Pflege, Köln i979, S. IO2-II3; TH. BRAChert, Lexikon historischer Maltechniken. Quellen - Handwerk - Technologie - Alchemie, München 200I, bes. S. I70, 88 f., I98 f; E. Skaug, Punch Marks from Giotto to Fra Angelico. Attribution, Chronology and Workshop Relationships in Tuscan Panel Painting, c. I330-I430, 2. Bde., Oslo 1993.

74 Kein anderer Buchmaler habe nach Meiss / Kırsch, Stundenbuch (zit. Anm. 36), S. I4, ,je derart vielfältige metallische Effekte erzielt“; sie bezeichnen die „endlosen Variationen in Kombination mit den üblichen Pigmenten“ als „vielleicht [...] größte Errungenschaft dieser Handschrift.“

75 Mit Ätzungen wurde entgegen ersten Erwägungen wohl nicht gearbeitet. Dies ließ sich in der kurzen Zeit vor den Originalen nicht verifizieren. Allerdings konnte für die vermutlich in unmittelbarer zeitlicher Nähe (wohl zwischen 1432 und I433) durch Belbello ausgestattete Bibel des Niccolò d'Este (Vatikanstadt, BAV, Barb. lat. 613) mit freundlicher Unterstützung von Angela Nuñez Gaitán neben der Verwendung von Lochmustern nur die häufige Bearbeitung des Goldgrundes mit Goldemulsion (unter anderem fol. 20or, 226r, 26or) sowie vereinzelt durch Ritzungen (fol. 205r), nicht jedoch durch Ätzungen festgestellt werden. Die farbliche Veränderung des Goldes auf Vatikanstadt, BAV, Barb. lat. 613, fol. 7Iv und 72v dürfte durch Oxidation hervorgerufen worden sein. 


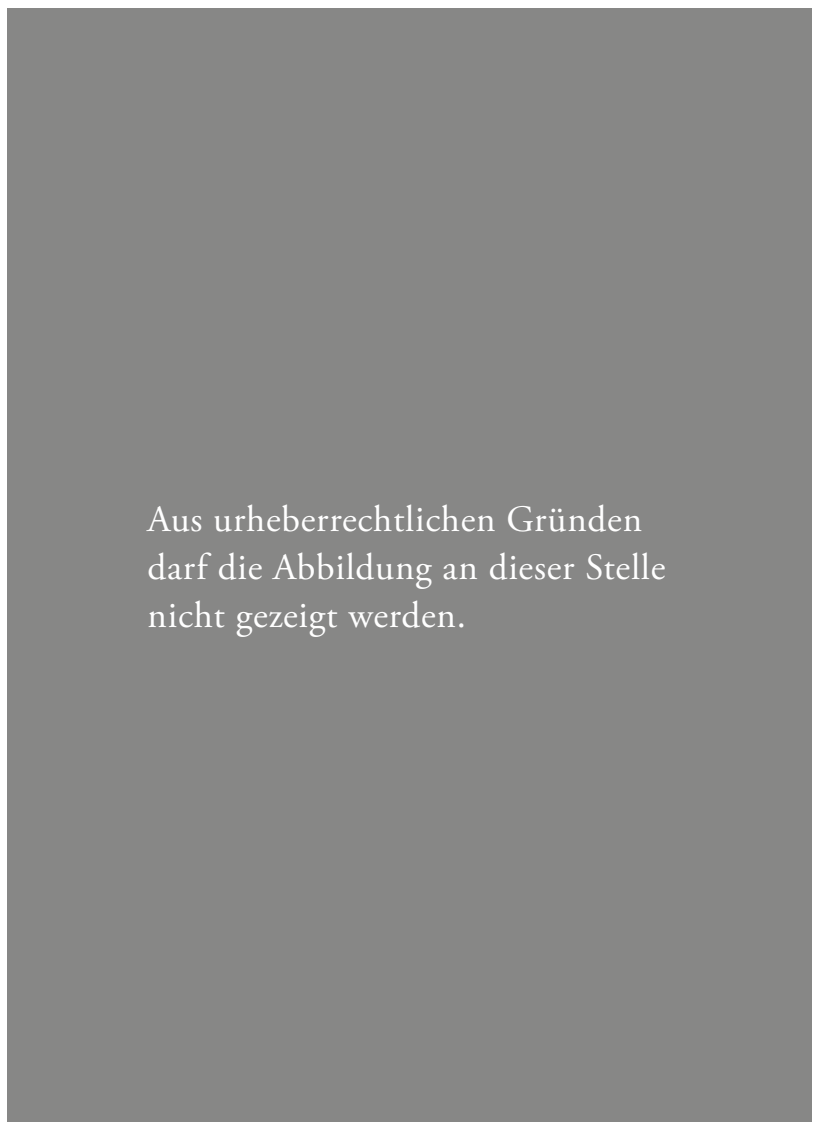

los der Ausstattung durch Belbello zugerechnet werden. ${ }^{76}$ Nach LF 22, fol. 55v endet jedenfalls die Beteiligung der de Grassi an der Ausstattung des Visconti-Stundenbuches und damit auch die Trecento-Ausstattung.

Wendet man sich nochmals der Frage nach dem Arbeitsprozess zu, in dem die ersten sieben Lagen von LF 22 entstanden sind, so gewinnt man mit der Lagenformel und Blickrichtung auf die Rahmen, besonders auch innerhalb des geringeren Buchschmucks, den Eindruck, dass sich die Ausstattung weitgehend an Doppelblättern orientiert hat, welche zumeist von einem Künstler auf beiden Seiten gestaltet wurden. Dominierend sind dabei die Doppelblätter der de Grassi. Die Interventionen Belbellos finden sich vorwiegend auf zusammengehörigen Einheiten: dem Doppelblatt fol. II/ı2 (Abb. I5), dem Einzelblatt fol. I3 oder dem Doppelblatt fol. $33 / 38$ (Abb. I6). Das Doppelblatt fol. 4Ir / 46v weist sogar ein sich in Aufteilung und Motivik völlig entsprechendes Dekorationsschema auf (mittig die Initiale, eine reiche von Tieren bevölkerte Landschaft im Bas-de-page, an den beiden Seiten und oben Weinblattranken mit phantastischen Blüten, Visconti-Emblemen sowie zwei Engelgruppen

76 Der in der ersten Lage von LF 22 verwendete Bolus ist bis auf fol. Ir farblos, ab der zweiten Lage wie auch auf fol. ir hellrot. 
an den oberen Ecken). ${ }^{77}$ Zudem taucht innerhalb der ersten sieben Lagen (mit leichter Varianz) ein Rückgriff auf das einfache Rahmenschema von BR 397, das von einer dreiseitigen gold-blauen bzw. -rosafarbenen Leiste bestimmt wird, auf. Diese Wiederaufnahme findet mit einer Ausnahme (fol. 53r) ausschließlich auf zwei Doppelblättern (fol. 43/44 sowie fol. 48/55, Abb. 19) und dies jeweils auf allen vier Seiten statt, ohne dass ein anderes Dekorationssystem zur Anwendung gekommen wäre. Wo mehrere Künstler auf einer Seite gearbeitet haben, betrifft dies nicht nur Fertigstellungen, sondern auch Änderungen. Sowohl Belbello als auch vermutlich Giovannino ${ }^{78}$ haben teils Bestehendes übermalt, ${ }^{79}$ was eine Händescheidung besonders erschwert.

Die Forschungsgeschichte zum Visconti-Stundenbuch, in welcher der Wunsch nach einer Hände- und einer Werkstattscheidung seit gut roo Jahren immer wieder von Neuem an die Grenzen der Evidenz, welche die zwei Bände darbieten, stößt, enthüllt zum einen einiges über die Disziplin selbst, über die Arbeitsweisen in der Werkstatt der Kunsthistoriker, über die Interessen und Ausrichtungen des Faches. Zum anderen legen die vielfachen unterschiedlichen Zuschreibungen an Künstler und Werkstätten innerhalb des Visconti-Stundenbuches nahe, dass es wohl ein Anliegen der ausführenden Künstler war, im Rahmen eines großen Formenreichtums einen relativ geschlossenen Gesamteindruck zu erzeugen. Selbst Belbello, welcher besonders in der Farbgebung, aber auch in der Gesamtwirkung gänzlich andere Akzente setzt, orientiert sich formal durchaus an der vorangegangenen Arbeit und definiert sie vielfach neu. Innerhalb der gemeinsamen Lagen von LF 22 geht die Annäherung an das Bestehende teilweise so weit, dass eine klare Scheidung oft nicht möglich ist und wohl auch nicht erwünscht war. Ähnlich manchen Gebräuchen der wissenschaftlichen Schreibwerkstatt sollte wohl nicht der Arbeitsprozess und die bricolage im Vordergrund stehen als vielmehr das Gesamtprodukt, das im Falle des Visconti-Stundenbuches auch nach 600 Jahren nichts von seiner Strahlkraft eingebüßt hat. Doch während das Kunstwerk Aussicht als monumentum aere perennius ${ }^{80}$ hat, ist das wissenschaftliche Werk weitgehend auf seine Rolle als (potentielles) Rädchen im transformativen Erkenntnisprozess beschränkt.

Universität Wien

Abbildungsnachweis: Abb. I, 2, 7-9, I5, I7: MeIss/Kirsch, Hours (zit. Anm. 2). - Abb. 3, 6, II, I3, I4, I6: Libro d'Ore Visconti. Ed. in facsimile (zit. Anm. I2). - Abb. 4, 5, IO, I2, I8, I9: nach Bollati (Hrsg.), Libro (zit. Anm. I4).

77 Trifft die Annahme Kirschs, Manuscripts (zit. Anm. I), S. 90, zu, dass LF 22, fol. 46v im I4. Jahrhundert begonnen und erst im I5. vollendet wurde, so hat Belbello sich mit der Ausgestaltung von fol. 4Ir, die Kirsch, ebd., alleinig dem Quattrocento zuschreibt, besonders eng an die Gestaltungsmuster der de Grassi angelehnt.

78 Kirsch, Manuscripts (zit. Anm. I), S. 65.

$79 \mathrm{Zu}$ den Übermalungen vgl. die Kommentare zu den einzelnen Miniaturen bei MeIss/Kirsch, Hours (zit. Anm. 2).

80 Horaz, Oden 30, I. 


\title{
BERTHOLD FURTMEYR
}

\author{
ZUSCHREIBUNGS- UND WERKSTATTFRAGEN
}

Katharina Hranitzky

\section{E I N L E I T U NG}

Der Illuminator Berthold Furtmeyr aus Regensburg, zwischen 1470 und I5OI urkundlich bzw. durch Inschriften in Codices nachweisbar, ${ }^{1}$ ist einer jener nicht sehr zahlreichen Künstler des Spätmittelalters, die als Schöpfer erhaltener Werke aus der Anonymität hervorgetreten sind bzw. deren archivalisch dokumentierte Namen mit konkreten Arbeiten verknüpft werden können. Für Berthold Furtmeyr und seine Werkstatt lässt sich sogar ein besonders umfangreiches Euvre zusammenstellen. Die große dem Regensburger Buchmaler gewidmete Ausstellung, die von November 20Io bis Februar 20II im Historischen Museum der Stadt Regensburg stattfand und anlässlich derer ein reich bebilderter Katalog mit Beiträgen zahlreicher Autoren erschien (im Folgenden als Furtmeyr-Katalog bezeichnet), ${ }^{2}$ gab erstmals Gelegenheit, die meisten der illuminierten Bände, die bis dahin von der Forschung mit Furtmeyr in Zusammenhang gebracht worden waren, ${ }^{3}$ ebenso wie einige weitere, noch nicht bekannte Arbeiten im Original zu bewundern und unmittelbar miteinander zu vergleichen. Dabei zeigte sich mit besonderer Deutlichkeit, was schon auf den bis dahin zur Verfügung stehenden Abbildungen teilweise zu erkennen gewesen und worauf auch in der Literatur, ${ }^{4}$ zuletzt in einigen der Katalogbeiträge, hingewiesen worden war, dass nämlich das „Furtmeyrsche Euvre“, wie es in der Ausstellung präsentiert wurde, alles andere als stilistisch homogen ist. Zwischen manchen der Exponate bestehen sogar erhebliche Stildiskrepanzen. Dieser Umstand lässt es dringend notwendig erscheinen, das Material erneut zu sich-

I Siehe zuletzt ausführlich H. WANDERwitz, Berthold Furtmeyr - sein Leben im sozialhistorischen Kontext, in: Furtmeyr-Katalog (zit. Anm. 2), S. 3II-325, hier bes. S. 317-320. Siehe auch E. KöNIG, Berthold Furtmeyr, in: Furtmeyr-Katalog (zit. Anm. 2), S. 3I-43.

2 Chr. Wagner/K. Unger (Hrsg.), unter Mitarbeit von W. Neiser, Berthold Furtmeyr. Meisterwerke der Buchmalerei und die Regensburger Kunst in Spätgotik und Renaissance. Katalog zur Ausstellung in Regensburg November 2010 bis Februar 2OII, Regensburg 20IO, mit Beiträgen unter anderem von B. HernAD, A. Hubel, E. König, P. Rudolph, H. Wanderwitz, K. Zimmermann (s. jeweils unten und Anm. i).

3 Als die bis dahin wichtigsten kunsthistorischen Untersuchungen zu Berthold Furtmeyr sind zu nennen: A. v. Rohr, Berthold Furtmeyr und die Regensburger Buchmalerei des 15. Jahrhunderts, Bonn 1967. - A. Hubel, Berthold Furtmeyr und die Regensburger Buchmalerei des ausgehenden Mittelalters, in: Regensburger Buchmalerei. Katalog zur Ausstellung in Regensburg Mai bis August 1987 (BSB, Ausstellungskataloge 39), München 1987, S. III-II8 und II9-I23 (Kat. I03-IIo). - R. Kahsnitz, Die Handschrift und ihre Bilder, in: J. JAnота (Hrsg.), Die Furtmeyr-Bibel in der Universitätsbibliothek Augsburg. Kommentarband zum Faksimile, Augsburg 1990, S. 65-I24. - Berthold Furtmeyr in München. Illuminierte Prachthandschriften, 2 Bde., Luzern 2oiı, Bd. I: B. Hernad, Die Münchener Furtmeyr-Bibel BSB Cgm 8oioa, Bd. 2: K.-G. Pfändnter, Das Salzburger Missale BSB Clm I5708-I57I2.

4 Siehe zum Beispiel Hernad, Münchener Furtmeyr-Bibel (zit. Anm. 3), S. I6. 
Abb. I: Linz,

Katholisch-theologische Privatuniversität (ehem. OÖLB, Cod. 154), Brevier für Augsburg, datiert I475, fol. I7r: Historisierte Deckfarbeninitiale mit Darstellung des psalmierenden Königs David, Ranken; Berthold Furtmeyr oder Mitarbeiter

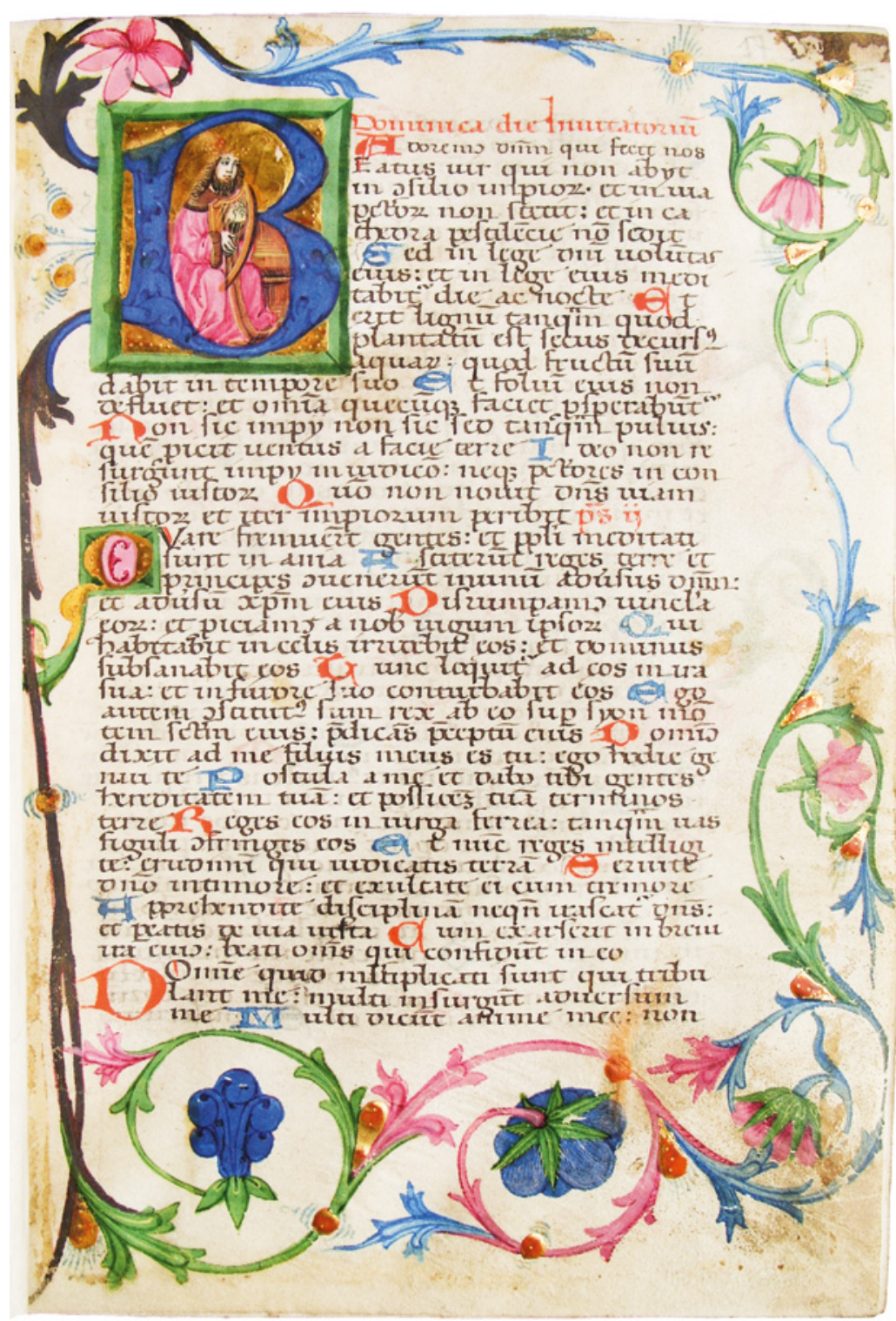

ten und wenigstens eine grobe Sortierung der ausgestellten Werke nach stilistischen Kriterien vorzunehmen. Außerdem sollen einige der weniger prominenten Objekte etwas genauer unter die Lupe genommen werden, um an ihnen aufzuzeigen, welche Schwierigkeiten sich bei der Beurteilung der Arbeiten aus Furtmeyrs Atelier ergeben können. Schließlich sei die Beschäftigung mit Furtmeyr als Reaktion auf die Ausstellung zum Anlass genommen, eine Reihe von Neuzuschreibungen an diesen Buchmaler vorzuschlagen. 


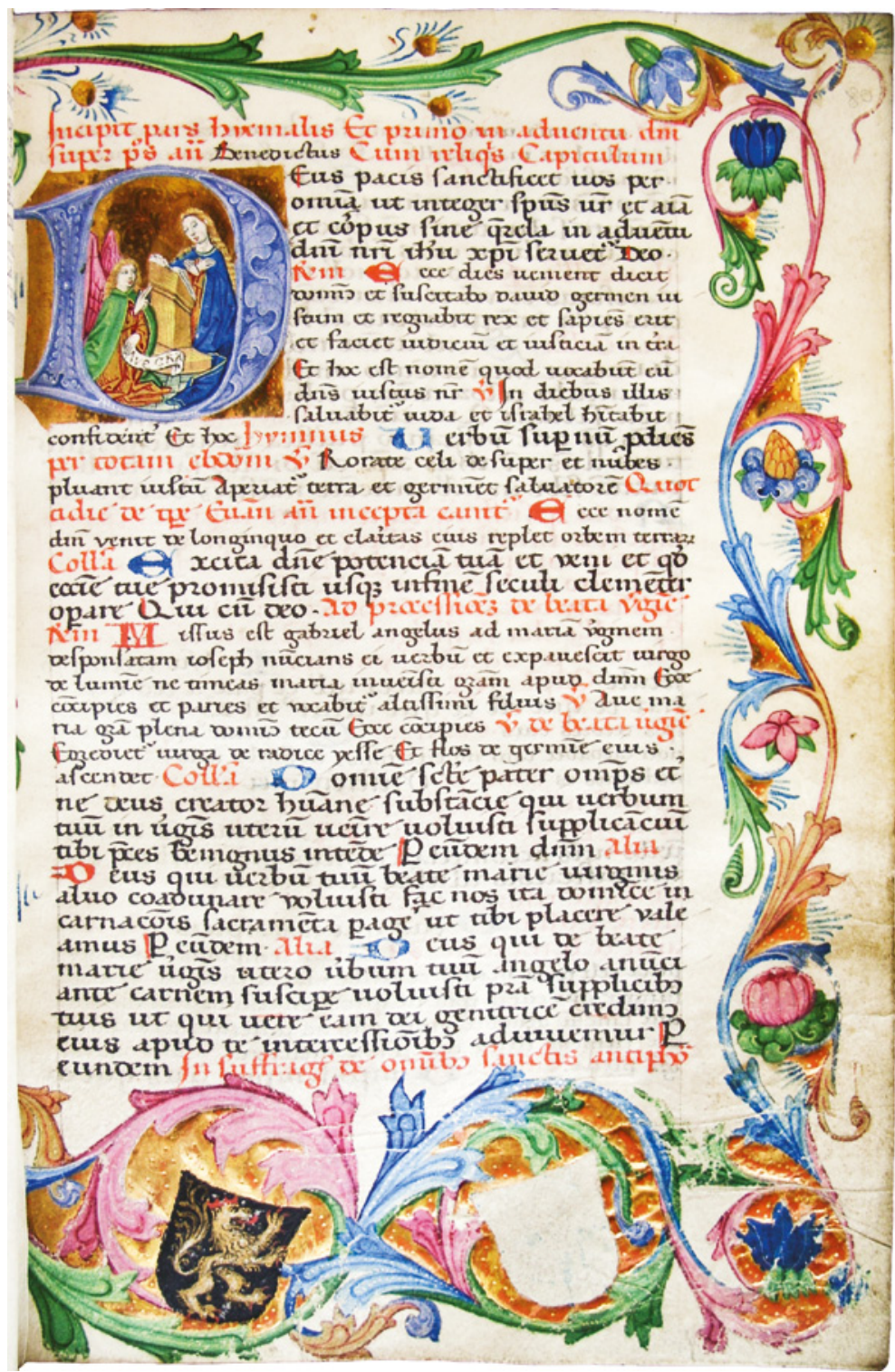

Abb. 2: Linz, Katholischtheologische Privatuniversität (ehem. OÖLB, Cod. I54), Brevier für Augsburg, datiert I475, fol. 8or: Historisierte Deckfarbeninitiale mit Darstellung der Verkündigung an Maria, Ranken; Berthold Furtmeyr oder Mitarbeiter

\section{DIE KERNGRUPPE DES FURTMEYRSCHEN GEUVRES}

Zwei seiner Arbeiten hat Berthold Furtmeyr bekanntlich signiert; von diesen beiden Werken muss jede umfassende und detaillierte Stiluntersuchung des Werks Furtmeyrs ausgehen (siehe unten). Der Name des Illuminators taucht zum ersten Mal in dem zwei Bände umfassenden Alten Testament in Augsburg auf (Universitätsbibliothek, Cod. I. $3.2^{\circ}$ III und IV), ${ }^{5}$ das von

5 Siehe zur Handschrift insbesondere: Janota, Furtmeyr-Bibel in Augsburg (zit. Anm. 3); Hubel, Furtmeyr und die Regensburger Buchmalerei (zit. Anm. 3), S. II9f. (Kat. IO4); G. HäGELE, Die Furtmeyr-Handschrif- 
Abb. 3: Linz, Katholischtheologische Privatuniversität (ehem. OÖLB, Cod. I54), Brevier für Augsburg, datiert I475, fol. 275r: Historisierte Deckfarbeninitiale mit Pfingstdarstellung, Ranken; Berthold Furtmeyr oder Mitarbeiter

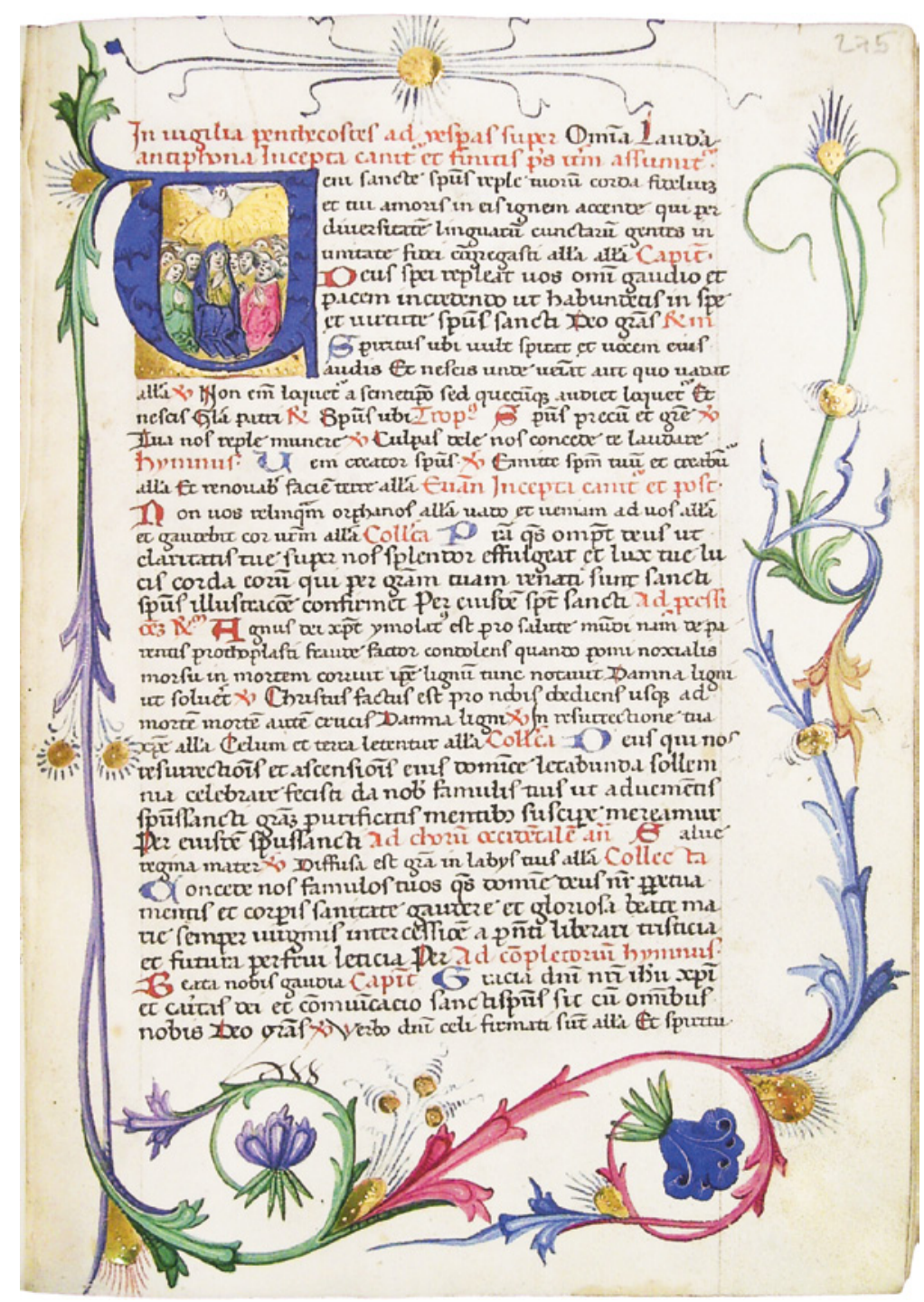

Georg Rörer aus Regensburg I468 fertiggeschrieben und von Furtmeyr zwischen diesem Datum und dem Jahr 1472 illuminiert wurde, wie aus den Inschriften auf den beiden Frontispizminiaturen sowie auf dem hinteren Spiegel von Band I hervorgeht. Die beiden Bände enthalten neben zahlreichen historisierten und unfigürlichen Deckfarbeninitialen mit Randschmuck (Abb. 4) rund 20 ganzseitige und fast 400 kleinere Miniaturen. ${ }^{6}$

ten der Sammlung Oettingen-Wallerstein ..., in: Furtmeyr-Katalog (zit. Anm. 2), S. 335-338; Furtmeyr-Katalog, S. 339-36I (Kat. 25-9I), Abb. 60-IO4, IO7-II9, 275-30I und andere, Taf. 42-59 und passim. Volldigitalisat der Handschrift unter der URL: http://www-kunstgeschichte.uni-r.de/index.php?furtmeyr-digital.

6 Auf fol. $2 \mathrm{v}$ in Cod. I. $3.2^{\circ}$ III wurden die Wappen der Erstbesitzer, Hans III. von Stauff zu Ehrenfels in der Oberpfalz (gest. 1478) und seiner Frau Margarete Schenk von Geyern, ca. I492 mit jenen Herzog Albrechts IV. von Bayern (gest. I508) und seiner Gattin Kunigunde von Österreich übermalt. 
Beim zweiten von Furtmeyr signierten Werk handelt es sich um das berühmte fünfbändige Prachtmissale, das der Salzburger Fürsterzbischof Bernhard von Rohr in Auftrag gab und das unter dessen beiden Nachfolgern fertiggestellt wurde (München, BSB, Clm 15708-I2). ${ }^{7}$ Furtmeyr löste ca. 1478 den Salzburger Buchkünstler Ulrich Schreier $\mathrm{ab}^{8}$ und war über zehn Jahre lang, bis nach I489, mit der Ausschmückung des Missales beschäftigt. ${ }^{9}$ Seine von der Jahreszahl I48I begleitete Signatur befindet sich auf der dem fünften Band (den Furtmeyr als Zweites illuminierte) vorgebundenen Miniatur mit den Wappen Bernhards von Rohr (Clm I57I2, fol. 89r). Der von Furtmeyr - mit größter Sorgfalt - ausgeführte Deckfarbenschmuck umfasst rund 45 ganzseitige Darstellungen (I4 davon sind Kanonbilder) und etliche kleinere Miniaturen, weiters zahlreiche historisierte und unfigürliche Deckfarbeninitialen (Abb. Io), schließlich üppigsten Randschmuck von atemberaubender formaler Vielfalt und Originalität. $\mathrm{Ob}$ die Kreuzigungsminiatur in Berlin, Kupferstichkabinett, Min. $125 \mathrm{O}^{10}$ zum ursprünglichen Bestand des Salzburger Missales gehörte, aus dem vier Kanonbilder fehlen, ${ }^{11}$ wäre noch zu klären.

Um diese beiden signierten Hauptwerke des Regensburger Buchmalers wurden aus stilistischen Gründen einige weitere reich illuminierte Bände sowie Einzelminiaturen gruppiert. Für diese Arbeiten gilt die Autorschaft Furtmeyrs seit langem als gesichert, sie bilden zusammen mit dem Augsburger Alten Testament und dem Salzburger Missale gleichsam den Kern des Furtmeyrschen Euvres. Allerdings bliebe im Einzelnen noch zu untersuchen, ob und in welchem Ausmaß jeweils Gehilfen an der Ausführung ihres Buchschmucks beteiligt waren (s. Anm. 20).

Bei der ältesten bisher bekannt gewordenen Handschrift, die Furtmeyr zugeschrieben werden kann, handelt es sich um ein zweibändiges Altes Testament in der British Library in London (Egerton ms. 1895-96) ${ }^{12}$, das von Rörer (siehe oben) schon 1465 für einen unbekannten Auftraggeber geschrieben wurde. Die Deckfarbenausstattung des Codex besteht aus 42 histo-

7 Siehe Pfändtner, Salzburger Missale (zit. Anm. 3); B. Hernad, Das Salzburger Missale Clm I5708-I57I2, in: Furtmeyr-Katalog (zit. Anm. 2), S. 367-370; Furtmeyr-Katalog, S. 370-4I6 (Kat. I04-233), Abb. 31I-340, Taf. 64-Io9d und passim. Volldigitalisat der Handschrift unter der in Anm. 5 angegebenen URL.

$8 \mathrm{Zu}$ Schreiers Anteil am Werk und zur Arbeitsaufteilung zwischen den beiden Buchmalern s. M. SchulLERJuckes, Ulrich Schreier und seine Werkstatt. Buchmalerei und Einbandkunst in Salzburg, Wien und Bratislava im späten Mittelalter, Wien, Universität, Diss. (masch.), 2009, S. 50-52, bes. auch Anm. I54. Verfügbar unter der URL http://othes.univie.ac.at/3288/.

9 Anhand der in die Darstellungen eingefügten oder auf Vorsatzblätter gemalten Wappen Bernhards von Rohr und seiner beiden Nachfolger Johann Beckenschlager (gest. 1489) und Friedrich Graf von Schaunberg (gest. I494) lässt sich eine ziemlich genaue Chronologie der Arbeiten Furtmeyrs erstellen. Siehe die unter anderem auf Rohr, Berthold Furtmeyr (zit. Anm. 3) beruhende Zusammenfassung der Entstehungsgeschichte des Missales bei Pfändnter, Salzburger Missale (zit. Anm. 3), S. I2 f. und Hernad, Salzburger Missale (zit. Anm. 7), S. 367-370.

Io Siehe Pfändnter, Salzburger Missale (zit. Anm. 3), S. I4, mit Angabe der älteren Literatur.

II Siehe zum Beispiel Hernad, Salzburger Missale (zit. Anm. 7), S. 369, Anm. I4, I5 und I9.

I2 Kahsnitz, Die Handschrift und ihre Bilder (zit. Anm. 3), S. 68, 90-93, und Abb. 65-68; Furtmeyr-Katalog (zit. Anm. 2), S. 306-308 (Kat. 2-IO), Taf. 2f., Abb. 254-258. Abbildungen und Beschreibung unter der URL http://www.bl.uk/catalogues/illuminatedmanuscripts/record.asp?MSID=2752und der URL http://www.bl.uk/ catalogues/illuminatedmanuscripts/record.asp?MSID=2763. 
Abb. 4: Augsburg, Universitätsbibliothek, Oettingen-Wallersteinsche Bibliothek, Cod. I.3.2 ${ }^{\circ}$ III, Altes Testament, Bd. I, im Schmuck signiert und datiert I470, fol. 384r: Unfigürliche Deckfarbeninitiale mit Ranken sowie zwei Miniaturen zum Richterbuch bzw. zum Buch Ruth; Berthold Furtmeyr und Werkstatt

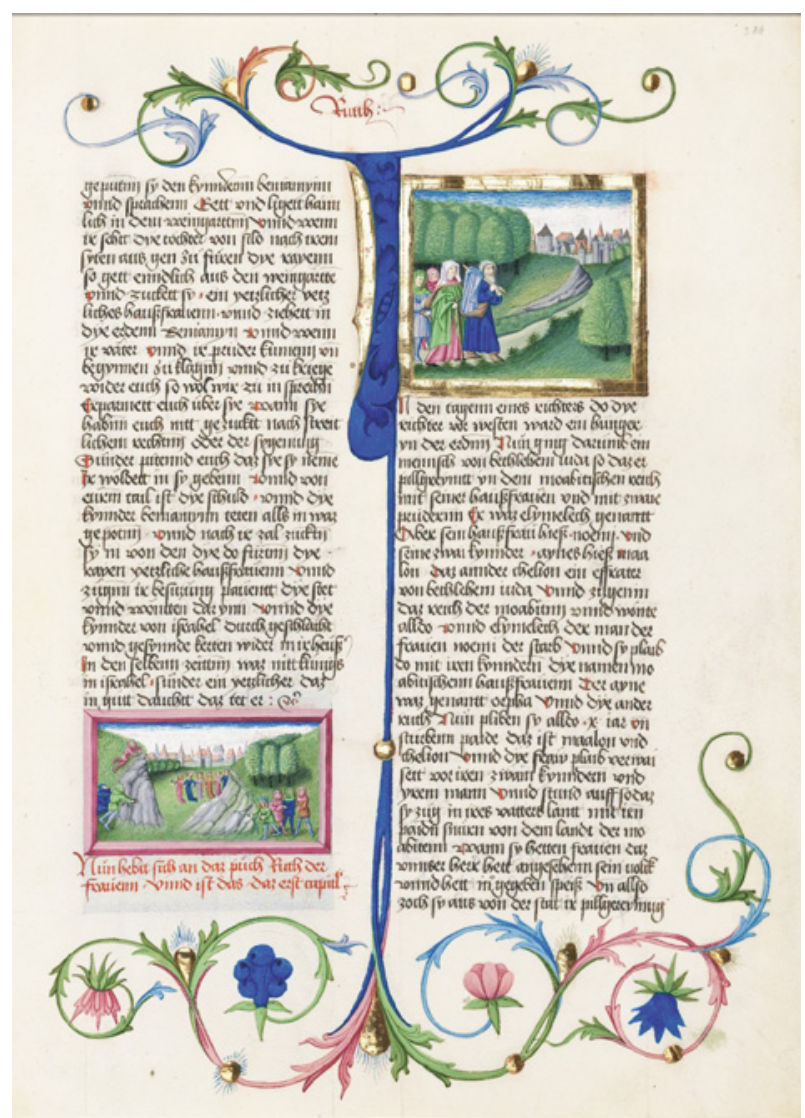

risierten und etlichen unfigürlichen Deckfarbeninitialen sowie aus sieben in Randmedaillons eingefügten figürlichen Darstellungen (Abb. I8).

Als eines der bedeutendsten Werke des Regensburger Illuminators ist die aus einem Band bestehende Furtmeyr-Bibel in München (BSB, Cgm 8oIoa) ${ }^{13}$ anzusehen, die nur die Texte von Genesis bis Rut enthält, aber das am dichtesten bebilderte der drei Furtmeyrschen Exemplare des Alten Testaments darstellt. Der Schmuck dieser Handschrift, die, so wird angenommen, noch vor der Augsburger Bibel angefertigt wurde, umfasst drei ganzseitige Bilder, 336 Bibelillustrationen sowie historisierte und unfigürliche Deckfarbeninitialen samt teilweise üppigem Randschmuck. ${ }^{14}$

I3 Hubel, Furtmeyr und die Regensburger Buchmalerei (zit. Anm. 3), S. II9 (Kat. Io3); Hernad, Münchener Furtmeyr-Bibel (zit. Anm. 3); B. Hernad, Die > Furtmeyr-Bibel< Cgm 8oroa, in: Furtmeyr-Katalog (zit. Anm. 2), 327 f.; Furtmeyr-Katalog, S. 329-334 (Kat. II-24), Taf. 4-4I, Abb. 262-275 und passim. Volldigitalisat der Handschrift unter der in Anm. 5 angegebenen URL.

I4 Empfänger waren Ulrich von Stauff zu Ehrenfels (gest. I472), der Bruder des Bestellers des Augsburger Exemplars (s. Anm. 6), und seine Gemahlin Clara Hofer von Lobenstein. Wie die Augsburger gelangte auch die Münchener Bibel höchstwahrscheinlich in den Besitz Herzog Albrechts IV. Die Wappen der Erstbesitzer wurden in diesem Exemplar jedoch nicht übermalt (vgl. Anm. 6). 


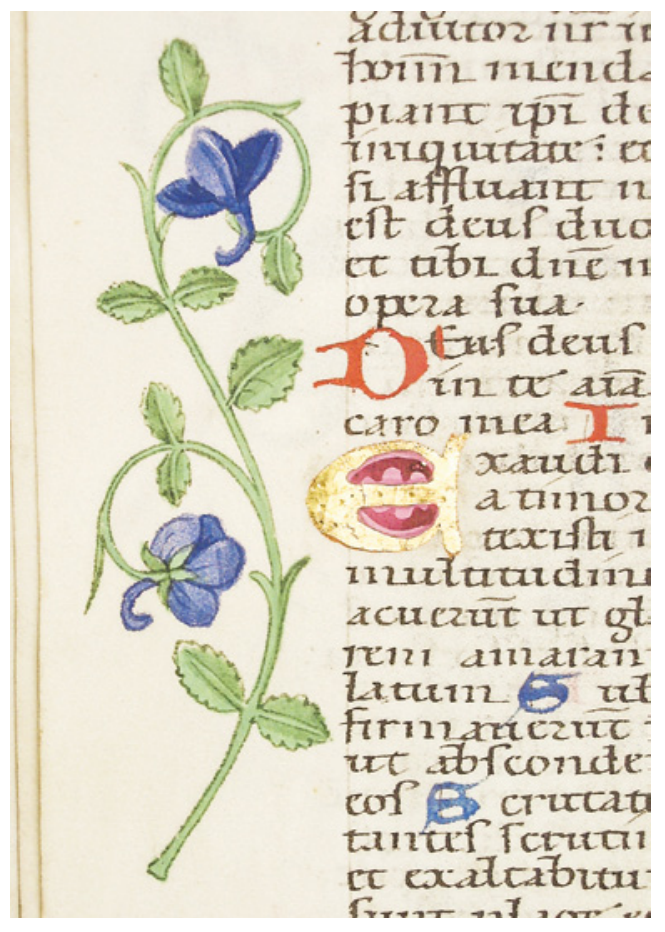

Abb. 5: Linz, Katholisch-theologische Privatuniversität (ehem. OÖLB, Cod. 154), Brevier für Augsburg, datiert I475, fol. 47v, Randschmuck (Detail); Berthold Furtmeyr oder Mitarbeiter
Das Kanonbild mit der Darstellung der Kreuzigung mit Maria und Johannes und den drei Marien (München, BSB, Clm I4045, fol. $32 \mathrm{v})^{15}$, das nachträglich in ein 1406 entstandenes Missale für St. Emmeram in Regensburg (offenbar statt des ursprünglichen Kanonbilds) eingebunden wurde, wird um I480/90 datiert, da es etwa auf der Stilstufe des Salzburger Missales steht.

Wohl nach I49I sind schließlich zwei Drehbilder (Astrolabien) zu datieren, die, auf Einzelblätter gemalt, in eine möglicherweise in Ingolstadt entstandene, heute in Heidelberg aufbewahrte astronomisch-astrologisch-mantische Handschrift eingebunden wurden („Heidelberger Schicksalsbuch“, Universitätsbibliothek, Cod. Pal. germ. 832, foll. I6r, I03r). ${ }^{16}$ Der Codex enthält außerdem über 500 Textillustrationen von anderer Hand (siehe unten). ${ }^{17}$

\section{WEITERE ZUGESCHRIEBENE} ARBEITEN

Die übrigen Werke, die in der Ausstellung von 20Io/20II als Arbeiten Furtmeyrs präsentiert wurden, stehen, wie sich bei genauerer Betrachtung zeigt, in einem ganz unterschiedlichen stilistischen Verhältnis zu Furtmeyrs Hauptwerken. Tatsächlich können sie zu drei Gruppen zusammengefasst werden. Davon besteht die erste aus Werken, bei denen zwar noch überprüft werden müsste, welchen Anteil an ihrer Ausstattung der Meister selbst hatte (siehe oben), die jedoch ihre Herkunft aus der Werkstatt des Regensburger Buchmalers eindeutig erkennen lassen. Die zweite Gruppe setzt sich aus Handschriften zusammen, die gewisse Analogien zu Furtmeyrs gesicherten Arbeiten aufweisen, sich jedoch im Vergleich zur ersten Gruppe stärker von diesen unterscheiden, so dass sie als „Schülerarbeiten“ bzw. als Werke aus dem weiteren Um-

I5 Hubel, Furtmeyr und die Regensburger Buchmalerei (zit. Anm. 3), S. I2I f. (Kat. I07), Taf. 79; Furtmeyr-Katalog (zit. Anm. 2), S. 366 (Kat. I03) und 533, Taf. 62. Volldigitalisat der Handschrift unter der in Anm. 5 angegebenen URL.

i6 Hubel, Furtmeyr und die Regensburger Buchmalerei (zit. Anm. 3), S. i22 f. (Kat. Io9), Taf. 8o; FurtmeyrKatalog (zit. Anm. 2), S. 428-443 (Kat. 24I-296) und 532, Abb. 348-355, 357-394. Zur Datierung s. K. ZIMmermann, Das Heidelberger Schicksalsbuch (Cod. Pal. germ. 832) ..., in: Furtmeyr-Katalog, S. 425-427, hier S. 426. Volldigitalisat der Handschrift unter der in Anm. 5 angegebenen URL.

I7 Erstbesitzer waren wohl Pfalzgraf Philipp der Aufrichtige (gest. 1508) und seine Frau Margarethe von BayernLandshut, worauf auch die Wappen in den beiden Furtmeyrschen Darstellungen hinweisen. 
kreis des Illuminators betrachtet werden müssen. Sie stammen allesamt aus dem letzten Jahrzehnt des I5. oder den ersten Jahren des I6. Jahrhunderts. ${ }^{18}$ Vollkommen heterogen ist schließlich die dritte Werkgruppe, die nur wenige Objekte umfasst. Diese weisen jedoch jeweils so gravierende Unterschiede zu den oben genannten Codices auf, dass sie Furtmeyr und seiner Werkstatt auf jeden Fall wieder abgeschrieben werden müssen. ${ }^{19}$

Festzuhalten ist, dass sich auch die erste Werkgruppe, auf die hier das Hauptaugenmerk gerichtet werden soll, keineswegs durch stilistische Homogenität auszeichnet. Nicht einmal das Konvolut der Hauptwerke Furtmeyrs ist in sich vollkommen einheitlich. Abgesehen von einer offenbar variierenden Beteiligung von Gehilfen, ${ }^{20}$ von der unterschiedlichen Entste-

I8 $\mathrm{Zu}$ dieser Gruppe, die hier nicht näher besprochen werden kann, gehören München, BSB, Clm 23032 und Clm 23024 sowie Bayerisches Hauptstaatsarchiv, DK Regensburg 443; die betreffenden Bände waren von RoHr, Berthold Furtmeyr (zit. Anm. 3), S. 95 f. (Nr. I2 f.), 98 und I63 einem Schüler Furtmeyrs gegeben worden; im Furtmeyr-Katalog (zit. Anm. 2, S. 532, Abb. 259 f.) und auch schon bei Hubel, Furtmeyr und die Regensburger Buchmalerei (zit. Anm. 3), S. I22 f. (Kat. I08), ıाо, Taf. I79 f. werden sie teilweise Furtmeyr selbst zugeschrieben. Zu den Handschriften siehe auch Hernad, Münchener Furtmeyr-Bibel (zit. Anm. 3), S. I5, Abb. 9-I6. Volldigitalisat von Clm 23024 unter der in Anm. 5 angegebenen URL. - Zu dieser Gruppe gehören auch einige Drucke, s. Anm. 56.

I9 Zu diesem Konvolut gehört etwa Cod. II6 der OÖLB in Linz (Furtmeyr-Katalog, S. 444 [Kat. 298], Abb. 398). Der Buchschmuck dieses im ersten Viertel des I6. Jahrhunderts entstandenen deutschen Gebetbuchs weist stilistisch nach Leipzig, siehe K. Hranitzky / M. Schuller-Juckes, Katalog der illuminierten spätgotischen Handschriften und Inkunabeln der Oberösterreichischen Landesbibliothek in Linz (in Vorbereitung). Zur spätgotischen Buchmalerei in Leipzig siehe A. TIF, Die Leipziger Buchkunst der Inkunabelzeit. Ökonomische Aspekte der gewerblichen Buchmalerei im frühen Buchgroßhandel zwischen Deutschland und Osteuropa um I500, Phil. Diss, Universität Wien (in Vorbereitung). - Auch der im Furtmeyr-Katalog (zit. Anm. 2) - S. 305 f. (Kat. I) und 527, Abb. I5, I20, 250-253 - als das älteste bekannte Werk Furtmeyrs präsentierte Cod. theol. et phil. $2^{\circ}$ IOO der Württembergischen Landesbibliothek in Stuttgart weicht stilistisch deutlich von den Arbeiten des Regensburger Buchmalers ab, mit denen er sich auch in qualitativer Hinsicht nicht messen kann. - Weiters ist Furtmeyrs Beteiligung an der Illustrationsfolge im Heidelberger Schicksalsbuch sehr anzuzweifeln, deren kleine Miniaturen den Bildlegenden im Furtmeyr-Katalog zufolge Furtmeyr persönlich ausgeführt haben soll - s. dagegen Zimmermann, Schicksalsbuch (zit. Anm. i6) sowie Rohr, Berthold Furtmeyr (zit. Anm. 3), S. 92, I65 f. - Sorgfältig zu prüfen ist schließlich die Zuschreibung der Miniatur auf fol. 2v im Ms. 33 des J. Paul Getty Museums in Los Angeles, die die Madonna mit dem Stifterpaar Herzog Albrecht IV. von Bayern und Kunigunde von Österreich zeigt (Furtmeyr-Katalog, zit. Anm. 2, S. 423 [Kat. 240], Abb. 347): Es umgibt sie ein Rahmen, der von einem in Augsburg geschulten Buchmaler ausgeführt wurde.

20 Bereits 1885 versuchte Berthold Haendcke im Salzburger Missale verschiedene Hände zu scheiden, siehe Hernad, Salzburger Missale (zit. Anm. 7), 369 f., mit Anm. 35. Kahsnitz, Die Handschrift und ihre Bilder (zit. Anm. 3) weist wiederum den Schmuck der Augsburger Bibel mindestens vier Händen zu. Es variiere nicht nur die Sorgfalt der Ausführung, sondern auch die Kompositionsweise. Furtmeyr selbst seien auf jeden Fall Frontispizminiaturen und Illustrationen der Genesis zuzuschreiben. Darüber hinaus sei er gegenüber seinen Auftraggebern für den „künstlerische(n) Gesamteindruck“ (S. IO9) verantwortlich gewesen. Eine „genaue Abgrenzung der Arbeit des Werkstattleiters von der seiner Mitarbeiter“ sei jedoch „immer mit Unsicherheiten belastet“ (ebd.). Die Münchener Bibel wirke auf jeden Fall viel einheitlicher. Auch Hernad, Münchener Furtmeyr-Bibel (zit. Anm. 3) betont, dass „die Illustrationen der drei Furtmeyr-Bibeln ... und die des Salzburger Missales ... auf jeden Fall das Werk mehrerer Hände, von Furtmeyr selbst und von Angehörigen seiner Werkstatt" sein müssen (S. I6). Siehe auch A. HubEL, Berthold Furtmeyr eine kunsthistorische Würdigung, in: Furtmeyr-Katalog (zit. Anm. 2), S. 45-59, hier 49. Ebenso wie Hu- 


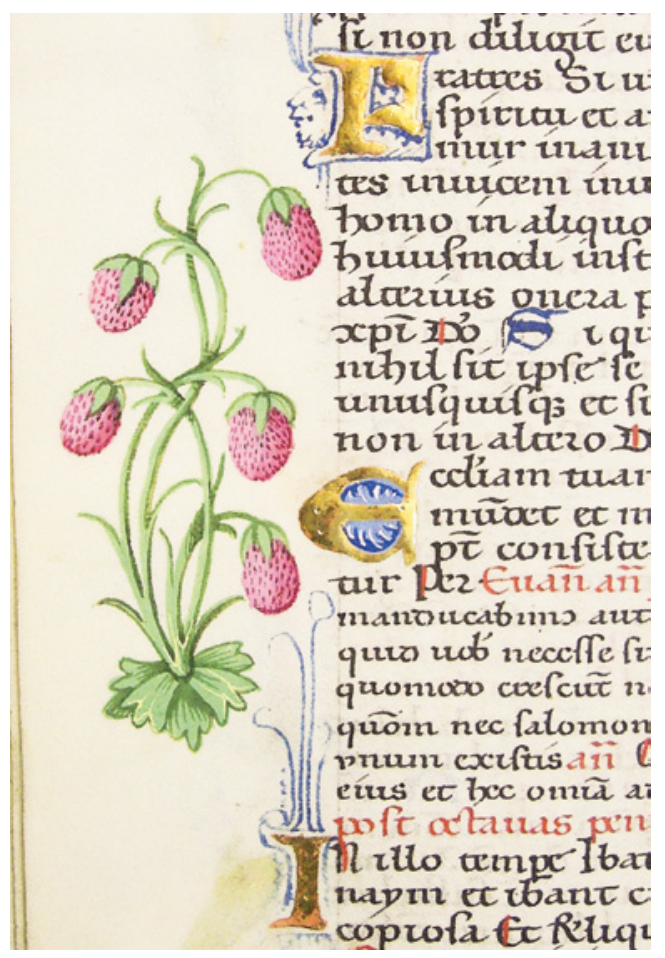

Abb. 6: Linz, Katholisch-theologische Privatuniversität (ehem. OÖLB, Cod. 154), Brevier für Augsburg, datiert I475, fol. 326v, Randschmuck (Detail); Berthold Furtmeyr oder Mitarbeiter hungszeit der Handschriften und der Übernahme von Stileigenheiten der verwendeten Vorlagen ${ }^{21}$ ist außerdem die Tatsache zu berücksichtigen, dass sich das Euvre Furtmeyrs, wie es der Furtmeyr-Katalog vorstellt, aus Büchern unterschiedlichsten Inhalts und Formats zusammensetzt, die für Auftraggeber verschiedensten Ranges und Standes angefertigt wurden. Die beobachteten Stilschwankungen zwischen den einzelnen Werken könnten demnach zum Teil dadurch zu erklären sein, dass diese verschiedene „Stillagen“ oder „Stilebenen“ repräsentieren, dass also Furtmeyr es auch vom Prestige und den finanziellen Möglichkeiten seiner Auftraggeber bzw. von der Art des Auftrags abhängig machte, welche Sorgfalt er bei der malerischen Ausführung walten ließ, wie abwechslungsreich er das Ornament gestaltete und welche Mühe er in die Bilderfindung investierte. ${ }^{22}$ Daraus folgt wiederum, dass eine eindeutige Unterscheidung zwischen eigenhändigen Arbeiten, bei denen der künstlerische Aufwand bewusst gering gehalten wurde, und solchen, die von

Gehilfenhand stammen, vermutlich nicht in jedem Fall gelingt. Dies sei im Folgenden an einigen Beispielen aufgezeigt.

BEL (ebd., S. 47) nimmt etwa auch KöNIG, Berthold Furtmeyr (zit. Anm. I), S. 38 an, dass die Werkstatt Furtmeyrs nicht allzu viele Mitglieder umfasste.

2I Zu dem in Furtmeyrs Atelier verwendeten Vorlagenschatz siehe besonders PFÄNDTNER, Salzburger Missale (zit. Anm. 3), S. I8-20 und P. Rudolph, Berthold Furtmeyr und seine gedruckten Vorbilder. Über die Herstellung und Bebilderung von Handschriften im Zeitalter des Buchdrucks, in: Furtmeyr-Katalog, S. II5-I23.

22 Der Begriff „Stillage“ wird hier nicht als Synonym von „Modus“ gebraucht (s. G. Schmidt, Probleme der Begriffsbildung, in: ders., Gotische Bildwerke und ihre Meister, Wien u. a. 1992, S. 313-356, hier S. 322-327), sondern zur Bezeichnung des bei den untersuchten Werken jeweils zu beobachtenden, offenbar mit der „Formgelegenheit“ (s. ebd.) variierenden Grads an gestalterischem und technischem Aufwand. - Von „unterschiedlichen Stilebenen“ spricht auch Hernad, Münchener Furtmeyr-Bibel (zit. Anm. 3), S. I6, und in demselben Sinn deutet Hubel, Furtmeyr - eine Würdigung (zit. Anm. 20), S. 49 die stilistische Uneinheitlichkeit der Kerngruppe des Furtmeyrschen Werks: „Mit Sicherheit kam es ... auf das Verhältnis von Preis und Leistung an: das Münchener Alte Testament dürfte mit Abstand am teuersten gewesen sein“; beim Salzburger Missale wiederum habe Furtmeyr „angesichts des luxuriösen Auftrags alle Register seines Könnens“ gezogen. Siehe auch Kahsnitz, Die Handschrift und ihre Bilder (zit. Anm. 3), S. 73 f. 


\section{EIGENH ÄNDIGE ODER VON ENGEN MITARBEITERN AUSGEFÜHRTE WER K E}

Der Werkstatt Furtmeyrs zuzuweisen ist etwa das I475 in Augsburg geschriebene Brevier für Augsburger Gebrauch, das sich heute in Linz befindet (Katholisch-theologische Privatuniversität, ehem. OÖLB, Cod. 154). ${ }^{23}$ Der Codex, dessen Empfänger bislang nicht mit Sicherheit ermittelt werden konnte, ${ }^{24}$ ist mit drei historisierten und zahlreichen unfigürlichen Deckfarbeninitialen samt Randdekor sowie mit Fleuronnée-Lombarden ausgestattet. Der Deckfarbenschmuck zeigt das charakteristische Furtmeyrsche Formenvokabular. Zur Füllung der Buchstabenkörper (Abb. I-3) dienen gewendelte Blattfriese mit nach vorne, nach hinten oder zur Seite hin, dabei manchmal kugelig, eingerollten Blattabschnitten, die je nach Drehung einen bogenförmigen oberen Rand und eine seitliche Einbuchtung, einen axtförmigen Mittel- und zwei sichelförmige Seitenlappen oder sichelförmige Blatt-

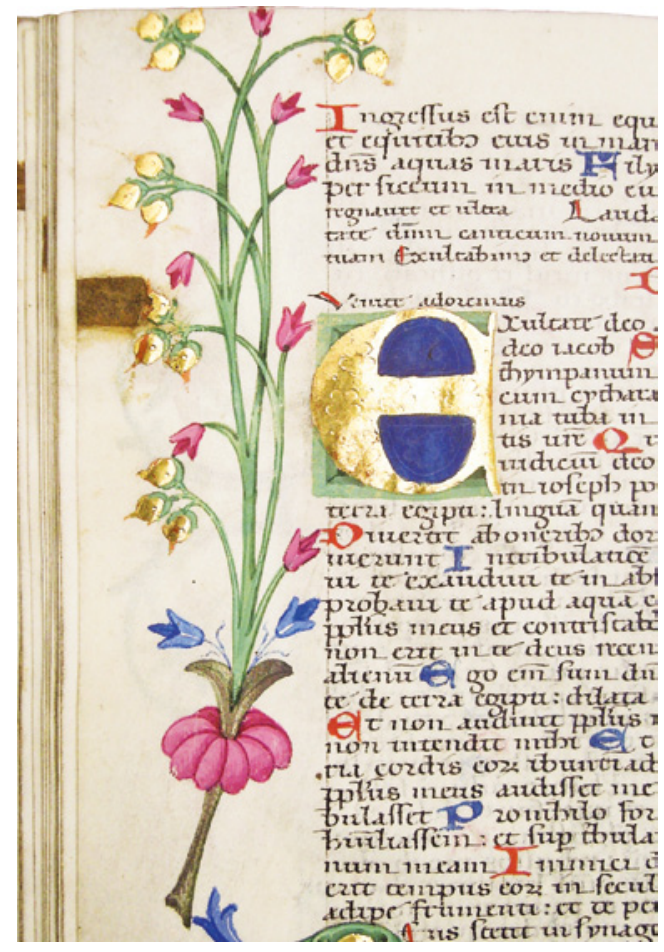

Abb. 7: Linz, Katholisch-theologische Privatuniversität (ehem. OÖLB, Cod. 154), Brevier für Augsburg, datiert I475, fol. 56v, Randschmuck (Detail); Berthold Furtmeyr oder Mitarbeiter zungen haben; außerdem kommen Blätter mit gebogtem Rand vor. Daneben stehen unter anderem gebuchtete und kopfstempelförmig eingeschnittene Blattfriese sowie Stufenbänder in Gebrauch. Die Initialen werden meistens von einem viereckigen, dabei oft gerahmten, oder einem zum Seitenrand hin mehrseitig begrenzten Grund in Blattgold oder Blau hinterfangen, der punziert (Abb. 7; s. Anm. 30) und mit eingeritzten Filigranranken verziert sein kann.

Der Randschmuck besteht aus elastisch wirkenden Ranken, ${ }^{25}$ die sich aus den Abläufen der Initialen (Abb. I-3, vgl. Abb. 4) oder aus „abgeschnittenen“ Stängeln (zum Beispiel fol. 4or)

23 Siehe K. Hranitzky, in: Von der Schatzkammer des Wissens zum Lernort. 235 Jahre „bibliotheca publica“Zehn Jahre Oberösterreichische Landesbibliothek, 57; dies., in: Furtmeyr-Katalog (zit. Anm. 2), S. 444 f., Kat. 299, Abb. 399 und 530; weiters Hranitzky/Schuller-Juckes, Katalog (zit. Anm. 19).

24 Das Bas-de-page der ersten Seite des Proprium de tempore (fol. 8or - Abb. 2) trägt zwei Wappenschilde, von denen der linke den Pfälzer Löwen enthält. Das rechte Wappen wurde zu einem unbekannten Zeitpunkt ausradiert. Spuren blauer und weißer Farbe weisen darauf hin, dass hier vielleicht das bayerische Wappen angebracht war. Der Auftraggeber könnte somit etwa eines der Mitglieder des Augsburger Domkapitels aus dem Hause Wittelsbach gewesen sein. Mit Sicherheit wird man den Erstbesitzer jedoch nicht mehr feststellen können, zumal nicht ausgeschlossen werden kann, dass der Pfälzer Löwe nachträglich eingefügt wurde.

25 Auf fol. 8or (Abb. 2) verdichten sich die enger mit Blättern besetzten Ranken, zwischen deren Gabelungen und in deren Medaillons sich Goldflächen spannen, zu einer Bordüre. 


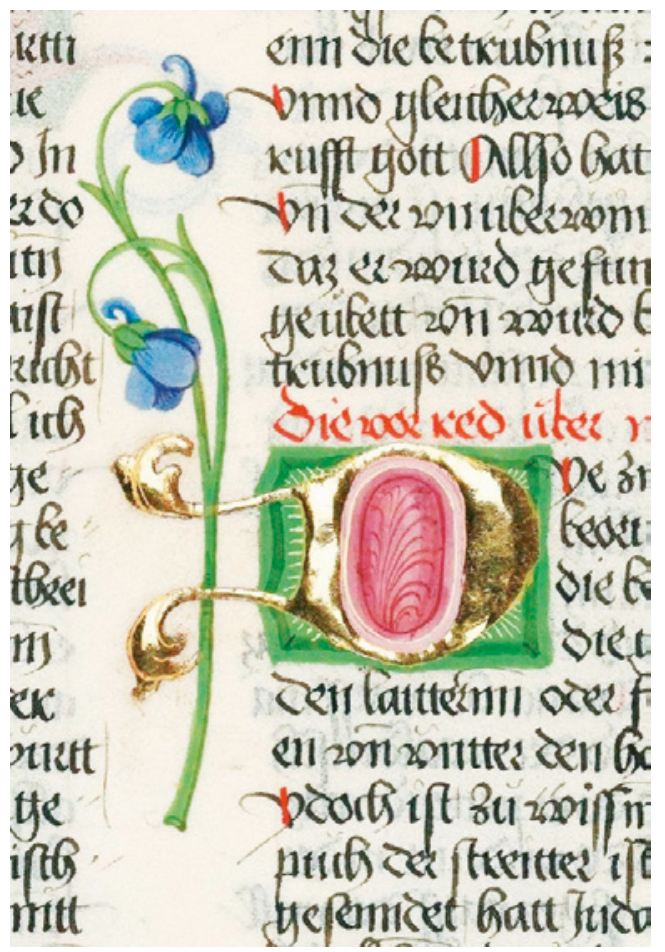

Abb. 8: Augsburg, Universitätsbibliothek, OettingenWallersteinsche Bibliothek, Cod. I.3.2 ${ }^{\circ}$ IV, Altes Testament, Bd. 2, fertiggeschrieben I468, im Schmuck datiert I472, fol. 3I4r, Randschmuck (Detail); Berthold Furtmeyr und Werkstatt entwickeln. Sie treiben schmale Blätter, die meist zu Dreiergruppen zusammengefasst sind, in je drei spitzen Blattzähnen enden und in der Mitte eine tropfenförmige Erhebung aufweisen. Daneben kommen kürzere, stumpf endende Blätter und Blätter aus gewellten, spitz zulaufenden Blattzungen, gelegentlich auch „Krallenblätter“ oder andere Sonderformen vor. Kennzeichnend sind des Weiteren die hakenförmigen und oft ineinander verhakten Rankenausläufer sowie die diversen Fantasieblüten, die in den Rankenmedaillons sitzen - hervorzuheben sind etwa dunkelblaue Kelchblüten mit nach außen eingerollten Blütenblättern und dreiteilige Blüten, deren Blätter dem Akanthus angeglichen sind. Bereichert wird der Rankenschmuck einerseits durch verschiedene Goldelemente - Tropfen und Perlen (Abb. I-3), Blüten (Abb. 7), rahmende Leisten (Abb. 2) -, andererseits durch die unterschiedlichsten Blütenbzw. Fruchtstängel, die sich formal von den schematisierten Blattranken abheben und auf den ersten Blick wie Naturstudien anmuten (Abb. 5, 6). Tatsächlich botanisch bestimmbar sind allerdings nur die allerwenigsten dieser Stängel, die sich (mit Ausnahme der Erdbeerstaude auf fol. 326v - Abb. 6) bald als sich der Natur lediglich annähernde Pflanzendarstellungen entpuppen. Doch ging es dem Illuminator des Breviers sichtlich nicht in erster Linie darum, den Betrachter durch eine naturalistische Wiedergabe real existierender Pflanzen zu beeindrucken. Er scheint vielmehr grundsätzlich bestrebt gewesen zu sein, seinen Motivschatz so weit wie möglich zu erweitern, und dazu kombinierte er den „herkömmlichen“ Akanthus samt Fantasieblüten sowohl mit gänzlich unwirklichen Elementen in Blattgold als auch mit Pflanzenmotiven, die gleichsam vorgeben, Naturstudien zu sein; vereinzelt ergänzte er diese Motive durch tatsächlich Natur abbildende Pflanzendarstellungen. All diese Elemente, die verschiedenen Realitätsebenen angehören, werden immer neu abgewandelt und gehen immer neue Verbindungen miteinander ein.

Diese Freude an der ornamentalen Variation und Diversität und am Spiel mit verschiedenen Realitätsebenen ist ebenfalls charakteristisch für Berthold Furtmeyr. Zwar stellt das kleine Brevier eine ganz andere „Formgelegenheit“ (s. Anm. 22) dar als die Bibeln und das Prachtmissale; vor allem in letzterem Werk, seinem prestigeträchtigsten und zweifellos bestbezahlten Auftrag, ließ der Illuminator seiner ungeheuren Kreativität freien Lauf, und auch die Bibeln, insbesondere jene in München, zeigen teilweise spektakuläre ornamentale Lösungen. Dennoch kann 
sich der abwechslungsreiche und sorgfältig ausgeführte Schmuck der Linzer Handschrift durchaus mit dem Dekor vor allem der rangniedrigeren Seiten in den Hauptwerken des Regensburger Illuminators messen. Tatsächlich finden sich sowohl in den Handschriften des Alten Testaments als auch im Salzburger Missale enge Analogien für die Blütenstängel des Breviers (Abb. 5-Io). ${ }^{26}$

Die Illuminierung des Augsburger Breviers könnte also unter persönlicher Beteiligung Furtmeyrs entstanden sein. Dem scheint auch die Gestaltung der winzigen Figuren in den Binnenfeldern der drei historisierten Initialen (Abb. I-3) zunächst nicht zu widersprechen. Diese zeigen zum einen den für Furtmeyr charakteristischen Faltenstil - man

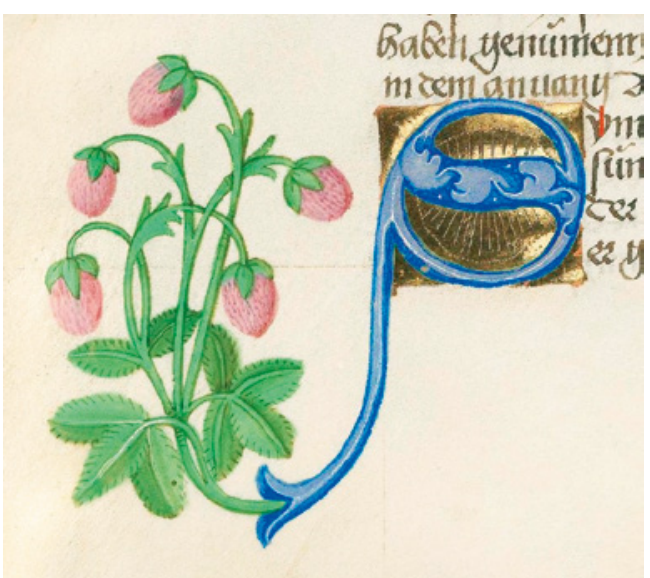

Abb. 9: Augsburg, Universitätsbibliothek, OettingenWallersteinsche Bibliothek, Cod. I.3.2 IV, Altes Testament, Bd. 2, fertiggeschrieben I468, im Schmuck datiert I472, fol. I2Ov, Randschmuck (Detail); Berthold Furtmeyr und Werkstatt vergleiche die eckig umbrechenden oder auch kurvig verlaufenden, teilweise seitlich eingeknickten Schlauch- und Dreiecksfalten sowie die auf dem Boden auslaufenden, dabei teilweise übereinander geschichteten Gewandbahnen (zu weiteren Merkmalen des Furtmeyrschen Gewandstils siehe unten) - und entsprechen zum anderen physiognomisch dem Furtmeyrschen Figurentyp, wobei die Gesichtszüge hier ebenfalls, wie bei Furtmeyr üblich, durch feine schwarze Zeichnung akzentuiert sind (Abb. I-3, II-I3). Allerdings ist das Inkarnat in Linz nur zaghaft mit Graugrün modelliert und das Weiß relativ dick aufgetragen. Des Weiteren ist beim Mantel des David (Abb. I) ein gewisser Mangel an Sorgfalt in der Ausführung zu beobachten. Schließlich zeigt die Verkündigung (Abb. 2) Unsicherheiten in der Komposition: Der unter der Sockelplatte des Lesepults durchscheinende schwarze Strich deutet darauf hin, dass Marias Mantel die Platte wahrscheinlich ursprünglich, ähnlich wie dann später in der großen Verkündigungsminiatur auf fol. 32v in Clm 15709, hätte überschneiden sollen. Dies hätte jedoch eine Verunklärung des räumlichen Verhältnisses von Marienfigur und Pult mit sich gebracht - die Figur würde zugleich hinter und neben dem Pult knien. Im Salzburger Missale war Furtmeyr offensichtlich bemüht, diesen Widerspruch abzuschwächen: ${ }^{27} \mathrm{Er}$ verzichtete von vornherein auf eine räumliche Staffelung von Figuren und Pult, ordnete diese

26 In der Münchener Bibel werden die Initialen zu Beginn der Bibelbücher in der Regel von sehr üppigen und auf geradezu spektakuläre Weise naturalistisch wiedergegebenen Blüten- und Fruchtranken begleitet, denen unter anderem den Linzer „Naturstudien“ motivisch entsprechende Veilchen und Erdbeeren entwachsen (foll. I74v, I84 ${ }^{\mathrm{r}}$ ). Der höhere Grad an Naturalismus, der diese Pflanzendarstellungen kennzeichnet, entspricht dem höheren Rang der Handschrift.

27 Häufig wird die exakte räumliche Stellung des Schreibers oder Lesers zu seinem Pult durch Verdecken von dessen Seitenkante mittels einer senkrecht herabfallenden Stoffbahn des Gewandes der betreffenden Figur verschleiert, vgl. zum Beispiel München, BSB, Cgm, 8oIoa, fol. $7^{\mathrm{r}}$ oder Augsburg, Universitätsbibliothek, Cod. I. $3.2^{\mathrm{o}} \mathrm{III}$, fol. $3^{\mathrm{r}}$. Siehe auch unten. 


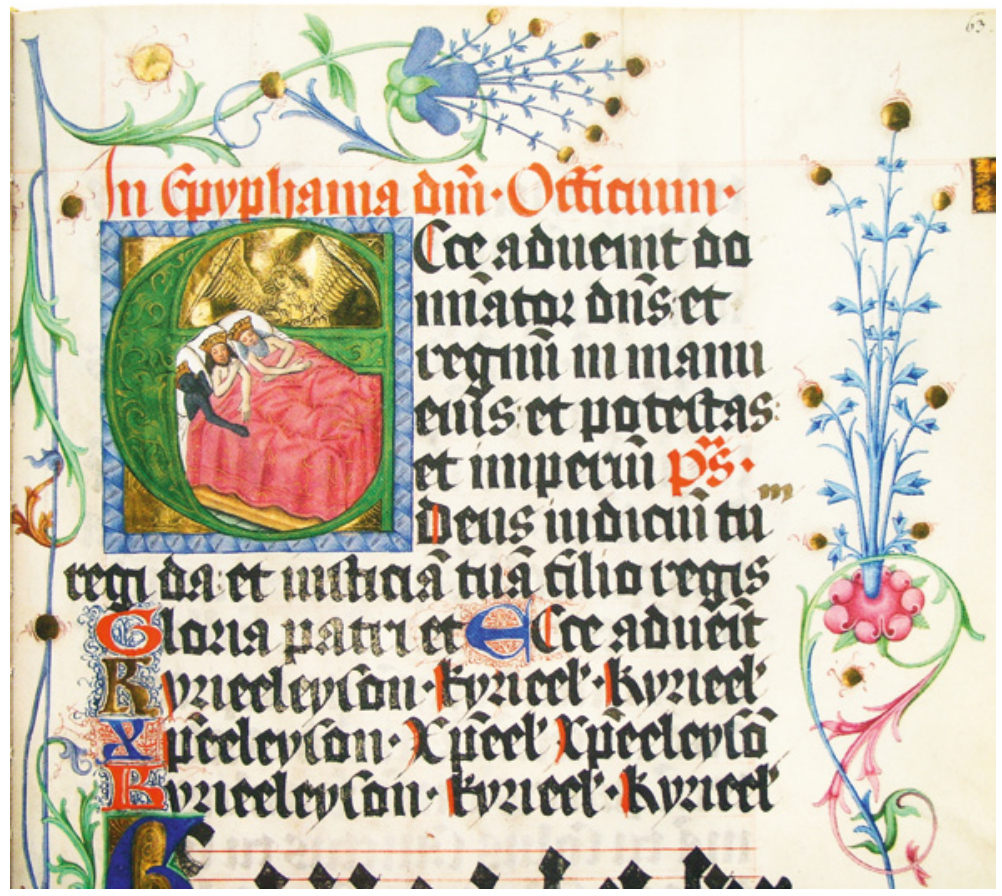

Abb. Io: München, Bayerische Staatsbibliothek, Clm 15708, Missale der Fürsterzbischöfe von Salzburg, Bd. I, zw. ca. I478 und frühestens I489, fol. 63r: Historisierte Deckfarbeninitiale mit Darstellung des Traums der hl. drei Könige, Randschmuck (Detail); Berthold Furtmeyr (und Werkstatt?)

vielmehr nebeneinander auf der Bildfläche an, wobei er ihre Konturen aneinander anschließen ließ. Im Linzer Brevier, für das möglicherweise die Komposition des Peutinger-Gebetbuchs in Stuttgart (Abb. I4, zur Handschrift siehe unten) maßgeblich war, entschied sich der ausführende Buchmaler für einen nicht ganz befriedigenden Kompromiss: Maria ist zwar deutlich hinter dem Pult angeordnet, hat dafür aber einen zu kurzen Körper. ${ }^{28}$ Die Verkündigung in Cod. I54 scheint somit stilistisch auf halbem Weg zwischen den inhaltlich entsprechenden Darstellungen im Peutinger-Gebetbuch und im Salzburger Missale zu stehen. Ob Furtmeyr in Brevier und Missale die Vorlage, die der Verkündigung des Stuttgarter Codex zugrundelag (siehe unten), stufenweise seinem persönlichen „Kunstwollen“ anpasste oder aber ob von einer Illuminierung des Breviers durch ein anderes Werkstattmitglied auszugehen ist, ist vorläufig nicht zu klären. Zu überlegen wäre auch, ob der Werkstattleiter sich nicht Entwurf und Ausführung des rein ornamentalen Buchschmucks, der dem vermutlich höheren Rang des Auftraggebers entsprechend möglichst abwechslungsreich und prunkvoll ausfallen sollte, vorbehalten und mit der Realisierung der Initialbildchen einen Mitarbeiter betraut haben könnte. ${ }^{29}$

28 Durch den nach vorne hin auslaufenden Zipfel ihres Mantels wird ihr eine halbwegs realistische Gesamtgröße restituiert.

29 Dass das Randornament bei Furtmeyr das dominante Element des Schmucks einer Seite sein kann, auch wenn diese eine figürliche Szene trägt, zeigen etwa die beiden Bibeln in Augsburg und München. 

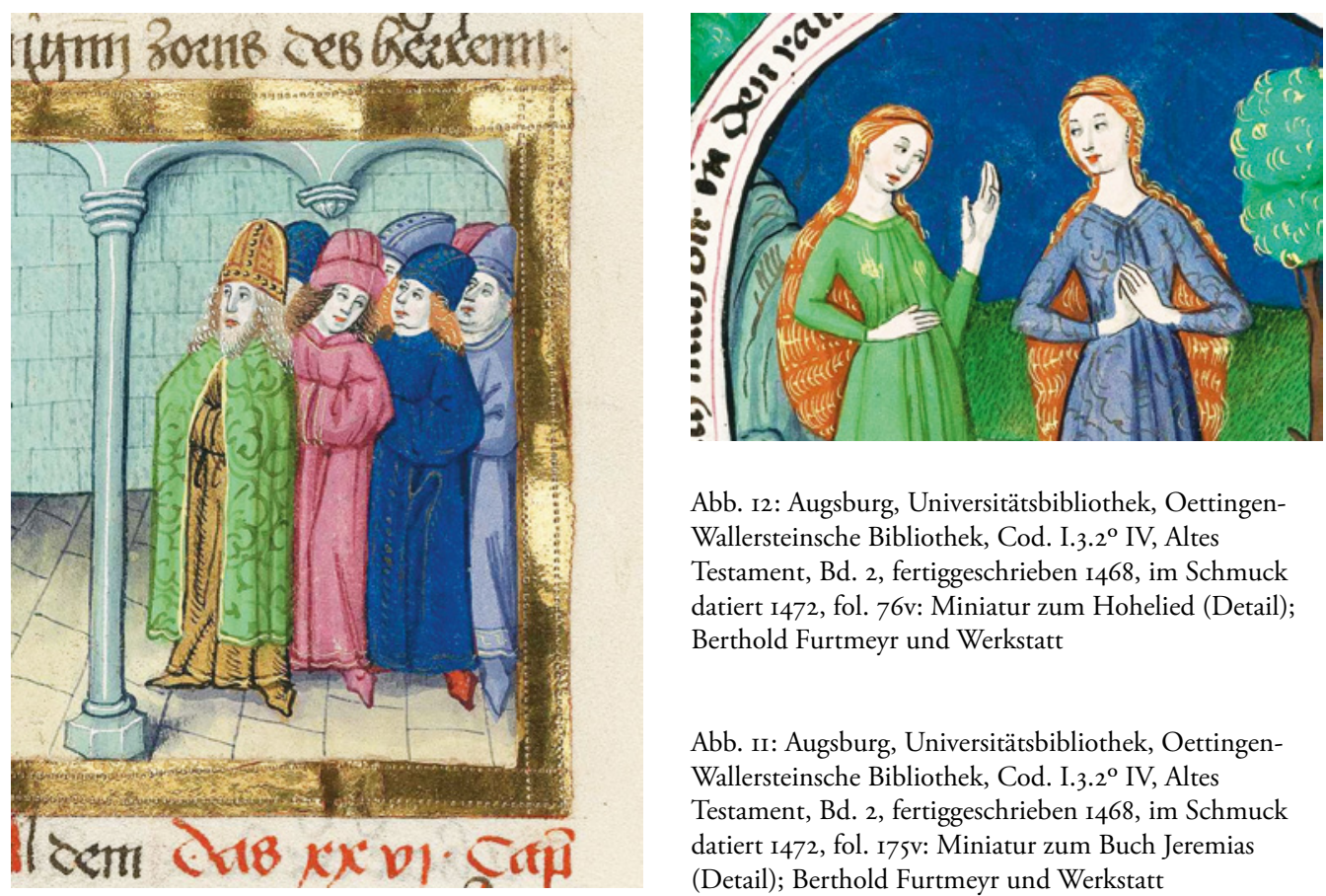

Abb. I2: Augsburg, Universitätsbibliothek, OettingenWallersteinsche Bibliothek, Cod. I.3.2 ${ }^{\circ}$ IV, Altes Testament, Bd. 2, fertiggeschrieben I468, im Schmuck datiert I472, fol. 76v: Miniatur zum Hohelied (Detail); Berthold Furtmeyr und Werkstatt

Abb. II: Augsburg, Universitätsbibliothek, OettingenWallersteinsche Bibliothek, Cod. I.3.2 IV, Altes Testament, Bd. 2, fertiggeschrieben I468, im Schmuck datiert I472, fol. I75v: Miniatur zum Buch Jeremias (Detail); Berthold Furtmeyr und Werkstatt

Interesse verdient das Augsburger Brevier auch insofern, als es sich dabei um die einzige bisher bekannte Handschrift aus der Werkstatt des Regensburger Buchmalers handelt, die Fleuronnée-Lombarden von der Hand des Florators des Salzburger Missales enthält. ${ }^{30}$ Schließlich weist der Inhalt des Codex darauf hin, dass Furtmeyr bereits vor seiner Verpflichtung durch Bernhard von Rohr offenbar Kunden auch außerhalb der Oberpfalz finden konnte.

An dieser Stelle ist ein kleinformatiges deutschsprachiges Gebetbuch in Durham /North Carolina (Duke University, Special Collections Library, German MS I) zu nennen, das, obwohl von Regina Cermann bereits 2009 der Werkstatt Furtmeyrs zugeschrieben, ${ }^{31}$ der Aufmerksamkeit der Autoren des Furtmeyr-Katalogs entging. Der Codex enthält neben einigen unfigürlichen Deckfarbeninitialen samt Randschmuck einen aus zwölf ganzseitigen und Is kleineren Miniaturen bestehenden Passionszyklus. Von Cermann um I470 datiert, steht die Handschrift stilistisch ungefähr auf der Stufe der Augsburger Bibel. Anders als in Linz nimmt sich im Durhamer Gebetbuch der aus wenigen Initialen und kurzen Rankenstängeln bestehende ornamentale Schmuck bescheiden aus. Das Hauptgewicht der Ausstattung liegt hier auf dem relativ umfangreichen Zyklus von klar komponierten und routiniert - wenn auch nicht übermäßig fein - ausgeführten Miniaturen, von denen die kleineren zudem eine teilwei-

30 Siehe hierzu Hranitzky / Schuller-Juckes (zit. Anm. 19). - Im Übrigen ist darauf hinzuweisen, dass in Cod. I54 offenbar dieselben fünfblättrigen Rosettenpunzen (Abb. 7) verwendet wurden wie zum Beispiel in Cgm 80 Ioa.

3I R. Cermann, Gebetbücher (Katalog der deutschsprachigen illustrierten Handschriften des Mittelalters 5, Lfg. 3). München 2009 , S. $232-238$ (Nr. 43. I. 4.). Ich danke der Autorin für ihren Hinweis auf ihre Publikation sowie für die Zurverfügungstellung von Fotomaterial. 


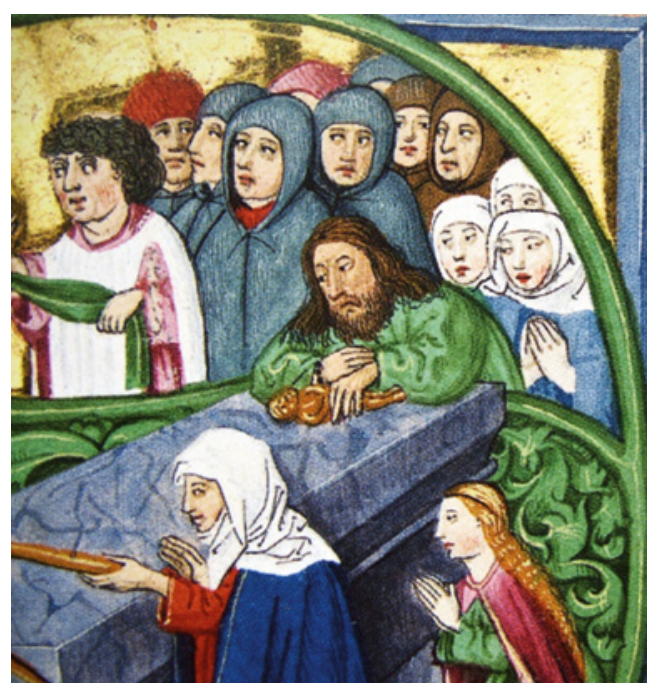

Abb. I3: München, Bayerische Staatsbibliothek, Clm I57I2, Missale der Fürsterzbischöfe von Salzburg, Bd. 5, im Schmuck signiert und datiert I48I, fol. 6Ir: Historisierte Deckfarbeninitiale mit Darstellung der Grablegung des hl. Virgil (Detail); Berthold Furtmeyr (und Werkstatt?) se ausgefallene Ikonographie zeigen. Möglicherweise sollte der Benützer des Gebetbuchs nicht durch allzu üppige pflanzliche Gebilde vom Inhalt der figürlichen Darstellungen abgelenkt werden. Zugleich könnte die Arbeitsteilung hier gegenüber dem Linzer Brevier genau umgekehrt erfolgt sein - vorausgesetzt, Furtmeyr war persönlich an der Illuminierung des Codex beteiligt, was noch sorgfältig geprüft werden müsste.

Mit verhältnismäßig einfachem Ornament sind auch zwei in der Bayerischen Staatsbibliothek in München verwahrte Codices, ein Regensburger Missale (Clm $\left.\mathrm{I}_{3022}\right)^{32}$ und eine 1475 in Regensburg fertig geschriebene und 1476 rubrizierte Abschrift des Speculum regiminis des Giacomo Filippo Forèsti ( $\mathrm{Clm}$ $\left.\mathrm{I}_{4004}\right)^{33}$, ausgestattet. Beide Bände zeigen lediglich die Grundformen des Furtmeyrschen Dekors, ohne jegliche Zusatzmotive. Zudem

kennzeichnet die beiden größeren figürlichen Darstellungen im Missale, das Kanonbild und die Te-igitur-Initiale, gewissermaßen eine Monumentalisierung des Furtmeyrschen Figurenstils, wie er einem in den ganzseitigen Darstellungen in der Münchener oder der Augsburger Bibel und besonders dann im Salzburger Missale entgegentritt: Es scheint hier quasi die Gestaltung der kleinen Bibelillustrationen ohne weitere Anpassung auf das größere Format übertragen worden zu sein. ${ }^{34}$ Der Vergleich zwischen dem Kanonbild im Regensburger Messbuch und den Kreuzigungsminiaturen im Salzburger Prachtmissale macht aber deutlich, dass man für das erstere zwar eine weniger differenzierte und aufwändige Art der Gestaltung wählte (man vergleiche, abgesehen von den Bordüren, die Gliederung der Gewänder, die Beschreibung des Umraums der Figuren und die Modellierung des Inkarnats), dass hier jedoch keineswegs ein weniger geschickter Illuminator am Werk war. In der Gesichtszeichnung entsprechen die Figu-

32 Rohr (zit. Anm. 3), Berthold Furtmeyr, S. 39; Hubel, Berthold Furtmeyr (zit. Anm. 3), S. i2o (Kat. IO5), Taf. 173; Furtmeyr-Katalog (zit. Anm. 2), S. 365 (Kat. IOo) und 520, Abb. 310. Volldigitalisat der Handschrift unter der in Anm. 5 angegebenen URL. Die in Regensburg gebundene Handschrift enthält keine mittelalterlichen Provenienzhinweise.

33 Siehe E. Wunderle, Katalog der lateinischen Handschriften der Bayerischen Staatsbibliothek München. Die Handschriften aus St. Emmeran in Regensburg, Bd. I: Clm I400o-I4I30, Wiesbaden I995, I3 f.; weiters: RoHR (zit. Anm. 3), Berthold Furtmeyr, S. 38; Furtmeyr-Katalog (zit. Anm. 2), S. 530. Volldigitalisat der Handschrift unter der in Anm. 5 angegebenen URL. Offenbar ebenfalls in Regenburg gebunden, enthält auch dieser Codex keine Hinweise auf seine ursprüngliche Herkunft.

34 Man vergleiche zum Beispiel auch die Darstellungen auf foll. $387 \mathrm{v}$ und $388^{\mathrm{r}}$ in Cgm 8 oroa. 
Abb. I4: Stuttgart, Württembergische Landesbibliothek, Cod. brev. 9I, „Peutinger-Gebetbuch“, Nachträge, vor 1465 ?, fol. Ir: Historisierte Deckfarbeninitiale mit Darstellung der Verkündigung an Maria, Ranken; Werkstatt oder Umkreis des Berthold Furtmeyr

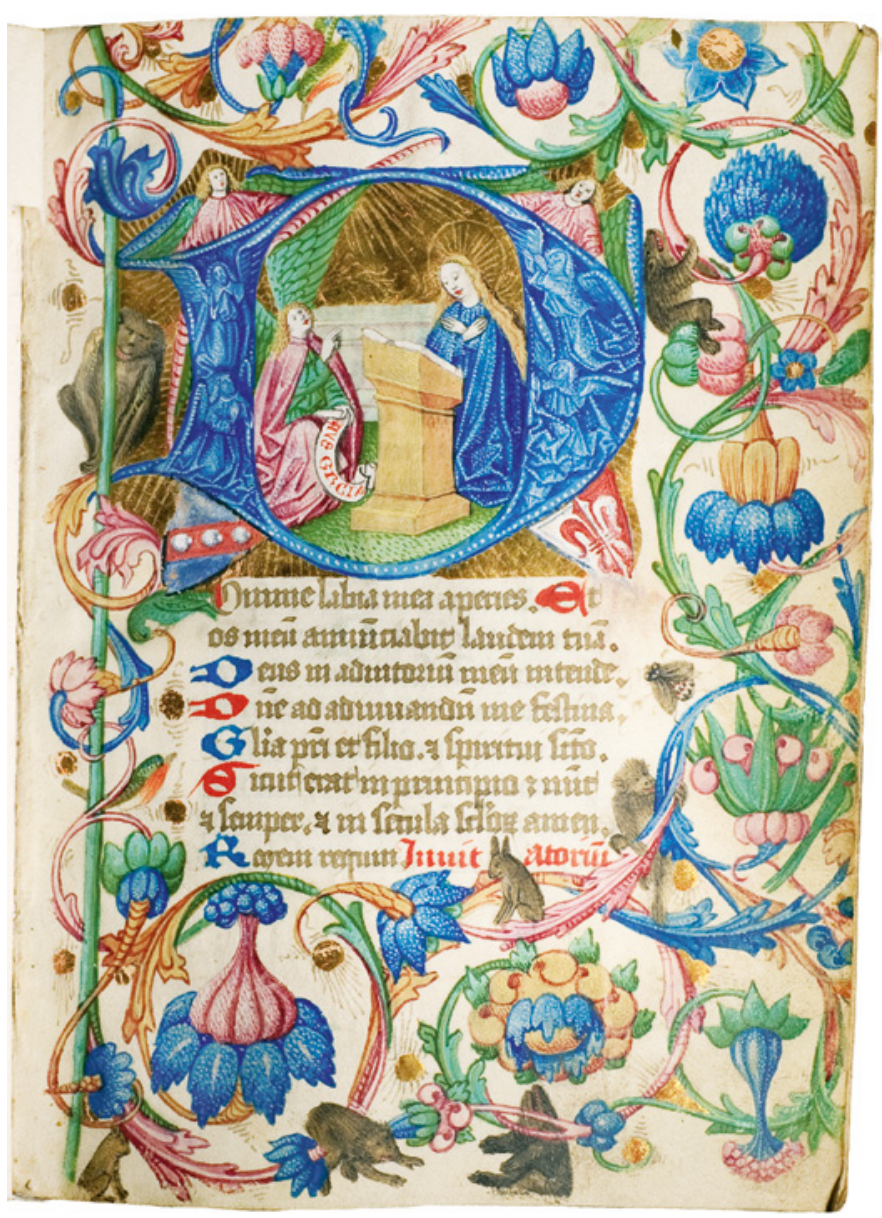

ren in Clm 13022 auch durchaus, teilweise sogar ziemlich exakt (vgl. zum Beispiel Clm I5709, fol. 45v), ihren Gegenstücken im Salzburger Missale. Die Darstellung in der Initiale zum ersten Adventsonntag, die aufgrund ihres geringeren Formats kaum eine Vereinfachung der Gestaltung erkennen lässt, ist wiederum durch eine einfühlsame Wiedergabe des innigen Verhältnisses von Maria und Jesukind gekennzeichnet; zudem entspricht die Gottesmutter physiognomisch zum Beispiel der Figur der Rut auf fol. 385v der Münchener Bibel. Dass Furtmeyr das Regensburger Missale eigenhändig, aber in einer niedrigeren Stillage, illuminierte, ist demnach denkbar. ${ }^{35}$ Ebenso wenig ist allerdings auszuschließen, dass für diese Art von Auftrag Mitarbeiter Furtmeyrs zuständig waren.

Problematischer ist die stilistische Beurteilung des nachgetragenen, vier historisierte und I3 unfigürliche Deckfarbeninitialen samt Begleitdekor umfassenden Buchschmucks im sogenannten Peutinger-Gebetbuch (Stuttgart, Württembergische Landesbibliothek, Cod.

35 Siehe auch Rohr, Berthold Furtmeyr (zit. Anm. 3), S. I35. 


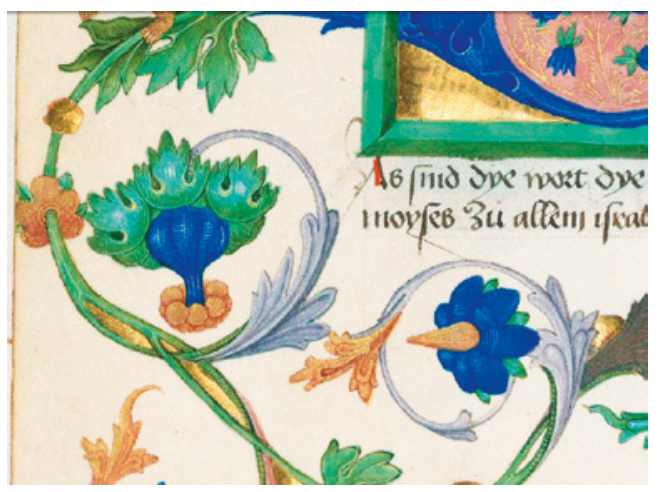

Abb. 15: Augsburg, Universitätsbibliothek, OettingenWallersteinsche Bibliothek, Cod. I.3.2 ${ }^{\circ}$ III, Altes Testament, Bd. I, im Schmuck signiert und datiert I470, fol. II7v, Randschmuck (Detail); Berthold Furtmeyr und Werkstatt brev. 9I; Abb. I4), von dem oben schon die Rede war. ${ }^{36}$ Auch hier entsprechen die verwendeten Ornamentformen dem Furtmeyrschen Repertoire, wobei der Randschmuck von großen, räumlich gedrehten Kompositblüten beherrscht wird. Für diese finden sich sowohl in den beiden reich illuminierten Bibeln als auch im Salzburger Missale enge Analogien (vgl. zum Beispiel Abb. I4 mit Abb. I5); dasselbe gilt für die im Rankengeflecht der ersten Seite turnenden Bären und Affen. Der figürliche Buchschmuck lässt sich hingegen nicht ohne Weiteres in das Furtmeyrsche Euvre eingliedern. In der Darstellung der Verkündigung (Abb. I4) sind Maria und der Engel jeweils in eine geschlossene, ungefähr tropfenförmige Gesamtform eingepasst (vgl. auch die einheitlich blaue Gewandung Mariens) ${ }^{37}$ und werden dadurch als umgehbare Volumina wahrgenommen. Als solche sind sie auch, anders als in den Verkündigungsszenen in Linz (Abb. 2) und im Salzburger Missale (siehe oben), in ein halbwegs klares räumliches Verhältnis zueinander und zu Marias Lesepult gebracht. Eine solche Auffassung ist für Furtmeyr durchaus ungewöhnlich, sind die Figuren in dessen Hauptwerken doch in der Regel mittels ihres vorwiegend nach dekorativen Gesichtspunkten drapierten und seitlich bzw. unterhalb ihres Körpers ausgebreiteten Gewandes in der Bildfläche verspannt (s. auch oben zur Komposition der Verkündigung im Salzburger Missale). Möglicherweise fußt die Verkündigungsminiatur im Peutinger-Gebetbuch auf einer stilistisch fremdartigen Vorlage. Eine Ausführung durch einen Mitarbeiter Furtmeyrs ist aber ebenfalls nicht auszuschließen.

Ungeklärt ist aber auch die Entstehungszeit der nachgetragenen Teile des Gebetbuchs. Die Literatur datiert sie, ausgehend von den Wappen auf fol. Ir, nach I498. ${ }^{38}$ Dabei wird meistens übersehen, dass sich in den Gebeten der ergänzten Teile ein Rupert nennt (fol. 224r),

36 Den Grundstock der Handschrift hatte der ebenfalls in Regensburg tätige Buchmaler Martinus opifex um I45O für einen weltlichen Herrn namens Ulrich illuminiert (siehe zum Beispiel V. E. Fiala/W. IrTenkauf, Codices breviarii [Cod. brev. I-I67] [Die Handschriften der Württembergischen Landesbibliothek Stuttgart, Reihe I, Bd. 3]. Wiesbaden 1977, S. II6-II9). Mit Furtmeyr in Zusammenhang gebracht wurden die Ergänzungen des unfertig gebliebenen Grundstocks von R. Suckale, Peutingergebetbuch, in: Regensburger Buchmalerei. Katalog zur Ausstellung in Regensburg Mai-August 1987 (Bayerische Staatsbibliothek, Ausstellungskataloge 39), München 1987, S. I08f. (Kat. 99). Siehe zuletzt Furtmeyr-Katalog (zit. Anm. 2), S. 444 (Kat. 297), 532, Abb. 506. Volldigitalisat der Handschrift unter der URL: http://digital.wlb-stuttgart.de/digitale-sammlungen / titeldaten / ?no_cache=I \& IDDOC=I006764.

Auch die beiden Engel, die die Szene präsentieren, sind jeweils einer einfachen geometrischen Form, einem Dreieck, eingefügt.

38 In diesem Jahr heirateten der Augsburger Ratschreiber Konrad Peutinger (gest. 1547) und Margarete Welser, auf die die Wappen verweisen. 
der aller Wahrscheinlichkeit nach mit dem in der Handschrift zweimal dargestellten Bischof (foll. 23Iv, 232v) identisch ist und daher zweifellos auch die Ergänzungen in Auftrag gab. Die Wappen, die heute zu sehen sind, müssen also über Vorgängerwappen gemalt oder nachträglich eingefügt worden sein. ${ }^{39}$ Identifiziert man Bischof Rupert, wie schon einmal vorgeschlagen wurde, ${ }^{40}$ mit Ruprecht II. von Pfalz-Simmern, der von 1492 bis 1507 Bischof von Regensburg war, ist das Gebetbuch höchstens, wenn überhaupt, um ein paar Jahre rückzudatieren. Der Umstand, dass das Amt des Bischofs von Regensburg schon früher, von I457 bis I465, ein Ruprecht innehatte, nämlich Ruprecht I. von der PfalzMosbach, rechtfertigt jedoch die Frage, ob man es bei dem Stuttgarter Gebetbuch nicht mit einem Werk des jungen Furtmeyr zu tun haben könnte. Tatsächlich weist das Ornament in den Nachträgen gewisse Analogien insbesondere zu jenem der Egerton-Bibel, aber auch der Augsburger Handschrift auf:

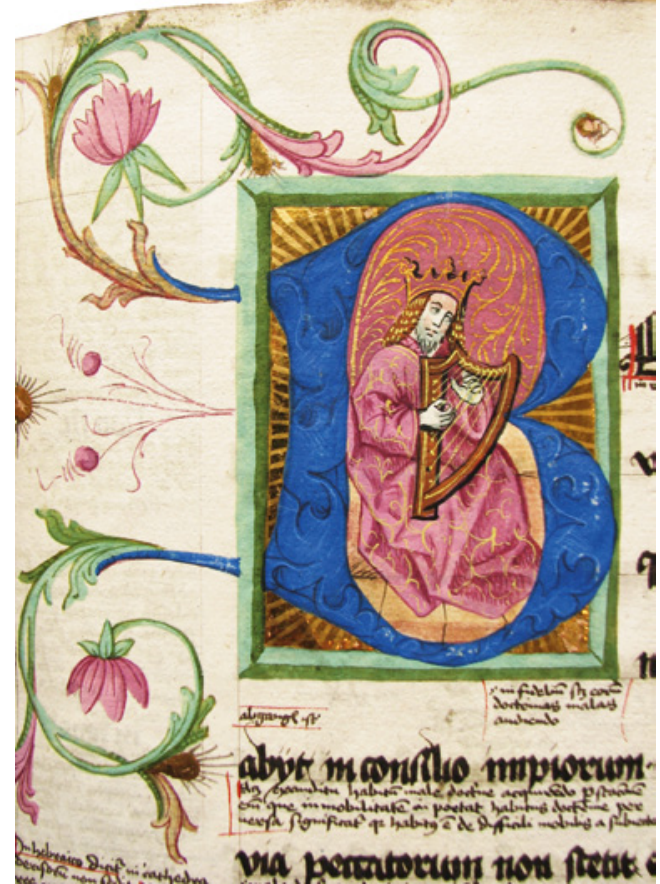

Abb. 16: Wien, Österreichische Nationalbibliothek, CVP 3743, Psalter mit Glosse, datiert I466, fol. 7r: Historisierte Deckfarbeninitiale mit Darstellung des psalmierenden Königs David; Berthold Furtmeyr oder Mitarbeiter Vergleichbar sind beispielsweise die unregelmäßigen Goldgründe der Initialen bzw. Rankenmedaillons mit den aufgemalten Strahlen und die konsequent spiralförmig eingerollten - nicht hakenförmigen oder ondulierenden - Rankenausläufer, an deren Enden Goldperlen sitzen. ${ }^{41}$ Des Weiteren könnten die verhältnismäßig zahlreich auftretenden Blätter aus langen geschwungenen Blattzungen mit linear eingezeichneter Mittelrippe, die in Augsburg (zum Beispiel Abb. 4) ebenfalls häufig verwendet werden, auf eine frühe Entstehung des Gebetbuchs hinweisen (s. auch unten). Schließlich lassen sich auch für die Gesichter der Figuren in Stuttgart am ehesten in der Londoner Handschrift Parallelen finden. Ob Furtmeyr die Nachträge zum Gebetbuch in Stuttgart eigenhändig ausführte, ist dennoch - zieht man auch die Möglichkeit einer frühen Entstehung dieser Teile der Handschrift in Betracht - vorläufig nicht eindeutig zu entscheiden.

39 Darauf weisen auch die Verwischungen im unteren Bereich des rechten Wappens und die unter dem Weiß durchscheinenden Farbflecken hin.

40 Siehe Fiala/Irtenkauf (zit. Anm. 36), S. ir6f.

4I Hakenförmige Rankenausläufer sind in der Augsburger Bibel hauptsächlich im zweiten Band zu finden, was darauf hindeutet, dass es sich dabei tatsächlich um ein besonders ab den I470er-Jahren verwendetes Motiv handelt. 


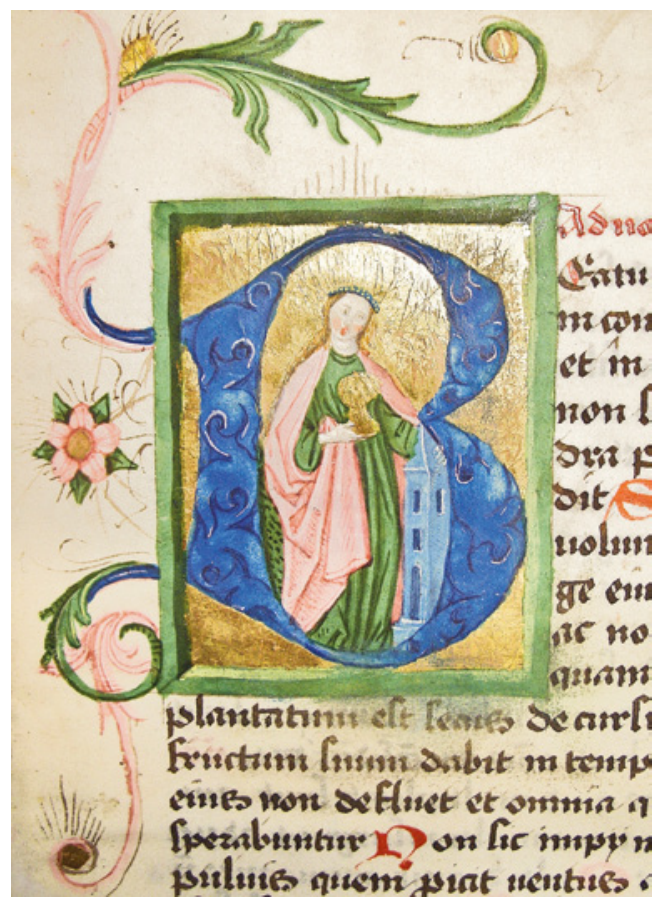

Abb. 17: St. Paul im Lavanttal, Stiftsbibliothek, Cod. 376-4, Brevier für Regensburg, vermutlich um I465, fol. 7r: Historisierte Deckfarbeninitiale mit Darstellung der hl. Barbara; Berthold Furtmeyr oder Mitarbeiter
NEUZUSCHREIBUNGEN -

\section{H A N D S C H R I F T E N}

Die Gruppe der Handschriften, deren Entstehung in Furtmeyrs Werkstatt als gesichert gelten kann, kann noch um einige weitere Bände ergänzt werden, von denen drei hier etwas genauer besprochen werden sollen. ${ }^{42}$ Bei den meisten dieser Codices dürfte es sich um frühe Werke aus dem Atelier Furtmeyrs handeln. Dies trifft auf jeden Fall auf einen mit einer historisierten und einer unfigürlichen Deckfarbeninitiale versehenen Psalter mit der Glosse des Nikolaus von Lyra (Cod. 3743) zu, der in der Österreichischen Nationalbibliothek verwahrt wird und ins Jahr I466 datiert ist. ${ }^{43}$ Die Ranken auf den Seitenrändern sind hier noch durchwegs spiralförmig eingerollt und treiben fast ausschließlich Blätter mit geschwungenen Blattzungen, deren Mittelrippen als Linien eingezeichnet sind - beide Merkmale scheinen also tatsächlich typisch für die Frühzeit der Werkstatt gewesen zu sein (siehe oben). Die Darstellung

42 Die beiden anderen müssten noch am Original untersucht werden. Um I465/70 sind vermutlich die beiden historisierten Initialen auf fol. $4{ }^{\mathrm{r}}$ in München, BSB, Clm I30Io (Statuta ecclesiae Ratisbonensis, I5.-I7. Jahrhundert) gemalt worden. Für die Bereitstellung seiner Notizen zur Handschrift danke ich Dr. Martin Roland, Österreichische Akademie der Wissenschaften, der die Initialen darin mit Clm 13022 in Verbindung bringt. Volldigitalisat des Codex unter der URL: http://daten.digitale-sammlungen.de/ -db/ooo4/bsbooo42759/images/index.html. - Sichtlich von einem Angehörigen der Furtmeyrschen Werkstatt stammt auch die historisierte Initiale mit Kreuzigung im Cgm 7I der BSB, die von Robert Suckale Martinus opifex zugeschrieben wurde (R. Suckale, Das künstlerische Umfeld, in: B. Gullath/J. Hamburger/K. Schneider/R. Suckale, Die Ottheinrich-Bibel. Kommentar zur Faksimile-Ausgabe der Handschrift Cgm 80Io/ı.2 der Bayerischen Staatsbibliothek München. Luzern 2002, S. I65-178, hier S. 172, Anm. 28). In physiognomischer Hinsicht scheinen die Figuren der Kreuzigung wiederum am ehesten den Akteuren der Bibelillustrationen in London zu entsprechen, was noch sorgfältig zu prüfen wäre.

43 Auf die Handschrift hat mich freundlicherweise Frau Dr. Regina Cermann, Universität Wien, aufmerksam gemacht, der ich für ihren Hinweis und die Zurverfügungstellung von Fotos danke. Der Psalter wurde in Regensburg gebunden, sein Erstbesitzer ist nicht bekannt. Zur Handschrift s. insbesondere die Beschreibung von F. LACKNER unter der URL http://manuscripta.at/_scripts/php/msDescription2.php?ID=7334sowie den in Vorbereitung befindlichen Bd. I8 der Reihe Die illuminierten Handschriften und Inkunabeln der ÖNB (Reihe I der Veröffentlichungen der Kommission für Schrift- und Buchwesen des Mittelalters der Österr. Akademie der Wissenschaften). 
des psalmierenden David in der Hauptinitiale (fol. $7 r$ - Abb. I6) wiederum vertritt, dem niedrigen Rang des Auftrags entsprechend, eine stark simplifizierte Variante des Furtmeyrschen Stils (vgl. zum Beispiel fol. 9rb in Cod. I. $3.2^{\circ}$ III). Dieser manifestiert sich deutlich sowohl in der Gewandgestaltung man vergleiche die gleichmäßig breiten, eckig umbrechenden Faltenschläuche, die sich deutlich von den tiefer liegenden Stoffpartien abheben und den Umriss der Figur betonen - als auch in der Physiognomie des David. Im Übrigen aber wurde die Darstellung schnell und mit wenig Aufwand ausgeführt. Das Faltenrelief wird nur summarisch, mit wenigen Strichen und rasch hingesetzten Schraffen, beschrieben, und auf eine Verdeutlichung der Gesamtplastizität der Figur mittels entsprechender Licht- und Schattenverteilung hat man ganz verzichtet. Des Weiteren ersetzen mit wenig Sorgfalt auf den weißen Papiergrund aufgetragene grünliche und rote Flecke eine echte Modellierung von Gesicht und Händen, und die die Gesichtszü-

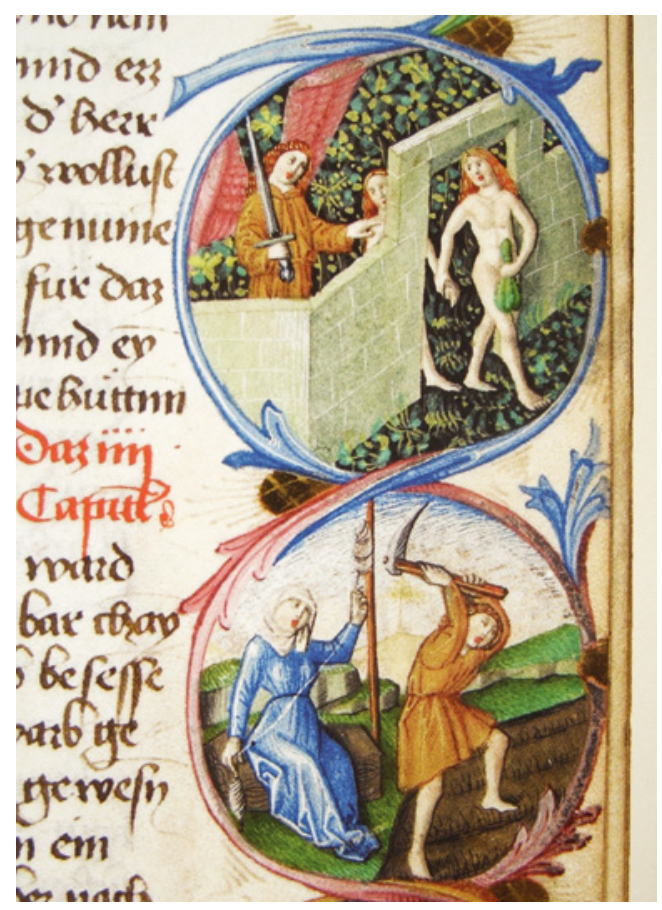

Abb: I8: London, British Library, Egerton ms. I895, Altes Testament, Bd. I; in Bd. 2, Egerton ms. I896, datiert I465, fol. 7r: Randmedaillons mit Darstellungen der Vertreibung aus dem Paradies und des arbeitenden Urelternpaars Adam und Eva; Berthold Furtmeyr zugeschrieben ge festlegende dunkle Zeichnung ist weniger fein als bei Furtmeyr sonst üblich. Dennoch muss auch in diesem Fall offen bleiben, ob hier Furtmeyr selbst auf einer besonders niedrigen Stilebene arbeitete oder ob er die Ausführung des Schmucks dieses anspruchslosen Codex ganz einem Gehilfen überließ.

Etwa um dieselbe Zeit, um I465, ist das Brevier für die Regensburger Diözese aus dem Kollegiatstift Spital am Pyhrn zu datieren, das sich heute im Besitz der Stiftsbibliothek St. Paul im Lavanttal befindet (Cod. 376-4; Abb. 17). ${ }^{44}$ Die kleine Pergamenthandschrift ist mit zwei Deckfarbeninitialen geschmückt, von denen die erste eine Darstellung der heiligen Barbara, die zweite ein bislang nicht identifiziertes Wappen umrahmt. Auch hier entspricht das Ornament dem frühen Typus (s. auch unten). Die Heiligenfigur wiederum zeigt eine besonders enge physiognomische Verwandtschaft zu der Eva mit dem Spinnrocken in London (Abb. I8), und auch für die enge Fältelung ihres Untergewandes finden sich die besten Vergleiche in Furtmeyrs frühen Werken (vgl. etwa den thronenden Schöpfer auf fol. 6r der Egerton-Bibel ${ }^{45}$ ).

44 Zur Handschrift siehe K. Holter, Die Bibliothek. Handschriften und Inkunabeln, in: Die Kunstdenkmäler des Benediktinerstiftes St. Paul im Lavanttal (Österreichische Kunsttopographie 37), Wien I969, S. 340-44I, hier S. 420, Abb. 623.

45 Furtmeyr-Katalog (zit. Anm. 2), Abb. 243. 
Bei der dritten Handschrift, auf die hier kurz eingegangen werden soll, handelt es sich um ein späteres Werk aus der Werkstatt des Regensburger Illuminators. Der mit einer historisierten und acht unfigürlichen Deckfarbeninitialen ausgestattete Papiercodex ${ }^{46}$ mit dem De dictis et factis regis Alfonsi Aragonae des Antonio Beccadelli und den Stratagemata des Sextus Julius Frontinus gehört zu einer Gruppe von handgeschriebenen und gedruckten Bänden, die das Wappen der Familie Rorbach enthalten und höchstwahrscheinlich von Sigmund von Rorbach, Reichshauptmann in Regensburg (I492-I5II) ${ }^{47}$, bestellt wurden (zu den weiteren bekannt gewordenen Werken aus dessen Bibliothek siehe unten und Anm. 54). Dass der Codex kaum früher als I480 entstanden sein kann, beweist das darin enthaltene Ornament, das aufgrund der Sorgfalt, mit der es ausgeführt wurde, und aufgrund seiner Motivik durchaus Furtmeyr selbst zugeschrieben werden könnte (siehe unten). Hingegen fällt es schwer, in diesem den Schöpfer der etwas unbeholfenen Darstellung des Autors auf fol. Ir zu sehen - man vergleiche die starre Haltung der halslosen Figur und ihren unmotiviert kleinteilig gefältelten Mantel, dessen Schlauchfalten zu dünnen Stegen verkümmert sind. Somit wird man den Band doch eher einem Mitarbeiter Furtmeyrs zuschreiben.

\section{BERTHOLD FURTMEYR ALS ILLUMINATOR VON INKUNABELN}

Bislang waren nur einige wenige gedruckte Bände mit Buchschmuck aus dem Atelier oder dem Umkreis Berthold Furtmeyrs bekannt. Eine dreibändige Inkunabel mit Ornament im Stil des Regensburger Illuminators war von Alheidis von Rohr entdeckt worden (siehe unten und Anm. 52), und Karl-Georg Pfändtner hat vor kurzem Fragmente eines gedruckten Regensburger Missales einem Nachfolger Furtmeyrs gegeben (s. Anm. 56); schließlich wird im Furtmeyr-Katalog ein sichtlich in der Werkstatt Furtmeyrs ausgeschmückter Band in Regensburg präsentiert (s. Anm. 48), ohne jedoch ausdrücklich mit dem Regensburger Illuminator in Zusammenhang gebracht zu werden. In den letzten Jahren förderte jedoch unter anderem die systematische Durchsicht österreichischer Bibliotheken eine ganze Reihe von Inkunabeln

46 Auf diesen Codex hat mich Dr. R. Cermann, Universität Wien, aufmerksam gemacht, der ich dafür herzlich danke. Er wurde zwischen 1992 und 1996 von Heribert Tenschert zum Verkauf angeboten (siehe H. Tenschert/E. König, 44 Manuskripte vom I4. bis zum frühen I7. Jahrhundert aus Frankreich, Flandern, Holland... [Leuchtendes Mittelalter VI = Katalog 3I], Rotthalmünster 1993, Kat. 58 bzw. H. TenscherT, Leuchtendes Mittelalter I-VI. 1989-I994. Fazit 1996: Die noch verfügbaren Manuskripte [Katalog 36], Rotthalmünster 1996, Kat. 99), bevor er 2002 bei Sotheby's zur Versteigerung kam (siehe Sotheby's, Fifty magnificent illuminated manuscripts, London, Tuesday 3 December 2002, London 2002, lot 27). Siehe auch die Schoenberg Database Of Manuscripts unter der URL http://dla.library.upenn.edu/dla/schoenberg/record. html?id=SCHOENBERG_3I449.

$47 \mathrm{Zu}$ Sigmund von Rorbach, der offiziell erst I499 als Reichshauptmann eingesetzt wurde, der aber schon ab I492 für dieses Amt vorgesehen war, siehe T.S. Beck, Kaiser und Reichsstadt am Beginn der frühen Neuzeit: die Reichshauptmannschaft in den Regensburger Regimentsordnungen I492-I555 (Regensburger Studien I8), Regensburg 20II, S. 52-90. Das Rorbachsche Wappen ist auf fol. $\mathrm{I}^{\mathrm{r}}$ des besprochenen Codex zu sehen. Ein zweites, jenes der Adelsfamilie Puchberg, aus der Sigmund von Rorbachs erste Frau Margarete stammte, ist auf fol. ${ }_{4} 6^{\mathrm{r}}$ in den Randschmuck eingefügt. Die Handschrift ist vermutlich noch vor I48I, dem Todesjahr Margaretes (s. Beck, 53), entstanden. 
zutage, die der Gruppe der eindeutig aus der Werkstatt Furtmeyrs stammenden Arbeiten zugeordnet werden können; davon enthalten drei Bände auch figürlichen Schmuck. Bei einigen weiteren Wiegendrucken dürfte es sich um Arbeiten von Buchmalern aus dem Umkreis Furtmeyrs handeln. Die zahlreichen neuen Funde belegen, dass das Atelier des Regensburger Buchmalers nicht nur Aufträge zur Illuminierung von Handschriften entgegennahm, sondern in großem Stil auch gedruckte Werke mit Buchschmuck ausstattete.

Die in den I470er-Jahren gedruckten Inkunabeln aus dem Atelier Furtmeyrs bilden eine stilistisch einheitliche Gruppe (Abb. 19-2I). ${ }^{48} \mathrm{Ihr}$ Ornament entspricht demjenigen etwa des Clm 13022 und des I475/76 datierten Clm I4004, die dieselbe Stillage vertreten (vgl. auch Abb. 3, 4). Die kraftvoll geschwungenen Ranken, die hauptsächlich Blätter mit tropfenförmiger Erhebung und kürzere, schmale Blätter treiben und an ihren Enden hakenförmig einschwingen, werden nur durch einige einfache Blüten (siehe oben) bereichert. Die meisten

48 Zu dieser Gruppe zählen: München, BSB, 2 Inc. c.a. 26 m (GW 6746: I470), zwei Initialen. - Ebd., 2 Inc. c.a. 30 a (GW I2424: I470), mit Fleuronnée eines Mainzer Florators, laut Vermerk I47I von Johannes Weißenberger, Kanoniker der Alten Kapelle in Regensburg, gekauft, eine historisierte Initiale, s. E. KöNIG, Buchschmuck zwischen Druckhaus und Vertrieb in ganz Europa: Peter Schöffers Hieronymus-Briefe von I470, in: Johannes Gutenberg - regionale Aspekte des frühen Buchdrucks. Vorträge der Internat. Konferenz zum 550. Jubiläum der Buchdruckerkunst am 26. und 27. Juni 1990 in Berlin, Berlin 1993, S. I30-I48, hier S. I36 f., Abb. 3 (ohne Zuschreibung). - Melk, Stiftsbibl., P 976 (GW 7079: ca. I470/72), I473 von Johannes Zinner, Kleriker der Diözese Eichstätt und Notar daselbst und in Passau, gekauft, eine Initiale. - Nürnberg, Stadtbibl., Ink. 23.2 ${ }^{\circ}$ (GW M34326: I472), 594.2 ${ }^{\circ}$ (GW 275I: nicht nach I473) und 252.2 (GW 4430: um I474/75), zwei bzw. je eine Initiale, jeweils Wappen des Dr. jur. Johann Lochner aus Nürnberg (zu Lochners Büchern siehe Chr. Sauer, Vor den Glockendons. Nürnberger Buchmalerei aus der zweiten Hälfte des I5. Jahrhunderts in der Inkunabelsammlung der Stadtbibliothek Nürnberg, in: Buchmalerei der Dürerzeit. Dürer und die Mathematik. Neues aus der Dürerforschung [Dürer-Forschungen 2], Nürnberg 2009, S. II-38, hier 34, Anm. 29). - München, BSB, 2 Inc. c.a. 34I (GW 4219: I475), zwei Initialen, mit Einband der Werkstatt „Stempelblüte III / Bamberg Kapuzinerkloster“, die bislang nicht mit Sicherheit lokalisiert wurde (s. die Einbanddatenbank unter der URL http://www.hist-einband.de/, außerdem mit Wappen des Hartmann Schedel sowie mit Fleuronnée einer Nürnberger Werkstatt. - Wilhering, Stiftsbibliothek, Ink. 24I (GW 3I84: nicht nach I475), eine Initiale, Fleuronnée eines Regensburger Florators (siehe oben). - München, BSB, 2 Inc. c.a. 440 (GW M31852: I476), zwei Initialen, spätestens seit 1500 in der Benediktinerabtei Prüfening. - Regensburg, Staatliche Bibliothek, 2 Inc. 304 (GW M26253: I476), eine Initiale (Furtmeyr-Katalog (zit. Anm. 2), S. $448 \mathrm{f}$. [Kat. 300], Abb. 402, ohne Zuschreibung). - Wien, ÖNB, Ink. 29-20 (GW 2753: nicht nach I476), sieben Initialen. - München, BSB, 2 Inc. c.a. 644 c (GW M478o6: I477), fünf Bände, fünf Initialen, in der ersten Wappen des Regensburger Domherrn Konrad Onsorg. - Kremsmünster, Stiftsbibliothek, Ink. $2^{\circ} 67$ (GW Mi7922: I478), eine Initiale, I479 von Abt Ulrich Schoppenzaun von Kremsmünster gekauft und hier mit Fleuronnée versehen und gebunden, eine Initiale (K. Holter, Bibliothek, in: Die Kunstdenkmäler des Benediktinerstiftes Kremsmünster: Die stiftlichen Sammlungen und die Bibliothek [Österreichische Kunsttopographie 43,2], Wien 1977, S. 123-220, hier S. 197, Abb. 426, 358, 397 [ohne Zuschreibung]). - Passau, Staatliche Bibliothek, Ink. 25 (GW I590: I478), zwei Initialen (Abb. 20). - Volldigitalisate der Münchener Bände unter der URL http://inkunabeln.digitale-sammlungen.de. - Ich danke Dr. Christine Sauer, Stadtbibliothek Nürnberg, herzlich für ihren Hinweis auf die Lochner-Inkunabeln und ihre Publikation (siehe oben) sowie für die Zurverfügungstellung von Aufnahmen. Für seinen freundlichen Hinweis auf die Inkunabel der ÖNB bin ich Mag. Armand Tif, Universität Wien, für die Bereitstellung eines Fotos des Passauer Bandes Dr. Christine Beier, Universität Wien, zu Dank verpflichtet. 


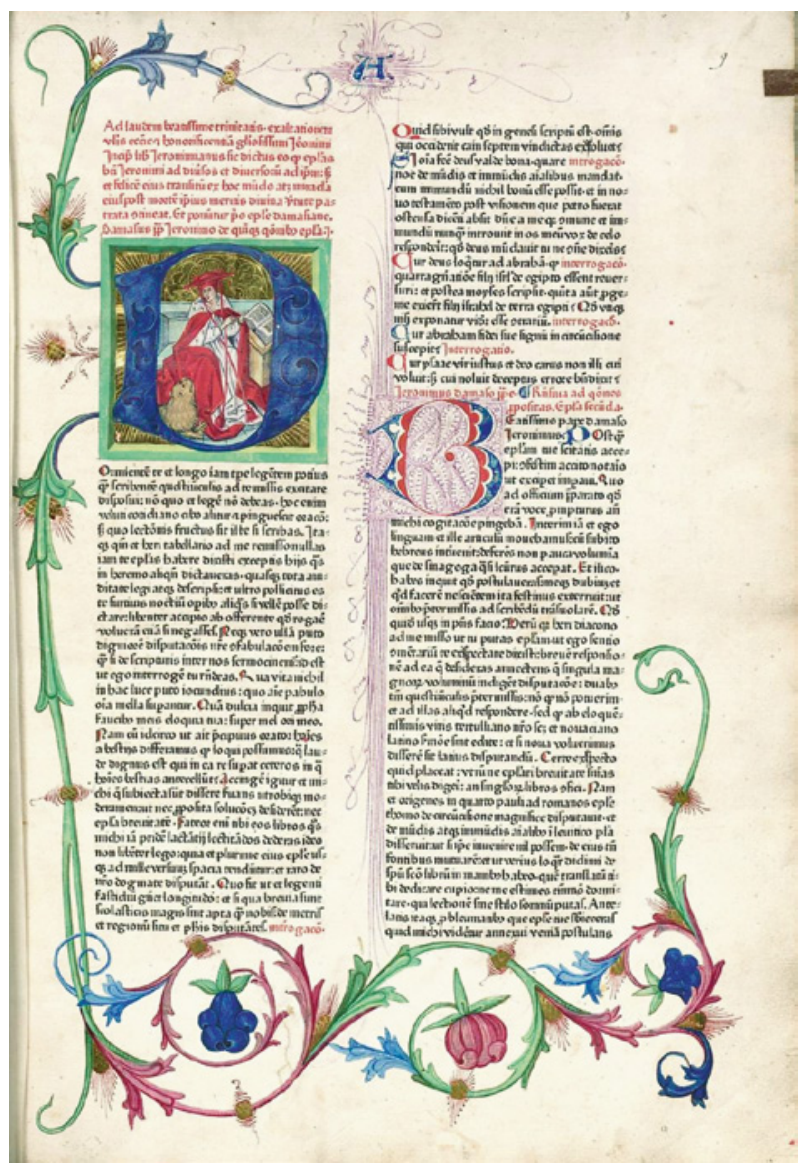

Abb. 19: München, Bayerische Staatsbibliothek, 2 Inc. c.a. 30a, Hieronymus, Epistolae, gedruckt in Mainz, I470 (GW I2424), fol. 9r: Historisierte Deckfarbeninitiale mit Darstellung des hl. Hieronymus mit dem Löwen, Ranken; Berthold Furtmeyr (?)

Drucke dieser Gruppe wurden in Regensburg gebunden, einige außerdem mit Fleuronnée ausgestattet, das nach Regensburg lokalisiert werden kann. ${ }^{49}$

Der älteste oder zweitälteste Band dieser Gruppe (2 Inc. c.a. 30 a, s. Anm. 48, Abb. 19) stellt in dieser Hinsicht eine Ausnahme dar, wurde er doch schon am Druckort, nämlich in Mainz, floriert und gebunden. Seinen Deckfarbenschmuck, eine historisierte Initiale mit Ranken, erhielt der Druck im Atelier Furtmeyrs, nachdem er von einem Regensburger Kanoniker gekauft worden war. Das Initialbild, eine Darstellung des Hieronymus mit dem Löwen, könnte Furtmeyr eigenhändig ausgeführt haben: Eine analoge Gewandbehandlung und Komposition - vgl. die vom senkrecht herabfallenden Gewand des Kirchenvaters verdeckte Pultkante (vgl. Anm. 27) - zeigt etwa die ikonographisch entsprechende Darstellung in der Initiale auf fol. $7 \mathrm{r}$ in Cgm 8oioa.

Die Inkunabel $2^{\circ} 67$ in Kremsmünster (s. Anm. 48) dürfte umgekehrt zuerst im Atelier Furtmeyrs auf Vorrat illuminiert und anschließend ohne bzw. mit einem provisorischen Einband verkauft worden sein. Im oberösterreichischen Benediktinerstift, wohin sie wohl bald nach Fertigstellung gelangte, wurde sie dann mit Fleuronnée versehen und (neu) gebunden.

49 Siehe dazu Hranitzky/Schuller-Juckes, Katalog (zit. Anm. i9). 
Abb. 20: Passau, Staatliche Bibliothek, Ink. 25, Jacobus Alvarottus, Super feudis, gedruckt in Lyon, 1478 (GW I590), Unfigürliche Deckfarbeninitiale mit Ranken; Berthold Furtmeyr oder Mitarbeiter

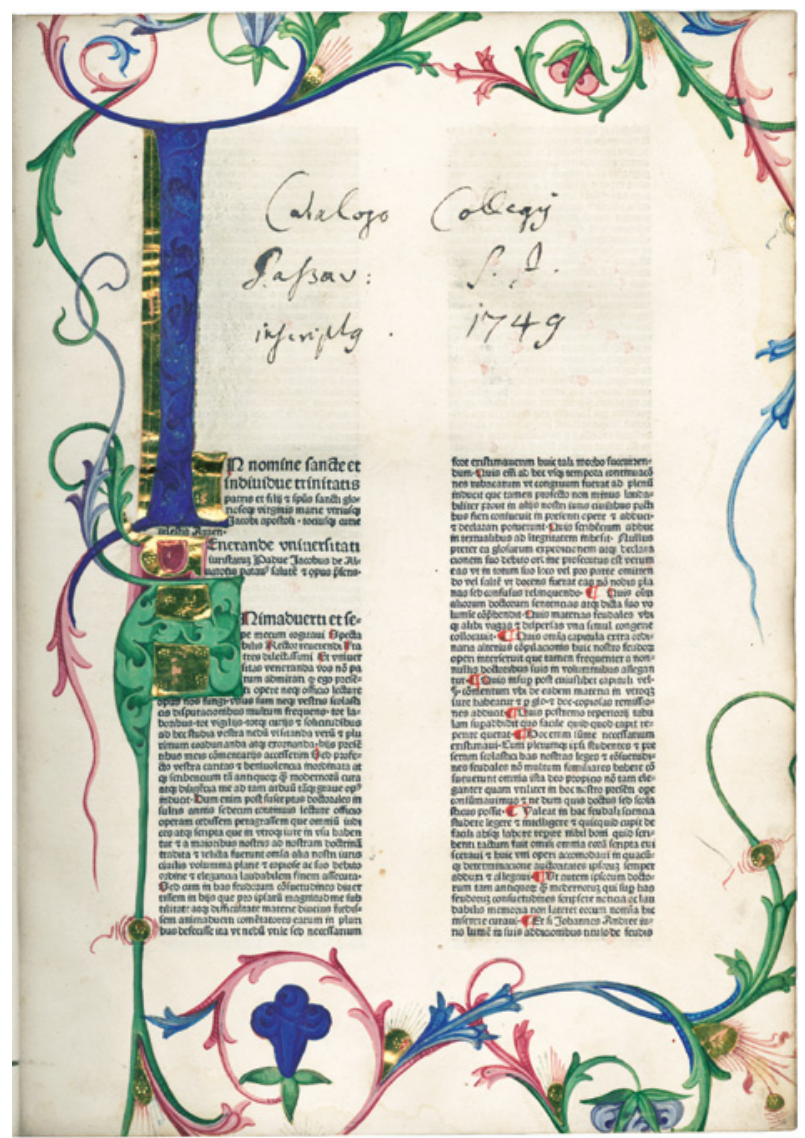

Ungewiss ist, ob Johann Lochner die Ausstattung der drei Bände, die aus seinem Besitz stammen (Nürnberg, Stadtbibliothek, Ink. $23.2^{\circ}, 252.2^{\circ}$ und $594.2^{\circ}$, s. Anm. 48), bei Furtmeyr in Auftrag gab oder ob er sein Wappen erst nachträglich darin anbringen ließ. Auch die Reihenfolge der Arbeiten an der in Nürnberg gedruckten und dort auch mit Fleuronnée versehenen Inkunabel 2 Ink. c.a. 34I der BSB München (s. Anm. 48) aus dem Besitz des Hartmann Schedel, dessen Wappen über die Furtmeyrschen Ranken gemalt wurde, ist vorläufig nicht zu rekonstruieren, nicht zuletzt weil der Einband dieses Drucks bislang nicht genau lokalisiert werden konnte. Ob ihre Illuminierung jeweils auf Bestellung oder Vorrat erfolgte, ist auch bei den übrigen Bänden der Gruppe nicht mehr mit Sicherheit festzustellen.

Entsprechend ihrem frühen Erscheinungsdatum steht die nicht nach I466 gedruckte Bibel der Stiftsbibliothek St. Florian (Ink. X/6 - Abb. 2I) ${ }^{50}$ auf einer etwas älteren Stilstufe als die eben besprochenen Bände. Das gilt auch noch für das in der Kantonsbibliothek Thurgau aufbewahrte Exemplar eines zwei Jahre jüngeren Bibeldrucks aus derselben Offizin (Ink. X.ooıı,

50 GW 4205; siehe K. Holter, Bibliothek und Archiv - Handschriften und Inkunabeln, in: Die Kunstsammlungen des Augustinerchorherrenstiftes St. Florian (Österr. Kunsttopographie 48), Wien 1988, S. 46, Abb. 243. 


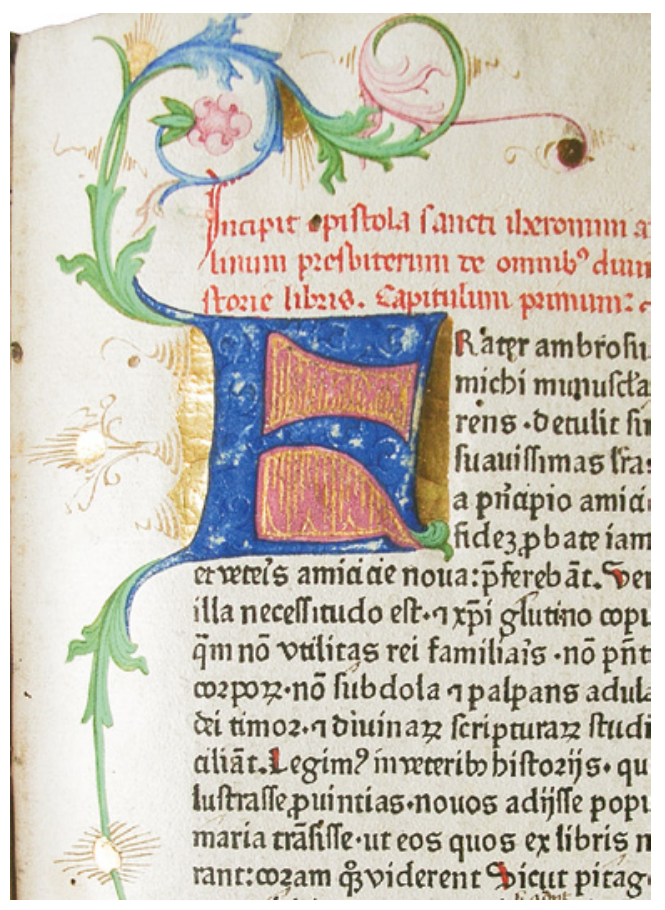

Abb. 2I: St. Florian, Stiftsbibliothek, Ink. X/6, Bibel, gedruckt in Strassburg, nicht nach I466 (GW 4205), Unfigürliche Deckfarbeninitiale mit Ranken; Berthold Furtmeyr oder Mitarbeiter nicht nach 1468 gedruckt). ${ }^{51}$ Das Ornament dieser beiden Bände entspricht sowohl jenem des im gleichen Jahr wie die St. Florianer Inkunabel entstandenen Cod. 3743 der Österreichischen Nationalbibliothek als auch dem des Missales in St. Paul (Abb. I6, I7).

Stilistisch uneinheitlich ist die Gruppe der in den I48oer- und I490er-Jahren gedruckten Bände; auch in der Sorgfalt der Ausführung sind innerhalb dieses Konvoluts Schwankungen festzustellen. Dies könnte dadurch zu erklären sein, dass Furtmeyr, der ab ca. 1478 am Salzburger Missale arbeitete, die Illuminierung der Drucke nun verstärkt Mitarbeitern überließ. I480 wurde die von Rohr genannte Inkunabel in Regensburg ${ }^{52}$ gedruckt. Das Rankenwerk ist hier deutlich zarter geworden, die Blätter mit den blasenartigen Erhebungen werden zugunsten langer, schlanker, den Rankenstielen angenäherter Blätter zurückgedrängt, die nur mehr durch wenige, ebenfalls dünner gewordene Blüten begleitet werden. Als motivische Neuerungen sind

kurze, schmale „Flügelblätter“ sowie Blätter mit zungenartig verlängertem und umgeschlagenem Mittellappen zu nennen. Schließlich kommen vermehrt Höhungen in Form von gepunkteten Linien vor. Der Dekor dieser Inkunabel zeigt deutliche Analogien zum zarten Akanthus der Beccadelli-Handschrift aus dem Besitz Sigmunds von Rorbach (siehe oben), aber auch zu den braunen Ranken im oberen Teil der beiden eingebundenen Miniaturen im „Heidelberger Schicksalsbuch“von ca. I49I. Das Rankenwerk mit den schlanken, teilweise weiß gepunkteten Blättern und den zierlichen Blüten könnte demnach dem späten Ornamentstil Furtmeyrs entsprechen. ${ }^{53}$

5I GW 4206; zur Inkunabel siehe M. LuginbüHL, H. Bothien, Meisterwerke des frühen Buchdrucks. Die Inkunabelschätze der Kantonsbibliothek Thurgau... Frauenfeld, Stuttgart, Wien 20II, 55-57, Nr. 83, mit zwei FarbAbb. Ich danke Frau Dr. Regina Cermann, Universität Wien, für den Hinweis auf diesen Band.

52 Staatl. Bibl., 2 Inc. 254 (GW M25372); siehe Rohr, Berthold Furtmeyr (zit. Anm. 3), S. 4I; Furtmeyr-Katalog (zit. Anm. 2), S. 449 (Kat. 303), Abb. 405. Der dreibändige Druck enthält laut RoHr insgesamt vier Initialen.

53 Zum Teil ähnliche Blattformen zeigen: München, BSB, 2 Inc. c.a. 927 (GW 4243: I480; drei Initialen, offenbar in Salzburg gebunden), Regensburg, Staatliche Bibliothek, 2 Rat.ep. 363a (GW M24660: I485; FurtmeyrKatalog, S. 42I [Kat. 239], Abb. 346); weiters Regensburg, Bischöfl. Zentralbibl. AK, Inc. I8oI (GW Mi2646: I48I), mit Wappen des Regensburger Kanonikers Johannes Gkrad; St. Florian Ink. X/I32A (GW 9132: I486; s. 
Etwa zehn bis Is Jahre später wurden zwei Bände illuminiert, die neben ornamentaler Ausstattung im Furtmeyrschen Stil auch je eine Miniatur enthalten. Der eine gehört zu einer Gruppe von Inkunabeln juristischen Inhalts mit einheitlichem Dekor, die zwischen 1489 und I495 gedruckt wurden und allesamt aus dem Besitz Sigmunds von Rorbach stammen. ${ }^{54}$ Bei der zweiten Inkunabel handelt es sich um einen Einzelband, der 1484 gedruckt, jedoch erst I490 gebunden und daher möglicherweise erst kurz vor diesem Datum ausgeschmückt wurde (Abb. 22). ${ }^{55}$ Während der nicht übermäßig fein ausgeführte, aber relativ reiche ornamentale Buchschmuck der Rorbach-Gruppe formal (und in der verhältnismäßig dunklen Farbigkeit) an den Dekor der I470er-Jahre anschließt, zeigen die wenigen fast rankenlosen Initialen im Salzburger Band eine durch schärfere Konturierung und Höhung bewirkte Verhärtung der Ornamentformen, wie sie auch dem Dekor der gegen Ende des Jahrhunderts entstandenen „Schülerwerke“ eignet; ${ }^{56}$ mit diesen späten Arbeiten verbinden den Salzburger Band auch be-

Holter, Bibliothek und Archiv, zit. Anm. 50, S. 50); Graz UB Ink. III 9505 (GW I2360: I486). - Etwas gröber die Initiale mit Ranken in München, BSB, 2 Inc. c.a. I203 a (GW 9815: I482); Volldigitalisat unter der URL http://inkunabeln.digitale-sammlungen.de), mit Wappen, Besitzvermerk und den mit der Jahreszahl I492 versehenen Initialen des Johannes Gkrad (siehe oben). - Abwechslungsreiches, aber etwas schematisiertes und in kräftigen Farben gehaltenes Ornament zeigt schließlich Ink. W II ıı der Universitätsbibliothek Salzburg (GW 3404: I480; Abb. unter der URL http://www.ubs.sbg.ac.at/sosa/inkunabeln/inkinit.htm), mit nicht identifiziertem Wappen, wohl ein „Schülerwerk“. - Ähnlich das Ornament in Regensburg, Staatliche Bibliothek, 2 Inc. 274 (GW 9154: 1478; Furtmeyr-Katalog, S. 449 [Kat. 302], Abb. 403), mit Wappen von Johannes Gkrad (siehe oben), sowie in zwei Inkunabeln in Maribor, Škofijski arhiv (R II5 und R I45), deren Kenntnis ich Mag. A. Tif, Universität Wien, und Dr. N. Golob, Universität Ljubljana, verdanke. - Als weitere Inkunabeln mit Schmuck im Furtmeyrschen Stil sind zu nennen: München, BSB, 4 L.impr.membr. 7 (GW M27397: I49I); Volldigitalisat unter der URL http://inkunabeln.digitale-sammlungen.de; dessen Dekor in einem anderen Exemplar des Drucks, Regensburg, Bischöfliche Zentralbibliothek AK, Inc. 1857, nachgeahmt (Furtmeyr-Katalog, zit. Anm. 2, S. 450 f. [Kat. 305], Abb. 407); weiters Regensburg, ebd., Inc. 200I (unpubliziert). - Volldigitalisate der drei Münchener Bände unter der URL http://inkunabeln.digitale-sammlungen.de.

54 Diese Gruppe umfasst: Ljubljana, NUK, Ti ro885 (GW 2887: I489); München, BSB, 2 Inc. c.a. 2377 b (GW 3622: I49I); ebd., 2 Inc. c.a. 2523 x (GW 3517 und 3500: I49I/92); ebd., 2 Inc. c.a. 3215 i (GW 7743: I495; das Wappen hier seitenverkehrt), die dem Text vorangestellte Miniatur wurde herausgeschnitten. Alle Bände enthalten das Wappen Rorbachs, außerdem Fleuronnée eines Regensburger Florators, s. dazu HranitzKy /Schuller-Juckes (zit. Anm. 19). - Die Kenntnis dieses Konvoluts (außer 2 Inc. c.a. 32I5 i) verdanke ich Dr. Regina Cermann, Universität Wien, die mich außerdem noch auf einen weiteren Druck aus dem Besitz von Rorbachs hinwies, der 1970 bei H. P. Kraus zur Auktion kam (siehe H. P. Kraus, One Hundred And Eighty Rare Books And Manuscripts [Catalogue I25]. New York 1970, Kat. I4; GW 4I58: I494). Der Dekor dieses Bandes scheint, soweit die Schwarzweiß-Abbildung im Auktionskatalog erkennen lässt, jenem der „Schülerwerke“ (s. Anm. I8 und 56) nahezukommen. - Volldigitalisate der drei Münchener Bände unter der URL http://inkunabeln.digitale-sammlungen.de. Zur Inkunabel in Ljubljana s. T. VignJević, Iz zibelke tiskarstva. Ilustracije v inkunabulah. Katalog zur Ausstellung in Ljubljana 200I, Ljubljana 200I, S. 48 (Kat. 19) m. FarbAbb. - Nicht ganz auszuschließen ist, dass Rorbach die auf Vorrat illuminierten Inkunabeln kaufte und darin sein Wappen anbringen ließ.

Salzburg, Universitätsbibl., Ink. W III 283 (GW 76ro); gebunden in Prüfening. Siehe auch die URL http:// www.ubs.sbg.ac.at/sosa/inkunabeln/inkminiatur.htm.

56 Vgl. mit den Salzburger Initialen zum Beispiel Furtmeyr-Katalog (zit. Anm. 2), Abb. 260 oder Hernad, Münchener Furtmeyr-Bibel (zit Anm. 3), Abb. I3 und 15. Zur Gruppe der „Schülerwerke“ siehe Anm. I8. 


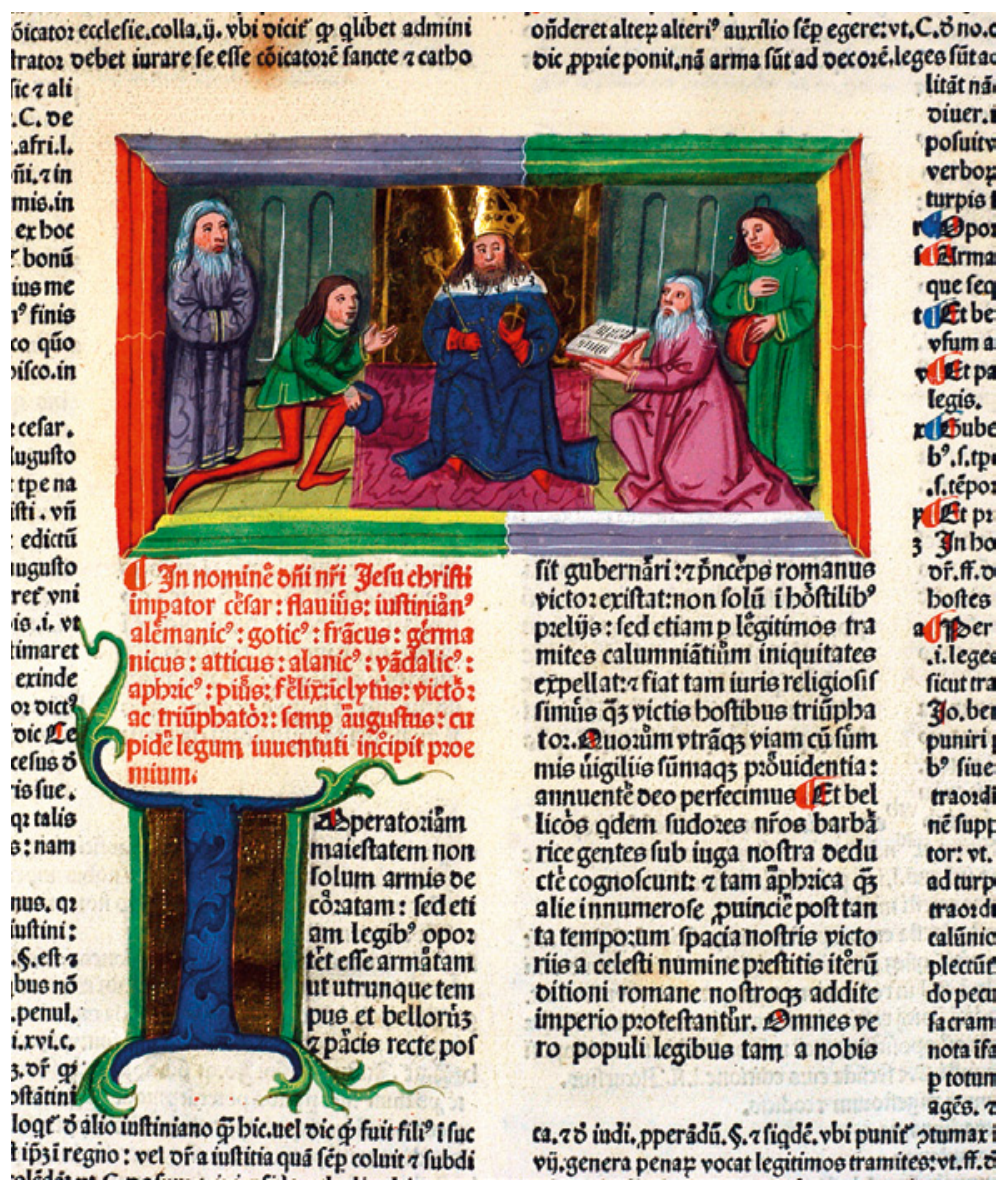

Abb. 22: Salzburg,

Universitätsbibliothek, Ink. W III 283, Corpus iuris civilis, Institutiones, gedruckt in Venedig, I484 (GW 76IO), Miniatur mit Darstellung der Übergabe der Gesetzestexte an Kaiser Justinian, unfigürliche Deckfarbeninitiale; Berthold Furtmeyr oder Mitarbeiter

stimmte Motive wie das des abgeschnittenen Rankenstängels mit sichtbarer Schnittfläche. Zweifellos wurde der ornamentale Schmuck in den Bänden Rorbachs von anderer Hand illuminiert als die Salzburger Inkunabel.

Ob die beiden Miniaturen jeweils vom Illuminator des vegetabilen Dekors oder von nur einer Hand ausgeführt wurden, ist vorläufig nicht eindeutig festzustellen. Die Rorbach-Inkunabel 2 Inc. c.a. 2377 b zeigt oberhalb der einleitenden Initiale eine gerahmte Darstellung zweier Schildknappen in modischer Kleidung mit Lanzen, die das Wappen von Rorbachs halten; in der Salzburger Miniatur werden dem thronenden Kaiser Justinian von einem knienden alten Mann in Gegenwart eines weiteren betagten und zweier junger Männer die Gesetzestex-

Analogien zu den dort genannten Handschriften zeigen die folgenden Exemplare eines I5oo gedruckten Regensburger Missales (GW M24655): München, BSB, 2 Inc. c.a. 3902 (Volldigitalisat unter der URL http://inkunabeln.digitale-sammlungen.de); Regensburg, Bischöfliche Zentralbibliothek AK, Inc. 1980 (Furtmeyr-Katalog, S. 420 f. [Kat. 236f.], Abb. 34I); Bamberg, Staatsbibliothek, I Qa 30 - I Qa 38, zu diesen Fragmenten siehe K.-G. Pfändtner, Vergessene Miniaturen - Die "Cutting"-Sammlung der Staatsbibl. Bamberg, in: Codices Manuscripti 69/70 (2009), S. I7-32, hier S. I8f. - Siehe auch die in Anm. 54 genannte, bei H. P. Kraus zum Verkauf angebotene Inkunabel. 
te überreicht (Abb. 22). Beide Miniaturen wurden von routinierter Hand unter Verwendung des bei Furtmeyr häufig wiederkehrenden Motivs der grauen, bildparallelen, durch schmale, rundbogige Vertiefungen gegliederten Wand ausgeführt: In Salzburg schließt diese den Bildraum nach hinten zu ab (vgl. zum Beispiel Cgm 8oroa, foll. Iv, 2v), in München dient sie der Umrahmung der Szene. Die Salzburger Miniatur zeigt zudem die für Furtmeyr charakteristische Faltenbildung der Gewänder, die hier allerdings vereinfachend durch wenige dicke Striche beschrieben wird. Modelliert wird in beiden Bänden summarisch durch schnelle Lavierung. ${ }^{57}$ In der Gesichtszeichnung scheinen insbesondere die Akteure der Präsentationsszene den Figuren zu ähneln, die die beiden Miniaturen in Heidelberg beleben, wenn diese auch eine höhere Stillage vertreten und eine entsprechend feinere Ausführung zeigen. ${ }^{58}$

\section{ZUSAMMENFASSUNG}

Aufgrund des großen Umfangs und der erstaunlichen stilistischen Heterogenität des Euvres, das sich der Werkstatt Berthold Furtmeyrs zuweisen lässt, ist davon auszugehen, dass der Regensburger Illuminator einerseits eine große Zahl von Gehilfen beschäftigte, denen er möglicherweise manchmal sogar die gesamte Ausstattung eines Werkes anvertraute, und andererseits bei seinen eigenhändig ausgeführten Arbeiten je nach Auftrag in einer mehr oder weniger hohen Stillage arbeiten konnte. In vielen Fällen ist daher eine Ausführung durch Furtmeyr selbst nicht zweifelsfrei festzustellen. Dennoch würde man durch eine gründliche und differenzierende vergleichende Stilanalyse aller Werke vermutlich zu einer etwas präziseren Vorstellung von der Arbeitsorganisation im Atelier des viel beschäftigten Regensburger Buchmalers gelangen. Eine solche umfassende und in die Tiefe gehende Studie steht tatsächlich, obgleich in der jüngeren Literatur, zuletzt anlässlich der großen Ausstellung in Regensburg, viele Aspekte der Kunst Berthold Furtmeyrs neu beleuchtet werden konnten, nach wie vor aus.

\section{NACHBEMERKUNG}

Abschließend sei noch auf zwei weitere, besonders reich illuminierte Handschriften hingewiesen, deren Schmuck ebenfalls Berthold Furtmeyr bzw. seiner Werkstatt zugeschrieben werden kann, von denen die Autorin jedoch bedauerlicherweise erst nach Fertigstellung des vorliegenden Aufsatzes Kenntnis erlangte, so dass sie hier nur mehr erwähnt werden können. Bei dem ersten dieser beiden Bände handelt es sich um eine verschollene Handschrift mit einer deutschen Übersetzung des „Itinerarium Beatae Virginis Mariae“.59 Der kleinformatige Codex,

57 Der auf den ersten Blick für Furtmeyr ungewöhnlich wirkende Rahmen aus verschiedenfarbigen Leisten, für die die Augsburger und Nürnberger Buchmalerei Pate stand, wurde in der Art Furtmeyrs profiliert (vgl. als beliebiges Beispiel das Kanonbild München, BSB, Clm 15708, fol. 74v). 
der mit 79 Miniaturen und zahlreichen Deckfarbeninitialen samt Randschmuck ausgestattet ist - es handelt sich um das bislang einzige bekannte illustrierte handgeschriebene Exemplar dieses Textes -, wurde 1994 aus der Bibliothek des Klosters Strahov gestohlen; es existiert davon nur mehr ein Mikrofilm, der immerhin die stilistische Zugehörigkeit des kleinformatigen Bandes zum Werk Furtmeyrs deutlich erkennen lässt. Gewisse Details des Rankenschmucks sprechen für eine Datierung des Codex gegen I480 (siehe oben). Um dieselbe Zeit ist vermutlich das Gebetbuch Cgm 725I der BSB München zu datieren, das ebenfalls von Furtmeyr und seiner Werkstatt illuminiert wurde. ${ }^{60}$ Der Schmuck dieses Codex besteht aus 74 Miniaturen und sehr zahlreichen, von Ranken begleiteten Initialen. Eine genaue kunsthistorische Untersuchung dieser beiden Handschriften, bei denen es sich um zwei bislang unbekannte Hauptwerke aus der Werkstatt Berthold Furtmeyrs handelt, ist geplant.

Universität Wien

Abbildungsnachweis: Abb. I-3, 5-7: Linz, Katholisch-theologische Privatuniversität. - Abb. 4, 8, 9, II, I2, I5: Augsburg, Universitätsbibliothek, Oettingen-Wallersteinsche Bibliothek (URL: http://www.bibliothek.uni-augsburg. de/dda/urn/urn_ubaoo20oo-ubaoo2199/). - Abb. ıо, I3: nach Pfändtner, Salzburger Missale (zit. Anm. 3), S. 43, 173. - Abb. I4: Stuttgart, Württembergische Landesbibliothek. - Abb. I6: Wien, Österreichische Nationalbibliothek (Foto: Fotosammlung Pächt-Archiv). - Abb. I7: St. Paul im Lavanttal, Stiftsbibliothek. - Abb. I8: nach Furtmeyr-Katalog (zit. Anm. 2), Taf. 3. - Abb. 19: München, Bayerische Staatsbibliothek. - Abb. 20: Passau, Staatliche Bibliothek. - Abb. 21: St. Florian, Stiftsbibliothek. - Abb. 22: Salzburg, Universitätsbibliothek.

Klosters Strahov, herzlich gedankt. Den Inhalt hat Regina Cermann bestimmt, s. die Beschreibung im Handschriftencensus unter der URL http://www.handschriftencensus.de/2265I.

60 Ich danke Frau Dr. Regina Cermann herzlich für den Hinweis auf das Gebetbuch und die Zurverfügungstellung ihrer in Bearbeitung befindlichen Beschreibung des Codex für den Katalog der deutschsprachigen illustrierten Handschriften des Mittelalters (Nr. 43. I. I30). 


\title{
DER EINZELNE IM VERBUND: KOOPERATIONSMODELLE IN DER SPÄTMITTELALTERLICHEN BUCHHERSTELLUNG
}

\author{
Lieselotte E. Saurma-Jeltsch
}

\section{E I N L E I T U NG}

Unsere Erwartungshaltung an ein Buch ist geprägt - insbesondere, wenn es sich um ein illustriertes Exemplar handelt - vom Umgang mit Druckwerken. Wir erwarten eine Einheit von Buch und Ausstattung, von Bild und Text, der Texte untereinander und schließlich der Ausstattung insgesamt. Ganz anders jedoch erleben wir Handschriften. Sammelhandschriften, deren Texte sich durch die nachbarschaftliche Beziehung in einem Buch neu kontextualisieren, ohne dass sich uns die Gründe für die entsprechende Zusammenstellung eröffnen, lassen uns ahnen, dass das Gesamte eines Handschriftenkörpers sich zwar als Einheit darbieten kann, ohne freilich einheitlich zu sein. Nicht immer braucht es vergleichbar elegante Erklärungen wie die psychoanalytische Interpretation, mit der jüngst George Edmondson den Begriff „Neighboring “ für Text- und Wissensorganisationen des Mittelalters eingeführt hat. ${ }^{1}$ Häufig liegt die Erklärung für scheinbar Unzusammengehöriges, Nichteinheitliches an der prekären Versorgungslage. Auch im Spätmittelalter existiert ein nur rudimentärer Markt für Bücher: Hersteller - Schreiber, Maler und Buchbinder -, aber auch Materialien wie Vorlagen, Beschreibstoffe, Pigmente sind oft nur schwer zu organisieren. Mit Ausnahme der großen Zentren - hier vor allem Paris ${ }^{2}$-, in denen Universität und Hof einen kontinuierlichen Bücherbedarf anmelden, wechseln die Abnehmergruppen relativ rasch, wenn auch das allgemeine Bedürfnis nach Büchern im Laufe des I4. und I5. Jahrhunderts sich bekanntlich zunehmend vergrößert. Werbeanzeigen, wie sie schon Richard und Mary Rouse für das I3. und frühe I4. Jahrhundert im Pariser Buchhandel nachweisen können ${ }^{3}$, sind in vergleichbar breiter Formulierung für eine unbekannte Klientel erst wieder bei Diebold Lauber bereits parallel zum Buchdruck bekannt. ${ }^{4}$ Von den Herstellungs- und Beschaf-

I G. Edmondson, The Neighboring Text: Chaucer, Boccaccio, Henryson, Notre Dame (IN) 20iI, S. 3-2I.

2 R. H. Rouse /M. A. Rouse, Manuscripts and their Makers. Illiterati et uxorati. Commercial Book Producers in Medieval Paris I200-I500 (Studies in Medieval and Early Renaissance Art History, 25), 2 Bde., London 2000 zum Buchhandel im Rahmen der Universität. Zu den weiteren Abnehmern und Auftraggebern liefert eine Übersicht G. Croennen, Patrons, Authors and Workshops: Books and Book Production in Paris around I400, in: Ders. (Hrsg.), Patrons, Authors and Workshops: Books and Book Production in Paris around 1400 (Synthema, 4), Louvain 2006, S. I-I9; siehe auch K. Fianu, Métiers et espace: topographie de la fabrication et du commerce du livre à Paris (XIIIe - XVe siècle), in: Ebenda, S. 2I-45.

3 Rouse / Rouse, Manuscripts (zit. Anm. 2), Bd. I, S. 36 für den Meister Alexander um I230; für Herneis le Romanceur Bd. I, S. 47 und Bd. 2, S. I50; für Richard de Montbaston Bd. I, S. 236, Fig. 24 und für Thomas de Maubeuge Bd. 2, S. 173 .

4 L.E. Saurma-Jeltsch, Spätformen mittelalterlicher Buchherstellung, 2 Bde., Wiesbaden 200I, Bd. I, S. 239242, dort weitere Literatur; zu Werbeanzeigen als Musterblätter siehe E. KwAKKEL, Commercial Organisati- 
fungsbedingungen her also ist das Sammelstück eher die Norm und die einheitlich ausgestattete Handschrift die Ausnahme.

Nun kann allerdings die Frage nach der Einheitlichkeit eines „Werks“ nicht allein über den Herstellungs- und Beschaffungsprozess beantwortet werden ${ }^{5}$, sondern - und dies muss uns als Kunsthistoriker besonders interessieren - es stellt sich grundsätzlicher die Frage, wie denn die Zeitgenossen diese definiert und bewertet haben. Christine de Pizan verweist auf eine dem Buch selbst innewohnende Kraft der Vereinheitlichung. Texte unterschiedlichster Gewichtung und Bedeutung werden in dem dreidimensionalen Objekt Buch vereint. ${ }^{6}$ Nicht nur die physische Vereinigung freilich trägt zu der Schönheit des Buches bei, sondern, so betont Christine in ihrem Prolog zu der für Elisabeth von Bayern zusammengestellten Handschrift ${ }^{7}$, sie selbst schaffe eine Ordnung, durchdringe die Texte, schreibe sie und statte sie mit Bildern aus. Damit gestalte sie ein „vollendetes“ Werk. ${ }^{8}$ Christine versteht sich hier nicht als Autorin, sondern als „Autorität", gemäß der sie nicht nur die Texte zusammenfügt, sondern sie sinnreich ordnet, schreibt und ausstattet. All diese Akte beglaubigt sie kraft ihrer Autorität als Einheit. Neuere kodikologische Untersuchungen haben freilich ergeben, dass diese Handschrift mitnichten einem dem Prolog entsprechenden klaren Ordnungs- und Gestaltungswillen unterlag. ${ }^{9}$ Planungswechsel, ja sogar eine Zuarbeit fremder Kräfte, die freilich eng mit Christine liiert waren und den Traditionen und Normen der Buchherstellung folgend ihr auch unterstanden, konnten beobachtet werden. Trotz dieser „Uneinheitlichkeit“ der Entstehung und keineswegs von Anbeginn an klarer Ordnung garantiert offenbar die Autorität von Christine den Eindruck der Einheitlichkeit. ${ }^{10}$

Zunehmend beginnt sich in der Forschung abzuzeichnen, dass größere Arbeitsverbünde ebenso wie kleinere Gruppen gerade wegen ihrer Unterordnung unter ein gemeinsames Konzept und die traditionellen Normen der Buchherstellung Werkstücke schufen, in denen die Spuren unterschiedlicher Hersteller nur sehr schwer nachzuzeichnen sind. Ezio Ornato zählt unter die unterschiedlichen Faktoren, die eine Handschrift einheitlich erscheinen lassen - Material, Herstellungsorganisation und Layouttraditionen -, auch bestimmte ästhetische Konstanten. Das zweifellos Wichtigste ist eine ,interne“ Regelhaftigkeit, die sowohl die Struktur als auch die Präsentation der Handschrift betrifft. Die gleichbleibende Abfolge der Blätter -

on and Economic Innovation, in: A. Gillespie/D. Wakelin (Hrsg.), The Production of Books in England. I350-1500, Cambridge u. a. 2011, S. I73-I9I, I84.

5 E. Ornato, Exigences fonctionelles, contraintes matérielles et pratiques traditionelles dans le livre médiéval: quelques réflexions, in: P. RücK (Hrsg.), Rationalisierung der Buchherstellung im Mittelalter und in der frühen Neuzeit. Ergebnisse eines buchgeschichtlichen Seminars. Wolfenbüttel I2. November - I4. November 1990 (elementa diplomatica, 2), Marburg a. d. Lahn 1994, S. 7-31, 8 f.

6 T. van Hemelryck/Chr. Reno, Dans l'atelier de Christine de Pizan. Le manuscrit Harley 443I, in: J.-L. Deuffic (Hrsg.), Du scriptorium à l'atelier. Copistes et enlumineurs dans la conception du livre manuscrit au Moyen Âge (Pecia, I3), Turnhout 20II, S. 267-286, besonders 269.

7 London, The British Library: Ms Harley 443I, fol. 3ra-d. Darin betont Christine die „schöne“ Vereinigung der Texte.

8 Die Worte ordener, parfiner und affiner spielen als eigene Leistung im Sinne der Aufbereitung eine wichtige Rolle; dazu van Hemelryck / Reno, Christine (zit. Anm. 6), S. 269 f. in Umschrift.

9 Ebenda, S. 278 ff.; siehe auch URL: <http://www.pizan.lib.ed.ac.uk> (I8. oI. 20I2).

IO Ebenda, S. 285 f. 
Haar- und Hautseite beim Pergament -, deren übereinstimmende Dimensionen sowie ein normierter Schriftspiegel, wenig variierende Zeilenzahlen und Zeilenlängen sind Elemente, die entscheidend zu dem Eindruck der Einheitlichkeit beitragen und als solche offenbar auch erwartet wurden. Ebenso wird eine Harmonisierung durch Regeln in den Auszeichnungssystemen bis hin zu den Bildern unterstützt.

Nun wird gerade am Beispiel der Bilder deutlich, dass es sich bei dem Streben nach dem regelhaften Buch mitnichten um ein absolut zu befolgendes Regime handelt, sondern viele Faktoren wiederum für eine gegenläufige Gestaltung sprechen. Bestimmte Teile einer Handschrift etwa sind nicht zu bebildern, der Text erfordert andere Hierarchien als die Bilder, traditionelle Gestaltungen entsprechen nicht dem Rest des Buches, oder Zeit, Material und Können der Hersteller vermögen eine solche Normierung gar nicht durchzuhalten. ${ }^{11}$

Den Zeitgenossen allerdings scheint eine in diesem weiten Rahmen abgesteckte einheitliche Gestaltung der Handschrift ein Anliegen gewesen zu sein. Nun fragt sich freilich, inwieweit dies auch für die künstlerische Gestaltung zutrifft. Hierzu hat die Kunstgeschichte selbst im letzten Jahrzehnt bedeutende Veränderungen durchgemacht. Während auch in der Buchmalerei-Forschung der Stil eines Meisters weiterhin im Vordergrund steht und damit eine Kunstgeschichte fortgeschrieben wird, die durch den Geniekult des 19. Jahrhunderts befeuert bis in die Frühzeit der Künstlerviten zurückreicht, hat sich in den letzten zwei Jahrzehnten wohl auch im Zuge der sozial- und kulturgeschichtlich ausgerichteten „New Art History“ ein Interesse an den unterschiedlichen Formen von Zusammenarbeit im Diskurs entwickelt, das zunehmend den „Personalstil“ in der Vormoderne in Frage zu stellen beginnt. ${ }^{12}$

Dass die Werkgruppen in Paris, Bologna oder auch etwas später in Avignon im I4. Jahrhundert mit ihrem System, die Arbeit in Lagen zu verteilen, die Einheit des Werkes nicht nach der künstlerischen Ausstattung definieren, ist uns vertraut. ${ }^{13}$ Aber sogar in einem hö-

II Zu der Resistenz der Systeme und den innerhalb dieser möglichen Innovationen siehe OrNato, Exigences (zit. Anm. 5), S. II ff.

I2 Aus der mittlerweile breiten Literatur nur einige Angaben: J. D. FARQUHAR, Creation and Imitation. The Work of a Fifteenth-Century Manuscript Illuminator (Nova University Studies in the Humanities, I), Fort Lauderdale (FL) I976, S. 4I-74; E. KöNIG, Französische Buchmalerei um I450. Der Jouvenel-Maler, der Maler des Genfer Boccaccio und die Anfänge Jean Fouquets, Berlin West 1982, S. I7-20; CHr. DE Hamel, A History of Illuminated Manuscripts, Oxford 1986, S. 173-185; J. J. G. Alexander, Medieval Illuminators and their Methods of Work, New Haven (CT) I992, S. I27 ff.; S. NAsH, Between France and Flanders. Manuscript Illumination in Amiens (The British Library Studies in Medieval Culture), London 1999, S. I4I-I45; Rouse/Rouse, Manuscripts (zit. Anm. 2); Chr. M. G. Andrews, The Boucicaut Workshop and the Commercial Production of Books of Hours in Early Fifteenth-Century Paris. Ph.D. dissertation, Northwestern University United StatesIllinois 2006, S. 65 ff.; URL: < http://search.proquest.com/docview/30529436I?accountid=II359> (I5. OI. 20I2); C. Reynolds, The Workshop of the Master of the Duke of Bedford: Definitions and Identities, in: Croenen (Hrsg.), Patrons (zit. Anm. 2), S. 437-472; M. B. Curd, Netherlandish Artists in England, I480-1690: Multicultural Collaboration and Competition. Ph.D. dissertation, Arizona State University 2007, S. I2 ff. und Kapitel 2; URL: < http://search.proquest.com/docview/304894695?accountid=II359> (05. OI. 20I2).

I3 Rouse/Rouse, Manuscripts (zit. Anm. 2), Bd. I, S. 237 ff.; A. Contr, La miniatura Bolognese. Scuole e botteghe. I270-I340, Bologna 198I, S. I4ff.; F. MANZARI, La miniatura ad Avignone al tempo dei papi (I3IO-I4IO), Modena 2007, S. 74 f., IO2 f. passim. 
fischen Werk wie der Wenzelsbibel am Ende des I4. Jahrhunderts bleiben die unterschiedlichen Maler ihrem eigenen Stil verpflichtet. ${ }^{14}$ Zwischen 15 und 25 Illuminatoren nimmt Gerhard Schmidt als verantwortlich an für die Ausstattung. ${ }^{15}$ Diese in vielen Bildern und Ranken der Wenzelsbibel geradezu liebevoll gepflegte jeweils besondere Ausdruckskraft der Gestaltung ist an einem Werk, das im Auftrag eines Hofes entstanden ist, doch erstaunlich, wenn wir an die weitgehend einheitlichen Stundenbücher denken, die ungefähr zur selben Zeit im Auftrag des Duc de Berry entstanden. ${ }^{16}$ Kooperationen, lagenweises Arbeiten voneinander unabhängiger Kräfte prägen ein Gesamtbild, das jedoch für solch große Unternehmungen der Regelfall ist. Für den Unternehmer und Buchhändler Pierre de Liffol lässt sich sogar zeigen, dass er die Ausstattung der zweibändigen Froissart-Chronik in mehreren Exemplaren gleichzeitig bearbeiten ließ und jeweils den zweiten Band an die Buchmaler weitergab, die den ersten bereits abgeschlossen hatten. ${ }^{17}$ Den Kunden war es offenbar wichtiger, das ansonsten vom Ausstattungsanspruch her einheitlich gestaltete Werk mit der von ihnen gewünschten Bilderzahl möglichst rasch in Händen zu halten, als dass ihnen an einer Einheitlichkeit der stilistischen Ausrichtung lag. An den städtischen Ateliers der Pariser Buchmalerei um 1300 haben Richard und Mary Rouse ebenso eindrucksvoll wie Jaroslav Folda an der Handschriftenproduktion in Akkon im I3. Jahrhundert ${ }^{18}$ durchaus vergleichbare Konzepte analysiert.

Die gemeinsame Leistung liegt in der Wenzelsbibel nicht in einer Angleichung der Ausdruckssprache der Buchmaler, sondern in der Bewahrung und Einhaltung eines übergreifenden Konzepts. Die Frage nach einer Einheitlichkeit der Formensprache ist gerade an einem solchen Werk verfehlt. Die Ausdruckssprache der Bilder ${ }^{19}$ gehört offenbar nicht nur zu den Variabeln, sondern darf vielleicht sogar mit einer gewissen Priorität zum Plaisir des Kenners verändert werden, wie man etwa bei den Werken der Gebrüder Limbourg vermuten könnte. Für die Harmonie des Eindrucks sind den Kunden anscheinend Material, Gliederungselemente, Layout und allenfalls einheitliche Rahmenbordüren ${ }^{20}$ und in Programm und Eindruck gleichbleibende Malerei wichtiger als ein übereinstimmender stilistischer Gestus.

I4 Wien, Österreichische Nationalbibliothek: Cod. 2759-2764; H. Heger u. a. (Hrsg.), Die Wenzelsbibel. Vollständige Faksimile-Ausgabe der Codices Vindobonensis 2759-2764 der Österreichischen Nationalbibliothek (Codices selecti, 70), Graz 1998.

I5 G. Sснмidt, Kunsthistorischer Kommentar, in: H. Heger u. a. (Hrsg.), Die Wenzelsbibel (zit. Anm. I4), Kommentarband 2, S. I25-250, 179.

I6 Ebenda, S. 240f.

17 G. Croenen / M. A. Rouse/R. H. Rouse, Pierre de Liffol and the Manuscripts of Froissart's Chronicles, in: Viator, 33, 2002, S. 26I-293, besonders $273 \mathrm{f}$.

I8 J. Folda, The Illustrations in Manuscripts of the „History of Outremer" by William of Tyre. Ph.D. dissertation, 3 Bde., Baltimore (MD) 1968, Bd. I, S. 65 ff.; derselbe, Crusader Manuscript Illumination at Saint-Jean d'Acre, I275-I29I, Princeton (NJ) 1976, S. II9 ff.

I9 AndRews, Boucicaut (zit. Anm. I2), S. 67 unterscheidet zwischen dem Boucicaut-Stil als Gruppenphänomen und dem je unterschiedlichen Ausdruck dieses Stils, wobei sie auch dabei nicht unbedingt an einen Individualstil, sondern eher an eine Subgruppe denkt.

20 S. van Bergen, A Matter of Collaboration? Manuscript-Production Practices as Revealed in Flemish Manuscripts with Miniatures by the Masters of Otto van Moerdrecht, in: A. M. W. As-VIJvers (Hrsg.), Ma- 
Zunehmend wird in der Forschung denn der Meisterstil an sich in Frage gestellt und überlegt, inwieweit die Qualität einheitlich erscheinender Stilsprachen nicht dem Werk eines Einzelnen, sondern einer eng aufeinander abgestimmten Kooperation mehrerer Kräfte zu verdanken sein könnte. Catherine Reynolds ${ }^{21}$ betont am Beispiel des „Bedford-Stils“, wie sie das Phänomen in Abgrenzung zum „Bedford-Meister“ nennen möchte, dass allenfalls die wechselnde Zusammenarbeit erfasst werden könne, nicht aber der Individualstil. Ebenso argumentiert Christine M. G. Andrews für den „Boucicaut-Stil“ und nennt das Konzept eines auf ein Individuum ausgerichteten Personalstils unrealistisch, habe doch die Kooperation kleiner Einheiten die Produktion getragen. ${ }^{22}$ Für den „Boucicaut-Stil“ folgt sie den Untersuchungen von Richard und Mary Rouse, die den jeweiligen „Haushalt“, die Familienmitglieder und allenfalls einen Lehrling oder Gesellen als zentrale Werkeinheit nachweisen konnten. ${ }^{23}$ Als geradezu paradigmatisch kann Anne van Buren die Arbeiten von Willem Vrelant analysieren. ${ }^{24} \mathrm{Zu}$ ähnlichen Schlüssen kommt auch Anne Korteweg am Beispiel des Meisters der Katharina van Cleve. ${ }^{25}$ Verwandt stellt sich ebenso die Organisation der Werkstatt Ulrich Schreiers für Michaela Schuller-Juckes dar. ${ }^{26}$ Massenproduktionen an Missalien, die etwa in Brügge sogar für einen weitgehend anonymen Markt entstanden sind und über die Maurice und Katharina Smeyers ${ }^{27}$ sowie Saskia van Bergen ${ }^{28}$ gearbeitet haben, oder

nuscript Studies in the Low Countries. Proceedings of the „Groninger Codicologendagen“ in Friesland, 2002 (Boekhistorische Reeks, 3), Groningen 2008, S. 105-126, besonders I08; van Bergen sieht auch eine Regelhaftigkeit im Sinne der Einheitlichkeit an der unterschiedlichen Verteilung von Rahmenbordüren zu Text- und Miniaturseiten.

2I Reynolds, Bedford (zit. Anm. I2), S. 449.

22 Andrews, Boucicaut (zit. Anm. I2), S. 44.

23 Rouse/Rouse, Manuscripts (zit. Anm. 2), S. 15, 33 ff. und 237.

24 A. H. van Buren, Willem Vrelant: Questions and Issues, in: Revue Belge d'Archéologie et d'Histoire de l'Art, 48, I999, S. 3-30; dieselbe, Collaboration in Manuscripts: France and the Low Countries, in: M. FarIES (Hrsg.), Making and Marketing. Studies of the Painting Process in Fifteenth and Sixteenth-Century Netherlandish Workshops, Turnhout 2006, S. 83-98, Pl. I und 2, hier besonders $90 \mathrm{ff}$.

25 A.S. Konteweg, Der Meister der Katharina von Kleve: Einzelgenie oder Arbeitsgemeinschaft?, in: R. DüCKers / E. KöNig u. a. (Hrsg.), Das Stundenbuch der Katharina von Kleve. MS M.917 und MS M.945, The Pierpont Morgan Library, New York. Kommentarband zum Faksimile, Gütersloh 2009, S. 25I-286, besonders 275 ff.; weitere Beispiele solcher Kooperationen ebenda, S. 26If.

26 M. Schuller-Juckes, Ulrich Schreier und seine Werkstatt. Buchmalerei und Einbandkunst in Salzburg, Wien und Bratislava im späten Mittelalter. Phil. Diss., Universität Wien 2009, besonders 9o ff.; URL: < http://othes. univie.ac.at/3288/I/2009-0I-07_9706640.pdf> (I8. oI. 20I2).

27 M. Smeyers, Pre-Eyckian Manuscripts Mass Production and Workshop Practices I, in: R. van Schoute / H. Verougstraete-MarcQ (Hrsg.), Le dessin sous-jacent dans la peinture. Colloque IX, I2-I4 septembre I99I; dessin sous-jacent et pratiques d'atelier (Document de travail/Université Catholique de Louvain, Institut Supérieur d'Archéologie et d'Histoire de l'Art, 27), Louvain-la-Neuve 1993, S. 59-73, Pl. 22-27; K. SMEYers / S. Vertongen, Manuscrits pré-Eyckiens. Production en masse et pratiques d'atelier II, in: Ebenda, S. 75-89, Pl. 28-32.

28 S. van Bergen, The Production of Flemish Books of Hours for the English Market: Standardization and Workshop Practices, in: B. Dekeyzer/J. van Der Stock (Hrsg.), Manuscripts in Transition. Recycling Manuscripts, Texts and Images, Paris/Dudley (MA) 2005, S. 27I-284; van Bergen, Collaboration (zit. Anm. 20). 
noch deutlicher die von Christine Beier ${ }^{29}$ analysierte Augsburger Massenproduktion im ausgehenden I5. Jahrhundert bemühen sich offensichtlich trotz einer Zusammenarbeit um die Gestaltung eines einheitlichen Produktes.

Zwei Parameter für den neuen Blick auf Kooperationsleistungen haben sich ebenfalls entschieden gewandelt: Die Annahme großer Werkstätten und streng geregelter Abläufe. Die Vorstellung großer Werkstätten ist abgelöst worden von den in den Quellen überlieferten Kleinbetrieben, die sich auf den Haushalt und allenfalls die Familiaren konzentrieren. ${ }^{30}$ Zunehmend finden sich Kennzeichen für Ad-Hoc-Kooperationen, die zur Bewältigung eines größeren Auftragsvolumens zusammengestellt werden. ${ }^{31}$ James Douglas Farquhar spricht sich gegen die Vorstellung hierarchisch geordneter Produktionsabläufe aus, die etwa in Stern- oder Kreisform von einem Zentrum aus gestaltet würden, sondern spricht von einem unregelmäßigen Netzwerk. ${ }^{32}$ Damit umschreibt er die Erfahrung rasch wechselnder Kooperationen, die keine Spezialisierung einzelner Gruppen erfordert, sondern diese übernehmen je nach Arbeitsanfall und Notwendigkeit die zu erledigenden Aufgaben. Der Begriff Produktionszirkel scheint sich ebenso für diese nach Bedarf organisierten Kooperationsformen zu eignen, ist doch damit gerade diese Form der Zusammenarbeit von jeweils sich verändernden, ad hoc zusammengestellten und allein zur Bewältigung einer Aufgabe sich koordinierenden Kleingruppen gemeint, die aber von einem Unternehmer initiiert wird. Insofern sind die Produkte, die mit dem Namen Diebold Laubers verbunden werden und in der Phase des breiten Angebots entstanden sind, hierfür charakteristisch. ${ }^{33} \mathrm{Im}$ Gefolge dieser Erfahrung von Kooperationen hat sich auch die Erwartung einer „eigenhändigen“ Produktion verändert und damit einhergehend sogar die Vorstellung, dass sich ein „Stil“ als Produkt einer physisch dem Individuum eingeschriebenen einmaligen Ausdrucksweise erweisen muss.

29 Chr. Beier, Missalien massenhaft. Die Bämler-Werkstatt und die Augsburger Buchmalerei im I5. Jahrhundert, in: Codices manuscripti, 48/49, 2004, S. 55-72.

30 Alexander, Illuminators (zit. Anm. I2), S. I27-I30; Rouse/Rouse, Manuscripts (zit. Anm. 2), Bd. I, S. 237 ff.; Andrews, Boucicaut (zit. Anm. I2), S. 46 f. und 73f.; L. Campbell, The Early Netherlandish Painters and their Workshops, in: D. Hollanders-Favart /R. van Schoute (Hrsg.), Le dessin sous-jacent dans la peinture. Le problème Maître de Flémalle-van der Weyden. Colloque III 6-8 septembre I979, Louvain-laNeuve i98I, S. 43-6I, 47; van Buren, Vrelant (zit. Anm. 24), S. 2I-23; van Bergen, Collaboration (zit. Anm. 20), S. ios f.; Reynolds, Bedford (zit. Anm. I2), S. 449; Korteweg, Katharina (zit. Anm. 25), S. 254; zur Ad-hoc-Zusammenarbeit M. Driver/M. OrR, Decorating and Illustrating the Page, in: Gillespie/WaKeLIN (Hrsg.), Production (zit. Anm. 4), S. I04-I28, besonders II7-II9.

3 I Korteweg, Katharina (zit. Anm. 25), S. 254; Farquhar, Creation (zit. Anm. I2), S. 4I f.; van Buren, Vrelant (zit. Anm. 24), S. 23 ff.; Andrews, Boucicaut (zit. Anm. I2), S. 46 ff.; Saurma-Jeltsch, Buchherstellung (zit. Anm. 4), S. $226 \mathrm{f}$.

32 J. D. FARQuhar, Making Connections in the Irregular Web of Manuscript Production of the Southern Netherlands, in: Journal of the Walters Art Gallery, 54, I996, S. I35-I46, I35.

33 Saurma-Jeltsch, Buchherstellung (zit. Anm. 4), Bd. I, S. ini-II3; van Bergen, Collaboration (zit. Anm. 20), S. 106 nimmt Buchhändler als Organisatoren an; van Buren, Vrelant (zit. Anm. 24), S. 23 sieht in Vrelant selbst den Entrepreneur. 


\section{EINHEITLICHKEIT IM ZUGE VON RATIONALISIERUNG}

\section{UND ALS ANGEBOT AN DEN KUNDEN}

Im Folgenden wird am Beispiel der Lauber-Handschriften nach den Gründen für eine einheitliche Ausstattung gefragt und damit unseren Eingangsüberlegungen folgend diese nicht als die Norm, sondern im Gegenteil als das Unerwartete und mithin Geplante verstanden. Gerade an den Lauber-Handschriften erweist sich die Entwicklung eines durch gewisse Konstanten sich auszeichnenden „Markenartikels“34 als die Errungenschaft, die sowohl den Benützern - vor allem zur besseren Orientierung - als auch den Herstellern im Sinne einer zunehmend standardisierten Herstellungsweise entgegenkommt. Ähnlich „genormt“ in ebendiesem Sinne erscheinen auch die für den englischen Markt hergestellten Stundenbücher aus dem Umkreis des Otto van Moerdrecht ${ }^{35}$, bei denen ebenso Abnehmererwartung und die Standardisierung einer rasch zu verfertigenden Produktion Hand in Hand gehen. Ein solch normiertes Produkt definiert sich zunächst - wie wir sahen - durch Inhalt, Ordnung der Texte, Gliederungselemente, Layout und Qualität der Materialien. Die Vereinheitlichung von Gestaltungs- und Ausstattungsmitteln der Bilder und Dekoration scheint im Laufe des I5. Jahrhunderts zuzunehmen. Nicht unwesentlich dürfte dies wiederum mit arbeitstechnischen Abläufen zusammenhängen, lässt sich doch eine Serienproduktion wie etwa diejenige von Willem Vrelant nur effizient zwischen den unterschiedlichen Gewerken gestalten, wenn ein Konsens über das Produkt besteht und nur die Ausnahmen kommuniziert werden müssen. ${ }^{36}$

Freilich ist der Spielraum für unterschiedliche Ausdrucks- und Gestaltungsmittel auch bei weitgehend genormten Werken immer noch sehr breit. Der Laubersche „Markenartikel“37 wird an der relativ schmalen Produktion der 3oer-Jahre entwickelt, die sich weitgehend auf Historienbibeln der Redaktion IIa - wie die Zürcher Handschrift (Abb. I) - konzentriert. ${ }^{38} \mathrm{Zu}$ den Kennzeichen der Codices gehören ihr Überformat, das relativ qualitätvolle Papier sowie der Komfort von Register, Buch- und Kapitelbezeichnungen und Bildüberschriften. Die Verwendung von aufgefalteten Einzelblättern, die auf Falz montiert werden, dient einerseits dem prestigeträchtigen Überformat. Andererseits wird damit auch eine rationalisierte Arbeitsweise möglich, vermindert sich doch dadurch der Ausschuss beachtlich. ${ }^{39}$ Eine geringe Organisation benötigt auch die Ausstattung, für die in den 3oer- und 4oer-Jahren relativ wenige Kräfte hinzugezogen wurden. Die typische Lauber-Handschrift ist von Malern der Gruppe A ausgestaltet, deren Formensprache, Farbgebung und ikonographische Modelle stark durchrationa-

34 Saurma-Jeltsch, Buchherstellung (zit. Anm. 4), Bd. I, S. 75-92; G. ViehHauser-Mery, Die ,Parzival'-Überlieferung am Ausgang des Manuskriptzeitalters. Handschriften der Lauberwerkstatt und der Straßburger Druck (Quellen und Forschungen zur Literatur- und Kulturgeschichte, 55 = 289), Berlin u. a. 2009, S. 28-30.

35 Van Bergen, Flemish (zit. Anm. 28), S. 273; dies., Collaboration (zit. Anm. 20), S. io7f.

36 Ebenda, S. IO7ff.; van Buren, Vrelant (zit. Anm. 24), S. $23 \mathrm{ff}$.

37 Saurma-Jeltsch, Buchherstellung (zit. Anm. 4), Bd. I, S. 75-92.

38 Es handelt sich ausschließlich um Handschriften der Redaktion IIa, dazu ebenda, Bd. I, S. 98 ff.; VIEHHAUSEr-Mery, Parzival (zit. Anm. 34), S. 30 f. und Anm. I3I.

39 Makulatur aus der eigenen Produktion wird in den Falzen weiter verwendet; dazu SAURMA-JeLTSCH, Buchherstellung (zit. Anm. 4), S. 90. 


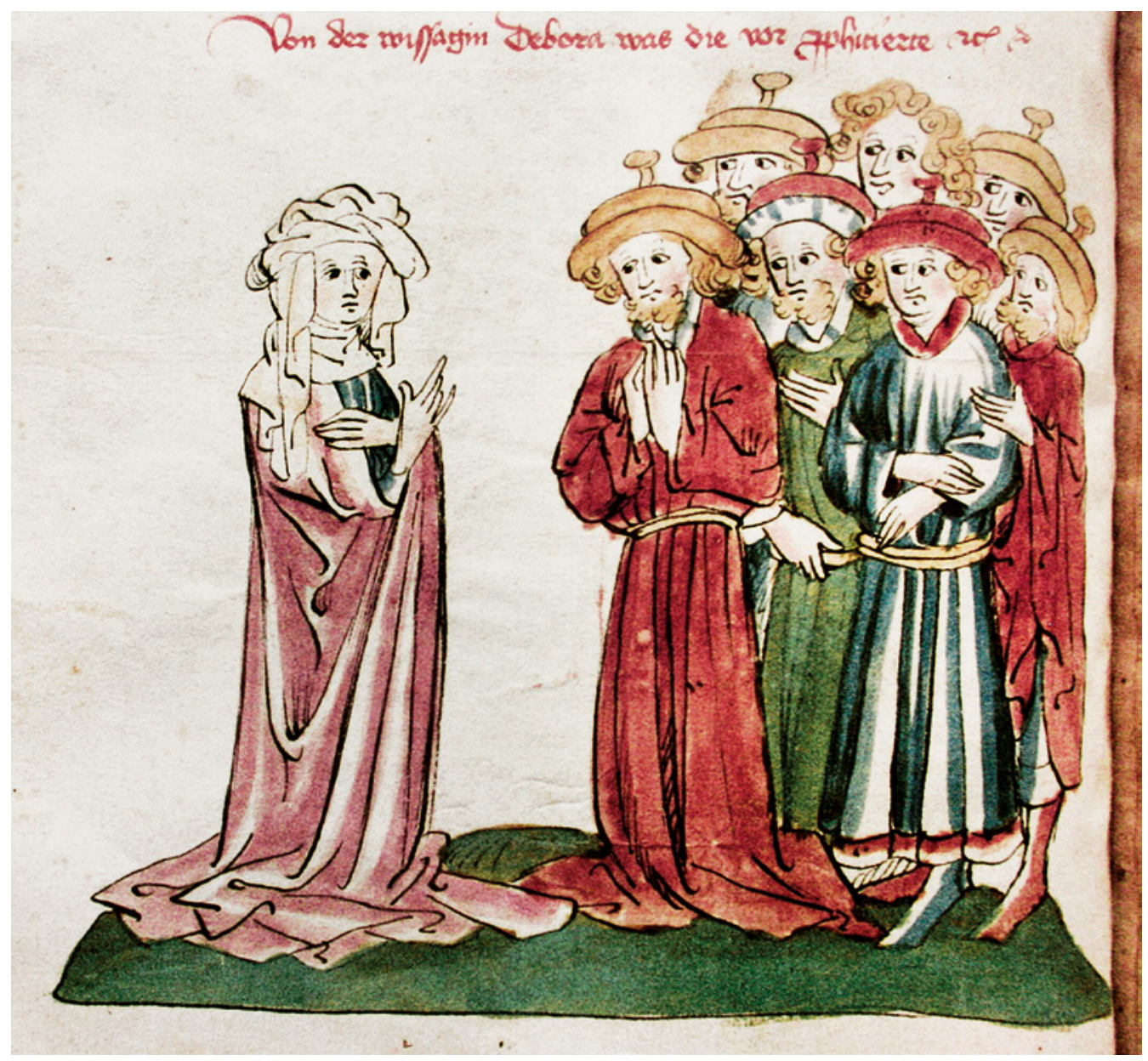

Abb. I: Zürich, Zentralbibliothek, C 5, fol. I64v: Weissagung der Debora; Hagenau, Werkstatt des Diebold Lauber, I43I-I437

lisiert sind. Die geschlossenen Umrisse mit den wenigen parallelen Linien, mit denen Röhrenfalten an den Gewändern der Israeliten vor der Prophetin Debora (Abb. I) gekennzeichnet werden, ebenso wie die schmale Kaskade von zwei sich folgenden und in einer dritten ruhenden Schüsselfalten an Deboras Mantel sind Formeln, die fast automatisiert verwendet werden. Die Gruppe um den Grauen Ritter, dem Parzival in der Wiener Handschrift (Abb. 2$)^{40}$ begegnet, kennt sie gleichermaßen. In etwas modernisierter Form taucht dieselbe Faltenkaskade auch in der Heidelberger Handschrift an Blanscheflurs Gewand auf, die sich gemeinsam mit Flore vor dem Amiral und seinem Gefolge zu rechtfertigen hat (Abb. 3). ${ }^{41}$ Die Gewohnheit, Lichter mit blanken Flächen zu schaffen und bei deckenden Farben, etwa dem intensiv

40 Viehhauser-Mery, Parzival (zit. Anm. 34), S. 53-67.

4I Heidelberg, Universitätsbibliothek: Cod. Pal. germ. 23; K. Zimmermann (Hrsg.), Die Codices Palatini germanici in der Universitätsbibliothek Heidelberg (Cod. Pal. germ. I-I8I), Bd. 6, Wiesbaden 2003, S. 6I-65. 
Abb. 2: Wien,

Österreichische

Nationalbibliothek,

Cod. 2914, fol. 289v:

Parzival trifft den

Grauen Ritter;

Hagenau, Werkstatt des Diebold Lauber, I440-I443

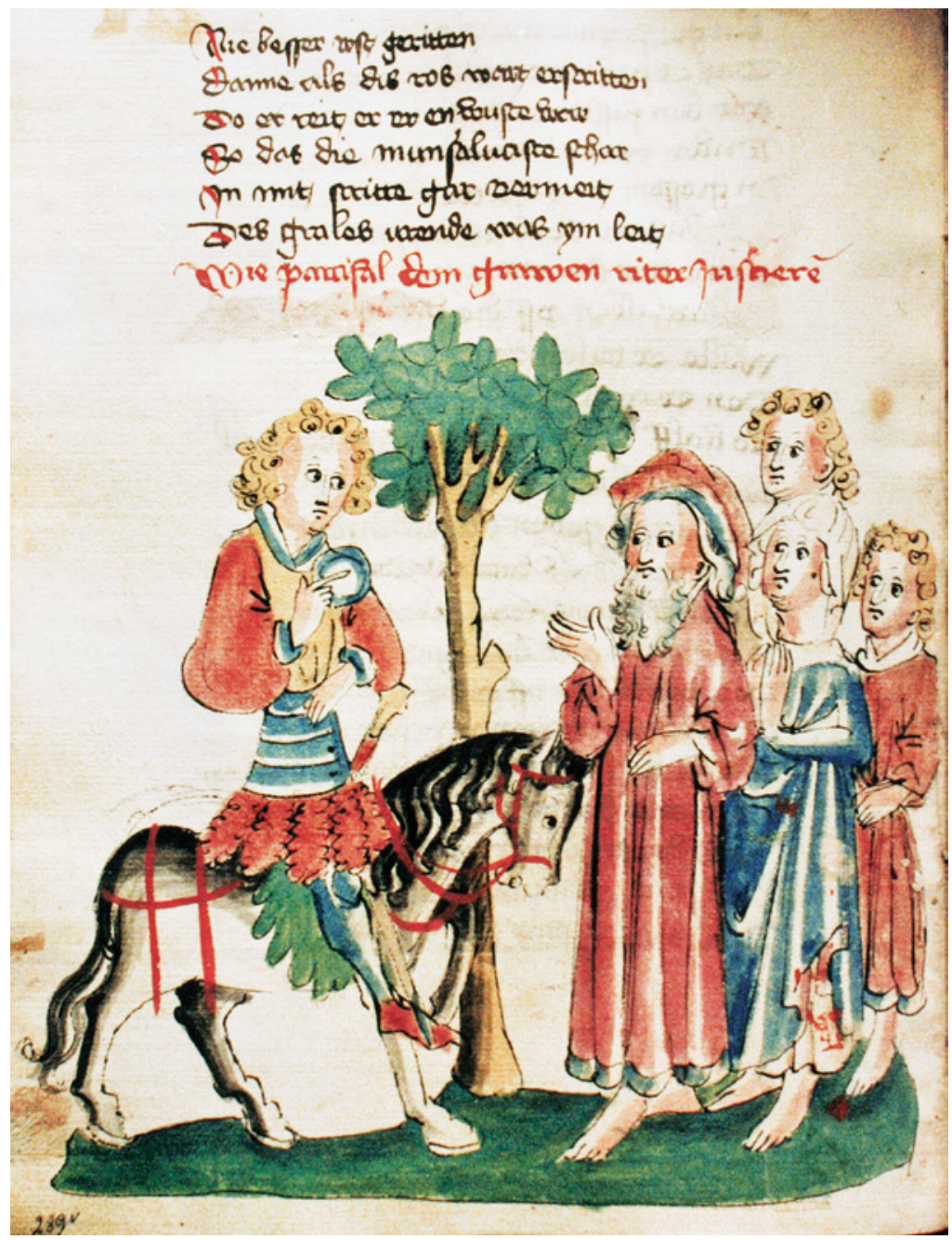

bräunlichen Rot, die Falten mit einer sicheren Feder nachträglich einzuzeichnen, verrät dieselbe Gestaltungsweise. Die Farbgebung wirkt weitgehend stereotypisiert: Rot, Blau und Grün sind die wichtigsten Farbklänge und wechseln sich ab. Gelb oder Braun, selten Grau werden für Haare oder Kopfbedeckungen eingesetzt. Am auffälligsten sind die Gesichter, die bis in die Details der Augengestaltung, der Haartracht immer dieselben Züge zusammenstellen. In die ovalen Augen ist im Augeninnern bzw. -äußeren die kräftige Pupille so platziert, dass alle Figuren leicht zu schielen scheinen. Ihre Gesichter sind nachträglich noch einmal konturiert und erhalten mit der einfachen Linie, die ins Kinn übergeht, und den kurzen Hälsen sowie den zwei Strichen für den Nasenrücken, den kurzen Brauenbögen und den zwei Strichen für den Mund ein gänzlich stereotypes Aussehen. Ebenso taucht die Lockenfrisur Flores unter den Israeliten und den Begleitern des Grauen Ritters auf.

In den Illustrationen der A-Gruppe wird eine Formensprache verwendet, die durchaus anpassungsfähig ist, aber in ihrer Selbstverständlichkeit bis in den einzelnen Strich so durch- 


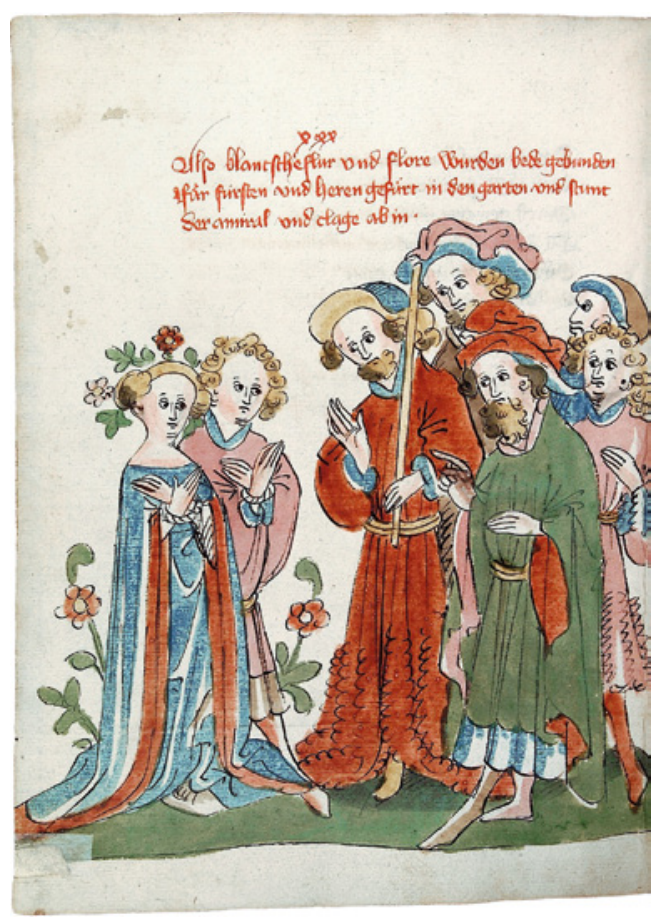

Abb. 3: Heidelberg, Universitätsbibliothek, Cod. Pal. germ. 362, fol. I73v: Flore und Blanscheflur gefangen vor dem Amiral; Hagenau, Werkstatt des Diebold Lauber, I $442-$ I 444 rationalisiert ist, dass unterschiedliche, aber gleich geschulte Illustratoren miteinander arbeiten können, ohne weitere Absprachen miteinander treffen zu müssen. Dass mindestens für die Farbgebung trotz der nahezu gleichförmigen Abfolge Angaben an Koloristen vorgegeben waren, lässt sich an einzelnen Manuskripten noch beobachten. Die Zürcher Historienbibel (Abb. I) erlaubt zum Beispiel, an dem vordersten Israeliten auf Höhe seines rechten Knies die Angabe $r$ für „rubrum“ zu erkennen. Ebenso ist auf der linken Schulter des hinter ihm stehenden, in eine grüne mit Pelzkragen versehene Houppelande gekleideten Israeliten das an ein Blatt erinnernde auf dem Kopf stehende $V$ für „vergaut“, das aus unterschiedlichen Substanzen gemischte Grün, zu sehen. Die rationalisierte Formensprache, aber auch die ebenso vereinfachte Ikonographie ${ }^{42}$ erfordern keine umfassende Organisation, sind doch die grundlegenden Bausteine für die Illustrationen bekannt. Es dürfte sich denn bei der Gruppe A um einen Kleinbetrieb handeln, wie er von Richard und Mary Rouse für Paris oder auch von Anne van Buren für niederländische Produktionen beschrieben wurde. ${ }^{43}$ Entweder ein Maler mit einem Gehilfen oder ein Familienbetrieb sind, ohne kopieren zu müssen oder auf weitergehende Anweisungen angewiesen zu sein, in der Lage, solch unterschiedliche Handschriftentypen wie Historienbibeln, Epen oder auch Wissensliteratur mit ihrem Repertoire zu bestreiten. Dass sich nicht ein einzelner Maler - wie noch die ältere Literatur vermutete - mit den über 30 erhaltenen Handschriften befasste, legt die erst allmähliche Normierung des Stils in der Frühzeit nahe. ${ }^{44}$

Die Einheitlichkeit der Formensprache, die hier vor allem mit einer Beschleunigung der Arbeit zu erklären ist, scheint denn von den Zeitgenossen nicht unbedingt als zu bewahrender Wert verstanden zu werden, wie die verblüffenden Veränderungen an der Heidelberger Bibel erkennen lassen. Die Gruppe A hat für dieses Großunternehmen einer deutschsprachigen Bibel in fünf Bänden den Maßstab für die Ausstattung gelegt. ${ }^{45}$ Die Bücher werden

42 Dazu etwa die Varianten zu den Geburtsdarstellungen Saurma-Jeltsch, Buchherstellung (zit. Anm. 4), Bd. I, S. 20I-204, Bd. 2, Abb. 285-292.

43

44 Dazu Saurma-Jeltsch, Buchherstellung (zit. Anm. 4), Bd. I, S. IOI-IO3.

45 Heidelberg, Universitätsbibliothek: Cod. Pal. germ. I9-23; Zimmermann (Hrsg.), Palatini (zit. Anm. 4I), S. $48-65$. 


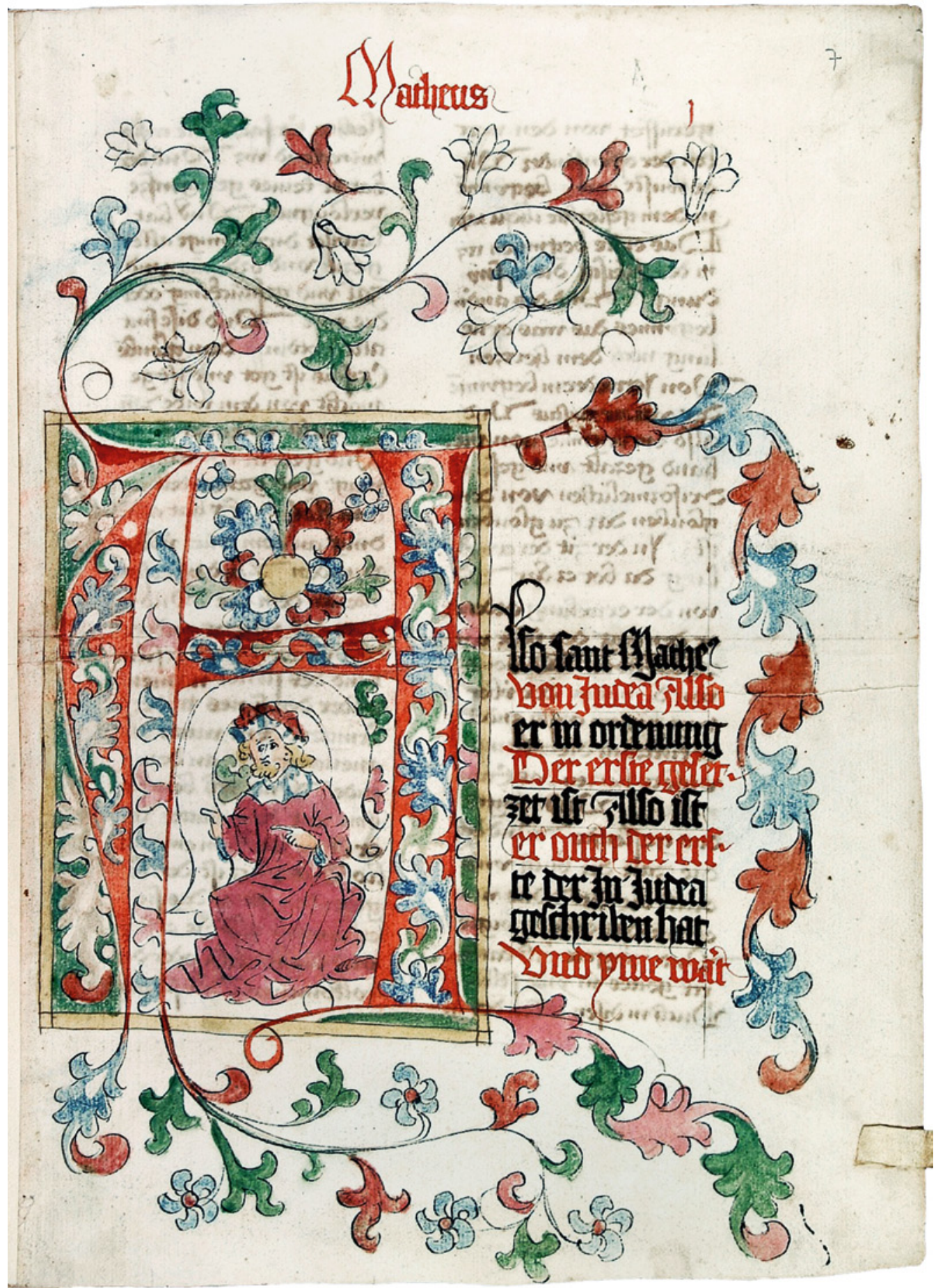

Abb. 4: Heidelberg, Universitätsbibliothek, Cod. Pal. germ. 23, fol. 7r: Initiale A; Hagenau, Werkstatt des Diebold Lauber, I44I-I449 


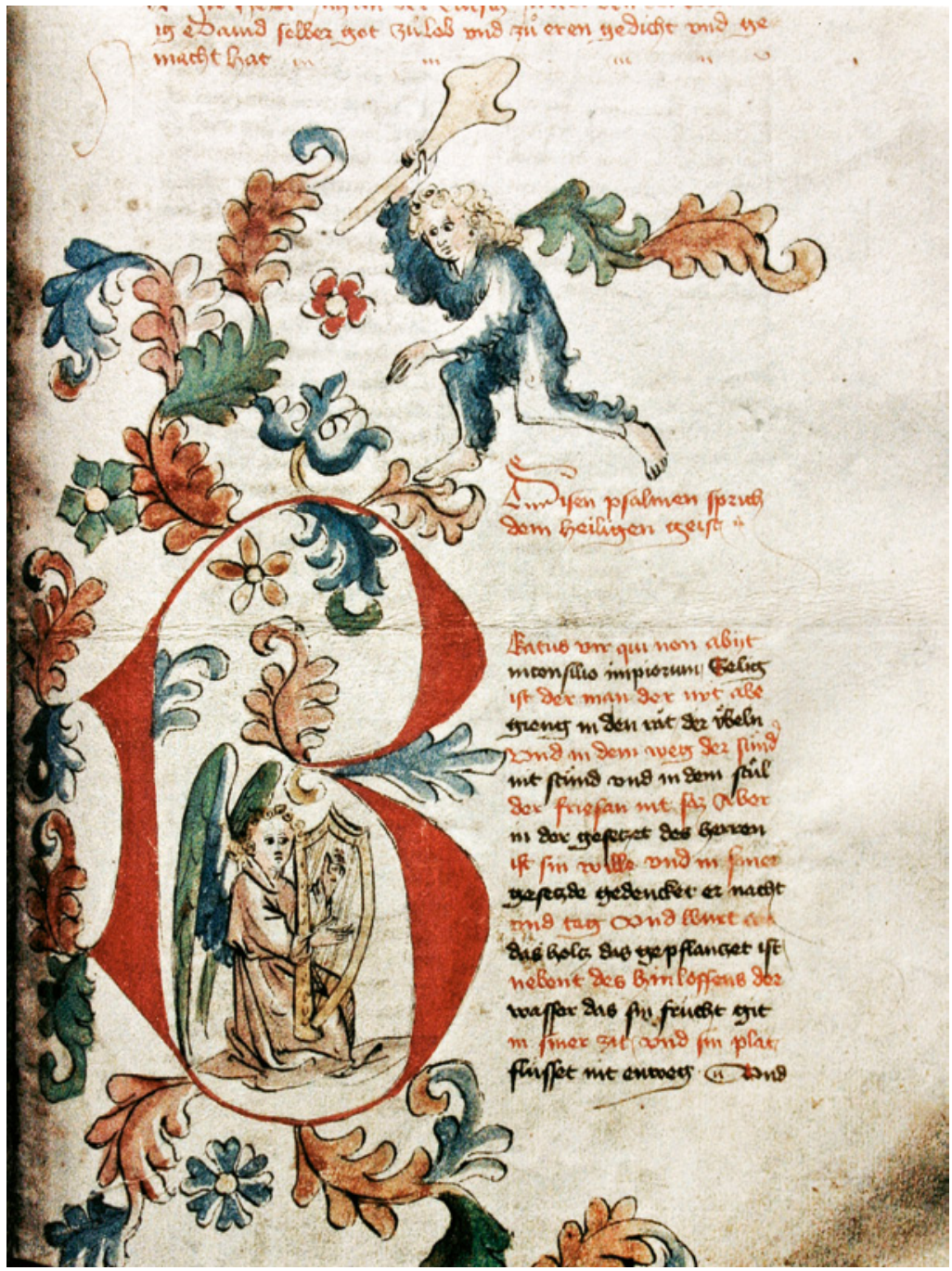

\author{
Abb. 5: München, \\ Bayerisches National- \\ museum, Bibl. 2502, \\ Bl. 423: Initiale B; \\ Hagenau, Werkstatt des \\ Diebold Lauber, I436
}

jeweils mit einem Diptychon aus Autorenbild und Initialseite eröffnet. Während der Arbeit an dieser Großaufgabe, die sich wohl längere Zeit hinzog, sind die Maler der A-Gruppe ausgeschieden und ließen eine teilweise unvollendete Ausstattung zurück. Nahezu alle in den späten 4oer-Jahren mit Ausstattungen der Lauber-Handschriften befassten Maler wurden hinzugezogen, um die Arbeit einigermaßen abzuschließen. ${ }^{46}$ Das Beispiel der A-Initiale in Cod. Pal. germ. 23 (Abb. 4$)^{47}$ mag genügen, um zu belegen, wie unbekümmert die neuen Maler mit der Hinterlassenschaft der alten umgesprungen sind. Die Gruppe der AMaler hatte im Laufe ihrer fast zwanzigjährigen Tätigkeit einen ganz besonderen Typus von Initialseite entwickelt. Charakteristisch hierfür ist die Beatus-Vir-Seite (Abb. 5) zu Beginn

46 Saurma-Jeltsch, Buchherstellung (zit. Anm. 4), Bd. I, S. II2-II7 passim und Bd. 2, S. 49-53.

47 Heidelberg, Universitätsbibliothek: Cod. Pal. germ. 23; Zimmermann (Hrsg.), Palatini (zit. Anm. 4I), S. 6I-65. 
der Psalmen in der Münchner Historienbibel. Im Buchstabeninnern sitzt der Harfe spielende Engel, und ein locker gestreutes Blattwerk ragt in den oberen Teil des Buchstabens und wächst in unregelmäßigen Abständen aus dem Buchstaben selbst heraus. Der eine Keule schwingende Wildmann bewegt sich in diesem Rankenwerk am oberen Blattrand. Das Ganze wirkt wie ein zufällig über den Seitenrand gestreutes Muster und ist geprägt von dem breitlappigen, alternierend von innen und außen gesehenen Blattwerk. In der Heidelberger Bibel erkennt man in der sitzenden Männergestalt mit dem breiten Schriftband ohne Weiteres den A-Stil. Der Buchstabe ist nachträglich eingepasst worden in einen einfachen Rahmen mit grün laviertem Hintergrund und relativ ungelenk gezeichneten Ranken. Ebenso sind der Buchstabenstamm und der Querbalken mit weiterem Rankenwerk versehen worden. Im oberen Binnenfeld sitzt ein Blumenmotiv und vor allem wachsen aus den Buchstabenenden unterschiedliche Rankentypen, die im Repertoire der A-Gruppe nie vorgekommen waren und in ihrer Zeichenweise auch gar nicht deren Gewohnheiten entsprechen. Alle Bände dieser Bibelausgabe zeigen auf unterschiedliche Weise das Bemühen, den von der AGruppe entwickelten Typus der Initialseite zu überformen und in ein das gesamte Blatt umfassendes Dekorationssystem umzugestalten. Nur minimale Veränderungen erfahren meist die Bildseiten, wogegen der Textbeginn in der alten Form offenbar nicht mehr den Erwartungen genügte und nahezu durchgehend, manchmal von mehreren Händen überarbeitet wurde. Hier war nicht der Stil der Maler das Entscheidende, sondern dieser wurde eingepasst in ein neues Konzept, dessen Einheitlichkeit im Layout als wichtiger als die Brüche in Form und zum Teil auch Farbgebung empfunden wurden.

\section{Hans Schilling als Verantwortlicher für Bild und Schrift?}

Hatten wir bisher die Einheitlichkeit der Ausstattung gleichsam als Nebenprodukt einer rationalisierten Arbeitsweise kennengelernt, so stellt sich nun die Frage, wie die Zeitgenossen gestalterische Einheit verstehen, wenn sogar ein Einzelner sich als hierfür verantwortlich bezeichnet. In der Colmarer Weltchronik ${ }^{48}$ wird im Schreiberkolophon nicht allein auf die Schrift, sondern auch auf die Bilder hingewiesen. Niemand anderer als der Hagenauer Schreiber, vielleicht auch als Notar amtierende spätere Unterschreiber des Luzerner Rats und anschließend Schreiber am Hofe von Matthias Corvinus Hans Schilling ${ }^{49}$ vermerkt hier, er habe das Buch geschrieben und $u$ ßgemolt. ${ }^{50}$ Hans Schilling von Hagenau hat mit dieser Prachthandschrift einen völlig neuen Standard im Umkreis Diebold Laubers gesetzt, der weg von der rationalisierten, genormten Handschrift hin zur kostbaren, auf einen Auftraggeber ausgerichteten Indivi-

48 Colmar, Bibliothèque de la Ville: Ms 305; Saurma-Jeltsch, Buchherstellung (zit. Anm. 4), Bd. 2, Katalog I4, S. I7-24.

49 Saurma-Jeltsch, Buchherstellung (zit. Anm. 4), Bd. I, S. I53 f.; N.H. Otт, Artikel „Schilling, Hans“, in: Neue Deutsche Biographie, 22, 2005, S. 77I [Onlinefassung]; URL: <http://www.deutsche-biographie.de/ pndI39599312.html> (23. OI. 20I2); K. Wanner, Artikel „Schilling, Johannes“, in: Historisches Lexikon der Schweiz [Onlinefassung]; URL: <http://www.hls-dhs-dss.ch/textes/d/Di4762.php > (30. OI. 20I2).

50 Colmar, Bibliothèque de la Ville: Ms 305, fol. 456v: Dis buch hat hans schilling geschrieben und ußgemolt In dem Jor do man zalte von der geburt Cristi viertzehen hundert funffzig und nun Jore bittent got vur in. 


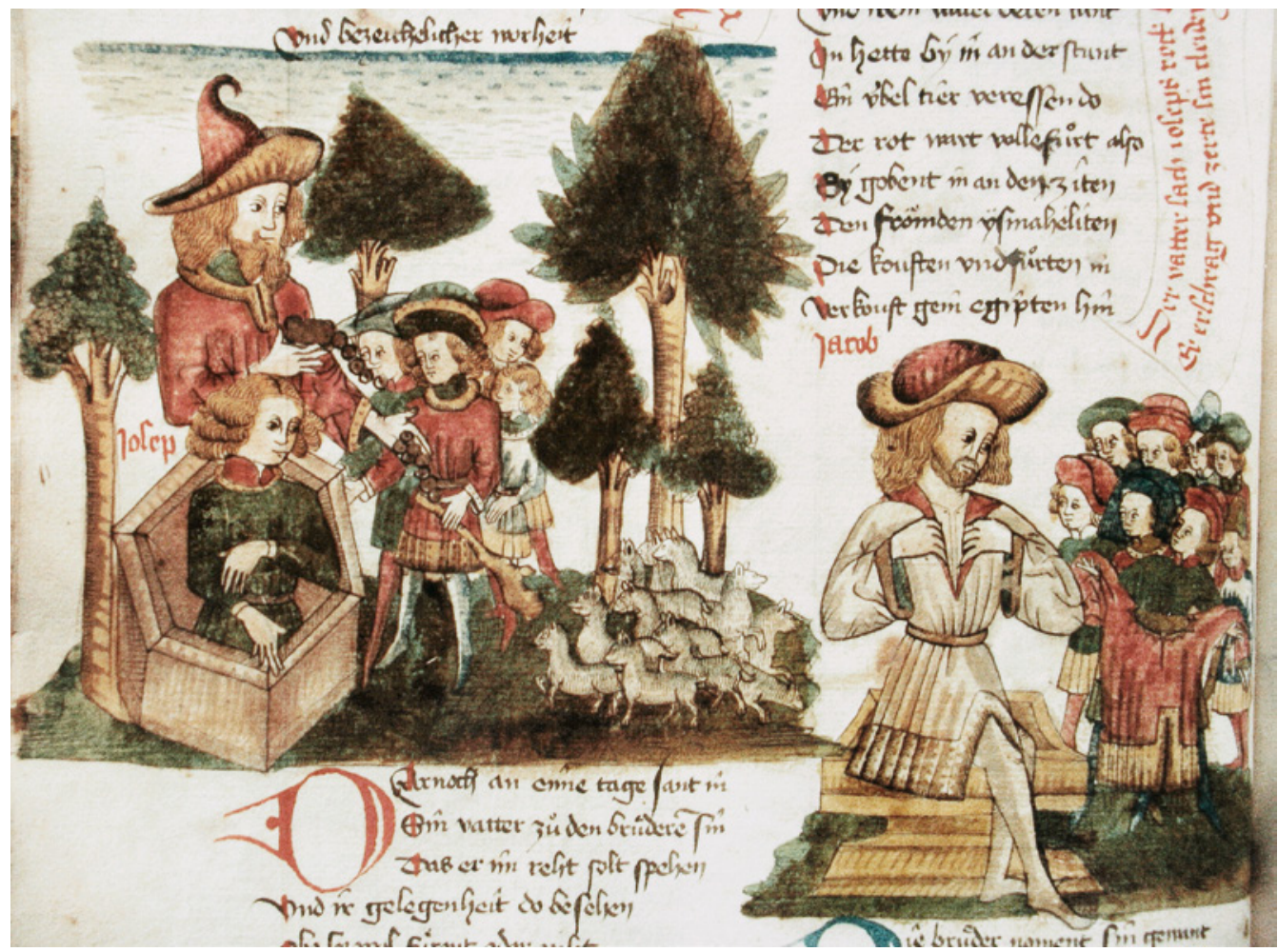

Abb. 6: Colmar, Bibliothèque de la Ville, Ms 305, fol. 68va und b: Verkauf Josephs, Jacobs Trauer; Hagenau, Werkstatt des Diebold Lauber und Hans Schilling, I459

dualfertigung abzielt. ${ }^{51}$ Seine Handschriften wollen - und so ist wohl auch das Kolophon zu deuten - „Meisterstücke“ sein, für die er verantwortlich zeichnet.

\section{DIE GESAMTHANDSCHRIFT IN IHRER VEREINHEITLICHTEN STRUKTUR}

Der Eintrag, die 1459 für den Ritter Adam von Ansoltzheim verfertigte Handschrift eigenhändig geschrieben und ausgemalt zu haben, ist umso erstaunlicher, als weder in der Schrift ${ }^{52}$ noch in den Bildern durchgehend dieselben Hände am Werk gewesen sein können. Allerdings ist überall das Bestreben erkennbar, das Werk als einheitlichen Körper zu gestalten. Bereits der Text selbst stellt eine komplexe Kompilation und - wie Danielle Jaurant betont - „Interpolation“53 unterschiedlicher Quellen dar, in der Übergänge verschliffen und

5I Saurma-Jeltsch, Buchherstellung (zit. Anm. 4), Bd. I, S. I43-I54; dagegen Christoph Mackert, der die Unterschiede als Varianten einer Hand deutet; Chr. Mackert, Ein typisches Produkt aus der Spätzeit der Lauber-Werkstatt? In: Chr. Fasbender (Hrsg.): Aus der Werkstatt Diebold Laubers, Berlin / Boston 20I2, S. 299326, 3II-3I3.

52 Zur Vereinheitlichung der Schrift ebenda, Bd. I, S. I35, Anm. 493; Mackert Produkt (zit. Anm. 5I), S. 3I2 f.

53 D. Jaurant, Rudolfs „Weltchronik“ als offene Form. Überlieferungsstruktur und Wirkungsgeschichte, Tübingen u.a. 1995 , S. 339-349. 


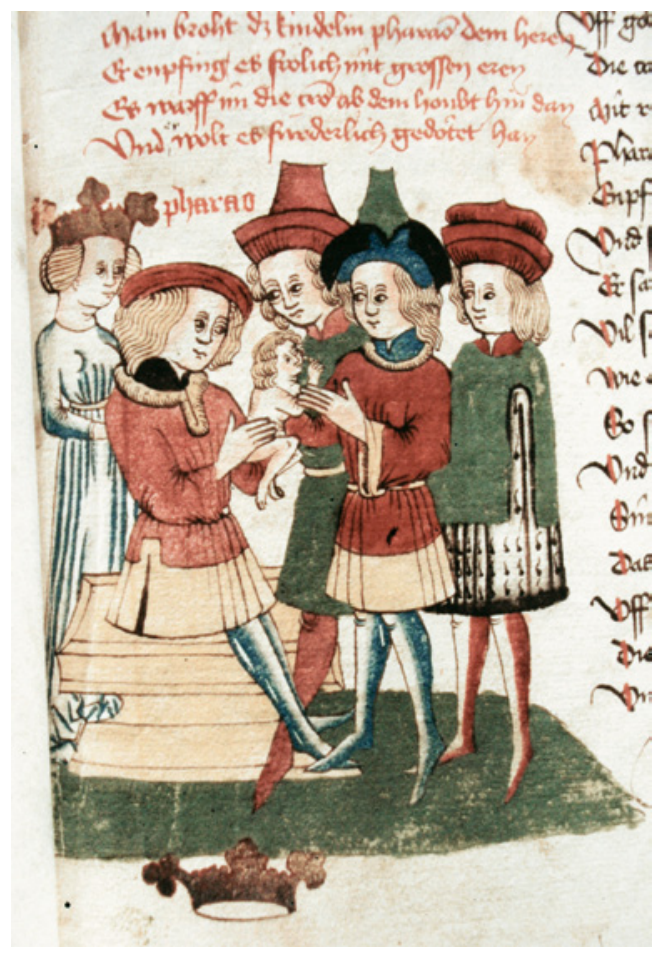

Abb. 7: Colmar, Bibliothèque de la Ville, Ms 305, fol. 94ra: Moses hat Pharaos Krone zerbrochen; Hagenau, Werkstatt des Diebold Lauber und Hans Schilling, I459
Prosatexte direkt in gereimte Partien eingeschoben sind. Mit drei üppigen Initialseiten (fol. Ir, 4r, I3r) und einer ganzseitigen Darstellung des Engelssturzes (fol. Ior) wird der Anspruch der Prunkhandschrift deutlich. Konsequent durchgehalten ist über die gesamte Handschrift mit 463 Blättern ein gleichbleibendes Auszeichnungssystem: Jeweils am oberen Blattrand jeder Rectoseite finden sich in rot-blau wechselnder Unziale geschrieben die Angaben zu den jeweiligen Büchern. Die Abschnitte sind mit roten und blauen Lombarden oder mit Initialen mit Fleuronnée ausgezeichnet. Am augenfälligsten ist die Illustrierung. In nahezu jeder Kolumne des zweispaltig geschriebenen Werks sitzt eine Illustration. Nicht nur, dass eine solche Entscheidung eine unglaubliche Bilderdichte mit sich bringt, sondern die Handschrift erhält durch diese rhythmisierte Abfolge eine unerwartete Regelhaftigkeit. Lediglich drei Darstellungen sind ganzseitig $^{54}$, wenige halbseitig ${ }^{55}$, so dass die Handschrift einen ununterbrochenen Strom an

einspaltigen Bildern aufzuweisen scheint. Durchgehend werden die Darstellungen durch rubrizierte gereimte Bildtitel ausgezeichnet, die öfter - vor allem bei Platzmangel - als Schriftbänder sich aus dem Bild hinaus in den Blattrand oder das Interkolumnium entwickeln. Die Illustrationen sind durch rubrizierte Namensbeischriften, die Bildtitel und ihre Stellung innerhalb der Spalten eng mit der Schrift verbunden. Dennoch grenzen sie sich gegen diese als eigenständiges Medium ab. Kräftige Farben bestimmen die Bilder: ein deckendes Rot, ein sehr intensives Deckfarbengrün, ein leuchtendes Blau sowie Gelb sind die wichtigsten Farben. Die rubrizierten Titel, Beischriften und Namen schaffen gemeinsam mit den in sich geschlossen wirkenden Bildern einen eigenen medialen Raum, gegenüber dem sich die relativ kleine Kursive des Textes optisch eher als Beiwerk denn als zentrales Medium darbietet. Diese Durchdringung des Schriftmediums mit bildlichen Akzenten wird durch die während der gesamten Handschrift durchgehaltene rote Strichelung der Textanfänge, die farbigen Anfangsbuchstaben und die üppigen Kadellen noch verstärkt.

54

55

Fol. Ior, 9or, I3Ir.

Fol. I95 rab, 203rab, 2I2rab, 22Irab, 228rab, 240vab, 293rab, 294rab, 30orab, 323vab, 324rab, 325rab, 344vab, $346 \mathrm{vab}, 348 \mathrm{rab}$, 35 Irab, 354rab, 356vab, 357vab, 364rab, 373rab, 375vab, 379rab; 38Ivab, $383 \mathrm{rab}$, 386vab, 39Irab, 404rab, $418 \mathrm{vab}, 423 \mathrm{rab}, 426 \mathrm{vb}$ (rechte Spalte), 456rab. 


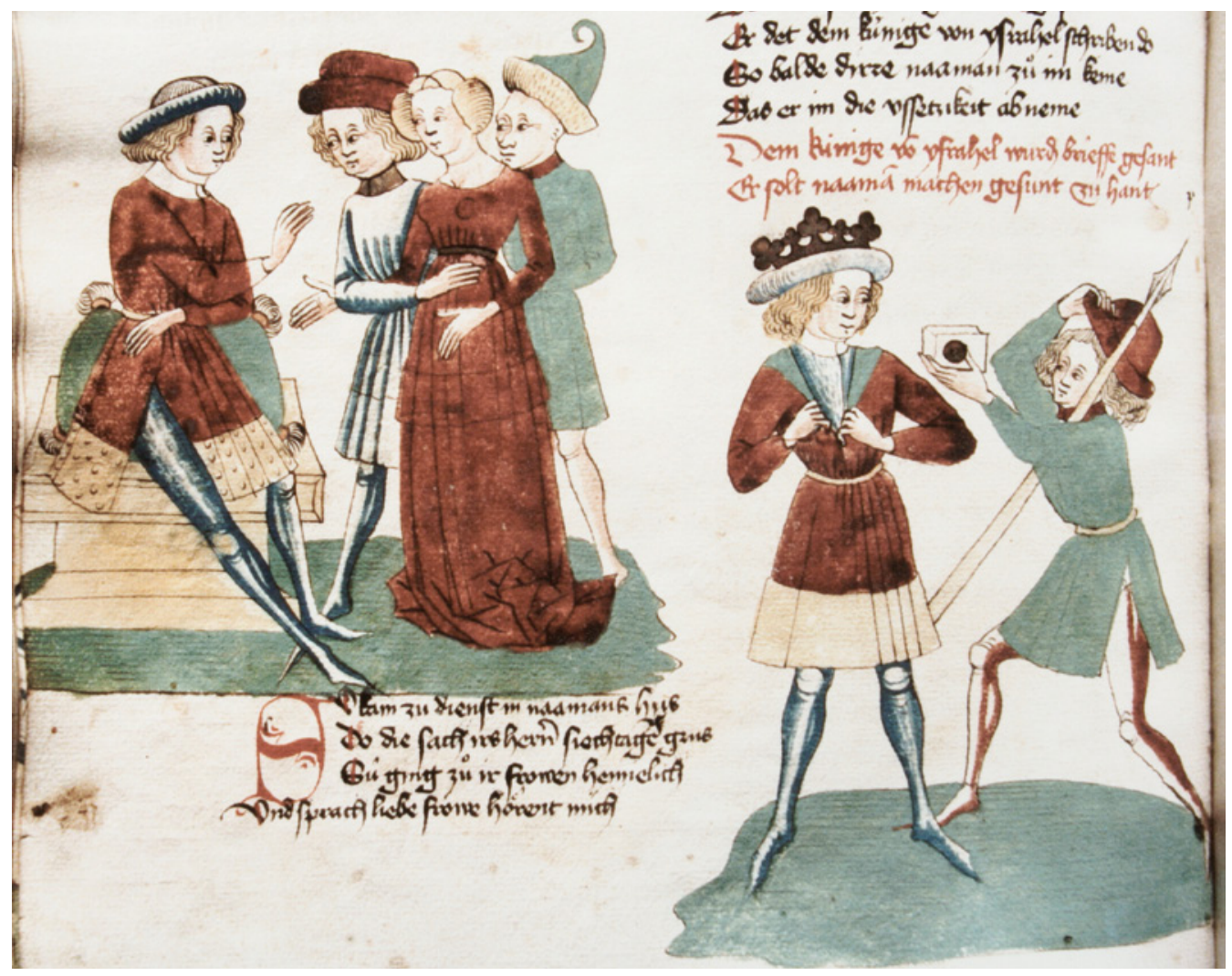

Abb. 8: Colmar, Bibliothèque de la Ville, Ms 305, fol. 39ova und b: Naeman und die israelitische Magd, Naemans Bote vor Joram; Hagenau, Werkstatt des Diebold Lauber und Hans Schilling, I459

Allein das Beibehalten eines gleich erscheinenden Farbkanons spricht dafür, dass auch für die Illustrationen die Einheitlichkeit des Werkes ein Gestaltungsziel war. Die kräftigen Farbakkorde wie auch die in sich geschlossenen Kompositionen, die meist die Figuren, seltener Architekturen oder Vegetation, dazu benützen, die Bilder mit virtuellen Rahmen nach links und rechts zu schließen, manchmal auch nach oben mit einem blau gestrichelten Himmel gegen den Text abzugrenzen, tragen zu der bestimmenden Eigenständigkeit der Bilder bei. Dies ist umso erstaunlicher, als, wie wir noch sehen werden, nicht nur die Formen, sondern auch die Farben und die stilistische Ausrichtung der Illustrationen innerhalb der Handschrift doch großen Wechseln unterliegen.

\section{Stereotype Formengebung}

Auf den ersten Blick scheint die Formengebung durch den ganzen Codex gleich zu bleiben. Der Verkauf Josephs und Jacobs Trauer um Joseph (Abb. 6) und die Illustration zum kleinen Moses, der Pharaos Krone zerbrach (Abb. 7), verwenden denselben Figurentypus. Die Gestalten stehen puppenhaft steif auf einem flachen grünen Terraingrund. Ihre riesigen Köpfe tragen auffällige Kopfbedeckungen. Die modischen Gewänder werden durch metallen harte, parallel verlaufende Faltenzüge gegliedert. Der vor dem Thron schwebend er- 


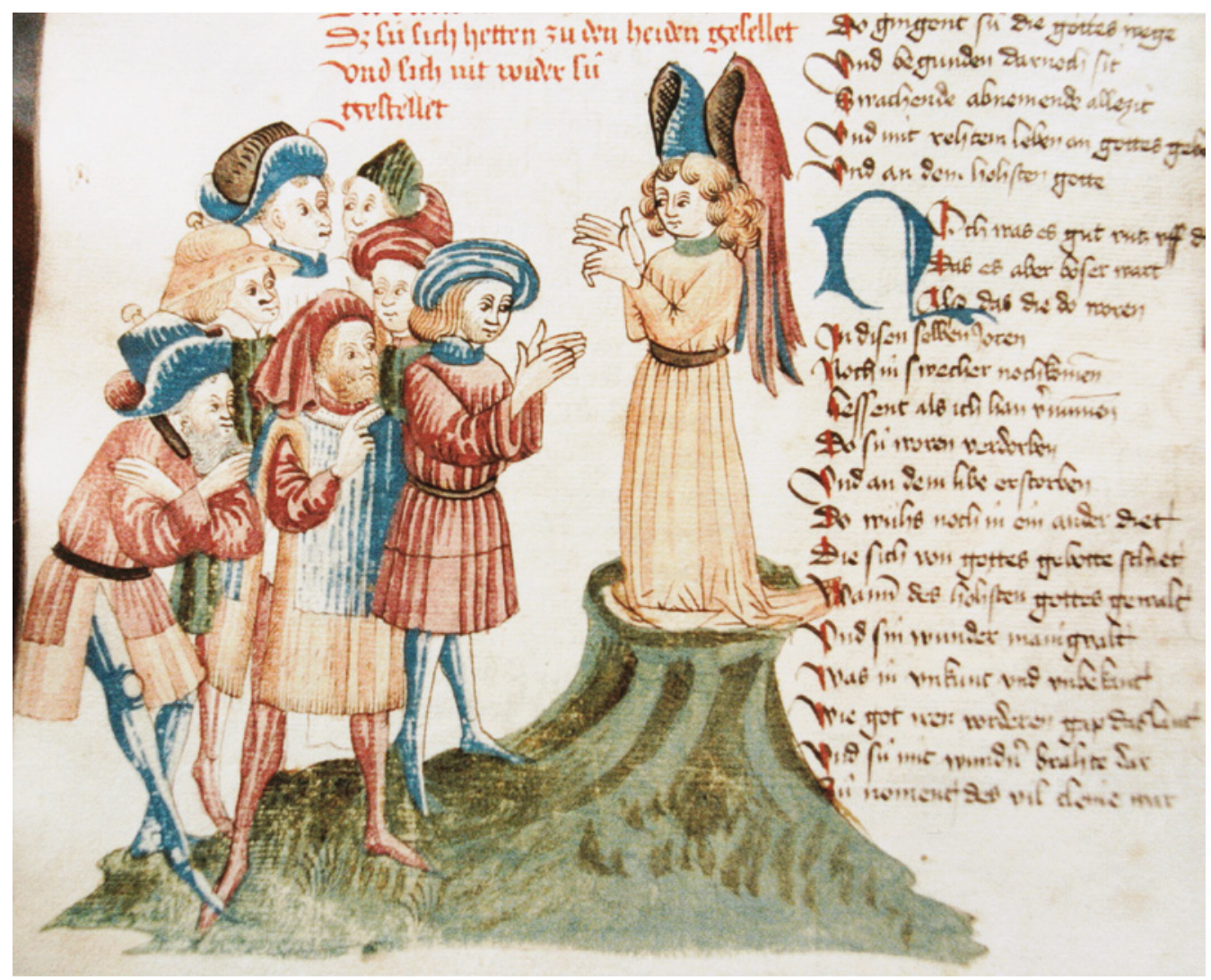

Abb. 9: Colmar, Bibliothèque de la Ville, Ms 305, fol. I92va: Ein Engel erscheint den Israeliten; Hagenau, Werkstatt des Diebold Lauber und Hans Schilling, 1459

scheinende Pharao wird gegenüber dem ebenfalls vor dem Thron sitzenden Jacob nur minimal verändert. Besonders charakteristisch ist die Einpassung der Gruppen in eine virtuelle Rahmung. Die sorgfältig aufgetragenen Farben, Blau, Rot, Grün und das helle Gelb, berücksichtigen streng die Konturen. Die Farbigkeit ist in den ersten Lagen wärmer und die Bilder sind in der Regel mit dem blau gestrichelten Himmel nach oben begrenzt. ${ }^{56}$ Trotz dieser tonigeren und wesentlich kleinteiligeren Farbgebung wirken die Darstellungen dennoch einheitlich.

Sogar Illustrationen, bei denen Änderungen auffallen, können noch demselben Typus zugeordnet werden: Die Darstellungen zu Naeman (Abb. 8), dem die jüdische Magd von dem Propheten Elisa berichtet, und zum Boten Naemans bei König Joram. Die Vergleichbarkeit betrifft wiederum den Formenschatz. Es sind dieselben hölzernen Gestalten, deren Gesichter uniform und regungslos wirken. Die Ägypter vor Pharao (Abb. 7) und die Sy-

56 In gleichbleibender Genauigkeit mit blauem Himmel sind die ersten sieben Lagen bis fol. 8Iv, bis zum Beginn der Josephsgeschichte, ausgearbeitet. Nur noch der Beginn der vierten Welt (fol. 233ra) wird mit David vor einem ebenso gestrichelten Himmel ausgezeichnet. 
rer vor Naeman (Abb. 8) haben rundliche Köpfe und die Gesichtszüge werden mit denselben knappen Formeln charakterisiert: Eine gerade Nase läuft in eine schmale, sanft gewölbte Braue über, die von einem Lidstrich begleitet wird. Die Augen sind mit einem offenen Oval eingezeichnet und erhalten im inneren bzw. äußeren Augenwinkel eine kräftige Pupille. Eine kurze wellige Oberlippe begleitet von einem kleinen Tupfer für die Unterlippe verschafft den Gesichtern ihr formelhaftes Aussehen. In beiden Illustrationen sind die Deckfarben vergleichbar flächig aufgetragen und die präzise gezeichneten Vor- und Nachzeichnungen bestimmen mit ihren sicheren, fast wie mit dem Lineal gezeichneten Linien die Binnengliederung. Die prägende Gestaltung erhalten die Figuren durch die über den Deckfarben liegenden, mit einem dunklen Braun oder Schwarz nachgezogenen Falten und durch die Präzisierung der Konturen. Nur das Blau ist zur Schattierung der Faltentäler eingesetzt. Der Vergleich lässt freilich auch Unterschiede erkennen. Am augenfälligsten verändert haben sich die Proportionen. Während die Ägypter (Abb. 7) mit ihren großen Köpfen zu klein wirken und eher den Brüdern Josephs gleichen (Abb. 6), haben sich die Syrer Naemans und vor allem Joram und der Bote (Abb. 8) deutlich gestreckt. Sie haben längere, an Insekten erinnernde Beine bekommen, die Köpfe besitzen nicht mehr die Übergröße und die Bewegungen sind weniger verhalten. Ungewöhnlich im üblichen Repertoire ist auch der Charakterkopf des hinter der Magd stehenden Syrers, der auf seinem kahlen Kopf eine phrygische Mütze mit einem Pelzaufschlag trägt. Sein schmales, lang gezogenes Gesicht mit der langen Nase und der ausgeprägt kantigen Stirn entspricht nicht den freundlichen uniformen Köpfen, die sonst die Norm sind.

Wann sich dieser andere Stil durchzusetzen beginnt, ist nicht klar zu entscheiden. Einzelne neue Gestalten, manchmal nur ungewöhnlich wirkende Gesichtszüge und eine sich allmählich verändernde Farbgebung sind ab dem Buch Josue (fol. 175va) zu verfolgen. ${ }^{57}$ Ein zunehmender Reichtum an Bewegung, emotionalisierten Gesichtern oder auch nur unterschiedlichen Charaktertypen scheint in manchen Illustrationen wie hinzugefügt. Entsprechend dem die Magd begleitenden Syrer (Abb. 8) tauchen am Rande oder zwischen den stereotypen Gestalten in den Figurengruppen - so etwa unter den Israeliten, denen ein Engel erscheint (Abb. 9) - vergleichbar „neue“ Gesichter auf. Die hinteren drei der Gruppe entsprechen mit ihren fein gezeichneten, in unterschiedlichen Ansichten gezeigten schmalen Köpfen dem Syrer. Ebenso vertreten die beiden Bärtigen am linken Gruppenrand denselben Typus, sind aber mit ihren flauschigen Bärten in einer Weise ausgearbeitet worden, wie wir dies an den holzschnittartigen Zeichnungen der bisherigen Beispiele nicht gesehen haben. Lediglich der Engel und die vorderste,

57 Bereits auf fol. I66ra dürfte Balaam nachträglich überarbeitet worden sein, dies betrifft das dunkel und kleinteilig schraffierte Faltengebirge, das sich um seine Fußpartie auftürmt. In den weiteren Bildern ändern sich am deutlichsten die gerüsteten Gestalten, so etwa auf fol. I55rb, I63rb. Freilich scheint bereits ab fol. II6r eine Überarbeitungsstufe mit einem sich stärker verfärbenden Rot hinzugekommen zu sein, das manchmal ins Bräunliche changiert und dem später eingesetzten Purpur entsprechen muss. Neue Typen tauchen in der Balaam-Sequenz ab fol. I63r auf. Hier wurde mehrfach übermalt und überzeichnet, so etwa auf fol. I64ra, I64va. Dagegen wurde auf fol. I66vb nur die Gruppe der Israeliten im üblichen Stil vollendet, während bei den Moabiterinnen lediglich die Vorzeichnung, Farbe, aber nicht die Präzisionszeichnung eingetragen wurden. 
direkt mit diesem kommunizierende Männergestalt entsprechen dem üblichen Kanon. Ungewöhnlich ist auch die Haltung des Alten am unteren Bildrand, der mit überkreuzten Armen in einer eleganten, weit ausgreifenden Beugung dem himmlischen Wesen seine Verehrung bekundet. An den Syrern wie den Israeliten spricht die Ausführung dieser fremden Elemente dafür, dass sie hinzugefügt und manchmal nicht einmal koloriert wurden, wie die hinterste Männergestalt der Israeliten, deren Gewand in der Vorzeichnung verblieb.

Auffällig an allen bisherigen Beispielen ist die scheinbar uniforme Farbgebung, die sich aber doch deutlich unterscheidet in der Wirkung und der Verwendung der Farbe. Während die Farbe in der Illustration zu Moses (Abb. 7) wie in überwiegenden Teilen der Handschrift, so auch bei Naeman (Abb. 8), flächig aufgetragen ${ }^{58}$ und lediglich das Blau zum zeichnerischen Schattieren eingesetzt wird, existieren Blätter wie das der Israeliten

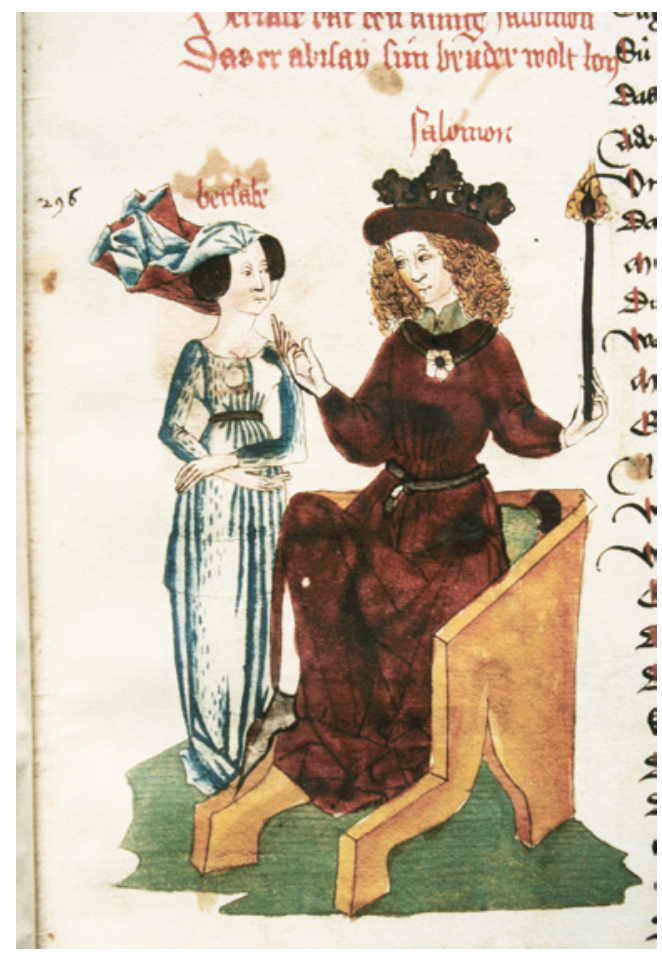

Abb. Io: Colmar, Bibliothèque de la Ville, Ms 305, fol. 337ra: Bethsabee bei Salomon; Hagenau, Werkstatt des Diebold Lauber und Hans Schilling, I459 vor dem Engel (Abb. 9), aber auch die Szenen Josephs (Abb. 6), in denen die Farben in mehreren Schritten aufgetragen und die Schattierungen mit einer dunkleren Variante der Grundfarbe auch in den grünen und roten Gewändern eingesetzt werden. Wechsel in der stilistischen Ausdrucksform gehen nicht unbedingt einher mit einer anderen Kolorierung, wie gerade diese vier Beispiele erkennen lassen.

\section{Farbgebung}

Im Laufe der Handschrift ändern sich die Farbtöne, was nicht allein mit den üblichen Schwankungen der Pigmentmischung zusammenhängt. Vielmehr werden zu Beginn der Handschrift die Töne wärmer aufgetragen, wogegen die späteren Illustrationen kalte Varianten derselben Farben verwenden. Die mehrfache Überarbeitung des kalten Grüns mit einer deckenden Olivfarbe, wie wir sie in der Josephsgeschichte (Abb. 6) und bei den Israeliten vor dem Engel (Abb. 9) am Terrain und den Bäumen sehen, wird in manchen Illustrationen und im Laufe des Bandes immer mehr aufgegeben. ${ }^{59}$ Ebenso wird auf die

58 Zu den Kolorierungswechseln Saurma-Jeltsch, Buchherstellung (zit. Anm. 4), Bd. I, S. I48-I5O.

Der Stand solcher Überarbeitungen kann nicht nur innerhalb der Lagen wechseln, sondern manchmal sogar innerhalb eines Blattes; auf fol. I69ra am Ende einer Lage fehlt die Überarbeitung, auf fol. I74rb ist entsprechend überarbeitet, auf fol. 177ra ist der Durchzug durch den Jordan intensiver überarbeitet als der Engel vor Josue in der rechten Spalte. 


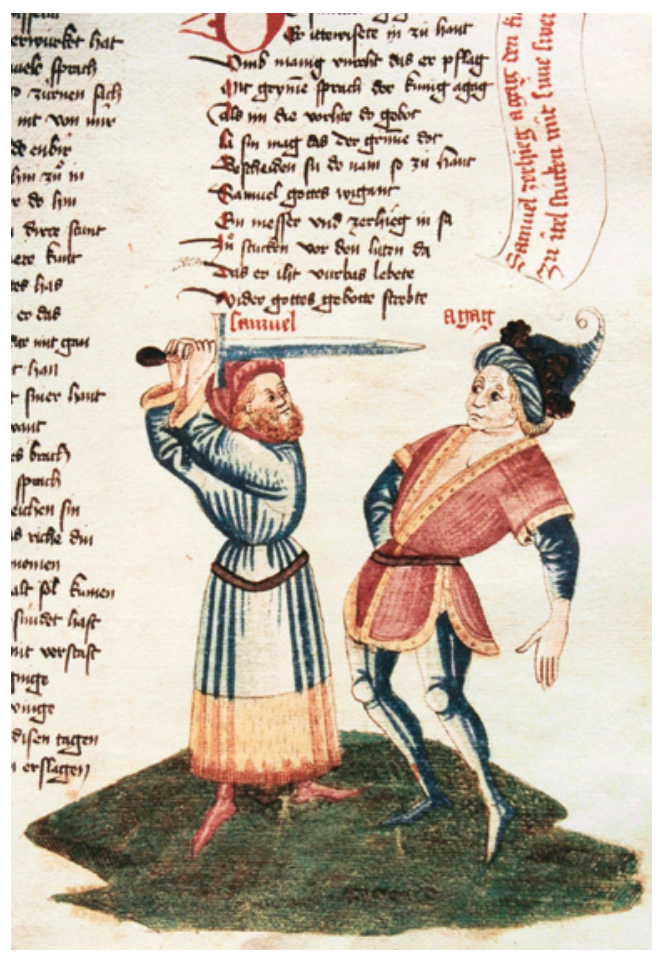

Abb. II: Colmar, Bibliothèque de la Ville, Ms 305, fol. 254rb: Samuel tötet König Agag; Hagenau, Werkstatt des Diebold Lauber und Hans Schilling, I459 hier vorherrschende strichelnde Bearbeitung von Haaren, Bärten, Pelzbesätzen, die der beschreibenden Schilderung unterschiedlicher Stofflichkeit dient, zunehmend verzichtet. Die entscheidendste Veränderung in der Farbgebung freilich betrifft die Darstellungen der 27. bis zur 29. Lage (fol. 3II346). Das in früheren Illustrationen nur sehr selten aufgetragene tiefrote, fast bräunliche Brasilholz nimmt in diesen Lagen eine immer größere Bedeutung an und bestimmt das Gewand Salomons (Abb. Io) vollständig. In den späteren Lagen wird diese Farbe nur noch selten eingesetzt und allenfalls zur Vertiefung eines karminroten Gewandes verwendet. ${ }^{60}$

\section{Mehrere Hände}

Nur auf wenigen Blättern und erst mit dem Blick auf die ältere oder nachfolgende Produktion wird deutlich, dass hinter den unterschiedlichen Gestaltungsmodi verschiedene Werkgruppen, wenn nicht Hände stehen. In anderem Zusammenhang haben wir drei

Ausdrucksformen unterschieden und vom Zeichner K einen Zeichner KI und einen weiteren - insbesondere in der Weltchronik nur schwer zu unterscheidenden - K2 getrennt. $^{61}$ Aber auch für KI ist die Weltchronik nur selten repräsentativ, wird doch gleichsam ein Gruppenstil K meist entscheidend für den Ausdruck. Ein solches Beispiel bleiben die Israeliten vor dem Engel (Abb. 9), unter denen zwar einzelne Physiognomien und eine neue Proportionierung und Beweglichkeit der Gestalten zu beobachten sind, aber dennoch der Gesamthabitus, wie auch in den Naeman-Szenen (Abb. 8), dem Bekannten entspricht. Die neuen Gestalten unter den Israeliten vor dem Engel (Abb. 9) tauchen freilich in manchen Blättern gemeinsam mit einer kantig ausfahrenden Figurenkontur auf, die im Gesamtkonzept dann doch fremd wirkt. König Agag, der von Samuel getötet wird (Abb. II), führt die variantenreiche Physiognomie der Israeliten und des Syrers fort und kennt dieselbe Proportionierung. Der nach hinten fallende Agag balanciert auf ähnlichen Insektenbeinen wie die Gestalten der Naeman-Sequenz (Abb. 8). Agag knickt - an einen Automaten erinnernd - in der Taille abrupt nach hinten, was wie eine gegenläufige Bewegung zu dem Israeliten wirkt,

\footnotetext{
6o So etwa auf fol. 363ra am Gewand Zambris und an Elas Hut. Die Farbe scheint Schwierigkeiten beim Trocknen verursacht zu haben, hinterlässt sie doch häufig auf der gegenüberliegenden Seite Abdrücke.

6i Saurma-Jeltsch, Buchherstellung (zit. Anm. 4), Bd. i, S. i5of.
} 
Abb. I2: Wiesbaden, Hessische Landesbibliothek, Hs 66, fol. I8v: Moses und Belial vor Salomon; Hagenau, Werkstatt des Diebold Lauber und Hans Schilling, I459

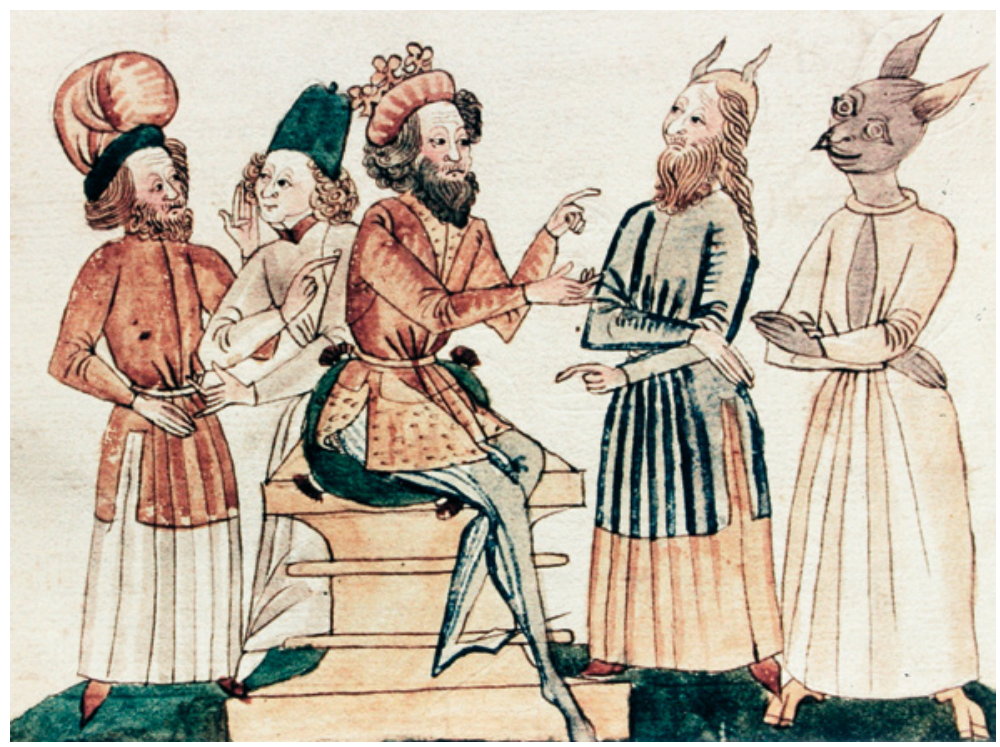

der sich dem Engel in Verehrungshaltung (Abb. 9) entgegen beugt. Identisch sind die Gesichtstypen Samuels und der älteren Israeliten bis in die wattige Kolorierung des Bartes. Freilich erweist sich auf den zweiten Blick die Agag-Episode trotz dieser Übereinstimmungen als überarbeitet. Die nahezu karikierend nachgearbeiteten Gesichter, vor allem des Königs, aber auch Samuels mit der Feder nachgezeichneter stärker gekrauster Bart und die verschärfte Betonung von schmaler Taillenpartie und ausladender unterer Körperhälfte werden beim Samuel durch eine harte Kolorierung überbetont.

Ähnliche Ansätze finden sich bereits in der älteren Hamburger Historienbibel ${ }^{62}$ und erscheinen ungefähr gleichzeitig zur Colmarer Handschrift im Wiesbadener Belial (Abb. I2). ${ }^{63}$ Insbesondere die breit dastehenden Gestalten, deren Gewänder am ausladenden Unterkörper metallen hart, lamellenartig gestaltet sind und von der relativ schmalen Taille nach unten und mit wenigen kurzen schematischen Strichen nach oben ausstrahlen, sind in einer deutlich gröberen, aber verwandten Weise angeordnet. Ebenso treffen wir dieselben Gesichter mit den schläfrigen, von schweren Lidern bedeckten Augen, die hochgezogenen schmalen Brauen und die grämlich oder leicht süffisant wirkenden Münder. Die Wiesbadener Belial-Handschrift ist vollständig geprägt von dem Stil des zweiten Colmarer Zeichners, der auch in der Hamburger Historienbibel tätig war und dem der Name Kı gegeben wur-

62 Hamburg, Staats- und Universitätsbibliothek Carl von Ossietzky: Cod 7 in scrin., fol. I8Ir; ebenda, Bd. 2, Abb. 185; zu der K-Gruppe sowie Lauber und Schilling auch U. BodemanN, Diebold Lauber, Hans Schilling und die heiligen drei Könige, in: Chr. Fasbender (Hrsg.), Aus der Werkstatt Diebold Laubers, Berlin/Boston 2012, S. 287-297.

63 Wiesbaden, Hessische Landesbibliothek: Hs 66; N.H. Отt, Artikel „Belial“ in: H. Frühmorgen-Voss (Begr.) / N. H. Отт/U. Bodemann (Hrsg.), Katalog der Deutschsprachigen illustrierten Handschriften des Mittelalters, München 1996, Bd. 2, Nr. 13. 0. 27., S. 83-85; ebenda, Bd. 2, S. I20-I22. 


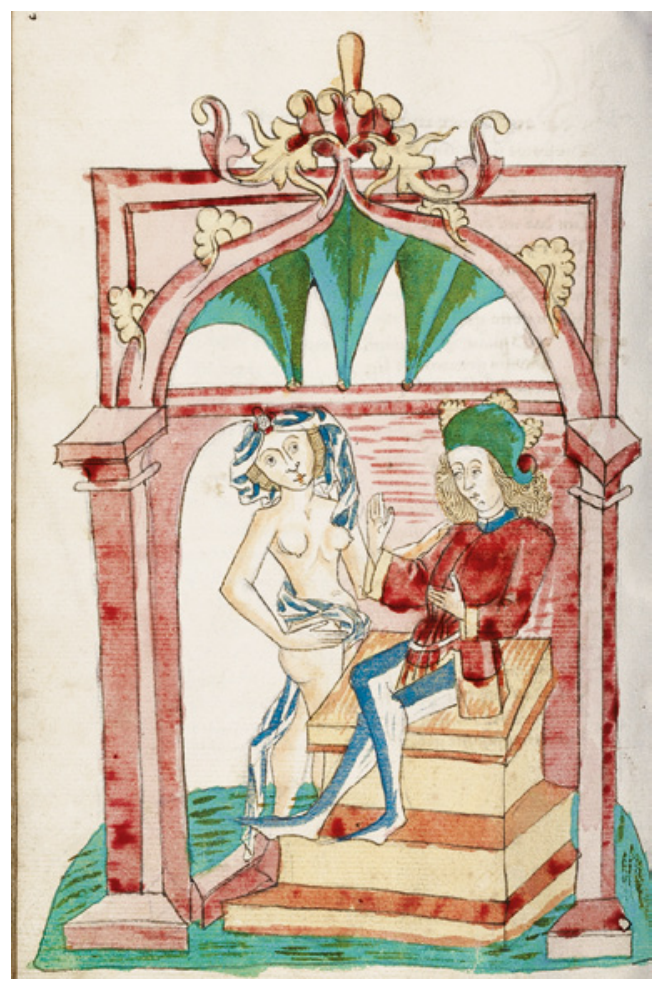

Abb. I3: Los Angeles (California), The J. Paul Getty Museum, Ms. Ludwig XV 9, fol. 284v: Die Verführung Josaphats; Hagenau, Werkstatt des Diebold Lauber und Hans Schilling, I459 de. ${ }^{64}$ Im Gegensatz zur Colmarer Handschrift freilich, wo wir ihn nur in Ansätzen und dann gleichsam wieder aufgenommen von einem allgemeinen K-Stil finden, kann er sich in der Wiesbadener Handschrift eigenständig entwickeln. Seine zügig gezeichneten, lediglich lavierten Federzeichnungen tragen ein völlig anderes Erscheinungsbild als die überarbeiteten Blätter in der Colmarer Weltchronik. Die überlängten Gestalten mit den kleinen Köpfen und den ausdrucksstarken, aber sehr gestaucht wirkenden Gesichtern gehen von der Linie aus. Die in den Hüften scharf einknickenden Silhouetten der ausladenden, oft breitbeinig dastehenden Gestalten sind bewegt, ja geradezu theatralisch. Die Ausdrucksstärke der Illustration täuscht dennoch nicht darüber hinweg, dass letztlich die Darstellung in Wiesbaden von einer ganz anderen Qualität ist als die ausgearbeiteten Colmarer Miniaturen. Es gibt denn manche Hinweise darauf, dass sich hinter den unterschiedlichen Temperamenten, die man in der Colmarer Handschrift nur ahnt und manchmal an einer anderen Verwendung des Kolorits, der

Linie, seltener auch - wie dann in der Wiesbadener Handschrift - an abweichenden Figurentypen und einem veränderten Verhältnis zur Räumlichkeit beobachten kann, nicht nur zwei, sondern durchaus auch drei unterschiedliche Illustratoren verbergen.

Sicher eine dritte Ausdrucksform findet sich in den Darstellungen, die wie diejenige Salomons und Bethsabees (Abb. Io) eine eigenartige Manieriertheit der Figuren favorisieren. Die beiden Gestalten sind stark gelängt und ihnen fehlt die Breite des Stehens, wie wir sie etwa bei den Syrern vor Naeman (Abb. 8) beobachtet haben. Als zarte, fast zerbrechliche Gestalt wächst Bethsabee von einer nur schmalen Bodenberührung auf und hat nichts von der schweren Massigkeit der israelitischen Magd. Elegant überkreuzt hält sie ihre feingliedrigen Arme und schaut aus einem vornehm gezeichneten Gesicht mit langer Nase, kleinem Mund und ebenso kleinen Schlitzaugen auf Salomon. Auch dessen Gesicht ist von demselben Typus. Mit einer gezierten Handbewegung präsentiert er sein Szepter. Auffällig sind sein fein gekraustes Haar und bei Bethsabee das von innen und außen sichtbare, abflatternde Kopftuch. Das harte Licht- und Schattenspiel an Kopftuch und Gewandsaum von Bethsabee ist unter der dicht roten Bema-

64 Saurma-Jeltsch, Buchherstellung (zit. Anm. 4), Bd. I, S. i5of. 
Abb. I4: Wiesbaden, Hessische Landesbibliothek, Hs 66, fol. 47r: Ein Zeuge sagt für Belial aus; Hagenau, Werkstatt des Diebold Lauber und Hans Schilling, I459

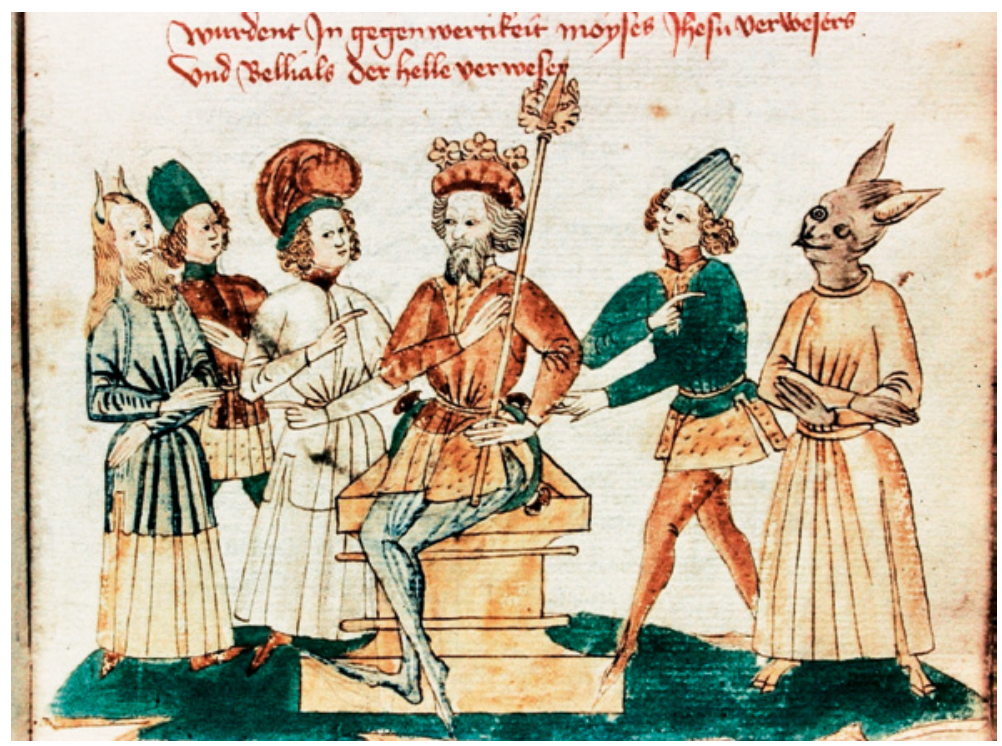

lung an Salomons Gewand nur noch erahnbar. Dieselben Kennzeichen lassen sich in Blättern der I469 datierten Balaam-und-Josaphat-Legende des Getty Museums (Abb. I3) wiederfinden. An diese Handschriften schließen sich auch die anderen Werke der K2-Gruppe an. ${ }^{65}$

Erst wenn wir die Ausdrucksformen in den jüngeren oder auch der älteren Handschrift mit der Colmarer Weltchronik verbinden, wird auch für die Weltchronik offensichtlich, dass die scheinbar einheitliche Illustrierung ein Werk ganz unterschiedlicher Hände, Gruppen gewesen sein muss. Im Gegensatz zu der vorher geschilderten A-Gruppe finden sich diese Ausdrucksformen keineswegs in einem gemeinsamen Verständnis einer zur Routine gewordenen Formensprache. Die einzelnen Ausdrucksweisen entwickeln in den weiteren Handschriften eine Eigenständigkeit, die der K-Stil insgesamt in der Colmarer Handschrift eben gerade nicht zulässt.

Am offensichtlichsten wird dies an der Wiesbadener Handschrift, die stark von der Zeichnung lebt. Ihre Ausstattung passt sich dem ganz anderen Handschriftentyp an, der vor allem im städtischen Notariat, wie Norbert Ott bewies, sein spezifisches Publikum gefunden hatte. ${ }^{66}$ Die Illustrationen streben dem Text folgend eine theatralische Performativität an. Sie wirken dynamisch und sind - wie die Verteidigung Belials durch einen Zeugen erkennen lässt (Abb. I4) - bereits in der ersten Vorzeichnung von einer schwungvollen Dynamik erfüllt. Die groben und sicheren Linien werden öfter korrigiert, sogar noch, wie auf dem anderen Blatt (Abb. I2) an den Füßen Salomons zu sehen ist, in der nach der ersten Lavierung

65 Vgl. dazu Stuttgart, Württembergische Landesbibliothek: Cod. Poet. et phil. $2^{\circ}$, fol. 19or; ebenda, Abb. I90; Eingangsbild von St. Gallen, Kantonsbibliothek: Ms. 343c, fol. 6v; ebenda, Taf. 3I; Hamburg, Staats- und Universitätsbibliothek: Cod. 7 in scrin., fol. 297v; ebenda, Abb. 178.

66 N.H. Отт, Rechtspraxis und Heilsgeschichte. Zu Überlieferung, Ikonographie und Gebrauchssituation des deutschen „Belial“ (Münchener Texte und Untersuchungen zur deutschen Literatur des Mittelalters), München / Zürich 1983 , S. 28I-285. 
angelegten weiteren Federzeichnung. Die Genauigkeit der Weltchronik wird im Belial mit einer die Szenen wie die Details bestimmenden Dynamik ersetzt, scheinen doch die kleinen Häkchen zur Schilderung eines Pelzbesatzes am Gewand von Belials Zeugen (Abb. I4) dessen Herbeieilen zu unterstützen und eher nebensächlich die so andere haptische Qualität des Pelzes im Gegensatz zum Tuch zu beschreiben.

Wie schon mehrfach beobachtet, arbeiten die Maler in mehreren Etappen ${ }^{67}$, in denen jeweils unterschiedliche Personen tätig sein können. Auf die Entwurfszeichnung, die wir im Belial deutlich sehen, folgt erst die Feinzeichnung. Die lavierenden Farben werden zuerst und erst später die Deckfarben aufgetragen. Dabei spielen das Rot, das manchmal eine bräunliche Variante eines Purpurs zu sein scheint, wie beim Salomon der Colmarer Handschrift (Abb. Io), ebenso wie das intensiv deckende Grün eine wichtige Rolle. Sie werden als letzte Farben aufgetragen und wirken insofern auch bestimmend. An der Naeman-Sequenz (Abb. 8) etwa zeigt der beim Kolorieren vergessene rechte Unterarm Naemans, mit dem er die israelitische Magd grüßt, wie großfächig die Farben gesetzt werden und trotz aller Sorgfalt auch in der Colmarer Handschrift gerade deshalb Fehler nicht zu vermeiden sind. Die deckenden Farben werden denn auch über mehrere Lagen gleichbleibend verwendet, was für einen zusammenhängenden Arbeitsschritt spricht. In der letzten Arbeitsphase werden freilich auch die bisher nur summarisch mit einer zartrosa Lavierung versehenen Gesichter mit ihren endgültigen Zügen ausgestattet. Die gleichbleibende Farbgebung und vor allem die Vereinheitlichung der Gesichter und Konturen tragen in der Colmarer Handschrift ganz entscheidend zum Eindruck einer einheitlichen Illustrierung bei.

In der Colmarer Handschrift bestand offensichtlich das Bestreben, die Individualstile zu überspielen, was wohl Aufgabe des sorgfältig arbeitenden „Ausmalers“ und Konturierers war. Was kann man sich nun angesichts dieser Erfahrungen als Aufgabe von Hans Schilling vorstellen, den wir als Schreiber und wohl auch als Akquisiteur von Kunden einigermaßen belegen können ${ }^{68}$ und der für den gesamten sehr anspruchsvollen Band verantwortlich zeichnet? Wichtigste Aufgabe ist zweifellos die Organisation der Vorlagen und die Gestaltung des Layouts gewesen. Den Text zu beschaffen - eine komplexe Kompilation - stellte eine große Herausforderung dar. Inwieweit diese Interpolation sogar neu vorgenommen wurde, ist ungewiss. Ein Abenteuer war aber auch die Organisation der 463 Blätter Papier. Zum Teil musste makuliertes Papier verwendet werden, das am Blattrand bereits beschrieben war und wahrscheinlich aus dem Bestand der genau in diesem Jahr von Hagenau nach Kleinlützel

$67 \mathrm{Zu}$ den Phasen des Arbeitens an englischen Manuskripten Driver/OrR, Decorating (zit. Anm. 30), S. III, dort ältere Literatur; P. Rudolph, Buchkunst im Zeitalter des Medienwandels. Die deutschsprachigen Bibelcodices der Henfflin-Werkstatt vor dem Hintergrund der spätmittelalterlichen Ikonographie, S. 22-3I für die Henfflin-Werkstatt; URL: < http://archiv.ub.uni-heidelberg.de/Artdok/volltexte/2009/740/ > (I2. OI. 2OI2); Saurma-Jeltsch, Buchherstellung (zit. Anm. 4), Bd. I, S. I8-20; dies., Die Illustrationen und ihr stilistisches Umfeld, in: H. Haeberli / Chr. von Steiger (Hrsg.), Diebold Schillings Spiezer Bilderchronik. Kommentar zur Faksimile-Ausgabe der Handschrift Mss. hist. helv. I. I6 der Burgerbibliothek Bern, Luzern I990, S. 3I-7I, 3I-37 zur Herstellung der Spiezer Chronik.

68 Saurma-Jeltsch, Buchherstellung (zit. Anm. 4), S. I43-I45 und I66. 
umziehenden Landvogtei stammt. Eine ungeheuer komplexe Organisationsaufgabe war die konsequente Gestaltung des Layouts und die Koordinierung der Malerarbeiten. Die Bilder selbst wurden in mehreren Arbeitsetappen hergestellt, wobei die entscheidendste diejenige der Feinzeichnung ist. Für den Gesamteindruck jedoch offenbar wesentlich wichtiger sind die auf jeden Fall in Lagen, wahrscheinlich noch größeren Einheiten erfolgende Kolorierung und deren Nacharbeit. Die Organisation der Bilder im Text, die Überschriften, aber vor allem die trotz der Schwankungen strukturell doch gleichartigen Bilder sind eine Leistung, die einem planenden und nachkontrollierenden Organisator zuzuschreiben ist. $\mathrm{Ob}$ dies Diebold Lauber, Hans Schilling oder eher ein dritter ist, lässt sich derzeit nicht sagen.

Einheitlichkeit, so haben wir gesehen, kann sehr unterschiedlich verstanden werden. Für den Zeitgenossen war die Einheitlichkeit des Gesamtcodex wesentlich wichtiger als diejenige der Ausdrucksformen der Illustratoren. Der Charme einer vereinheitlichten Ausstattung durch die Gruppe A in der Lauber-Produktion entsprang einer Rationalisierung der Arbeit, die freilich auch für den Abnehmer nicht ohne Bedeutung war: Ihm wurde ein Produkt zur Verfügung gestellt, dessen Illustrationen ihm bereits vertraut sein mussten und die er jedenfalls leicht zu entziffern wusste. Ganz anders gestaltet sich das Thema der Einheitlichkeit in den Arbeiten, die wir mit Hans Schilling in Verbindung bringen können. Während in der Colmarer Handschrift zwar das System des ,irregular web“, also einer ungeregelten Zusammenarbeit, herrscht, wie sie Farquhar nennt, liegt dem Ganzen dennoch ein gemeinsames Einhalten bestimmter Gestaltungsregeln zugrunde. Hier besteht die Absicht, eine gemeinsam gestaltete Prunkhandschrift zu schaffen. Nun sind freilich auch die anderen Handschriften der Spätphase von den Ausdrucksweisen her einheitlicher, ob sie nun von den Malern KI oder K2 oder auch anderen Kräften ausgestattet wurden. Es scheint, dass hier eine gewisse Angemessenheit der Illustration in Bezug zum Thema der Handschriften angestrebt wird. Der rasche, theatralische Zeichenstil wird für eine Belial-Handschrift als richtig empfunden, während für Balaam und Josaphat oder etwa auch den Stuttgarter Ammenhausen eine neue Mischung aus zeichnerischer Fertigkeit mit koloristischer Bravour eingesetzt wird. Die Definition des Einheitlichen wird offenbar nicht nur durch die Beziehung zwischen Auftraggeber und Hersteller, arbeitstechnische und ökonomische Faktoren bestimmt, sondern folgt eventuell auch einer Vorstellung von Angemessenheit, die sich anhand der Texte oder deren Funktionen erst erklären ließe.

Universität Heidelberg

Abbildungsnachweis: Abb. I, 2, 5-I2, I4: Lieselotte E. Saurma-Jeltsch. - Abb. 3, 4: Universitätsbibliothek Heidelberg. - Abb. I3: The J. Paul Getty Museum, Los Angeles (CA). 


\title{
FÜR GOTTESDIENST, BIBLIOTHEK UND VERKAUF - BUCHAUSSTATTUNG IM ROOKLOOSTER BEI BRÜSSEL
}

\author{
Christine Beier
}

Als der Maler Hugo van der Goes I475 dem weltlichen Leben den Rücken kehrte, um Mönch zu werden, ${ }^{1}$ entschied er sich für den Eintritt in das 1374 gegründete und seit I4I2 der Windesheimer Kongregation angehörende Rooklooster (Rouge-Cloître) ${ }^{2}$ im Zonienwald bei Brüssel. Ein Grund für diese Wahl mag gewesen sein, dass sein Halbbruder Nikolaus in diesem Augustiner-Chorherrenkloster als Donat lebte, ${ }^{3}$ aber auch der damalige Abt, Thomas van Vessem (I475-I485), kam dem Künstler entgegen, von dessen Ruhm bereits ein Mitbruder, Gaspar Ofhuys, berichtete. ${ }^{4}$ Hugo van der Goes wurden die Ausübung seines Berufes und der Empfang von Bewunderern und potentieller Kunden ermöglicht, zu denen der zukünftige Kaiser Maximilian gehörte. ${ }^{5}$ Diese Zugeständnisse, die das Missfallen einiger Mitbrüder erregten, sind aber vielleicht weniger der übergroßen Gutmütigkeit des Abtes ${ }^{6}$ als vielmehr dem Kalkül zuzuschreiben, dass Gäste des berühmten Malers als Wohltäter der Gemeinschaft in Frage kamen. Thomas van Vessem standen jedenfalls die Mittel zur Verfügung, den Ausbau des Klosters voranzutreiben: Während seiner Abtszeit ist der Kreuzgang eingewölbt worden und der Ausbau der Bibliothek fand seinen Abschluss ${ }^{7}$ (die Bücher wurden zuvor in vier Zellen über dem Refektorium aufbewahrt) ${ }^{8}$.

Die im Kloster verbrachten Jahre Hugos van der Goes haben Kunsthistoriker zu der Vermutung veranlasst, dass der Künstler dort auch als Illuminator tätig war. ${ }^{9}$ Doch konnten dem Tafelmaler keine illuminierten Handschriften zugewiesen werden, und auch die von Gerard Lieftinck in einer Abhandlung zur Buchausstattung im Rooklooster vertretene These, dass der Halbbruder Hugos, Nikolaus, ein dort geschriebenes Brevier ausstattete, ${ }^{10}$ ließ sich nicht verifizieren. ${ }^{11}$ Der figürliche Schmuck des Breviers wird mittlerweile dem Umkreis des Wiener

I J. G. SANDER, Beiträge zur Biographie Hugos van der Goes und zur Chronologie seiner Werke, in: Repertorium für Kunstwissenschaft, XXXV, I9I2, S. 519-545, zum Eintrittsjahr siehe S. $527 \mathrm{f}$.

2 A. Maes, Rouge-Cloitre. Rood Klooster, Brüssel I964, S. I4, 23.

3 SANDER, Beiträge (zit. Anm. I), S. 527.

4 Ebd., S. 52I.

5 Ebd., S. 52I.

6 I. Gielemans, Anecdota ex codicibus hagiographicis. Canonicis regularis in Rubea Valle prope Bruxellas, hrsg. von Hagiographi Bollandiani, Brüssel ı895, S. 228.

7 Ebd., S. I46.

8 Ebd., S. 228, Anm. 2.

9 G. I. Lieftinck, De meester van Maria van Bourgondië en Rooclooster bij Brussel, in: Bulletin \& nieuws-bulletin/Koninklijke Nederlandse Oudheidkundige, 17, 1964, Sp. 255-294, bes. Sp. 270; MaEs, Rouge-Cloitre (zit Anm. 2), S. 37; W. Kohl/E. Persoons/G. Weiler, Monasticon Windeshemense, T. i, Brüssel i976, S. iı8. Brüssel, Königliche Bibliothek, Ms. IV 860, I477 datiert; Lieftınck, De meester van Maria van Bourgondië (zit. Anm. 9), Sp. 275.

iI A. van Buren, The Master of Mary of Burgundy and his Colleagues: The State of Research and Questions of Method, in: Zeitschrift für Kunstgeschichte, 38, 1975, S. 286-309, bes. S. 290, 293; etwas offener und vorsich- 
Meisters der Maria von Burgund zugewiesen, ${ }^{12}$ und für einen Teil der Deckfarbenmalerei in dem ebenfalls aus dem Rooklooster stammenden Brevier in der British Library in London (Add. ms. II863) wird dieselbe Herkunft vermutet. ${ }^{13}$

Ein weiteres buchmalerisches Hauptwerk aus dem Rooklooster, die Bildinitialen zu Beginn der Abschrift der Proprietatibus rerum des Bartholomäus Anglicus ${ }^{14}$ (Abb. I2), das Lieftinck noch für die Arbeit des Konventualen Simon Logghen hielt, ${ }^{15}$ wurde von Delaissé ohne nähere Spezifizierung einem Brüsseler Atelier zugewiesen. ${ }^{16}$ Frédéric Lyna stimmte ihm in seinem I954 erschienenen Aufsatz zu dieser Handschrift insofern zu, als er aufgrund der hohen Qualität der Bildinitiale an einer Ausführung durch die Augustiner-Chorherren zweifelte, während er sich durchaus vorstellen konnte, dass die ornamental verzierten Initialen im Rooklooster eingefügt wurden. ${ }^{17}$ Für die großformatigen Miniaturen in den Werken des Chorherren Johannes Gielemans († I487; Abb. 9-II) schließlich haben Dagmar Thoss und Otto Pächt im Katalog Flämische Schulen II gegen eine Anfertigung durch Klosterangehörige argumentiert ${ }^{18}$ und fanden darin vor allem durch Untersuchungen von James Marrow Bestätigung. ${ }^{19}$ Auch Bodo Brinkmann äußerte sich skeptisch, was ein klostereigenes Buchmaleratelier betrifft, wobei er vor allem auf die stilistischen Unterschiede zwischen der Ausstattung der Breviere und der Gielemans-Handschriften hinwies. ${ }^{20}$ Lediglich die Malerei im Londoner Brevier Add. ms. II864 konnte er sich, wegen ihrer geringen Qualität, als hauseigene Produktion vorstellen. ${ }^{21}$

tiger äußerte sich H. WiJsMan, Handschriften voor het hertogdom. De mooiste verluchte manuscripten van Brabantse hertogen, edellieden, kloosterlingen en stedelingen, Alphen 2006, S. I20.

T. Kren, Vienna Master of Mary of Burgundy or Workshop/Follower, Rooclooster Breviary, in: Illuminating the Renaissance, hrsg. von T. Kren/S. McKendrick, Ausstellungskatalog, Los Angeles, The J. Paul Getty Museum, 2003, S. I52 f.

I3 T. Kren, Ghent associates, Rooclooster Breviary, in: Illuminating the Renaissance (zit. Anm. I2), S. I79-I89, bes. 187 .

I4 Brüssel, Königliche Bibliothek, Ms. 213.

I5 Liefinck, De meester van Maria van Bourgondië (zit. Anm. 9), Sp. 258.

I6 L. M. J. Deilaissé, Les Manuscrits à Peintures, in: Bruxelles au XV'me Siècle, Brüssel I953, S. II7-I3I, bes. S. 127 .

I7 F. Lyna, Een weinig bekend I5de-eeuws verlucht handschrift uit Rooklooster, in: Nederlands Kunsthistorisch Jaarboek, 1954, S. 299-303, bes. S. 300.

I8 O. Р̈̈снт / D. Thoss, Flämische Schule II, Textband, Wien I990 (Österreichische Akademie der Wissenschaften, Philosophisch-historische Klasse, Denkschriften $2 \mathrm{I} 2$ = Veröffentlichungen der Kommission für Schriftund Buchwesen des Mittelalters, Reihe I: Die illuminierten Handschriften und Inkunabeln der Österreichischen Nationalbibliothek 7), S. II4.

I9 J. H. Marrow, Moral and Didactic Treatises, in: The Splendor of the Word. Medieval and Renaissance Illuminated Manuscripts at the New York Publik Library, hrsg. von J. J. G. Alexander/J. H. Marrow/L. Freeman SAndlaer, Oostkamp 2005, S. 407-4I2; J. H. Marrow, Le Maître de Johannes Gielemans, in: Miniatures flamandes I404-I482, hrsg. von B. Bousmanne/Th. Delcourt, Ausstellungskatalog, Brüssel/Paris, Bibliothèque nationale de France/Bibliothèque royale de Belgique, 20II, S. $202 \mathrm{f}$.

20 B. Brinkmann, Die flämische Buchmalerei am Ende des Burgunderreichs. Der Meister des Dresdener Gebetbuchs und die Miniaturisten seiner Zeit, Textband, S. 343, Anm. 2. Die Fleuronnée-Initialen passen in die Tradition des Klosters, zu den Deckfarbenmalereien ist mir jedoch nichts Vergleichbares aufgefallen. 
Damit sind fast sämtliche bedeutenden Buchmalereien aus dem Rooklooster als auswärtige Produktion bewertet worden - die blühende höfische und bürgerliche Buchkultur in Flandern, die leistungsfähigen Buchmalerateliers die Existenz ermöglichte, bot offensichtlich auch dem Rooklooster ausreichend Möglichkeiten, Handschriften anspruchsvoll ausstatten zu lassen. Dennoch, Klöster waren im I5. Jahrhundert auch in Flandern nicht nur Käufer von Büchern, sondern gehörten zu den wichtigsten Herstellern und Ausstattern von Handschriften. ${ }^{22}$ Aus schriftlichen Quellen geht hervor, dass auch die Augustiner-Chorherren des Rookloosters Bücher nicht nur gekauft haben oder als Geschenk erhielten, ${ }^{23}$ sondern dass sämtliche zur Buchherstellung notwendigen Arbeitsschritte von ihnen selbst geleistet werden konnten, vom Verfassen, Kopieren und Illuminieren bis zum Binden. ${ }^{24}$

In den knappen, von Gaspar Ofhuys verfassten Nachrufen auf seine Mitbrüder werden diese Tätigkeiten immer wieder erwähnt, ${ }^{25}$ was zeigt, wie wichtig und angesehen sie waren und dass sie zur klösterlichen Buchkultur gehörten, die sich dadurch wesentlich von der höfischen und bürgerlichen unterschied. Wie sich die Personalunion von Herstellern und Benutzern auswirkte und ob die Verbindungen innerhalb der Kongregationen stilistische Entwicklungen förderten, die unabhängig von den lokalen Traditionen verliefen, und wie ein möglicher Austausch ausgesehen haben könnte, sind nicht nur aus kunsthistorischer Sicht interessante Fragen. Die besonderen Bedürfnisse der Klöster scheinen zum Beispiel die Einführung und Durchsetzung von Neuerungen, die für die gesamte Entwicklung des Buchwesens von Bedeutung waren, gefördert zu haben, wie die Organisation des in den Büchern bewahrten Wissens. So wurde den Handschriften im Rooklooster im I5. Jahrhundert fast regelmäßig ein Inhaltsverzeichnis vorgeschaltet, und zwischen 1532 und 1538 ist ein Verbundkatalog angelegt worden, der mehrere Klosterbibliotheken in den Niederlanden und im westlichen Deutschland umfasste. ${ }^{26}$ Auf Anzeichen der überregionalen Verflechtung der Buchkultur des Rookloosters haben bereits Dagmar Thoss und Otto Pächt mit der Bemerkung hingewiesen, dass die Fleuronnée-Initialen in den Handschriften des Rookloosters größte Verwandtschaft zu Zierinitialen in holländischen Handschriften zeigen, in denen ähnlich großformatige, kolorierte Motive anzutreffen sind, ${ }^{27}$ während die professionellen Ateliers in Flandern kleinteiliges Fleuronnée verwendeten, das sich in der Regel eng um die Lombarden kräuselt - wenn sie überhaupt diesen Initialtyp einsetzten.

22 Etwas ausführlicher zu diesem Thema unter anderem M. SMeYers, Flämische Buchmalerei vom 8. bis zur Mitte des I6. Jahrhunderts, Stuttgart 1999, S. 268-278; C. ReYnolds, Illuminators and the Painter's Guilds, in: Illuminating the Renaissance (zit. Anm. I2), S. 15-33, bes. S. I9.

23 Beispiele hierfür bei P. FAIDER, Le livre manuscrit du XVe au XIX ${ }^{e}$ siècle, in: Le Livre estampe. L'édition en Brabant du XVe au XIXe siècle, Mémorial de l'exposition d'art ancien à Bruxelles, Gembloux 1935, S. 9-2I, bes. S. I8.

24 Gielemans, Anecdota (zit. Anm. 6), S. i74.

25 Abgedruckt in Gielemans, Anecdota (zit. Anm. 6), S. 297-303.

26 Wien, Österreichische Nationalbibliothek, Ser. nov. I2694; Corpus Catalogorum Belgii. The medieval booklists of the Southern Low Contries, Bd. 4: Provinces of Brabant and Hainault, hrsg. von A. Derolez/B. Victor/W. Bracke, Brüssel 200i, S. i79; P. F. J. Оввемa, Problems of editing the Rooklooster Register, in: Middeleeuwse bibliotheken en boekenlijsten in de Zuidelijke Nederlanden, Brüssel 2005, S. 7I-76. 
Die Angehörigen der flämischen Klöster gingen im I5. und I6. Jahrhundert bei der Buchausstattung unterschiedlich vor - es scheint alles möglich gewesen zu sein, von der Auftragsvergabe an professionelle Buchmaler(ateliers), an andere Klöster oder an Kleriker, die als Illuminatoren tätig waren (was zum Beispiel die Rechnungsbücher der Prämonstratenserabtei Averbode belegen, nach denen unter anderem Kanoniker aus Löwen und das Augustiner-Chorherrenkloster Korsendonk für das Illuminieren von Chorbüchern bezahlt wurden), ${ }^{28}$ bis zur hauseigenen Produktion anspruchsvoll ausgestatteter Stundenbücher für den Verkauf. Für letztere liefert die Karmeliterin Cornelia van Wulfschkercke ein Beispiel. ${ }^{29}$ Aber auch die Namen von Geistlichen in Zunftbüchern aus der zweiten Hälfte des I5. Jahrhunderts zeigen, dass diese an der kommerziellen Buchausstattung beteiligt waren. ${ }^{30}$

Wie groß der Beitrag der Klöster zur Entwicklung der spätmittelalterlichen Buchmalerei in Flandern tatsächlich war, inwieweit die Ordenszugehörigkeit oder vielleicht doch eher Zufälligkeiten wie die Reformwilligkeit eines Abtes, einer Äbtissin oder die Anwesenheit ausgebildeter Buchmalerinnen oder Buchmaler entscheidend waren, kann erst beurteilt werden, wenn mehr Einzeluntersuchungen zu den Klöstern vorliegen und wenn man Methoden findet, die Produktion vor Ort von bezahlter Buchmalerei zu unterscheiden. Im Folgenden soll versucht werden, eine Vorstellung von der hauseigenen Produktion des Rookloosters zu vermitteln. Ein Problem dabei ist, dass die großen Chorbücher wie Antiphonare, Gradualien und Missalien, die den eigentlichen Anlass für die volle Entfaltung reichen Schmuckes boten, verloren sind. Doch mit Hilfe der ehemaligen Bibliotheksbestände des Klosters lässt sich ein Eindruck von der Buchausstattung des Klosters gewinnen, von der in den Chroniken des Hauses berichtet wird.

\section{JOHANNES GIELEMANS UND GASPAR OFHUYS ÜBER \\ DIE BUCHPRODUKTION IM ROOKLOOSTER}

Es sind zwei Klosterchroniken überliefert, die, wenn auch spärlich, Auskunft über Art und Weise der Buchherstellung im Rooklooster geben: Eine von beiden ist das zwischen 1483 und 1485 verfasste Novale Sanctorum, in dem Johannes Gielemans (I427-I487) neben Heiligenleben und Mirakelberichten auch Einzelheiten über die Geschichte des Klosters und über seine Mitbrü-

28 P. LefÈVre, Transcriptions, enluminures et reliures de manuscrits liturgiques aux XV ${ }^{\mathrm{me}}$ et $\mathrm{XVI}^{\mathrm{me}}$ siècles, in: Archives, Bibliothèques et Musées de Belgique, I2, I935, S. 8-24, bes. S. I2, I6.

29 A. Arnould, De la production de miniatures de Cornelia van Wulfschkercke au couvent des carmélites de Sion à Bruges, Brüssel 1998. Auch die Nonnen des Klosters Mariendaal waren mit dem Illuminieren von Handschriften beschäftigt (R. vAN DE VEN, Het boekbedrijf te Diest gedurende de I5de en I6de eeuw, in: Handschriften uit Diestse kerken en kloosters, Ausstellungskatalog, Diest 1983, S. 13-23, bes. S. I4f.).

30 Reynolds, Illuminators (zit. Anm. 22), S. 20; weitere Beispiele für Buchschmuck produzierende Klöster bei SMeYers, Flämische Buchmalerei (zit. Anm. 22), S. 269-278; W. Lourdaux/M. Haverals, Bibliotheca vallis sancti Martini in Lovanio. Bijdrage tot de studie van het geestesleven in de Nederlanden (I5de-I8de eeuw). II: De geschiedenis van de bibliotheek en de evolutie van haar inhoud, Leuven 1982, zur Buchausstattung: S. 219-232 (englische Zusammenfassung). In Kohl/Persoons/WeILer, Monasticon (zit. Anm. 9), werden unter 3.2.3. für jedes Kloster Schreiber, Illuminatoren und Buchbinder aufgeführt, soweit sie in den Schriftquellen erwähnt sind. 
der festgehalten hat. ${ }^{31}$ Die andere stammt von Gaspar Ofhuys (I456-I532), der für seinen Catalogus fratrum choralium Rubeae Vallis die Schriften von Gielemans auswertete und ergänzte. ${ }^{32}$

Gielemans hat seine Geschichte des Klosters als Dialog zwischen einem Senior und einem Iunior angelegt. Auf die Frage des Juniors nach angemessenen Arbeiten für einen Geistlichen antwortet der Senior, dass fast alle Kirchenbücher (mit denen hier die Chorbücher gemeint sein dürften) des Rookloosters von Mitbrüdern geschrieben wurden. Allerdings erwähnt er auch zwei Ausnahmen: Ein Missale wurde von den Augustiner Chorherren in Windesheim gekauft, und ein Graduale stammt aus dem Kloster Bethlehem. ${ }^{33}$ Außerdem berichtet Gielemans, dass Christian de Veris († I432), der als Vierter die Profess im Rooklooster abgelegt hatte, die alten Chorbücher geschrieben hat. Diese waren - wie Ofhuys ergänzt, nach dem Beitritt des Klosters zur Windesheimer Kongregation - verkauft worden, und ihr Erlös diente dem Erwerb von Materialien für neue Bücher, die für die Kirche (pro ecclesia) und für die Bibliothek (pro libraria) bestimmt waren. ${ }^{34}$ Offensichtlich gab es einen nicht unbedeutenden Handel mit Chorbüchern, wobei an einem Ort als liturgisch veraltet betrachtete Handschriften für andere Kirchen oder Klöster durchaus noch brauchbar gewesen zu sein scheinen.

Zur Ausstattung dieser Bücher äußerten sich Gielemans und Ofhuys nicht, doch die Kapazität für alle notwendigen Arbeitsgänge scheint vorhanden gewesen sein: Gielemans berichtet, dass mehrere Brüder nicht nur Texte kopierten, sondern diese auch gebunden ${ }^{35}$, mit Fleuronnée-Initialen ausgestattet und illuminiert haben; auch das Glätten von Pergament wird erwähnt. ${ }^{36}$ Doch nennt er weder Namen noch Zeitspanne, und so lassen sich keine Zuordnungen vornehmen. Ofhuys gibt in seinen kurzen Nachrufen für einige seiner Mitbrüder an, dass sie auch Bücher ausgestattet haben, ohne allerdings konkrete Werke aufzuführen. Im Monasticon Windeshemense wurden die Schriften der beiden Chronisten ausgewertet und die Namen zusammengestellt: ${ }^{37}$ Ausdrücklich als Illuminator und Florator wird nur Simon Logghen bezeichnet, der als 54. die Profess ablegte und 1489 starb. ${ }^{38}$ Von Arnoldus Vrancken († I538) wird be-

3I Wien, Österreichische Nationalbibliothek, Cod. Ser. nov. I2708 und Cod. Ser. nov. I2709; Auszüge publiziert in Gielemans, Anecdota (zit. Anm. 6), S. 80-197.

Brüssel, Königliche Bibliothek, Ms. II 48o, foll. 20v-273r; Ausgabe in Gielemans, Anecdota (zit. Anm. 6), S. 197-303; der Catalogus wurde von Ofhuys (1456-1532) begonnen und nach seinem Tod bis I668 ergänzt, Kohl / Persoons / Weiler, Monasticon (zit. Anm. 9), S. ini f. Bethleem; reliqua communiter aestimantur in hoc loco conscripta. Zitiert nach Gielemans, Anecdota (zit. Anm. 6), I73.

34 Frater vero Chrstianus de Veris dudum scripserat antiquos libros chorales, qui omnes care satis venditi sunt, et pretium eorum ad materiam novorum librorum tam pro ecclesia quam pro libraria redactum, zitiert nach GIELEMANS, Anecdota (zit. Anm. 6), I74; für die Ergänzung von Ofhuys siehe Gielemans, Anecdota (zit. Anm. 6), S. 204 f.

$35 \mathrm{Zu}$ den Einbänden siehe P. Verheyden, La reliure en Brabant, in: Le Livre estampe. L'édition en Brabant du XVe au XIXe siècle, Mémorial de l'exposition d'art ancien à Bruxelles, Gembloux 1935, S. I40-I89, bes. S. $149-156$.

36 ... et quam plures alii fratres aut scribunt aut ligant libros aut florant aut illuminant aut pumicant, zitiert nach Gielemans, Anecdota (zit. Anm. 6), S. I74.

37 Kohl/Persoons / Weiler, Monasticon (zit. Anm. 9), S. ir8.

38 Gielemans, Anecdota (zit. Anm. 6), S. 233: Frater iste illuminator seu florator librorum aliqualiter fuit. 
richtet, dass er Initialen malen konnte, ${ }^{39}$ und Judocus de Breda soll ebenfalls Bücher ausgemalt haben. ${ }^{40}$ Von Aegidius de Wilde ( $\left.\dagger_{1503}\right)$ heißt es hingegen lediglich, dass er das heilige Land beschrieben und gezeichnet habe. ${ }^{41}$

Dafür, dass nicht nur alte Chorbücher verkauft wurden, sondern auch vereinzelt gegen Bezahlung (pro pretio) kopiert wurde, gibt es ebenfalls einen Hinweis. So berichtet Ofhuys, dass der I472 verstorbene Johannes Bac mit Zustimmung des Abtes für auswärtige Auftraggeber schreiben durfte. Mit dem eingenommenen Geld hat Bac zwei Bilder für das Refektorium gekauft. ${ }^{42} \mathrm{Ob}$ er die Bücher auch ausstattete, lässt sich nicht sagen, aber die von ihm signierte und 1465 datierte Kopie der Vita sanctorum (Brüssel, Königliche Bibliothek, Ms. 197), die bis zu ihrer Überführung in die Königliche Bibliothek in Brüssel im Rooklooster verblieben ist, enthält Fleuronnée-Initialen, wie sie auch in anderen Rooklooster-Handschriften aus der zweiten Hälfte des I5. Jahrhunderts zu finden sind.

\section{WERKE AUS DEN ERSTEN JAHRZEHNTEN \\ NACH DER GRÜNDUNG DES KLOSTERS}

Der Geistliche Gilles Olivier gründete 1359 eine Klause im Zonienwald bei Brüssel, die auf Initiative eines seiner Anhänger, Guillaume Daneels, zunächst verlegt und dann 1372 in ein Kloster umgewandelt wurde. ${ }^{43}$ Wegen der geringen Einkünfte war die Anzahl der Konventualen beschränkt, zunächst auf vier Kanoniker und vier Konversen, doch nach der Fertigstellung der Kirche 1385 wurde auf zwölf Konventualen erhöht, und 1392 hob der Bischof von Cambrai die Beschränkung für die Aufnahme von Novizen auf. ${ }^{44}$ Es wurde lange vermutet, dass das Rooklooster schon in diesen ersten Jahrzehnten ein bedeutendes Skriptorium unterhielt, denn aus seiner Bibliothek blieben 23 geistliche Texte in niederländischer Sprache erhalten, die im I4. Jahrhundert und zu Beginn des I5. Jahrhunderts entstanden sind und dem Kloster den Ruf einbrachten, eines der ältesten Zentren für die Produktion mittelniederländischer Literatur gewesen zu sein. ${ }^{45}$ In seiner 2002 publizierten Dissertation über diese Handschriftengruppe hat Erik Kwakkel Zweifel angemeldet, dass die Bücher von

39 Ebd., S. 258: insignis artifex in depingendis litteris.

40 Ebd., S. 260: domui huic servivit in compingendis libris.

4I Ebd., S. 235, Anm. I: Desriptionem terrae promissionis in rotula longa et larga descripsit et depinxit. Pierre Hamblenne hat darauf hingewiesen, dass auf fol. I4Iv in Ms. II 253I auf einem in eine Fleuronnée-Initiale eingefügtem Schriftband der Name Egidius Willis steht und damit der Schreiber Aegidius de Wilde aus dem Rooklooster gemeint sein könnte, denn die dortige Kopie des Textes diente als Vorlage für Ms. II 253I (P. HaMBLENne, Quelques manuscrits de Bethléem [Herent], in: Manuscripts in Transition. Recycling Manuscripts, Texts and Images, hrsg. von B. Dekeyzer/J. van der Stock, Paris u. a. 2005, S. 325-334, bes. S. 328, Anm. 40). Vor allem Motive der Binnenfeldfüllungen sind tatsächlich in Büchern aus dem Rooklooster wiederzufinden, doch ist mir keine vergleichbare Randleiste aufgefallen.

Gielemans, Anecdota (zit. Anm. 6), S. 196, Anm. 2.

43 Maes, Rouge-Cloître (zit. Anm. 2), S. 6-I3.

44 Kohl/Persoons/Weiler, Monasticon (zit. Anm. 9), S. i26.

45 E. KwAKkel, Die dietsche boeke die ons toebehoeren, Löwen 2002 (Miscellanea Neerlandica XXVII), S. 2, I4. 


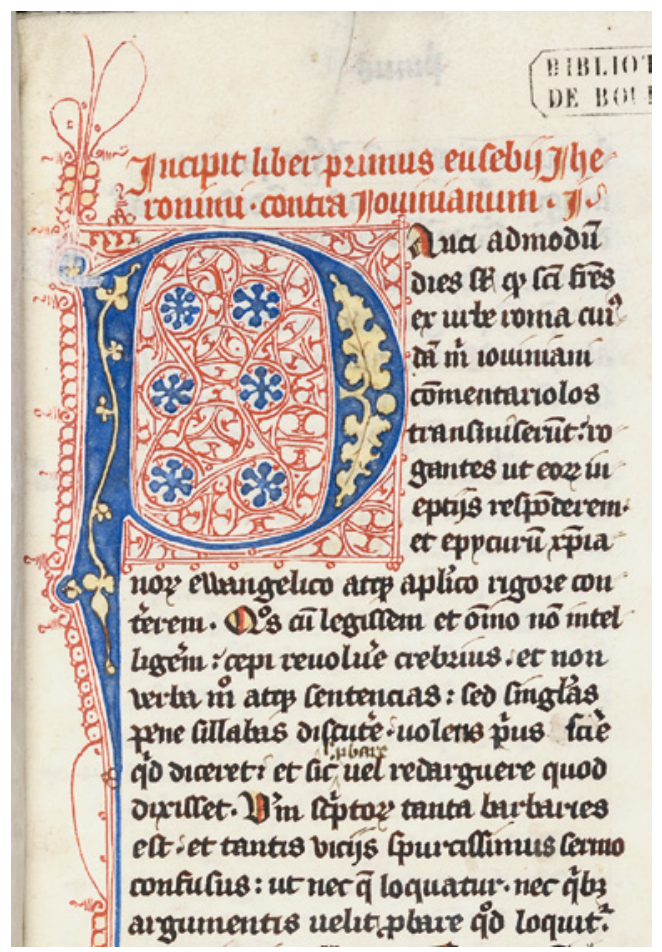

Abb. I: Brüssel, Königliche Bibliothek, Ms. 472-79, f. 5r, Rooklooster, 1396

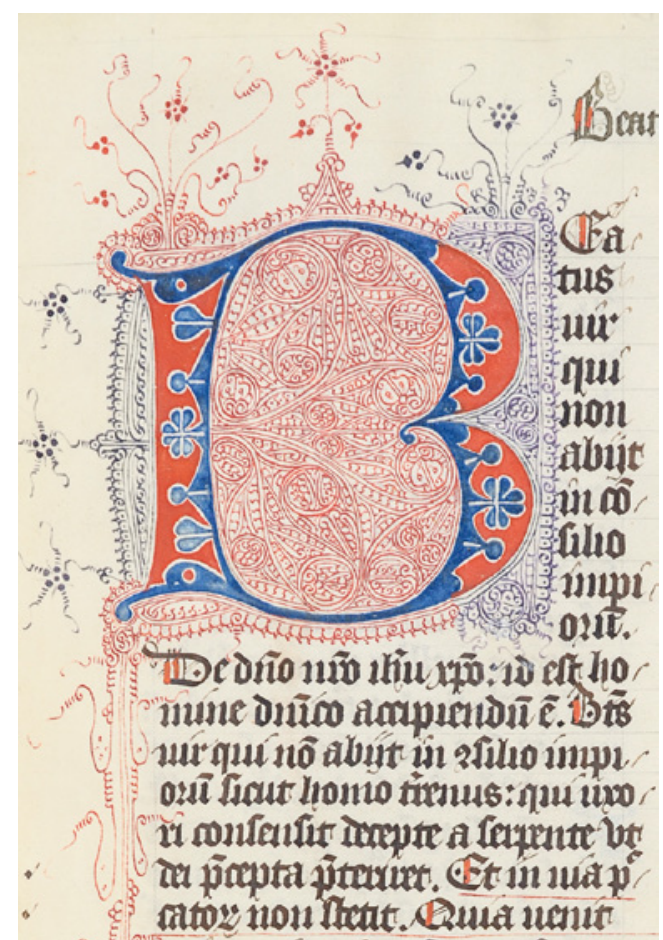

Abb. 2: Brüssel, Königliche Bibliothek, Ms. 65, f. 2r, Rooklooster(?), spätes I4. Jahrhundert

den Augustiner-Chorherren selbst geschrieben worden sind, und argumentiert stattdessen für die Kartause in Herne als Entstehungsort. ${ }^{46}$

Auch wenn diese bedeutende Handschriftengruppe nicht im Rooklooster entstanden sein sollte, kann man dem Bericht von Johannes Gielemans doch entnehmen, dass man sich nicht nur auf den Ankauf verließ, sondern dass zumindest die Herstellung der Chorbücher teilweise durch einen Angehörigen des Stiftes, nämlich Christian de Veris († I432), geleistet wurde. Da diese Bücher nach I4I2 verkauft wurden, können sie nicht mehr für eine Einschätzung möglicher hauseigener Buchausstattung herangezogen werden. Die älteste erhaltene und datierte, sicher im Rooklooster entstandene Handschrift mit Buchschmuck scheint eine Kopie der Werke von Hieronymus in der Königlichen Bibliothek in Brüssel zu sein (Ms. 472-479). ${ }^{47}$ Laut Inschrift auf fol. 228v wurde sie 1396 im Rooklooster kopiert und gebunden, weshalb man davon ausgehen kann, dass auch die drei Fleuronnée-Initialen auf foll.

46 Ebd.

47 Die Untersuchung stützt sich auf die Listen von E. Persoons, Handschriften uit kloosters in de Nederlanden in Wenen, in: Archives et Bibliothèques de Belgique/Archief- en Bibliotheekwezen in België, 38, I967, S. 59-IO7 und Kohl/Persoons/Weiler, Monasticon (zit. Anm. 9), S. II5f. Es konnten die Bestände der Österreichischen Nationalbibliothek in Wien, der Königlichen Bibliothek in Brüssel, der National Library in London und der Pariser Bibliotheken (Bibliothèque nationale, Bibliothèque Mazarine, Bibliothèque d'Arsenal) berücksichtigt werden. 
Abb. 3: Brüssel, Königliche Bibliothek, Ms. 3IO, f. Ir, Christus am Ölberg, Rooklooster, I42I

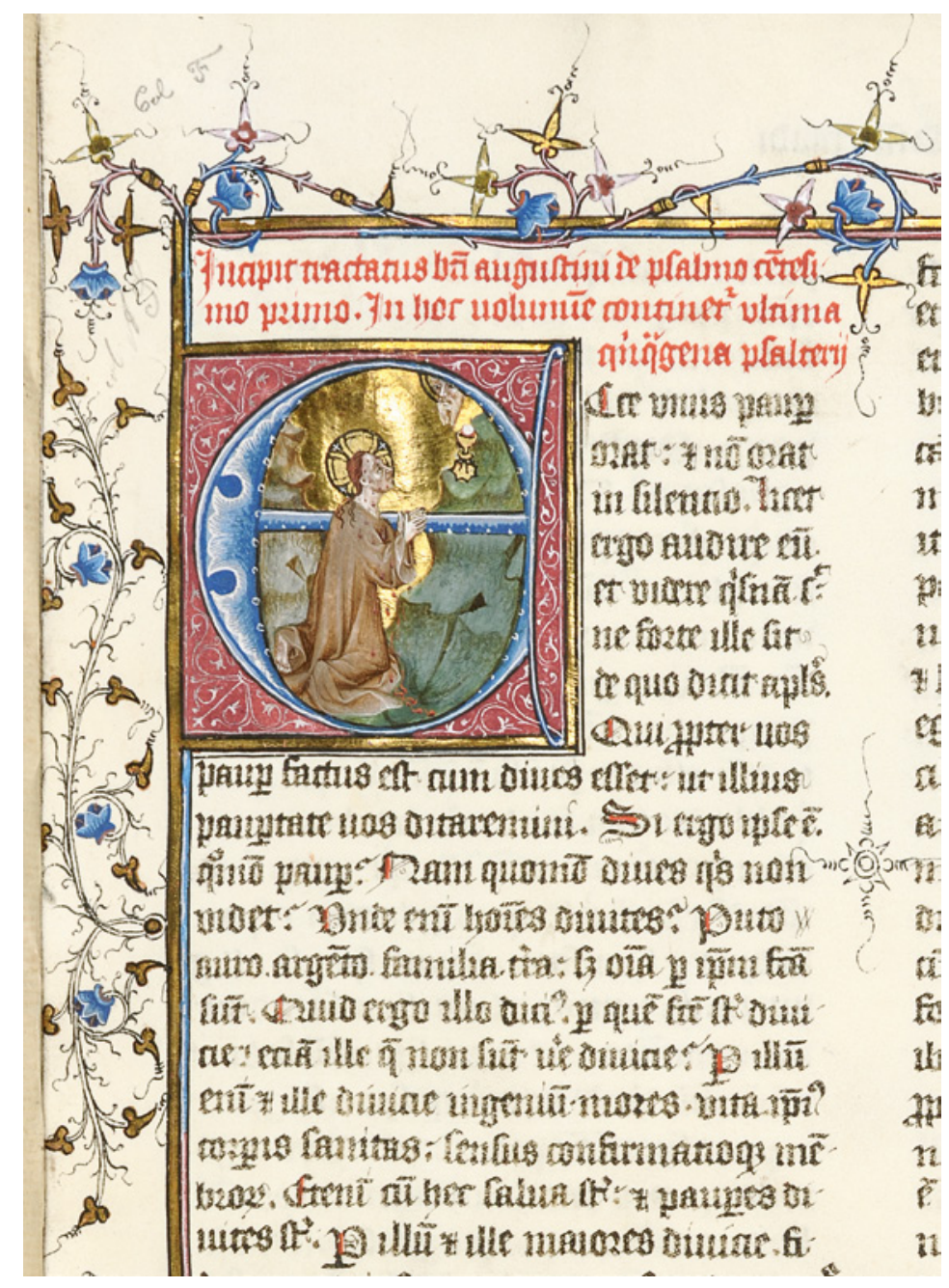

5r, 5IV und 203r vor Ort eingefügt wurden: ${ }^{48}$ Es handelt sich um blaue Lombarden (zu Beginn des Textes auf fol. $5 \mathrm{r}$ mit gelb kolorierten, blattförmigen Aussparungen, Abb. I), umgeben von rot gezeichneten Ornamenten, deren bestimmende Motive Doppelknospen in Medaillons als Flächenfüllung und von großen Bögen unterbrochene Perlenreihen als Besatzmotiv für die Randleisten sind. Eine weitere Arbeit dieses Florators markiert den Anfang des Werkes De claustro animae von Hugo von St. Viktor, das ebenfalls aus der Bibliothek des Rookloosters stammt. ${ }^{49}$

Von diesen Zierinitialen unabhängig, aber untereinander übereinstimmend zeigt sich der Buchschmuck in zwei weiteren frühen Handschriften: Die Fleuronnée-Initialen in einer Kopie

48 Eine weitere Initiale befindet sich auf fol. 228r, doch gehört sie zu einem Nachtrag aus der zweiten Hälfte des I5. Jahrhundert und weist die in dieser Zeit im Rooklooster üblichen Zierformen auf.

49 Paris, Bibliothèque Mazarine, Ms. 724, fol. Ir. 
des Psalmenkommentars von Augustinus (Ms. 65, Abb. 2) ${ }^{50}$ und in einem Homiliar (Sommerteil, Ms. 289, nur die großen Initialen auf foll. Ir und CXIIIr) ${ }^{51}$ weisen ein übereinstimmendes Motivrepertoire und eine gleichmäßig sichere, in den Einzelformen konstante Zeichnung auf, was die Ausführung durch einen einzigen Florator vermuten lässt. Keine der beiden Handschriften enthält einen Schreibervermerk, doch wurde der Augustinus-Band laut Eintrag auf fol. 259r I4I4 im Rooklooster gebunden (der Einband ist nicht erhalten), und in der liturgischen Handschrift gibt es mehrere in der zweiten Hälfte des 15 . Jahrhunderts nachgetragene Fleuronnée-Initialen, die sicher im Kloster entstanden sind (foll. IVr, VIr, XVIv und andere). ${ }^{52}$ Einige der für den Florator von Ms. 65 und Ms. 289 charakteristischen Motive wie die Verzierung der rot-blau gespaltenen Buchstabenkörper mit kreuzweise geteilten Mittelmotiven zwischen kugelbesetzten Spitzen und die zur Fleuronnée-Füllung der Binnenfelder gehörenden Ranken mit lyraförmigen Blüten in der Mitte ihrer zu Spiralen eingerollten Enden wurden in einem weiteren Homiliar (Winterteil) des Rookloosters nachgeahmt (Ms. 2I8, zum Beispiel fol. I3ra, I3rb). ${ }^{53}$ Dieser jüngere, etwas ungelenk arbeitende Zeichner hat die Motive phantasievoll durch Drachen, Eichenblätter und Eicheln ergänzt.

Die früheste nachweisbare Handschrift, die ihren figürlichen Schmuck vor Ort erhalten hat, wurde I42I im Rooklooster geschrieben. Es handelt sich um einen weiteren Band des Psalmenkommentars von Augustinus (Brüssel, Königliche Bibliothek, Ms. 310). ${ }^{54}$ Das Buch ist mit einer Bildinitiale zu Beginn des Textes auf fol. Ir ausgestattet, die einen Blut schwitzenden Christus am Ölberg zeigt (Abb. 3). An die Initiale schließt eine Leiste an, die um drei Seiten des Textspiegels geführt und von einer Ranke mit blauen Blüten begleitet wird. Zwischen den Kolumnen und auf dem Textrand sind von Zierlinien eingefasste Kreise mit und ohne Goldfüllung platziert. Der Psalmenkommentar enthält nur diese eine Initiale zu Beginn des Textes, und mir sind in den übrigen Handschriften aus dem Rookloosters keine weiteren Arbeiten des Illuminators aufgefallen. ${ }^{55}$

Die voneinander unabhängigen Stilidiome, die bei den Zierinitialen aus dem späten I4. und dem beginnenden 15 . Jahrhundert zu beobachten sind, deuten auf eine unterschiedliche Ausbildung der Floratoren oder Buchmaler. Dass sie keine wirkliche Nachfolge vor Ort hatten und zwischen ihnen kein Motivaustausch stattfand, könnte ein Hinweis darauf sein, dass sie nur vorübergehend im oder für das Kloster tätig waren.

50 Augstinus, Quinquagena prima de psalmis, Brüssel, Königliche Bibliothek, Ms. 65 .

5I Homiliarum, Pars aestiva, Brüssel, Königliche Bibliothek, Ms. 289.

52 Der Einband von Ms. 289 soll ebenfalls im Rooklooster angefertigt worden sein, J. van DEN GHEYn, Catalogue des manuscrits de la Bibliothèque Royale de Belgique, Bd. 3, Brüssel 1903, S. 2 II.

53 Homiliarum, Brüssel, Königliche Bibliothek, Ms. 2I8.

54 Augustinus, Ultima quinquagena psalterii, Brüssel, Königliche Bibliothek, Ms. 310; fol. 238v: Iste liber est fratrum canonicorum monasterii rubee vallis alias sancti pauli in zonia Et a quodam fratre eiusdem monasterii regulari concanonico scriptus est et finitus Anno domini $M^{\circ}$.CCCC ${ }^{\circ}$.XXI. XVIII die februarii secundum morem et modum dyocesis Camaracensis. J. van DEN GHeYn, Catalogue des manuscrits de la Bibliothèque Royale de Belgique, Bd. 2, Brüssel 1902, S. 407.

$55 \mathrm{Zu}$ den für vorliegende Untersuchung herangezogenen Handschriften siehe Anmerkung 49. 


\section{ORNAMENTINITIALEN VON SIMON LOGGHEN, ARNOLDUS VRANCKEN, JUDOCUS DE BREDA UND ANDEREN}

Weder vom Illuminator des Psalmenkommentars noch von den oben vorgestellten Floratoren lässt sich eine Linie zur Ausstattung der Handschriften und Inkunabeln ziehen, die nach der Mitte des I5. Jahrhunderts einsetzte. Das älteste datierte Werk dieser Gruppe, der im Verlauf der vorliegenden Untersuchung 34 Handschriften und fünf Inkunabeln zugeordnet werden konnten, ${ }^{56}$ ist eine Kopie der Historia ecclesiastica des Eusebius Caesariensis, übersetzt von Rufinus, die laut nachgetragenem Explicit 1462 von Johannes Gielemans vollendet worden ist (Abb. 4). ${ }^{57}$ Als jüngstes Beispiel konnte eine 1546 datierte Kopie von Schriften des Ambrosius ${ }^{58}$ ausgemacht werden (Abb. 7). Die meisten der in diesen fast 90 Jahren ausgestatteten Bücher haben Fleuronnée-Initialen erhalten, manchmal koloriert (Abb. 6) oder mit Deckfarbenranken an den Enden der Randleisten kombiniert (Abb. 8). ${ }^{59}$ Der lange Zeitraum, in dem diese Art von Buchschmuck gepflegt wurde, deutet ebenso wie die verhältnismäßig große Anzahl der Werke, die stilistische Entwicklung der Zierformen und die Zusammenarbeit mehrerer Floratoren, die die gleichen Motive in unterschiedlicher Ausführung, aber übereinstimmender Anordnung und ähnlicher Auswahl verwendeten, darauf hin, dass es in diesem Zeitraum im Rooklooster eine hauseigene Produktion dekorierter Handschriften gegeben hat und dass jüngere Konventsmitglieder in dieser Kunst ausgebildet wurden.

Neben Floratoren, die ganz dem Stil des Rooklooster-Fleuronnées verhaftet waren, scheinen bisweilen auch Kräfte beteiligt gewesen zu sein, die ein eigenes Formenrepertoire mitbrachten. Sie übernahmen einzelne der vor Ort üblichen Motive und wirkten gleichzeitig vorbildlich. Daraus ergibt sich ein komplexes Wechselspiel von Austausch, Entwicklung und persönlichem Stil. Einen Eindruck davon kann man mit Hilfe der Abbildungen im Tafel-

56 Handschriften: Brüssel, Königliche Bibliothek, Mss. 197, 213, 242-265, 289 (nachgetragene Initialen auf foll. 4r, 6r, 7r, I6v, 3Iv), 312-320, 356-379, 472-479 (nachgetragene Initiale auf fol. 226r), I208-I210, 2037-2048, II 5819, IV 860 (nur die Fleuronée-Initialen); London, British Library, Add. ms. II863 (nur die FleuronnéeInitialen), Add. ms. 11864 (nur die Fleuronnée-Initialen); Paris, Bibliothèque de l’Arsenal, Ms. 507, Ms. 540; Paris, Bibliothèque Mazarine, Ms. 562 (nur die Fleuronnée-Initialen), Ms. I773 (I538 datiert); Wien, Österreichische Nationalbibliothek, Cod. Ser. nov. I2704 bis I27IO, I2800, I28II, I28I2, I28I4, I2853, I2890. Inkunabeln: Brüssel, Königliche Bibliothek, B 73, B 572, B I251; Wien, Österreichische Nationalbibliothek, Ink. 4.F.36.

57 Brüssel, Königliche Bibliothek, Ms. II 5819; Explicit mit Datierung auf fol. 244v: Explicit hystoria ecclesiastica tripartita. completa kalendis Junii Anno domini. $1462^{\circ}$. per manus fratris iohannis gielemans cuius anima post mortem requiescat.

58 Brüssel, Königliche Bibliothek, Ms. 242-265, Explicit mit Datierung auf fol. 274v: Liber monasterii Rubeevallis in Zonia iuxta bruxellam. Hoc volumen pro prima et maiori parte scripsit frater Hubertus de wijse professus in dicto monasterio. Ultimam vero partem complevit frater Cornelius Wischaven sacerdos professus etiam in eodem monasterio. Oretur igitur pro ipsis ferventer ex charitate. Item multa in isto volumine scripta sunt festivis diebus. Non venundetur. - Orate delectissimi fratres pro me fratre huberto de wyse confratre vestro. Anno xv.xlvi ianuarii xxviii, zitiert nach van DEN GHeYn, Catalogue (zit. Anm. 54), S. 4I.

59 Weitere Beispiele abgebildet bei Рёснт / Thoss, Flämische Schule II (zit. Anm. I8), Tafelband, Abb. 209f., 2I6, 218 . 


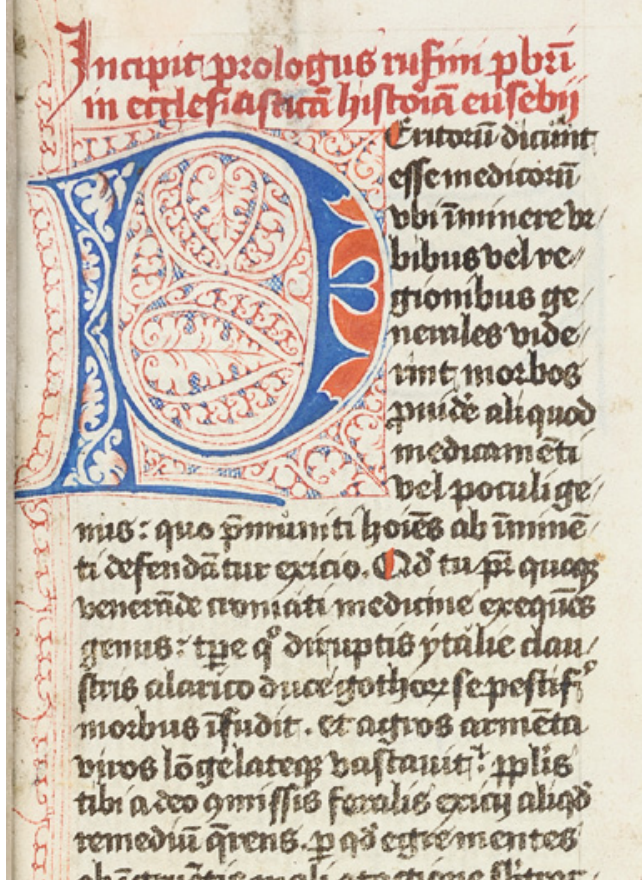

Abb. 4: Brüssel, Königliche Bibliothek, Ms. II 5819, f. Ir, Rooklooster, I462

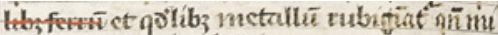

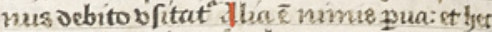

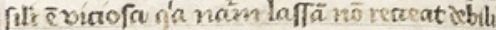

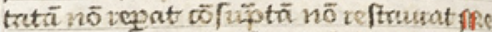
viocris añ itter hor è landabilis. nä ralose-

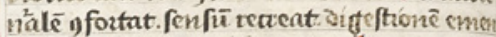
Dat corp? medocrit puxgat it te quo as ith taté n'es alia é b́a et lyec laudabilis ẽ fi non fit nima.alia nö vera vot i febubzet ljer min? laudabilis रे fiact pos sicet: Inapot eroy E lib. vy? De infirm

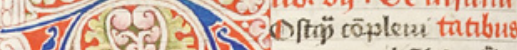

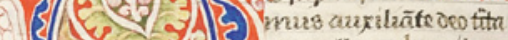

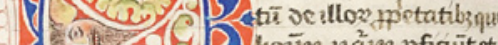

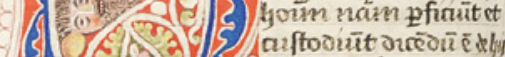

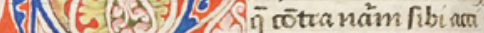

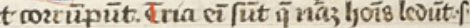

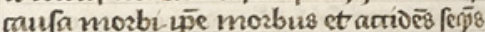
mozbū caufa nozbi č zo oñ pueit mala

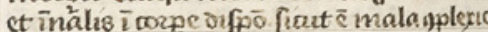
nimia repletio of ianutio bitutis deftio nizalitatù alteratio.et gtinuitatis Diffolutio

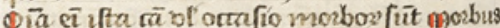

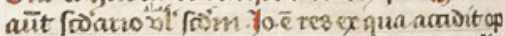
pofitioi corpis lefiōis nocumētü fiaut ẽ fubs

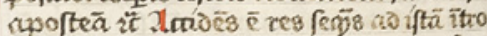

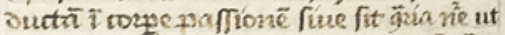

Abb. 6: Brüssel, Königliche Bibliothek, Ms. 213, f. 53v, Rooklooster, letztes Viertel I5. Jahrhundert

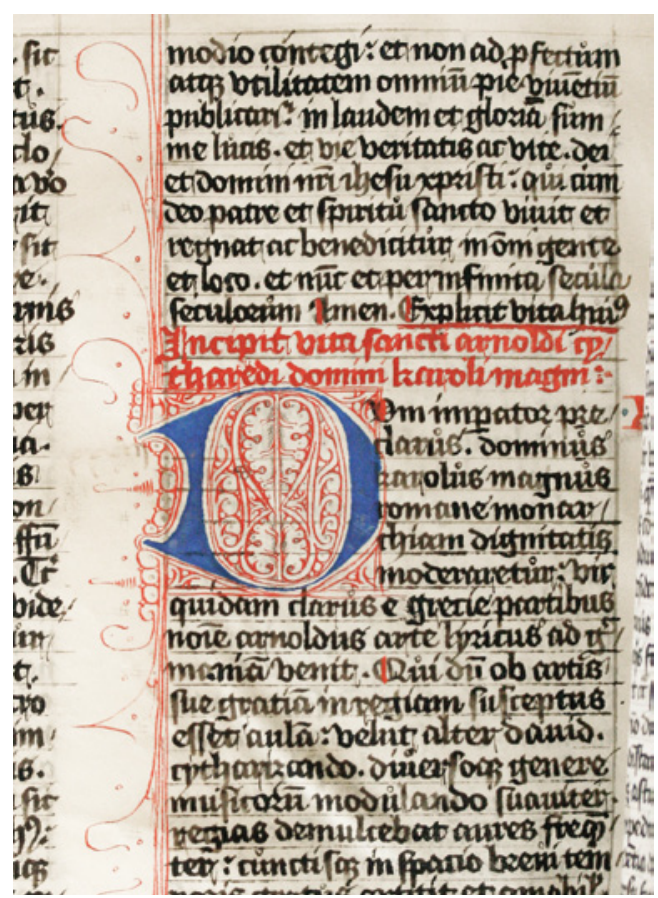

Abb. 5: Wien, Österreichische Nationalbibliothek, Ser. nov. I2706, f. I77v, Rooklooster, zwischen I470 und I486

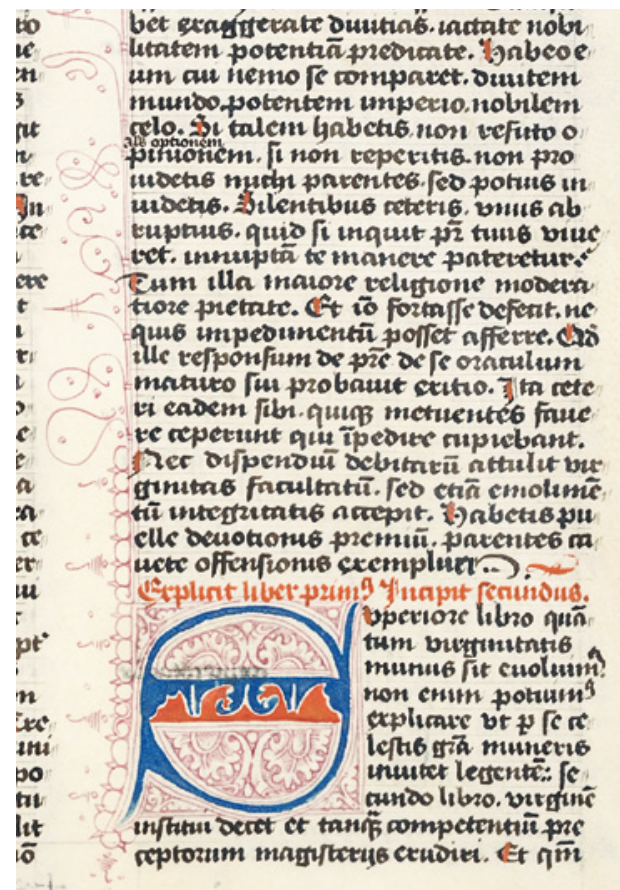

Abb. 7: Brüssel, Königliche Bibliothek, Ms. 242-265, f. 57r, Rooklooster, I546 
Abb. 8: Wien,

Österreichische

Nationalbibliothek,

Ser. nov. I2706, f. Ir,

Rooklooster, zwischen

I470 und 1468

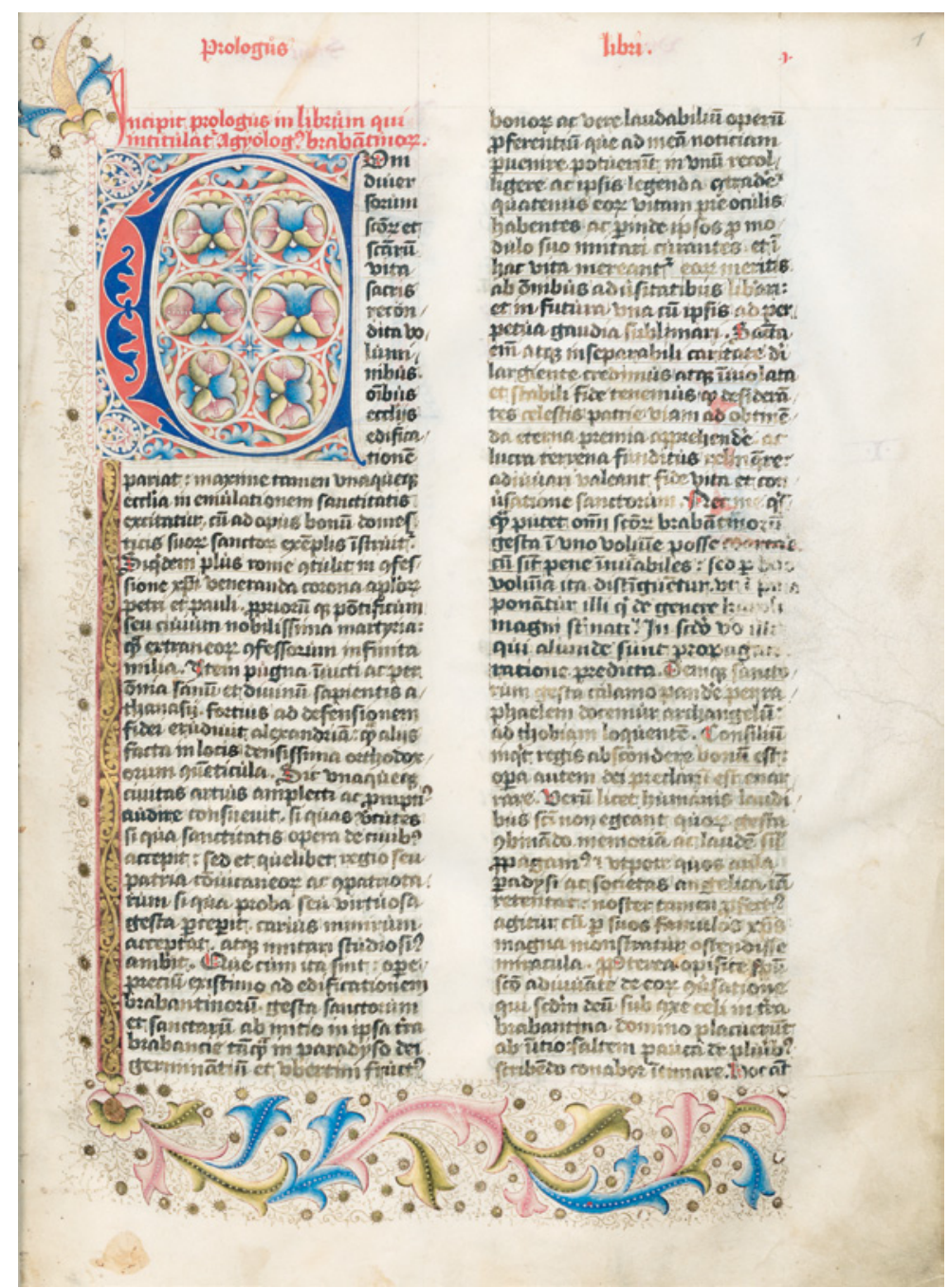

band des Kataloges Flämische Schule II von Dagmar Thoss und Otto Pächt gewinnen. Die Abbildungen 2IO, 218, 22I, 222, 238 zeigen die Variante des Rooklooster-Fleuronnées, die am häufigsten anzutreffen ist. ${ }^{60}$ Das kleinteiligere, mit kräftigem Grün akzentuierte Fleuronnée, das die Abbildungen 219 und 225 wiedergeben, scheint nur im Novale Sanctorum des Johannes Gielemans (Wien, Österreichische Nationalbibliothek, Cod. Ser. nov. I2708) vorzukommen, an dem offensichtlich weitere Floratoren mitarbeiteten, die nicht im Rooklooster ausgebildet worden sind. Doch haben diese Zeichner vor Ort verwendete Motive

6 Рёснт / Thoss, Flämische Schule II, Tafelband. Weitere, vor allem späte Beispiele dieser Variante in O. Pächt/U. Jenni, Holländische Schule, Tafelband, Wien I975, Abb. 262, 263, 268, 269, 330, 332-334; warum diese zum Teil deutlich für den Gebrauch in Holland bestimmten Handschriften mit den für das Rooklooster charakteristischen Initialen ausgestattet wurden, bleibt zu untersuchen: Ser. nov. I2908 (Abb. 262, 268; Textband, S. 87) enthält auch flämische Miniaturen, und die Zuordnung nach Holland der in Abb. 330 und 332-334 gezeigten Handschriften erachteten schon Ulrike Jenni und Otto Pächt als fraglich (Ibid., Textband, S. 26). 
wie die plastisch aufgefassten Gebilde aus Blättern und Blüten an den Enden der Randleisten in ihr Repertoire integriert.

Ein Motiv ist besonders auffällig und wurde während des gesamten Zeitraums in unterschiedlichen Ausprägungen verwendet: Bereits in der 1462 datierten Historia ecclesiastica ist als Teil der Binnenfeldfüllung ein blattartiges Gebilde mit eigentümlich gekerbtem Rand anzutreffen (Abb. 4): Jeweils drei nach außen gerichtete Bögen werden durch einen nach innen gerichteten Bogen begrenzt, der der Kontur Rhythmus verleiht. Unterstrichen wird dieser Rhythmus durch parallele Linien, die Blattrippen andeuten. Die Mitte des Blattes kann durch einen oder zwei Striche markiert (Abb. 4, 5), tropfenförmig geöffnet (Abb. 7) oder gespalten und mit Knospen gefüllt sein (Abb. 6). Neben (und in Kombination mit) den Fadenausläufern, deren Besatz aus Knospenreihen mit abbiegenden, manchmal abwechselnd rund und spitz ausschwingenden (Abb. 5, 7), am Ansatz durch zwei bis drei Querstriche „zusammengeschnürten“ Fäden besteht (Abb. 4, 6, 7), ist das Blatt in seinen Variationen und in zunehmend plastischer Ausgestaltung eines der konstantesten Motive in der FleuronnéeTradition des Rookloosters, das auch zur Zier der wenigen, mit plastisch modellierten Ranken kombinierten und mit Gold akzentuierten Initialen verwendet wurde (zum Beispiel Abb. 8, Zwickel des Initialfeldes). ${ }^{61}$ Die Ranken selbst sind aus dicken, in drei Spitzen endenden Blättern zusammengesetzt und haben eine gepunktete Mittellinie.

Die allgemein gehaltenen, wahrscheinlich auch unvollständigen Angaben bei Gielemans und Ofhuys lassen keine Zuordnung der Initialen an einen der namentlich genannten Chorherren zu. Doch stimmen schriftliche Quellen und erhaltene Werke insofern überein, als sie darauf hindeuten, dass sich eine bemerkenswerte hauseigene Buchausstattung erst in der zweiten Hälfte des I5. Jahrhunderts entwickelte, die dann bis weit in das I6. Jahrhundert andauerte. Dass daneben auch Buchmalereien professioneller, klosterfremder Ateliers von den Chorherren wahrgenommen und geschätzt wurden, zeigen die im Folgenden vorgestellten Werke.

\section{DER MEISTER DES JOHANNES GIELEMANS UND SEINE MITARBEITER}

Da es durchaus vorkam, dass Klosterinsassen zwar Fleuronnée-Initialen in die Bücher einfügten, aber für Miniaturen oder Bildinitialen Illuminatoren von außerhalb engagierten, ${ }^{62}$ ist es fraglich, ob einer der Buchmaler des Rookloosters in der Lage war, figürlichen Buchschmuck zu liefern. Der in das Binnenfeld einer für die hauseigene Produktion typischen Fleuronnée-Initiale eingefügte Kopf mit etwas grob gezeichneten Gesichtszügen lässt Zweifel aufkommen, dass die Floratoren in Figurenmalerei ausgebildet waren (Abb. 6). Ein ähnlich unbeholfen wirken-

6I Im Skriptorium von Sint Maartensdal in Löwen wurde ein sehr ähnliches, nur in einigen Details abweichendes Motiv verwendet (zum Beispiel Brüssel, Königliche Bibliothek, Ms. I36, f. 93v; Ms. I40, f. 7r; Ms. I56-I57, f. Ir), das auch in Deckfarben übertragen wurde (zum Beispiel Brüssel, Königliche Bibliothek, Ms. I48, f. ı9r; Wien, Österreichische Nationalbibliothek, Ink. I.F.39, ff. Ir, 7r). Wie es zu den Ähnlichkeiten kommt und ob sie das Ergebnis einer besonderen Beziehung zwischen den beiden Klöstern sind, ist noch zu klären.

62 CH. BeIER, Missalien massenhaft, in: Codices manuscripti, 48/49, 2004, S. 55-72, bes. S. 6I. 
Abb. 9: Wien, Österreichische Nationalbibliothek, Ser. nov. I2706, f. IIv, Karl der Große als Schutzpatron brabantischer Heiliger, Atelier des Meisters des Johannes Gielemans, zwischen 1470 und $\mathrm{I} 486$

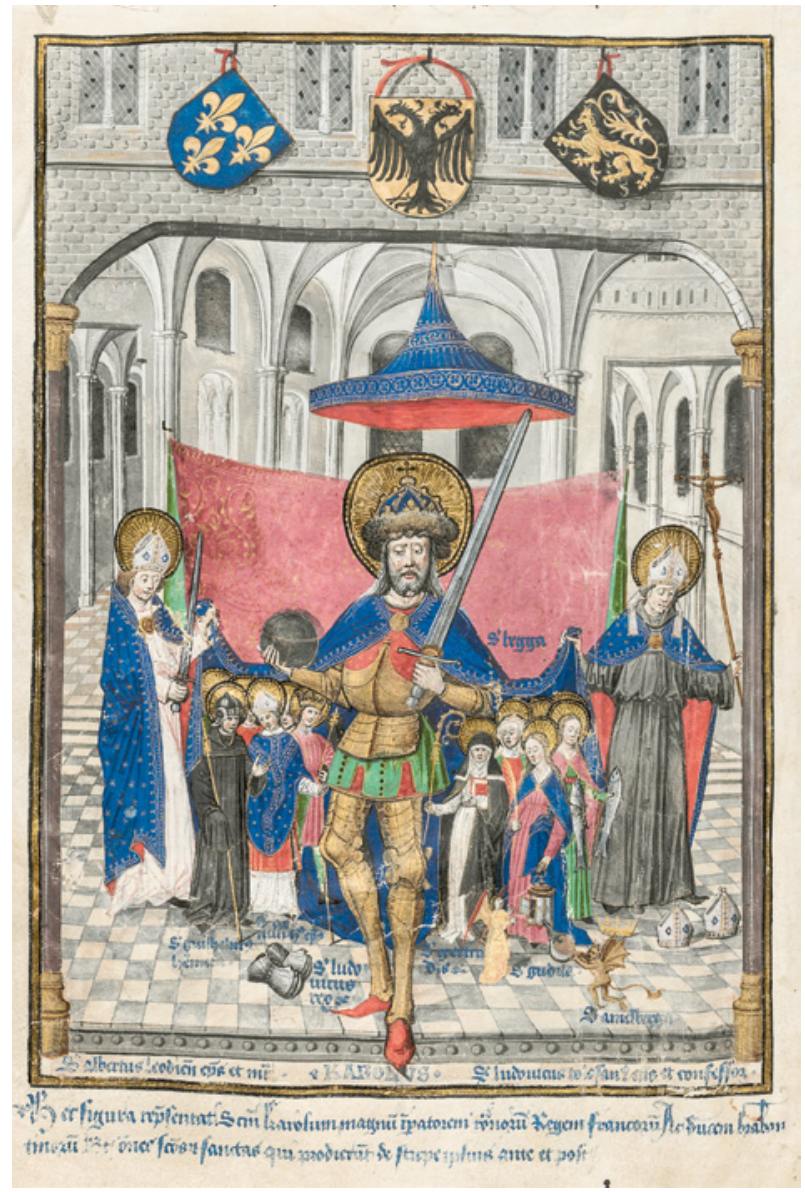

des, bereits von Smeyers ${ }^{63}$ als hauseigene Produktion angeführtes Beispiel für die Verknüpfung figürlichen Buchschmuckes mit dem für das Rooklooster charakteristischen Fleuronnée ist im Sanctilogium des Johannes Gielemans zu finden. ${ }^{64}$ Frédéric Lyna wies zudem darauf hin, dass aliqualiter in der Beschreibung der Fähigkeiten von Simon Logghen, dem einzigen in den Quellen ausdrücklich als Illuminator bezeichneten Konventsmitglied, eine deutliche Einschränkung ist und außerdem der Begriff miniator o. Ä. fehlt. ${ }^{65}$

Die Ausstattung der beiden Bände des von Johannes Gielemans verfassten Hagiologium Brabantinorum (Wien, Österreichische Nationalbibliothek, Cod. Ser. nov. I2706, fol. IIv, Abb. 9; Cod. Ser. nov. I2707, fol. IVv) mit jeweils einer ganzseitigen Miniatur ${ }^{66}$ ist jedenfalls einem Illuminator von außerhalb übertragen worden, worauf bereits Dagmar Thoss und Otto

63 Smeyers, Flämische Buchmalerei (zit. Anm. 22), S. 270.

64 Wien, Österreichische Nationalbibliothek, Cod. Ser. nov. I28II, Abb. 2I2 in O. Р̈̈снт / D. Thoss, Flämische Schule II (zit. Anm. I8), Tafelband.

65 Für das vollständige Zitat zu Simon Logghen siehe Anm. 38; LynA, Een weinig bekend Isde-eeuws verlucht handschrift (zit. Anm. I7), S. 30I.

66 Рёснт/Thoss, Flämische Schule II (zit. Anm. I8), Textband, S. II2-II5 und Tafelband, Abb. 2I5, 2 I7. 


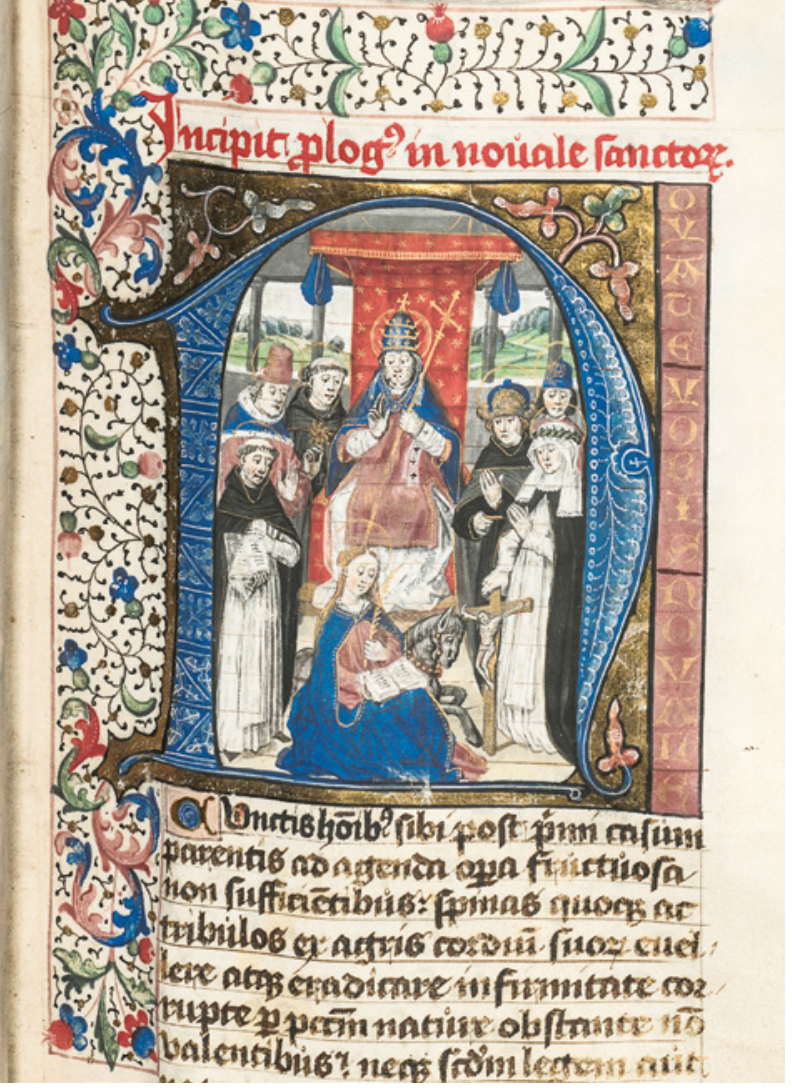

Abb. Io: Wien, Österreichische

Nationalbibliothek, Ser. nov. I2708, f. Ir, Thronender Papst, umgeben von Heiligen, Atelier des Meisters des Johannes Gielemans, nach 1485

Pächt in ihrem 1990 erschienenen Katalog hingewiesen haben. ${ }^{67}$ Ihnen sind stilistische Verbindungen zu den Buchmalereien von Loyset Liédet aufgefallen, und mit der Zuschreibung der Deckfarbenmalereien der übrigen großen Gielemansschriften waren sie sehr vorsichtig. ${ }^{68}$ Dank der von James Marrow erheblich erweiterten Werkkenntnis lassen sich mittlerweile der Tätigkeitszeitraum des Illuminators auf ca. I460 bis I485 eingrenzen und sein Kundenkreis überblicken, zu dem sowohl Geistliche als auch Angehörige von Aristokratie und Adel vor allem aus Brüssel und Umgebung gehörten; ${ }^{69}$ und auch die Spannweite der künstlerischen Möglichkeiten des Illuminators ist besser einschätzbar. Man darf davon ausgehen, dass auch die Miniatur zu Beginn des Historiologium Brabantinorum (Wien, Österreichische Nationalbibliothek, Cod. Ser. nov. I27IO, fol. 2v) mit den typischen kegelförmigen Bäumchen und die Initialen der beiden Bände des Novale Sanctorum (Wien, Österreichische Nationalbibliothek, Cod. Ser. nov. I2708, fol. Ir, Abb. Io; Cod. Ser. nov. I2709, fol. IIIr, Abb. II) der ihm zuzuordnenden Werkgruppe angehören: Die Farbkomposition der Bildinitiale im ersten Band des Nova-

67 Р̈̈снт / Thoss, Flämische Schule II (zit. Anm. I8), Textband, S. II4.

68 Ebd., S. II5-II7.

69 J.H. Marrow, Le Maître de Johannes Gielemans, in: Miniatures flamandes (zit. Anm. 19), S. 202 f.; siehe auch D. VANwijnsberghe, La miniature „flamande“. Vers la cartographie fine d'une production transrégionale, in: Miniatures flamandes (zit. Anm. 19), S. 19-37, bes. S. 29. 
Abb. II: Wien, Österreichische

Nationalbibliothek, Ser. nov. I2709, f. IIIr, Gnadenstuhl, von Heiligen verehrt, Atelier oder Nachfolger des Meisters des Johannes Gielemans, nach 2485

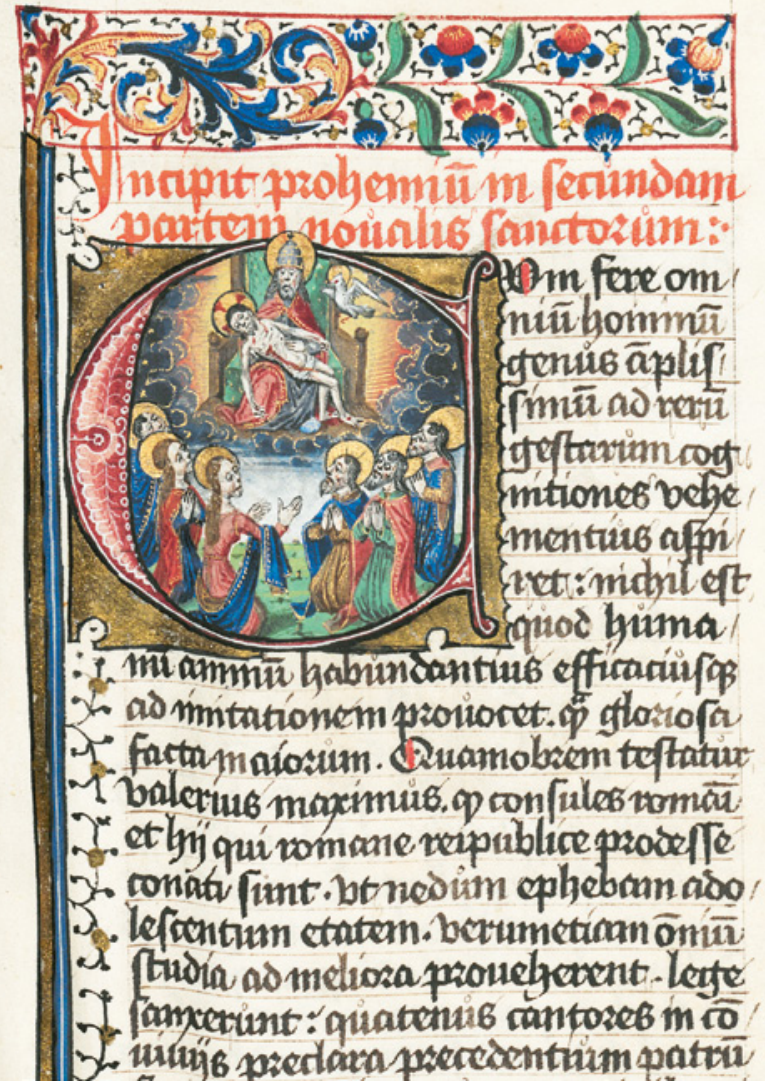

le Sanctorum, die von zwei Rottönen, leuchtendem Blau, Grau, Schwarz und kühlem Grün dominiert wird, stimmt ebenso mit der der Miniaturen überein, wie die Modellierung der Gesichter, deren große, grau schattierte Augen und zarte Wangentönungen auf etwas weißlichem Inkarnat denen der Miniatur im Hagiologium gleichen, ebenso wie die Details der Kleidung (Abb. 9/Io).

Im zweiten Band des Novale Sanctorum fällt die Qualität der Ausführung deutlich ab, vor allem, wenn man die mageren und in ihren Haltungen ungeschickter angelegten Figuren betrachtet. Auch die Farben erscheinen durch die dunkle Modellierung kräftiger (Abb. II). Doch es sind die gleichen Töne wiederzufinden, und der als weite Ebene gestaltete Boden, auf dem Maria und die Apostel knien, ist, wenn auch nur angedeutet, mit kleinen kegelförmigen, seitlich geneigten Bäumen oder Büschen besetzt. Ein weiteres Argument für die Zusammengehörigkeit der Werke bietet die Ornamentik: Die Zier der Buchstabenkörper weist deutliche Übereinstimmungen auf, auch wenn die Ausführung im zweiten Band wieder unbeholfener wirkt (Abb. Io, II). Die Bordüren wurden in beiden Handschriften mit einer roten Linie umrissen und bestehen unter anderem aus dünnstängeligen Ranken, an denen sichelförmige Blätter sowie Blüten mit roten oder blauen kugelförmigen Pollen und drei Blütenblättern in der Gegenfarbe sitzen. Dieser Bordürentyp ziert, gemeinsam mit einer dem Gielemans-Meister zugeschriebenen Bildinitiale, auch das Frontispiz einer Handschrift aus dem Konvent der Riches-Claires in 
Brüssel (Brüssel, Konvent der Urbanisten oder Riches-Claires, Nr. I3162 bis, S. 17), wobei die Symmetrie der Ranken auch im zweiten Band des Novale Sanctorum anzutreffen ist. ${ }^{70}$

Die Qualitätsschwankungen, die zwischen den Bildinitialen zu beobachten sind, dürften darauf zurückzuführen sein, dass der Gielemans-Illuminator nicht allein arbeitete, sondern ein Atelier unterhielt. Es ist nicht ausgeschlossen, dass er seine Werke im Rooklooster ausführte und bei dieser Gelegenheit Konventsangehörige mitarbeiteten. Vor allem die Bildinitiale im zweiten Band des Novale Sanctorum, deren Qualität vielleicht einem Verkauf auf dem flämischen Markt mit seinen heftig konkurrierenden Ateliers nicht genügt haben könnte, ließe sich auf diese Weise erklären. Doch sind bisher keine weiteren Arbeiten dieses schwächeren Illuminators in den Handschriften und Inkunabeln des Rookloosters nachweisbar.

Grundsätzlich ist eine Zusammenarbeit zwischen dem Brüsseler Atelier und Angehörigen des Rooklosters durchaus zu belegen, denn an der Ausstattung der Gielemans-Werke waren, wie oben bereits erwähnt, auch die Floratoren des Klosters beteiligt, deren charakteristische Fleuronnée-Initialen in einfachen und besonders prunkvollen Versionen die Textgliederung ersichtlich machen. ${ }^{71}$

\section{DAS SKRIPTORIUM DES ROOKLOOSTERS}

Von einem weiteren namenlosen Buchmaler stammt die Bildinitiale am Anfang der Enzyklopädie des Franziskaners Bartholomäus Anglicus (ca. II9O-I250), in deren Binnenfeld ein Mönch am Schreibpult in einer bis zum Rand mit Büchern gefüllten Studierstube zu erkennen ist (Abb. I2; die Handschrift enthält auch die für das Rooklooster charakteristischen Fleuronnée-Initialen, Abb. 6) ${ }^{72}$. Die grauen Haare und die individuell wirkenden Gesichtszüge des Mönches, die sich durch eine relativ große, an der Wurzel leicht geknickte Nase, einen kleinen Mund und angedeutete Augenringe auszeichnen, haben Frédéric Lyna zu der Interpretation veranlasst, dass es sich hier um ein Porträt des alternden Chorherren Paulus Petrus handelt, der das Buch seiner Meinung nach kopiert hat, und dass wir somit einen Einblick in das Skriptorium des Rookloosters erhalten. ${ }^{73}$ Obwohl es sich nicht um ein Porträt des Paulus Petrus handeln kann, denn die braune Kutte mit Kapuze und geknotetem Strick entspricht dem Habit der Franziskaner - wir haben demnach ein Autoren- und kein Schreiberbild vor uns -, ist die Darstellung doch immer wieder als Blick in das mittelalterliche Skriptorium eines Klosters, möglicherweise des Rookloosters, gedeutet worden. ${ }^{74}$

Die hier verwendete Bildformel eines Autors in einer Stube mit Pult, Bett und Büchern ist in der spätmittelalterlichen Buchmalerei häufiger zu finden, vor allem Darstellungen von

70 Vanwijnsberghe, La miniature „flamande“ (zit. Anm. 69), S. 29, Abbildung auf S. 27, Ill. 9.

7I P̈̈снт /Thoss, Flämische Schule II (zit. Anm. I8), Tafelband, Abb. 2I6, 2I8.

72 Darauf, dass diese Initialen im Kloster ausgeführt wurden, hat bereits Frédéric Lyna hingewiesen, LyNA, Een weinig bekend Isde-eeuws verlucht handschrift (zit. Anm. I7), S. 300.

73 Ebd., S. 30I.

74 E. Dhanens, Hugo van der Goes, Antwerpen 1998, S. 53, 127, und S. 372, Anm. 91; H. Meyer, Die illustrierten lateinischen Handschriften im Rahmen der Gesamtüberlieferung der Enzyklopädie des Bartholomäus Anglicus, in: Frühmittelalterliche Studien, 30, 1996, S. $368-395$, bes. S. 376. 
Abb. I2: Brüssel, Königliche Bibliothek, Ms. 213, f. 2r, Bartholomäus Anglicus, Rooklooster, unbekannter Buchmaler, letztes Viertel I5. Jahrhundert

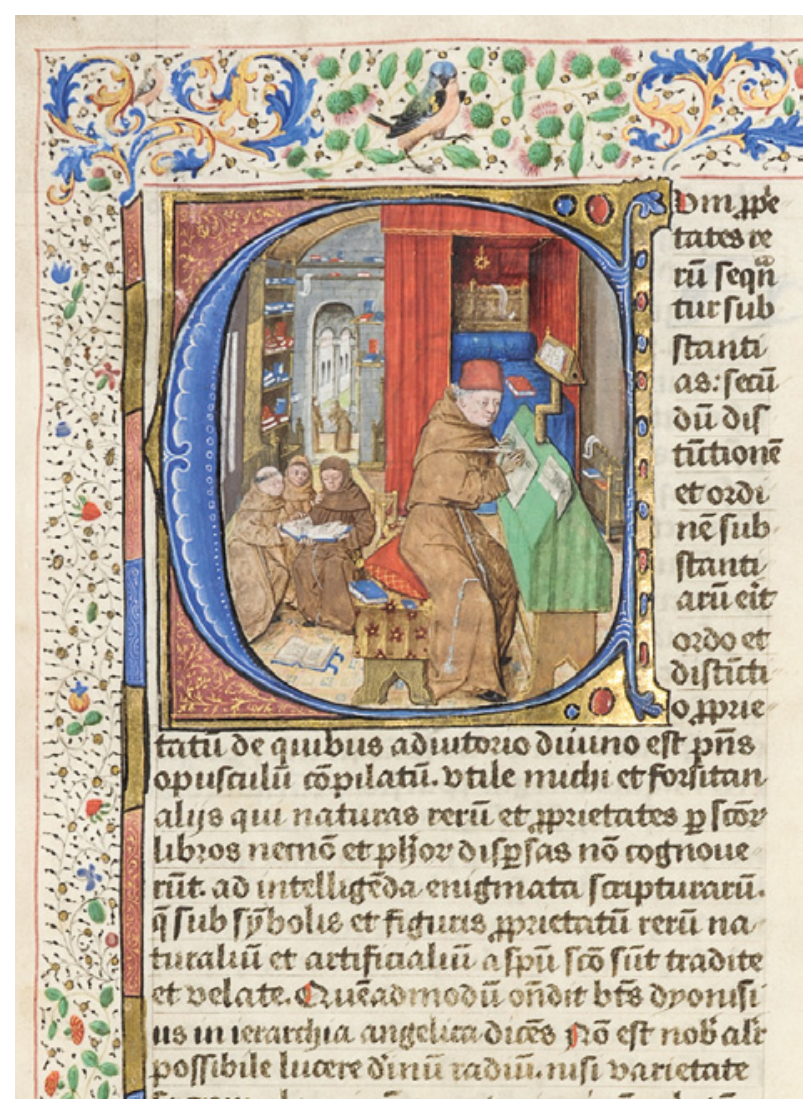

schreibenden Kartäusern (Brüssel, Königliche Bibliothek: Ms. 9I2I-23, fol. 25r ${ }^{75}$ Ms. II63, fol. $67 \mathrm{r}^{76}$ ) und Evangelisten (zum Beispiel Venedig, Biblioteca Nazionale Marciana, Ms. lat. I, 99, fol. 78Iv $)^{77}$ sind zu nennen, aber auch Jean Miélot (Brüssel, Königliche Bibliothek, Ms. 9278-80, fol. Ior) ${ }^{78}$, Christine de Pizan (Brüssel, Königliche Bibliothek, Ms. 9009-II, fol. II8v ${ }^{79}$ ) oder der Prophet Ezra (Philadelphia Museum of Art, The Philip S. Collins Collection, acc. no. 46-65-2, fol. I09v) ${ }^{80}$ wurden bei ihrer Arbeit in vergleichbaren Räumen abgebildet. Man wird deshalb kaum davon ausgehen können, dass die Bildinitiale die Situation in einem Franziskanerkloster des 13. Jahrhunderts oder im Rooklooster wiedergibt, doch diese Art von

75 P. Durrieu, La Miniature Flamande au temps de la cour de Bourgogne (I4I5-I530), Brüssel und Paris I92I, Planche LXVII.

76 Abbildung auf dem Cover von Kwakkel, Die dietsche boeke (zit. Anm. 45).

77 Abgebildet in E. Morrison/T. Kren (Hrsg.), Flemish Manuscript Painting in Context, Recent Research, Los Angeles 2006, Fig. 13.5.

78 Abgebildet auf dem Cover von Chr. De Hamel, Medieval Craftsmen. Scribes and Illuminators, London $2004^{8}$ (erste Ausgabe I992).

79 Abbildung in „Als ich can“, Liber Amicorum in Memory of Professor Dr. Maurits Smeyers, hrsg. von B. CARDON/J. VAN DER STOCK/D. VANwIJNSBERGHe, Löwen 2002 (Corpus van verluchte handschriften I2), Ill. 9.

80 Ebd., Ill. 4a. 
komfortabel möblierter Studierstube passt vermutlich eher zu einem wohlhabenden Augustiner-Chorherrenkonvent im I5. als zur Zelle eines Bettelmönches im I3. Jahrhundert. Andererseits verorten die drei gemeinsam in einem Buch lesenden Novizen und die rundbogige Öffnung im Hintergrund, die den Blick in einen Kreuzgang und auf zwei weitere Mönche freigibt, die Studierstube in einem Franziskanerkloster und binden das Tun des Autors in die kommunikativen Strukturen der Gemeinschaft. Das Bild zeigt das Verfassen und Kompilieren, Lesen und Sammeln von Büchern.

Was nicht gezeigt wird, ist die arbeitsteilig organisierte Herstellung von Büchern, die die Bezeichnung „Skriptorium“ rechtfertigt und die, wie sowohl Chroniken als auch Handschriften bezeugen, im Rooklooster stattgefunden hat. In welchen Räumen die einzelnen Arbeitsgänge durchgeführt wurden, lässt sich nicht mehr sagen, aber man darf spekulieren, dass die für das Kompilieren, Kopieren oder Fleuronnée-Zeichnen notwendige Konzentrationsleistung eine andere Umgebung forderte als das Glätten des Pergaments oder das werkzeugintensivere Binden der Bücher. Und es ist wohl auch zu bezweifeln, dass Johannes Gielemans seine Werke in dem einen Raum verfasste und sich in einen anderen begab, wenn er nicht als Autor tätig war, sondern als Kopist.

Ob Gielemans an der Ausstattung seiner Werke oder der von ihm kopierten Texte beteiligt war, lässt sich ebenfalls nicht mit Bestimmtheit entscheiden. Doch ist es nicht unwahrscheinlich, dass er zu denen gehörte, die in der Lage waren, das für das Rooklooster charakteristische Fleuronnée zu zeichnen. Für die Zier der Initialen in seinen großformatigen Werken wie dem Hagiologium Brabantinorum und dem Novale Sanctorum wurden jedoch verschiedene Floratoren herangezogen, und die großen Miniaturen stammen ebenso wie die Bildinitialen von einem professionellen Buchmaler. Diese Vorgehensweise ist auch bei den Brevieren in Brüssel und London ${ }^{81}$ zu beobachten, deren Lombarden in der für das Rooklooster typischen Art geschmückt sind, während die aufwendigeren Bildinitialen einem klosterfremden Buchmaler übertragen wurden. Für die Ausstattung der verlorenen Chorbücher kann man Ähnliches vermuten: Wenn man die Herkunft eines Antiphonars oder Graduales aus dem Rooklooster nachweisen möchte, wird es mehr bringen, sich die Zierformen der unmittelbar mit der Schreibarbeit verknüpften Cadellen oder die Fleuronnée-Initialen genau anzusehen, als die Malereien in Deckfarben und Gold.

Universität Wien

Abbildungsnachweis: Abb. I-4, 6, 8, I5: Brüssel (Brussel), Bibliothèque royale/Koninklijke Bibliotheek. - Abb. 5, 7, 9-I4: Wien, Österreichische Nationalbibliothek.

8I Brüssel, Königliche Bibliothek, Ms. IV 360; London, British Library, Add. ms. II863. 


\title{
BENEDETTO BORDON AND THE ILLUMINATION OF VENETIAN CHOIRBOOKS AROUND 1500: PATRONAGE, PRODUCTION, COMPETITION*
}

\author{
Lilian Armstrong
}

In the last quarter of the fifteenth century, choirbooks created for Italian churches and monasteries were frequently manuscripts, despite the fact that since 1465 many texts were being printed rather than written by hand. In the late fifteenth and early sixteenth centuries, sets of magnificently illuminated choirbooks were created in many Italian cities, and some remain in the churches and monasteries for which they were created: Siena, Bologna, Parma, Ferrara, Lodi, Brescia, Padua, Vigevano, Florence, Piacenza, and others. ${ }^{1}$ But in contrast, the evidence of choirbook production around 1500 in Venice is more fragmentary. This essay presents some little-known Venetian manuscript examples and suggests that printed choirbooks provided competition to any potential manuscript choirbook commissions in that period.

\section{VENETIAN CHOIRBOOKS IN THE EARLY FIFTEENTH CENTURY}

Churches and monasteries required liturgical books containing the chants to be sung at Mass and at the Divine Office. Graduals contained the chants for the Mass; Antiphonaries contained the chants for the Divine Office; Choir (or Ferial) Psalters, often combined with Hymnals, provided the daily " (unchanging) items of the Office". ${ }^{2}$ Italian choirbooks in the fifteenth and sixteenth centuries were typically very large, so that groups of clerics could see the chants as they stood in front of high lecterns on which the choirbooks rested (Fig. I). Size alone meant that any commission of a set of choirbooks was a serious financial commitment.

In the first half of the fifteenth century, choirbook production in Venice was dominated by Cristoforo Cortese (active, I390s-I445), the best-known Venetian miniaturist of that period. ${ }^{3}$ Characteristic of his works is a Gradual illuminated around 1427 for the Carthusian monks

* Acknowledgments: I should like to express my gratitude to the many scholars who have assisted me in shaping the material for this article, in particular: Jonathan J. G. Alexander, Christine Beier, Izabela Korczyńska, Pier Luigi Mulas, and Ekaterina Zolotova.

I See, among others, M. G. Ciardi Dupré, I corali del duomo di Siena, Milan, i972; B. Giovannucci Vigi, Il Museo della Cattedrale di Ferrara: Scultura, Pittura, Miniatura, Florence, 200I, pp. 55-64; G. Mariani Canova, I corali, in: La Basilica di San Petronio, 1984, pp. 249-68; F. Lollini, I graduali della Basilica di San Petronio, in: Petronio e Bologna. Il volto di una storia: Arte, storia e culto del Santo patrono, exhib. cat., Bologna, Palazzo di Re Enzo and Palazzo del Podestà, 24 november 200I-24 February 2002, Ferrara, 200I, pp. I48-I53; L'Oro e la Porpora: Le arti a Lodi nel tempo del vescovo Pallavicino (I456-I497), ed. M. MarubBI, Milano, 1998; P. L. Mulas, Giovanni Giacomo Decio: Il miniatore dei corali di Vigevano, Vigevano, 2009; M. Bollati, ed., I corali benedettini di San Sisto a Piacenza, Bologna, Editrice Compositori, 20II.

2 J. Harper, The Forms and Orders of Western Liturgy, Oxford, I99I, pp. 6I-63.

3 S. Marcon, Cortese, Cristoforo, in: Dizionario biografico dei miniatori italiani (hereafter DBMI), ed. M. Bolati, Milano, 2004, pp. 176-I80. 


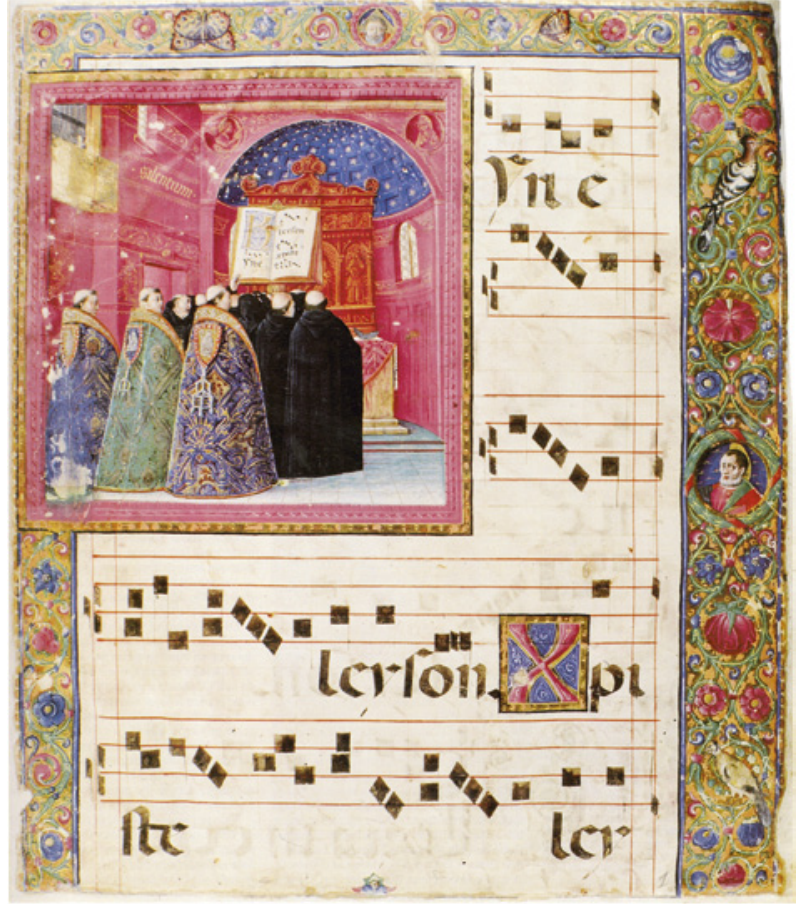

Fig. I: Master of the Pico Pliny, Benedictine Monks chanting, in Kyriale for San Giorgio Maggiore, Venice, I467-70 (Venice, Abbazia di San Giorgio Maggiore, Kyriale K, fol. Ir).

at Sant'Andrea della Certosa, Venice (Fig. 2). Its opening page is elaborately decorated with brilliantly colored curling acanthus leaves and a spectacular peacock in the outer margin. ${ }^{4}$ In the lower margin are half-length figures in white, Carthusian monks, hands folded in prayer as they gaze at an image of their patron, Saint Andrew. The Sant'Andrea Gradual and other corali that were illuminated by Cortese and his workshop indicate a steady production of choirbooks in a late Gothic style for Venetian churches and monasteries throughout the first half of the fifteenth century. After the death of Cortese, sometime after I445, the city apparently lacked a workshop in Venice capable of executing major choirbook commissions. This situation is suggested by the fact that miniaturists from Lombardy and Emilia - Belbello da Pavia and the Master of the Pico Pliny (see Fig. I) - were called upon to illuminate choir books for the Benedictine Abbey of San Giorgio Maggiore between 1467 and $1470 .{ }^{5}$

4 Venice, Biblioteca Nazionale Marciana, MS Lat. III, I8 [=2283]. See Biblioteca Marciana Venezia, ed. M. Zorzi, Venice, I988, pp. I38-I39, TAV. LXXVII (entry by S. Marcon); G. Mariani Canova, La miniatura nei manoscritti liturgici delle Certose Venete nel Quattrocento, in: La Certosa di Vedana: Storia, cultura e arte in un ambiente delle Prealpi Bellunesi (Atti del Colloquio, Sospirolo [Belluno], 2I octtobre I995), Florence, I998, pp. I59-I8I, esp. I62-I65.

5 G. Mariana Canova, Il recupero di un complesso librario dimenticato: I corali quattrocenteschi di S. Giorgio Maggiore a Venezia, in: Arte veneta, 28, 1973, pp. 38-64; Caligrafia di Dio: La miniatura celebra la parola, exhib. cat. ed. G. Canova Mariani / P. Ferraro Vettore, Modena, I999, pp. I88-i89, no. 45 (entry by S. Marcon), pp. 206-207, no. 52, Kyriale K (entry by S. Marcon); and P. Palladino, Treasures of a Lost Art: Italian Manuscript Painting of the Middle Ages and Renaissance, New York, Metropolitan Museum of Art, 2003, pp. II4-I25. For Belbello see F. Lollini, Giovanni Belbello da Pavia, in: DBMI (cit. n. 3), pp. 273-276; and for the 
Fig. 2: Cristoforo Cortese, Vision of Isaiah, in Antiphonary for Sant'Andrea della Certosa, Venice, c. 1427 (Venice, Biblioteca Nazionale Marciana, MS Lat. III, I8 [=2283], fol. Ir)

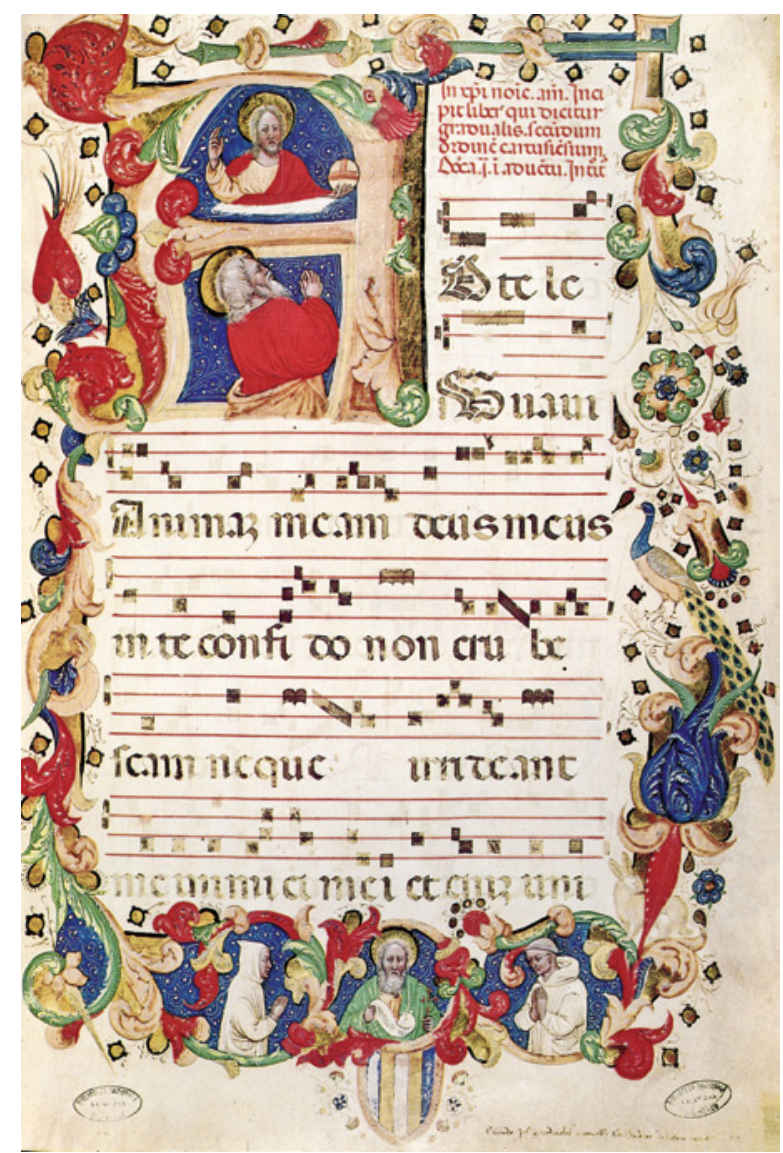

\section{SIX ANTIPHONARIES FROM SAN NICOLÒ DELLA LATTUGA, VENICE}

In the I490s, Benedetto Bordon (active I470s - I530), a miniaturist trained in Padua, established his presence in Venice, and rapidly became the leading miniaturist in the Serenissima. ${ }^{6}$ This was a period of extraordinary artistic production in Venice, in painting, sculpture, and architecture. One might imagine that the many new churches and monasteries in the Renaissance style in Venice would have commissioned sets of choirbooks, either to amplify older manuscripts or to celebrate newly constructed edifices. ${ }^{7}$ But to date, only

Master of the Pico Pliny see: L. Armstrong, Il Maestro di Pico: un miniatore veneziano del tardo Quattrocento, Saggi e Memorie di Storia dell'Arte, 17, 1990, pp. 7-39 (reprinted as The Pico Master: A Venetian Miniaturist of the Late Quattrocento, in Studies of Renaissance Miniaturists in Venice, London, 2003, pp. 233-338).

6 On Bordon see S. Marcon, Bordon, Benedetto, in: DMBI (cit. n. 3), pp. I2I-I25, with ample bibliography. For documents, note especially, M. Billanovich, Benedetto Bordon e Giulio Cesare Scaligero, in: Italia medioevale e umanistica, XI, I968, pp. I87-256.

7 On newly constructed Renaissance churches in Venice see: U. Franzoi / D. Di Stefano, Le chiese di Venezia, Venice, 1976; R. Lieberman, Renaissance Architecture in Venice I450-I540, New York, 1982; J. McAndrew, L'Architettura veneziana del primo Rinascimento, ed. by R. Munman/C. Kolb, Venice, I983. 


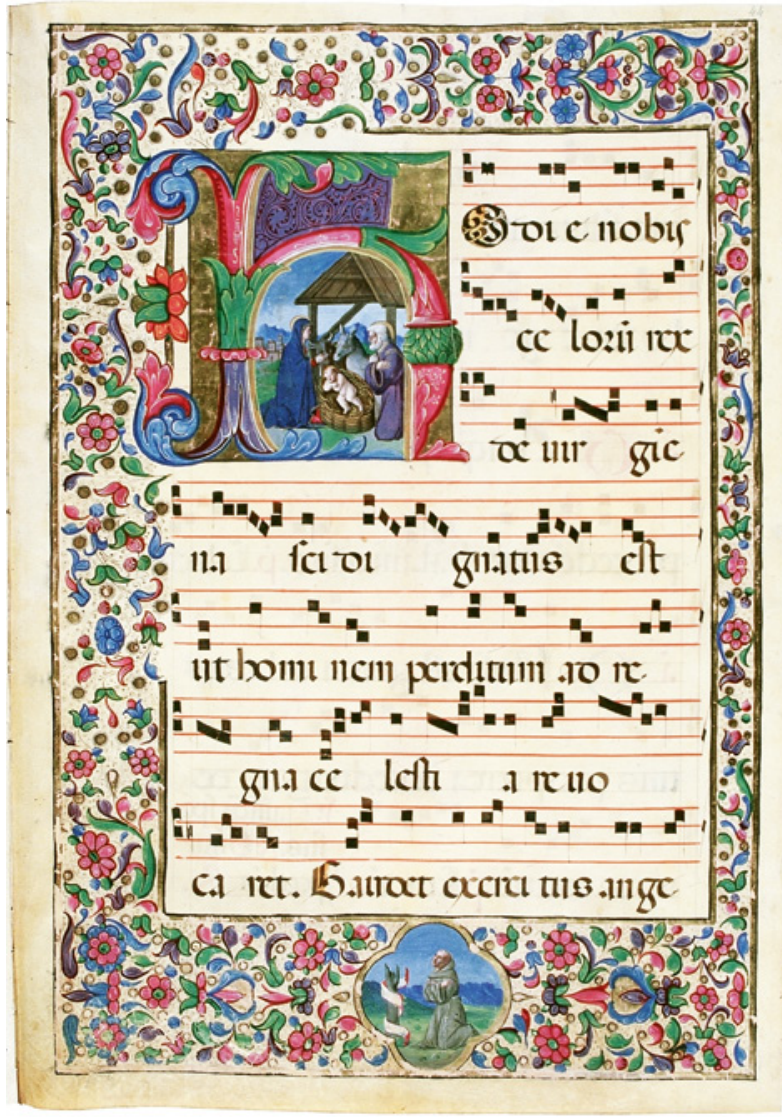

Fig. 3: Benedetto Bordon, Nativity and border with Portrait of a Franciscan, originally fol. $85 \mathrm{v}$ in San Nicolò Antiphonary no.I, c. I500 (Vatican City, Biblioteca Apostolica Vaticana, MS Ross. II95, fol. 46r)

one full set of Antiphonaries is known from around I500, illuminated by Bordon, probably between I494 and I5I4 for a small Franciscan oratory in Venice, San Nicolò della Lattuga, or San Nicolò dei Frari. ${ }^{8}$ Fragments of other choirbooks suggest other commissions, but overall the production appears to have been sparse.

The evidence for the "San Nicolò Antiphonaries" depends on a composite manuscript in the Rossiana Collection of the Biblioteca Apostolica Vaticana that consists of forty-six very large folios excised from Franciscan Antiphonaries and bound together in a single volume; and on four

8 The earlier studies of these choirbooks are: G. Angioli, Codici rinascimentali della Chiesa di S. Francesco a Lucignano in Valdichiana, in: Miniatura, 5/6, I993/1996, pp. 27-40, and color plates VIII-XIV; and L. Armstrong, Benedetto Bordon, Aldus Manutius, and LucAntonio Giunta: Old Links and New, in: Aldus Manutius and Renaissance Culture, ed. D. Zeidberg (Villa I Tatti: The Harvard University Center of Italian Renaissance Studies, I5), Florence, I998, pp. I6I-183, esp. I67-176 (reprinted in L. Armstrong, Studies [cit. n. 5], pp. 642-682, esp. 653-682). For a recent survey of the commission, see: L. Armstrong, Benedetto Bordon and the "San Nicolò Antiphonaries": New Discoveries, in: Libri miniati per la chiesa, per la città, per la corte in Europa: lavori in corso (Atti del Convegno Internazionale, Università di Padova - Museo Diocesano di Padova - Biblioteca Capitolare di Padova, 2-4 dicembre 20Io), Padova, Il Poligrafo, 20I4 (forthcoming). 


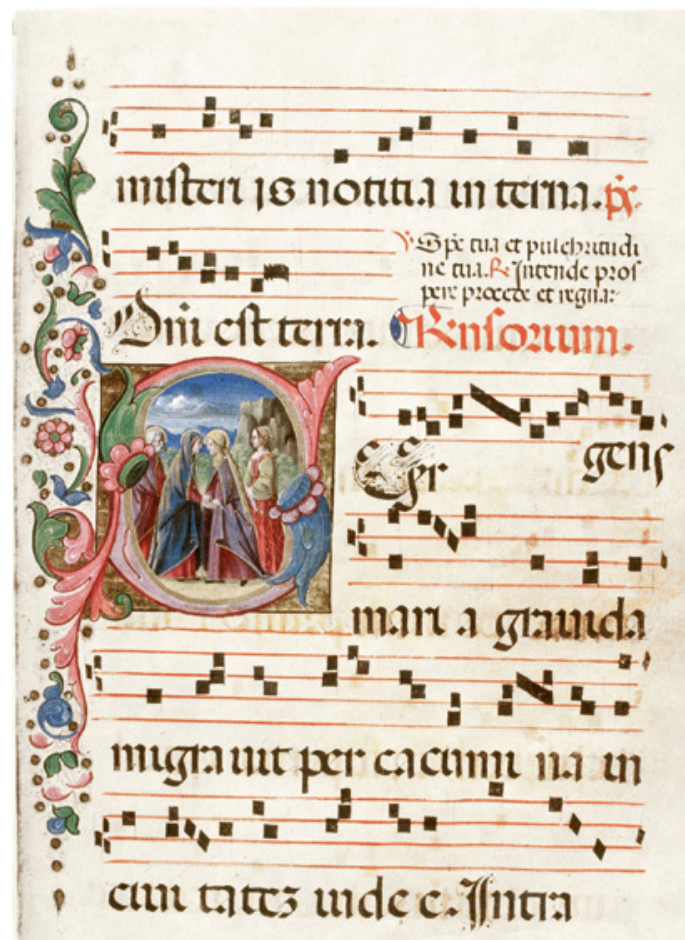

Fig. 4: Benedetto Bordon, Visitation, originally fol. $98 \mathrm{r}$ in San Nicolò Antiphonary no. 4, c. 1500 (Vatican City, Biblioteca Apostolica Vaticana, MS Ross. II95, fol. I4r)

extant volumes, supplemented by detached folios from a fifth volume. ${ }^{9}$ Each of the forty-six folios in Rossiana II95 exhibits a large historiated initial and three of the folios in addition have full borders (Figs. 3, 4). It is immediately evident that the folios originally belonged to a Franciscan community, as there are several portraits of friars in the miniatures. The Renaissance style of the Rossiana miniatures is also evident. The figures are anatomically correct, and they are situated in clearly defined three-dimensional spaces. The deep landscapes contain occasional buildings and sweeping blue mountain ranges. The attribution of the miniatures to Benedetto Bordon, initially proffered by Hans Tietze in I9II, is supported by stylistic comparisons to his documented works. ${ }^{10}$ For example, the Nativity in a historiated initial of the Rossiana manuscript (see Fig. 3) can be compared to the Nativity, signed by Bordon, in an Evangeliary for the Benedictine Church of Santa Giustina in Padua from I523 (Fig. 5). ${ }^{11}$ Similar compositions, figure types, and rich

9 Vatican City, Biblioteca Apostolica Vaticana, MS Ross. 1195 , parchment, $555 / 572 \times 380 / 410 \mathrm{~mm}$. See also nn. 8 , I4, I8-20.

io H. Tietze, Die illuminierten Handschriften der Rossiana in Wien-Lainz (F. Wickhoff, Beschreibendes Verzeichnis der illuminierten Handschriften in Österreich, Vol. V), Leipzig, 1911, nr. 344, pp. I57-159.

II Dublin, Chester Beatty Library, MS W. I07. For the contract see Billanovich, Benedetto Bordon (cit. n. 6), pp. 249-250; for detailed listing of miniatures, see H. K. SzÉPE, No. 175. Evangeliario, in: La miniature a 
colors are common to both. The figures in the Santa Giustina miniature are more monumental, explained by the fact that they were painted some fifteen years later in Bordon's career.

On the lower margin of the Rossiana folio that initiates the chants for Septuagesima is a kneeling friar, in front of whom is a banderole wound around a post, inscribed F. PETRUS D. LUSCIGNANO. ${ }^{12}$ Fra Pietro was a friar at San Nicolò della Lattuga in Venice, where he was the Guardian (prior) from I494 to 1513 , when he resigned because of old age and ill health. ${ }^{13}$ Further facts about the Rossiana folios were established by Gabriela Angioli, who discovered two Franciscan antiphonaries now in Arezzo, from which many folios had been excised. ${ }^{14}$ Angioli recognized that fifteen of the Rossiana folios were originally in the two Antiphonaries in Arezzo. On the last folio of one of the volumes in Arezzo is a Latin poem addressed to the Reverendum sacre Theologie professorem Petrum Pulcectam de Luciniano, certainly the same person as the friar depicted in the miniature mentioned above. ${ }^{15}$ The

Padova dal medioevo al settecento, exhib. cat. ed. by G. Baldissin Molli / G. Canova Mariani / F. Toniolo, Padua, Palazzo della Ragione, 2I March - 27 June, I999, Modena, I999, pp. 412-415.

I2 Vatican City, Biblioteca Apostolica Vaticana, MS Ross. II95, fol. 46r. See Armstrong, Studies (cit. n. 5), Color Pl. XII.

I3 Armstrong, Bordon, Aldus, and Giunta (cit. n. 8).

I4 Arezzo, Museo Medioevale e Moderno, MS I78I (on deposit in Biblioteca della Città di Arezzo); and Arezzo, Biblioteca del Seminario Vescovile, MS 75 [I. I9] (on deposit in Archivio Capitolare). See G. Angroli, No. I5, Antifonario festivo diurno e notturno, in: Codici miniati in territorio Aretino (Secoli XII-XV), exhib. cat. ed.

G. LazZI, Florence, I990, pp. 67-70; and Angioli, Codici rinascimentali (cit. n. 8).

is MS No. I78I, fol. I88v (fol. I84r in second foliation):

Marsilii umbri Sempronij in Reverendum sacre Theologie professorem Petrum Pulcectam de Luciniano.

Sancta dei carthis modulamur carmina nostris: dulcibus et resonant atria sacra modis.

Sex sumus ingenti pretio $\mathrm{qu}^{\mathrm{e}}$ volumina: Petrus lucinianus opus munere sponte tulit.

Omnia si pereant: semper tamen ipse manebit non modo per libros sed quia rectus erat.

Eiusdem in eundem

Larga manus petri fuit: ut vacinia (sic) foelix. Aurum cum minyo cornua nostra colant.

Quo variis animum referamus moribus olim ipsius ornatum: quique futurus eras.

Dum canis ergo: memor dominum cantare: paravit qui nos perpetui muneris esse deo.

Eiusdem in eundem

Munere me cantas Petri: qui semper amavit et puer et senior dogmata cuncta dei.

Senensis patria Neptumni vixit in urbe plebi nobilibus gratus et ipse duci

Vere est exemplar cupienti vivere semper: Hunc sequere ut de te fama loquatur idem. 
Fig. 5: Benedetto Bordon, Nativity, in Evangeliary for Santa Giustina, signed, $1523-25$ (Dublin, Chester Beatty Library, MS W. I07, fol. 3v)

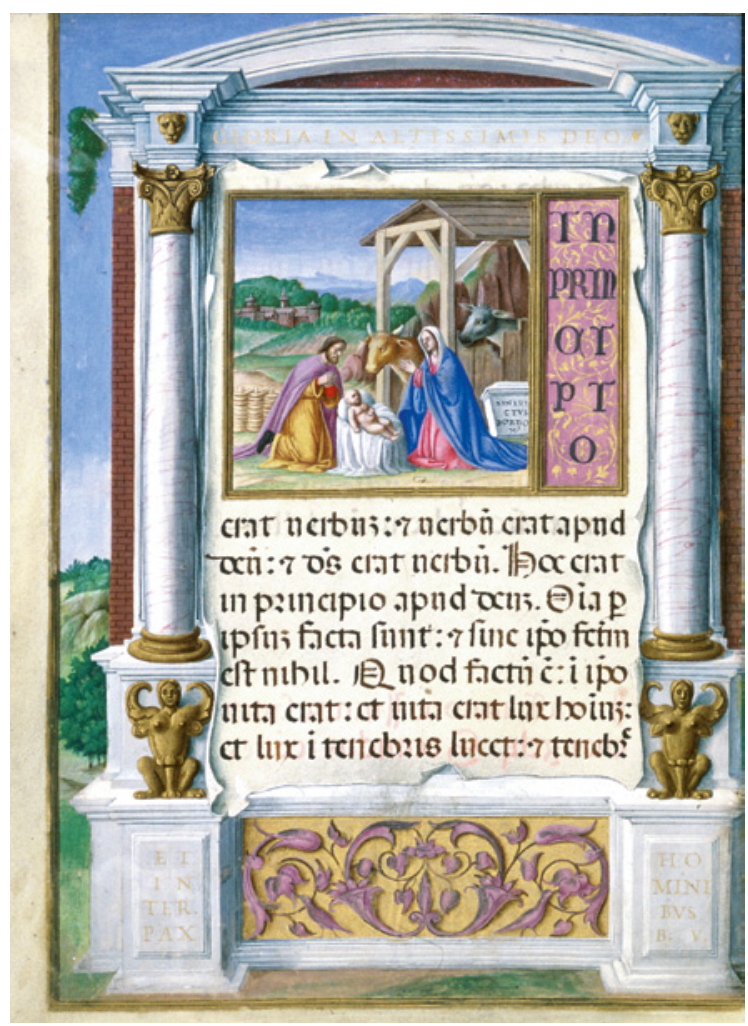

verses include the information that there were originally six volumes, and that Fra Pietro was from the area of Siena, but that he lived in in the city of Neptune, that is, Venice (Senensis patria Neptumni vixit in urbe).

Also confirming that there were originally six volumes is a description written in 1782 by Guglielmo della Valle when he saw the six manuscripts intact in the church of San Francesco in Lucignano, near Siena. ${ }^{16}$ Della Valle mentions the exact volume for some of the miniatures that he thought were most beautiful. For example, he located the Visitation, "Nel metà del libro 4. la Vergine ch piglia per mano S. Elisabetta". The miniature is in the Rossiana manuscript in the Vatican (see Fig. 4), and this folio is missing in one of the volumes in Arezzo. ${ }^{17}$ The della Valle indications make it possible to recognize that the two volumes in Arezzo were San Nicolò Antiphonaries nos. 4 and 5 .

Three more discoveries permit reconstructing the original position of all of the Rossiana folios. Following a suggestion of Jonathan Alexander, I located what was originally San Nicolò Antiphonary no. $I$ in the Special Collections Library of the University of Michigan ${ }^{18}$; Ulrike

i6 G. Della Valle, Lettere senesi di un socio dell'Accademia di Fossano sopra le belle arti, 3 vols., Venice and Rome, 1782-1786, II, pp. 246-247.

I7 Vatican City, Biblioteca Apostolica Vaticana, MS Ross. II95, fol. I4r.

I8 Ann Arbor, Michigan, University of Michigan, Special Collections Library, MS 246. See Armstrong, Benedetto Bordon and the "San Nicolò Antiphonaries" (cit. n. 8). 
Bauer-Eberhardt has identified San Nicolò Antiphonary no. 3 in the Bayerische Staatsbibliotek ${ }^{19}$; and again advised by Jonathan Alexander, I recognized that eight folios at Columbia University in New York were originally from San Nicolò Antiphonary no. 6. ${ }^{20}$ The extant volumes substantiate that each of the six had about 220 folios and between 15 and 20 large historiated initials, for a total of over Ioo. Collectively, the six San Nicolò Antiphonaries constitute the most significant choirbook commission in Venice around 1500.

Further issues of production are raised by the San Nicolo Antiphonaries. There was a change in format after the completion of Antiphonaries $I$ and 2, which contain the Temporale chants from Advent through Holy Saturday. The pages in Antiphonaries nos. I and 2 are ruled for seven tetragrams (seven lines of text and music), and most of the large miniatures are equal in height to two tetragrams (see Fig. 3). In contrast, the folios of Antiphonaries nos. 3, 4, 5 , and 6 are slightly larger, but are ruled with only six lines of text and music (see Fig. 4). The miniature for the Feast of the Visitation was originally in Antiphonary no. 4, which contains the Sanctorale feasts from Corpus Christi through the Feast of St. Lawrence on August Io. The image of the meeting of the Virgin Mary and Elizabeth is still scaled to occupy a space equal in height to two tetragrams, but since each tetragram occupies more vertical surface, the historiated initial is also larger. The change in format enabled Benedetto Bordon to create more imposing figures and more detailed compositions. Since contemporary miniaturists were paid by the size and "solemnity" of the compositions, ${ }^{21}$ the larger miniatures in the San Nicolò Antiphonaries no. 3 - no. 6 would have been more costly than those in the first two volumes. We may thus assume that the patrons increased their financial contributions for the commission, rather than diminishing support for the project. ${ }^{22}$

\section{OTHER CHOIRBOOK COMMISSIONS FROM BENEDETTO BORDON AND HIS WORKSHOP}

A single folio and a related cutting from a Franciscan Choir Psalter now in the Staatliche Graphische Sammlung, Munich, were convincingly attributed to Bordon some years ago by Ulrike Bauer-Eberhardt. ${ }^{23}$ Its handsome historiated initial "B", with King David playing a fiddle (Fig. 6), is markedly similar to the Vision of Isaiah in the San Nicolò Antiphonary no. I

I9 Munich, Bayerische Staatsbibliothek, Clm 30205; see U. Bauer-Eberhardt, Ein unbekanntes Antiphonar mit Miniaturen von Benedetto Bordon als Neuerwerbung der Bayerischen Staatsbibliothek, in: Codices manuscripti, 76/77, 20II, pp. 42-50.

20 New York, Columbia University, Rare Books Library, Plimpton MS 40H (I-8). See Armstrong, Benedetto Bordon and the "San Nicolò Antiphonaries" (cit. n. 8).

2I A. Melograni, La miniatura e i suoi costi. I corali tardo quattrocenteschi della Cattedrale di Ferrara: Un'analisi dei documenti, dei materiali e della mano d'opera, in: Bollettino d'Arte, nn. 133-134, July - December 2005, pp. I5I-I80.

22 For further discussion of patronage issues, see Armstrong, Benedetto Bordon and the "San Nicolò Antiphonaries" (cit. n. 8).

23 Munich, Staatliche Graphische Sammlung, Inv. Nr. 40I98, parchment, $539 \times 374 \mathrm{~mm}$, 2I lines of text. See U. Bauer-Erberhardt, Die italienischen Miniaturen des I3. - I6. Jahrhunderts, Staatliche Graphische Sammlung, München, Munich, 1984, pp. 26-28, Cat. no. 6/I and Color Pl. I. 
Fig. 6: Benedetto Bordon, King David, and border with St. Peter, and a Franciscan emblem, detached folio from a Choir Psalter (Munich, Staatliche Graphische Sammlung, Inv. Nr. 40198)

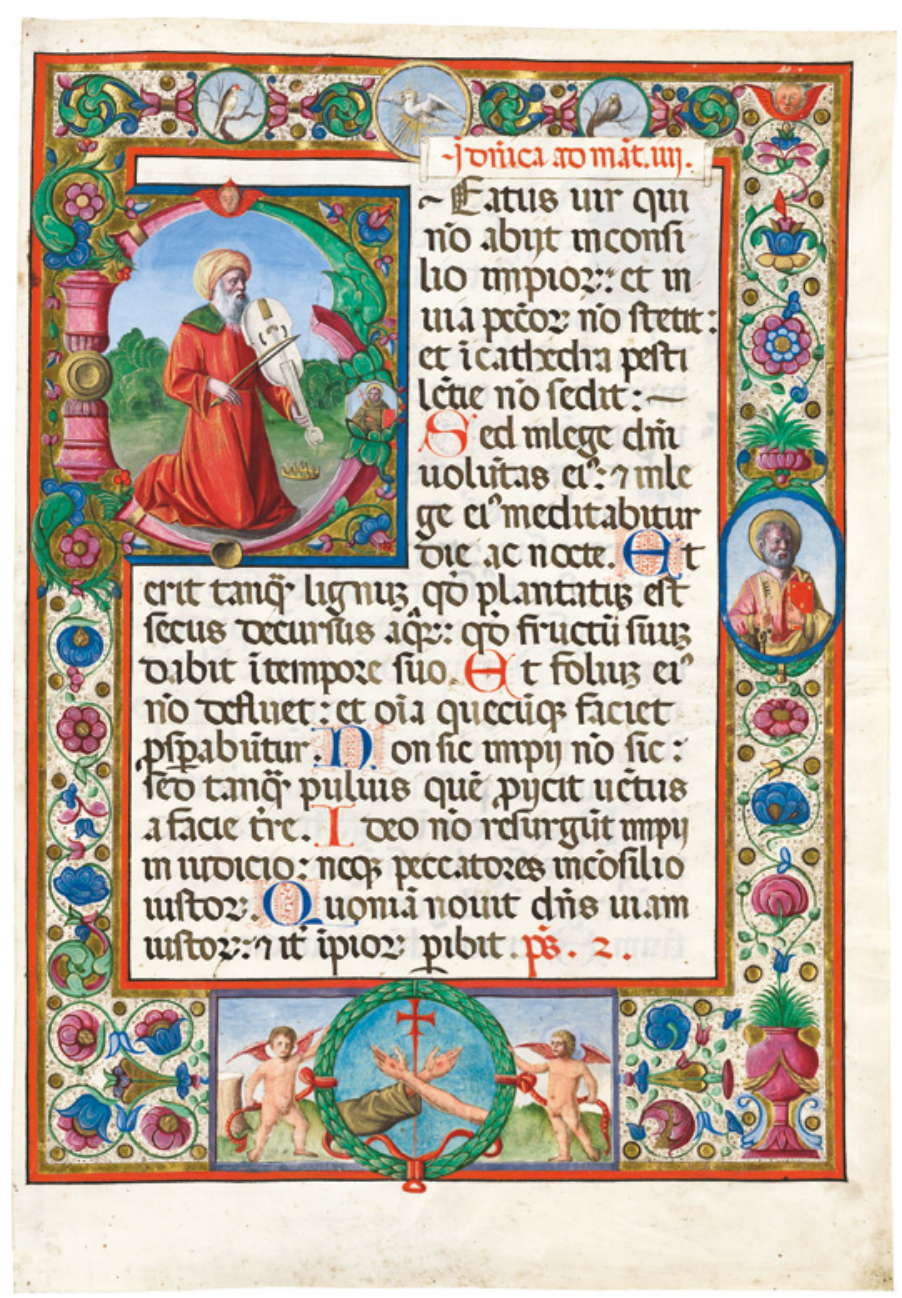

(Fig. 7), not only in the figure of a turbaned patriarch with a white beard, but also in the formation of the capital letter, incorporating motifs from classical architecture. The brilliant red and yellow of the garments worn by David and Isaiah in each initial are contrasted to the deep greens of trees in the middle ground, similarly touched with golden highlights. At the bas-de-page is the Franciscan emblem of the crossed arms of Christ and St. Francis flanked by two putti. ${ }^{24}$

A second fragment in Munich also exhibits a historiated initial of very high quality (Fig. 8). ${ }^{25}$ Probably originating from the same Choir Psalter as the Franciscan folio just discussed, the cutting depicts the Psalmist in the Waters in the initial "S" of Psalm 68 (69), Salvum

24 The putti flanking the Franciscan emblem in the lower margin are less robust than Bordon's usually are, signaling participation of a member of his workshop.

25 Munich, Staatliche Graphische Sammlung, Inv. No. 40I4O, parchment, $392 \times 225 \mathrm{~mm}$, cutting, with intial "S" with David in the Waters. See Bauer-Eberhardt, Die italienischen Miniaturen (cit. n. 23), pp. 26-28, Cat. No. 6/2. 


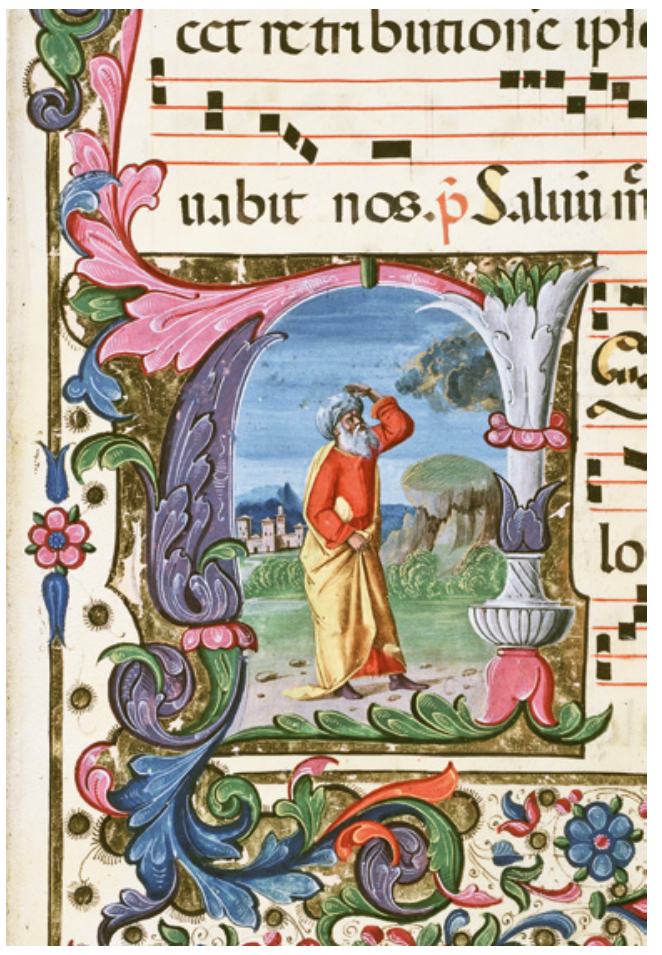

Fig. 7: Benedetto Bordon, Vision of Isaiah, originally fol. $2 \mathrm{r}$ in San Nicolò Antiphonary no. I, c. 1500 (Vatican City, Biblioteca Apostolica Vaticana, MS Ross. II95, fol. 45r) me fac. The interrupting of the letter " $S$ " in order to provide a more open field for the figure of the Psalmist is typical of many of the letters in the San Nicolò Antiphonaries. Innovative, however, is the idealized musculature of the white-bearded nude, whose body is shown half-length above the blue water which breaks in delicate, white tipped waves around his lower torso. In the distance is a line of buildings, also blue as if reflecting the waters.

A date in the later I490s for the Munich folios would accord with the date of the San Nicolò Antiphonaries with which they have much in common. Although smaller in dimensions than the folios from the San Nicolo Antiphonaries, it is possible that the Munich Choir Psalter also originated at San Nicolò. In the Inventory of I5IS made at San Nicolò after the death of Fra Pietro da Lucignano, is the following: Item Uno Psalmista [choir psalter] in carta bona miniato el qual ha comprato el Reverendo Padre Maestro Petro da Lucignano costo ducati vinti. ${ }^{26}$ The fact that a half-length image of St. Peter appears in the border of the Munich page (see Fig. 6) also suggests that it might have been illuminated for Fra Pietro, since St. Peter would have been his patron saint.

The Munich Psalmist in the Waters leads to the attribution of four detached folios from another Choir Psalter and Hymnal, now in the Free Library of Philadelphia. ${ }^{27}$ The four folios are considerably larger than the Munich folio with King David, and one of them duplicates the text of Psalm 68 (69) and image of the Psalmist in the Waters (Fig. 9). Thus the folios cannot have originated from the same manuscript as the Munich folios. The Philadelphia Psalmist in the Waters, however, is stylistically closely related to the Munich cutting. The pose of the Philadelphia figure is almost identical, but the execution is not as refined, and there are no background details to enhance the sense of space. The capital " $\mathrm{S}$ " is again interrupted, but it is formed of two dolphins, slightly less elegantly defined than the components of the Munich letter.The other three folios in Philadelphia also have historiated initials: a man with

26 Venice, Archivio di Stato di Venezia, Convento di San Nicolo della Lattuga, Busta N. 2, Inventario I5I5, fol. Iv.

27 Philadelphia, Free Library of Philadelphia, Rare Book Collection, MS Lewis E-M 70:5-8, folios 53, 96, Io4, and $\mathrm{I} 84$ from a Choir Psalter and Hymnal; parchment, $555 \times 390 \mathrm{~mm}$, folio numbers in red Roman numerals in the upper margins. 


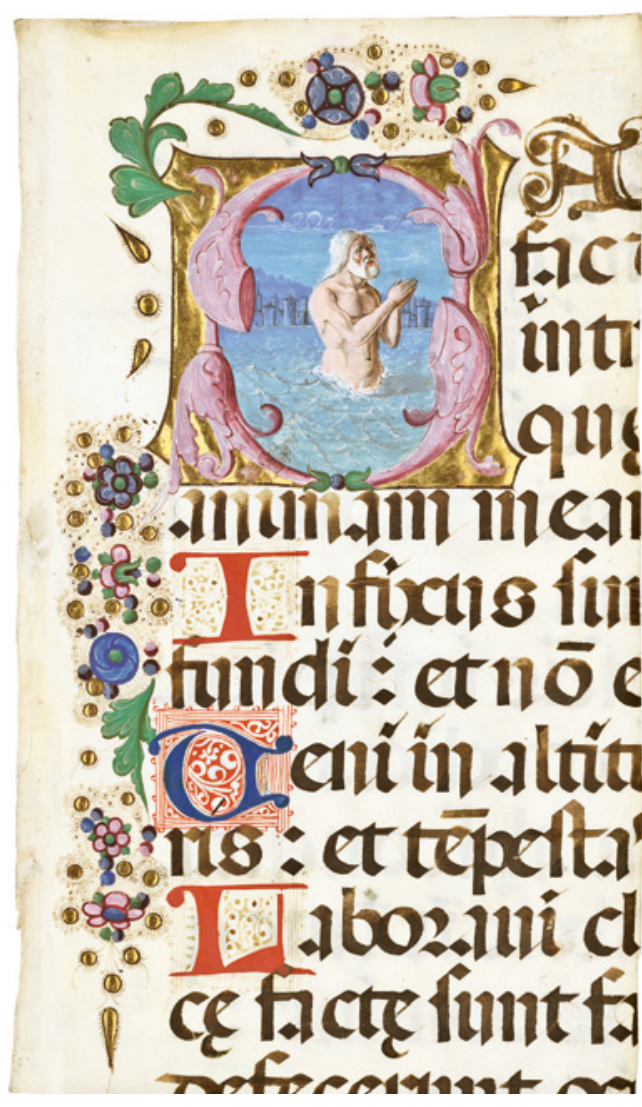

Fig. 8: Benedetto Bordon, Psalmist in the waters (Psalm 68 [69]), cutting from a Choir Psalter (Munich, Staatliche Graphische Sammlung, Inv. Nr. 40I40)

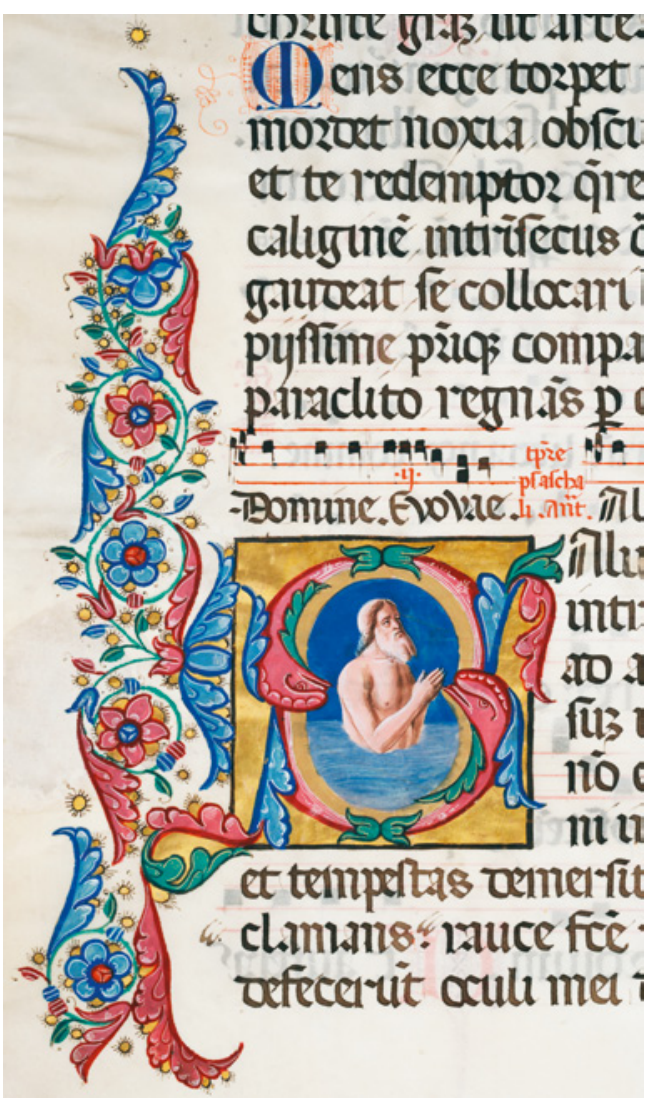

Fig. 9: Benedetto Bordon, workshop, Psalmist in the waters (Psalm 68 [69]), detached folio from a Choir Psalter (Philadelphia, Free Library, MS Lewis E-M 70:7)

a short beard points to his eye, initiating Psalm 26 (27), Dominus illuminatio mea, originally folio 53 verso; and a young man playing a lute initiates Psalm 8o (8I), Exultate deo. Most elaborate of all is a leaf with an initial " $\mathrm{C}$ " surrounding an image of God the Father, blessing with his right hand and with his left hand touching a globe that rests on his knee (Fig. Io). The dignified frontally posed figure resembles the God the Father of the Trinity initial in the newly identified San Nicolò Antiphonary no. 3 in the Bayerische Staatsbibliothek. ${ }^{28}$ The initial begins the hymn Conditor alme syderum, to be sung at Vespers during Advent. ${ }^{29}$ The figures and the decorative borders all follow types found in Bordon workshop manuscripts, but unfortunately the iconography of the initials is not unusual, and there are no indications of patronage.

28 Bauer-Eberhardt, Ein unbekanntnes Antiphonar (cit. n. I9), Fig. 4.

29 http://libwww.library.phila.Gov/medievalman/index.cfm. This Free Library web page identifies the texts on the rectos and versos of MS Lewis E-M 70:5-8. 


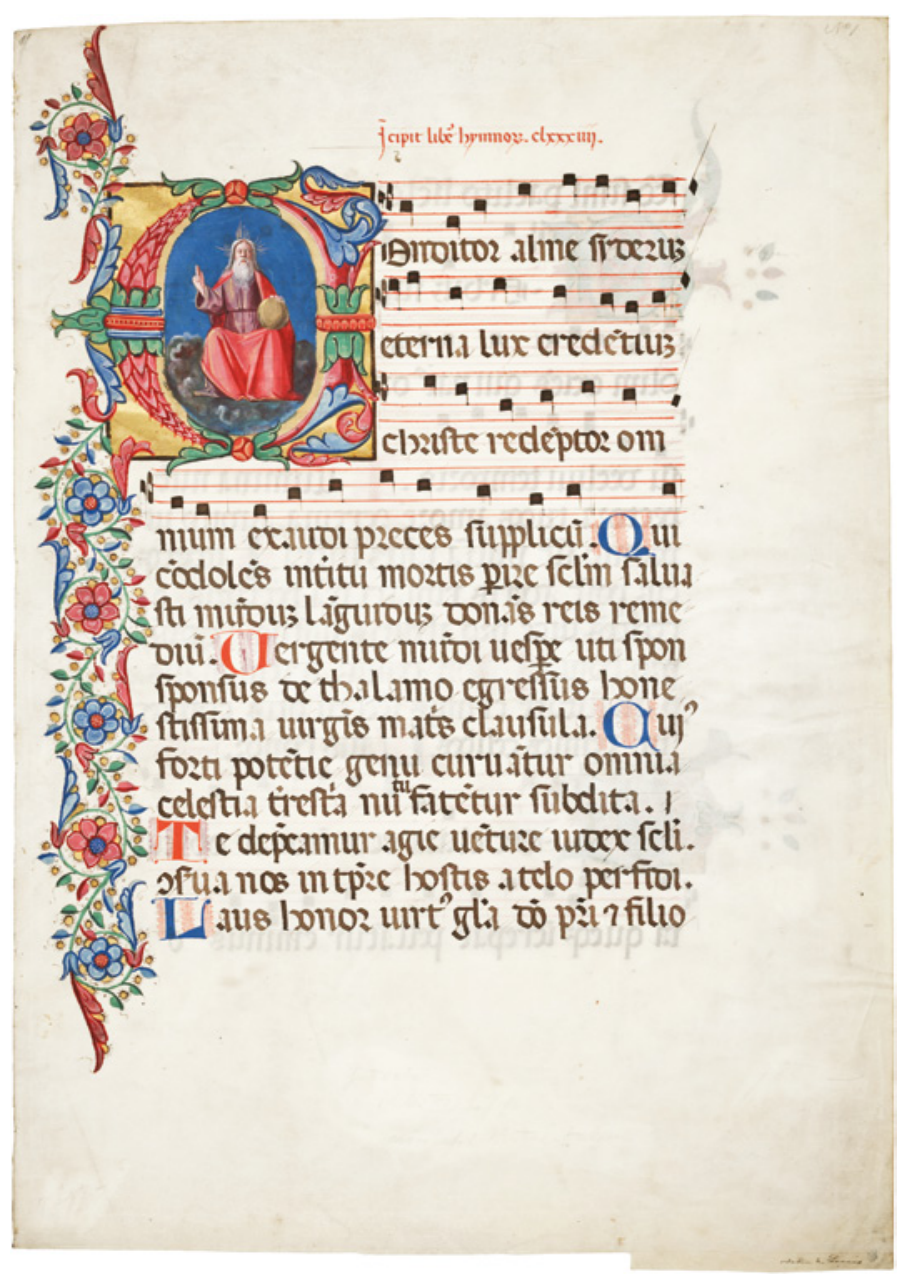

Fig. Io: Benedetto Bordon, workshop, God the Father, detached folio from a Choir Psalter (Philadelphia, Free Library, MS Lewis E-M 70:5)

\section{CHOIRBOOKS FOR SAN SEBASTIANO?}

The finest surviving choirbook fragments that can be attributed to Benedetto Bordon are two folios in the Jagiellonian University Library in Cracow, identified by Pier Luigi Mulas ${ }^{30}$; and a folio in the State Historical Museum, Moscow, recently published by Ekaterina Zolotova. ${ }^{31}$

30 Cracow, Jagiellonian University Library, I. R. I897, folio numbered xvii from a Gradual, with historiated initial of the Nativity, parchment, $602 \times 450 \mathrm{~mm}$; and I. R. 1900, folio from a Choir Psalter, with historiated initial of Christ and the Pharisees, and full border with roundels of SS John the Baptist, Sebastian, and Jerome, parchment, $50 \mathrm{I} \times 4 \mathrm{I} 6 \mathrm{~mm}$; initial size $228 \times 230 \mathrm{~mm}$. Z. AmeIsenowa, Rękopisy I Pierwodruki iluminowane Biblioteki Jagiellońskiej, Wrocław - Kraków, I958, pp. 55-56, no. 58; and p. 64, no. 7I; and P. L. Mulas, I libri a stampa pergamenacei della Collezione Melzi a Chantilly e alcune miniature di Benedetto Bordon, in: Rivista di Storia della Miniatura, I3, 2009, pp. I79-189, esp. p. I88, n. I3.

Moscow, State Historical Museum, Mus. 3197-a, f. 3. Folio from a Gradual, with an historiated initial of the Annunciation to the Shepherds, parchment, $595 \times 440 \mathrm{~mm}$. See E. Zolotova, Miniatures by Benedetto Bordon 
The most distinctive of these is a folio in Cracow which was originally in a Choir Psalter (Fig. II). Judging from the text and images, the leaf was the frontispiece of a volume with Psalms and Hymns for Eastertide, as the text is Psalm Io9 (IIO), beginning Dixit dominus domino meo sede a dextris meis, sung at Matins of Saturday in the time of Easter, and also at Vespers on Sundays in Eastertide.

The very large initial " $\mathrm{D}$ " encloses a scene of Christ and the Pharisees in the Temple. The Temple is represented as if it were an aisled Renaissance church with classical columns leading back to a rounded apse with a gold hemispherical dome. Christ stands in the center of the apse; several figures with haloes stand under the arches nearest to him, while Pharisees are seated under the arches nearer to the viewer. On the walls of the apse are words inscribed in gold: QUID VOBIS VEDETUR DE CHRISTO (What do you think of the Messiah / Chirst?"); and CUIUS FILIUS EST ("Whose son is he?"); and to the right of Christ: QUIS EX VOBIS ARGUET ME DE PECCATO ("Which of you convicts me of sin?"). The words are from Matthew 22:42 and John 8:45, passages in which Christ asks the Pharisees concerning the Messiah. Their answer to the question "Whose son is he?" appears in gold letters by the head of one of the Pharisees, "DAVID".

The scene demonstrates the exceptional visual and intellectual skills of Benedetto Bordon. The architecture defines a monumental Renaissance space, inhabited by appropriately scaled figures under the grey vaults of the nave. Presumably Bordon was advised by ecclesiastics in his choice of subject, but the clarity with which he conveys the theological message is extremely impressive. The perspectival focus on Christ, the modest positions of his disciples close to the apse, and the dominating size of the Pharisees convey the tense and serious mood of the exchange. Later in his career, Bordon represented the same subject in the Evangeliarium for Santa Giustina, again with dignified figures, but this time standing and facing each other (Fig. I2). ${ }^{32}$ The architectural ambience is relatively complex, but the lateral grouping of the figures in the Evangeliarium miniature is much simpler than in the Cracow Choir Psalter.

The saints represented in the borders of the Cracow folio - St. Sebatian, St. Jerome, and St. John the Baptist - provide hints as to its commission. With his prominent placement in the center of the lower margin, St. Sebastian may be considered crucial to the identification of the patrons. Almost equally prominent is St. Jerome, depicted in the outer margin. I should like to propose that the Choir Psalter might have been commissioned for the newly constructed church of San Sebastiano in Venice, which was a Hieronimite foundation, thus explaining the choice of saints that are represented in the margins. ${ }^{33}$ The rebuilding of San Sebastiano on the designs of Antonio Abbondi, known as Il Scarpagnino, was initiated

in Moscow Collections, in: Gatherings in Honor of Professor M. I. Sviderskaya, (in Russian), Moscow, 20IO, pp. 248-259; and E. Zolotova, Western European Book Miniatures of the $12^{\text {th }}-17^{\text {th }}$ Centuries. Catalogue of Illuminated Manuscripts in Moscow Libraries, Museums and Private Collections, Moscow, 2OIO, pp. II2-II3; cat. no. 55 .

32 See note II.

33 See below for further discussion of the provenance. 


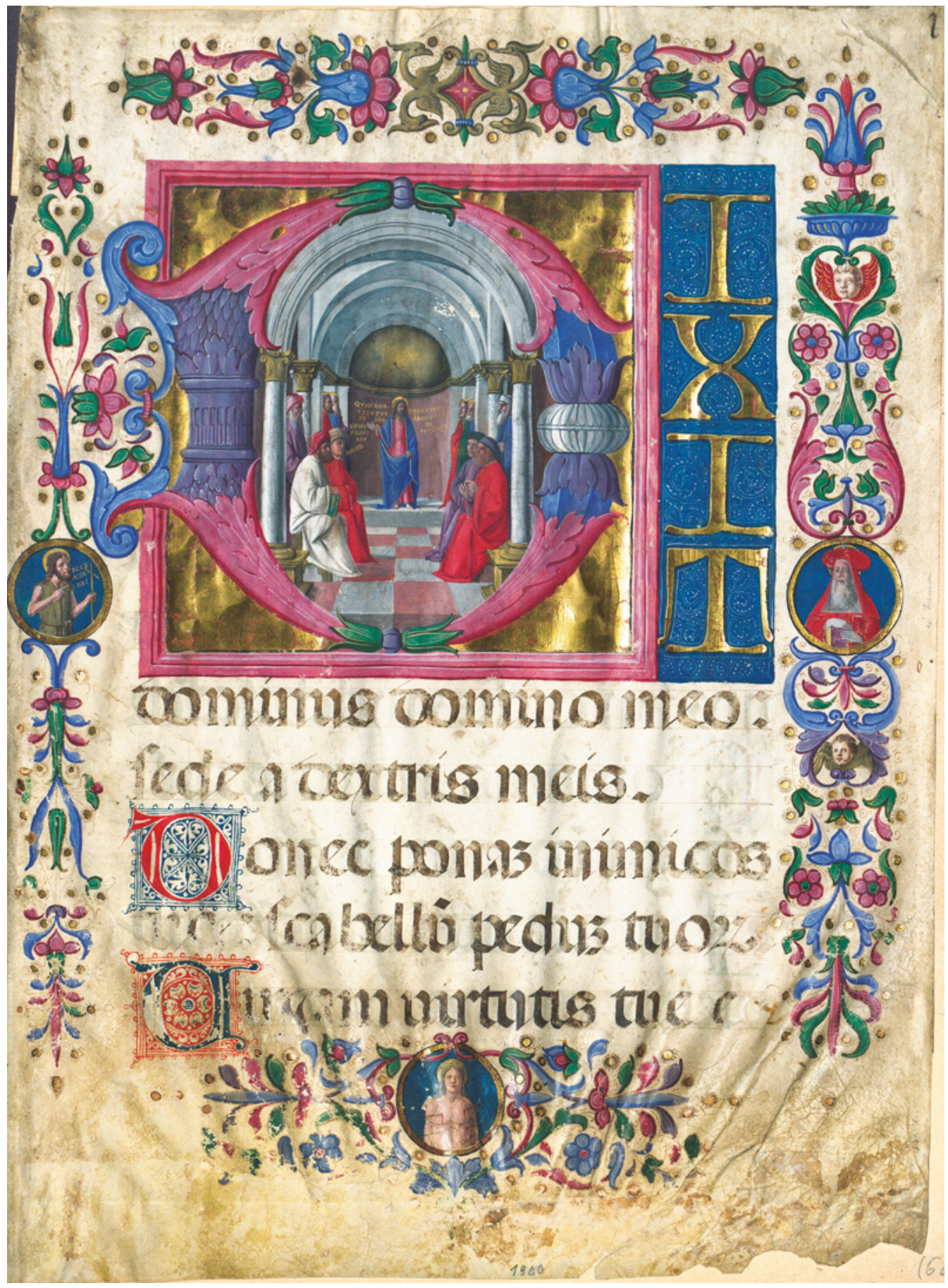

Fig. II: Benedetto Bordon, Christ and the Pharisees, detached folio from a Choir Psalter, perhaps from San Sebastiano, Venice (Cracow, Jagiellonian University Library, I.R. 1900) 
Fig. I2: Benedetto Bordon, Christ and the Pharisees, in Evangeliary for Sta Giustina, I523-25 (Dublin, Chester Beatty Library, MS W. I07, fol. 23r)

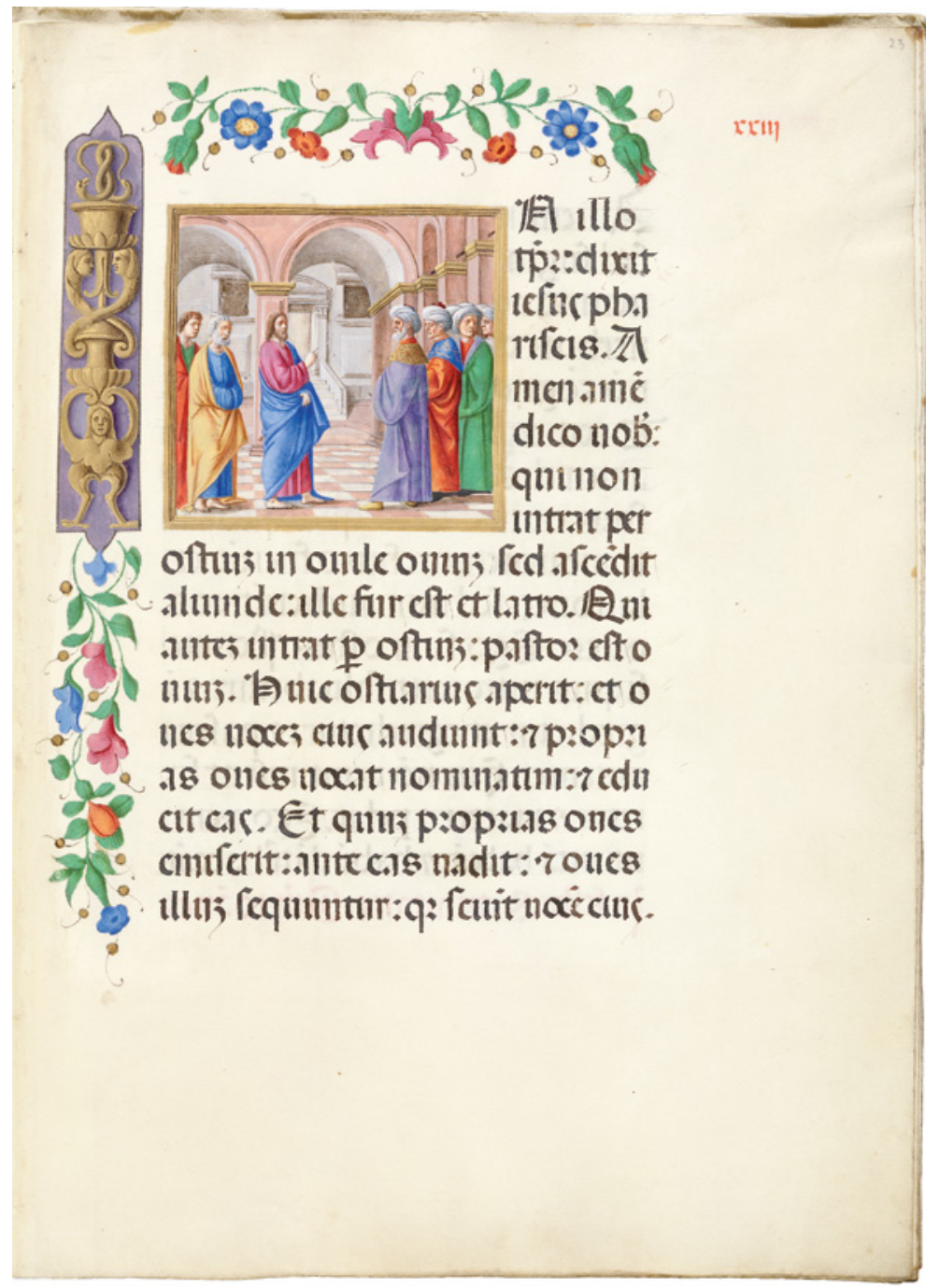

in 1505 and continued through the early decades of the sixteenth century. ${ }^{34}$ The church is aisleless, but its nave terminates in a sanctuary with a semi-circular domed apse ${ }^{35}$ that is similar to the apse in Bordon's miniature, which would thus be a flattering evocation of the new construction. The date in the first or second decade of the sixteenth century is appropriate for the complex miniature, and the stress on a Renaissance architectural setting would also be in accord with such a commission.

34 P. Paoletti di Osvaldo, L'Architettura e la scultura del Rinascimento in Venezia, Venice, I893, pp. I22, 283-285; Franzoi/di Stefano, Le chiese di Venezia (cit.n. 7), pp. I82-I84; Lieberman, Renaissance Architecture in Venice (cit. n. 7), Pls. 34, 35.

35 Lieberman, Renaissance Architecture in Venice (cit. n. 7), Pl. 34. 


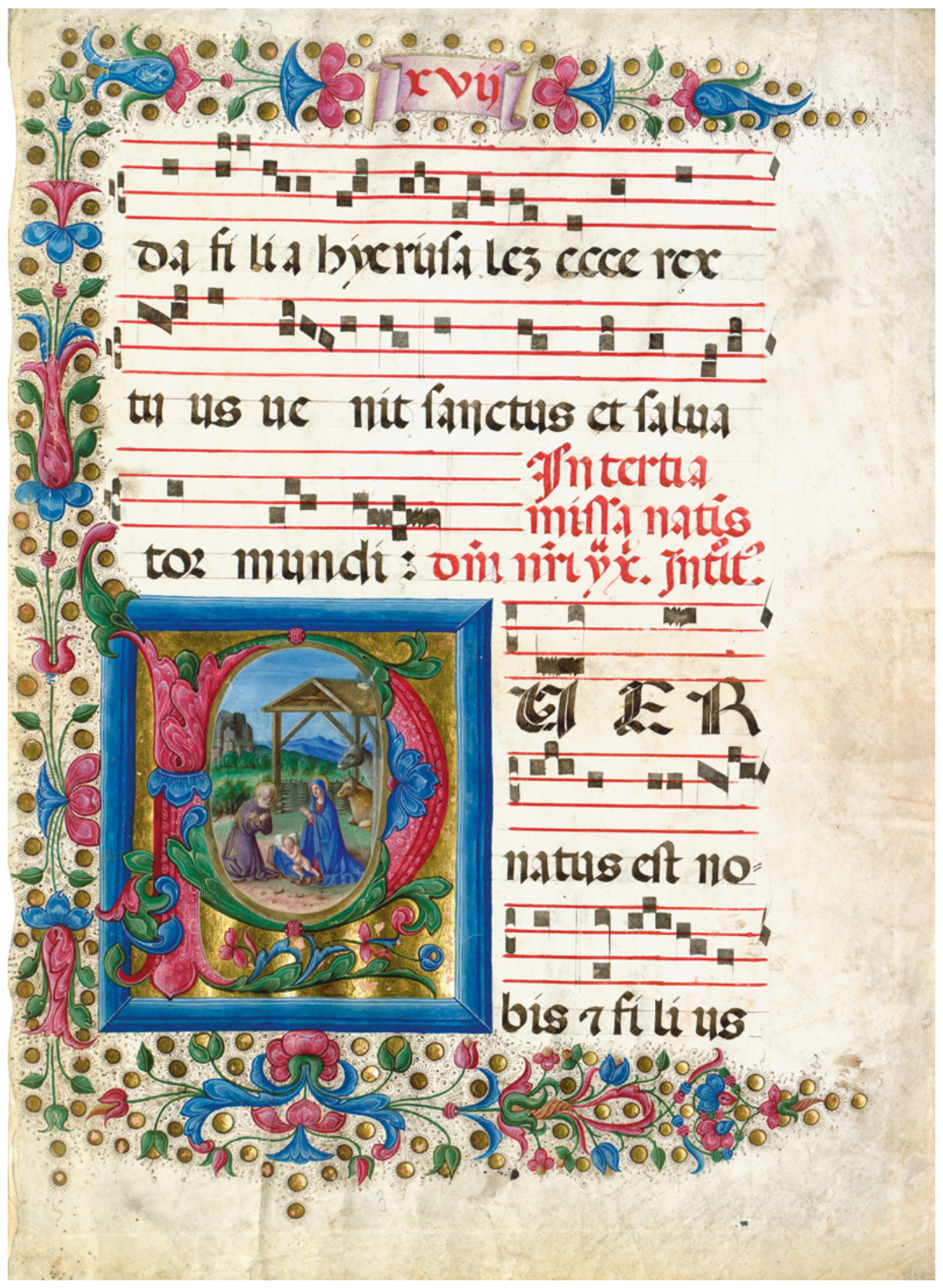

Fig. 13: Benedetto Bordon, Nativity, detached folio from a Gradual, Temporale, c. I5IO-15 (Cracow, Jagiellonian University Library, I. R. 1897) 


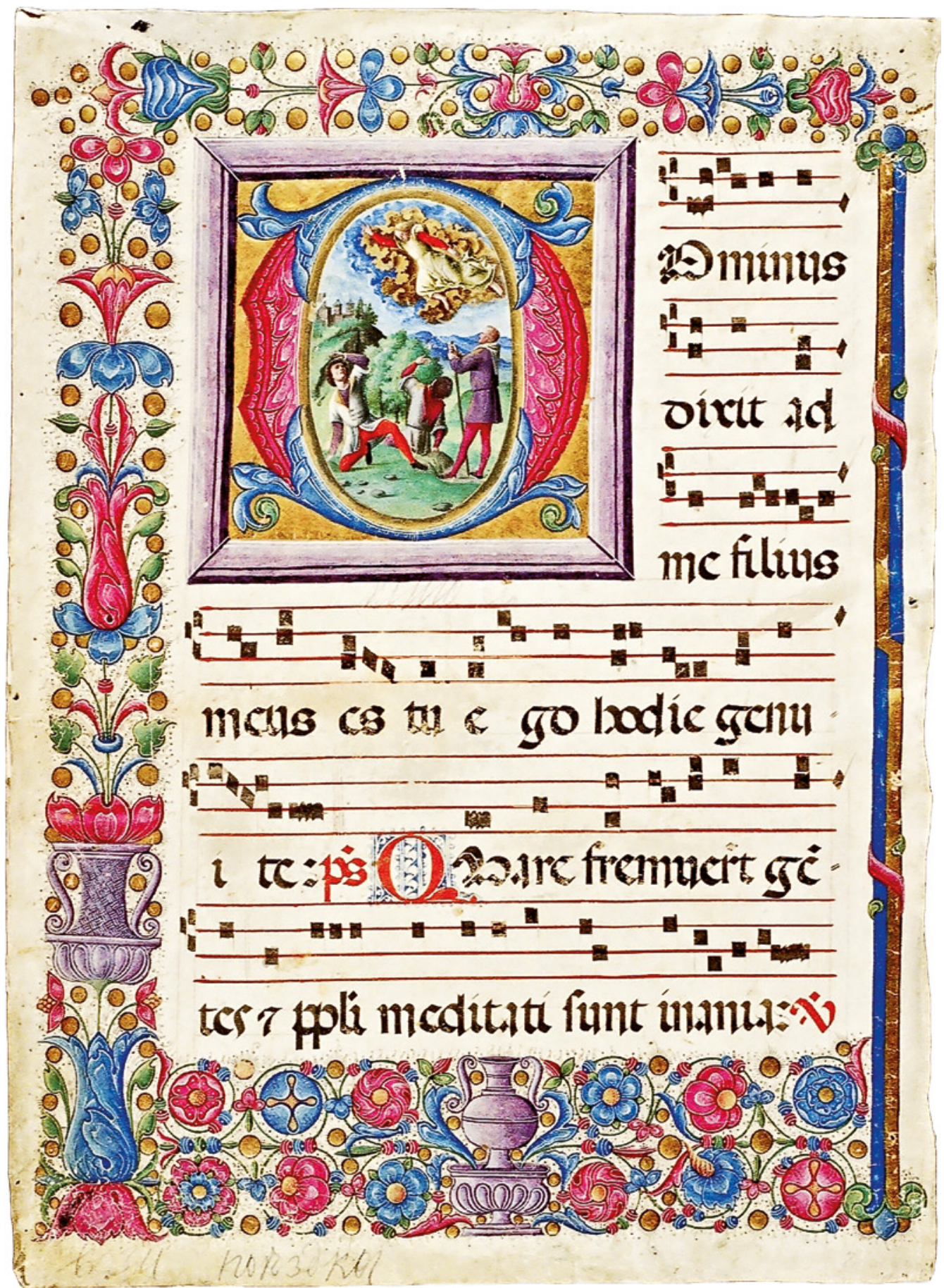

Fig. I4: Benedetto Bordon, Annunciation to the Shepherds, detached folio from a Gradual, Temporale, c. I510-20 (Moscow, State Historical Museum, Mus. 3197-a, fol. 3r) 
Very beautiful, but with more standard iconography, is the second detached folio in Cracow, from a Gradual. ${ }^{36}$ The folio is numbered xvii in the upper margin, and includes a rubric indicating the introit for the third mass (or principal missa solemnis) for the Feast of the Nativity (Fig. 13). The recto has floral borders in three margins and a handsome historiated initial "P" (Puer natus est) with a miniature of the Nativity. The composition is very similar both to the Nativity in San Nicolò Antiphonary no. I (see Fig. 3) and to the signed Nativity in the Evangeliarium for Santa Giustina of 1523 (see Fig. 5). St. Joseph and the Virgin Mary are kneeling, adoring the nude Christ Child who is lying on the ground between them. To the right is a wooden shed in which are the ox and the ass. In all three cases the background consists of verdant fields and trees, a town with walls and towers, and distant blue mountain ranges.

The handsome page should be dated sometime after the San Nicolò Antiphonary and earlier than the Santa Giustina miniature, that is, around 1515 or a little later. Suggesting this chronological sequence is the framing of the narrative scenes in these three compositions of the Nativity. The San Nicolò Nativity is surrounded by an elaborately painted capital "H" which in turn is placed on a rectangle of gold leaf, but the area is not otherwise framed. The bowl of a capital "P" encloses the Cracow Nativity, and the letter is again surrounded by gold. But around the entire area is painted a blue, illusionistically three-dimensional frame that is almost square in shape. The Nativity in the Santa Giustina Evangeliary of 1523 is an independent miniature, no longer represented within an initial. Around the scene, however, is a square bronze-colored frame that is also illustionistically three-dimensional, so that the image approximates an Albertian panel painting.

I propose that the Cracow Nativity folio originally belonged to the same Gradual as a detached folio in the State Historical Museum in Moscow (Fig I4) ${ }^{37}$ Although both folios have been trimmed slightly, the dimensions are nearly the same: the Cracow folio measures $602 \times 450 \mathrm{~mm}$, and the Moscow one is $595 \times 440 \mathrm{~mm}$. The lay-out with six tetragrams and a historiated initial equal in height to three tetragrams, is the same on both folios, and the script also appears to be very similar. The text, "Dominus dixit ad me flius meus..." is to be sung at the first mass at Christmas, and the Moscow folio would thus precede the Cracow leaf in a Gradual. ${ }^{38}$

The decorative borders and the historiated initials of the Cracow and Moscow folios also have much in common. Many of the floral and gold-dot motifs of the upper and left margins are identical, although the Moscow border adds classical vases to the ensemble. Like the Cracow Nativity, the Moscow Annunciation to the Shepherds is surrounded by an illusionistic three-dimensional frame, but in purple rather than blue. The Moscow Annunciation to the Shepherds includes many elements that make an attribution to Benedetto Bordon appropriate. It may be compared to the same subject represented in the Santa Giustina Evangeliary of 1523 (Fig. I5), in which there are also two shepherds in contorted poses seated on the ground. Interestingly, the pose of the shepherd on the left in the Moscow folio is reversed in

36 See note 30 .

37 See note 3 I.

38 Compare, for example, Ciardi Dupré, I corali del Duomo di Siena (cit. n. I), pp. 78, 80-8I, inI. 


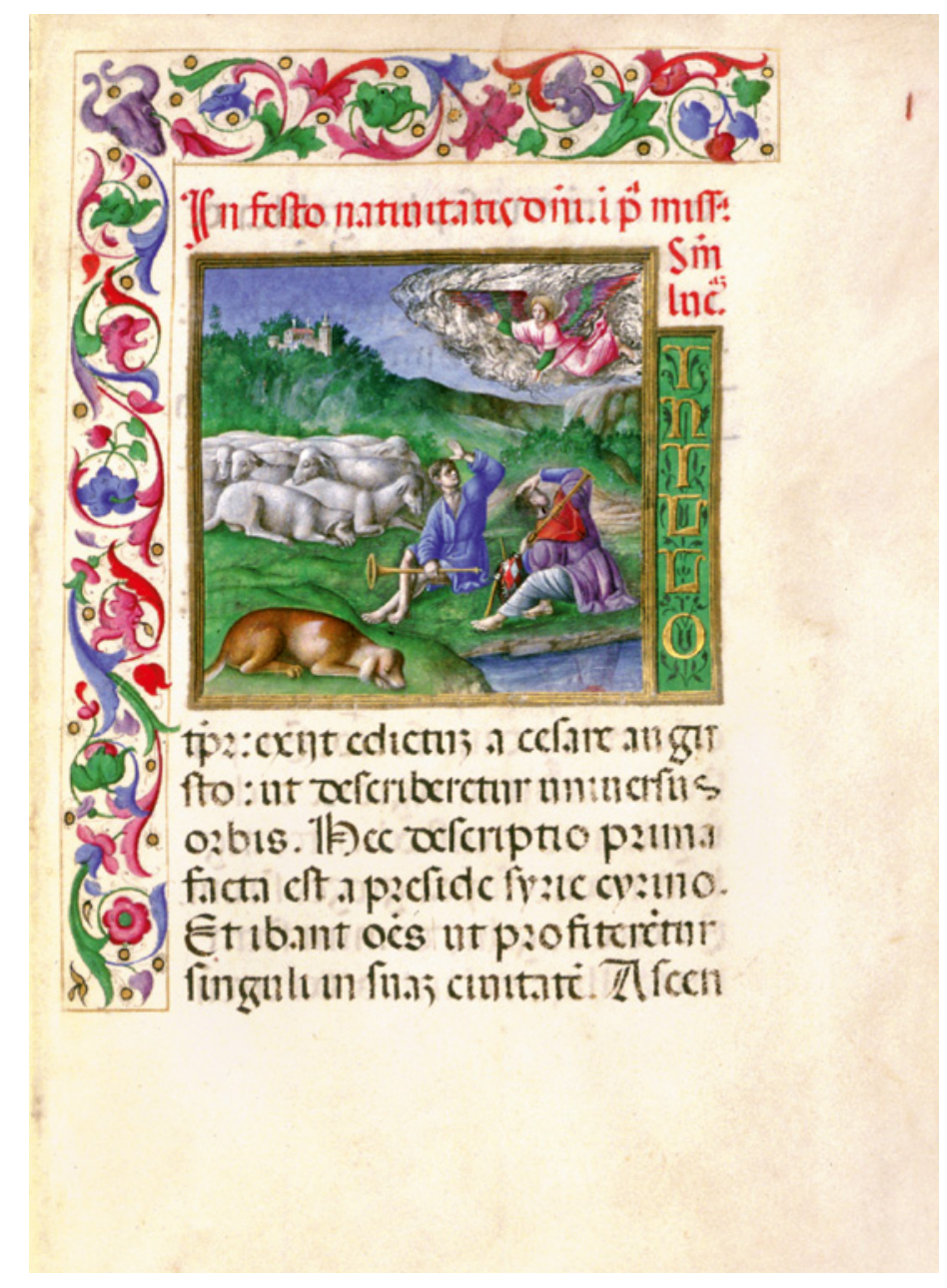

Fig. 15: Benedetto Bordon, Annunciation to the Shepherds, in Evangeliary for Sta Giustina, 1523-25 (Dublin, Chester Beatty Library, MS W. 107, fol. Iv)

the Evangeliarium miniature, as if the model had been drawn first from the front and then from behind. The more static pose of the shepherd standing on the left in the Moscow folio, who leans back on one leg, is a position frequently found in figures by Bordon (see Fig. 7). The bright red stockings of the shepherds contrast with the green fields and trees, and in both the Nativity and in the Annunciation to the Shepherds the hills rise on the left and blue mountains slope down to the right.

Nothing on the two Gradual folios themselves indicates their provenance beyond the fact that the miniatures are distinctly Venetian, and are attributable to the Veneto miniaturist Benedetto Bordon. Izabela Korczyńska has determined from the inventory of the Jagiellonian University Library that the two folios with the Nativity and the Christ and the Pharisees (I. R. I897 and I. R. I900) entered that collection in I886, purchased from a collector named Gieysztor as a part of the Jan Sierakowski collection. ${ }^{39}$ In addition, the folios were said to have

39 I am very grateful to Izabela Korczyńska of the Graphic and Cartography Department of the Jagiellonian 
come from San Giovanni in Borgo, Pavia. Korczyńska proposed that the most likely member of the Gieysztor family was Jakub Wilhelm Kasper Gieysztor (I827-I897) who sold a part of his collection in Warsaw. ${ }^{40}$ It is not clear at what period the Cracow folios were located in San Giovanni in Borgo, Pavia. One possibility is that they were commissioned from Benedetto Bordon for use in San Giovanni in Borgo. Alternatively, many manuscripts from Venetian monastic institutions were removed from their original locations during the seventeenth and eighteenth centuries. ${ }^{41}$ San Giovanni in Borgo was itself suppressed in I805. Unfortunately, nothing is known of the Moscow folio's earlier history. San Sebastiano remains a possibility for the Moskow and Cracow folios, but this can only be a supposition.

\section{CORALI PRINTED BY LUCANTONIO GIUNTA， I 499-I5O7}

By the time that Benedetto Bordon and his workshop were illuminating the antiphonaries for San Nicolò, books had been being printed in Venice for over twenty-five years. The first printing presses opened in Venice in 1469 , and by 1500 Venice was the greatest center for printing in all of Europe. During the I490s four different printers applied for privileges to print choirbooks in Venice, but only LucAntonio Giunta and his printer, Johannes Emericus de Spira, had the resources and technical knowledge necessary to print successfully the huge volumes with complex musical texts. ${ }^{42}$ Giunta published a two-volume Graduale in I499-I500; a four-volume Antiphonarium in 1503-1504; and a Psalmista (or Choir Psalter) in $1507 .{ }^{43}$ The paper bifolia for the Antiphonarium measure over 500 millimeters in height and over 700 millimeters in width. Some of the examples were printed on vellum, also a demanding and expensive technique. Black ink was used for the many sizes of type, and red ink provided rubrics and the red lines of the music staves. ${ }^{44}$ Furthermore, woodcut historiated initials were designed to initiate the major chants. The Giunta choirbooks are thus among the largest and most impressive volumes ever printed.

The visual evidence indicates Benedetto Bordon designed the woodcuts for Giunta's choirbooks. ${ }^{45}$ Drawings in Bordon's workshop would have formed the basis both for miniatures and for designs drawn on woodblocks and cut by woodcutters. If the woodcut images of King David in Prayer from the 1499 Gradual, or the Vision of Moses from the 1503 Antiphonary are compared with the manuscript Vision of Isaiah from the San Nicolo Antiphonary no.I, the

University Library for her communications of December $201 \mathrm{I}$ and January $20 \mathrm{I} 2$ regarding the provenance of the folios.

40 H. Moścıcki, Gieysztor, Jakub Wilhelm Kasper (I827-I897), in: Polski Słownik Biograficzny, Vol. 7, Polska Akademia Umiejetności, Kraków 1948-1958, pp. 459-460.

4I A. ZorZI, Venezia scomparsa, 2 vols., Milan, 1977, passim.

42 M.K. Duggan, Italian Music Incunabula: Printers and Type, Berkeley, University of California Press, I992, passim.

43 V. Masséna, Prince d'Essling, Les Livres à figures Venetiens de la fin du XVe Siècle et du Commencement du XVIe, Florence and Paris, I907-I9I4, nos. I208, I402; I70; P. CAMERINI, Annali dei Giunti, 2 vols. Florence, Sansoni, I962, I, pp. 99-I00, no. 46; pp. I08-IIO, no. 58; p. I33, no. II3.

44 See especially Duggan (cit. n. 42) for discussion of printing music.

45 L. Armstrong, Woodcuts for Liturgical Books published by LucAntonio Giunta in Venice, I499-I5OI, in: Word and Image, I7, 200I, pp. 65-93, esp. p. 66 (and Armstrong, Studies (cit. n. 5), pp. 683-73I, esp. p. 686). 


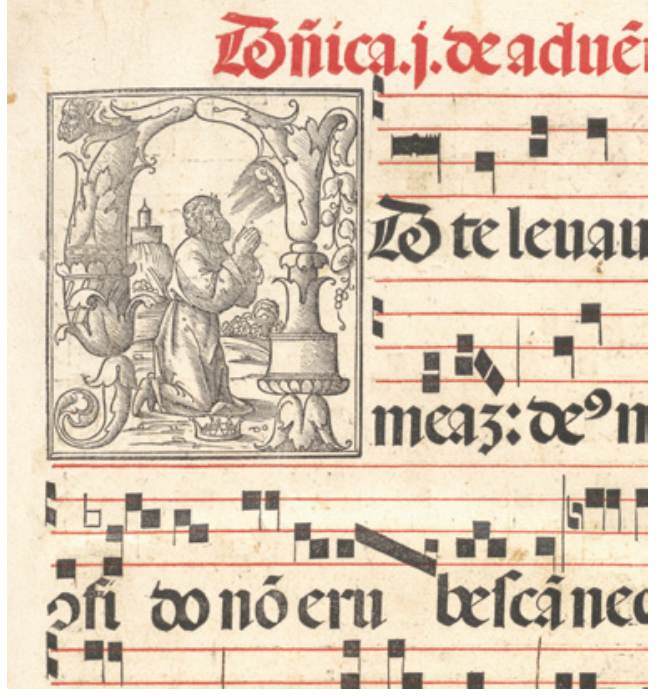

Fig. I6: Benedetto Bordon, designer, David praying, woodcut in Graduale romanum, Venice, LucAntonio Giunta, I499-I500, Vol. I, fol. Ir (Berkeley, CA, University of California, Berkeley, Music Library, $\left.\mathrm{fM} 2 \mathrm{I}_{49} . \mathrm{V}_{4} \mathrm{G} 7\right)$

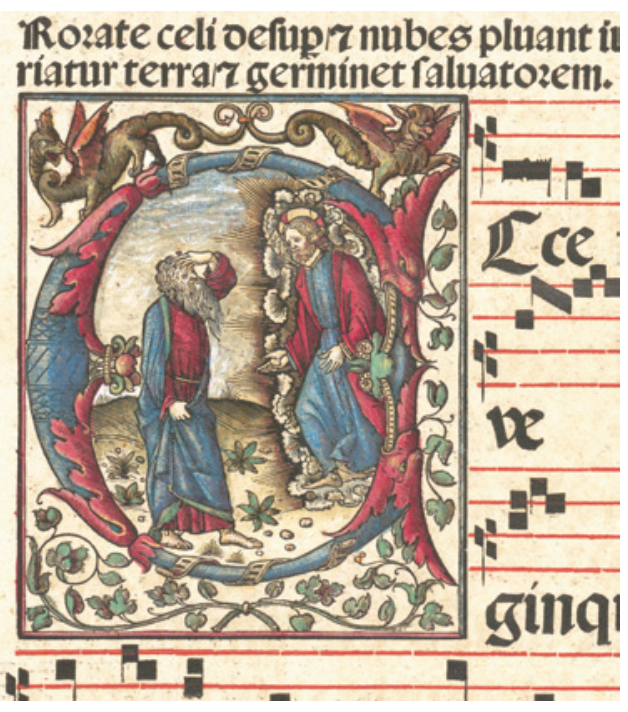

Fig. 17: Benedetto Bordon, designer, Vision of Moses, woodcut in Antiphonarium romanum, Venice,

LucAntonio Giunta, I503, Vol. I, fol. 2r (Berkeley, CA,

University of California, Berkeley, Music Library, fM2150. $\mathrm{V}_{452)}$

formal similarities become apparent (Figs. 16, 17, and see Fig. 7). The monumental figures of Isaiah and Moses stand in dignified poses, leaning back on one foot in a typical Bordon manner. Their hands grasp their robes in a comparable gesture as they shield their eyes from the brilliance of the Divine. Also striking is the similarity of the two initials, the " $\mathrm{A}$ " of the woodcut King David in Prayer and the "A" of the painted Vision of Isaiah. The acanthus leaves swirl in baroque curves, and classical vases are incorporated as supports.

It is not surprising that LucAntonio Giunta would have turned to the versatile Bordon for woodcut designs, as he was known to have edited and published a book himself, as well as handilluminating incunabula, and being documented as a designer of woodcuts for a Triumph of Caesar in $1504 .{ }^{46} \mathrm{It}$ is highly probable that Giunta's project of printing choirbooks was well-known in Venice even before the actual appearance of any of the volumes in I499. If the authorities at a church or monastery were contemplating acquiring new Choirbooks in the I49os, they might have considered waiting to see what the new printed books would look like. They might have assumed (wrongly, perhaps) that the printed volumes would be easier to acquire and cheaper. The anticipation of the elaborate printed Choirbooks may be one reason why there is only evidence of a very few manuscript choirbook commissions from this period in Venice. ${ }^{47}$

46 L. Armstrong, The Triumph of Caesar Woodcuts of 1504 and Triumphal Imagery in Venetian Renaissance Books, in: Grand Scale: Monumental Prints in the Age of Dürer and Titian, exhib. cat. ed. by L. Silver and E. Wyскоғғ, Wellesley College, and New Haven and London, Yale University Press, 2008, pp. 52-7I.

To the list of detached folios with initials stylistically related to the Bordon workshop should be added: Ligabue Collection, Folio from an Antiphonary; Response for Sunday of Pentecost, historiated initial of Pentecost, vellum, $380 \times 275 \mathrm{~mm}$ [S. MArcon, Frammenti d'arte: Miniature dalla Collezione Ligabue, Trebaseleghe 


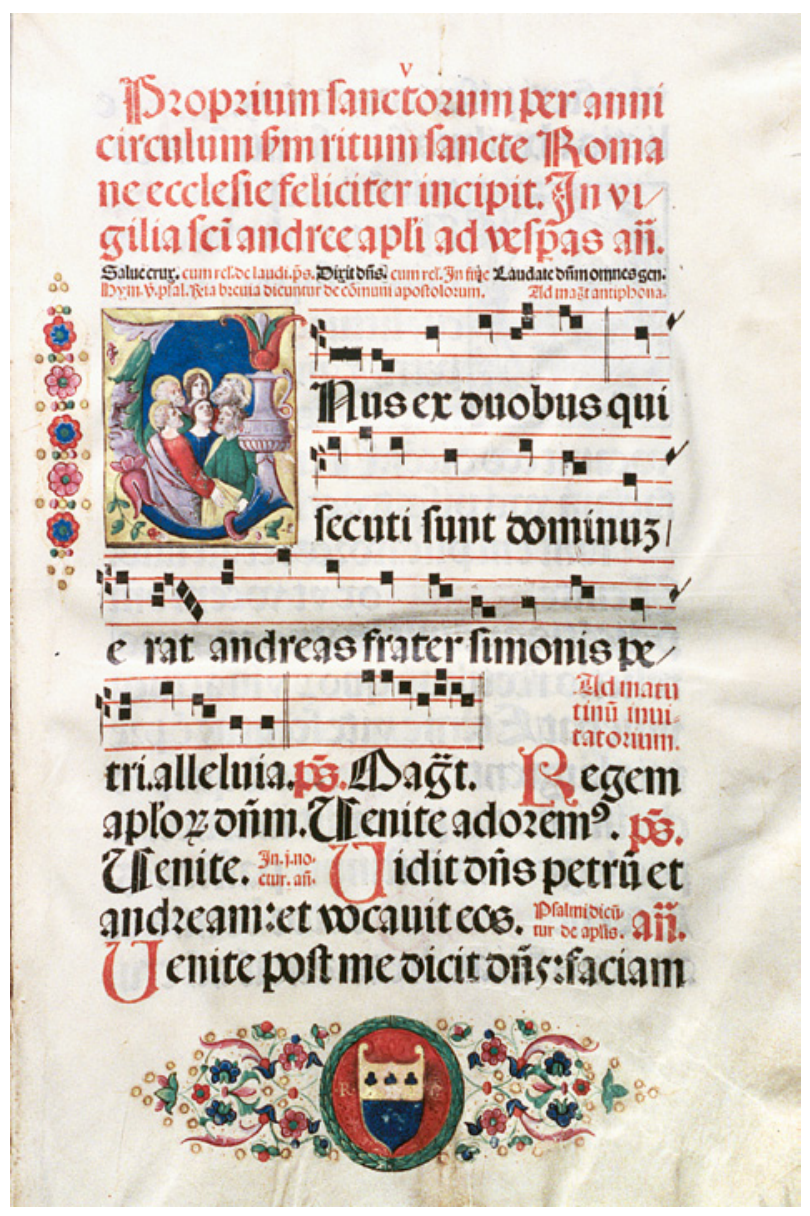

Fig. 18: Benedetto Bordon, designer, Saints, woodcut in Antiphonarium romanum, Venice, LucAntonio Giunta, 1504, Vol. 3, fol. 5r, with hand-illumination and coat of arms of Raniero Fioravanti (Venice, Archivio Storico Patriarcato)

\section{MANUSCRIPTS AND PRINTED CHOIRBOOKS FOR}

\section{SAN RAFFAELE ARCHANGELO}

Seven choirbooks have been preserved that belonged to the parish church of San Raffaele Archangelo in Venice, a church in Dorsoduro, not far from San Nicolò. ${ }^{48}$ Four of these

(Padua), Il Punto, 2009, pp. II2-II5, cat. no. 20]; and Chicago, Chicago Art Institute, Inv. I5. 555, folio from a Gradual, Common of Saints, Introit for Vigil of Feast of one Apostle, historiated initial with half-length St. Peter, vellum, $501 \times 340 \mathrm{~mm}$ (Information thanks to Jonathan Alexander).

In a weaker style, but nevertheless probably Venetian, and also elaborately illuminated is: Evanston, IL, Northwestern University Library, McCormick Library of Special Collections, De Ricci i, Franciscan Gradual, Temporale with Feasts from Easter to the Twenty-Fourth Sunday after Pentecost, vellum, 270 ff, 490 ×320 mm; fol. Ir Resurrection in an "R", full border with SS. Francis and Anthony of Padua(?), and Annunciation; fol. $54 \mathrm{v}$, Ascension in a "V"; fol. 74v, Pentecost in a "S", and IHS in glory in lower margin; fol. I08r, Altar with Angels supporting Host. I thank Sigrid Pohl Perry for information about this Gradual.

48 Venice, Archivio Storico Patriarcato, on deposit from the Chiesa di San Raffaele Archangelo, Venice, 7 Choirbooks, each including the coat of arms of Raynerio Floravanti: 3 printed choirbooks, Antiphonarium, 


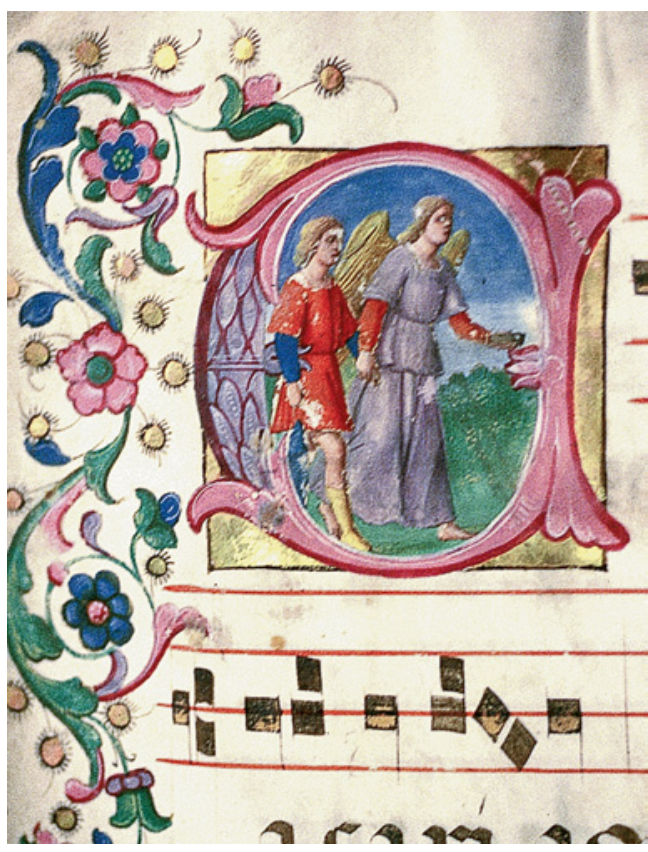

Fig. 19: Benedetto Bordon, workshop, Tobias and the Angel, in Gradual for Church of San Raffaele Archangelo, Venice (Venice, Archivio Storico Patriarcato)

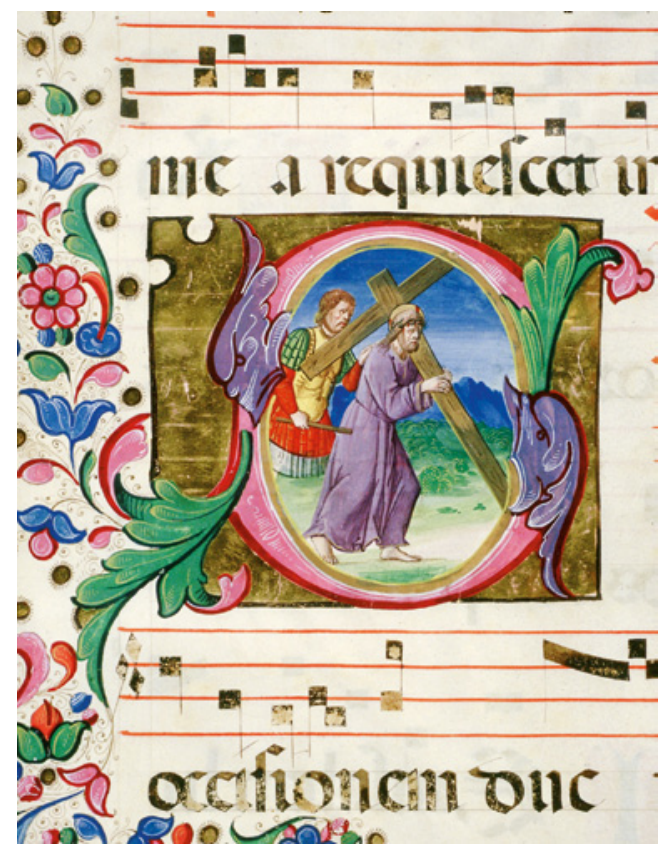

Fig. 20: Benedetto Bordon, Christ carrying the Cross, originally fol. $199 \mathrm{r}$ in San Nicolò Antiphonary no. 2, c. I500 (Vatican City, Biblioteca Apostolica Vaticana, MS Ross. II95, fol. 24r)

choirbooks are manuscripts and three are printed choirbooks. The heterogeneous nature of the San Raffaele set was probably a more common phenomenon of choirbook acquisition in the early sixteenth century than the stylistically unified manuscript choirbooks for San Nicolò. All of the San Raffaele books were decorated with the coat of arms of the parish priest, Raniero Floravanti (Fioravanti), who died in 1513 . However, inscriptions in the manuscripts make it clear that they were presented to the church in $15 \mathrm{I} 8$ and 1522 following a bequest from Fioravante's will.

Viewing the opening folio of the San Raffaele copy of Volume 3 of Giunta's Antiphonarium, Sanctorale of 1503-I5O4 reveals its resemblance to contemporary manuscript choirbooks (Fig. I8). Strikingly, the woodcut initial of the Apostles has been hand-illuminated with tempera and gold leaf; and floral motifs and a coat of arms have been painted in the inner and lower margins. Presumably unwilling to pay an even higher price for the Antiphonarium, the woodcut initials other than the one on the opening folio have not been illuminated.

Volume I of Giunta's Antiphonarium, Temporale with Feasts from Advent through Holy Saturday, was also acquired for San Raffaele, as was his Psalmista of 1507, and these too

Vols. I and 3, Venice, LucAntonio Giunta, I503-I504; and Psalmista, Venice, LucAntonio Giunta, I507; and 4 manuscripts: Gradual, Temporale for Feasts from Advent to Holy Saturday vellum, late $14^{\text {th }}$ century, $550 \times 370 \mathrm{~mm}$ (on exhibit in the Museo Diocessano, Venice); and three Graduals, Temporale Easter through Twenty-fourth Sunday after Pentecost (donated March 6, I522); Sanctorale and Common of Saints (donated September 25, I522); Gradual for Feasts of St. Raphael Archangel and Nicetas (donated June I, I5I8). The information about the donations is found in inscriptions in the three $16^{\text {th }}$-century Graduals. 
had hand-illuminated woodcuts and coats of arms on their first folios. Because of the coats of arms, it seems likely that the three Giunta choirbooks were acquired before the death of Fioravanti in I5I3. However, in his testament Rainiero Fioravanti's left a bequest for acquiring further liturgical books, since the church had Antiphonaries, but apparently needed Graduals. His heirs acquired manuscripts, not printed books, to fulfill the bequest. This may mean that they were unable to afford or to obtain printed Graduals.

Three of the manuscripts that they commissioned were decorated by undistinguished miniaturists, but for the fourth, the heirs did apparently go to Benedetto Bordon, head of the most famous illuminator's workshop in Venice, for one small initial. It appears in a Graduale et Kyriale with special chants for the Feasts of St. Raphael and St Nicetus, the two patron saints of the church (Fig. 19). The miniature shows the Archangel Raphael walking hand in hand with Tobias, who holds a fish with which he will cure his father's blindness. Comparison may be made with the more complex but substantially similar composition of Christ carrying the Cross from one of the San Nicolo Antiphonaries (Fig. 20). Whatever the quality of the choirbook illuminations, Rainerio Fioravante's nephews were proud of carrying out the request, as they had all their names inscribed at the end of the volume: Benedictus, JoanPetrus, and Ludovicus.

\section{CONCLUSION}

Around 1500 Benedetto Bordon dominated the production of illuminated choirbooks in Venice, as is indicated by the reconstructed volumes whose commission came from San Nicolò della Lattuga, and by a number of detached folios, heretofore largely unknown, demonstrating other commissions. Simultaneously, Bordon and his workshop appear to have been actively designing woodcuts for LucAntonio Giunta, whose printed choirbooks rivaled manuscripts. Even these printed choirbooks could be embellished by adding coats of arms and coloring the woodcuts. These media were in competition with each other around I500, but both kinds of choirbooks were soon to disappear. Manuscripts would become too expensive, and printers would realize that smaller format choirbooks could be produced more easily. No other choirbooks of such magnitude were ever printed in Venice, and even the Giunta series of I499 to 1507 exists only in a few rare copies.

Wellesley College

Illustration credits: Fig. I: Venezia, Abbazia di San Giorgio Maggiore. - Fig. 2: Su concessione del Ministero per i Beni e le Attività Culturali, Biblioteca Nazioneal Marciana, divietato di riproduzione. - Figs. 3, 4, 7, 20: Per concessione della Biblioteca Apostolica Vaticana, ogni diritto riservato. - Figs. 5, I2, I5: Dublin, Trustees of the Chester Beatty Library. - Figs. 6, 8: München, Staatliche Graphische Sammlung. - Figs. 9, Io: Used by permission of the Rare Book Department, Free Library of Philadelphia. - Figs. II, I3: Kraków, Biblioteka Jagiellońska, I. R. I900. - Fig. I4: Moscow, State Historical Museum. - Figs. 16, I7: Berkeley, CA, University of California, Berkeley, Music Library. - Figs. I8, 19: Per concessione del Ufficio Promozione Beni culturali della Diocesi di Venezia. 


\title{
„ASTANTES STOLIDOS SIC IMMUTABO STULTOS“- VON NACHLÄSSIGEN SCHREIBERN UND VERSTÄNDIGEN BUCHMALERN. ZUM ZUSAMMENSPIEL VON TEXT UND BILD IN KONRAD KYESERS ,BELLIFORTIS“
}

\author{
Regina Cermann
}

Mit der in der Überschrift zitierten Zeile (Chantilly, fol. I46r), ${ }^{1}$ die Konrad Kyeser in seinem ,Bellifortis' der Königin von Saba in den Mund gelegt hat, düpierte die altorientalische Herrscherin um I4OO die europäische Jugend. Aber auch wir werden - durchaus unfreiwillig - noch heute vom Autor als Ahnungslose vorgeführt. Neben einer schwierigen Überlieferungslage und einer unbefriedigenden Forschungssituation trägt nicht zuletzt der Verfasser selbst Schuld an der Misere. ${ }^{2}$ Mehrfach hat er den Text für sein opulentes kriegstechnisches Bilderwerk umformuliert. ${ }^{3}$ In einer Version (Göttingen 63) erwähnt er Schwierigkeiten mit kopierenden Schrei-

I Die im Text gebrauchten Handschriftensiglen finden sich am Ende des Beitrages aufgelöst. Nicht mehr mit einbezogen werden konnten in die Studie zwei Handschriftenzeugen, die mir erst während der Drucklegung bekannt geworden sind: I. Madrid, Real Biblioteca de San Lorenzo de El Escorial, Ms. Y. II. 2I. Vgl. L. Villena, Una copia desconocida de Bellifortis, in: Actas II Congreso de la Sociedad Española de Historia de las Ciencias. Jaca, 27. September - I. Oktober 1982, hg. von M. Hormigón Blánquez. 3 Bde. Saragossa 1984, Bd. 3, S. 405-426. 2. Florenz, Biblioteca Nazionale Centrale, inv. vol. II.III. 3I7 (Magl. Cl. XIX, num. Ios bis). Vgl. G. Mazzatinti, Inventari dei manoscritti delle biblioteche d'Italia. Bd. Io, Florenz 1900, S. 37; 48 Fotos als Verzeichniseinheiten im Online-Katalog der Fotothek der Biblioteca Hertziana in Rom (http://foto.biblhertz.it) als Teil des „Gernsheim Corpus of Drawings“ (Nr. 179919-179966; Einträge vom 5. 4. 2006 von Verena Gebhard). Während die Handschrift in Madrid als lateinischer Textzeuge der geordneten Sieben-Kapitel-Fassung angehört, handelt es sich bei dem Codex in Florenz um einen deutschen Vertreter der gestörten Sieben-Kapitel-Fassung (s. Anm. 3), der New York IO4 am nächsten zu stehen scheint.

2 Zum Stand der Forschung sowie zu neuen Ansätzen für die Genese und Interpretation des Werkes vgl. R. Cermann, Der ,Bellifortis‘ des Konrad Kyeser (Codices Manuscripti \& Impressi, Supplementum 8). Purkersdorf 2013.

3 Vier Textversionen, darunter eine deutsch-lateinische, die offenbar Fragment geblieben ist (Wien 6562B), dürften auf den Autor selbst zurückzuführen sein, nämlich Göttingen 64a, Göttingen 63, Wien 6562B, Rom 1994 bzw. Chantilly. Von den letzten beiden Codices, die das ursprünglich auf zehn Kapitel verteilte Material nur mehr in sieben Kapiteln darbieten, hängen weitere Überlieferungsträger ab, vgl. das Stemma bei CermanN (zit. Anm. 2), S. 94 f. Eine später vorgenommene Umgruppierung der Sieben-Kapitel-Version zerstört hingegen Kyesers Konzeption. Für diese gestörte Fassung liegt eine recht getreue deutsche Übersetzung vor (unter anderem Wien 3068), die aufgrund von Missverständnissen jedoch unmöglich von Kyeser selbst stammen kann. Eine andere, von der Forschung bislang nicht weiter beachtete Übertragung in die Volkssprache (Hauptvertreter Wolfenbüttel; lat.-dt. Rudimente unter anderem in Rom I888) stellt eine etwa zeitgleich entstandene freiere Prosa-Bearbeitung von Kyesers Versen dar. Aus dieser geht eine Neukonzeption mit zusätzlichem Bildmaterial hervor (erweiterte Sieben-Kapitel-Fassung), die derzeit unter dem Notnamen (Ps.)-Hartlieb firmiert und nur auf Deutsch existiert (Tenschert, Wien 3062, Berlin 204I). Im Lichte jüngerer Quellenfunde könnte sie womöglich als authentisch erachtet werden, vgl. Johannes Hartlieb, ,Kräuterbuch`' Zum ersten Mal kri- 
bern und Malern, die allerdings angeblich mittlerweile überwunden seien. ${ }^{4} \mathrm{Da}$ jedoch in allen uns erhaltenen Codices, auch in den beiden Widmungsexemplaren Göttingen 64a und Göttingen 63 an König Wenzel IV. (136I-I4I9) bzw. König Ruprecht von der Pfalz (I352-I4IO), der sogenannte Nabelschnurzauber korrumpiert vorliegt, ${ }^{5}$ hat der Autor es am Ende offenbar nicht mehr für nötig befunden, den Text abschließend noch einmal korrigierend durchzuschauen. Die höchst problematische Transkription und Übersetzung von Götz Quarg leisten schließlich ein Übriges, um Missverständnissen und Fehldeutungen Tür und Tor zu öffnen, verleiten sie doch dazu, allen Warnungen Hermann Heimpels zum Trotz, sich bequemlichkeitshalber doch ihrer oftmals zu bedienen. ${ }^{6}$ Zudem wurde durch diese Edition eine Zehn-Kapitel-Fassung zum Referenzwerk erhoben (Göttingen 63), die bis auf eine Abschrift aus der Mitte des I5. Jahrhunderts (Innsbruck) und ein Exzerpt, das nur aus einem einzigen Folio besteht (Istanbul), keine weitere Nachfolge gefunden hat. Kyesers Ausgabe letzter Hand dürfte aber eher in der SiebenKapitel-Version Rom 1994 oder Chantilly zu erblicken sein, von denen zu großen Teilen die weitere Filiation sowie Umarbeitungen und Übersetzungen abhängig sind.

Wer auch immer im Mittelalter einen ,Bellifortis' besitzen wollte, benötigte eine illustrierte Vorlage. Die Bilder gehören konstitutiv zum Werk dazu, sie entspringen genauso wie der Text dem Kopf des Autors. Allein vom Text her lässt sich das Bildprogramm nicht rekonstruieren, es sei denn, man erfände es neu; vice versa erschließt sich der intendierte Sinn und Zweck nicht immer sogleich aus den Illustrationen. ${ }^{7}$ Exemplarisch soll anhand der Seite mit der Königin von Saba vorgeführt werden, wie sich Text und Bild gegenseitig erhellen. Da Verse und Bildelemente in den Handschriften keineswegs stabil überliefert werden, soll die besagte Stelle in verschiedenen Codices betrachtet werden. Vom lateinischen Text her lassen sich zwei Fassungen unterscheiden, eine sechs- und eine zehnzeilige. Quarg hat seinerzeit die kürzere nach der Zehn-Kapitel-Version von Göttingen 63 publiziert (I405), ${ }^{8}$ die wir sonst nur noch aus Innsbruck kennen, wo jedoch das dazugehörige Bild nicht ausgeführt worden ist (auf fol. 134r gibt es lediglich den entsprechenden Freiraum dafür). Das redende Ich tritt somit nur in Göttingen 63 (fol. I22r) dem Betrachter visuell vor Augen (Abb. I): Zu sehen bekommen wir eine hoheitsvolle Erscheinung en face, die durch Krone auf dem Haupt, Zepter in der linken, Reichsapfel in der rechten Hand, hermelingefüttertes bzw. -besetztes Gewand, Schellengürtel, Collier, offenes blondes Haar und schwarze Hautfarbe als orientalische Herr-

tisch hrsg. von G. HAYER und B. SChNell (Wissensliteratur im Mittelalter 47). Wiesbaden 20IO, S. 9-17, 2I f., Cermann (zit. Anm. 2), S. 20-22, mit Anm. 77-8I.

4 Göttingen 63, fol. 2v ... subscriptorum et depictorum impedimente cessante ...

5 Göttingen 63, fol. 94r. Vgl. hierzu Cermann (zit. Anm. 2), S. 88-93.

6 G. Quarg, Conrad Kyeser aus Eichstätt. Bellifortis. Umschrift und Übersetzung. Düsseldorf 1967. H. Heimpel, Rezension zu Quarg (zit. Anm. 6), in: Göttingische Gelehrte Anzeigen 223, I97I, S. II5-I48.

7 Es gibt nur eine Handschrift, in der nicht alle Bilder ausgeführt worden sind, sondern öfters der für sie reservierte Platz frei geblieben ist (Heidelberg). Hingegen existieren sechs Handschriften bzw. Handschriftenfragmente und ein Frühdruck, die nur den Bildbestand überliefern (Wien 6562A, Besançon, Frankfurt, Paris, Weimar, Wien 3069, Marschalk), sowie eine weitere Handschrift, bei der der Text nur zu Beginn hinzugefügt wurde (Rom I888).

8 Quarg (zit. Anm. 6), S. 90. 
Abb. I: Göttingen, Niedersächsische Staatsund Universitätsbibliothek, $2^{\circ} \mathrm{Cod}$. Ms. philos. ${ }_{3}$, fol. I22r

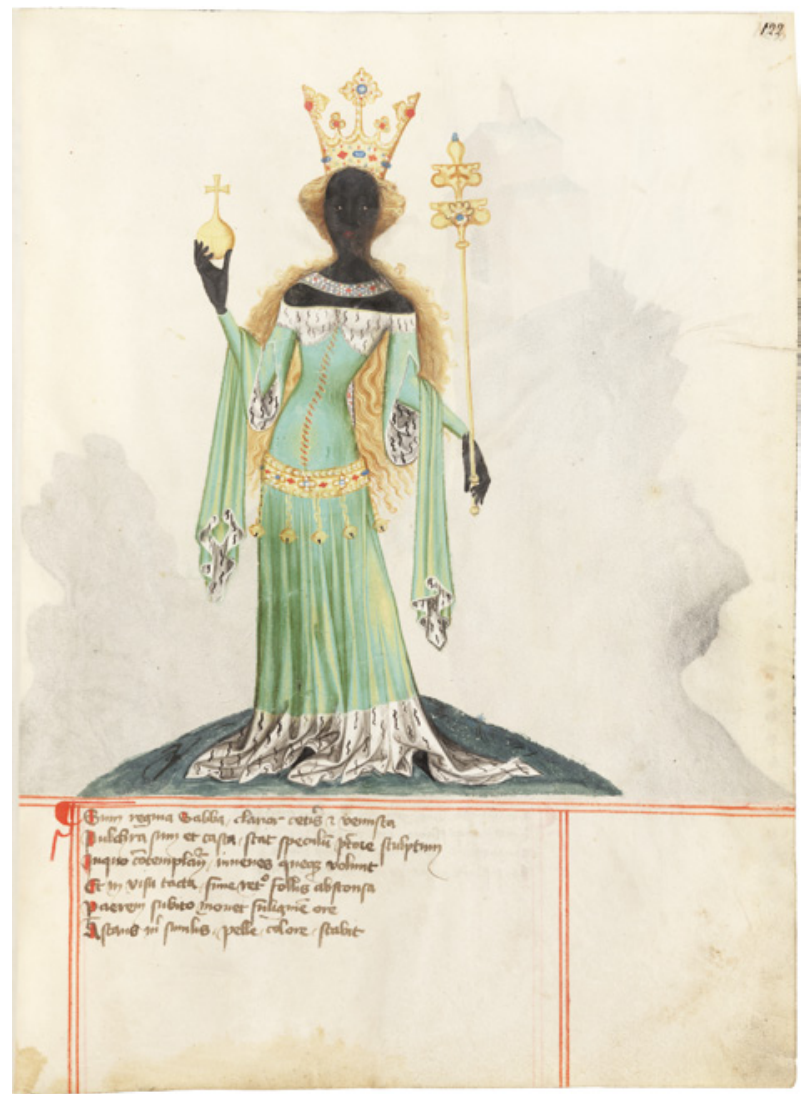

scherin von ausgesuchter Schönheit vorgestellt wird. Sie spricht ihr Gegenüber folgendermaßen an (Transkription nach Göttingen 63, fol. I22r):

Sum regina Sabba clarior ceteris et venusta

Pulchra sum et casta stat speculum pectore ${ }^{9}$ sculptum

Inquo contemplantur ${ }^{10}$ iunenes queque $e^{11}$ volunt

Et in visu tacta fune ${ }^{12}$ retro follis absconsa ${ }^{13}$

Per aerem subito mouet fuliginem ore

Astans mihi ${ }^{14}$ similis pelle colore stabit.

9 Quarg (zit. Anm. 6), S. 90 liest pictore. Innsbruck, fol. I34r ohne Abbreviatur pectore.

IO Hier reflexiver Gebrauch, abgeleitet von der aktiven Nebenform contemplo. Freundlicher Hinweis von Carmen Rob-Santer.

II Das von Quarg (zit. Anm. 6), S. 90 gelesene quecumque bereits von Heimpel (zit. Anm. 6), S. il7 zu queque korrigiert. Innsbruck, fol. I34r quoque.

I2 Genuswechsel bei funis, hier offenbar Femininum (freundlicher Hinweis von Carmen Rob-Santer). Vgl. jedoch Anm. 3I.

I3 Innsbruck, fol. i34r abscondita.

I4 Quarg (zit. Anm. 6), S. 9o liest nisi statt mihi. Innsbruck, fol. I34r ohne Abbreviatur michi. 
Quarg verfehlte den Sinn der Rede, weil er zwei folgenreiche Lesefehler in Zeile 2 und 6 beging: Er las pictore statt pectore sowie nisi statt mihi. Auf diese Weise entging ihm nicht nur der zu Täuschungszwecken auf der Brust der Figur montierte Spiegel (stat speculum pectore sculptum), ${ }^{15}$ sondern auch der eigentliche Plot, der darin besteht, dass das Standbild - durch ein heimlich in Bewegung gesetztes Seil eines rückwärts befindlichen Blasebalgs - dem vor ihm stehenden und sich im Spiegel betrachtenden Jüngling ungalant Ruß in das Gesicht bläst, so dass dieser nun wie die Schöne selbst mit schwarzem Antlitz dasteht. Interessanterweise wird im Text mit keiner Silbe die dunkle Hautfarbe der Königin erwähnt, ${ }^{16}$ während im Bild weder der tückische Spiegel, der für den Trick notwendig ist, damit sich das potentielle Opfer möglichst dicht vor der Figur positioniert, noch das versteckte Seil samt Blasebalg gezeigt wird, durch dessen Betätigung ein Luftstoß den Ruß aus dem Mund herauskatapultiert. Erst in der Kombination von Text und Bild erschließt sich somit das Gemeinte. Kyeser muss dem Miniaturisten folglich Anweisungen erteilt haben, wie das Bildnis genau auszusehen habe.

Die längere Textversion zur Königin von Saba, die zugleich auch die ältere ist, da sie bereits in der Zehn-Kapitel-Fassung Göttingen 64a vorkommt (um I4O2), welche der Fachwelt jedoch erst 1995 näher bekannt gemacht worden ist, ${ }^{17}$ lebt später in der Sieben-Kapi-

I5 QUaRg (zit. Anm. 6), S. 90 übersetzt stat speculum pictore sculptum ..., „hier steht mein Bild, vom Künstler geschaffen".

I6 Weshalb J. Devisse, M. Mollat, L'image du noir dans l'art occidental. Bd. 2,2 Des premiers siècles chrétiens aux „grandes découvertes“. Les Africains dans l'ordonnance chrétienne du monde (XIVe-XVIe siècle). Fribourg 1979, Taf. 26, S. 38 f., 266 auch wähnten, sie wäre erst nachträglich koloriert worden (bereits revidiert von G. Suckale-Redlefsen, Mauritius. Der heilige Mohr/The Black Saint Maurice. München /Zürich I987, S. 24). Losgelöst vom biblischen Kontext war den Autoren vollkommen rätselhaft, was Kyeser bewogen haben mochte, diese Figur in seine Sammlung aufzunehmen. Über den seltsamen Part, den die orientalische Herrscherin in dem Werk spielt, hat man sich auch andernorts Gedanken gemacht: So billigte man ihr vorrangig eine gliedernde Funktion zu und wollte in ihr eine Personifikation des Elements Luft bzw. eine Stellvertreterin der verbotenen Künste (Katoptromantie) erkennen, vgl. Th. BerG, U. Friedrich, Wissenstradierung in spätmittelalterlichen Schriften zur Kriegskunst. Der ,Bellifortis' des Konrad Kyeser und das anonyme ,Feuerwerksbuch', in: J.-D. MülLER (Hrsg.), Wissen für den Hof. Der spätmittelalterliche Verschriftlichungsprozeß am Beispiel Heidelberg im I5. Jahrhundert (Münstersche Mittelalter-Schriften 67). München 1994, S. I69232, hier S. 198 f. und S. Heimann-Seelbach, Rezension zu Müller, Wissen für den Hof (zit. Anm. i6), in: Göttingische Gelehrte Anzeigen 248, 1996, S. 258-283, hier S. 27I. G. Suckale-Redlefsen, Schwarze in der Kunst Böhmens unter den Luxemburgern, in: J. FAJT (Hrsg.), Kunst als Herrschaftsinstrument. Böhmen und das Heilige Römische Reich unter den Luxemburgern im europäischen Kontext. Berlin 2009, S. 328-345, hier S. 339-342 sah in der schwarzen Gesichtsfarbe vor allen Dingen ein angsterregendes Element (Lesart und Übersetzung stillschweigend von QuaRg [zit. Anm. 6], S. 90 übernommen; in Zeile 4 ist fune vor retro zu ergänzen; beim deutschen Text wurde die letzte Zeile vergessen).

17 Konrad Kyeser, Bellifortis. Feuerwerkbuch. Farbmikrofiche-Edition der Bilderhandschriften Göttingen, Niedersächsische Staats- und Universitätsbibliothek, $2^{\circ}$ Cod. Ms. philos. 64 und $64 a$ Cim. Einführung und Beschreibung der kriegstechnischen Bilderhandschriften von U. Friedrich. Anmerkungen zum lateinischen Text, Transkription und Übersetzung der Vorrede von F. RäblE. München 1995. Die Handschrift befand sich während des 19. Jahrhunderts in englischem Privatbesitz (Richard Heber [1773-1833], Sir Thomas Philipps [1792-1872]), sie wurde 1972 aus dem Kunsthandel von der Göttinger Universitätsbibliothek erworben. 
tel-Fassung weiter fort. Außer in Göttingen 64a (fol. I3Ir) begegnen die zehn Verse noch in vier weiteren Handschriften: Rom 1994 (fol. I53v+I54r), Chantilly (fol. I45v+I46r), Wien 5278 (fol. I58v) und Rom 1986 (fol. I90v+I9Ir). Ohne Text wird das Motiv in drei weiteren Codices überliefert: Rom I888 (fol. 324r), Frankfurt (fol. I84r), Weimar (fol. 3I5r). In Besançon und Wien 5342A dürfte die entsprechende Passage fehlen, weil es sich hier um mehr oder minder umfangreiche Fragmente handelt. In Karlsruhe, Köln, Colmar, New York 58, Straßburg sowie in den später erfolgten Bearbeitungen der Sieben-Kapitel-Fassung (gestörte bzw. erweiterte Version) scheint der kunstvolle Gegenstand hingegen bewusst ausgespart worden zu sein.

Transkription ${ }^{18}$ nach Chantilly, fol. I46r:

Sum Regina sabba ceteris pulchrior et venusta ${ }^{19}$

Qua ${ }^{20}$ clareo $^{21}$ gemmis sceptro prolis ${ }^{22}$ et armillis

Capillis sparsis ${ }^{23}$ aurea $q u e^{24}$ corona regali

Ego decorosa regio 25 pomo decorata

$E^{26}$ contemplatum ${ }^{27}$ michi speculum pectore iunctum ${ }^{28}$

Junenes $^{29}$ quo stolidi rite queque contemplantur

Noueris ${ }^{30}$ si funem retrahes pendentem occulte ${ }^{31}$

ffollis summit aerem verberans ${ }^{32}$ prosuperior ${ }^{33}$

Ethiopum terras faciet resilire pro ${ }^{34}$ omnes

astantes stolidos ${ }^{35}$ sic in mutabo stultos ${ }^{36}$.

I8 Karin Zimmermann und Wolfgang Metzger verdanke ich die abweichenden Lesarten von Rom 1994, partiell auch von Rom 1986, die sie mir übermittelt haben, als die Volldigitalisate von den beiden Handschriften noch nicht online gestellt waren.

I9 Wien 5278 fenusta.

20 Unsichere Lesung, vielleicht auch Que (Göttingen 64a, Wien 5278) oder Quo (Rom 1994).

2I Göttingen 64a clarior.

22 Göttingen 64a, Rom 1994 perlis. Wien 5278 ebenfalls prolis.

23 Göttingen 64a spersis.

24 Fehlt in Göttingen 64a. Rom 1994 aureaque.

25 Göttingen 64a regni.

26 Göttingen 64a, Rom 1994 Est. Wien 5278 ebenfalls Et.

27 Die Partizipialform contemplatum besitzt hier passive Bedeutung. Freundlicher Hinweis von Carmen RobSanter.

28 Rom 1994, Rom 1986 mentum. Göttingen 64a, Wien 5278 dagegen ebenfalls iunctum.

29 Wien 5278 Juventutes. Göttingen 64a Quo iuuenes.

30 Wien 5278 Veneris.

3I Göttingen 64a occultum - vgl. dagegen Anm. I2.

32 Rom 1994, Rom 1986 verberas.

33 Göttingen 64a, Rom 1994, Wien 5278 persuperiora.

34 Göttingen 64a, Wien 5278 per. Rom 1994 peromnes.

35 Rom 1994 stolido.

36 Wien 5278 stultas. Dagegen Göttingen 64a Astantes stolidos sic immutabit eos. 


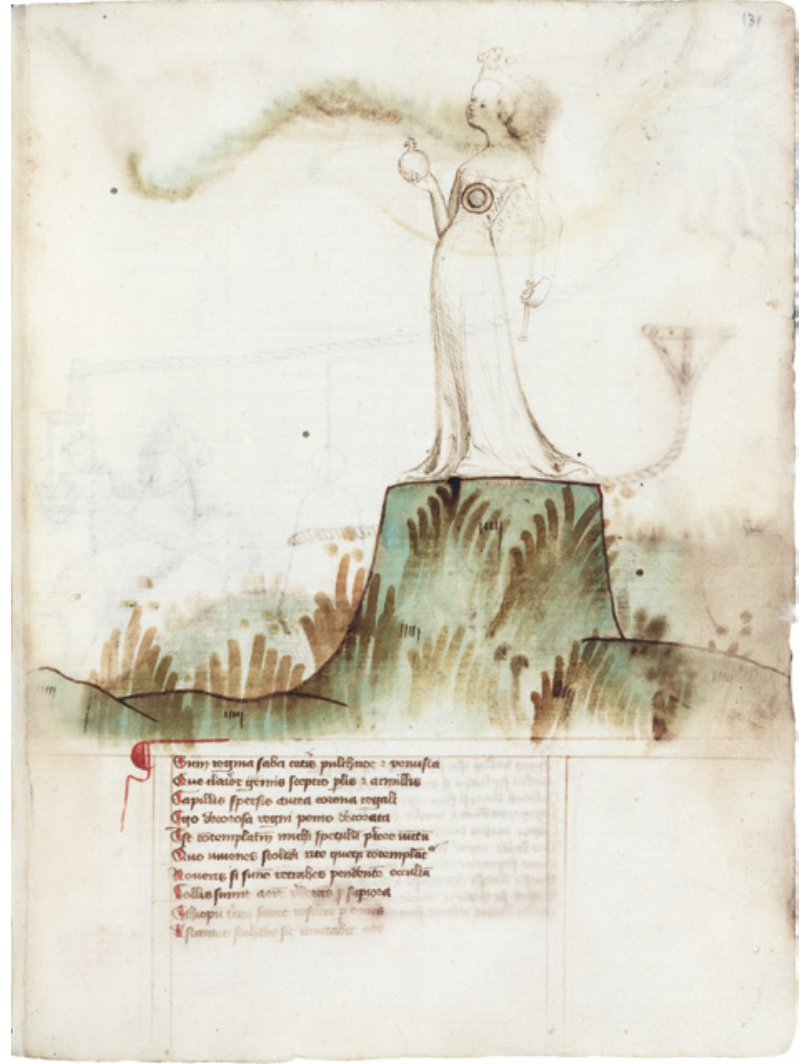

Abb. 2: Göttingen, Niedersächsische Staatsund Universitätsbibliothek, $4^{\circ} \mathrm{Cod}$. Ms. philos. 64a, fol. I3Ir (das rechts im Bild zu sehende Seil und die Haspel schlagen von der Rückseite durch)

In dieser Fassung wird die äußere Erscheinung der Königin, ihr kostbares Gepränge und ihre Herrschaftsinsignien, detailliert beschrieben (Edelsteine, Zepter, Spangen, offenes Haar, Krone, Reichsapfel), auch der Spiegel auf der Brust findet Erwähnung. Dargestellt wird sie in Göttingen 64a jedoch keineswegs so prunkvoll wie in Göttingen 63 (Abb. 2): Die grazile Gestalt ist lediglich als zarte Federzeichnung angelegt, wie in Göttingen 63 trägt sie eine Krone und hält Zepter sowie Reichsapfel in den Händen, das Haar scheint diesmal aufgesteckt ${ }^{37}$ vor allen Dingen aber ist das mit der Stupsnase keck nach oben gerichtete Gesicht vollkommen bleich. Stattdessen erregt ein kleiner runder Spiegel, der mittig auf ihrer Brust platziert ist und durch dezente Kolorierung eigens betont wird, die Neugier. Der Text beschreibt diesmal genauer den Vorgang, wie durch den Blasebalg Luft nach oben transportiert wird, wodurch schließlich „Erde der Äthiopier“ ausgestoßen wird, so dass die albernen Jünglinge beschmutzt und genarrt zurückspringen. Diese Version ist ein wenig derber, werden doch die Dastehenden mit Dreck beworfen, ohne dass die Grobheit - auf die es so oder so hinausläuft - durch eine maliziöse Anspielung auf die gleiche Hautfarbe zumindest rhetorisch ein wenig sublimiert worden wäre.

37 Bei näherer Betrachtung bemerkt man jedoch entlang des Rückens feine Wellenlinien, die herabfallende Locken andeuten sollen. 
Von einigen, nicht sonderlich gravierenden Abweichungen abgesehen, die wahrscheinlich auf Abschreib- bzw. Lesefehlern beruhen dürften, wird der längere Text in den SiebenKapitel-Handschriften weiter tradiert. Auch bei der bildlichen Darstellung schleichen sich Modifikationen ein, die von einem sukzessiven Schwinden des Wissens um den Bildgegenstand Zeugnis ablegen: In Rom 1994 (fol. 153v) und Weimar (fol. 315r) spreizt die Herrscherin ihre Rechte ohne den Reichsapfel geziert vom Körper ab (Abb. 3). In Chantilly (fol. I45v), Wien 5278 (fol. I58v) und Wolfenbüttel (fol. II2r) zieht sie die leere Hand vor die Brust an den Spiegel heran, so dass dieser von ihr nun zum Teil verdeckt und somit in seiner Funktion beeinträchtigt wird (Abb. 4). Nur eine vermeintliche Verbesserung stellt Rom I888 (fol. 324r) dar; hier wandert der Spiegel von der Brust in die vom Körper abgewinkelte rechte Hand hinüber. Dies wirkt vordergründig zwar recht plausibel, nur kann der arglistig ersonnene Blickfang auf diese Weise seinem intendierten Zweck nicht mehr dienen, da der Abstand zwischen dem Schmutz spotzenden Gesicht und dem Spiegel bzw. dem angelockten Betrachter zu groß und unbestimmt wird. Überraschend findet man ausgerechnet in einem untextierten Überlieferungszeugen aus der Mitte des I5. Jahrhunderts, nämlich in Frankfurt (fol. I84r), eine kongeniale Lösung für das Thema (Abb. 5), wo sowohl der bislang nur mit Worten erläuterte Mechanismus als auch der Effekt vollständig in Bildsprache umgesetzt werden: Das Standbild wurde mit allen Attributen ausgestattet (Zepter, Krone, Reichsapfel, auf der Brust sitzendem Spiegel), auch das Haar fällt offen herab. Zum ersten Mal wird hier eine ebenfalls erwähnte Spange gezeigt; als Brosche oder Fibel wurde sie an der linken Schulter appliziert. Offenbar handelt es sich keineswegs um ein harmloses Schmuckstück, denn an ihr setzt das Mundstück des Blasebalgs an, der plötzlich hinter ihrem Rücken aufkragt. An seinem Ende baumelt ein Seil herab, an dem kurz zuvor von unsichtbarer Hand gezogen worden sein muss, denn aus dem Mund der Schönen sprüht feiner Staub heraus, der einem der drei Jünglinge, die ihr gerade Avancen machen, direkt ins Auge weht. Dieser wurde vom Zeichner zusätzlich in ein Narrengewand gesteckt, um ihn für alle sichtbar als Gefoppten vorzuführen. Hier muss der Maler den Text neu gelesen und nicht einfach gedankenlos seine Vorlage kopiert haben, um dem Rezipienten auf diese Weise das Verständnis zu erleichtern. ${ }^{38}$

In Wolfenbüttel (fol. IIIv) wird der Effekt schließlich unumwunden durch einen neuen Beitext verraten: Ein yetliche schone fraw wirt bezaichnet bej der kungin von salba [!] damit man Einen yetlichen man mag leichen vnd alle schpech vnd verporgne sach mag innen werden. In allen anderen deutschsprachigen Versionen (gestörte bzw. erweiterte Sieben-Kapitel-Fassung), wo sich der Akzent stärker zur praktischen Nutzanwendung hin verlagert, zeigte man

38 Von R. Schilling, Die illuminierten Handschriften und Einzelminiaturen des Mittelalters und der Renaissance in Frankfurter Besitz. Frankfurt 1929, S. 210-213, Taf. LXX f. wurde die Zeichnung - offenbar ohne den hier fehlenden Text in Parallelhandschriften zu konsultieren - allein aufgrund der Bildmotive als Trugbild gedeutet (,wohl ein Trugbild, da ihm mit dem Blasebalg Luft eingeblasen wird“). Nach L. E. Saurma-Jeltsch, Spätformen mittelalterlicher Buchherstellung. Bilderhandschriften aus der Werkstatt Diebold Laubers in Hagenau. 2 Bde. Wiesbaden 200I, Bd. I, S. 70, Anm. 99, S. 77, I22, Anm. 440, S. 135, Anm. 492, S. 159, Anm. 53, S. 160, Bd. 2, S. 37-4I, Kat. I. 24 dient der Blasebalg zum Aufblasen der Figur „Trugbild: Drei Jünglinge werben um eine Dame, die eine künstliche, mit Balg aufgeblasene Figur ist (Lockvogel?)“. 


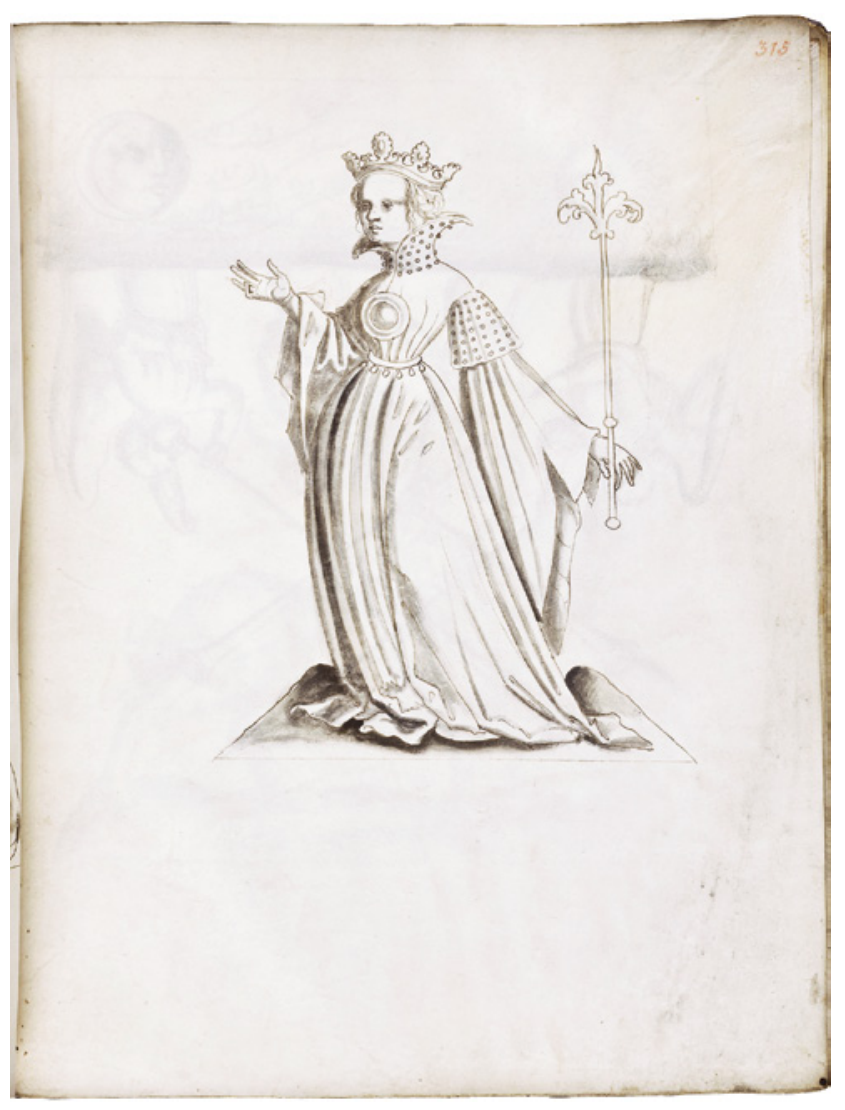

Abb. 3: Weimar, Herzogin Anna Amalia Bibliothek, Cod. Fol. 328, fol. 315r

offenbar kein Interesse mehr für derartige, im höfischen Kontext anzusiedelnde Spielereien; die Statue wurde ersatzlos aus dem Repertoire gestrichen. ${ }^{39}$

39 Andere, mehr funktionale Automaten, die Staunen erregen sollten, verblieben dagegen im Bestand, so der als Feuerzeug fungierende Philoneus (Göttingen 63, fol. 64v), die flammenspeiende Herrscherbüste (Göttingen 63, fol. 96v), der scheinbar endlos sprudelnde Heronsbrunnen (Göttingen 63, fol. 124v), das Glockenspiel (Göttingen 63, fol. 133r), der Wohlgeruch verströmende Löwenbändiger (Göttingen 64a, fol. 158v). Zu derartigen Automaten vgl. B. Franke, Gesellschaftsspiele mit Automaten - „Merveilles“ in Hesdin, in: Marburger Jahrbuch für Kunstwissenschaft 24, 1997, S. 135-158, bes. 138, I52, Anm. 39 (Automat, der Personen, die davor stehen bleiben, mit Mehl oder Ruß einstaubt), J. Tripps, Das handelnde Bildwerk in der Gotik. Forschungen zu den Bedeutungsschichten und der Funktion des Kirchengebäudes und seiner Ausstattung in der Hoch- und Spätgotik. 2., erweiterte Auflage. Berlin 2000, S. I3-I5, 23I f., Automaten in Kunst und Literatur des Mittelalters, hrsg. von K. Grubmüller, M. Sтоск (Wolfenbüttler Mittelalter-Studien 17). Wiesbaden 2003. Eine Vorstellung von derartigen, plötzlich in Aktion tretenden Apparaten vermitteln uns heute beispielsweise noch der krähende und mit den Flügeln schlagende Hahn der astronomischen Uhr in Straßburg (1352-I354; Straßburg, Musée des Arts décoratifs) und die von Michael von Freiburg geschaffenen lebensgroßen beweglichen Figuren für die 1385 errichtete Orgel im Münster, ebd. (sogenannte Roraffen: Trompeter, Brezelmann, Löwenbändiger Samson). Der in Padua ausgebildete Arzt und Ingenieur Johannes Fontana (ca. 1395-ca. I455) zeigt uns in seinem ,Bellicorum instrumentorum liber cum figuris' (München, Bayerische Staatsbibliothek, Cod. icon. 242; Padua, um I420; online unter http://nbn-resolving.de/urn:nbn:de:bvb:I2-bsbooor3084-8) die technische 
Abb. 4: Chantilly, Musée Condé, Ms. 348, fol. $145 \mathrm{~V}$

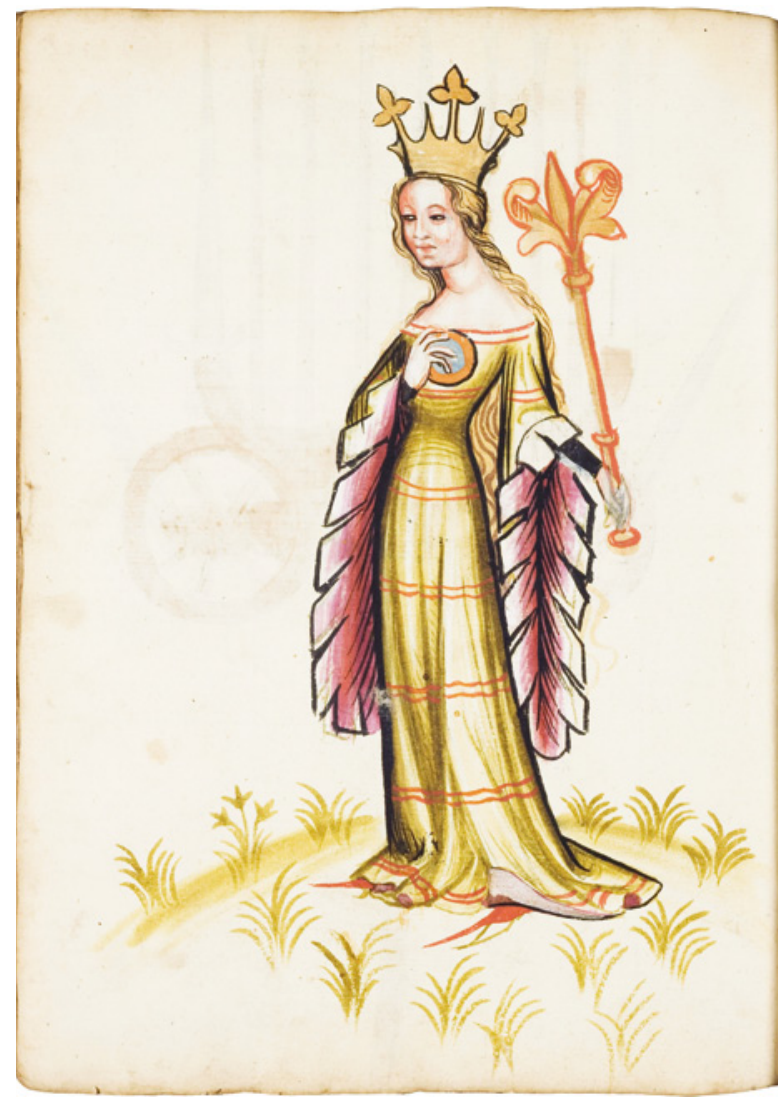

Dass die Zeichner öfters auf der Suche nach einer passenden Umsetzung des spielerisch verklausulierten Inhalts waren, zeigt sich auch beim Nabelschnurzauber (Göttingen 63, fol. 94r). Anders

Seite solcher Konstruktionen (vgl. zum Beispiel fol. 63v Feuerhexe). Vgl. auch die hierzu soeben erschienene Edition: Johannes Fontana. „Liber instrumentorum iconographicus“. Ein illustriertes Maschinenbuch. Hrsg., übersetzt und eingeleitet von H. Kranz (Boethius 66). Stuttgart 20I4. Der von 1393 bis I424 in Italien lebende Ingenieur Konrad Gruter schildert in seinem Maschinenbuch I424 eine andere Art und Weise, wie man mit ahnungslosen Gästen Scherze durch das plötzliche Verschwärzen ihrer Haut getrieben hat (wohl mittels Silbernitratlösung); vgl. D. Lohrmann, H. Kranz, U. Alertz, Konrad Gruter von Werden, De machinis et rebus mechanicis. Ein Maschinenbuch aus Italien für den König von Dänemark, I393-I424. 2 Bde. (Studi e testi 428 und 429). Vatikanstadt 2006, hier Bd. 2, S. I6-I8, 262. Eine Rezeptur für trügerisches Waschwasser bietet unter anderem Nürnberg, Germanisches Nationalmusem, Hs. 3227a, fol. I05r; vgl. T. EhLert, R. Leng, Frühe Koch- und Pulverrezepte aus der Handschrift GNM 3227a (um 1389), in: Medizin in Geschichte, Philologie und Ethnologie. Festschrift für Kundolf Keil. Hrsg. von D. Gross, M. Reininger. Würzburg 2003, S. 289320, hier S. 297, Anm. 90 (die Handschrift wurde nicht vom Pfaffen Hanko Döbringer geschrieben, wie vielfach in der Literatur zu lesen ist; dieser Name wurde lediglich auf fol. 43r über der Rubrik in roter Tinte nachgetragen. Ein kleines Merkzeichen markiert die Stelle, wo er eigentlich hingehört. In korrekter Reihung lautet die Überschrift: Hie hebt sich an der ander meister gefechte. hanko pfaffen. dóbringers: Andres Juden. Josts von der nyssen. Niclas prewßen ect.), vgl. den Interneteintrag mit entsprechender Abbildung unter http://wiktenauer. com/wiki/Codex_Döbringer_(MS_3227a); Fassung vom I3. OI. 2013. 


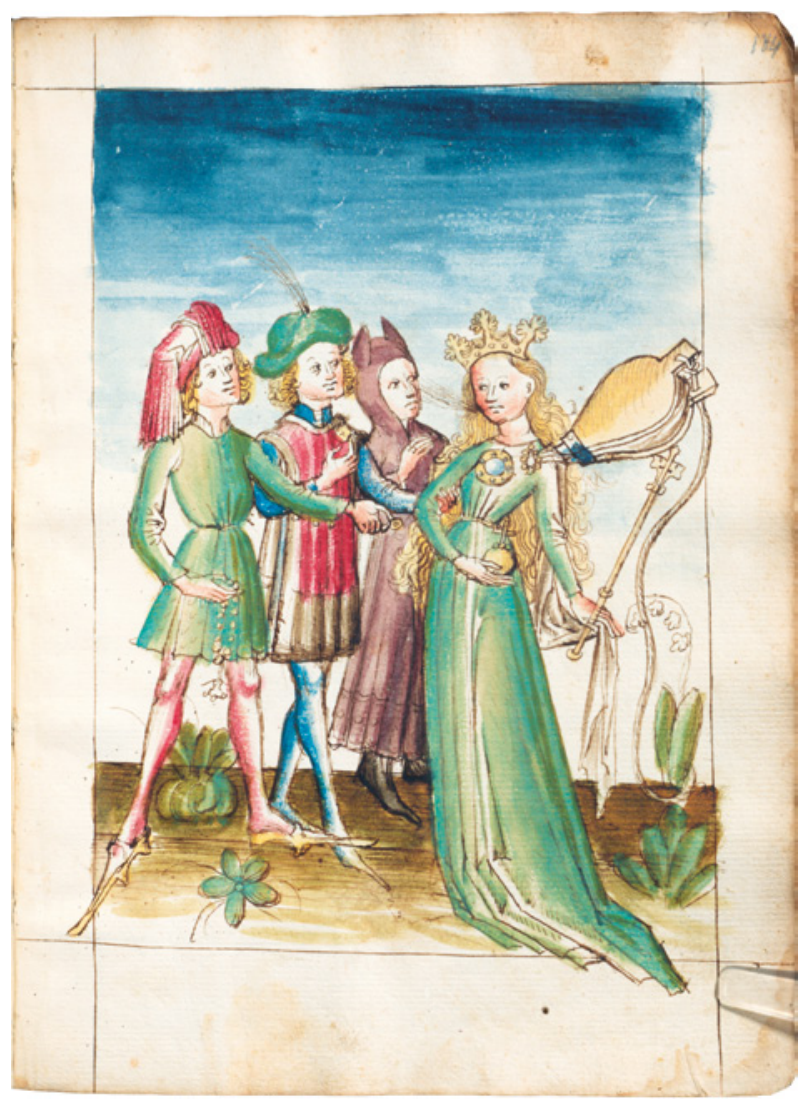

Abb. 5: Frankfurt, Universitätsbibliothek, Ms. germ. qu. I5, fol. I84r

als bislang geglaubt, handelt es sich hierbei nicht um einen magisch verbrämten, schauerlich geheimnisvollen Ritus. ${ }^{40}$ Vielmehr wird scherzhaft das Rezept zur Herstellung eines sogenannten Diebslichtes geboten, mit dessen Hilfe man angeblich Personen, die man bestehlen will, einschläfern kann. In der ältesten Darstellung Göttingen 64a (fol. 89v) ziehen zwei Knaben, der eine forsch mit der brennenden Kerze in der Hand, der andere auf einem Stecken reitend, den er mit einer Peitsche munter antreibt, zu einer Burg den Hügel hinauf. Auf den harmlosen, unernsten Charakter des zu Imaginierenden verweisen nur die beiden kleinen Kinder, die als handlungstragende Protagonisten in späteren Handschriften zudem stets als drollige, nackte Putten auftreten. Weiteren Aufschluss erhalten wir mittels des Bildes nicht. In der jüngeren Zehn-Kapitel-Fassung Göttingen 63 (fol. 94r) wird ein wenig mehr Hilfestellung zum Entschlüsseln der Szene geboten: Durch eine Wolkendecke lugt der Mond auf das Geschehen herab; ein Turmbläser hält während der nächtlichen Stunde Wacht (Abb. 6). ${ }^{41}$ Auch diese Bildfindung scheint man noch nicht als ideal empfunden zu haben, denn wenig später wird in der Sieben-Kapitel-Fassung

40 Zur bisherigen Interpretation vgl. R. LeNG, Ars belli. Deutsche taktische und kriegstechnische Bilderhandschriften und Traktate im I5. und 16. Jahrhundert. Bd. I: Entstehung und Entwicklung. Bd. 2: Beschreibung der Handschriften (Imagines medii aevi I2/I-2). Wiesbaden 2002, Bd. I, S. I26-I28. Zur neuen Deutung Cermann (zit. Anm. 2), S. 88-93.

4I In der Kopie in Innsbruck (fol. IO2r) fehlt der Nachthimmel mit dem Mond, nur der Turmbläser ist zu sehen. 
Abb. 6: Göttingen, Niedersächsische Staats- und Universitätsbibliothek, $2^{\circ}$ Cod. Ms. philos. 63, fol. 94r

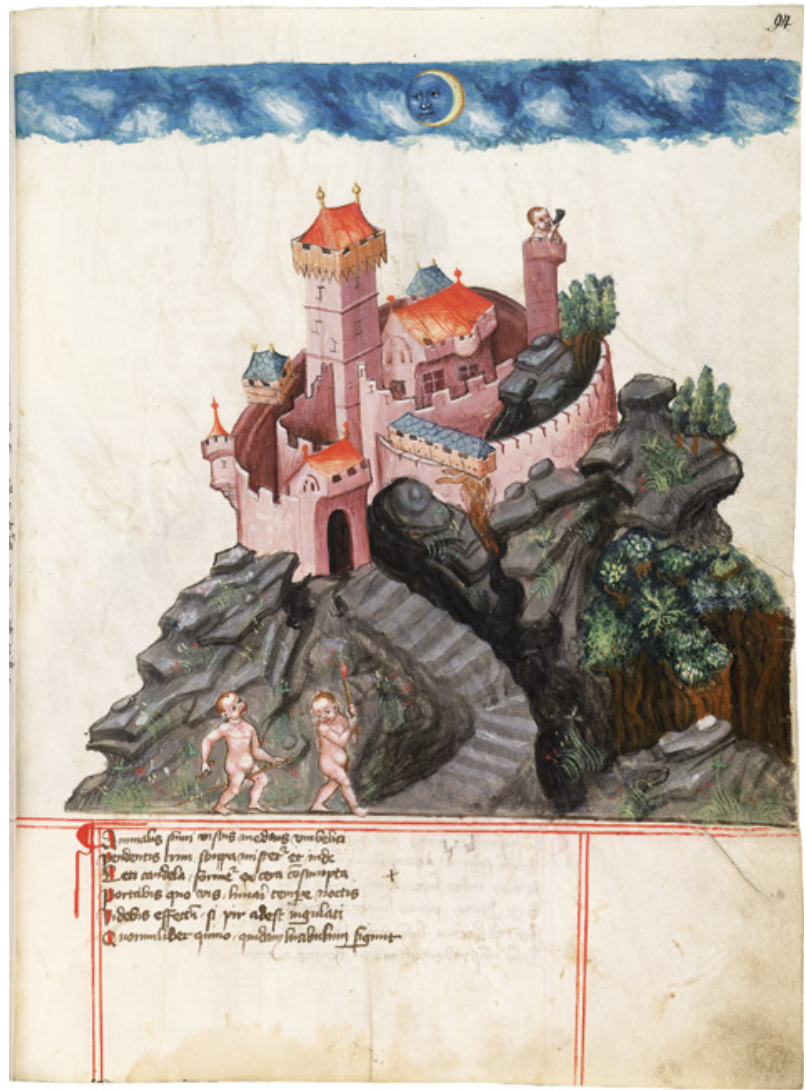

der Nachtwächter demonstrativ als ein auf dem Turm eingeschlummerter gezeigt (Abb. 7). ${ }^{42}$ Da Kyeser in seinem Text den zu erzielenden Effekt mit der Kerze nicht verrät (Göttingen 63, fol. $94 \mathrm{r}$... Portabis quo vis lunari tempore noctis / Videbis effectum si pir ${ }^{43}$ adest uigula $<\mathrm{n}>t i^{44}$ ), muss der Illuminist die Lösung für das Rätsel, das die Phantasie moderner Forscher stark angeregt hat, noch gekannt haben. Mit der Zeit ging diese Kenntnis jedoch verloren. In Frankfurt (fol. 65r) zum Beispiel, wo für die Königin von Saba eine eigenständige, intelligente Lösung gefunden wurde, wird der Nabelschnurzauber durch Beiwerk eher verunklärt (Abb. 8): Ohne erkennbaren Grund wird die Fläche oben rechts mit einer Windmühle ausgefüllt, auf die ein führerloser Packesel zustrebt. ${ }^{45}$ Wie in Chantilly (fol. 7ov) steht ein mittlerweile auf vier nackte

42 Rom 1994 (fol. 70v), Rom 1986 (fol. 79r), Chantilly (fol. 70v), Wien 5278 (fol. 73r), Straßburg (fol. I24r), Karlsruhe (fol. 55v), Colmar (fol. 34r), Weimar (fol. I75r).

43 Bereits Heimpel (zit. Anm. 6), S. in korrigierte das von Quarg (zit. Anm. 6), S. 6o f. falsch gelesene pin bzw. falsch erschlossene pinguedo zu pir.

44 Hier liegt in allen überkommenen Handschriften Textverderbnis vor: Statt des zu lesenden iugulati dürfte dort ursprünglich vigulāti gestanden haben (also vigulanti bzw. vigilanti).

45 So auch in der ebenfalls textlosen Parallelhandschrift Paris (fol. 84r). Beide Handschriften enthalten das Wappen der elsässischen Grafen von Lichtenberg (Schild: aufrecht nach links/heraldisch rechts schreitender schwarzer Löwe auf weißem bzw. silbernem Grund, rot bordiert [Frankfurt, fol. sr; gespiegelt: Frankfurt, fol. 42r, Paris, 


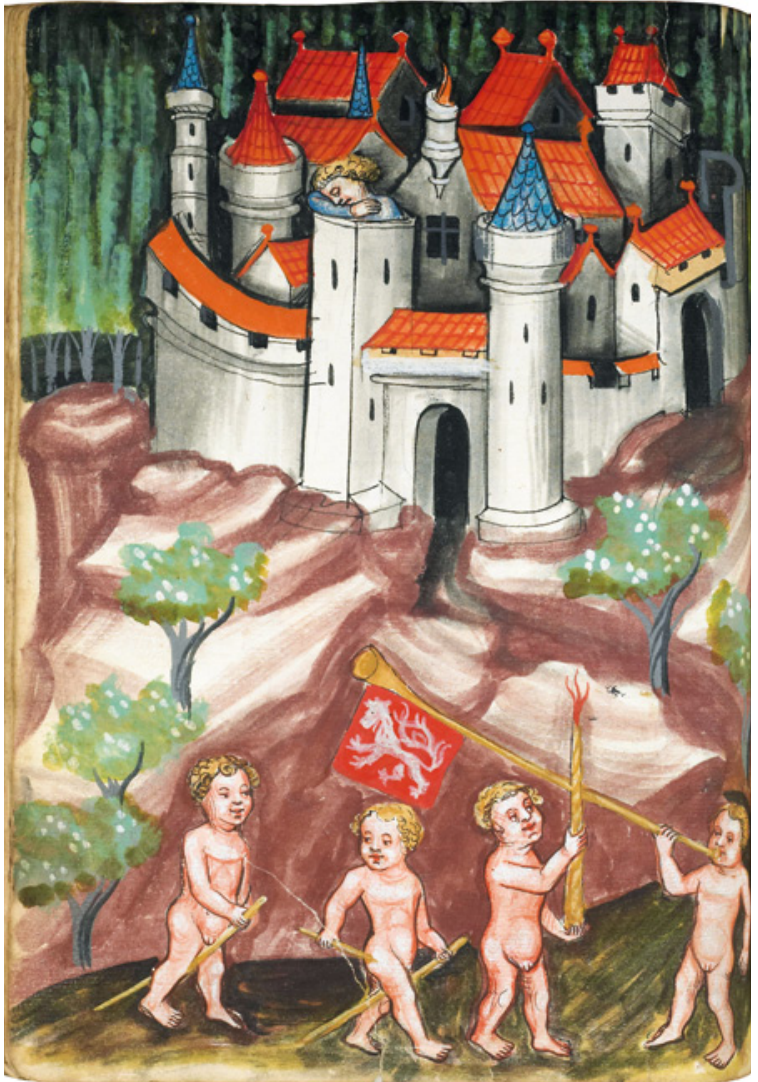

Abb. 7: Chantilly, Musée Condé, Ms. 348, fol. $70 \mathrm{v}$

fol. Irr]; Helmzier: weißer Schwanenkopf auf langem Hals; Standarte: quergestreifter rot-weiß-roter Wimpel). Schilling (zit. Anm. 38), S. 2io f., Saurma-Jeltsch (zit. Anm. 38), Bd. 2, S. 38, U. Friedrich, Herrscherpflichten und Kriegskunst. Zum intendierten Gebrauch früher ,Bellifortis'-Handschriften, in: Der Codex im Gebrauch (Akten des Internationalen Kolloquiums II.-I3. Juni 1992), hrsg. von H. Keller, Ch. MeIER, D. Hüpper (Münstersche Mittelalter-Schriften 70). München 1996, S. I97-210, hier S. 20I, 210 und Leng, Ars belli (zit. Anm. 40), Bd. 2, S. 428 weisen die Helmzier fälschlicherweise den Grafen von Hanau zu (dort handelt es sich jedoch um einen weißen aufsteigenden halben Schwan mit aufgestellten Flügeln), vgl. Сн. Becher, O. Gamber (Hrsg.), Die Wappenbücher Herzog Albrechts VI. von Österreich. Ingeram-Codex der ehem. Bibliothek Cotta (Jahrbuch der Heraldisch-Genealogischen Gesellschaft Adler, 3. Folge, Bd. I2). Wien/Köln/Graz 1986, S. 40 f., 96 f., I2of. Stilistisch schließt sich Frankfurt eng mit Günther zusammen: Beide werden der Diebold-Lauber-Werkstatt in Hagenau zugeschrieben. Von den drei Handschriften überliefert einzig Günther auch den Text, doch fehlt darin ausgerechnet das Blatt mit der Königin von Saba. - Vielleicht handelt es sich bei dem Windmühlen-Motiv um ein verstecktes Wortspiel bzw. eine Redewendung. So wie später Miguel de Cervantes seinen Don Quijote in einem aussichtslosen Kampf gegen Windmühlen anrennen lässt (Buch I, Kapitel 8). Vgl. auch Deutsches Wörterbuch von J. und W. Grimm. I6 Bde. in 32 Teilbänden. Leipzig I854-I96I. Quellenverzeichnis Leipzig I97I, Bd. 30, Sp. 313-315 „Windmühle“, bes. Sp. 314, I $\beta$ bildlich für sonderbare, rasch wechselnde Gedankengänge (Windmühle im Kopf haben), B. Beier (Red.), Harenberg Lexikon der Sprichwörter und Zitate. Mit 50.000 Einträgen das umfassendste Werk in deutscher Sprache. Dortmund 1997, S. 1383 „Dem Wind und dem Narren laß seinen Lauf". Eine Windmühle findet sich auch im Hintergrund einer bislang nicht recht gedeuteten Szene: Frankfurt (fol. 128r), Günther (fol. 92r), Paris (fol. I42r). Vermutlich geht es um das Ableiten eines stehenden Gewässers 
Abb. 8: Frankfurt, Universitätsbibliothek, Ms. germ. qu. 15 , fol. $65 \mathrm{r}$

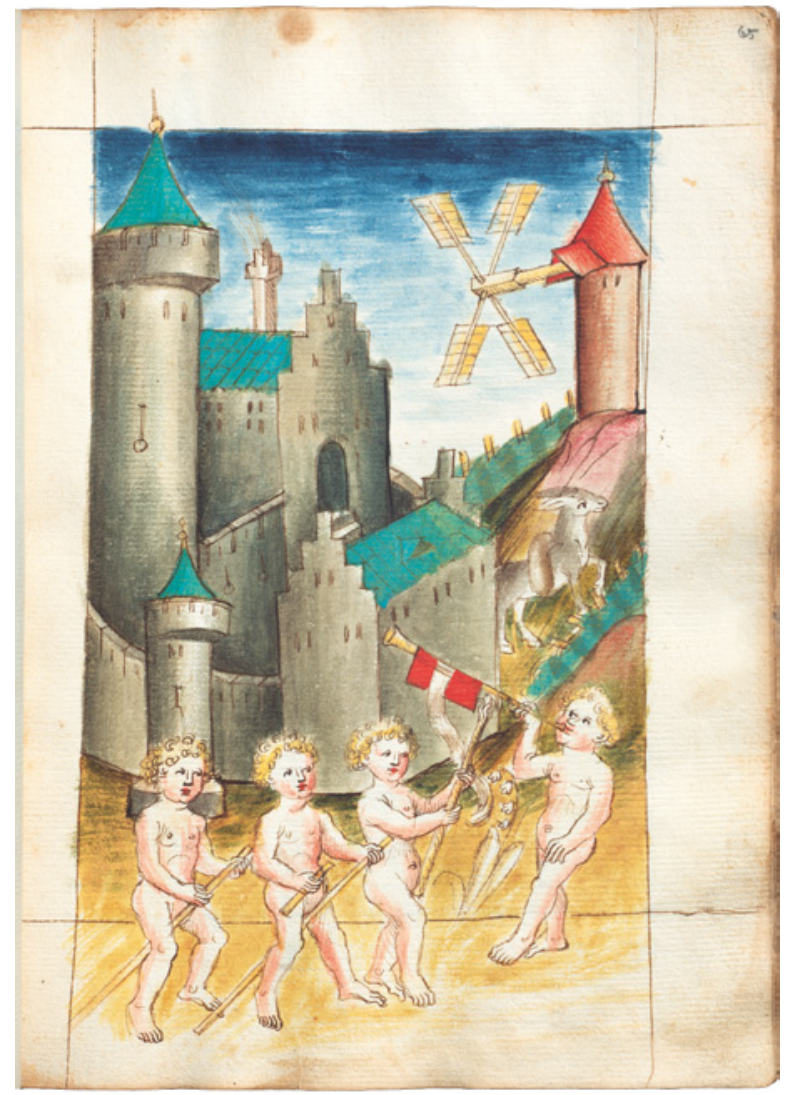

Knaben angewachsener Trupp bereit, die Burg unter Fanfarenschall im Sturm einzunehmen. ${ }^{46}$ Ausgerechnet das für das Verständnis aufschlussreichste Indiz, nämlich der wachhabende bzw. bereits eingeschläferte Posten, wurde jedoch für überflüssig erachtet und fortgelassen. In vielen weiteren Handschriften ist er ebenfalls verschwunden. ${ }^{47}$ Die um I43O entstandene wortgetreue deutsche Übersetzung offenbart vollends, ${ }^{48}$ dass mit dem verderb-

mit Hilfe von Quecksilber. In Göttingen 63 (fol. 6or) ist der Text nicht illustriert, dafür aber in Göttingen 64a (fol. 54v Wasserablauf) und den nachfolgenden Sieben-Kapitel-Fassungen (Mann leert Krug [in ein Gewässer] aus). In den von Chantilly (fol. IIIr) abhängigen Handschriften ist unverständlich von servum sagittinum/sagittinium/sagutuum/sagittuum/sagituum die Rede statt des wohl ursprünglichen servum fugitivum (= Quecksilber). Vgl. Quarg (zit. Anm. 6), S. 39; Antiquariat Heribert Tenschert, Rotthalmünster, Katalog XXV (= Leuchtendes Mittelalter II). Passau 1990, S. 215 (zu fol. 72r). In Wien 3062, fol. 238r heißt es später Dye naturlichen maister sprechen kocksilber In ain teich thw der verderb in wann ez müeßye auß brechen.

46 Vier Kinder werden auch in Rom 1994 (fol. 7ov), Rom 1986 (fol. 79r), Weimar (fol. 175r), Paris (fol. 84r) gezeigt: Zwei von ihnen reiten, einer hält die wundersame Kerze, ein anderer bläst die fahnengeschmückte Fanfare.

47 Göttingen 64a (fol. 89v), Paris (fol. 84r), Frankfurt (fol. 65r), München 30150 (fol. 26r), Göttingen 64 (fol. 26v), Wien 55 I8 (fol. 3Iv), Rom I889 (fol. 25v), Wien 3068 (fol. I5r), New York I04 (fol. Iov), Wolfenbüttel (fol. I65v), München 356 (S. I4I), Tenschert (fol. I7r).

48 Überliefert in Göttingen 64 (fol. 26v), Rom I889 (fol. 25v), Wien 3068 (fol. I5r), New York IO4 (fol. IOv), Köln (fol. 9iv), Colmar (fol. 34r), New York 58 (fol. 42v, 43r). 


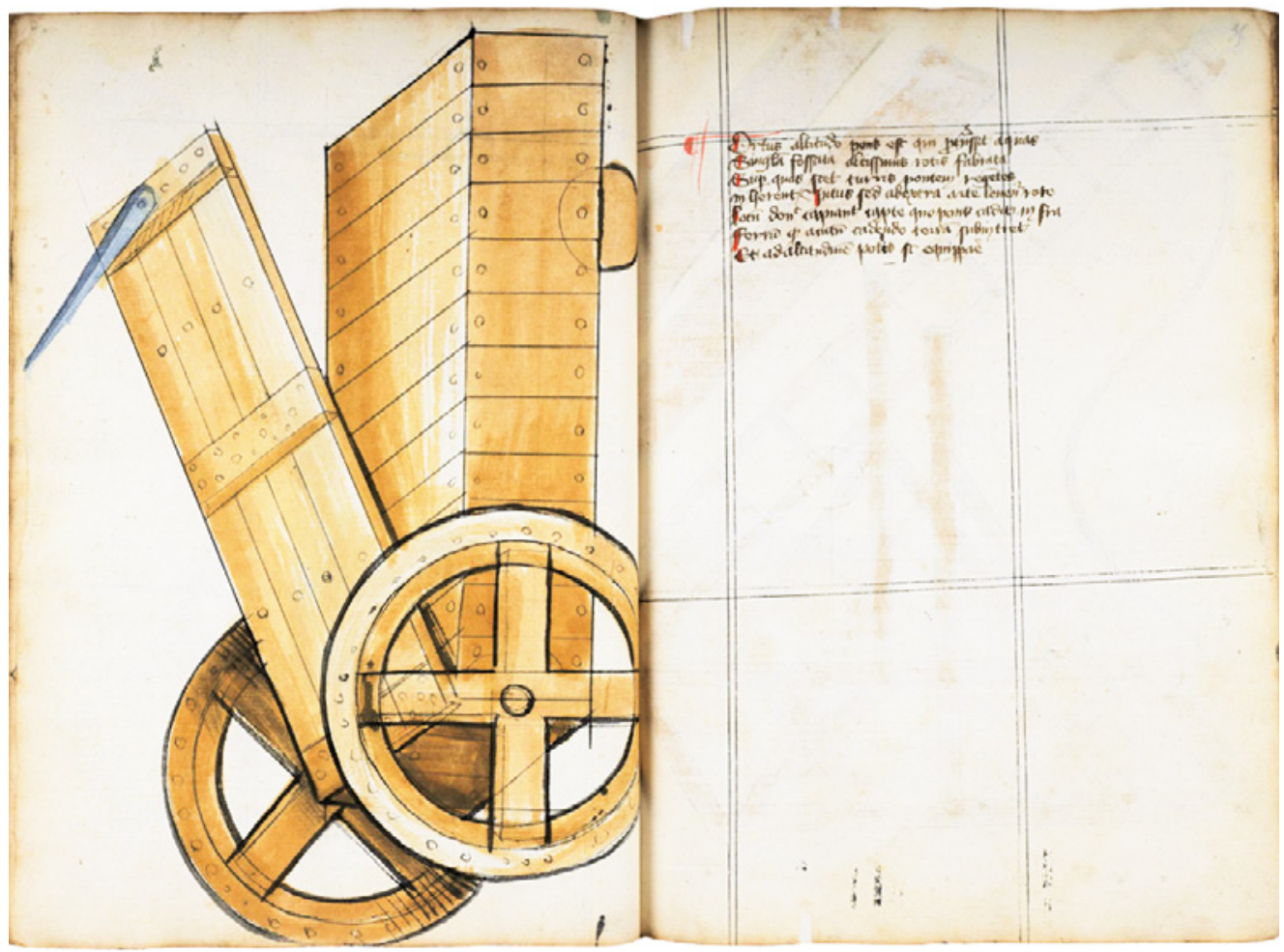

Abb. 9: Chantilly, Musée Condé, Ms. 348, fol. 34v + 35r

ten Text, in dem von einer kerczen des todes die Rede ist (aufgrund von leti candela statt ursprünglich wohl ceci candela), und dem heiteren kindlichen Treiben im Bild keine Kongruenz mehr zu erzielen ist. In Karlsruhe (fol. 55v) und München 356 (S. I4I) hat man sich deshalb womöglich mit einer knappen Paraphrase beholfen, um auf diese Weise auf die kinderleichte Eroberung einer Burg anzuspielen. ${ }^{49}$

Bei der Königin von Saba und dem Nabelschnurzauber haben Buchmaler Veränderungen vorgenommen, die einem besseren Verständnis dienlich waren. Nicht immer stellen derartige Eingriffe aber tatsächlich eine sinnvolle Verbesserung dar: In Göttingen 63 (fol. 49r) wird ein fahrbarer Belagerungsturm, eine sogenannte Ebenhöhe, auf zwei hohen Rädern beschrieben, die mittels einer Fallbrücke zum Überwinden von Wassergräben gebraucht werden soll. Die Darstellung entspricht der Beschreibung. ${ }^{50}$ In Chantilly (fol. 34v) wurde jedoch oben rechts

49 Karlsruhe (fol. 55v) Wie man mit einer kerzen gat in ein huß do nieman under gedin mag; München 356 (S. I4I) manig schlosß wirt verlorn durch daz stück. In Handschriften mit der freieren Übertragung blieb die für den Nabelschnurzauber vorgesehene Stelle bezeichnenderweise leer (Rom I888, fol. 269r [nachfolgend mit einer anderen Zeichnung ausgefüllt], Wolfenbüttel, fol. 52v), wobei das Motiv in Wolfenbüttel später entsprechend der Darstellung in München 356 nachgetragen wurde (fol. I65v), jedoch ohne die erhellende Sentenz.

50 Mit nach rechts weisender Fallbrücke dargestellt in Innsbruck (fol. 52r), Weimar (fol. 88v) und bei Marschalk. In Göttingen 64a (fol. 27v), Rom 1994 (fol. 34v), Rom 1986 (fol. 38r), Besançon (fol. 30v), Wien 5342A (fol. Io6r), 
plötzlich ein drittes, kleineres Rad hinzugefügt (Abb. 9). Über seine Funktion muss man sich schon im 15. Jahrhundert den Kopf zerbrochen haben. In Wien 5278 (fol. 34r) und Rom I888 (fol. I8or) wurde das zusätzliche Detail zunächst einfach übernommen, während man in Wolfenbüttel (fol. 34r), Wien 3062 (fol. 85v) und Berlin 204I (fol. 85v) hin- und hergerissen war: Irritiert unterlegte man die drei Räder am rechten Rand mit einer grünen Bodenscholle und definierte so das ursprünglich hochformatige Bild in ein queroblonges um (Abb. Io). In Straßburg (fol. 57v), Heidelberg (fol. 74v), Wien 5518 (fol. 9v), Göttingen 64 (fol. 4v), Rom I889 (fol. 3v), Wien 3068 (fol. 4v), New York 104 (fol. 37r), Kopenhagen (fol. 19r) ist man dagegen resoluter vorgegangen und hat den Wagen gekippt (Abb. II), ${ }^{51}$ so dass aus dem hohen Gefährt demonstrativ ein breites wurde, das auf drei bzw. vier Rädern aufliegt. Diese Änderung folgt zwar einer innerbildlichen Logik, missachtet aber dezidiert den Text, in dem ausdrücklich von altitudo pons bzw. hohi

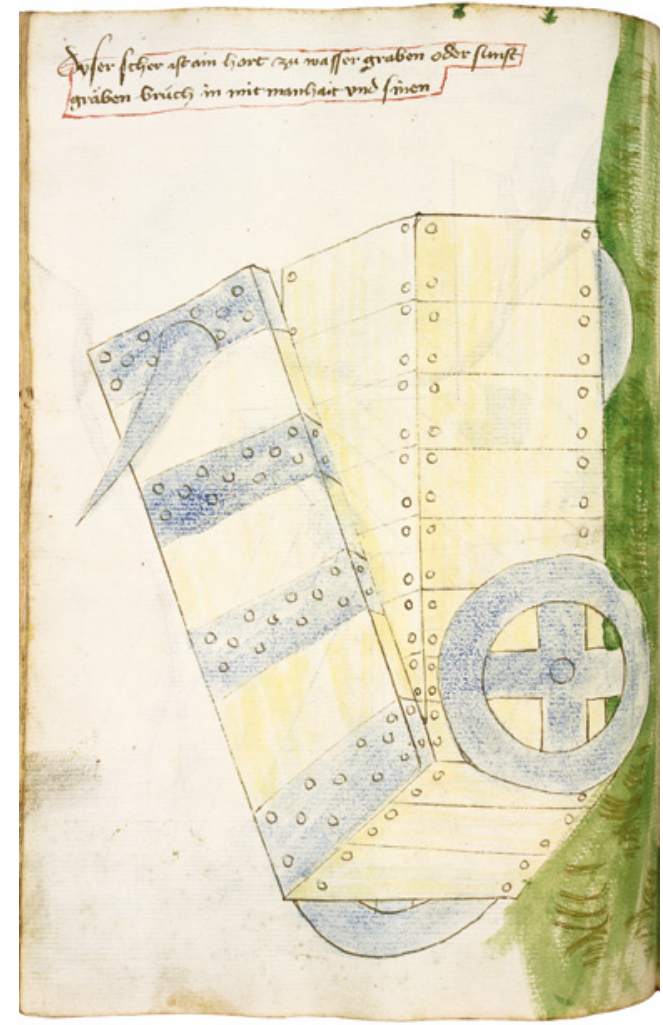

Abb. Io: Wien, Österreichische Nationalbibliothek, Cod. 3062 , fol. $85 \mathrm{v}$ bruck die Rede ist.

Offenbar durch Nachlässigkeit hat sich in Wien 5278 ein Fehler eingeschlichen, der sich durch die weitere, von diesem Codex abhängige Überlieferung schleppt: Die Vorlage für Wien 5278, das ist der Codex in Chantilly, zeigt auf fol. 88r eine Spannvorrichtung für Armbrüste, bestehend aus einem Holzsockel, einem Flaschenzug mit einer Seilspindel und einer Handkurbel (Abb. I2). Der zweizeilige Text verrät nicht viel mehr, als dass diese vorzügliche und nützliche Gerätschaft virgo trahendi (Spannjungfer) bzw. in Handschriften der gestörten SiebenKapitel-Version virga trahendi/ziechrüt heißt. Versehentlich erscheinen diese Gegenstände in Wien 5278 allesamt auf dem Kopf stehend (Abb. I3), vermutlich weil die Lagen während des

Frankfurt (fol. 84r), Karlsruhe (fol. 2Iv), Colmar (fol. I7v), New York 58 (fol. 23v) fällt die Klappe dagegen links zur Seite.

5I Vermutlich auch in München 30150 (fol. 4r). Unklar sind die Verhältnisse in München 235, hier ist das Gefährt offenbar zweimal abgebildet worden, auf fol. 36v (Wagen gekippt, mit drei Rädern) und auf fol. 58r (hoher Wagen auf zwei Rädern, Klappe links). In New York 58 taucht das Gebilde nach fol. 23v ebenfalls noch einmal auf (fol. 24v Wagen gekippt, schräg in den Raum gestellt [= Wien 3068, fol. 4v, Kopenhagen, fol. I9r], mit drei Rädern), jedoch mit falschem Beitext (der zur Aufstiegswippe auf fol. 22v [unten] gehört). Für letzteren Fall dürfte das Zusammentreffen der geordneten mit der gestörten Sieben-Kapitel-Fassung verantwortlich sein; vgl. das Stemma bei Cermann (zit. Anm. 2), S. 94. 


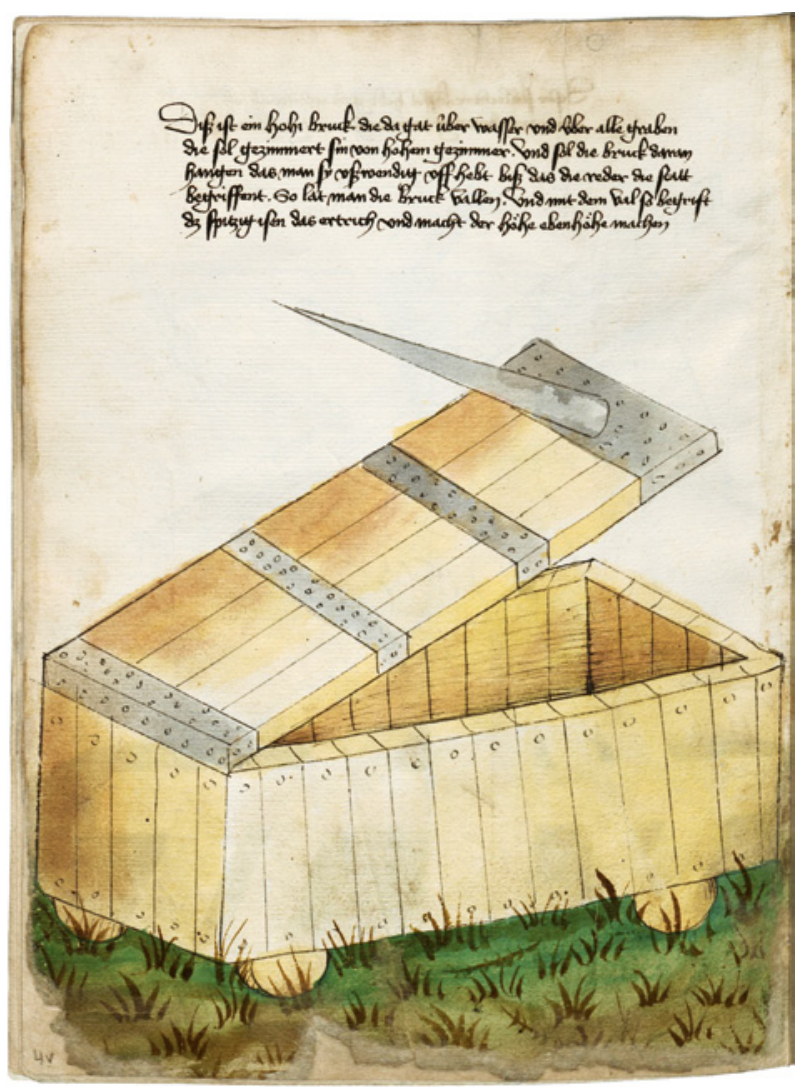

Abb. II: Wien, Österreichische Nationalbibliothek, Cod. 3068, fol. 4v

Schreib- und Malprozesses in Unordnung geraten waren. Da der Text jedoch richtig herum zu lesen ist, hat man das Missgeschick seinerzeit nicht bemerkt. Unbeirrt werden die Dinge als abstrakte, sinnentstellte Gebilde in Straßburg (fol. 64r), München 30150 (fol. 54r), Heidelberg (fol. 93r), ${ }^{52}$ Wien 5518 (fol. 58r), Göttingen 64 (fol. 55r), Rom I889 (fol. 54r), Wien 3068 (fol. 54r), New York I04 (fol. 86r) weiter tradiert. ${ }^{53}$

Ein anderes Mal wussten sich Buchmaler aus einer Verlegenheit zu helfen: Als innovative Bilderfindung des ,Bellifortis' gelten die Planetenreiter, deren Zug zum ersten Mal in Göttingen 63 das Werk eröffnet. ${ }^{54}$ Gewöhnlich werden in den Bildkünsten die personifizierten Pla-

52 Nur partiell als schwache Ritzzeichnung erkennbar.

53 In Kopenhagen nicht vorhanden.

54 Während R. Leng, Stoffgruppe 39. Feuerwerks- und Kriegsbücher, in: Katalog der deutschsprachigen illustrierten Handschriften des Mittelalters, Bd. 4/2, Lfg. 3-4, hrsg. von U. Bodemann, P. Schmidt, Ch. Stöllinger-Löser. München 2009, S. 205 von angeblich „leicht erreichbaren Vorlagen für die Planetenbilder“ ausgeht, hat er zuvor die spezifische Darstellung zu Pferde noch als Novum erklärt, vgl. LENG, Ars belli (zit. Anm. 40), Bd. I, S. I2I. Reitende Planetengötter stellen auch nach dem Aufkommen des ,Bellifortis' die Ausnahme dar. Beispiele außerhalb dieser Tradition finden sich im sogenannten Mittelalterlichen Hausbuch (Privatbesitz, ehem. Waldburg Wolfegg) und in einigen wenigen astrologisch-astronomischen Handschriften, zum Beispiel Los Angeles, J. Paul Getty Museum, Ms. Ludwig XII 8, Abb. im Bildindex 
neten stehend, sitzend oder auf einem Wagen fahrend abgebildet. ${ }^{55} \mathrm{Im}$ Text ist lediglich von Fahnen der Planeten die Rede (vgl. zum Beispiel Göttingen 63, fol 7r Sum vexillum Jouis...). Entsprechend werden in der frühesten Version, Göttingen 64a, auch nur schlichte Standarten gezeigt (ebd., fol. 2v). Erst in der Prunkhandschrift für Wenzel bzw. Ruprecht erhalten die Herrscher des Himmels ihren imposanten Auftritt (Göttingen 63, fol. 6r, 7r, 8r, 9r, [9ar], Ior, Iov). Die Idee hierfür dürfte aus dem kriegerischen Kontext erwachsen sein, denn die Fahne gibt in der Schlacht den Standort des Befehlshabers bzw. Heerführers an. ${ }^{56}$ In Karlsruhe ging der Planetenzug - vielleicht durch Neubindung - verloren, möglicherweise war er darin aber auch niemals enthalten. ${ }^{57}$ In Colmar ist er nur fragmentarisch überliefert (fol. $2 \mathrm{r} \mathrm{Ju}$ piter, fol. 3 r Luna); da Luna dort jedoch als Mann vorgestellt wird, was einer Sonderform entspricht, ${ }^{58}$ die Kyeser ${ }_{4} 405$ in Göttingen 63 (fol. Iov) eingeführt hat und der all jene Ver-

der Kunst und Architektur (www. bildindex.de), Paris, Bibliothèque nationale de France, Ms. allemand ro6 oder Wolfenbüttel, Herzog August Bibliothek, Cod. Guelf. 29.I4 Aug. $4^{\circ}$, fol. 84r. Vgl. Katalog der deutschsprachigen illustrierten Handschriften des Mittelalters, Bd. I, bearb. von N. H. Отt, U. Bodemann, G. FISCher-HeEtfeld. München 199I, S. 422-424, 437-44I, 470-474, Abb. 203, 214.

55 Vgl. D. Blume, Regenten des Himmels. Astrologische Bilder in Mittelalter und Renaissance (Studien aus dem Warburg-Haus 3). Berlin 2000.

56 V. Schmidtchen, Kriegswesen im späten Mittelalter. Technik, Taktik, Theorie. Weinheim 1990, S. 237.

57 Laut Leng, Ars belli (zit. Anm. 40), Bd. 2, S. 430 sind „die meisten Blätter“ in Karlsruhe „an neuen Falzen eingeklebt, alte Lagen- oder Foliobezeichnungen fehlen, so daß sich die gestörte Reihenfolge nicht mehr rekonstruieren läßt“. Die Blätter wurden „in starke, mit neuem braunen Leder überzogene Holzdeckel“ eingebunden. Bei LenG, KdiH (zit. Anm. 54), S. 222 heißt es nur noch, die Folia seien ,gelegentlich in gestörter Reihenfolge“; die Darstellungen auf fol. IIor-II2v erachtet er für „vergröbernd angedeutete und textlose Planetenbilder“ (ebd., S. 223; tatsächlich handelt es sich um die Bildsequenz Rom 1994, fol. I3Ir-I33v [aus dem sechsten, pyrotechnischen Kapitel]). Die Handschrift folgt weitgehend der geordneten Sieben-Kapitel-Fassung: Im Vergleich mit Rom 1994 fehlen neun Motive vor fol. I, eins vor fol. 3, je zwei vor fol. 59 und 65, an falscher Stelle eingereiht sind fol. 94 und fol. 106 (beide gehören - in umgekehrter Reihenfolge - vor fol. IOO), vertauscht wurden fol. 86/87, fol. I05/IO7, fol. II7/II8 sowie die Blätter der letzten beiden (?) Lagen (einer korrekten Motivfolge entspräche die Reihung 125/130/126/131/132/122/134/133/129/123/124, wobei dazwischen sechs Motive fehlen [darunter die Königin von Saba]; fol. I27 und I28 sind leer), Zusatzmotive auf fol. IO2v (ein geiegede), fol. I35v (Ein schin von bilder zü machen), fol. I37r (von anderung des wetters - laut LeNG, KdiH [zit. Anm. 54], S. 224 eine „magische Anleitung zur Vertreibung eines Burgwächters" [!]) und fol. $139 \mathrm{r}$ (von spise wie man die behaltet in einer beslossenen stat die warm ist). Das lateinische Fragment in Budapest mit den sieben Planetenreitern und einem wilden Mann zu Pferde weist zwar ein ähnlich großes Format auf wie Karlsruhe (403×279 bzw. 405×289 mm), Schreiber und Zeichner sind jedoch nicht identisch; außerdem ist auf den zum ,Bellifortis' gehörenden Seiten in Karlsruhe stets ein Textspiegel ausgegrenzt worden. Vgl. Sigismundus rex und imperator. Kunst und Kultur zur Zeit Sigismunds von Luxemburg I387-I437. Ausstellungskatalog Budapest, I8. März - I8. Juni 2006, Luxemburg, I3. Juli - I5. Oktober 2006. Hrsg. von I. TAKÁcs. Mainz 2006, S. 29I, 396-398, Kat. 4. IO7. Über ein vergleichbares Folioformat verfügt sonst nur noch Rom $1994(405 \times 280 \mathrm{~mm})$, alle anderen ,Bellifortis'-Exemplare sind kleiner, nur eines größer (Erlangen: $430 \times 290 \mathrm{~mm}$ ).

58 Bei dieser Variante treten alle Planetengötter, auch Venus, als Mann auf. Auf diese Besonderheit hat zuerst F. SAXL, Verzeichnis astrologischer und mythologischer illustrierter Handschriften des lateinischen Mittelalters in römischen Bibliotheken (Sitzungsberichte der Heidelberger Akademie der Wissenschaften, phil.-hist. Kl., Jg. 1915, 6.7. Abh.). Heidelberg 19I5, S. II4 hingewiesen. Saxl wollte die Idee hierfür von Turnieren oder Festspielen ableiten, da Frauenrollen in öffentlichen Schauspielen von Männern übernommen wurden. Die Erklärung ist jedoch unlogisch, da die Männer entsprechend als Frauen kostümiert waren, vgl. P. HeLAs, Lebende 


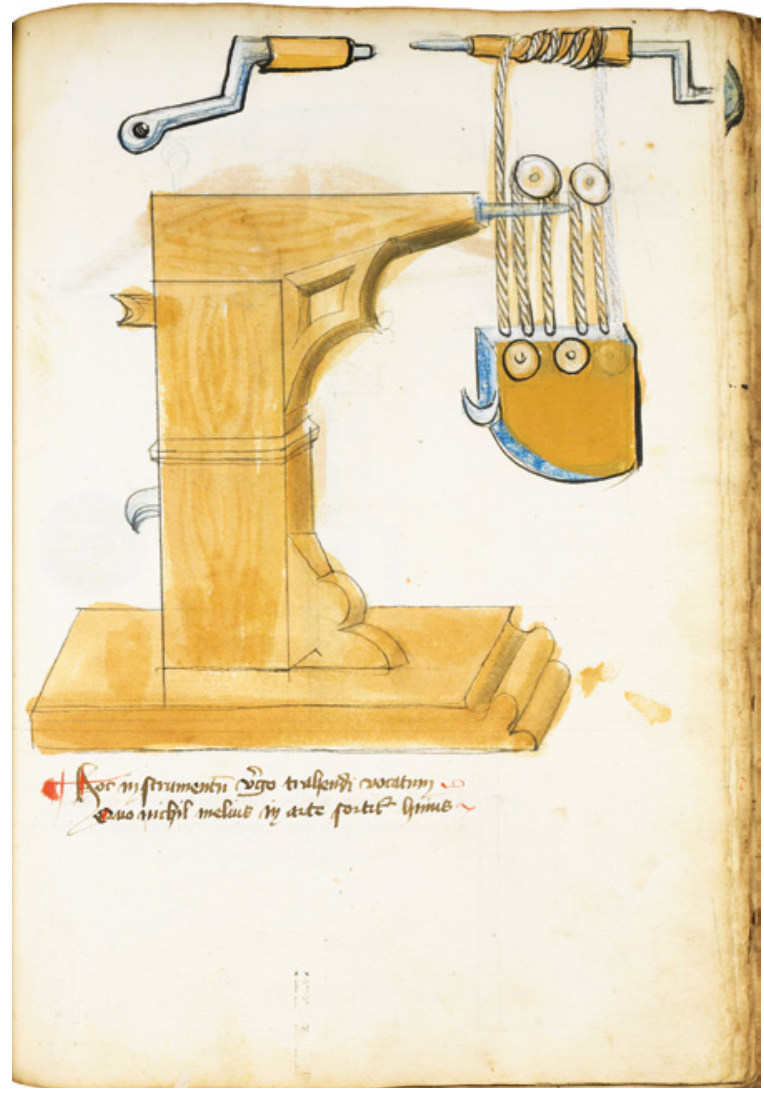

Abb. I2: Chantilly, Musée Condé, Ms. 348, fol. $88 \mathrm{r}$

treter der verschiedenen Sieben-Kapitel-Fassungen folgen, die von Chantilly (fol. 7v) abhängig sind (das sind Wien 5278 [fol. 7v], Straßburg [fol. 2Ir], , $^{59}$ München 30150 [fol. 89v], Göttingen 64 [fol. 9or], Rom I889 [fol. 89r], Wien 3068 [fol. 98r], New York I04 [fol. 5r] sowie Rom I888 [fol. II5r], Tenschert [fol. 8r], Wien 3062 [fol. 2I8r], Berlin 204I [fol. I87v]), ${ }^{60}$ während in dem Überlieferungszweig, der von Rom 1994 (fol. gr) ausgeht, der Traditionsfaden abreißt, so dass in Rom 1986 (fol. Ior) und Frankfurt (fol. I2r) Luna in traditioneller Weise wieder durch eine Frau verkörpert wird, ${ }^{61}$ muss man sich bei Colmar womöglich gezielt um eine

Bilder in der italienischen Festkultur des I5. Jahrhunderts (Acta humaniora). Berlin 1999, S. 67 f., Anm. 46 f., S. I22-I26. Außerdem wird Luna bei Kyeser zunächst nackt dargestellt, vgl. Göttingen 63 (fol. Iov) und Innsbruck (fol. I2v), erst in den Sieben-Kapitel-Fassungen ist die Gestalt schicklich gewandet.

59 Dort zwar als Mars beschriftet, dieser ist jedoch auf fol. $23 \mathrm{r}$ dargestellt (die Reiter auf Blatt $2 \mathrm{I}$ und 25 sind vertauscht: Luna und König Alexander fungieren hier fälschlich als Mars und Sol).

60 In Wien 5518, Heidelberg, Kopenhagen fehlt der gesamte Planetenzyklus; in Wolfenbüttel lediglich die entsprechende Darstellung (nach fol. Io).

6I Anhand von Besançon, Wien 5342A, Weimar, Günther, vermutlich auch Paris lässt sich der Sachverhalt nicht überprüfen, da die Himmelsregenten dort abhanden gekommen sind. Das Fragment in Budapest zeigt Luna noch als Mann (fol. 8v), Venus aber bereits als Frau (fol. 6v). 
Abb. 13: Wien, Österreichische Nationalbibliothek, Cod. 5278 , fol. $88 \mathrm{v}$

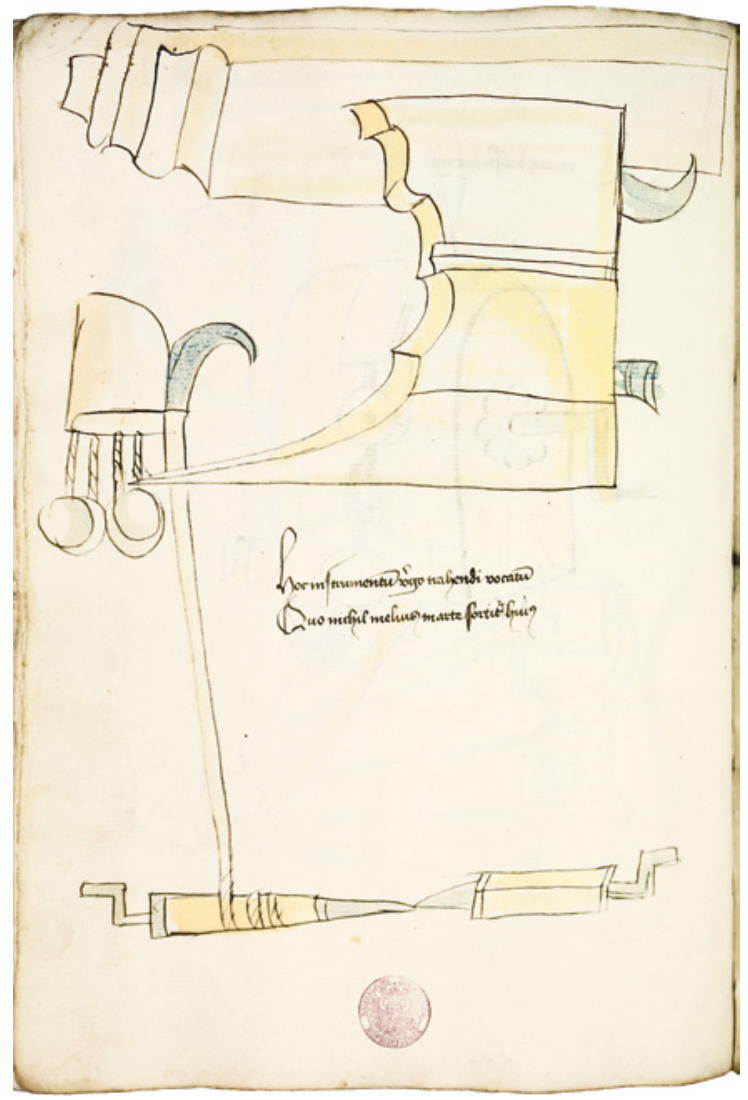

zweite Vorlage bemüht haben, um diese Lücke zu schließen. ${ }^{62}$ Mit demselben Problem war der Maler und Büchsenmeister Augustin Dachsberger aus München konfrontiert, als er I443 die Kölner Handschrift verfertigte. ${ }^{63}$ Er könnte über seinen Dienstherrn, einen Markgrafen von Rötteln, ${ }^{64}$ der entweder mit dem badischen Markgrafen Wilhelm (reg. I428-I44I, gest.

62 In den zweisprachigen Codices Köln, Colmar, New York 58 laufen zwei verschiedene Überlieferungsstränge zusammen: In Hinblick auf Reihenfolge, lateinischen Text und Ikonographie folgen sie dem Überlieferungszweig, der durch Rom 1994 repräsentiert wird. Da sie aber zugleich die deutsche Übersetzung von Wien 3068 (oder einem anderen Vertreter dieser Gruppe, zum Beispiel New York Io4) kennen, müssen sie mit diesem anderen Überlieferungszweig in Berührung gekommen sein.

63 Köln, fol. Ir Disses ist ein büxen buich vnd hat gemachet augustinus dachß̧erger von münchen ein moler vnd büxenschiesser in dem iore do man zalt von xpūs geburt. I443. Vgl. V. SснміDтchen, Dachsberg, Augustinus, in: ${ }^{2}$ Verfasserlexikon 2, 1979, Sp. 32 f., Leng, Ars belli (zit. Anm. 40), Bd. 2, S. 430 f., Leng, KdiH (zit. Anm. 54), S. $225-237$.

64 Dieser wird von ihm auf fol. $84 \mathrm{r}$ erwähnt ... min her marggraff von rôttelen hat disse zug. In einem Büchsenmeisterbuch (Wien, Österreichische Nationalbibliothek, Cod. 3064) wird auf den Markgrafen nochmals in Zusammenhang mit einem Rezept zur Salpetergewinnung rekurriert (fol. I2v Also zugelt der marckraffvon Rotel salpeter), vgl. H. Menhardt, Verzeichnis der altdeutschen literarischen Handschriften der Österreichischen Nationalbibliothek. 3 Bde. (Veröffentlichungen des Instituts für deutsche Sprache und Literatur I3-I5). Berlin I960-I96I, Bd. 2, S. 853 f., Leng, Ars belli (zit. Anm. 40), Bd. I, S. 237, Bd. 2, S. 33I f., Leng, KdiH (zit. Anm. 54), S. I7of. 


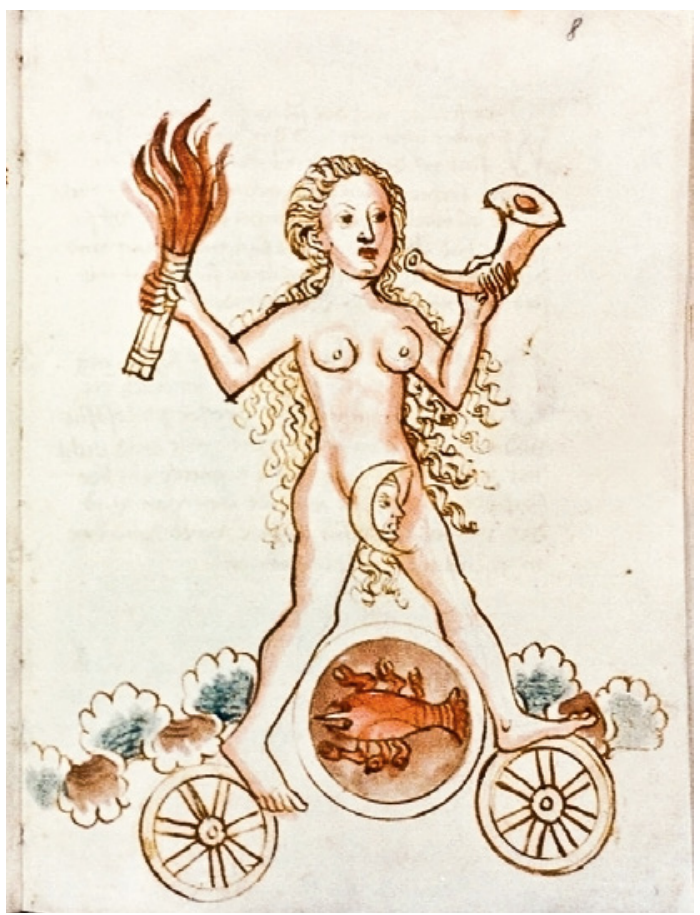

Abb. I4: Köln, Historisches Archiv der Stadt, Best. $7020\left[\mathrm{~W}^{*}\right]$ 232, fol. 8r

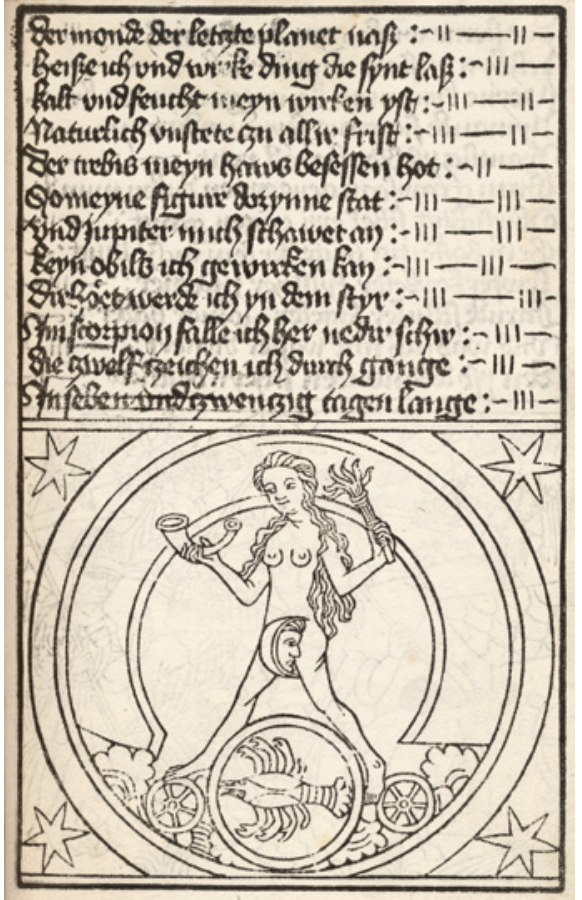

Abb. I5: Schweinfurt, Bibliothek Otto Schäfer, OS I033, fol. $7 \mathrm{r}$

I482) oder Rudolf IV. (reg. I44I-I487) zu identifizieren ist, ${ }^{65}$ beide aus der Nebenlinie Hachberg-Sausenberg, an eine geeignete Vorlage gelangt sein. Von Kyesers Bildidee und seinen Planetenversen findet sich in dieser Handschrift keine Spur mehr (Abb. I4). Der Abschnitt wurde komplett gegen eine neue Version eingetauscht, die später (um I465/70) als Blockbuch von Basel aus größere Verbreitung fand (Abb. I5) ${ }^{66}$ Der alternative Text war nachweislich jedoch schon früher in Umlauf, wie sich durch Codex 3009 der Österreichischen Nationalbibliothek belegen lässt, der interessanterweise 1437 in castro Baden (wohl Burg Baden in Badenweiler) geschrieben wurde. ${ }^{67}$ Die Federzeichnungen in Köln und die Holzschnitte im Blockbuch ver-

65 Vgl. Leng, Ars belli (zit. Anm. 40), Bd. 2, S. 43I f., W. K. von Isenburg, Stammtafeln zur Geschichte der europäischen Staaten. Bd. I, Marburg 1965, Taf. 83.

66 Blume (zit. Anm. 55), S. 160-167, 207-209, 230-234, Abb. 174-187. Das Basler Wappen (Bischofsstab) findet sich auf dem Holzschnitt mit den Kindern des Merkur. Blume datiert das Blockbuch fälschlicherweise noch um I430. Neuere Wasserzeichenuntersuchungen stützen dagegen eine Ansetzung um I465/I470, vgl. hierzu das an der Bayerischen Staatsbibliothek in München angesiedelte Projekt „Blockbücher aus bayerischen Sammlungen “ unter http://www.bayerische-landesbibliothek-online.de/xylographa sowie den Ausstellungskatalog Blockbücher des Mittelalters. Bilderfolgen als Lektüre, hrsg. von S. Mertens, E. Purpus, C. Schneider. Gutenberg-Museum Mainz, 22. Juni i99I bis I. September I99I. Mainz I99I, S. 202 f., 4IO.

67 Wien, Österreichische Nationalbibliothek, Cod. 3009, fol. 23v-25r. Der Abschnitt fol. I45r-162v ist auf fol. I62v datiert Expliciunt articuli passionis $x \bar{p} i$ cum suis orationibus ad omnes horas finiti In castro Baden In diebus Rogacionum Anno domini 1437 deo gratias. Vgl. Menhardt (zit. Anm. 64), Bd. 2, S. 764-777, BluME (zit. Anm. 55), S. 208. Ein castrum Baden bei Badenweiler ist seit II58 bezeugt. I437 gehörte die Burg 
halten sich in einigen Details, aber nicht immer, seitenverkehrt zueinander (insbesondere bei den Attributen sowie bei den Sternzeichen); sie stehen nicht zwingend in direkter Abhängigkeit, vermutlich gehen sie nur auf ein gemeinsames Urbild zurück, was auch durch andere handschriftliche Kopien aus der Zeit nahegelegt wird. ${ }^{68}$

In New York 58 blieb Kyesers Text zu den Planeten zwar erhalten (mitsamt der deutschen Übersetzung), aber auf die Reiter wurde entweder bewusst verzichtet oder man verfügte ebenfalls über keine bildliche Vorlage mehr. Jedenfalls hat man sich hier wie anfangs schon in Göttingen 64a mit schlichten Fahnen begnügt.

Den Markgrafen von Rötteln, die mit dem Kölner ,Bellifortis‘ und dem Wiener Cod. 3009 in Verbindung zu bringen sind, könnte womöglich noch in anderer Hinsicht eine Vermittlerrolle zugefallen sein: In Wien 5278 notierte ein unbekannter Fechtmeister nachträglich auf fol. I2r, dass er 1428 auf dem Basler Münsterplatz bei einem Zweikampf dem Basler Juncker Heinrich von Ramstein gegen den spanischen Abenteurer Johannes von Merlo assistiert hat. ${ }^{69}$ Vorsitzender Kampfrichter bei dieser Auseinandersetzung war aber niemand anders als Markgraf Wilhelm von Hachberg, Herr zu Rötteln und Sausenberg. ${ }^{70}$ Der spektakuläre Schaukampf in Basel,

den verarmten Grafen von Freiburg (seit I424 war sie an einen Verwandten, Hans von Vaumarcus, verpfändet); der letzte männliche Nachkomme des Grafengeschlechts, Johan von Freiburg-Neuchâtel, übertrug die Burg 1444 seinen beiden Neffen, den Söhnen des oben genannten Wilhelm von Hachberg-Sausenberg (I406-I482): Rudolf IV. (I427-I487) und Hugo (gest. I445), vgl. T. ZotZ, A. Zettler (Hrsg.), Die Burgen im mittelalterlichen Breisgau. II. Südlicher Teil, Halbband A-K (Archäologie und Geschichte. Freiburger Forschungen zum ersten Jahrtausend in Südwestdeutschland I6). Ostfildern 2009, S. 47-7I. - Daneben käme auch Burg Hohenbaden in Baden-Baden in Frage (als Innenspiegel wurde ein Brief vom Bürgermeister und Rat der Stadt Straßburg an den Markgrafen Bernhard von Baden gebraucht); wohl nicht gemeint sein dürfte das Landvogteischloss Baden im Aargau; aufgrund der Schreibsprache auszuschließen ist Baden bei Wien, wenngleich dies unlängst noch behauptet wurde (F. P. KNApp, Die Literatur des Spätmittelalters in den Ländern Österreich, Steiermark, Kärnten, Salzburg und Tirol von I273 bis I439. II. Halbband [Geschichte der Literatur in Österreich. Von den Anfängen bis zur Gegenwart, hrsg. von H. Zeman. Bd. 2/2]. Graz 2004, S. 277).

68 Blume (zit. Anm. 55), S. I6I-I64, 207-209 geht unter anderem aufgrund der „idealen Nacktheit“ von einem antiken Vorbild aus, das zwischen I425 und I437 in Basel rezipiert worden ist. Der von Blume zusammengetragenen Handschriftengruppe aus der Lauber-Werkstatt (Salzburg, Universitätsbibliothek, Ms. M II I80, fol. I29r-I3Ir, um I438-I440; Rom, Biblioteca Apostolica Vaticana, Cod. Vat. lat. I370, fol. 97r-99r, nach I456; Darmstadt, Universitäts- und Landesbibliothek, Hs. 266, fol. 20v-22v, I454) kann noch eine weitere hinzugesellt werden: Heidelberg, Universitätsbibliothek, Cod. Pal. germ. 300, fol. 36v (Konrad von Megenberg, Buch der Natur, Hagenau, I443-I45I), vgl. M. Miller, K. Zimmermann, Die Codices Palatini germanici in der Universitätsbibliothek Heidelberg (Cod. Pal. germ. I82-303) (Kataloge der Universitätsbibliothek Heidelberg VII), Wiesbaden 2005, S. 445-448, Volldigitalisat unter http://nbn-resolving.de/urn:nbn:de:bsz:I6diglit-22050. Blume verzeichnet darüber hinaus noch weitere Handschriften dieses Typus.

69 Wien 5278, fol. I2r anno domini $M^{\circ}$ cccc vicessimo octauo dominica antte lucie do vaht Ju< $>$ ckher hainrich von Ramstain myt dem spanyol, der sich $n a<\mathrm{m}>$ pt her Johan demerlan. da lert ich Ju<n $>$ ckher hainrich von Ramstain vnd dez selben nachtes kam ain erd bydem, daz die lut $v \beta$ den hüssern fluchen. der kamen funff, die ich hort yettschlich liut sprachen, ir weren súben. Do waz ach Cünrat Schirmaister (i. d. Fechtmeister), bartolomeus dez schirmaisters sälligen tochterman, xliiij Jar alt. Aufgrund des erwähnten Erdbebens lässt sich das Ereignis lokalisieren, vgl. A. Bernoulli, Basler Chroniken. Bd. IV. Leipzig I890, S. 436.

70 Bernoulli (zit. Anm. 69), S. 40-43, I55-160, $436 \mathrm{f}$. 


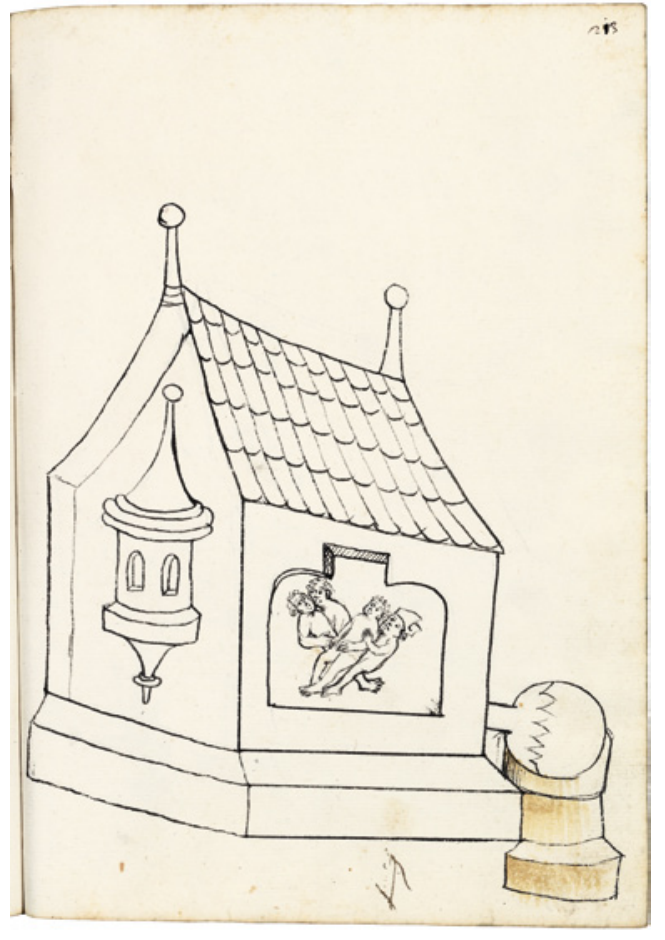

Abb. I6: Rom, Biblioteca Apostolica Vaticana, Cod. Pal. lat. 1888 , fol. $213 \mathrm{r}$ der 1605 von Miguel de Cervantes noch in seinem ,Don Quijote‘ für erwähnenswert befunden wurde, ${ }^{71}$ dürfte für die Verbreitung des ,Bellifortis'von einiger Bedeutung gewesen sein: An diesem Tage war ein für diese Literaturgattung sicherlich höchst aufgeschlossenes Publikum in großer Zahl versammelt (Adel, städtisches Patriziat, Fechtmeister). Dass die Stadt in gewisser Weise eine Drehscheibe für das Werk gewesen sein muss, lässt auch New York I04 vermuten: Das um I445 entstandene Exemplar erhielt später von dem Basler Buchbinder Johannes de Pulco seinen Einband. ${ }^{72}$ Bei dem Wappen auf fol. 29r könnte es sich um dasjenige der Familie von Flachsland handeln (schwarzer Schrägrechtsbalken in Gelb). ${ }^{73}$ Hans von Flachsland (I4I2-I476), der 1460 bei der Gründung der Basler Universität eine wesentliche Rolle gespielt hat, trat I463 in die Dienste von Markgraf Rudolf von Baden und amtierte als dessen Landvogt auf der Burg Rötteln. ${ }^{74}$

Nicht von ungefähr dürfte sich ein weiterer Fechtmeister für den ,Bellifortis‘ interessiert haben: Für den berühmten Hans Talhofer entstand 1459 die Handschrift in Kopenhagen, der er stolz seine eigene Fechtlehre beifügte. ${ }^{75}$

7I Buch IV, Kapitel 49.

72 J. Hamburger, ,Feuerwerkbuch von I420' and Konrad Kyeser, ,Bellifortis', in: The Splendor of the Word. Medieval and Renaissance Illuminated Manuscripts at The New York Public Library, hrsg. von J. J. G. Alexander, J. H. Marrow, L. Freeman Sandler. New York 2005, S. 344-352, Nr. 79. Vgl. Einbanddatenbank (http://www.hist-einband.de/) Werkstatt wooors2.

73 Vgl. Johann Siebmachers Wappenbuch von 1605 , hrsg. und mit einem Nachwort versehen von H. AppuHN. Dortmund 1994, Taf. 197. Die Grundfarbe des Schildes ist in New York I04 nach der Farbaufnahme, die mir Jeffrey Hamburger freundlicherweise zur Verfügung gestellt hat, leider nicht ganz sicher zu bestimmen (statt Gelb wäre auch ausgeblichenes Rot denkbar).

74 Vgl. S. Sснüрвасн-Guggenbühl, Flachslanden, Hans von, in: Historisches Lexikon der Schweiz, Version vom 28. I0. 2005. URL: http://www.hls-dhs-dss.ch/textes/d/Di92I4.php. M. BACKEs, „[...] von dem nabel hinauff ein menschlich vnd hübsch weyblichs bilde/vnd von dem nabel hin ab ein grosser langer wurm. "Zur Illustrierung deutscher Melusinehandschriften des I5. Jahrhunderts, in: Literaturwissenschaftliches Jahrbuch N. F. 37, 1996, S. 67-88, hier S. 72. A. KRIEGER, Regesten der Markgrafen von Baden und Hachberg I050-1515, Bd. 4: Regesten der Markgrafen von Baden von I453-I475, I. und 2. Lieferung. Innsbruck I9I2, Nr. 9564, 9706. Vischer, Flachsland, Hans von, in: Allgemeine Deutsche Biographie. Bd. 7. Leipzig 1878, S. 87 f.

75 Leng, Ars belli (zit. Anm. 40), Bd. 2, S. 43I f., R. Leng, Stoffgruppe 38. Fecht- und Ringbücher, in: Katalog der deutschsprachigen illustrierten Handschriften des Mittelalters, Bd. 4/2, Lfg. I-2, hrsg. von N. H. Oтт, 
Aktuelles Tagesgeschehen wirkte sich noch auf andere Weise auf den ,Bellifortis‘ aus: Das in Göttingen 63 (fol. II4v) prachtvoll ausgemalte Bad nach Philon, welches ein auf Stelzen aufgebockter stattlicher Holzbau mit mehreren Kammern ist, wobei man auf ein eigenes Frauenund ein Herrenabteil geachtet hat, wird in den nachfolgenden Handschriften auf einen kleinen Bildausschnitt reduziert. Wir erblicken jetzt nur noch den ehemaligen Vorbau mit einer Kammer, in der Männlein und Weiblein meist gesellig beieinander hocken. ${ }^{76} \mathrm{Zu}$ Zeiten des Basler Konzils (I43I-I449) nutzte der Zeichner von Rom I888 (fol. 2I3r) die Bildgelegenheit zu einem subversiven Kommentar, indem er einen Bischof - kenntlich durch seine Mitra - in reichlich verfänglicher Lage exponierte (Abb. I6). Das kirchengeschichtliche Großereignis, auf dem schließlich auch die drängende Hussitenfrage gelöst wurde, könnte für die um I430 verstärkt einsetzende Distribution des ,Bellifortis' mit verantwortlich gewesen sein. ${ }^{77} \mathrm{Zu}$ dieser Zeit war Konrad Kyeser die Herrschaft über sein Werk längst entglitten. Seine literarisch-artifizielle Intention wurde von seinen Rezipienten durch mutwillige Umstellungen ${ }^{78}$ und thematische Erweiterungen ${ }^{79}$ zerstört. Der zum Teil schwer verständliche, von Anfang an verderbte

U. Bodemann, Ch. Stöllinger-Löser. München 2008, S. 35-38, 47-5I. - Wien 5342A, vom Anfang des I6. Jahrhunderts (Kopie nach älterer Vorlage, vielleicht Rom I986), in der Literatur jedoch bislang um I430 datiert, vgl. Leng, Ars belli (zit. Anm. 40), Bd. I, I36f., Bd. 2, S. 437, war ursprünglich mit einer Kopie nach dem von Hans Talhofer für Leutold von Königsegg zwischen I446 und I459 erstellten Fechtbuch in Königseggwald, Schlossbibliothek, Hs. XIX I7-3 zusammengebunden, nämlich mit Wien, Kunsthistorisches Museum, KK 5342B (um I480-I500), vgl. LenG, Fecht- und Ringbücher (zit. Anm. 75), S. 58-60.

76 Gruppe von Frauen und Männern: Rom 1994 (fol. II6r), Besançon (fol. Io8r), Karlsruhe (fol. 98r), Rom I986 (fol. I43r), Frankfurt (fol. I3or), Colmar (fol. 52v), New York I04 (fol. I8r). Gruppe von Frauen: Wien 3068 (fol. 35r). Unbestimmt: Chantilly (fol. I13r), Wien 5278 (fol. I23r), Wolfenbüttel (fol. 84v), Wien 5342A (fol. I30r). Paar in zärtlicher Umarmung: München 30150 (fol. 35v), Göttingen 64 (fol. 36r), Rom I889 (fol. 35r). Paar beim Einseifen oder Einsalben: Weimar (fol. I6rv). Massageszene: Wien 3062 (fol. 137v), Berlin 204I (fol. II8r). Zwei sich umarmende männliche Paare: Rom I888 (fol. 2I3r). Ein größerer Mann, der seine Arme um zwei andere, sich an den Händen fassende legt: Straßburg (fol. I05v - wohl aus dem Menschenknäuel in Wien 5278 entwickelt). Nur Außenansicht mit eintretender Frau: Köln (fol. 79r). Nur Außenansicht ohne jedwedes Personal: Göttingen 64a (fol. I2or). Architektonisch reduzierte Fassung von Göttingen 63 ohne Figuren: Innsbruck (fol. I26v). Kein Bild, nur Text: New York 58 (fol. 63r).

77 Um I430 sind sechs Handschriften entstanden: Rom 1986, München 30150, Göttingen 64, Heidelberg, Wien 3068, Rom I888. Wenig später, noch in den I430er-Jahren, erfolgte die deutsche Neubearbeitung Tenschert und Wien 3062, die mit den Hussitenkriegen in Verbindung zu bringen ist, vgl. CermanN (zit. Anm. 2), S. I8-27. In das fünfte Dezennium des I5. Jahrhunderts fallen Köln (I443) und New York IO4 (I445).

78 Zur gestörten Sieben-Kapitel-Version gehören München 30150, Göttingen 64, Wien 3068, New York IO4, Kopenhagen, Wien 55I8, Rom i889. Vgl. Ch. zu Waldburg Wolfegg, Der Münchener ,Bellifortis' und sein Autor, in: Bayerische Staatsbibliothek, Konrad Kyeser, Bellifortis, Clm 30150 (Kulturstiftung der Länder - Patrimonia 137). München 2000, S. 2I-60, hier S. 25. Die Missachtung der ursprünglichen Konzeption zeigt sich bereits darin, dass von den Einleitungen zu den sieben Kapiteln nur zwei, nämlich diejenigen zum dritten und siebten, übrig bleiben, vgl. Friedrich (zit. Anm. 45), S. 208. Möglicherweise ist für diese Umorganisation eine Handschrift wie Straßburg verantwortlich, wo die ursprüngliche auf sieben Kapitel verteilte Bildfolge aufgrund von Fehlbindung und Lücken - zumindest heute - stark gestört ist und nur die beiden besagten Einleitungen noch vorhanden sind (fol. 45r, 99v; vgl. Quarg [zit. Anm. 6], S. XXX).

79 Zur erweiterten Sieben-Kapitel-Fassung mit neu formuliertem deutschen Text in Prosa ([Ps.]-Hartlieb) zählen Tenschert, Wien 3062, Berlin 204I, Berlin 62I. Hier wurden systematisch die letzten Hinweise auf den 
Text wurde zu einer vernachlässigbaren Verfügungsmasse für anders gelagerte Interessen. Verstärkt auf praktische Belange ausgerichtete Neukonzeptionen gewannen die Oberhand, ${ }^{80}$ wobei so manche, auf ein höfisches Publikum abzielende Facette nicht mehr verstanden bzw. geschätzt wurde. ${ }^{81}$ Der ,Bellifortis' wurde zum Steinbruch, er zerstob in einer disparaten Streuüberlieferung. ${ }^{82}$ Seine wahre Originalität und Eigenart gilt es in den auf uns überkommenen Relikten neu zu entdecken. ${ }^{83}$

Siglen:

Berlin 62I Berlin, Staatsbibliothek zu Berlin - Preußischer Kulturbesitz, Ms. germ. quart. 62I

Berlin 204I Berlin, Staatsbibliothek zu Berlin - Preußischer Kulturbesitz, Ms. germ. quart. 204I

Besançon Besançon, Bibliothèque municipale, Ms. $1360^{84}$

Autor eliminiert (Äußerungen in der I. Person Singular); vgl. Friedrich (zit. Anm. 45), S. 209. Integriert in große Sammelwerke wurde der ,Bellifortis‘ in Rom 1888 (ein weiterer dazugehöriger Band ist verloren; vgl. W. MetzGer, Ein Bilderzyklus des Spätmittelalters zwischen Hofkunst und ,Magia Naturalis‘. Cod. Pal. lat. I888 der Vatikanischen Bibliothek und das Weimarische Kunst- und Wunderbuch, Cod. Fol. 328, in: Opere e giorni. Studi su mille anni di arte europea dedicati a Max Seidel, hrsg. von K. Bergdolt, G. Bonsantr. Venedig 200I, S. 253-264), Weimar (mit vier verschiedenen ,Bellifortis'-Fassungen) und Erlangen.

80 Schon früh ist der ,Bellifortis 'Überlieferungsgemeinschaften eingegangen mit Büchsenmeisterbüchern (zum Beispiel Wien 3069: datiert I4II), Fechtbüchern (zum Beispiel Wien 5278: um I416/20) oder dem ,Feuerwerkbuch von I420' (zum Beispiel Straßburg: um I420-30?; auf fol. Ir nennt sich dort ein Joh. Eybenstock, der mit dem Besitzer von Wien 5278 verwandt gewesen sein könnte, vgl. Wien 5278, fol. Ir Liber maigisti [!] Nicolay de Eywensto..., Menhardt [zit. Anm. 64], Bd. 2, S. II20 liest noch eywenstock, - wenn es sich hier nicht um eine Herkunftsangabe handeln sollte [Bergbaustadt Eibenstock im Erzgebirge]. Gemäß Nachträgen auf fol. $37 \mathrm{r}$ und 9ir gehörte der Straßburger Codex von ca. 1598 bis 1627 einem gewissen Sigmund Heldt [eventuell mit dem gleichnamigen Juristen aus der ehrbaren Nürnberger Familie Held, gen. Hagelsheimer zu identifizieren, der I638 der Ratsbibliothek 269 Drucke vermacht hat; vgl. R. Jürgensen, Bibliotheca Norica. Patrizier und Gelehrtenbibliotheken in Nürnberg zwischen Mittelalter und Aufklärung. 2 Bde. Wiesbaden 2002, Teil I, S. 34, Anm. 50]; über das Straßburger Thomasstift in die dortige Universitätsbibliothek gelangt [Stempel auf fol. Iv]; die Schreibsprache des ,Feuerwerkbuchs' ist Bodensee-Alemannisch/Ost-Schwäbisch [fol. Ir-I8r, 28r-29v], die des anonymen Büchsenmeisterbuchs Nordbairisch [fol. 30r-36v]; vgl. auch die Beschreibung in der Datenbank Calames unter http://www.calames. abes.fr/pub/ms/D47Aiso3o und Quarg [zit. Anm. 6], S. XXX, XLV). Besonders das, Feuerwerkbuch'sollte sich nachfolgend als beliebte Erweiterung erweisen (München 30I50, Heidelberg, Göttingen 64, Rom I889, New York I04, Tenschert, Wien 3062, Berlin 204I, Berlin 62I). Vgl. LenG, KdiH (zit. Anm. 54), S. I53-192, Leng, Fechtund Ringbücher (zit. Anm. 75), S. 47-5I, 58-60, Cermann (zit. Anm. 2), S. 85 mit Anm. 429.

8I Der das Werk eröffnende Planetenzug wurde zum Beispiel in der gestörten Sieben-Kapitel-Version ausrangiert und ganz an das Ende gestellt; für die Königin von Saba hatte man offenbar gar keine Verwendung mehr.

82 Vgl. Leng, Ars belli (zit. Anm. 40), Bd. I, S. I45-I47, Leng, KdiH (zit. Anm. 54), S. 208.

83 Lange Zeit haben sich insbesondere Militär- und Technikhistoriker, Sprengstoffexperten, Chemiker und Ingenieure für den ,Bellifortis' interessiert. Vgl. den Forschungsüberblick zu kriegstechnischen Traktaten bei LeNG, Ars belli (zit. Anm. 40), Bd. I, S. 24-46. Wichtige Impulse für ein umfassenderes, adäquates Verständnis sind vor allen Dingen von Heimpel (zit. Anm. 6), Berg / Friedrich (zit. Anm. i6), Friedrich / Rädle (zit. Anm. i7) und Friedrich (zit. Anm. 45) ausgegangen.

84 Abbildungen im Internet unter http://memoirevive.besancon.fr/ark:/48565/aOII32352902Iansbb8/I/ bzw. http:// www.enluminures.culture.fr/documentation/enlumine/fr/rechguidee_oo.htm. 


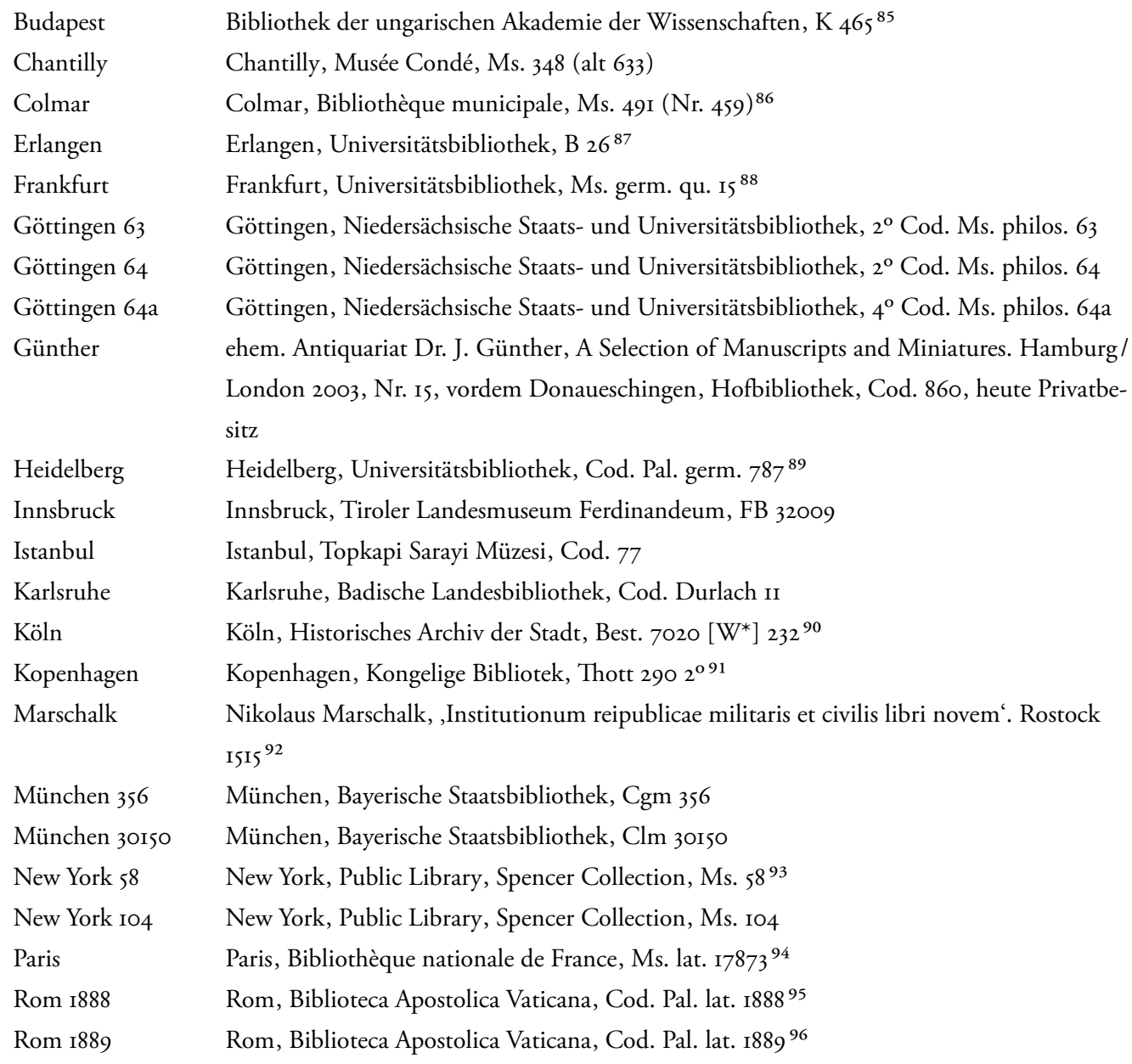

85 Abbildungen unter http://kepkonyvtar. $m$ tak.hu: $8 \mathrm{o} /$ ? $\mathrm{docId}=443$ bis $\mathrm{Id}=456$.

86 Volldigitalisat unter http://bvmm.irht.cnrs.fr/resultRecherche/resultRecherche.php?COMPOSITION_ $\mathrm{ID}=\mathrm{I} 2850$.

87 Volldigitalisat neuerdings unter http://bvbmr.bib-bvb.de/webclient/DeliveryManager?pid=4555786\&custom_ att_2=simple_viewer.

88 Volldigitalisat unter http://nbn-resolving.de/urn:nbn:de:hebis:30:2-I4639.

89 Volldigitalisat unter http://nbn-resolving.de/urn:nbn:de:bsz:I6-diglit-I5389.

90 Digitalisierter Mikrofilm im digitalen Historischen Archiv der Stadt Köln unter http://historischesarchivkoeln. $\mathrm{de} / \mathrm{de} /$ lesesaal/verzeichnungseinheit/173087/Best.+7020+232.

9I Volldigitalisat unter http://www.kb.dk/da/nb/materialer/haandskrifter/HA/e-mss/thalhofer/thott-2_29o.html.

92 Volldigitalisat unter http://nbn-resolving.de/urn:nbn:de:bvb:I2-bsboooo3I40-6.

93 Abbildungen im Internet unter: http://digitalgallery.nypl.org/nypldigital/dgkeysearchresult.cfm?parent_ $\mathrm{id}=\mathrm{I} 85767 \&$ word $=$.

94 Abbildungen in der Datenbank http://images.bnf.fr/jsp/index.jsp.

95 Volldigitalisat neuerdings unter http://digi.ub.uni-heidelberg.de/diglit/bav_pal_lat_ı888.

96 Volldigitalisat künftig einsehbar über http://digi.ub.uni-heidelberg.de/de/bpd/index.html. 
Rom 1986 Rom, Biblioteca Apostolica Vaticana, Cod. Pal. lat. $1986^{97}$

Rom 1994 Rom, Biblioteca Apostolica Vaticana, Cod. Pal. lat. $1994{ }^{98}$

Straßburg Straßburg, Bibliothèque Nationale et Universitaire, Ms. $2259^{99}$

Tenschert ehem. Antiquariat H. Tenschert, Rotthalmünster, Katalog XXV, I990, Nr. 2I, heute Privatbesitz

Weimar Weimar, Herzogin Anna Amalia Bibliothek, Cod. Fol. $328^{100}$

Wien 3062 Wien, Österreichische Nationalbibliothek, Cod. 3062

Wien 3068 Wien, Österreichische Nationalbibliothek, Cod. 3068101

Wien 3069 Wien, Österreichische Nationalbibliothek, Cod. $3069^{102}$

Wien 5278 Wien, Österreichische Nationalbibliothek, Cod. 5278

Wien $5342 \mathrm{~A}$ Wien, Kunsthistorisches Museum, KK 5342A

Wien 5518 Wien, Österreichische Nationalbibliothek, Cod. 5518

Wien $6562 \mathrm{~A}$ Wien, Kunsthistorisches Museum, KK 6562A

Wien $6562 \mathrm{~B}$ Wien, Kunsthistorisches Museum, KK 6562B

Wolfenbüttel Wolfenbüttel, Herzog August Bibliothek, Cod. Guelf. I6ı Blank. ${ }^{103}$

Universität Wien

Abbildungsnachweis: Abb. I, 2, 6: Universitätsbibliothek, Göttingen. - Abb. 3: Klassik Stiftung Weimar, Herzogin Anna Amalia Bibliothek. - Abb. 4, 7, 9, I2: cliché CNRS-IRHT, (C) Bibliothèque et archives du château de Chantilly. - Abb. 5, 8: Universitätsbibliothek Johann Christian Senckenberg, Frankfurt am Main. - Abb. Io, II, I3: Österreichische Nationalbibliothek, Wien. - Abb. I4: Christoph zu Waldburg Wolfegg. - Abb. I5: Dr.Otto-Schäfer-Stiftung e. V., Schweinfurt. - Abb. I6: Biblioteca Apostolica Vaticana, Rom.

97 Volldigitalisat neuerdings unter http://digi.ub.uni-heidelberg.de/diglit/bav_pal_lat_I986.

98 Volldigitalisat neuerdings unter http://digi.ub.uni-heidelberg.de/diglit/bav_pal_lat_I994.

99 Digitalisat unter http://bvmm.irht.cnrs.fr/resultRecherche/resultRecherche.php?COMPOSITION_ID=I4533 einsehbar.

Ioo Volldigitalisat im Internet unter http://ora-web.swkk.de/digimo_online/digimo.entry?source=digimo. Digitalisat_anzeigen\&a_id=I669.

IoI Volldigitalisat über den Datensatz im ÖNB-HANNA-Katalog aufrufbar: http://data.onb.ac.at/rec/ALooI77243.

IO2 Volldigitalisat über den Datensatz im ÖNB-HANNA-Katalog aufrufbar: http://data.onb.ac.at/rec/ALooI47695.

IO3 Volldigitalisat unter http://diglib.hab.de/mss/I6I-blank/start.htm. 


\title{
DIE HANDWERKERBILDER IN DEN HAUSBÜCHERN DER NÜRNBERGER ZWÖLFBRÜDERSTIFTUNGEN IM KÜNSTLERISCHEN KONTEXT IHRER ENTSTEHUNGSZEIT UND IM SPIEGEL DER JAHRESABRECHNUNGEN DER STIFTUNGSHÄUSER
}

\author{
Christine Sauer
}

Wohl als Seniorenwohnheime oder als Altersheime würde man heute die beiden Zwölfbrüderhäuser bezeichnen, in denen die fünf im Mittelpunkt der folgenden Ausführungen stehenden, spätmittelalterlichen und frühneuzeitlichen Handschriftenbände entstanden. ${ }^{1}$ Das Mendelsche Zwölfbrüderhaus wurde I388 von dem Nürnberger Patrizier Konrad Mendel († I4I4) gegründet, in das Landauersche zog 1510 sein Fundator ein, der ehemalige Montanunternehmer Matthäus Landauer ( $†$ I5I5). ${ }^{2}$ In Anlehnung an die Zahl der Apostel sind in diesen beiden Häusern jeweils zwölf Männer, die alt und verarmt waren und sich nicht mehr von ihrer Hände Arbeit ernähren konnten, aufgenommen und bis zu ihrem Tod versorgt worden. Die Brüder - so wurden die in die Stiftungen zugelassenen Männer genannt - sollten gemeinschaftlich im Stiftungshaus leben und als äußeres Zeichen für ihre Zugehörigkeit eine einheitliche Kleidung tragen. Neben der Erwerbslosigkeit werden als Voraussetzung für die Aufnahme der Nachweis des Nürnberger Bürgerrechts und die Fähigkeit genannt, Gebete wie das „Vater Unser“ und das „Ave Maria“ sowie das Glaubensbekenntnis sprechen zu können. Denn analog zu anderen Stiftungen der damaligen Zeit hatten die zwölf Brüder eine geistige Gegengabe für Verpflegung und Unterkunft zu erbringen: Sie mussten für Mitglieder der Stifterfamilien Mendel und Landauer sowie des Rats und für verstorbene Mitbrüder fürbitten. Außerdem hatten sie regelmäßig an Messen teilzunehmen und zu beten. Die 1525 in Nürnberg eingeführte Reformation gefährdete den Bestand der beiden Armenhäuser nicht. Auch am auf Erbauung fokussierten Tagesablauf änderte sich in der Folge wenig; konsequent wurde jedoch - gemäß des Bekenntnisses zum protestantischen Glauben - auf sämtliche Fürbitten für Tote verzich-

I Nürnberg, Stadtbibliothek, Amb. $317.2^{\circ}, 317 \mathrm{~b} .2^{\circ}$ und $318.2^{\circ}$ aus dem Mendelschen Zwölfbrüderhaus und Amb. $279.2^{\circ}$ und $279 \mathrm{~b} .2^{\circ}$ aus dem Landauerschen Zwölfbrüderhaus; Volldigitalisate der fünf Bände unter www.nuernberger-hausbuecher.de mit Beschreibung der Bände und weiterführender Literatur.

2 Zur Geschichte der beiden Einrichtungen grundlegend sind Das Hausbuch der Mendelschen Zwölfbrüderstiftung zu Nürnberg. Deutsche Handwerkerbilder des I5. und I6. Jahrhunderts, hrsg. von W. Treue u. a., München 1965 , und J. Ahlborn, Die Familie Landauer. Vom Maler zum Montanherrn (Nürnberger Forschungen II), Nürnberg 1969, S. IOI-II6. In den letzten Jahren sind beide Stiftungen wieder in das Interesse der Forschung getreten: M. KIrchHofF, Gedächtnis in Nürnberger Texten des I5. Jahrhunderts. Gedenkbücher, Brüderbücher, Städtelob, Chroniken (Nürnberger Werkstücke zur Stadt- und Landesgeschichte 68), Nürnberg 2009, S. I07-I50; C. SAUER, In das verordnete permente buch wie gepreuchlich zu mablen: Rechnungsbücher als Quellen für die Erschließung von Pfleger- und Handwerkerbildern in den Hausbüchern der Nürnberger Zwölfbrüderstiftungen, in: Mitteilungen des Vereins für Geschichte der Stadt Nürnberg 98, 20II, S. 8I-I33. 
tet. So konnten beide Stiftungen über Jahrhunderte kontinuierlich fortbestehen, bis sie I806 nach dem Übergang Nürnbergs an das Königreich Bayern aufgelöst wurden.

Mit Nutznießern aus der Gesellschaftsschicht der Handwerker, der Beteiligten an der Nahrungsmittelproduktion und der Dienstleister vertraten beide Stiftungen eine im transalpinen Raum neue Form der Armenfürsorge. ${ }^{3}$ Wohl als Teil eines Versuchs, das Vorrecht der Stifterfamilie Mendel auf die Besetzung des Pflegeramts und damit auf die Verwaltung des Stiftungseigentums zu sichern, entstand um I425 und damit rund 40 Jahre nach der Gründung der erste Band des heute so genannten Hausbuchs, einer erst seit den I92oern belegten modernen Bezeichnung. ${ }^{4}$ In dieser Handschrift erhielt ein jeder Pfleger einen Eintrag über Antreten von und Ausscheiden aus dem Amt. Im Anschluss folgten die in seiner Amtszeit im Stiftungshaus verstorbenen Brüder. Matthäus Landauer nahm sich diesen Band zum Vorbild und ließ I5II für seine Stiftung eine ebensolche Handschrift anlegen. Die Einträge erfolgten allerdings nicht in der üblichen Liste; für sie fand man eine besondere Form: Jedem Pfleger wurde mindestens eine, jedem Bruder exakt eine Seite zugebilligt. Name und Amtszeit des Pflegers ergänzte ein an Stifterdarstellungen angelehntes Bild, das den Amtsinhaber mit seiner zu diesem Zeitpunkt lebenden Frau und den bereits verstorbenen Gattinnen kniend mit neben jeder Person abgebildetem Familienwappen vor einem Altar zeigt. Bei den Handwerkern sind im oberen Seitendrittel handschriftlich der Name des Bruders, sein Beruf, das Eintrittsdatum in die Stiftung, das Todesdatum, das Alter sowie oftmals auch die Todesursache oder markante Charaktereigenschaften angegeben worden. Darunter wurde derselbe Mann in der typischen, von der Stiftung gestellten Tracht aus Kutte und Mantel mit Kapuze (Gugel) abgebildet und somit erkennbar als einer der Zwölfbrüder dargestellt, gleichzeitig aber bei der Verrichtung seines bis zum Eintritt in das Brüderhaus ausgeübten Berufs wiedergegeben.

Als nach den Amtszeiten der Pfleger geordnete Mitgliederverzeichnisse sind die Hausbücher aus der Rechnungslegung abzuleiten und mit Verwaltungsschrifttum verwandt: Sie weisen $\mathrm{Zu}$ - und Abgang der Brüder nach und dokumentieren so die Einhaltung des Stifterwillens. Aufgrund der chronologischen Abfolge können die Einträge jedoch auch als Aufzeichnung über die Geschichte der Brüderhäuser interpretiert werden. Die Handschriften fungierten somit in einem als Mitgliederverzeichnisse, Chroniken der Zwölfbrüderhäuser und rechtskräftige Nachweise für die Erfüllung des Stiftungszwecks. ${ }^{5}$ Dabei ist den Bänden aufgrund der gefundenen Form der Text-Bild-Kombination ein gewisser repräsentativer Zweck nicht abzusprechen. In dieser Form und mit diesen Aufgaben sind sie einmalig; gleichartige Zeugnisse existierten in keinem der zahlreichen nach dem Nürnberger Vorbild errichteten Zwölfbrüderhäuser. ${ }^{6}$

3 Zum Stiftungstyp s. G. Fouquet, Zwölf-Brüder-Häuser und die Vorstellung vom verdienten Ruhestand im Spätmittelalter, in: N. Bulst/K.-H. SpIEss, Sozialgeschichte mittelalterlicher Hospitäler (Vorträge und Forschungen 65), Ostfildern 2007, S. 37-56.

4 Zum Anlass für die Anlage der Handschrift Kirchнoff, Gedächtnis in Nürnberger Texten (zit. Anm. 2), S. I36-I39; zur Bezeichnung als Hausbuch s. SAUER, In das verordnete permente buch (zit. Anm. 2), S. 96-IO3.

5 Dazu zuletzt Kirchноғf, Gedächtnis in Nürnberger Texten (zit. Anm. 2), S. I2O-I23; SAuer, In das verordnete permente buch (zit. Anm. 2), S. 96-IO3.

6 Vgl. K. Goldmann, Zur Geschichte der Mendelschen Zwölfbrüderstiftung, in: Das Hausbuch der Mendelschen Zwölfbrüderstiftung (zit. Anm. 2), S. 7-3I, bes. S. 22 ff. 
Für den heutigen Betrachter erfüllen die Hausbücher noch eine weitere Aufgabe. Weil der Nachweis eines tatsächlich ausgeübten Berufs Voraussetzung für die Aufnahme war, musste das im Bild vorgestellte Handwerk eindeutig erkennbar sein. Auf die Wiedergabe von Herstellungsprozessen, den dabei eingesetzten Werkzeugen und Arbeitshilfen sowie den an Wänden, Böden, Tischen und Laden zur Schau gestellten Ausgangsmaterialien und Endprodukten ist deshalb großer Wert gelegt worden. ${ }^{7}$ Weil die beiden Handschriften bis zur Aufhebung der Stiftungen außerdem kontinuierlich fortgeführt wurden und am Schluss auf fünf Bände mit fast I. 200 Handwerkbildern anwuchsen, gelten die Hausbücher heute als eine der wichtigsten Bildquellen zum europäischen Handwerk in Mittelalter und Früher Neuzeit. In Kooperation mit dem Germanischen Nationalmuseum und mit Fördermitteln der Deutschen Forschungsgemeinschaft konnten sie vollständig digitalisiert und in Verknüpfung mit einer verbalen Erschließung 2009 ins Netz eingestellt werden. ${ }^{8}$ Allerdings muss bei einer angemessenen Bildinterpretation berücksichtigt werden, dass die Bilder im Verlauf der Jahrhunderte einem mehrfachen Wandel unterlagen. Für die frühen, vor ca. I6oo entstandenen und im Folgenden ausschließlich herangezogenen Darstellungen gilt, dass sie trotz der vordergründig so realitätsnah wirkenden Gestaltung in mehrfacher Hinsicht als künstliche Konstrukte zu bezeichnen sind: So war keiner der vorgestellten Brüder nach dem Eintritt in die Stiftung noch in seinem Beruf tätig, ihre Darstellung bei der Arbeit in Stiftungstracht in einer Werkstatt kann folglich niemals in der bildlich fixierten Form stattgefunden haben. Auch darf bei der Wiedergabe der Personen nicht von Porträts gesprochen werden, denn die Künstler wurden - wie noch zu zeigen sein wird - erst Wochen nach dem Tod des dargestellten Handwerkers mit der Anfertigung des Bildes beauftragt.'

Pfleger- und Brüderbilder sind anfangs von denselben Malern ausgeführt worden. Die Darstellungen von Pflegern und Handwerkern hoben sich in der Ikonographie und dem Zeitpunkt der Ausführung voneinander ab: Die Wiedergaben in der Form eines Stifterbildes entstanden zum Amtsantritt und damit zu Lebzeiten der Abgebildeten, die somit Einfluss auf ihre Darstellung nehmen konnten. Um I6oo setzte sich der Brauch durch, für die Pfleger in Öl auf Pergament gemalte Brustbildnisse anfertigen zu lassen, die von zum Teil namentlich bekannten Künstlern wie Lorenz Strauch (I554-1630), Hieronymus Franz Fuchs (I634-1690), Paul Decker d. J. (I685-1742) oder Christian Friedrich Carl Kleemann (1735-I789) signiert worden sind. Die Pflegerbilder unterscheiden sich also nun in Bildthema, Technik und Qualität von den Brüderbildern. Für Letztere nämlich gilt ein völlig anderer Befund: Keines der Brüderbilder trägt eine Künstlersignatur, keines kann bisher einem namentlich bekannten Maler zugewiesen werden. ${ }^{10}$ Dabei war an der Ausführung eine Vielzahl unterschiedlicher, oft von Bild zu Bild wechselnder Hände beteiligt. Allein für den ersten Band des Mendel-

7 Zur Entstehung dieser Handwerkerbilder zuletzt SAUER, In das verordnete permente buch (zit. Anm. 2), S. 8696 sowie zum Quellenwert der Hausbücher für die Handwerksgeschichte Handwerk im Mittelalter, hrsg. von C. SAUER, Darmstadt 2012.

8 S. Anm. I.

9 Zum Realitätscharakter s. SAUER, In das verordnete permente buch (zit. Anm. 2).

Io Für die Ausnahmen siehe unten den Abschnitt über die Jahresabrechnungen. 
schen Hausbuchs unterschied Heinz Zirnbauer 26 verschiedene Maler. ${ }^{11}$ Eine vergleichbare kunsthistorische Aufarbeitung fehlt bisher für die übrigen vier Bände.

In zwei verschiedenen Anläufen soll im Folgenden eine Annäherung an die anonymen Hersteller der Brüderbilder versucht werden. Die Entstehung des ersten Bandes des Mendelschen Hausbuchs fällt in das I5. Jahrhundert und damit in die Blütezeit Nürnbergs als Zentrum der Buchmalerei. Dennoch lassen sich nur wenige Überschneidungen mit den vor Ort ansässigen Ateliers von Illuministen feststellen. Es soll daher zunächst der Frage nachgegangen werden, wie sich die kolorierten Federzeichnungen innerhalb der lokalen Produktion von Buchmalerei verorten lassen. Im zweiten Durchgang stehen die Darstellungen des I6. Jahrhunderts im Mendelschen und Landauerschen Hausbuch im Mittelpunkt. Anhand erhaltener Abrechnungen können die Maler einiger Miniaturen identifiziert und ihre Stellung in einem Zeitalter rekonstruiert werden, als die Buchmalerei zu einem Nischenprodukt für Luxushandschriften geworden war.

\section{DIE KOLORIERTEN FEDERZEICHNUNGEN IM}

ERSTEN BAND DES MENDELSCHEN ZWÖLFBRÜDERBUCHS

IM KÜNSTLERISCHEN KONTEXT IHRER ZEIT

Die ältesten 326 Handwerkerdarstellungen befinden sich im ersten Band der Mendelschen Zwölfbrüderstiftung, der 1425 angelegt und bis 1549 fortgeführt wurde. ${ }^{12}$ Es handelt sich dabei um eine Papierhandschrift mit kolorierten Federzeichnungen. Erst gegen Ende des Bandes und damit zeitlich gesehen um die Jahrhundertwende mehren sich gerahmte Darstellungen mit farbigen Hintergründen. Bis dahin wurden die Handwerker zumeist ohne präzise räumliche Angabe auf Erdschollen oder einem angedeuteten Fußboden wie auf einer Bühne platziert, während der Hintergrund im Papiergrund stehen blieb. Der erste Mendelband bietet dabei Gelegenheit zu Einblicken in die Vielfalt der in Nürnberg hergestellten Buchmalerei über einen Zeitraum von ca. I25 Jahren.

Der Auftraggeber der Handschrift, Marquard Mendel († I438), zog während seiner Amtszeit durchgehend einen Maler heran und unterscheidet sich damit von seinen Nachfolgern. ${ }^{13}$ Dieser Maler fertigte im Zeitraum von I425 bis I 438 rund 120 erhaltene Handwerkerbilder an. Er fällt durch eine treffende Beobachtung der verschiedenen Herstellungsprozesse bei gleichzeitiger Beschränkung auf wenige Figurentypen auf. Als Chiffre für das meist hohe Alter der Dargestellten verwendete er einen Kopftypus mit grauem, spitz zulaufendem Vollbart und beginnender Glatze (Abb. I); seltener kommen runde, bartlose Gesichter mit kurzem Haar vor (Abb. 2). Bei der halblangen, monoton gleichbleibenden Stiftungstracht bestanden wenige Möglichkeiten für die Unterbringung der zu dieser Zeit so beliebten, gestaucht auf dem Bo-

iI H. Zirnbauer, Geschichte des Mendelschen Brüderbuchs und kunstgeschichtliche Würdigung seiner Bilder, in: Das Hausbuch der Mendelschen Zwölfbrüderstiftung (zit. Anm. 2), S. 93-97.

I2 $\mathrm{Zu} \mathrm{Nürnberg,} \mathrm{Stadtbibliothek,} \mathrm{Amb.} 317.2^{\circ}$ noch immer grundlegend das 1965 herausgekommene Faksimile; s. dazu Anm. I.

I3 Zirnbauer, Geschichte des Mendelschen Brüderbuchs (zit. Anm. 2), S. 93, 95 f. hält fest, dass die Brüderbilder in Nürnberg, Stadtbibliothek Amb. $317.2^{\circ}$, fol. Ir- $59 \mathrm{v}$ „unzweifelhaft von einer Hand“ sind. 


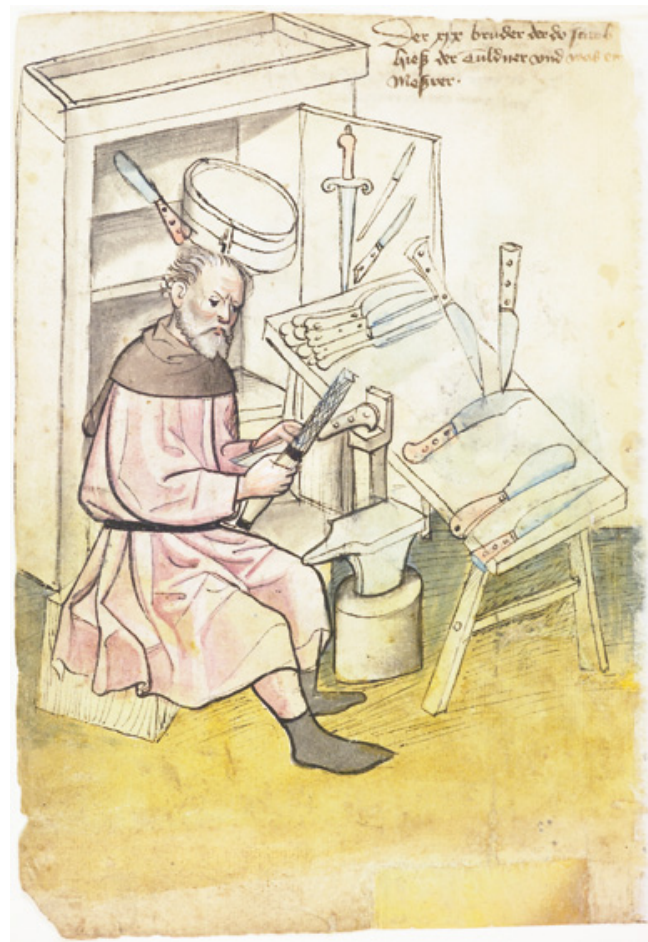

Abb. I: Nürnberg, Stadtbibliothek, Amb. $317.2^{\circ}$, fol. I2v

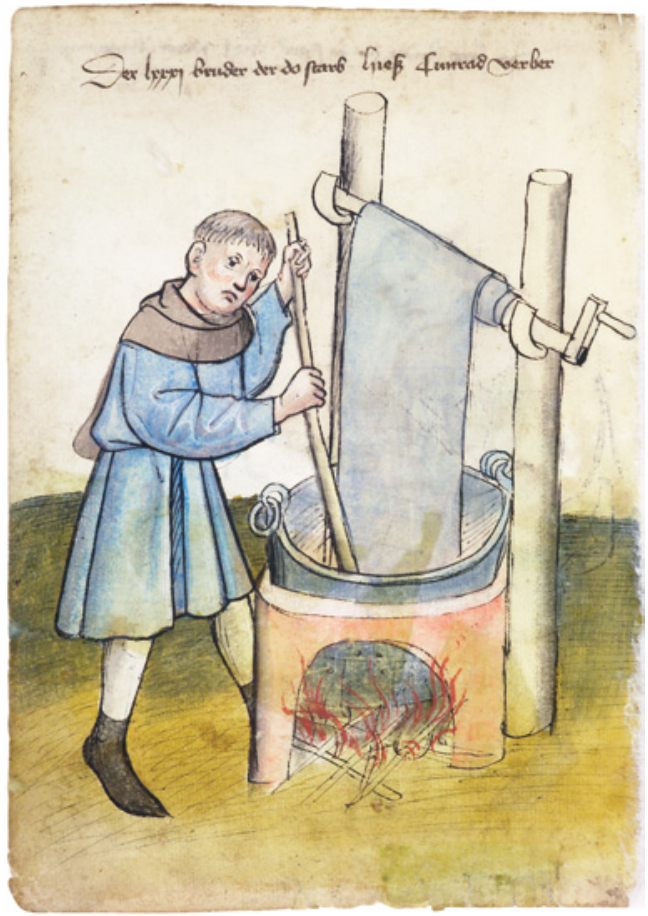

Abb. 2: Nürnberg, Stadtbibliothek, Amb. 317.2 ${ }^{\circ}$, fol. 37v

den aufliegenden Faltenzüge (vgl. Abb. I). Auffallend ist der kräftige schwarze Strich, mit dem Außenkonturen und Umrisse von Hauptfaltenzügen gerahmt werden; der Binnengliederung dienen feinere schwarze Linien mit Schraffuren oder Farbmodellierungen (Abb. 2). Diese Feinzeichnungen sowie die sparsam eingesetzten, gebrochenen Faltenmotive weisen oft nur einen vagen Bezug zu den darunterliegenden Formen auf. Eine differenzierte Ausarbeitung von Figuren und Gewändern wurde offensichtlich nicht angestrebt.

Nur dieser Buchmaler konnte bisher in einer weiteren Handschrift nachgewiesen werden, die Hanns Hubach in der Concordia Seminary Library in St. Louis entdeckte. ${ }^{14}$ Es handelt sich dabei um ein frühes, I429 datiertes Exemplar des sogenannten ,Iatromathematischen Hausbuchs', eines um I400 wohl in Nürnberg entstandenen und weit verbreiteten, für Laien bestimmten astromedizinischen Kompendiums in der Volkssprache. ${ }^{15}$ Die Illustrationen in Gestalt von Monatsarbeiten und Tierkreiszeichen, Planeten- und Komplexionsbildern so-

I4 Zur Handschrift in der Concordia Seminary Library, St. Louis, MO, USA s. http://www.atla.com/ CDRICollection/HAUSBUCI.html für eine Handschriftenbeschreibung durch Hanns Hubach und http:// www.atla.com/digitalresources/results.asp?pagenumber=I\&clı=HAUSBUCI für das Volldigitalisat.

S. dazu: Vom Einfluss der Gestirne auf die Gesundheit und den Charakter des Menschen. Kommentar zur Faksimile-Ausgabe des Manuskriptes C 54 der Zentralbibliothek Zürich (Nürnberger Kodex Schürstab), hrsg. von G. KeIL, Luzern 1983 sowie G. Keil/F. Lenhardt: „Iatromathematisches Hausbuch“, in: Die deutsche Literatur des Mittelalters. Verfasserlexikon, 2. Aufl., hrsg. von K. Ruн u. a., Bd. 4, Berlin I983, Sp. 347-351. 


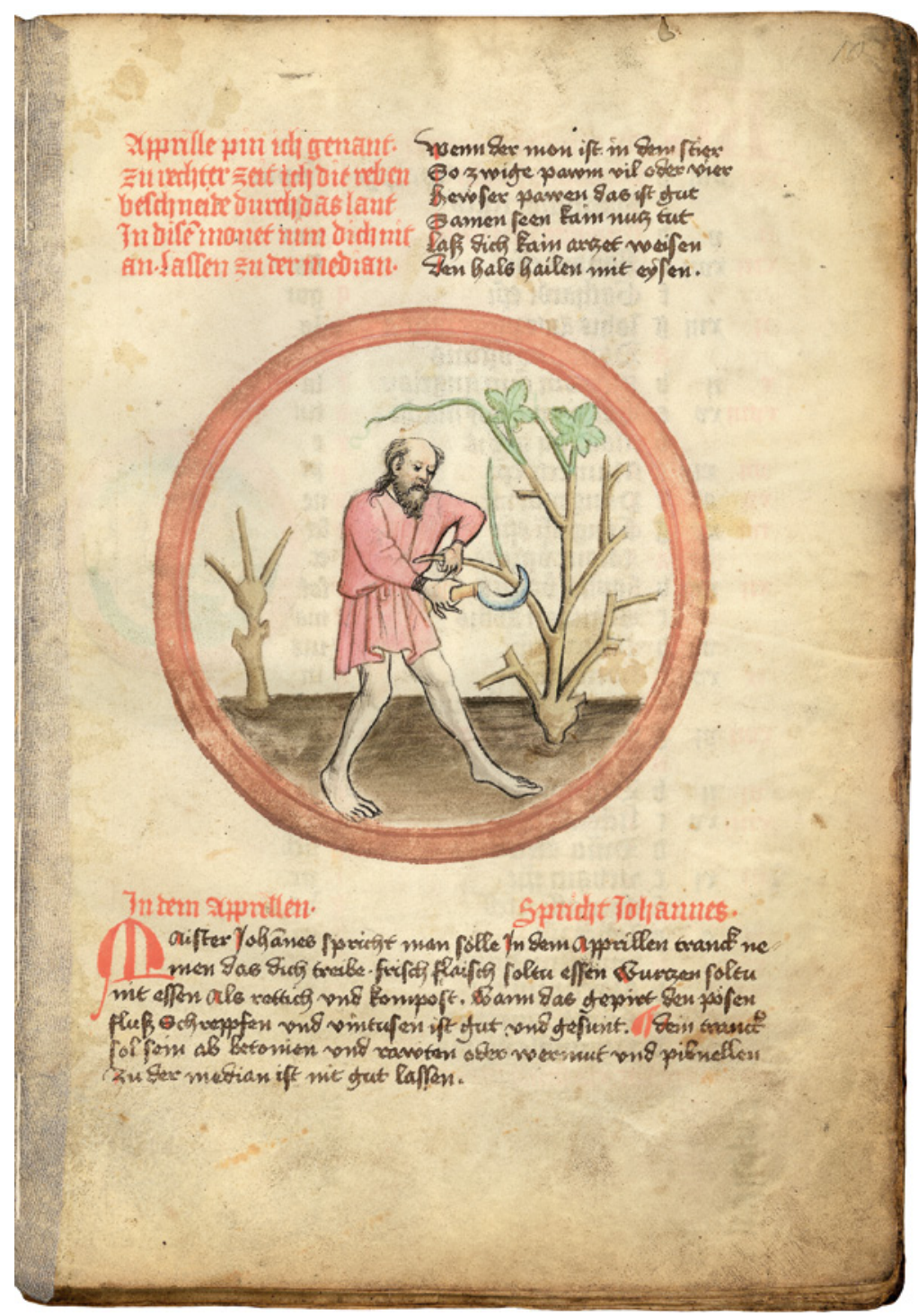

Abb. 3: St. Louis, Concordia Seminary Library, MedizinischAstrologisches Hausbuch, fol. 6r

wie Lehr- und Merkschemata weisen mit den Handwerkerdarstellungen übereinstimmende technische und stilistische Merkmale etwa im Einsatz der dominanten schwarzen Konturen oder der Gesichter mit den Knopfaugen, kleinen Nasen und Mündern sowie oft unmotiviert angesetzten, großen Ohren auf (Abb. 3, 4). Beim Vergleich muss allerdings der Zuschnitt der Bilder in der medizinischen Handschrift auf den vermutlich adligen Besteller berücksichtigt werden: Es sind nahezu ausschließlich jugendliche, bartlose Gesichtstypen vertreten, die Kleidung wird durch zahlreiche dem höfischen Umfeld entlehnte modische Accessoires aufgewertet, die Gewandfaltenmotive fallen durchweg reicher aus. Der versatzstückweise Einsatz von einzelnen Faltenmotiven ist aber mit den fast gleichzeitig um I425 angefertigten Handwerkerbildern im Mendelschen Hausbuch vergleichbar (vgl. Abb. 2 und 4). 
Der Maler legte also nicht nur für Marquard Mendel eine Bilderhandschrift an, sondern nahm zur selben Zeit weitere Aufträge wohl aus dem Umfeld des Nürnberger Patriziats entgegen. Er dürfte somit zu den professionellen Buchmalern eines der Laienateliers zu zählen sein, die sich im frühen I5. Jahrhundert in Nürnberg niederließen. ${ }^{16}$ Damit sind Vermutungen widerlegt, denen zufolge die Handwerkerbilder in der Anlageschicht des Hausbuchs dem 1438 als Bruder im Mendelschen Zwölfbrüderhaus verstorbenen, ehemaligen Stuhlschreiber Johannes zuzuschreiben seien. ${ }^{17}$ Für eine professionelle Ausbildung spricht ferner die Tatsache, dass auch die Nachfolger des ersten Mendelmalers demselben künstlerischen Umfeld entstammen dürften. ${ }^{18}$ Sie bevorzugten jedoch auf-

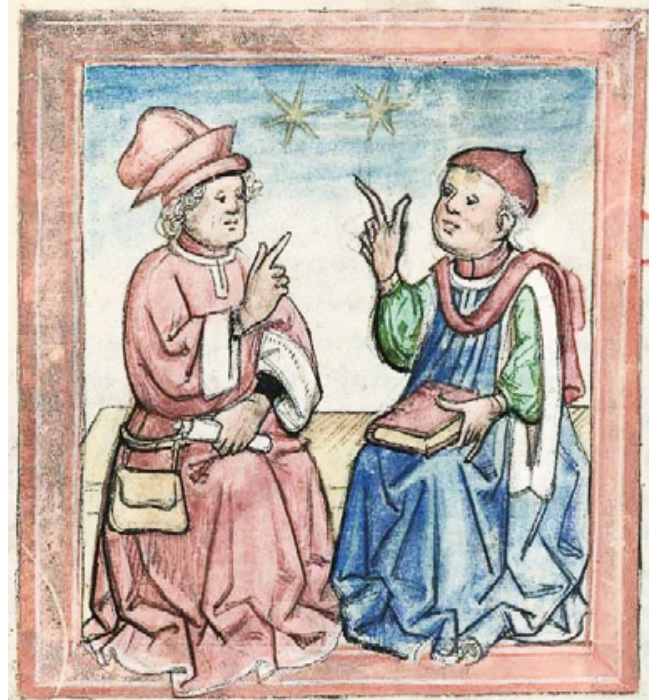

Abb. 4: St. Louis, Concordia Seminary Library, Medizinisch-Astrologisches Hausbuch, fol. 27r wendigere Faltensysteme, die mit in Deckweiß aufgesetzten Lichtern und in einem abschattierten Gewandfarbton gestalteten Tiefen plastischer gegliedert werden, und schließen damit an in den I440er-Jahren in Nürnberg übliche Formen an. ${ }^{19}$ Als in den I45oer-Jahren vermittelt durch Hans Pleydenwurff († I472) und ein in seinem Umfeld tätiges Glasmalereiatelier die Rezeption der niederländischen Malerei in Nürnberg einsetzte, finden sich in den I470er-Jahren am Mendelbuch beteiligte Maler, die einen hart gebrochenen Gewandfaltenstil mit Schraffuren und den markanten Doppellinien mit ösenartigen Köpfchen in den Faltentälern pflegten (Abb. 5). ${ }^{20}$ Ein Vergleich mit ei-

i6 K.-G. Pfändtner. Das Missale ecclesiae Bambergensis der Stiftsbibliothek Göttweig und die Nürnberger Miniaturmalerei der ersten Hälfte des I5. Jahrhunderts, in: Codices manuscripti, H. 48-49, 2004, S. 43-54 (Textbd.), 43-66 (Tafelbd.).

I7 Stuhlschreiber Johannes in Nürnberg, Stadtbibliothek, Amb. 317.2 ${ }^{\circ}$, fol. 62r; zu seiner Aufgabe auch als Maler s. Kirchноғf, Gedächtnis in Nürnberger Texten (zit. Anm. 2), S. I4I-I44 und SAuer, In das verordnete permente buch (zit. Anm. 2), S. 97-99.

I8 Zirnbauer, Geschichte des Mendelschen Brüderbuchs (zit. Anm. I3), S. 96, zu den an Nürnberg, Stadtbibliothek, Amb. $317.2^{\circ}$, fol. 6or-87r, beteiligten Händen 2-4.

I9 Vgl. Nürnberg, Stadtbibliothek, Amb. 317.2 ${ }^{\circ}$, fol. 68r mit Göttweig, Stiftsbibliothek, Cod. I rot, fol. 75r; zum Göttweiger Missale s. Pfändtner, Das Missale ecclesiae Bambergensis (zit. Anm. I6), S. 43-47 mit Abb. II.

20 S. dazu C. Sauer, Vor den Glockendons. Nürnberger Buchmalerei aus der zweiten Hälfte des I5. Jahrhunderts in der Inkunabelsammlung der Stadtbibliothek Nürnberg, und K. Georgi, Was Vorlagen verraten. Einem fränkischen Buchmaler auf der Spur, in: Dürer-Forschungen 2, 2009, S. II-38 und 65-IOI. Zur Bedeutung von Hans Pleydenwurff s. jetzt auch R. Suckale, Die Erneuerung der Malkunst vor Dürer, Petersberg 2009, S. IO3-2I2 und die folgende Anm.; zu den Glasmalereien vgl. H. Scholz, Bamberger Glasmaler in der Werkstatt Michael Wohlgemuts? Zur ehemaligen Kreuzgangsverglasung des Nürnberger Klaraklosters, in: Glas. Malerei. Forschung. Internationale Studien zu Ehren von Rüdiger Becksmann, hrsg. von H. Scholz u. a., Berlin 2004, S. 23I-244. 


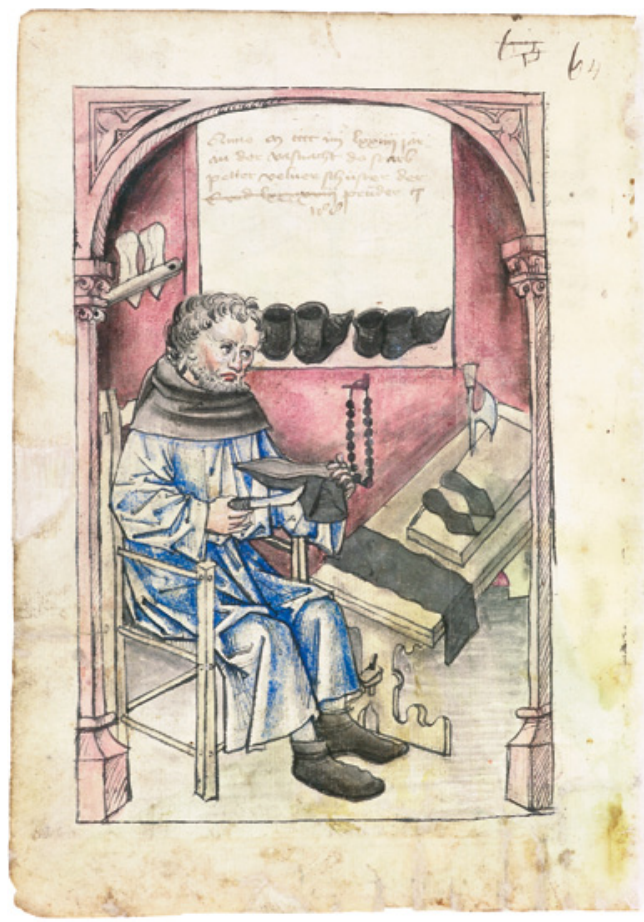

Abb. 5: Nürnberg, Stadtbibliothek, Amb. 317.2 ${ }^{\circ}$, fol. 93V

ner Zeichnung der Pleydenwurff-Werkstatt aus der Zeit um I465/66, die den segnenden Christus vorstellt, belegt, dass der Maler im Mendelbuch im Umfeld dieses einflussreichen Malers bzw. der Glasmalereiwerkstatt anzusiedeln ist (Abb. 6). ${ }^{21}$ Die plastische Gewandgestaltung durch Farbmodellierungen schließlich, die von den, Werkstätten um Hermann Schedels Falcuccius-Druck' in den I48oer- und I49oer-Jahren gepflegt wurde, findet einzelne Reflexe im Hausbuch, jedoch in einer sichtbar flüchtigeren Ausführung, die auch zu einer Vergröberung durch den Verzicht auf eine feinere Ausarbeitung von Details führt (Abb. 7, 8). ${ }^{22}$ Offensichtlich wurde im Hausbuch größeres Gewicht auf die Geschwindigkeit der Ausführung als auf die Ausarbeitung von Details gelegt.

Konnten bis dahin immer wieder Berührungspunkte mit Entwicklungen der zeitgenössischen Malerei und Buchmalerei aufgezeigt werden, so finden sich in der zweiten Hälfte des 15 . Jahrhunderts durchaus auch Beispiele für eine zunehmende Entfernung. Schon I470-I472 und damit fast zeitgleich mit dem Maler der hart brechenden Gewandfalten wurde mehrmals ein Maler für das Mendelbuch engagiert, der für Gewänder geschlossene Konturen bevorzugte und die so entstandenen Flächen durch schwarze Linien mit darübergelegten Querstrichen gliederte. Die klaren Formen mit der kräftig schwarzen Zeichnung erinnern an die zeitgenössische Textilproduktion (Abb. 9, Io). ${ }^{23}$ Der Maler eines Klingenschmieds, dessen Gewand nur durch wenige mit der Feder gezogene Linien gegliedert, aber weder durch Schraffuren noch durch Farbe mo-

2I Vgl. Nürnberg, Stadtbibliothek, Amb. 317.2 ${ }^{\circ}$, fol. 93v mit der Zeichnung in Erlangen, Graphische Sammlung der Universität, B 6o; zu letzterer s. Zeichnen vor Dürer. Die Zeichnungen des I4. und I5. Jahrhunderts in der Universitätsbibliothek Erlangen, hrsg. von H. Dickel, bearb. von S. BuCK und G. Messling, mit Beiträgen von I. Brahms, Petersberg 2009, S. il6-II8, Kat. 4I. - Zu Hand 8 im Hausbuch s. Zirnbauer, Zur Geschichte des Mendel-Brüderbuchs (zit. Anm. 13), S. 96.

22 Vgl. Nürnberg, Stadtbibliothek, Amb. 317.2 ${ }^{\circ}$, fol. Io9r mit Nürnberg, Stadtbibliothek, Med. 31.2 ${ }^{\circ}$, Bl. ara; zu den „Sermones medicinales septem“ des Nicolaus Falcuccius, Pavia I48I-84 (GW 9704) s. SAuer, Vor den Glockendons (zit. Anm. 20), S. 26-31; zu Hand in im Hausbuch s. Zirnbauer, Zur Geschichte des MendelBrüderbuchs (zit. Anm. 13), S. 96.

Zur Hand 6 auf Nürnberg, Stadtbibliothek, Amb. 317.2 ${ }^{\circ}$, fol. 88v-92r s. Zirnbauer, Zur Geschichte des Mendel-Brüderbuchs (zit. Anm. 13), S. 96; zum Bilderteppich (Privatbesitz, Teppich mit Apostelabschied, Fränkisch, um I470/80) s. B. Kurth: Die deutschen Bildteppiche des Mittelalters, Wien I926, Bd. i S. I85 f., 280 f. zu Taf. 3 Iо. 
delliert wird, scheint hingegen der zeitgenössischen Holzschnittproduktion nahegestanden zu haben. Ein Vergleichsbeispiel findet sich in der Druckgrafik des Illuministen und Briefmalers Georg Glockendon, zum Beispiel einem 1497 verlegten Einblattdruck. ${ }^{24}$ Auffällig viele Darstellungen im Hausbuch müssen als dilettantisch bezeichnet werden und lassen eine Beherrschung der Wiedergabe von Körper oder Raum vermissen. ${ }^{25}$ Dies änderte sich erst im 16. Jahrhundert, als von 1526 bis 1533 ein Maler mit herausragenden zeichnerischen Fähigkeiten tätig wurde, der deshalb in den Umkreis Albrecht Dürers eingeordnet worden ist. ${ }^{26}$

Für die kolorierten Federzeichnungen im Hausbuch wurde also gegen Ende des I5. Jahrhunderts nicht nur auf die immer noch in Nürnberg tätigen Ateliers von Malern und Buchmalern zurückgegriffen, sondern offensichtlich auch auf Künstler mit unterschiedlicher Vorbildung, darunter vielleicht auch aus dem Umfeld der mit dem Holzschnitt beschäftigten Briefmaler und Reißer. Kennzeichnend ist in vielen Fällen eine schnelle Ausführung, bei der auf feine Pinselarbeit oder eine sorgfältige Planung der Bildsujets verzichtet und gerne auf bereits im Hausbuch vorhandene Modelle in Form von Darstellungen desselben Berufs zurückgriffen wird, um diese zu kopieren. Aber auch die sich ändernde Wertschätzung der Zeichnung, die in den Werkstätten des I5. Jahrhunderts zunächst für Vorlagensammlungen genutzt, dann aber

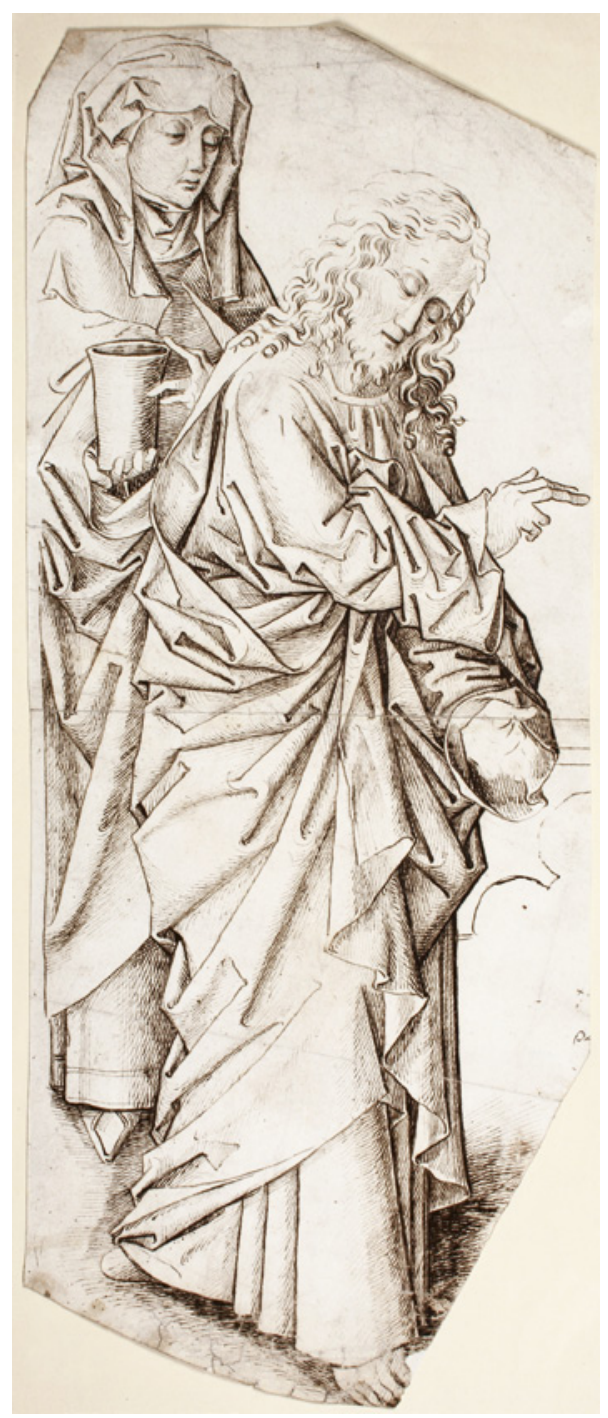

Abb. 6: Erlangen, Graphische Sammlung der Universität, B 60

24 Vgl. Nürnberg, Stadtbibliothek, Amb. 317.2 ${ }^{\circ}$, fol. II4v mit Hamburg, Kunsthalle, Inv. Nr. IO499; den Einblattdruck mit den Asketen Jakob und Johann Baptista von Georg Glockendon aus dem Jahr I497 behandelt U. Timann, Untersuchungen zu Nürnberger Holzschnitt und Briefmalerei in der ersten Hälfte des i6. Jahrhunderts mit besonderer Berücksichtigung von Hans Guldenmund und Niclas Meldemann (Kunstgeschichte I8), Münster I993, S. 26 mit Abb. 3. - Zu Hand ir im Hausbuch s. Zirnbauer, Zur Geschichte des Mendel-Brüderbuchs (zit. Anm. 13), S. 96.

25 Zum Beispiel Nürnberg, Stadtbibliothek, Amb. 317.2 ${ }^{\circ}$, fol. IO5r, I2Ov; zu den Händen II und I3 im Hausbuch s. Zirnbauer, Zur Geschichte des Mendel-Brüderbuchs (zit. Anm. I3), S. 96.

26 Nürnberg, Stadtbibliothek, Amb. 317.2 ${ }^{\circ}$, fol. I4Ir-I48v von Hand I8 im Hausbuch; zu dieser Zirnbauer, Zur Geschichte des Mendel-Brüderbuchs (zit. Anm. 13), S. 97. 


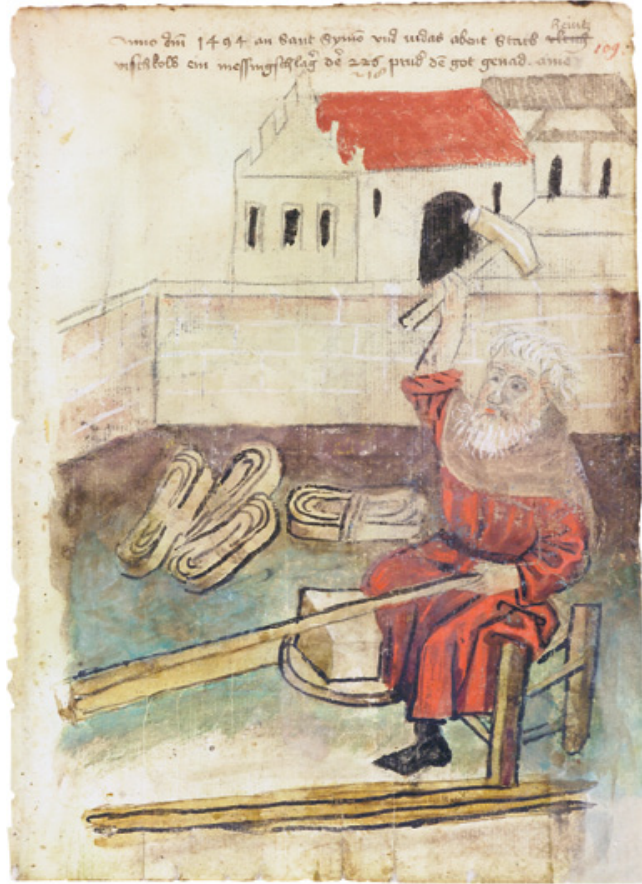

Abb. 7: Nürnberg, Stadtbibliothek, Amb. 317.2 ${ }^{\circ}$, fol. Io9r rasch als Ausdruck künstlerischen Erfindungsgeistes verstanden wurde, spiegelt sich in den Handwerkerbildern des ersten Hausbuchbandes. Er gewährt somit Einblicke in eine anderweitig so nicht fassbare Vielfalt von unterschiedlichen Handwerkszweigen, sozusagen die „Szene“, aus der sich die an der Ausführung von Malereien in Büchern beteiligten Künstler rekrutierten und in die die Produktion der genuinen Buchmalereiwerkstätten in der zweiten Hälfte des I5. Jahrhunderts eingebettet gesehen werden muss. Gerade die Illuministen, die nach I450 für die Ausgestaltung der Inkunabeln herangezogen wurden, oder die auf Luxushandschriften spezialisierten Maler wie Jacob Elsner oder Mitglieder der Familie Glockendon sind in den Hausbüchern kaum oder gar nicht vertreten. ${ }^{27}$ Auch diese Abgrenzung kann als Zeichen für die Zuordnung der Handschrift zum Verwaltungsschrifttum gewertet werden.

\section{DIE HANDWERKERDARSTELLUNGEN IM SPIEGEL DER}

\section{JAHRESABRECHNUNGEN DES I6. JAHRHUNDERTS}

Beim zweiten Annäherungsversuch an die bei den Handwerkerbildern beteiligten Buchmaler bilden die im Stadtarchiv Nürnberg erhaltenen Abrechnungen der Pfleger den Ausgangspunkt. ${ }^{28}$ Jährlich zu St. Walpurgis, dem I. Mai, hatten die vom Rat eingesetzten, für die Belange der Stiftungshäuser verantwortlichen Pfleger eine Aufstellung der Ausgaben und Einnahmen vorzulegen. Entgegen der bisher geltenden Meinung, darin befänden sich nur Angaben zur Bezahlung von Naturalien wie Getränken, Lebensmitteln und Kleidung, ergab eine erneute Durchsicht, dass in den Faszikeln tatsächlich auch Bezahlungen für die an Reparaturen und Instandsetzungsarbeiten beteiligten Handwerker sowie für die Maler zu finden sind. Gleich das erste auf uns gekommene, von dem Pfleger Sigmund Held († 1558) für das Jahr I534/35 erstellte Konzept einer Jahresabrechnung enthält einen entsprechenden Eintrag im typischen Wortlaut: Item mer zalt von dem verstorbenen bruder fachelhawer vnd dem schaffer in

27 Zur Nürnberger Buchmalerei um I5oo zuletzt Heilige und Hasen. Bücherschätze der Dürerzeit, bearb. von T. ESER/A. GreBE, Nürnberg 2008.

28 Ausführlich mit Edition der für die Buchmalereien relevanten Rechnungsbelege SAUER, In das verordnete permente buch (zit. Anm. 2). 


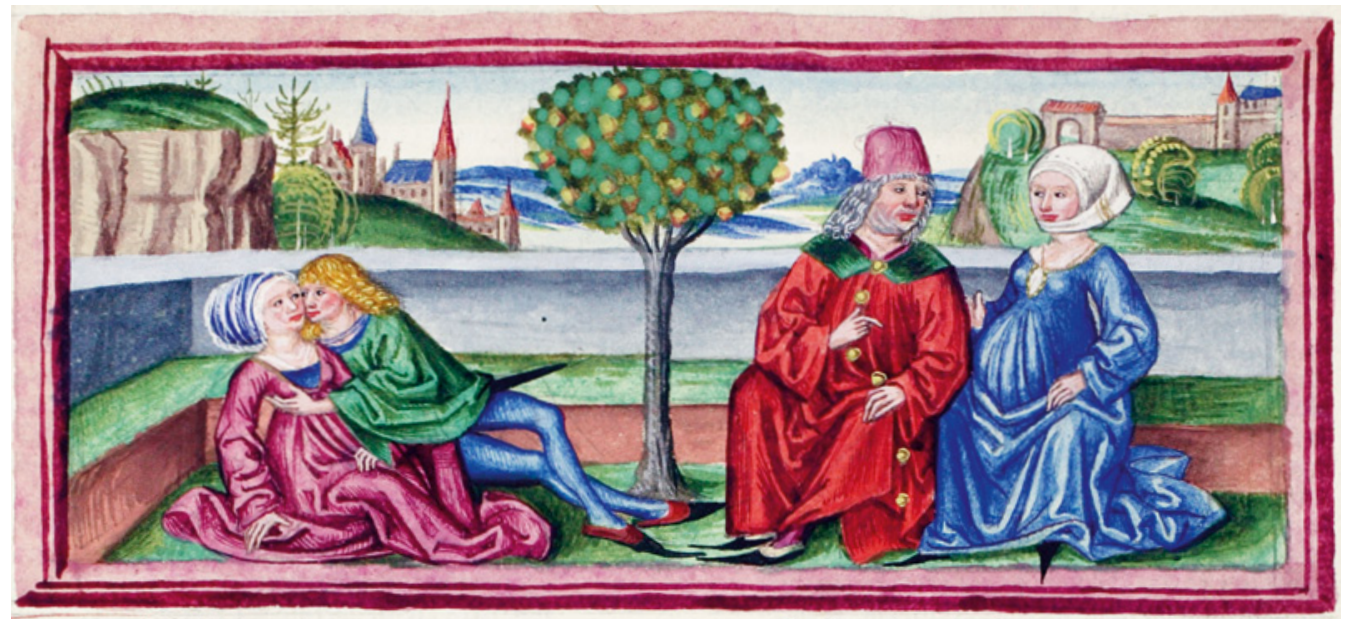

Abb. 8: Nürnberg, Stadtbibliothek, Med. 3I.2, Bl. aIa

das todten puch zu mallen in halt der stifftung I lb I2 dn [I Pfund I2 Pfennige]. ${ }^{29}$ Der Eintrag bezieht sich auf den am I. August I534 verstorbenen Feilenhauer Peter Pauernschmidt und den diesem am 7. September 1534 nachgefolgten Schaffer Kunz Thannler. ${ }^{30}$ Held bezeichnet die heute als Hausbuch bekannte Handschrift als „Totenbuch“ und verweist damit auf eine mögliche ursprüngliche Funktion im Rahmen der Memoria oder des Totengedächtnisses, die aber I534 nach Einführung der Reformation gewiss nicht mehr aktuell war. Er könnte mit diesem Begriff aber auch eine zentrale Eigenschaft der Handschrift im I5. und I6. Jahrhundert umschreiben: Eines Eintrags und damit eines Bildes würdig wurden die Handwerker nach ihrem Tod. ${ }^{31}$ Erst für die Toten konnte der schriftliche Eintrag unter Nennung des Todesdatums erfolgen, und erst nach der Bestattung wurde die Darstellung des Handwerkers bei der Arbeit angefertigt. Diese Art der Buchführung belegen sowohl die Reihenfolge der Bildeinträge nach dem Todesdatum als auch die Angaben in den Jahresabrechnungen. Aus späteren Belegen, in denen neben dem Namen des Dargestellten auch das Datum der Bezahlung des Malers festgehalten wurde, ergibt sich, dass zwischen dem Tod und der Ausführung des Bildes mindestens zwei Wochen, in der Regel aber sechs bis acht Wochen und manchmal mehrere Monate vergehen konnten. Einmal mehr erweisen sich somit die Bilder als nur scheinbar realitätsnah: Bei den Dargestellten kann es sich nicht um Porträts handeln, vorgestellt werden stets Typen von alten Männern mit weißem Haupt- und Barthaar und Falten im Gesicht (Abb. I-2, 5, 7 , Io). Erst als um I60o die Buchführung umgestellt wurde und der Basiseintrag mit dem Eintreten in die Stiftung erfolgte, entstanden in den Stiftungsstuben von Malern nach der Natur direkt in das Buch gemalte Bildnisse. Beim Blättern durch die Handschrift lässt sich in

29 Zu Nürnberg, Stadtarchiv, D 9 Nr. A 89 s. SAuER, In das verordnete permente buch (zit. Anm. 2), S. IO3f., I27 mit Abb. 9.

30 Nürnberg, Stadtbibliothek, Amb. $317.2^{\circ}$, fol. 152v-I53r.

3I Zum Folgenden SAuer, In das verordnete permente buch (zit. Anm. 2), S. IO3-I23. 


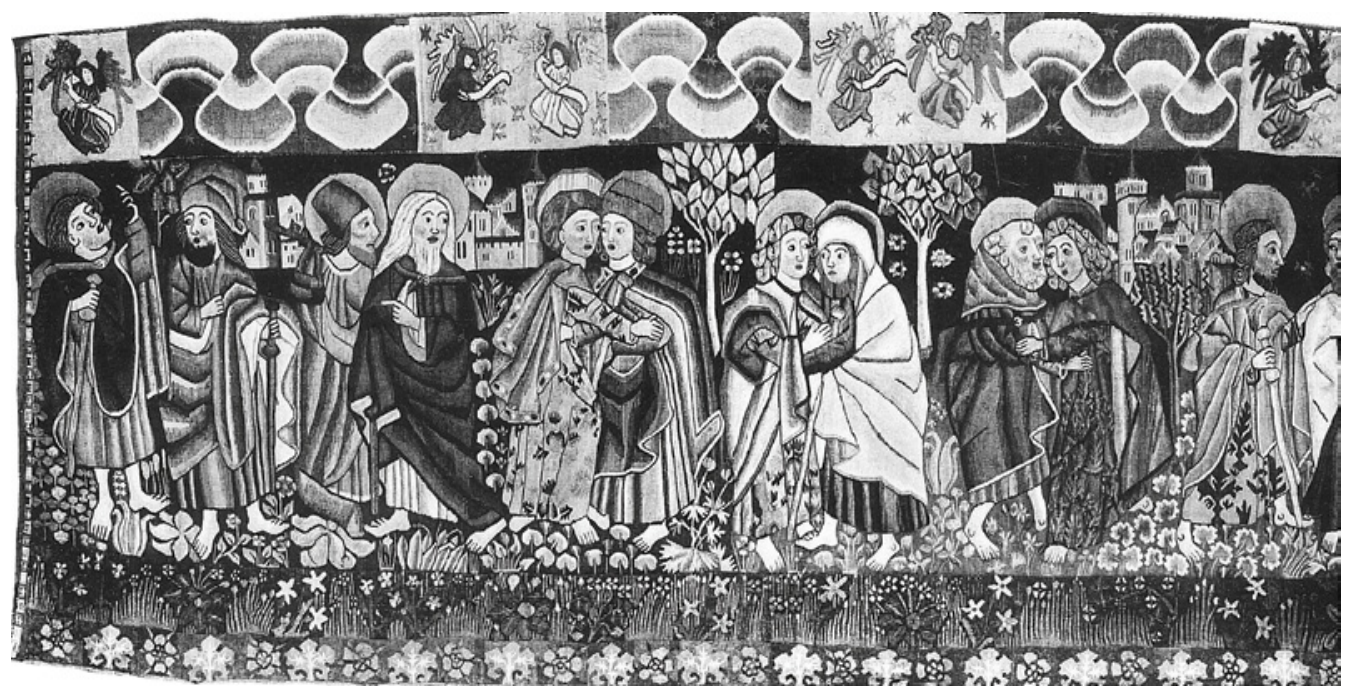

Abb. 9: Privatbesitz, Teppich mit Abschied der Apostel

der Folge im Verlauf des 17. Jahrhunderts eine zunehmende Individualisierung bei den Handwerkerdarstellungen bemerken.

I534/35 bezahlte Sigmund Held für zwei Bilder I Pfund I2 Pfennige, für ein Bild somit 2I Pfennige (I Pfund = 30 Pfennige); in der zweiten Hälfte des I6. Jahrhunderts sollte I Pfund für ein Bild üblich werden - ein moderater Lohn in Anbetracht der Tatsache, dass zu ungefähr derselben Zeit der unten genannte Stadtmaler Hieronymus Beheim für acht kolorierte Federzeichnungen 5 Gulden erhielt ( I Gulden = 8 Pfund I2 Pfennige). ${ }^{32}$ In der Regel erfolgte wie bei Held die Anweisung der Bezahlung anonym an „den Maler“. Nur bei Willibald Schlüsselfelder, Pfleger des Mendelschen Zwölfbrüderhauses von 1565 bis 1589, finden sich zwei namentliche Nennungen. Zum 23. Juni 1566 hielt er fest: adi ditto dem Schlencken maler von ainem brueder zu molen $25 d n$ (= 25 Pfennige) ${ }^{33}$ Es muss sich dabei um Michael Schlenk handeln, der für die Darstellung des bereits sechs Monate vorher am I2. Januar I566 verstorbenen Färbers Heinrich Huber mit etwas weniger als i Pfund entlohnt wurde (Abb. II). Warum die Bezahlung unter dem sonst üblichen Lohn blieb, erschließt sich nicht. Schlenk, der von 1549 bis I565 als Maler und Zöllner beim Vestner- bzw. Spittlertor fassbar ist, könnte noch I572 bis I574 die Imhoffs mit Kupferstichen versorgt und somit einen Kunsthandel betrieben haben. ${ }^{34}$ Das Handwerkerbild ist bis jetzt das einzige bekannte Zeugnis seiner Malerei und auch sein einziger Beitrag zu den Hausbüchern. Nach 1565 zog er als Soldat nach Italien, wo er in Genua I576 das letzte Mal erwähnt wird.

32 Siehe unten bei Anm. 40.

33 Zu Nürnberg, Stadtarchiv, D 9 Nr. A 90 s. SAuer, In das verordnete permente buch (zit. Anm. 2), S. I23, I27.

Zu diesem s. Nürnberger Künstlerlexikon (NKL), hrsg. von M. H. Grieb, München 2007, S. I336; hier werden die Nachweise für den Kunsthandel (Willibald Imhoff, Enkel und Erbe Willibald Pirckheimers (Quellen zur Geschichte und Kultur der Stadt Nürnberg 24), bearb. von H. PoHL, Nürnberg 1992, S. 205, 221, 225) mit einem Sohn von Michael Schlenk in Verbindung gebracht. 
Kurz darauf beschäftigte Willibald Schlüsselfelder den Maler Hieronymus Beheim († I578). ${ }^{35}$ Bei der Abrechnung von insgesamt sieben Brüderbildnissen wird er 1572 und 1573 namentlich genannt, zum Beispiel am 3. Januar 1573 anlässlich der Bezahlung für die Darstellung eines am 29. Oktober I572 verstorbenen Messerers: Adi 3. jenner Jeronimo Peham maler von Hans Prechtell ainem verstorbnen brueder einzumalen $\mathrm{I} l \mathrm{~b}$ $2 d n$ (= I Pfund 2 Pfennige; Abb. I2). ${ }^{36} \mathrm{Be}-$ heim nutzte die ganze Breite der Seite für die in Feder und Pinsel mit Wasser- und Deckfarben ausgeführte Miniatur. Die räumliche Gestaltung bleibt in fast allen seinen Handwerkerbildern gleich: Durch einen Steinbogen gewährt er Einblick in den Innenraum einer Werkstatt, wobei sich rechts oder links des Handwerkers ein Fenster mit einem Ausblick auf eine Landschaft öffnet. Offensichtlich war Beheim ein routinierter Maler, der einerseits großen Wert auf die Wiedergabe

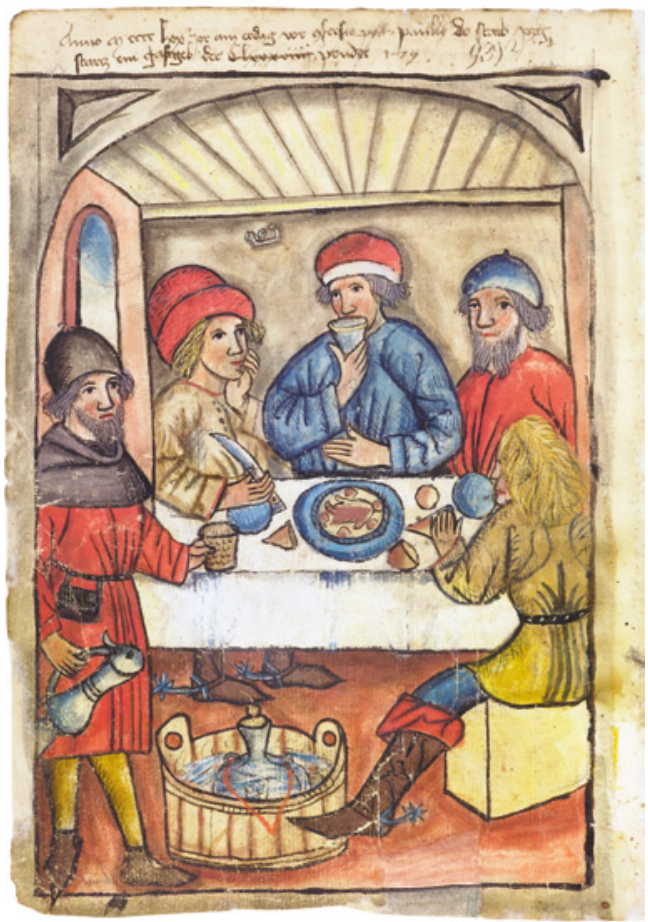

Abb. Io: Nürnberg, Stadtbibliothek, Amb. $317.2^{\circ}$, fol. $88 \mathrm{v}$ der handwerklichen Tätigkeiten legte, andererseits sich bei den Köpfen auf einige wenige, stereotyp wiederholte Formen beschränkte (Abb. 13). Auffallend sind die zuletzt mit schwarzer Feder in nervösem Strich aufgesetzten Konturen und Falten in den Gesichtern. Gerade bei Haupt- und Barthaar bevorzugte er eine typische gebogte Linie. 1576 engagierte Tobias Panzer, Ratsschreiber und Pfleger des Landauerschen Zwölfbrüderhauses von I563 bis I593, denselben Maler für ebenfalls sieben Bildnisse. Obwohl Hieronymus Beheim nicht namentlich genannt wird, erschließt sich die Identität aus dem in der Abrechnung verwendeten Titel „Stadtmaler“ und aus den stilistischen Übereinstimmungen der Bilder. Am 8. Dezember rechnete Tobias Panzer insgesamt 7 Gulden 2I Pfennige mit dem Maler ab, somit bei einem mit dem Mendelbuch identischen Stückpreis von I Pfund 3 Pfennigen: Adi 8. decembris 1576 dem statmaler bezalt alls der 7. nacheinander verstorbene bruder inns buch gemablt $7 l_{21} d n$ (Abb. I4) ${ }^{37}$ Beheim nutzte für diese auf Pergament ausgeführten Malereien dieselbe Technik und dasselbe Layout.

35 NKL (zit. Anm. 34), S. 98 f.; , Der Mahler Ordnung und Gebräuch in Nürnberg.' Die Nürnberger Maler(zunft)bücher ergänzt durch weitere Quellen, Genealogien und Viten des I6., I7. und I8. Jahrhunderts, hrsg. von A. TACKe, bearb. von H. Ludwig/A. Tacke/U. Timann, Berlin 200i, S. $356 \mathrm{f}$.

36 Zur Abrechnung in Nürnberg, Stadtarchiv, D 9 Nr. A 9r s. SAuer, In das verordnete permente buch (zit. Anm. 2), S. I23-I25, I28.

$37 \mathrm{Zu} \mathrm{Amb.} 279.2^{\circ}$, fol. 49v-52v und dem Rechnungsbeleg Nürnberg, Stadtarchiv, B 35 Nr. A 530 s. SAUER, In das verordnete permente buch (zit. Anm. 2), S. I23-I25, I30 f. 


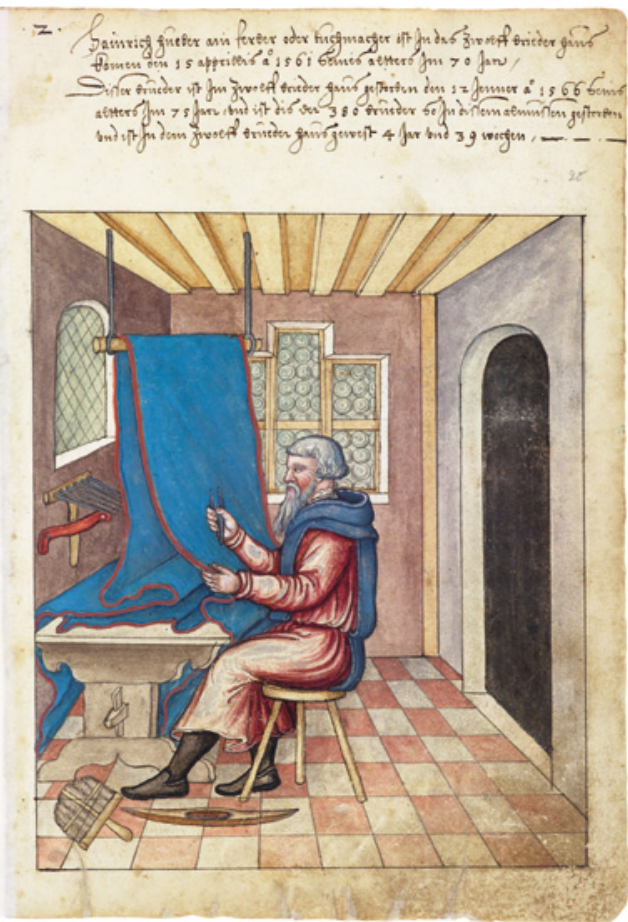

Abb. II: Nürnberg, Stadtbibliothek, Amb. 317b.2 $2^{\circ}$ fol. 2 or

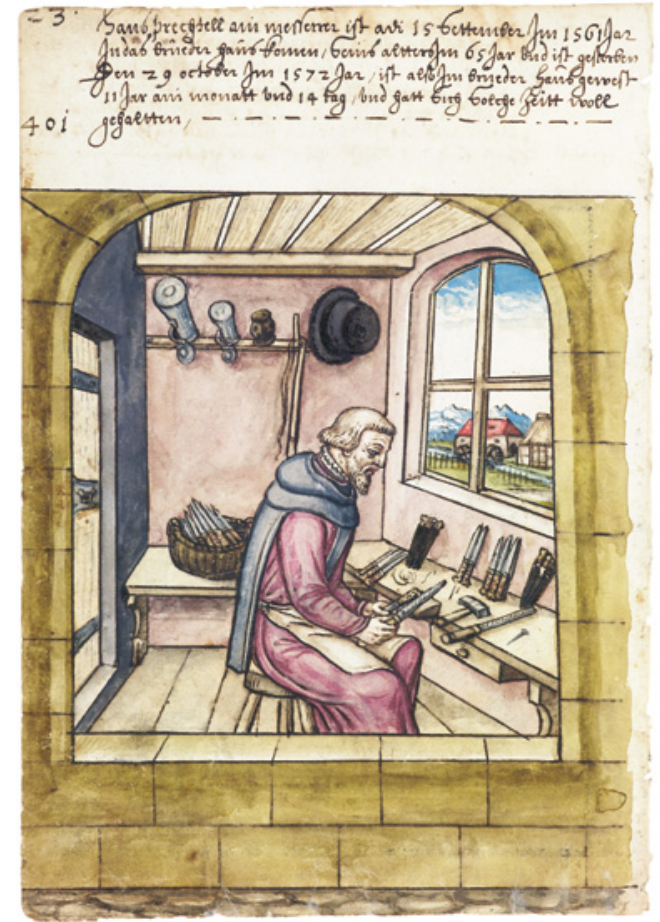

Abb. I2: Nürnberg, Stadtbibliothek, Amb. 317b.2 $2^{\circ}$ fol. 29v

Anscheinend war er für die Landauersche Stiftung aber schon seit den I540er-Jahren tätig, denn bereits aus dieser Zeit finden sich sehr ähnliche Darstellungen mit denselben eben genannten Eigenschaften. ${ }^{38}$

Hieronymus Beheim wird in Belegen aus den Jahren 1572/3 und 1576 als Stadtmaler bezeichnet. Dieses Amt trat er 1546 an und hatte es bis zu seinem Tod 1578 inne. Wie sein Vorgänger Georg Pencz († I550) nahm er die Funktion als ausgebildeter Flach- oder Tafelmaler ein. Gegen einen festen Jahreslohn verpflichtete er sich bei der Anstellung, dem Rat der Stadt Nürnberg in vielerlei Hinsicht zu Diensten zu stehen. Pencz hatte 1532 folgendes Versprechen festhalten lassen: das ich denselben meinen Herrn mit meiner Kunst zum Reissen, malen Visir zu machen und allem anndern das in meinem verstanndt ist vnndt sein wurdt als offt sy das an mich begern vor anndern, gegen zimlicher belonung gewertig sein vnnd dienen will. ${ }^{39}$ Auch Beheim wird also dem Rat mit allen seinen Fähigkeiten zu Diensten gestanden haben, insbesondere durch gezeichnete Entwürfe, Malereien und originalgroße Zeichnungen, die Auftraggebern als Vorstellung von einem in Auftrag gegebenen Objekt zur Approbation vorgelegt wurden. Dem Rat war er schon vor dieser Anstellung bekannt, denn in dessen Auftrag entstand von I533 bis 1536 das Haller-Buch, eine Prachthandschrift mit genealogischen

$38 \mathrm{Ab}$ fol. 28v in Nürnberg, Stadtbibliothek, Amb. 279.2 ${ }^{\circ}$ dürfte er immer wieder beteiligt gewesen sein.

39 G. Gmelin, Georg Pencz als Maler, in: Münchner Jahrbuch der Bildenden Kunst, 3. Folge, Bd. I7, I966, S. 49-126, bes. S. II8. 


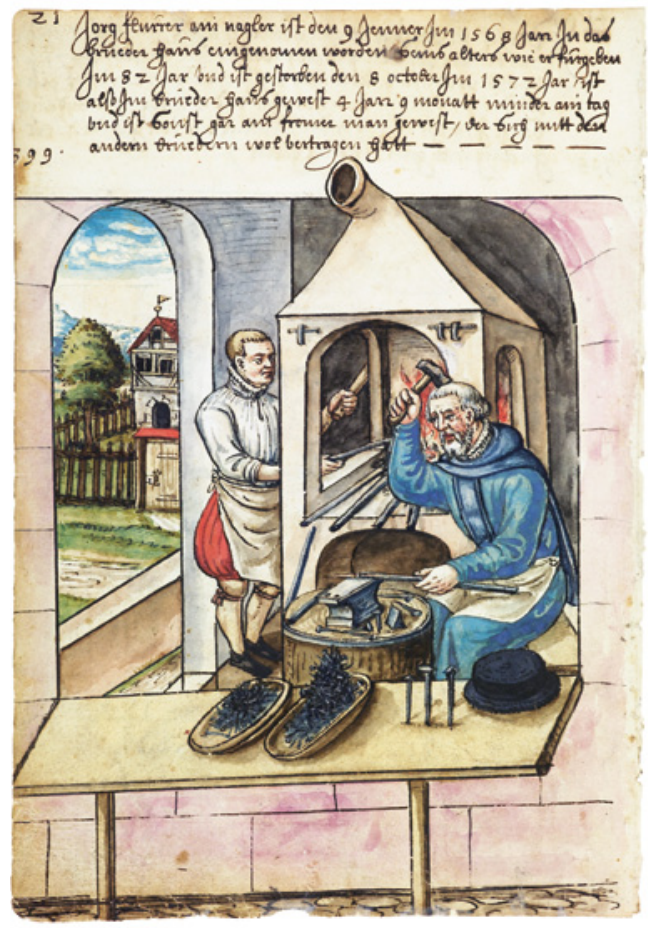

Abb. 13: Nürnberg, Stadtbibliothek, Amb. 317b.2 ${ }^{\circ}$, fol. 28v

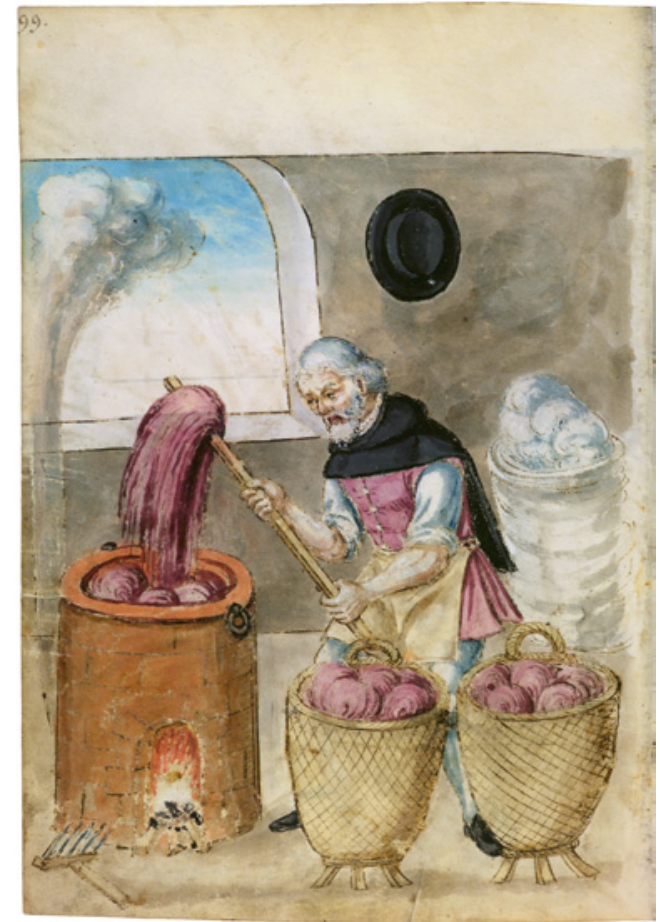

Abb. I4: Nürnberg, Stadtbibliothek, Amb. $279.2^{\circ}$, fol. 50v

Ausführungen zu den seit 1350 im Kleinen und Großen Rat vertretenen ratsfähigen und ehrbaren Geschlechtern. ${ }^{40}$ Die nach ihrem Autor Konrad IV. Haller (I464-I545) benannte Handschrift kostete den Rat insgesamt über 170 Gulden, davon entfielen auf die beteiligten Maler Erasmus Süß († 1583) Io6, Nicolaus Stör († 1562) 19, Hans Plattner († 1562) 2, Georg Pencz 3 und Hieronymus Beheim 5 Gulden. Bisher waren zum Anteil der einzelnen Künstler nur Spekulationen möglich; aufgrund der für Hieronymus Beheim gesicherten Brüderbilder in den Hausbüchern können ihm nun mindestens sieben der genealogischen Darstellungen und Wiedergaben von Familienepitaphien sowie der Abbildungen zu Topographie und Handwerkerbrauchtum zugeschrieben werden (Abb. I5). ${ }^{41}$ Eine dritte, künstlerisch anspruchslose Arbeit von der Hand Hieronymus Beheims datiert aus dem Jahr 1545. Die mit

40 Nürnberg, Staatsarchiv, Rst. Nürnberg, Handschriften 2II; s. dazu Gmelin, Georg Pencz (zit. Anm. 39), S. 82, IOI-IO4; A. GüMBEL, Georg Pencz und das Nürnberger Hallerbuch, in: Neue archivalische Beiträge zur Nürnberger Kunstgeschichte, Nürnberg 1919, S. 24-27; Norenberc - Nürnberg, I050-I806, bearb. von P. FLEISCHManN, München 2000, S. 30 Kat. 3 .

4I Neben Nürnberg, Staatsarchiv, Rst. Nürnberg, Handschriften 2II, fol. 3r, 47v, 48r, 246v, 30Ir möglicherweise auch die Falttafeln mit der Ansicht Nürnbergs und dem Gesellenstechen auf fol. 56 und 59. Zum selben Ergebnis war bereits H. RöTtinger, Erhard Schön und Niklas Stör, der Pseudo-Schön. Zwei Untersuchungen zur Geschichte des alten Nürnberger Holzschnittes (Studien zur deutschen Kunstgeschichte 229), Straßburg 1925, S. 226 gekommen, indem er die Kosten zur Anzahl der von einer Hand ausgeführten Malereien in Relation setzte. 


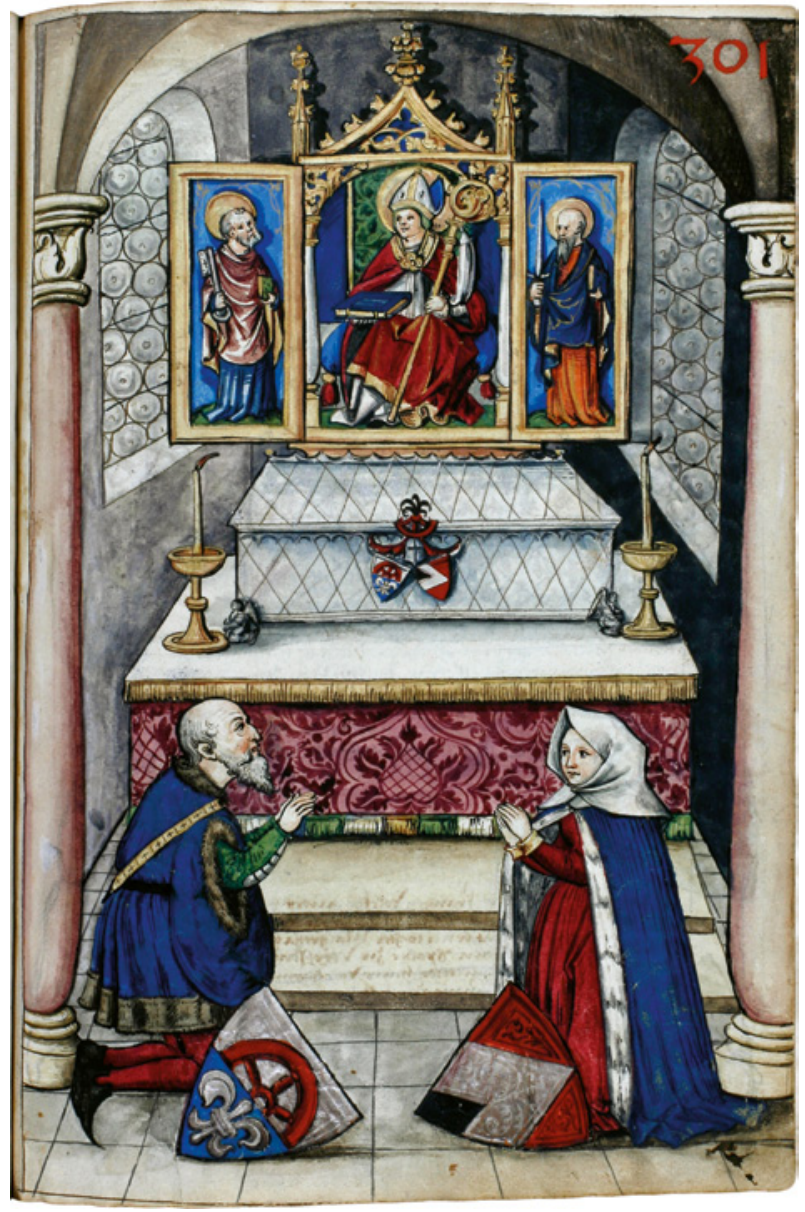

Abb. I5: Nürnberg, Staatsarchiv, Reichsstadt Nürnberg, Handschriften 2II, fol. 30Ir

dem Monogramm $I B$ signierte Karte diente der Dokumentation des Laufs der Pegnitz zwischen Malmsbach und Oberbürg und enthält keine figürlichen Elemente für einen Vergleich mit seinen sonstigen Malereien. ${ }^{42}$ Zur Konturierung der Baumkronen werden allerdings dieselben gebogten Linien eingesetzt, die auch in den Landschaften der Brüderbilder bzw. für die Einfassung von Haupt- und Barthaaren in allen seinen Miniaturen benutzt wurden.

Zwei an der Ausführung der Hausbücher beteiligte Maler können somit namentlich nachgewiesen werden. Beider Tätigkeit fällt in die Jahrzehnte, als mit der Illuministenfamilie Glockendon die Buchmaler als eigener Berufsstand ausstarben. Wie dann seit der Wende vom I5. zum I6. Jahrhundert öfter belegt und durch Michael Schlenk und Hieronymus Beheim nochmals bestätigt, übernahmen zu dieser Zeit ausgebildete Tafelmaler auch die in Büchern auszuführenden Malereien. Für Michael Schlenk erscheint charakteristisch, dass er sich nicht

42 Nürnberg, Staatsarchiv, Reichsstadt Nürnberg, Karten und Pläne Nr. 308; s. dazu P. Fleischmann, Die handgezeichneten Karten des Staatsarchivs Nürnberg bis I806 (Bayerische Archivinventare 49), München I998, Nr. I6. 
ausschließlich von der Kunst ernährte. Als Nebenerwerbe dienten die Ausübung des Zöllneramts und vielleicht der Kunsthandel; nach 1565, vermutlich aber in den siebziger Jahren gab der Maler alle diese Tätigkeiten auf und wurde Söldner. Möglicherweise sprechen diese Sachverhalte dafür, dass Schlenk kein besonders gefragter Maler war. Hieronymus Beheim hingegen empfahl sich den Pflegern wohl durch seine Funktion als Stadtmaler. An den Hausbüchern waren somit Künstler beteiligt, die heute eher für die Übernahme von Kleinaufträgen wie Karten und Buchmalereien bekannt sind als durch Wand- oder Tafelgemälde. Für sie werden oft Nebenerwerbstätigkeiten oder Ämter wie die Funktion eines Zöllners oder Stadtmalers genannt, die ihnen ein geregeltes Einkommen sicherten. Da weitere Namen von Buchmalern in den Abrechnungen des I6. Jahrhunderts zum Mendelschen und Landauerschen Stiftungshaus nicht genannt werden, ist die Beteiligung von Hieronymus Beheim am HallerBuch auch als Fingerzeig auf Objektgruppen zu werten, die in Zukunft zur Identifikation weiterer an den Hausbüchern beteiligter Künstler ausgewertet werden könnten: Gemeint ist die durchaus signifikante Zahl von bebilderten Chroniken und Geschlechterbüchern, deren Produktion auch im I6. Jahrhundert nicht abriss, bzw. von Bilderhandschriften zum Nürnberger Fastnachtsbrauchtum, dem Schembartlauf, und den Handwerkertänzen, deren Produktion nach 1539 einsetzte. ${ }^{43}$ Die Erforschung dieser Künstler steht zumindest in Nürnberg erst am Anfang; das Haller-Buch belegt, dass vor allem Flachmaler von diesen in durchaus namhaften Zahlen hergestellten, aber stark spezialisierten Nischenprodukten profitierten. Wenn tatsächlich Hieronymus Beheim kein Einzelfall ist und die Künstler der Hausbücher aus demselben Umfeld von Malern rekrutiert wurden, die auch Schembartbücher, Chroniken und Familienbücher ausführten, könnte eine wechselseitige Betrachtung zu einem besseren Verständnis der Entwicklung der Buchmalerei im I6. Jahrhundert beitragen.

\section{BUCHMALEREI IN VERWALTUNGSSCHRIFTGUT}

Die Hausbücher sind letztendlich Verwaltungsschriftgut. Wie die jährlich vorzulegenden Abrechnungen dienten sie dem Nachweis einer rechten Erfüllung des Stiftungszwecks, jedoch in einer besonders eigenwilligen und in keiner anderen Stiftung gefundenen Form. Mit den Handschriften wurde über die Abfolge der Pfleger und alle in ihrer Amtszeit gestorbenen bzw. ab I6oo die in ihrer Amtszeit eingetretenen Brüder Buch geführt. Originellerweise geschah dies nicht in Form von Listen, sondern in Wort und Bild. Wohl auch aufgrund dieses Verwendungszwecks können die Hausbücher als repräsentative Handschriften bezeichnet werden; eine Ausführung als Luxusprodukte war allerdings nicht angedacht. Erst als die Buchführung I596 im Landauerschen und I6I3 im Mendelschen Zwölfbrüderhaus umgestellt wurde und der Bildeintrag bereits zum Zeitpunkt des Eintritts in die Stiftung erfolgte, wurden die Handschriften zu einem Medium der Selbstdarstellung. Jetzt bestimmten die Handwerker, mit

43 Es fehlen bisher Untersuchungen zu den Herstellungsbedingungen dieser Handschriften in Nürnberg; einzig zu den Geschlechterbüchern liegen neue Forschungen vor: Н. Воск, Die Familiengeschichtsschreibung der Welser, in: Mitteilungen des Vereins für Geschichte der Stadt Nürnberg 95, 2008, S. 93-162; Ders., Bebilderte Geschlechterbücher, in: Bürgermacht \& Bücherpracht. Augsburger Ehren- und Familienbücher der Renaissance, hrsg. von C. EMMENDÖRfFER/H. ZäH, Luzern 20II, S. 57-65. 
welchen Attributen sie dargestellt werden wollten. Zum selben Zeitpunkt begannen die zahlungsfähigeren Pfleger, die angesagten Porträtmaler ihrer Epoche zu verpflichten, die für die Handwerker in keinem Fall in Anspruch genommen wurden.

Die besondere Art der Buchführung in den Hausbüchern, die bei sorgfältiger Pflichterfüllung dazu führte, dass in größeren zeitlichen Abständen ein oder zwei Bilder in Auftrag zu geben waren, resultierte in ständig wechselnden Auftragnehmern. Dem Anspruch der Handschriften und der damit verbundenen Bezahlung entsprechend waren an der Ausführung der Bilder eine Vielzahl unterschiedlicher und verschieden gut ausgebildeter Maler beteiligt, die häufig nicht viel Zeit oder Mühe auf die Malereien verwendeten und auf eine feine und detaillierte Pinselarbeit verzichteten. Gerade diese Vielfalt eröffnet aber auch die Möglichkeit, die Bilder als Belege für die Bandbreite der Produktion in einem bestimmten Zeitraum, für bewusste Abstufungen in der Qualität der Ausführung oder für die möglicherweise unterschiedliche Vorbildung der sich als Buchmaler betätigenden Künstler zu verstehen. Offensichtich wurden für die Hausbücher nicht nur Mitglieder professioneller Buchmalerateliers herangezogen, sondern möglicherweise auch Mitglieder aus Berufsgruppen anderer grafischer Gewerbe sowie Personen betraut, die im Umgang mit Farbe geübt, aber nicht für figürliche Darstellungen geschult waren. Um die Mitte des I6. Jahrhunderts übernahmen dann nachweislich ausgebildete Flach- oder Tafelmaler die Aufgabe, die Handwerkerbilder in die Bücher zu malen. Eine übergreifende Auswertung mit den im selben Zeitraum entstehenden Chroniken, Schembart- und Geschlechterbüchern könnte für alle genannten Gattungen zu neuen Erkenntnissen führen.

Stadtbibliothek Nürnberg, Handschriften und Alte Drucke

Abbildungsnachweis: Abb. I, 2, 5, 7, 8, IO, II, I2, I3, I4: Stadtbibliothek Nürnberg. - Abb. 3-4: Concordia Seminary Library, St. Louis, MO, USA. - Abb. 6: Erlangen, Graphische Sammlung der Universität. - Abb. 9: nach Kurth, Die deutschen Bildteppiche (zit. Anm. 23). - Abb. 15: Staatsarchiv Nürnberg. 


\section{VERZEICHNIS DER ERWÄHNTEN HANDSCHRIFTEN UND FRÜHEN DRUCKE}

Aachen, Domschatz

- Inv. Grimme Nr. 25: I2

Alba Iulia, Biblioteca Națională a României, Filiala

Batthyaneum

- Ms. II-3: 88, 90, 104, 88

Angers, Archives départementales de Maine et Loire - G7: 33

Ann Arbor (Michigan), University of Michigan, Special Collections Library

- MS 246: $227 \mathrm{f}$.

Antwerpen, Museum Mayer van den Bergh

- MS Inv. 607: 42

Arezzo, Biblioteca del Seminario Vescovile

- MS 75 (I. 19): 226-228

Arezzo, Museo Medioevale e Moderno

- MS I78I: 226-228

Assisi, Biblioteca Communale

- Ms. I-I5: 49

Augsburg, Diözesanmuseum St. Afra

- DMA IOO3 (vormals Hs. I5a): 23

Augsburg, Universitätsbibliothek

- Oettingen-Wallersteinsche Bibliothek, Cod. I.3.2 ${ }^{\circ}$

III: I50-I53, I57, I59, I62, I64 f., I67, I69, I53, I64

- Oettingen-Wallersteinsche Bibliothek, Cod. I.3.2 ${ }^{\circ}$

IV: I5O-I52, I58 f., I6I, I58, I59, I6I

Baltimore, Walters Art Museum

- MS W. 222: $78 \mathrm{f} ., 78$

- MS W. 759-762: 37

- MS W. 9I5: 37

Bamberg, Staatsbibliothek

- I Qa 30-I Qa 38: 174

- IX. A. 28: 60, 59

- Msc.Bibl.5: 47, 48

- Msc.Bibl.76: $2 \mathrm{I}$

- Msc.Bibl.I40: I2, I4, 2I, 23

- Msc.Can.I6: 64

- Msc.Can.19: 53

- Msc.Can.25: 6o f., 60

- Msc.Can.26: 64
- Msc.Can.46: 64

- Msc.Can.51: 63, 63

- Msc.Can.6o: 64, 64, 65

- Msc.Jur.Io: 60, 57, 58

- Msc.Jur.I9: 53, 52

Bergamo, Biblioteca Civica Angelo Mai

- Cassaf. I.2I: $129 \mathrm{f}$.

Berkeley (Kalifornien), University of California, Berkeley, Music Library

- fM2I49.V4G7: 240 f., $24 I$

- fM2150.V452: 240f., $24 I$

Berlin, Staatsbibliothek zu Berlin Preußischer Kulturbesitz (SBPK)

- Ms. germ. quart. 62I: $268 \mathrm{f}$.

- Ms. germ. quart. 204I: 245, 259, 262, $267 \mathrm{f}$.

Berlin, Staatliche Museen zu Berlin Preußischer Kulturbesitz, Kupferstichkabinett

- Ms. 78 B г6: 38,40

- Min. I250: I52

Besançon, Bibliothèque municipale

- Ms. 1360: 246, 249, 258, 262, $267 \mathrm{f}$.

Bologna, Archivio di Stato

- Registro memoriale, Ufficio dei memoriali 73: $53 \mathrm{f}$, 53

Bologna, Biblioteca Universitaria

- Cod. 346: 61, 62

Boulogne-sur-Mer, Bibliothèque municipale

- Ms. 86: I2I

Brügge (Brugge), Grootseminarie

- Hs. 54/100: 38

- Hs. 77/98: 33, 37

Brüssel (Brussel), Königliche Bibliothek (Bibliothèque royale/Koninklijke Bibliotheek)

- Ms. 65: 209 f., 208

- Ms. 136: 2I4

- Ms. I40: 140

- Ms. I48: 214

- Ms. I56-I57: 214

- Ms. I97: 207, 2II 
- Ms. 213: 203, 2II, 2I4, 218-220, 2I2, 219

- Ms. 218: 219

- Ms. 242-265: 2II, 2I4, 212

- Ms. 289: 2Iof.

- Ms. 310: 210, 209

- Ms. 3I2-320: 2II

- Ms. 356-379: 2II

- Ms. 472-479: 208f., 2II, 208

- Ms. II63: 219

- Ms. I208-I2IO: 2II

- Ms. $1787: 38$

- Ms. 2037-2048: $2 \mathrm{II}$

- Ms. 25I2: 38

- Ms. 9009-II: 219

- Ms. 9I2I-23: 219

- Ms. 9278-80: 219

- Ms. I0607: 42

- Ms. II 480: 206

- Ms. II 253I: 207

- Ms. II 58I9: 2II, 2I4, $2 I 2$

- Ms. IV 360: 220

- Ms. IV 860: 202, $2 \mathrm{II}$

- Ink. B 73: 2II

- Ink. B 572: 2II

- Ink. B I25I: 2II

Budapest, A Magyar Tudomanyos Akademia Könyvtära

- K 465: 26I, 269

Budapest, Országos Széchényi Könyvtár

- Cod. lat. 222: 98

- Ink. I0о: 84, 94, I00

Cambrai, Bibliothèque municipale

- Ms. 87: 42

- Ms. 99 (IOO): 38

Cambridge, Emmanuel College

- Ms. I. I.6: II7

Cambridge, The Fitzwilliam Museum

- Ms. McClean i36: 60

- Ms. 300: 29

Cambridge, Sidney Sussex College

- Ms. IOI: 53
Chantilly, Musée Condé

- Ms. 348 (alt 633): 245 f., 249-25I, 254-259, 262,

$267,269,253,256,258,262$

Chicago (Illinois), Chicago Art Institute

- Inv. I5. 555: 142

Colmar, Bibliothèque municipale (Bibliothèque de la Ville)

- Ms 305: 189-201, I90-193, I95, I96

- Ms. 49I (Nr. 459): 249, 255, 257, 259, 26I-263,

267,269

Darmstadt, Universitäts- und Landesbibliothek

- Hs. 266: 265

Den Haag, Koninklijke Bibliotheek

$-74 \mathrm{G}$ 3I: 38

$-78 \mathrm{D} 40: 33,36$

Dublin, Chester Beatty Library

- MS W. I07: 225f., 233, 238 f., 227, 235, 239

Durham (England), Chapter Library (Cathedral Library)

- Ms. C. I. 3: 58

- Ms. C. I. 6: 58

- Ms. C. I. 9: 58

Durham (North Carolina), Duke University, Special

Collections Library

- German MS i: i6if.

Erfurt, Universitätsbibliothek

- Cod. 96: 46

Erlangen, Graphische Sammlung der Universität

- B 26: 261, 269

Evanston (Illinois), Northwestern University Library, McCormick Library of Special Collections

- De Ricci I: 242

Florenz (Firenze), Biblioteca Medicea Laurenziana (BML)

- Ms. Conv. Soppr. 582: 47

- Ms. Edili. 86: 58

- Ms. Plut. I dex. I-I7: 50

- Ms. Plut. I sin. IO: $5 \mathrm{I}$

- Ms. Plut. III sin. 9: 50

- Ms. Plut. V sin. 2: 47, 50

Florenz (Firenze), Biblioteca Nazionale Centrale

- BR 397: I25-I47, I27-I29, I34, I40, I44 
- inv. vol. II. III. 317 (Magl. Cl. XIX, num. Iosbis): 245

- LF 22: I25-I47, I30, I35-I43, I46

Frankfurt, Universitätsbibliothek

- Ms. germ. qu. 15: 245, 249, 251, 255, 257, 259, 262, $267,269,254,257$

Gerona (Katalanien), Arxiu Capitular

- C. $52: 48$

Glasgow, Glasgow University Library

- Ms. Hunter 374: 129

Göttingen, Niedersächsische Staats- und Universitätsbibliothek

$-2^{\circ}$ Cod. Ms. philos. 63: 245-248, 252-255, $257 \mathrm{f}$., 260-262, 267, 269, 247, 255

$-2{ }^{\circ}$ Cod. Ms. philos. 64: 248, 257, 259f., 262, 267269

$-4^{\circ}$ Cod. Ms. philos. 64a: 245f., 248-250, 252, 254, 257 f., 26I, 265, 267, 269, 250

Göttweig, Stiftsbibliothek

- Cod. I rot: 277

- Ink. I47: 85, 88, 92, 90

Graz, Universitätsbibliothek

- Cod. 32: IIO

- Cod. 459: 83

- Ink. III 9505: 173

- Ink. IV 9704: 98

- Ink. II 9780: 98

Hamburg, Staats- und Universitätsbibliothek Carl von Ossietzky

- Cod 7 in scrin.: 197, 199

Heidelberg, Universitätsbibliothek

- Cod. Pal. germ. 19-23: 186-189

- Cod. Pal. germ. 23: I88f., I87

- Cod. Pal. germ. 300: 265

- Cod. Pal. germ. 362: 184, I86

- Cod. Pal. germ. 787: 259 f., 268 f., 262

- Cod. Pal. germ. 832: I54, I72, I75

Heiligenkreuz, Stiftsbibliothek

- Cod. Neukloster A 4: 88-90, IO2

- Cod. Neukloster A I3: 98

Herzogenburg, Stiftsbibliothek

- Cod. I2: 94, IOI

- Cod. 75: 94 f., 98
- Cod. 329: 94

- Ink. I09: 94

- Ink. I23: I23

Innsbruck, Tiroler Landesmuseum Ferdinandeum

-FB 32009: 262, 267, 269

Istanbul, Topkapi Sarayi Müzesi

- Cod. 77: 269

Karlsruhe, Badische Landesbibliothek

- Durlach II: 249, 255, 258f., 26I, 267, 269

- St. Peter perg. 92: 29

Klosterneuburg, Stiftsbibliothek

$-\mathrm{CCl}_{75}: 98$

- $\mathrm{CCl}$ 239: 96, 99

$-\mathrm{CCl} 305: 98$

$-\mathrm{CCl} 325: 96$

- $\mathrm{CCl}$ 604: 98

- CCl 6I2: 83f., 92, 96-I00

- $\mathrm{CCl}$ 958: 96

$-\mathrm{CCl}$ I028: 83

- $\mathrm{CCl}$ II92: 98

- CCl II93: 83

- $\mathrm{CCl}$ II95: 83

- Cod. typ. 29: 96

- Cod. typ. 30: 96

Köln, Historisches Archiv der Stadt

- Best. $7020\left[\mathrm{~W}^{*}\right]$ 232: 249, 257, 263-265, 267, 269 ,

264

Königseggwald, Schlossbibliothek

- Hs. XIX I7-3: 267

Kopenhagen (København), Kongelige Bibliotek

- Thott $2902^{\circ}: 259,262,267,269$

Krakau (Kraków), Biblioteka Jagiellońska

- I.R. I897: 232, 238-240, 236

- I.R. I900: 232 f., 239 f., 234

Kremsmünster, Stiftsbibliothek

- Ink. $2^{\circ} \mathrm{Kb} 49: 83$

- Ink. $2^{\circ}$ a: $169 \mathrm{f}$.

Lille, Bibliothèque municipale

- Ms. 607 (92): 38, 39

Linz, Katholisch-theologische Privatuniversität

- ehem. Linz, Oberösterreichische Landesbibliothek, Cod. I54: I57-I6I, I64, I49, I50, I5I, I54, I56, I57 
Linz, Oberösterreichische Landesbibliothek

- Cod. II6: I55

- Cod. I54 s. Linz, Katholisch-theologische Privatuniversität

Linz, Oberösterreichisches Landesmuseum

- Inv. Nr. I89-I906 Ms. I: 98

Ljubljana, Narodna in Univerzitetna Knjižnica (Slowenische National- und Universitätsbibliothek)

- Ti ro885: 173

London, British Library

- Add. II863: 203, 21I, 220

- Add. II864: 203, 2II

- Add. I644I: 44

- Add. I7006: 34, 38

- Egerton 945: 42, 42

- Egerton I895: I52 f., I65, I67

- Egerton I896: I67

London, Victoria \& Albert Museum

- Museum No. 276.4-17: 89

- Museum No. 276.9: 90

Los Angeles, The J. Paul Getty Museum

- Ms. 33: 155

- Ms. Ludwig XII 8: $260 f$.

- Ms. Ludwig XV 9: 198 f., 198

Madrid, Biblioteca Nacional

-Ms. Vitr. 2I-4: 46

Madrid, Real Biblioteca de San Lorenzo de El Escorial

- Ms. A. I. 5: 46

- Ms. Y. II. 2I: 245

Mailand (Milano), Bibliotheca Ambrosiana

- Ms. A 79 inf.: 123

Mailand (Milano), Biblioteca Trivulziana

- Cod. 2262: I29f., I33

Maribor, Škofijski arhiv

- R II5: 173

- R I45: 173

Melbourne, National Gallery of Victoria

- Felton 1254/3: 42

Melk, Stiftsbibliothek

- P 129: 98

- P 586: 98
- P 976: I69

Modena, Biblioteca Estense

- Ms. 842: I4I

Moskau, Staatsbibliothek

- F 205: 89

Moskau, Staatliches Historisches Museum

- Mus. 3197-a: 232, 238-240, 237

München, Bayerische Staatsbibliothek

- Cgm 7I: I66

- Cgm 356: 257 f., 269

- Cgm 725I: I76

- Cgm 8oioa: I53, I58f., I62 f., I70, I75

- Clm 5: 62

- Clm 4452: IO-I5, I0, I7f.

- Clm 4453: I2 f., 20

- Clm 6346: $64 \mathrm{f}$.

- Clm 6347: 56-58, 63, 55, 56

- Clm izoro: 166

- Clm I3022: I62 f., I66

- Clm I4004: I62

- Clm I4045: I54

- Clm I5708-I2: I52, I56, I59-I64, I72, I60

- Clm I5709: 159, I63

- Clm I5712: I52, I62

- Clm 23032: I55

- Clm 23024: I55

- Clm 23338: 23

- Clm 30150: 257, 259f., 262, 267-269

- Clm 30205: 228, 23I

- Cod. hebr. 200: IOI-IO3

- Cod. icon. 242: 252

-2 Inc. c.a. $26 \mathrm{~m}: 169$

-2 Inc. c.a. 30 a: I69 f., $I 70$

- 2 Inc. c.a. 34I: I69, I7I

- 2 Inc. c.a. $440: 169$

-2 Inc. c.a. 644 c: 169

-2 Inc. c.a. 927: 172

- 2 Inc. c.a. 1203 a: 173

-2 Inc. c.a. 2377 b: $173-175$

-2 Inc. c.a. 2523 x: 173

-2 Inc. c.a. $32 \mathrm{I} 5 \mathrm{i}:$ I73

-2 Inc. c.a. 3902: 174 
- 4 L.impr.membr. 7: 173

München, Bayerisches Hauptstaatsarchiv

- DK Regensburg 443: 155

München, Bayerisches Nationalmuseum

- Bibl. 2502: I88 f., I88

München, Staatliche Graphische Sammlung

- Inv. Nr. 18847 Z: 89

- Inv. Nr. 40I40: 229 f., $23 I$

- Inv. Nr. 40198: 228-230, 229

New York, Columbia University, Rare Books Library

- Plimpton MS $4 \mathrm{OH}(\mathrm{I}-8): 228$

New York, Metropolitan Museum of Art, The Cloisters Collection

- Acc. No. 54. I. 2 (Stundenbuch der Jeanne

d'Evreux): III

- Acc. No. 58.7Ia, b: 78

- Acc. No. 54. I. I: I25

New York, New York Public Library

- MA I3: 90

- Spencer Ms. 56:29, 29

- Spencer Ms. 58: 249, 257, 259, 263, 265, 267, 269

- Spencer Ms. I04: 245, 257, 259 f., 262 f., 266 f., $268 \mathrm{f}$.

New York, The Pierpont Morgan Library

- M. 436: 54

- M. 713: 105

-M. 729: 42

- M. I042: 30, 4I

Nürnberg, Germanisches Nationalmuseum

- Hs. 3227a: 253

Nürnberg, Staatsarchiv

- Reichsstadt Nürnberg, Handschriften 2II: 284f.,

286

- Reichsstadt Nürnberg, Karten und Pläne Nr. 308:

$285 \mathrm{f}$.

Nürnberg, Stadtarchiv

- B 35 Nr. A 530: 283

- D 9 Nr. A 89: 28I

- D 9 Nr. A 90: 282

- D 9 Nr. A 91: 283

Nürnberg, Stadtbibliothek

- Amb. 279.2 ${ }^{\circ}: 27 \mathrm{I}-288,275,285$
- Amb. 279b. $2^{\circ}: 27 \mathrm{I}-288$

-Amb. $317.2^{\circ}: 27 \mathrm{I}-288,278,280,283$

- Amb. 3I7b. $2^{\circ}: 27 \mathrm{I}-288,284,285$

-Amb. 318.2 ${ }^{\circ}: 27 \mathrm{I}-288$

- Ink. $23.2^{\circ}:$ I69, I7I

- Ink. $252.2^{\circ}:$ I69, I7I

- Ink. $505.2^{\circ}: 87$

- Ink. 594.2 ${ }^{\circ}:$ I69, I7I

- Med. 3I.2 ${ }^{\circ}: 28 \mathrm{I}$

Oxford, Balliol College

- Ms. 2: 56

Oxford, Bodleian Library

- Ms. Canon. Bibl. lat. 56: 47, 50

- Ms. Douce II8: 42

- Ms. Lat. th. b. 4: 47 f., 50

Padua, Biblioteca Antoniana

- Ms. 51: 47

Padua, Biblioteca Capitolare

- Ms. A I4-I6: 5I

- Ms. B. I4-I6: 5I

- Ms. C 47: 37

- Ms. D 34: 37

Padua, Biblioteca del Seminario

- Ms. 353: 42

Paris, Bibliothèque de l'Arsenal

- Ms. 507: 2II

- Ms. 540: 2 II

- Ms. 3142: 30

- Ms. 6329: 42

Paris, Bibliothèque Mazarine

- Ms. 473: 78

- Ms. 562: 2II

- Ms. 724: 209

- Ms. 766: 58

- Ms. I773: 2II

Paris, Bibliothèque nationale de France

- allemand I06: 26I

- fr. 1589: 30, 3I

- fr. $1633: 30-32,31$

- fr. I2400: $42-44,43$

- lat. I8: 58, 6I

- lat. 22: 46, 62, 46 
- lat. $375: 32$

- lat. 503: 122

- lat. 757: I26, I3If.

- lat. $947: 59$

- lat. I023: 29

- lat. 3323: 29

- lat. 5185 CC: 35

- lat. 5690: 117

- lat. 8504: 30,30

- lat. I0435: 42

- lat. I0525: 29

- lat. 15619: I2I

- lat. 17873: 245, 257, 262, 269

- lat. I80I4: I25

- nouv. acq. lat. 3093: I25, I43

- nouv. acq. lat. 3189: $48 \mathrm{f}$.

- nouv. acq. fr. 5243: 132

- nouv. acq. fr. I625I: 42

- nouv. acq. fr. 2454I: II3 f., IIS

- Smith-Lesouëf 2I: 61, 62

- Smith Lesouëf 22: 132, I43

Paris, Bibliothèque Sainte-Geneviève

- Ms. 782: 29

- Ms. II77: 46

- Ms. I273: 4I

Paris, Centre historique des Archives nationales

- J 950, no I2: 69

- J 950, no I3: 66-79

- J 950, no I4: 66-79

- J 950, no 15: 69

Passau, Staatliche Bibliothek

- Ink. 25: I69, I7I

- Ink. 26: 85, 91 f., 95 f., I00, 99

- Ink. 28: 84f., 96, 102

- Mst. 2: IO2

Pesaro, Biblioteca Oliveriana

- Ms. 1336: 48

Philadelphia, Free Library, Rare Book Collection

- MS Lewis E-M 70:5-8: 230f., 23I, 232

Philadelphia, Philadelphia Museum of Art, The Philip S. Collins Collection

- acc. no. 46-65-2: 219
Poitiers, Bibliothèque municipale

- MS 30: 79

Prag (Praha), Knihovna Národní muzeum

- Ms. XIII A I2: I26, I32

Prag (Praha), Národní knihovna České republiky

- XXIII.C.I20: 33, 33

Privatbesitz

- Burdett Psalter-Hours: 32, 33

- ehem. Antiquariat Dr. J. Günther, A Selection of

Manuscripts and Miniatures. Hamburg/London

2003, Nr. 15 , vordem Donaueschingen, Hofbiblio-

thek, Cod. 860: 262, 269

- ehem. Antiquariat H. Tenschert, Katalog XXV,

I990, Nr. 2I: 257, 262, 267 f., 270

Regensburg, Bischöfliche Zentralbibliothek, Alte Ka-

pelle

- Inc. I80I: 172

- Inc. 1857: 173

- Inc. I980: 174

- Inc. 200I: I73

Regensburg, Staatliche Bibliothek

-2 Inc. 254: 172

- 2 Inc. 274: 173

- 2 Inc. 304: 169

- 2 Rat. ep. 363a: 172

Rom, Archivio di Stato

- Reg. 3193: 123

Rom, Biblioteca Casanatense

- Ms. 459: 130

Rom, S. Croce in Gerusalemme

- Cor. D: I2I

Saint-Omer, Bibliothèque d'agglomération

- Ms. I74: 32, 32

Salzburg, Universitätsbibliothek

- Ink. W II IIо: I73

- Ink. W III 36: 92

- Ink. W III 38: 92

- Ink. W III 283: I73-I75, I74

- Ms. M II I80: 265

Schweinfurt, Bibliothek Otto Schäfer

- OS I033: 264, 264 
St. Florian, Stiftsbibliothek

- Cod. XI/385: IOI

- Ink. X/6: I7If., I72

- Ink. X/IO7: $83 \mathrm{f}$

- Ink. X/282: 83 f., 89

- Ink. X/289: 83f., 89, 92

- Ink. X/I32A: 172

St. Gallen, Kantonsbibliothek Vadiana

- Ms. 343c: 199

St. Louis (Missouri), Concordia Seminary Library

- Medizinisch-Astrologisches Hausbuch: 275 f., 276,

277

St. Paul im Lavanttal, Stiftsbibliothek

- Cod. 376-4: 167, 172, 166

St. Pölten, Diözesanbibliothek

- Cod. r: 82 f., 88, 92, 95 f., 82, 84, 86, 87

- Cod. I05: 98

- Ink. II2: 96, IOI

- Ink. 274: IOI

- Ink. 293: 293

- Ink. 295: IOI

- Ink. 296: IOI

- Ink. 305: 96, I0I

- Ink. 309: IOI

Stockholm, Kungliga biblioteket

- Vu I6: 44

Straßburg, Bibliothèque Nationale et Universitaire

- Ms. 2259: 249, 255, 259, 260, 262, 267 f., 270

Stuttgart, Württembergische Landesbibliothek

- Cod. brev. 91: 160, I63-165, I63

- Cod. poet. et phil. $2^{\circ}$ : 199, 201

- Cod. theol. et phil. $2^{\circ}$ IOO: 155

Thurgau, Kantonsbibliothek

- Ink. X.ooII2: I7If.

Toledo, Archivo de la Catedral

- Ms. 56. 19: 33

- Ms. Res. 25: 48, 54, 54

Tournai, Bibliothèque de la Cathédrale de Tournai - A I7: 42

Tours, Bibliothèque municipale

- Ms. I023: 33, 35
Turin, Biblioteca Nazionale

- K.IV. 29 (verbrannt): 125, I43

Turin, Museo Civico d'Arte Antica

- Ms. 47: I25

Valenciennes, Bibliothèque municipale

- Ms. 838: 37

Vatikanstadt (Città del Vaticano), Biblioteca Apostolica Vaticana

- Archivio di San Pietro, B. 78: II7f., I20 f., I24, II9

- Archivio di San Pietro, C. I29: I05-I24, I06, 108,

II2, II6

- Barb. lat. 613: 145

- Pal. lat. I888: 245 f., 249, 25I, 258 f., 262, 267, 269,

266

- Pal. lat. I889: 257, 259 f., 262, 267-269

- Pal. lat. 1986: 249, 255, 257 f., 262, 267, 270

- Pal. lat. 1994: 245 f., 249, 25I, 255, 257 f., 26I-263,

267,270

- Ross. II95: 224-229, 238-24I, 244, 224, 225, 230, 243

- Vat. lat. I7: $56 \mathrm{f}$.

- Vat. lat. II55: 122

- Vat. lat. 1370: 265

- Vat. lat. I375: 47

- Vat. lat. 4933: I2O, I20

- Vat. lat. 7793: I22

- Vat. lat. 13674: I24

Venedig (Venezia), Abbazia di San Giorgio Maggiore

- Kyriale K: 222, 222

Venedig (Venezia), Archivio di Stato di Venezia

- Busta N. 2, Inventario I515: 230

Venedig (Venezia), Archivio Storico Patriarcato

- Chorbücher für die Kirche San Raffaele Archangelo: $242-244,242,243$

Venedig (Venezia), Biblioteca Nazionale Marciana

- MS Lat. I, 99: 219

- MS Lat. III, I8 (=2283): 22I f., 223

- MS Z 4 (=I538-I539): 56

Verona, Biblioteca Capitolare

- CXCIV: 34

Weimar, Herzogin Anna Amalia Bibliothek

- Cod. Fol. 328: 246, 249, 251, 255, 257 f., 262, 267, 269, 252 
Wien, Dominikanerbibliothek

- Cod. 33/33: 98

- Cod. I22/89: 98

- Cod. I48/II8: 98

- Cod. 4I5/2I2: 98

- Cod. 416/213: 98

- Inc. W 55: 98

- Inc. W I29: 98

- Inc. W I94: 98

Wien, Kunsthistorisches Museum

- KK 5342A: 249, 258, 262, 267, 270

- KK 5342B: 267

- KK 6562A: 246, 270

- KK 6562B: 245, 270

Wien, Österreichische Nationalbibliothek

$(\mathrm{Cod} .=\mathrm{CVP})$

- Cod. 1389: 62

- Cod. 1946: 83

- Cod. 257I: $5 \mathrm{I}$

- Cod. 2759-2764

- Cod. 2914: I84, I85

- Cod. 3009: $264 \mathrm{f}$.

- Cod. 3062: 245, 257 f., 262, 267 f., 270, 259

- Cod. 3064: 263

- Cod. 3068: 245, 257, 259 f., 262 f., 267, 270, 260

- Cod. 3069: 246, 268, 270

- Cod. 3743: I66f., I72, I65

- Cod. 4575: 93

- Cod. 4632: 93

- Cod. 5278: 249, 25I, 255, 259f., 262, 265, 267 f., 270,263

- Cod. 5518: 257, 259 f., 262, 267, 270

- Cod. Ser. nov. 12694: 204

- Cod. Ser. nov. I2704-I27IO: 2II

- Cod. Ser. nov. 12706: 203, 214-217, 212, 213, 215

- Cod. Ser. nov. 12707: 203, 215f.

- Cod. Ser. nov. I2708: 203, 206, 2IIf., 216f., 216

- Cod. Ser. nov. I2709: 203, 206, 216-217, 217

- Cod. Ser. nov. I2710: 216

- Cod. Ser. nov. I277I: 38

- Cod. Ser. nov. I2800: $2 \mathrm{II}$

- Cod. Ser. nov. I28II: 2II, 2 I4
- Cod. Ser. nov. I28I2: 2II

- Cod. Ser. nov. I28I4: 2II

- Cod. Ser. nov. i28r9: 72 f., 77

- Cod. Ser. nov. I2853: 2 II

- Cod. Ser. nov. I2890: 2 II

- Cod. Ser. nov. I2908: 213

- Ink. I.F.39: 2I4

- Ink. 2.A.2: 98

- Ink. 2.C.2: 84f., 92, 94, $96 \mathrm{f}$.

- Ink. 2.E.4: 83

- Ink. 4.B.I3: 98

- Ink. 4.F.36: 2II

- Ink. 4.G.7: 83

- Ink. 5.B.8: 98

- Ink. 5.F.4: 98

- Ink. 5.F.34: 98

- Ink. 6.A.I4: 84, 92, 94, I00, 90, 9I

- Ink. 6.D.7: 98

- Ink. 6.F.24: 98

- Ink. 6.G.8: 98

- Ink. Iо.A.20: 84 f., 92, 96, 103

- Ink. Io.G.22: 94

- Ink. II.A.24: 98

- Ink. II.E.I2: IOI

- Ink. II.H.24: 94, IOI

- Ink. I5.A.9: 98

- Ink. I5.A.IO: 98

- Ink. I6.A.23: 84, 92, 94

- Ink. I7.D.I5: 84, 94

- Ink. I8.A.I3: 83 f., 92 f., 94, 96, I00, 92, 95

- Ink. 2.E.4: 94, 97

- Ink. 25.C.23: 83

- Ink. 25.D.5: 83

- Ink. 26.B.I: 98

- Ink. 26.C.6: 98

- Ink. 29-20: 169

Wiesbaden, Hessische Landesbibliothek

- Hs 66: 197-200, 197, 199

Wilhering, Stiftsbibliothek

- Ink. 24I: I69

Wolfenbüttel, Herzog-August-Bibliothek

- Cod. Guelf. 29.I4 Aug. 4: 26I 
- Cod. Guelf. I6I Blank.: 25I f., 257, 258f., 262, 267, 269

Zürich, Zentralbibliothek

\section{ANDERE WERKE}

Avignon, Cathédrale Notre-Dame des Doms

- Simone Martini, Fresko des Hl. Georg (verloren):

$\mathrm{I} 23$

Erlangen, Graphische Sammlung der Universität

- B 6o (Zeichnung): 278, 279

Florenz (Firenze), Galleria degli Uffizi

- Giotto, Ognissanti-Madonna: II4

Hamburg, Kunsthalle

- Inv. Nr. 10499 (Einblattdruck): 279

New York, Frick Collection

- Duccio, Versuchung Christi: II3, II4

Nürnberg, Staatsarchiv

- Reichsstadt Nürnberg, Karten und Pläne Nr. 308: 286

Padua

- Arenakapelle (Cappella degli Scrovegni): 5I, III
- C 5: I83 f., I86, 184

Zwettl, Stiftsbibliothek

- Cod. typ. I/Ir: 89, 104
Paris, Louvre

- Simone Martini, Kreuztragung: II2 f.

Paris, Musée des Arts et Traditions

- ico. 77.2. I (Schriftamulett): 68

Privatbesitz

- Teppich mit Abschied der Apostel: 278, 282

Rom, St. Peter

- Giotto, Navicella: I07, III, II4f., I23

Siena, Museo dell'Opera del Duomo

- Duccio, Einzug in Jerusalem: II2 f., II3

Siena, Palazzo Pubblico

- Simone Martini, Maestà: Io9f., II2, III

Vatikanstadt (Città del Vaticano), Pinacoteca Vaticana

- Giotto, Stefaneschi-Altar: I07-I09, II4 f., I07, II8

\section{VERZEICHNIS DER GEKÜRZT ZITIERTEN BIBLIOTHEKEN}

BAV Vatikanstadt (Città del Vaticano), Biblioteca Apostolica Vaticana

BL London, The British Library

$\mathrm{BnF} \quad$ Paris, Bibliothèque nationale de France

BSB München, Bayerische Staatsbibliothek

BML Florenz (Firenze), Biblioteca Medicea Laurenziana

HAB Wolfenbüttel, Herzog-August-Bibliothek

SBPK Berlin, Staatsbibliothek zu Berlin Preußischer Kulturbesitz

SUB Göttingen, Niedersächsische Staats- und Universitätsbibliothek

WLB Stuttgart, Württembergische Landesbibliothek 


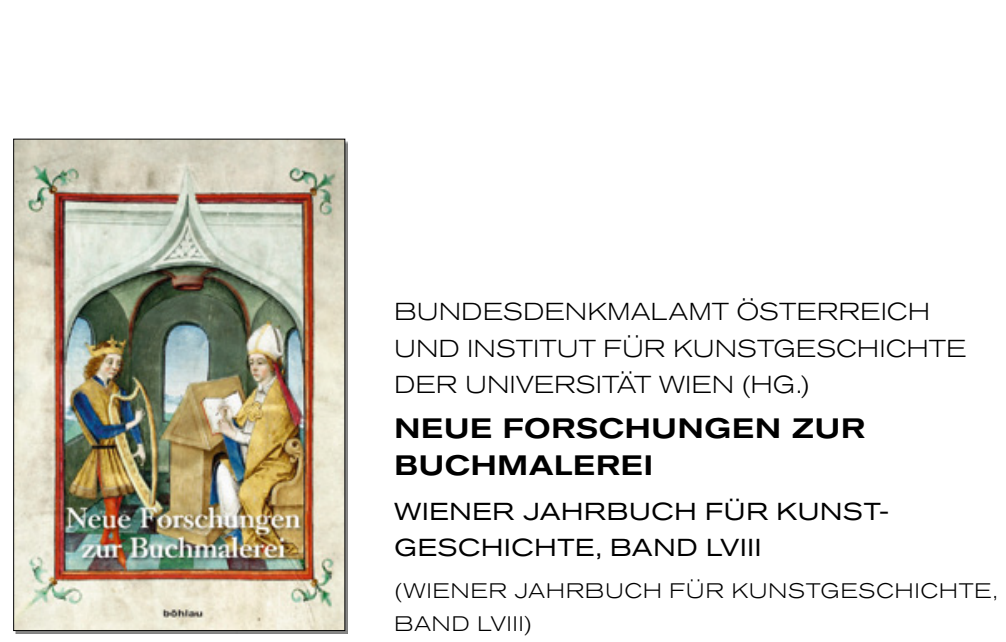

Der neue Band des Wiener Jahrbuchs für Kunstgeschichte ist der mittelalterlichen und Renaissance-Buchmalerei gewidmet. In den ersten drei Beiträgen, die sich mit der Ausstattung von Handschriften befassen, geht es um religiöse Diagramme, die Medialität von ausgemalten Büchern und hochrangige Bildvorlagen für Stundenbücher. Darüber hinaus enthält der Band neun Beiträge, die aus einem internationalen Kolloquium über Buchmalerei in Inkunabeln hervorgegangen sind und Einblick in die kunstgeschichtlichen Aspekte des zentralen Medienwechsels vom geschriebenen zum gedruckten Buch gewähren. Der Band repräsentiert damit wesentliche Perspektiven moderner Buchmalereiforschung - ihre Herausforderungen ebenso wie ihre methodische und thematische Vielfalt.

2010. 273 S. 195 FARB. ABB. GB. 185 × 260 MM. I ISBN 978-3-205-78476-O

BÖHLAU VERLAG, WIESINGERSTRASSE I, A-IOIO WIEN, T: + 43 I 33024 27-O INFO@BOEHLAU-VERLAG.COM, WWW.BOEHLAU-VERLAG.COM | WIEN KÖLN WEIMAR 


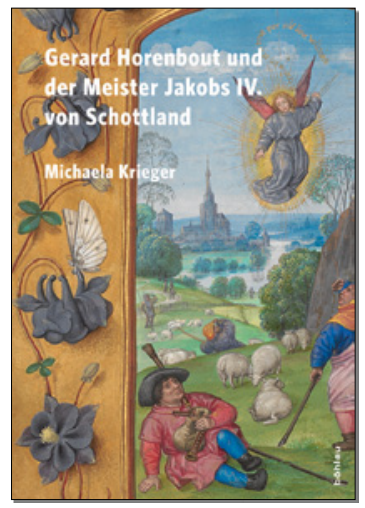

MICHAELA KRIEGER

GERARD HORENBOUT UND DER MEISTER JAKOBS IV. VON SCHOTTLAND

STILKRITISCHE ÜBERLEGUNGEN ZUR FLÄMISCHEN BUCHMALEREI

Die Miniaturen, die dem Anonymus mit dem Notnamen Meister Jakobs IV. von Schottland und/oder dem gut dokumentierten Künstler Gerard Horenbout zugeschrieben werden, gehören zu den faszinierendsten Beispielen flämischer Buchmalerei um 1500. Die genaue stilkritische Analyse, deren Möglichkeiten und Grenzen im vorliegenden Buch ausgelotet werden, führt Leser und Betrachter in das zentrale Problem der Gestaltung der dreidimensionalen Wirklichkeit ein. Zugleich wird ein Eindruck von der Arbeitsweise des Buchmalers und von den Entwicklungsprozessen vermittelt, denen er und seine Mitarbeiter unterworfen waren. Zahlreiche Abbildungen unterstützen die Argumentation. Darüber hinaus bieten sie einen visuellen Zugang zur überaus reichen flämischen Handschriftenproduktion dieser auch für die Ausbildung unserer heutigen Sehgewohnheiten wichtigen Zeit.

2012. 597 S. 234 S/W- UND 24 FARB. ABB. GB. $185 \times 260$ MM.

ISBN 978-3-205-78726-6

BÖHLAU VERLAG, WIESINGERSTRASSE I, A-IOIO WIEN, T: + 43 I 33024 27-O INFO@BOEHLAU-VERLAG.COM, WWW.BOEHLAU-VERLAG.COM | WIEN KÖLN WEIMAR 


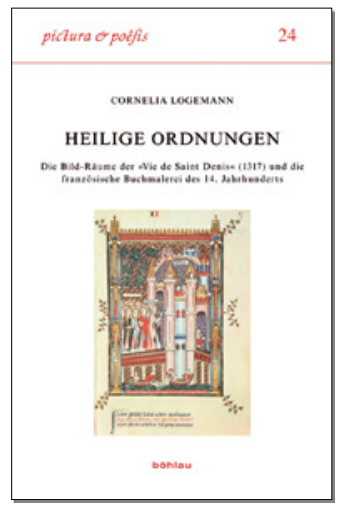

\section{CORNELIA LOGEMANN}

\section{HEILIGE ORDNUNGEN}

DIE BILD-RÄUME DER „VIE DE SAINT DENIS“ (1317) UND DIE FRANZÖSISCHE BUCHMALEREI DES 14. JAHRHUNDERTS

(PICTURA ET POESIS, BAND 24)

Noch heute wird die Vorstellung und Bewertung von Raum in der Geschichte der Malerei häufig von Kategorien neuzeitlicher (zentral-)perspektivischer Darstellung dominiert. Dagegen will dieses Buch am Beispiel der französischen Buchmalerei des Spätmittelalters zeigen, dass vor und parallel zur „Entdeckung der Perspektive“ zwischen Giotto und Brunelleschi noch ganz andere, nicht weniger komplexe und bedeutungshaltige Bild-Räume errichtet wurden. Ausgehend von der berühmten Bilderhandschrift „Vie de Saint Denis“ von 1317 - und unter Einbeziehung zeitgenössischer, teils unpublizierter Schriftquellen - werden so der Seh- und Verstehenshorizont des französischen 14. Jahrhunderts und spezifisch mittelalterliche Raumkonzepte aufgezeigt Die Spannweite reicht dabei von Stadt-Topographien über „raumhaltige“ Meditationsanweisungen bis hin zu diagrammatischen Ordnungen des Kosmos.

2009. 511 S. 180 S/W-ABB. 16 FARB. ABB. AUF 16 TAF. GB. $178 \times 260$ MM.

ISBN 978-3-412-20052-7

BÖHLAU VERLAG, URSULAPLATZ I, D-50668 KÖLN, T:+49 22I 9I3 90-O INFO@BOEHLAU-VERLAG.COM, wWW.BOEHLAU-VERLAG.COM | WIEN KÖLN WEIMAR 


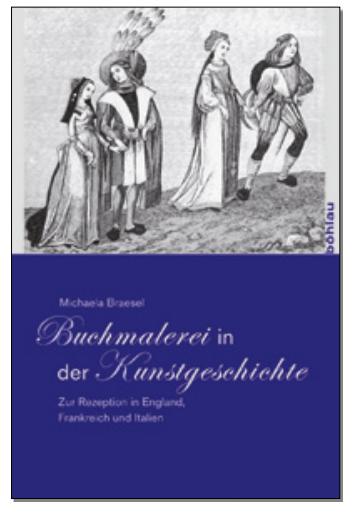

MICHAELA BRAESEL

BUCHMALEREI IN DER KUNSTGESCHICHTE

ZUR REZEPTION IN ENGLAND, FRANKREICH UND ITALIEN

(STUDIEN ZUR KUNST, BAND 14)

Bisher war die Geschichte der Buchmalerei eher ein vernachlässigter Gegenstandsbereich der Kunstgeschichte. Mit dem vorliegenden Band wird nun für Italien, England und Frankreich eine Lücke innerhalb der kunsthistorischen Forschung geschlossen. Chronologisch, geographisch und thematisch geordnet werden verschiedene Bereiche der Buchmalerei mit ihren Fragestellungen und Anliegen vorgestellt.

Die Autorin zeigt, wie sich die Rezeption von der Zeit der ersten Erwähnung von Buchmalern bei Vasari bis zum frühen 19. Jahrhundert wandelte. Deutlich wird dabei, dass stärker als kunsthistorische oder zeitästhetische Urteile andere Motive - antiquarische Interessen, juristische, kirchengeschichtliche und historische Studien - Veränderungen in der Rezeption der Buchmalerei begründeten.

2009. VI, 568 S. 49 S/W-ABB. AUF 16 TAF. GB. $170 \times 240$ MM.

ISBN 978-3-412-20300-9

BÖHLAU VERLAG, URSULAPLATZ I, D-50668 KÖLN, T: + 49 22I 9I3 90-O INFO@BOEHLAU-VERLAG.COM, WWW.BOEHLAU-VERLAG.COM | WIEN KÖLN WEIMAR 

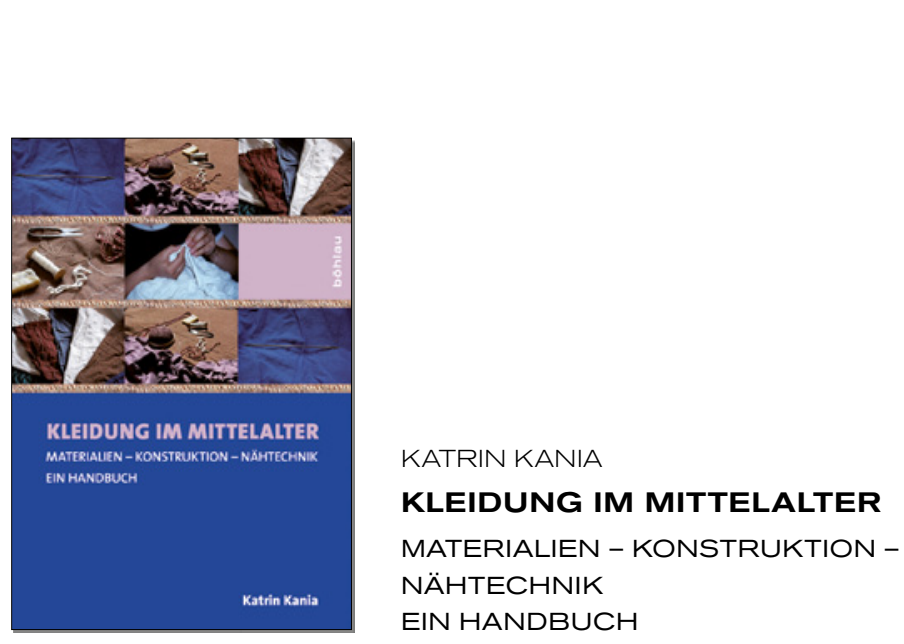

Leicht verständlich und fundiert geleitet das vorliegende Handbuch durch die komplexe Welt der mittelalterlichen Kleidung. Die Grundlagen und Bedeutungen verschiedener Materialien, Näh-, Stich- und textiler Techniken werden ebenso erläutert wie die Voraussetzungen, Grenzen und Möglichkeiten der Forschung.

Eine Analyse der erhaltenen mittelalterlichen Kleidung ermöglicht die Darstellung der Entwicklungslinien in der Zeit von 500 bis 1500. Erläuterungen zur rekonstruierten Schneidertechnik des Mittelalters sowie ein ausführlicher, bebilderter Katalog der überlieferten Kleidungsstücke und Rekonstruktionszeichnungen vervollständigen das Handbuch.

Damit liegt ein Handbuch vor, das für das Verständnis, die Rekonstruktion und die Erforschung mittelalterlicher Kleidung unverzichtbar ist.

2010. 529 S. 357 S/W- UND 51 FARB. ABB. AUF 24 TAF. GB. $170 \times 240$ MM.

ISBN 978-3-412-20482-2

BÖHLAU VERLAG, URSULAPLATZ I, D-50668 KÖLN, T:+49 22I 9I3 90-O INFO@BOEHLAU-VERLAG.COM, WWW.BOEHLAU-VERLAG.COM | WIEN KÖLN WEIMAR 


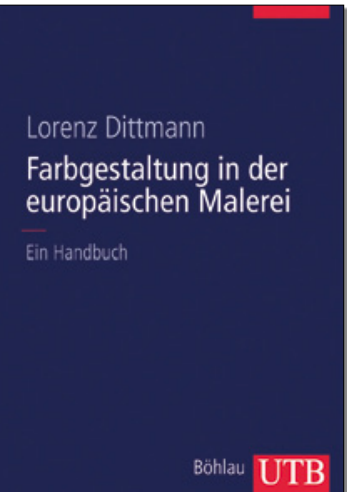

LORENZ DITTMANN

\section{FARBGESTALTUNG IN DER EUROPÄISCHEN MALEREI}

EIN HANDBUCH

(UTB FÜR WISSENSCHAFT 8429 L)

Trotz einer Fülle an kunsthistorischer Literatur, die sich mit der Farbgestaltung und Farbtheorie einzelner Künstler oder Epochen befasst, gibt es bislang nur wenige Gesamtdarstellungen. In vollständig überarbeiteter Form wird nun ein Standardwerk der Koloritgeschichte als Studienbuch neu aufgelegt. Es illustriert in einem einzigartigen Überblick die Praxis der Farbgestaltung in der Malerei vom frühen Mittelalter bis in die 2. Hälfte des 20. Jahrhunderts. Vom Mosaik über Buchmalerei hin zum Tafelbild werden die farbgestalterischen Strategien einzelner Künstler, nach Epochen und Regionen geordnet, erläutert. Ein Glossar mit den wesentlichen Fachbegriffen sowie kommentierte Angaben zur relevanten Forschungsliteratur komplettieren das Handbuch.

2010. 333 S. BR. $170 \times 240$ MM. | ISBN 978-3-8252-8429-9

BÖHLAU VERLAG, URSULAPLATZ I, D-50668 KÖLN, T:+49 22I 9I3 90-O INFO@BOEHLAU-VERLAG.COM, WWW.BOEHLAU-VERLAG.COM | WIEN KÖLN WEIMAR 
Welche Voraussetzungen müssen gegeben sein, damit ein illuminiertes Buch entstehen kann, und in welcher Weise bestimmen sie dessen Gestalt? Die Bedingungen, unter denen Bücher im Mittelalter produziert wurden, gehören zu den zentralen Themen der Buchmalereiforschung. In den Beiträgen des vorliegenden Bandes geht es sowohl darum, Untersuchungsmethoden vorzustellen, die eine differenziertere Sicht auf die Vorgehensweise der Buchmaler bei der Ausstattung von Handschriften und frühen Drucken ermöglichen, als auch nach Erkenntnissen zu fragen, die sich daraus für das Verständnis der Illustrationen gewinnen lassen. 